


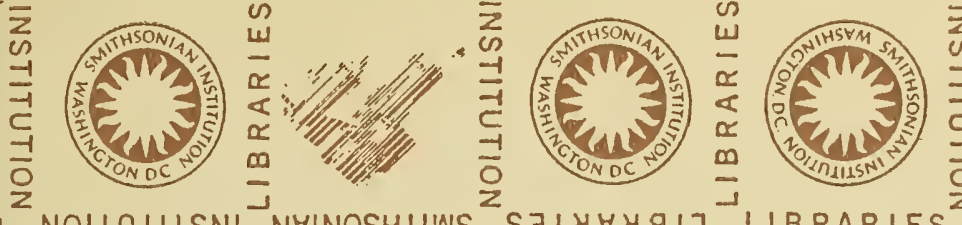

$z$

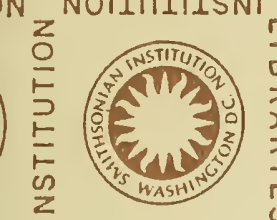

7
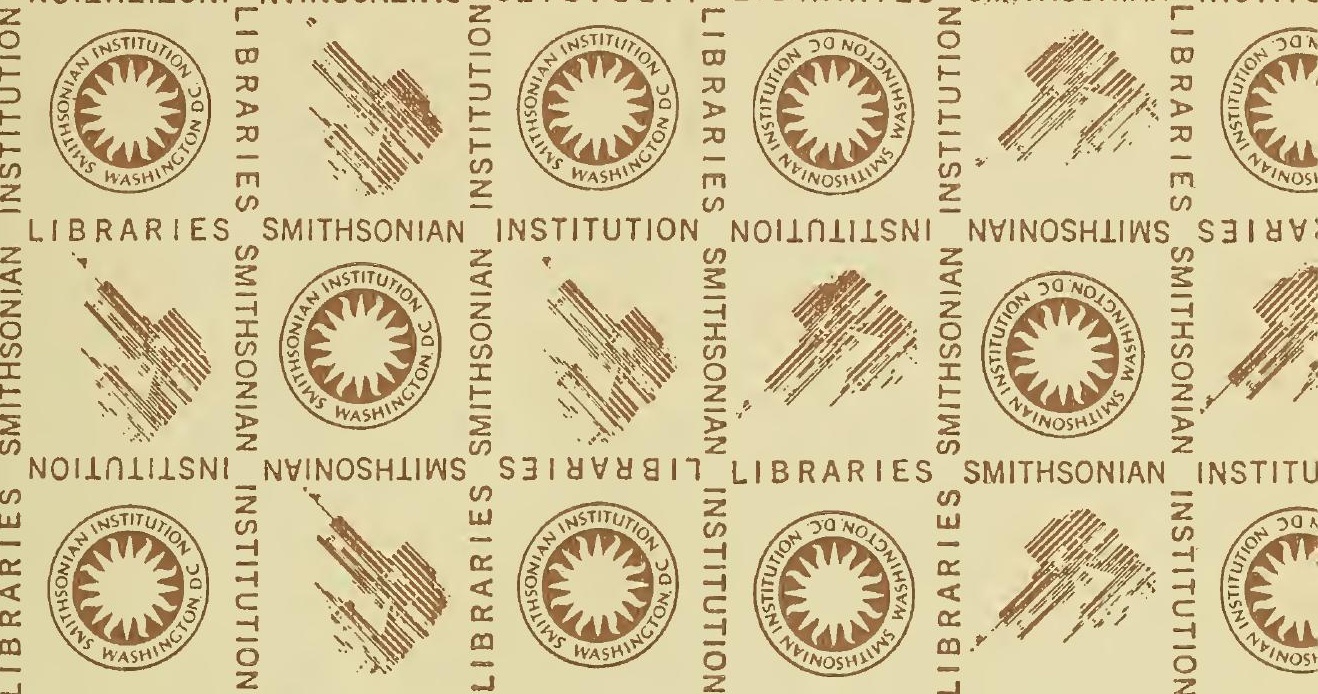

SMITHSONIAN

INSTITU
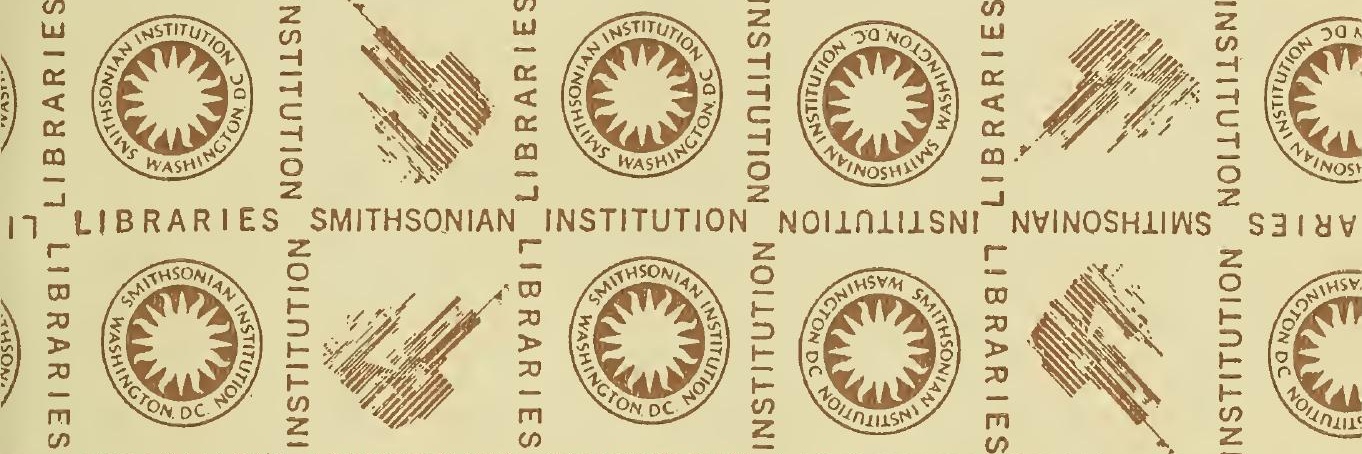

$S \exists I 8 \forall$
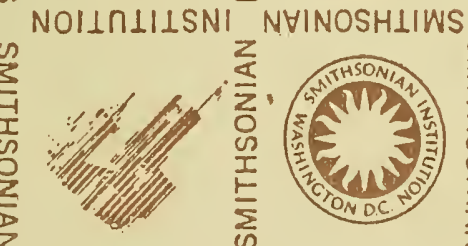

o

LIBRARIES SMITHSONIAN
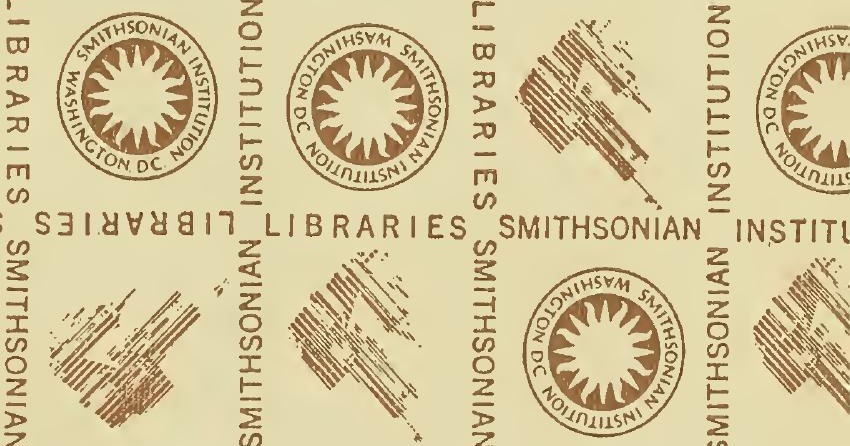

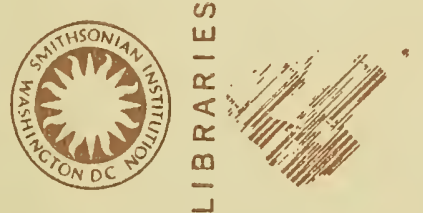

NOIINLILSNI NYINOSHLIWS
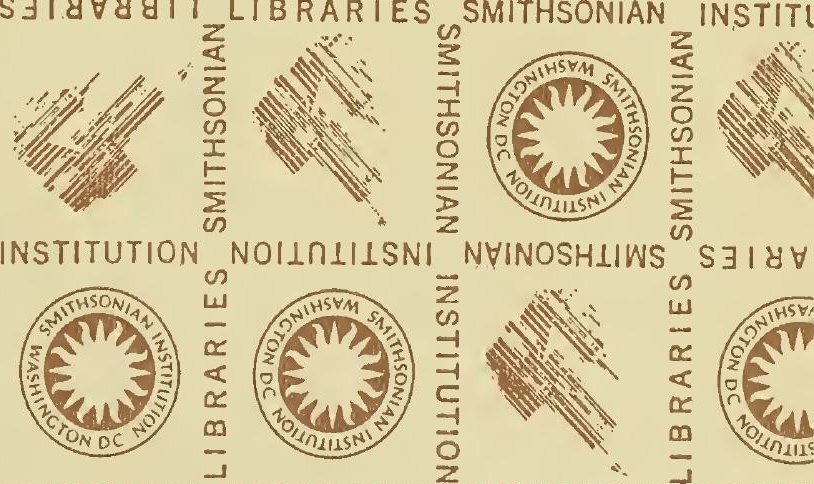
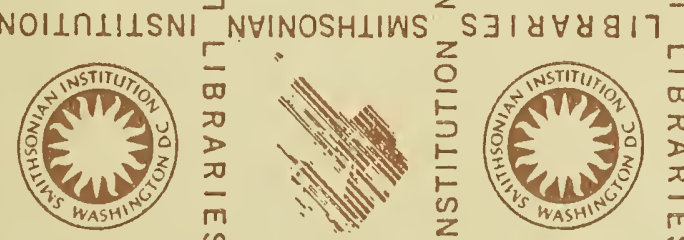

LIBRARIES SMITHSONIAN
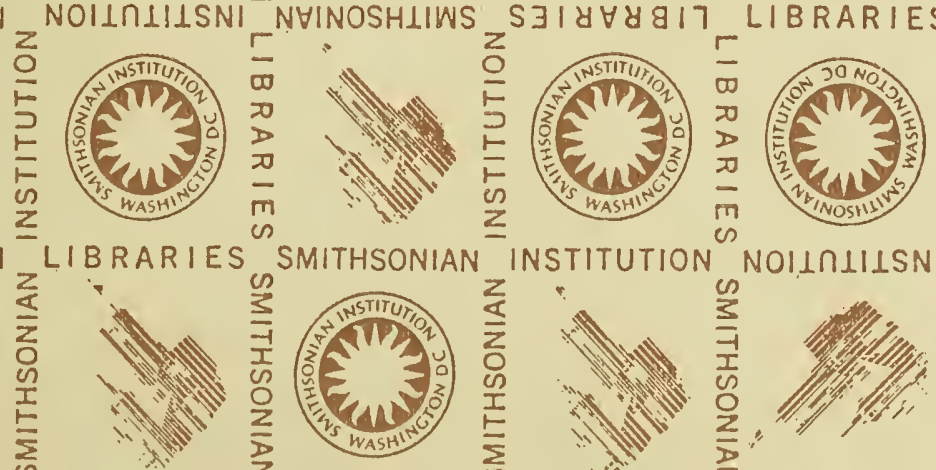

SMITHSONIAN

INSTITL

INSTITUTION NOIINLILSNI

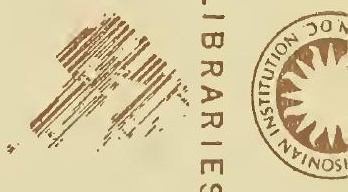

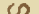
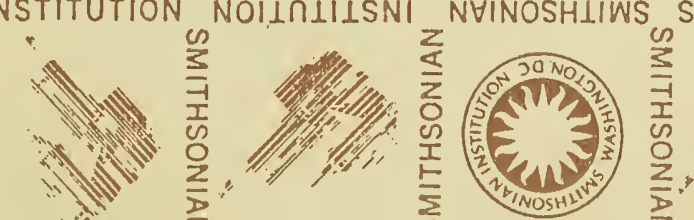





\section{Some Reviews of}

\section{FORE AND THEIR STORY}

"Every sailor-man, ashore or afloat, will be fascinated beyond measure with this book."-Pall Mall Gazette.

" $\mathrm{Mr}$ Keble Chatterton is probably the leading literary authority on the history of ships and the sea, and he now adds a volume which, in many respects is the most attractive of all.-Bookman.

"One is amazed at the vastness of the task to which $\mathrm{Mr}$ Chatterton applied himself, with no illusions as to its magnitude or its exactions, and only less amazed at his success in producing out of the chaos of widelyscattered fragments a coherent, presentable and authentic whole."-Glasgow Herald.

"Admirably illustrated at every step."-Scotsman.

"The author is well known to most yachtsmen, and no one talks as an enthusiast to enthusiasts with more grip and power. A salt-water savour pervades the entire book. More than 150 excellent illustrations embellish a book of singular interest and charm."-Northern Whig.

"Copiously and beautifully illustrated."-

Yorkshire Daily Observer.

"Mr Keble Chatterton's work is a labour of love. In this more than usually handsome volume he traces the history of the fore-and-after in a most engaging manner. A sumptuous volume."-Glasgow Citizen.

"This splendid book of $35^{\circ}$ pages, with its I 50 illustrations and plans-a volume which every keen yachtsman will hasten to add to his most cherished possessions."-Standard. 


\section{Reviews Continued from previous Page}

"Intensely interesting. . . The amount of information is indeed astonishing, even considering the size of the volume."-Glasgow Nerws.

"Thorough and exhaustive are the words best fitted to describe the splendid book which $\mathrm{Mr}$ E. Keble Chatterton has produced on the story of the fore $\mathcal{E}$ aft rig. Long and thorough research into the records of past ages formed the first stage towards the production of the book. Every scrap of information which could be gleaned from the story of sailing boats on the Nile in ancient times has been supplemented by the records of the production of fishing boats, cargo-carriers and pleasure yachts in modern times, and to all these records of the past the author has added a personal visit and examination of the present type of fore $\mathcal{E}$ aft rig in Holland, Belgium $\Xi^{2}$ France, on the Continent of Europe, as well as within the British Islands, so that the book is an authentic and most trustworthy history of the fore $\mathcal{E}$ aft rig from its first adoption in Europe about the year 1475, to the present day. And as it is not likely to be superseded by any other book of the same class, it will long remain a monumental history of this type of sailing vessel."-

Dundee Advertiser.

"To yachtsmen in particular this will prove an extremely fascinating volume, more especially as it contains a large number of pictures of considerable historical interest."-Syren.

"A really interesting book, we confess to the greatest pleasure in its perusal."-rachting Monthly. 



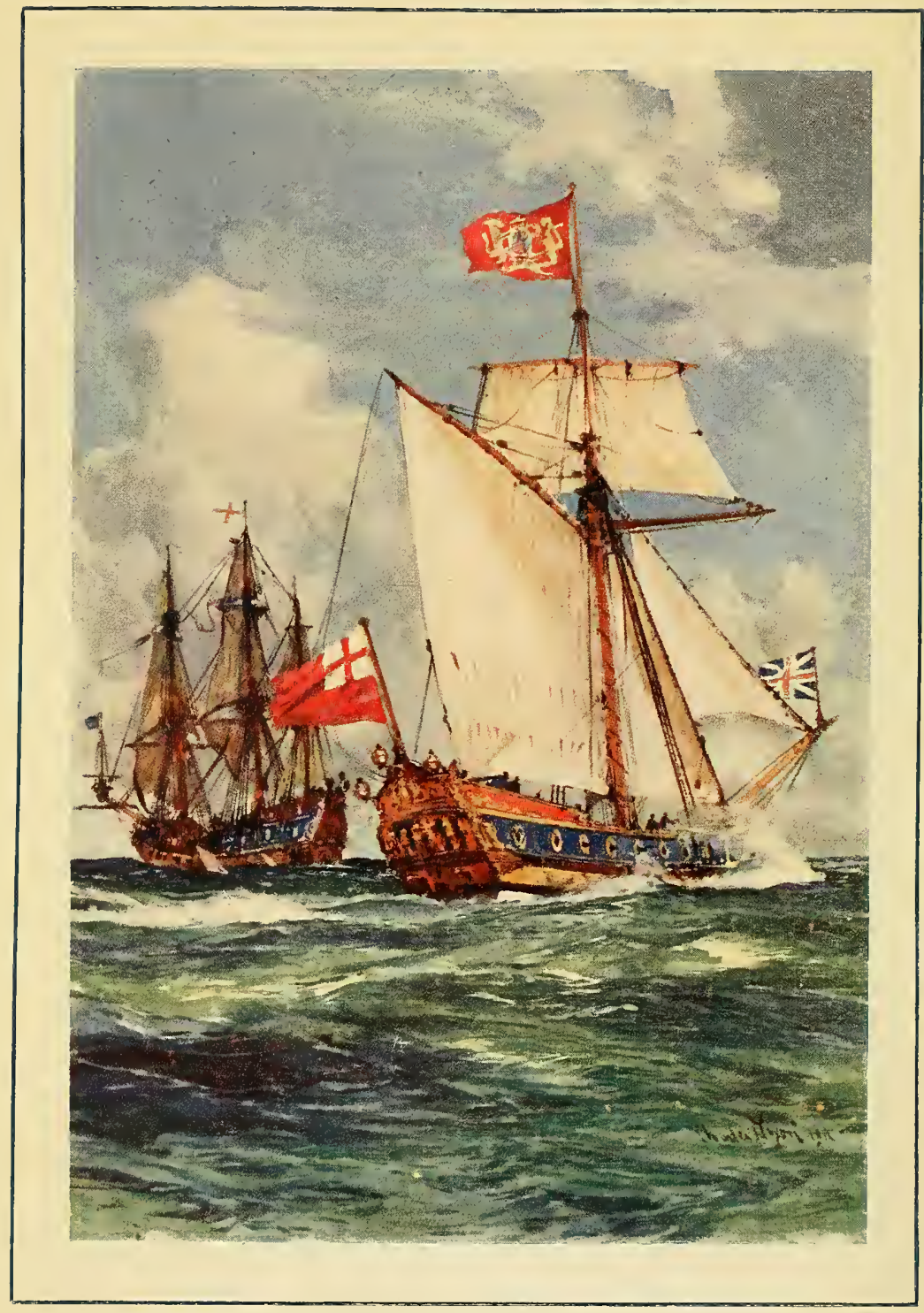

CHARLES II'S YACHT' MARY.'

This was the second yacht of the same name, and the first English-built yacht to be so called. The first yacht which Fingland ever posses'ed was the 'Mary' presented to Charles II by the Dutch in t66o. She was a little sntaller but very" sinuilar to the second "Mary: The details for the alove picture have betn taken from a contemporary sketch by Van der Velde. This second 'Mary' was built by Phineas Pett at Chatham, and launched in 1677 . She was of 166 tons, carried six guns and a crew of twenty. Her dimensions were: length $65 \frac{1}{2} \mathrm{ft}$, beam $2 \mathrm{r}^{\frac{2}{2}} \mathrm{ft}$., depth $8 \frac{3}{4} \mathrm{ft}$, and she drew $7 \frac{1}{\mathrm{f}} \mathrm{ft}$. of water. Although only six guns were munuted she had port holes for more, as may be seen. 


\title{
FORE \& AFT CRAFT AND THEIR STORY
}

AN ACCOUNT OF THE FORE \& AFT RIG FROM THE EARLIEST TIMES TO THE PRESENT DAY

\author{
BY \\ E. KEBLE CHATTERTON \\ AUTHOR OF \\ "SAILING SHIPS E THEIR STORY," "THE ROMANCE OF THE SHIP," \\ "Q SHIPS \& THETR STORY," "DOWN CHANNEL IN THE "vIVETTE," \\ "THE ROMANCE OF PIRACY," \\ E.c., E.c.
}

NEW \&० CHEAPER EDITION

WITH OVER I 50 ILLUSTRATIONS \& PLANS

\section{LONDON}

SEELEY, SERVICE \& CO., LIMITED

$3^{8}$ GREAT RUSSELL STREE'T

1922 


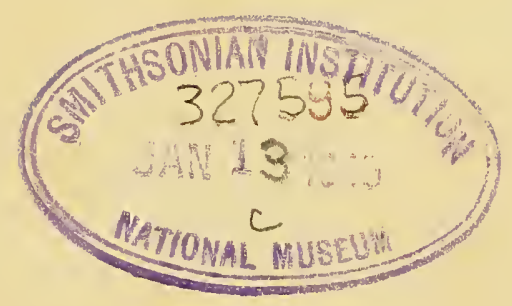

Printed in Great Britain 
THE MEN OF

THE FORE-AND-AFT RIG,

YACHTSMEN, PILOTS, FISHERMEN, COASTERS,

I DEDICA'TE

THESE PAGES 



\section{PREFACE TO SECOND \& CHEAPER EDITION}

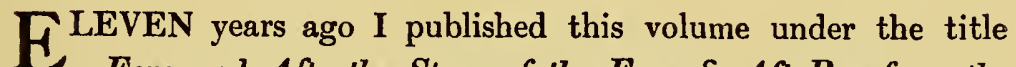
Fore and Aft; the Story of the Fore \& Aft Rig from the Earliest Times to the Present Day, which the press and public were kind enough to receive with such enthusiasm that it has long since been out of print. As the demand has continued insistent, it has been decided to reprint the book, and it now appears under the title Fore \& Aft Craft and Their Story. It was pointed out that many persons whose interests were not closely connected with the sea failed to grasp immediately the character of the book from its original title, and it is hoped that under its new name this interesting story of one of the most important developments in maritime progress may reach a still larger section of the public.

E. KEBLE CHATTERTON.

June 1922. 



\section{PREFACE}

TWHE fore-and-aft rig, though of much later origin than that 1 of the square-sail, is far more varied in its developments. If we reckon by actual numbers we shall find that to-day, while the square-rigged ship is gradually becoming rarer and rarer, yet the fore-and-after still continues to thrive, to multiply and to improve in every way-in design of hull no less than in details of gear.

It is, therefore, only fit and proper that the history of the fore-and-aft type of vessel should follow that of her older sister, and the following pages will show that her story is full of interest and fascination. So much confusion and error exist among sailing-men in regard to the place or manner of the origin and evolution of their craft that it is well that the facts should be set right at once. As to the nethods of investigation which have been employed in collecting the material for this book, the ensuing pages will explain.

Additional to my own independent research, I have laid myself under obligation to that of various other writers, and especially I desire to mention the following:- Pritchett's Sketches of Shipping and Craft, Warington Smyth's Mast and Sail, Clark's History of Yachting, Chapman's Architectura Navalis, Cooke's Shipping and Craft, Charnock's History of Marine Architecture, Hulsius's Voyages, Tanner's Descriptive Catalogue of the Naval MSS. in the Pepysian Library, Pepys' Diary, Evelyn's Diary, the two volumes on Fachting in the Badminton Library, Leslie's Old Sea Wings, Guest's History of the Royal Yacht Squadron, articles by Heckstall Smith in the new edition of the Encyclopoedia Britannica and Lloyd's Calendar. I am also indebted for certain details to the Yachting Monthly. 
I wish to return thanks for the assistance rendered me in various galleries and museums both in England and Holland during my investigations, and have also to express my gratitude to the following gentlemen, who so kindly placed various designs and photographs at my disposal:-Mr. Walter Wood for permission to reproduce the photographs of the Yorkshire cobble, the Thames bawleys, the Scarborough fishing-ketch, and the Galician lateener; to Mr. Norman S. Carr (who has made many of the sketches) for the photographs of the Cornish fishing craft, the Ostend fishing-smack, the reefing-gear of the Bristol Channel pilot-cutter, the Isle of Marken botters, the smaller photograph of the hoogarts fishing fleet, and the modern boier yachts; to Mr. Harold Clayton for the designs of the Bristol Channel pilot-cutter Faith; to Mr. C. Devereux Marshall for the photograph of Maud; to Mr. Albert Strange for the designs of the Seal, Sheila II., Cherub III., and Norma; to Mr. Colin Archer for the designs of the Norwegian redningskoite, the photographs of the Norwegian pilot-cutter and of the Fram; to M. G. Soé for certain information connected with, and the plans of, the Frederikshaven fishing-boat, the Belgian lugger, the Dunkirk fishing-ketch, the Gravelines lugger, the Boulogne herring-drifter, the chasse-marée of St. Malo, the Equihen lugger, the sardine luggers of Brittany and of the Vendée, the Newfoundland barquentine, the Breton fishing-schooner, and the Marseilles pilot craft.

It may be added that since the following pages were written another cruise has been undertaken through the Netherlands, and further opportunities have been taken advantage of in order to confirm previous impressions and deductions regarding local craft.

August 1911.

E. KEBLE CHATTERTON. 


\section{CONTENTS}

CHAP.

PAGE

I. INTRODUCTION 17

II. The Origin of the Fore-And-Aft Rig 27

III. Origin of the Fore-And-Aft Rig in Northern EURope

44

IV. The Development of the Fore-And-Aft Rig in Holland

V. The Introduction of Yachts into England

VI. The Influence of Holland on the Development of the Fore-And-Aft Rig

VII. The Fore-and-Aft Rig to-day in Great Britain and America

VIII. The Modern Fore-And-Aft Rig in Scandinavia, Holland, Belgium, France, and Southern Europe 277 


\section{ILLUS'TRATIONS AND PLANS}

First English-built Yacht, the second Mary Frontispiece

1. Italian Harbour, with Lateener

PAGE

2. Mediterranean Tartana

33

3. Scheveningen Herring-Buss 51

4. Seventeenth Century Herring-Busses 54

5. Dutch Buss-ships 56

6. Dutch Galley 58

7. An Early Sixteenth Century Fore-and-After 59

8. Fore-and-Afters 64

9. The Dutch Polar Expedition 64

10. A Galley and other Fore-and-Afters in the Purt of Amsterdam $\quad 70$

11. Dutch Sloops 74

12. The Origin of the Schooner (First Stage) 76

13. 'The Origin of the Schooner (Second Stage) 78

14. Dutch Market Barge 82

15. A Seventeenth Century Dutch River Scene 84

16. Seventeenth Century Dutch Sloops 92

17. A Dutch Yacht and other Craft 94

18. Dutch Shipping $\quad 96$

19. A Dutch Boier and other Craft 102

20. A Seventeenth Century Dutch Sloop 104

21. Dutch Admiralty Yacht 106 


\section{ILLUS'TRATIONS AND PLANS}

22. Seventeenth Century Dutch Galleot

23. Nineteenth Century Dutch Galleots

24. View of the Maas

25. Kof-Tjalk

26. Sail-plan of Kof-Tjalk

2\%. Enkhuizen Beurtman

28. Paviljoen-Pom

29. Dutch Cutter

30. The Yacht in which Charles II. sailed

31. Semale Ship

131

32. Yorkshire Billy-Boy

134

33. The English Yacht, the second Mary

134:

34. Some of Charles II.'s Yachts

35. Eighteenth Century Dutch Hoeker-Yacht

36. Nineteenth Century Dutch Craft

37. Eighteenth Century Craft

38. Fore-and-Afters of the Thames

174

39. Dutch Schuyt

176

40. Hatch-boat in Gravesend Reach

178

41. English Revenue-Cutter

178

42. Dutch Revenue-Cutter

43. Lines of a Cutter of the Year 1781

184

44. Design for a Yacht

45. A British Sloop-of-War

46. Scotch Trading Smacks

47. Fishing Smack 
51. The Yacht Jullanar

52. Brighton Mackerel Craft

53. Brighton Hoggies

54. Scarborough "Mule"

222

55. Old Yarmouth Cobble

56. Scarborough Ketch

57. The Thames Bawley

58. The Thames Bawley

230

59. Sloop-rigged Barges

60. Old Thames Barge with Square-sails

61. Cowes Ketch

62. Cornish Fishing Craft

63. Reefing-gear of Bristol Channel Pilot Craft

64. Internal Accommodation and Deck-plan of the Bristol

\section{Channel Pilot-Cutter Faith}

241

65. Bristol Channel Pilot-Cutter

66. Lines of Bristol Channel Pilot-Cutter Faith

248

67. Sail-plan of Bristol Channel Pilot-Cutter Faith

249

68. The Britannia

252

69. The Maud

252

70. Sail-plan of the Seal

71. The Outlook

79. Accommodation and Deck-plan of the Seal

72-A. Lines of the 10-ton Yacht Seal

73. American Cat-boat

74. The Westward

75. Sailing Lifeboat

76. Norwegian Pilot-Cutter

7\%. Details of the Seal and her Dinghy 


\section{ILLUSTRATIONS AND PLANS}

78. Sail-plan of Sheila II.

79. Plan of Cabin and Construction of Sheila II.

80. Lines of Sheila II.

271

81. Sail-plan of Cherub III.

273

82. Lines of Cherub III.

275

83. Sail-plan of Norma

274

84. Lines of Norma

275

85. Accommodation Plans of Norma

278

86. The Fram

279

87. Accommodation Plans of Cherub III.

280

88. Frederikshaven Fishing-boat

281

89. Sail-plan of Norwegian Lifeboat

283

90. Dutch Tjalks

288

91. A Smaller Dutch Tjalk

290

92. Lines of Norwegian Lifeboat

290

93. Dutch Klipper

291

94. Dutch Botters

293

95. Isle of Marken Botters

295

96. Hoogarts Fishing Fleet

296

97. Accommodation Plans of Norwegian Lifeboat

296

98. Dutch Schokkers

297

99. Flushing Harbour, with Fleet of Hoogarts

297

100. Hoogarts of Walcheren

298

101. Dutch Boier

299

102. Ostend Fishing Smack

302

103. Modern Boier Yachts

302

104. Lines of Belgian Lugger

302

105. Zuyder Zee Kub-boats

303

106. Modern Dutch Una-rig 
107. Scheveningen Pink

108. Katwijk-Pom

109. Sail-plan of Belgian Lugger

110. Lines of Gravelines Lugger

311

111. Lines of Dunkirk Fishing Ketch

312

112. Dunkirk Fishing Ketch

113. Gravelines Lugger

114. Sail-plan of Boulogne Herring Drifter

115. Lines of Boulogne Herring Drifter

116. Chasse-Marée of St. Malo

117. Lines of St. Malo Chasse-Marée

118. Fishing Lugger of Equihen

119. Lines of Equihen Fishing Lugger

120. Sardine Fishing Lugger of the Coast of Brittany

121. Sardine Lugger of the Vendée

122. Lines of Sardine Lugger of the Vendée

123. Barquentine of St. Malo

124. Breton Fishing Schooner

125. Egyptian Dahabeiah

126. Lines of St. Malo Barquentine

127. Galician Sardine Boat

128. Lines of Breton Fishing Schooner

129. Sail-plan of Marseilles Pilot-boat

130. Lines of Marseilles Pilot-boat 


\section{FORE AND AFT}

\section{H A P T E R I}

\section{INTRODUCTION}

THE appearance of this present volume fulfils a 1 promise which was made a couple of years ago. In the last chapter of my Sailing Ships and their Story the reader may remember that I remarked that "it would be quite impossible here to trace in such complete detail the history and development of the fore-and-afters as we have done of the larger sailing ships; that, indeed, demands a separate volume to itself." It is now proposed within the compass of the following pages to attempt to perform on behalf of the fore-and-afters that which I essayed to do for the full-rigged ship and her near relatives. For such a task needs the scope of more than a few pages in order that full justice may be done to the subject. In the previous volume the merest outline had to suffice for the reader's interest, for in covering so large an area as the history of every kind of sailing-ship that had evolved during a period of six thousand years there remained to me little enough opportunity of dealing adequately with that rig which to-day exists in far greater numbers than the square-sail rig.

Whilst it is true that the steamship and motorpropelled vessels are increasing as the square-rigged ship is disappearing, the fore-and-aft is the only kind of sailing craft that continues to multiply, and 
that irrespective altogether of what the motor or steam-engine may be doing. For to the fisherman, the pilot, the yachtsman, and to many a coaster and inland trader the fore-and-after belongs exclusively. Sometimes she is nowadays fitted with an auxiliary motor engine, but oftener she is without so useful an accessory. The important fact remains that if you were to count up all the sailing craft of the world you would find that an overwhelming proportion of these are rigged fore-and-aft fashion and do not carry even so much as one square-sail to set when running free.

That being so, it is but fair that the origin and evolution of the fore-and-aft rig should have its full meed of consideration; and it is hoped that the following pages may be not less interesting to the lover of ships and the sea than were the chapters on the history of the larger kind of sailing-ship designed not for coasting or inland waters but for traversing the vast expanse of the ocean.

It is permissible to emphasise at the outset more particularly the aim which has here been in view and the method which has been employed. This volume is neither an attempt to record the peculiarities of every conceivable kind of sailing craft in all the corners of the four continents, nor is it a mere history of yachting. What has been aimed at has been, firstly, to find out, as far as the most patient and extensive historical research will permit, the actual beginnings of the rig, and then to show in chronological order the general manner in which during the ensuing centuries this went on developing, and how it became modified to suit particular and local purposes, but with especial regard to the manner in which it has been employed over the seas of northern Europe.

For years the desire to get at the heart of this matter has haunted me, and it is only after the most 
diligent research among existing records and the examination of pictorial representations by contemporary craftsmen, after following up all sorts of clues in the most out-of-the-way places, and, finally, after studying practically every printed book on a marine subject from the first days of printing to the present day, to say nothing of innumerable manuscripts, prints, and so on, that at last it was possible to piece together the scattered fragments into one coherent whole. 'This was preceded by a familiarity of handling fore-and-aft rigged vessels, an experience that began in boyhood and still continues. But in order to leave no loophole for error, after the libraries, museums, and art galleries of England had been ransacked, and its various kinds of fore-and-aft rigged craft studied, the same experience was gone through in that foreign country which saw the origin and the earliest developments of the rig. We must recollect that about the close of the sixteenth century the Netherlands were becoming wonderfully wealthy and powerful on the sea. 'Thus during the next century they were the great ocean-carriers, the "waggoners of the sea," as they were called. 'Thus followed also those three great Anglo-Dutch naval wars. Living so close to the North Sea, having always to fight for the security of their land against the encroachment of the waves, intersected with innumerable canals and waterways, with the mighty Scheldt and Maas rivers running through their midst, with the expansive Zuyder Zee on one side of the land and the still vaster North Sea on the other, it would have been surprising had not the Dutch become sailor-men. And when in addition they became colonists and obtained valuable interests in India, Java, and America, a still keener interest in shipping and its manifold details became essential. It was primarily owing to the shallowness and the narrowness of her national waterways, to the absence 
of good roads for carrying traffic, that the fore-andaft rig developed so wondrously in Holland. The happy combination of an ancient sea-instinct, together with that potent cause of invention-necessity-brought about in the Low Countries the origin of the yacht, the fishing-smack, and the familiar pilotboat.

'Therefore, in order to supplement the many data which England afforded, a lengthy visit was paid to Holland; and that this might be done thoroughly from one end to the other, it was undertaken in the only manner in which such an investigation can rightly be made. It was not to be a land voyage, but by sea and river and canal. Starting out in a little fore-andaft rigged yacht of from four to five tons from Southampton Water, with a crew of two all-told, consisting of the writer and the artist who has made many of the illustrations in this book, the English shore was followed to the eastward. After putting in at Newhaven and Ramsgate, a course was set for Calais ; from there sailing along the French and Belgian coasts to Ostend, to the new port of Zeebrugge, and across the wide estuary of the Scheldt to the Dutch port of Flushing, in the island of Walcheren. 'Thence still pursuing our way northwards, sometimes by canal, sometimes along the bold tidal rivers bearing their heavy traffic, consisting of every species of fore-andaft rig, we eventually arrived at Amsterdam and the Zuyder Zee. With the details of so interesting a cruise one need not weary the reader: perhaps he may have the opportunity of reading the account in another volume at some other date. Everywhere pencil and camera were employed to gather in from passing craft the most fascinating data connected with the Dutch craft. Ashore the various ports and havens were scrutinised so as to study the rig of these sailing vessels, and their skippers and crews were asked to supplement what was not immediately manifest. For 
weeks and weeks we sailed in their company; we saw how they employed devices unknown to our own seamen; we noted them in fair weather and foul; observed them tide-cheating, "trekking," or running in and out of crowded locks with that dexterity which is peculiar to the Dutch sailor-man. We went on board them and examined their gear, talked with the men who built them, wandered in and out of their shipbuilding yards, gathered scraps of information, now from the skipper of a paviljoen-pom, now from a haven-meester, a yachtsman, or an antiquary.

But besides all this we endeavoured to ransack also every picture, print, book, or other evidence in every museum, library, and picture gallery which the various inland and sea-ports contained and were likely to throw an illuminating light on the origin and history of the fore-and-aft rig. In short, the most meticulous care was expended, regardless of time or expense, so that at last a satisfactory and reliable investigation might have been made. Armed with this knowledge, still further researches were undertaken afterwards in England, with fortunate success to crown one's efforts. Whatever value all this expenditure of time, labour, and travel may possess, is to be found in the following pages. It was essential that the journey of inquiry should have been undertaken in this manner, for many of the most interesting sources of information were right off the tourist track and, because of their island situation, inaccessible except by water. It was further impossible, also, to get an adequate idea of the Dutch craft (which of all kinds of ships have altered least from their origin centuries ago to the present day) except by sailing in their company day after day, mile after mile. But all this was only part of the whole scheme which aimed at settling once and for all some of the wrong impressions which exist regarding the history of the particular class of vessel to which we are devoting our attention. 
On another page the English-built Mary the second will be found reproduced exactly as she was sketched under way by a contemporary artist of her owner, Charles II. ; whilst the striking frontispiece to this book represents an attempt to bring her to life again, and to fire the reader's imagination so that he may see her as she appeared in the seventeenth century with her royal owner on board. This has been done by one of the ablest of our modern marine artists, Mr. Charles Dixon, working from existing historical details which may be regarded as absolutely authentic.

The first Mary (to which the second English-built Mary bore resemblance) represents a landmark in the history of all British shipping, and is especially of interest to yachtsmen in all parts of the world, for she introduced an altogether novel type of craft to our country, and set going the beginnings of the entirely new sport of yachting, a sport that is happily now spreading not merely throughout the British Isles, but to all sea-girt civilised countries of the world. Since it is to Britain secondly, and primarily to Holland, that this sport is due, we cannot exaggerate the importance which this vessel bears in regard to historical progress.

But although necessarily in this volume the pride of place belongs to Holland and Britain, yet it is not exclusively to these countries that the fore-and-after belongs, as many of the illustrations will show. The North Sea, the Baltic, and the English Channel will ever be associated with this rig especially. For these waters where harbours are many, whose narrow, and frequently difficult, entrances need handiness in the sailing-ship, there is nothing so suitable as the rig we are discussing. That is the especial claim which such craft possess : that is the reason why they have received so much encouragement. Plenty of fore-and-aft craft have crossed the Atlantic, and some have even voyaged 
to Africa, India, Australia, and elsewhere. But such voyages are not so suited to these craft as for the fullrigged ship with her boomless square-sails and manifold conveniences for diminishing that injurious chafing which comes from the continuous rolling during a protracted cruise over the waves of the ocean. Able to go through weather which many a fore-and-after could not look at, majestic and lovely as the fullrigged ships are to the eye, yet handy they are not, and they are ill-suited for the special work of the cutter or yawl, a large part of whose time is spent dodging in and out of harbours or turning to windward in confined channels. A square-rigged ship, for instance, would be as absurd on Dutch waterways as a botter or hoogarts would look trying to cross the Atlantic. It is, however, essential to bear in mind that in the world's vast scheme of division of labour there is a necessity for both forms of craft.

After we have shown, then, the important debt which the fore-and-aft rig owes to Holland, we shall proceed to see how this rig took root in England, and thence we shall be able to witness it developing not merely in the yacht, but in the Revenue-cutter and the fishing-smack, and the vessels of the sixteenth, seventeenth, eighteenth, nineteenth, and twentieth centuries. Yawls, sloops, cutters, lifeboats, boms, catboats, pinks, klipper-aaks, boiers, schokkers, botters, hoogarts, tjalks, kubboats, fishing craft, pilot craft, market barges, cargo-carriers, Admiralty sailing craft, hoekers, galleots, Dutch, English, French, Belgian, Danish, Swedish, and Norwegian craft, Yorkshire cobbles, and Mediterranean lateeners, whale-boats and motor-schooners-all these we shall investigate for the purpose of witnessing the manner in which the rig has developed. And in addressing myself to that same appreciative public who were kind enough to welcome Sailing Ships and their Story, I am in hopes that they may find once more that an increased familiarity with the evolution of the 
craft which we all love so well may have the reverse effect of that spirit which breeds contempt through closer association. To me personally the joy and delight of voyaging in any kind of sailing vessel is intensified a thousandfold if $I$ am able to know her ancestry, and I cannot think that it is otherwise with my brother sailing-men, whether professional or amateur.

'Two of the most romantic considerations in the world are found in history and the ship: so that when these two are united we have afforded a subject that is magnetic in its power to attract. The man who is genuinely fond of ships aspires to know more about them. He is not content to rest satisfied with the knowledge as to the way they are handled: he wants to know something of what may be termed the philosophy of the ship. He longs to get right back to first ship-principles, and to ascertain the forces that have been at work to model, if not the ocean-carrier, at any rate the smaller type of craft in which he has sailed for so long a time. He is anxious to know what sort of craft were those prototypes, how they were rigged, whether they could get to windward, what they looked like under way, and so on. It is to such inquiries as these that this volume comes with a desire to give answer. Even to the man who does not put to sea in his own craft, but for all that has an affection for the things of the sea, perhaps it may not be unwelcome to learn how the little sailing vessel which he sees bobbing up and down in the bay can trace her pedigree back through the ages of the bluff-bowed sloops, and even to the sixteenth-century Dutchmen.

Surely it can be no lost labour to foster an interest in-even a real love for-ships of any kind. There is nothing healthier both for mind and body, there is no pastime, no form of recreation which is at once so instructive and so beneficial to character as 
the sport of ships. 'The more you learn about them the more you become appalled at your own ignorance, and so proportionately you press on to get acquainted with the things that you long to know. Added to this must be borne in mind the fact that we are an island race, and that it is a matter of honour that we should hand on the great sea-tradition to posterity, and not suffer it to die out in an age of excessive comfort and luxury. Many people are tied to town life by the claims of their daily work, gladly though they would, if they could, rush off for the greater part of the year to go wandering round the coast in some sort of vessel. But next to such a possibility the best means of keeping up an interest in seafaring matters consists in reading about them, so that the imagination is fired and the progress of maritime matters is not allowed to be regarded as something that does not matter, something belonging to other people's business, but becomes a personal matter and one in which all who are proud of the name British feel deeply concerned.

It has been well said that in these days of mechanical propulsion the only educated sailors who still exist are yachtsmen, and it is with a desire of interesting them and their younger brothers that I have written the following pages. For in the matter of ships there is a common meeting - ground for enthusiasts irrespective of ages. We need not bring up that old dictum about Waterloo and the playing fields of Eton, but many an embryonic admiral has learnt some of his first and most valuable sea lessons from an acquaintance made with small sailing craft. Prior to that some stirring sea-picture or sea-story had captivated his imagination and sent his thoughts to work in a new world. To-day there is so little in common between the ships of war and the ships of pleasure that it is useless to attempt a comparison, but what is possible is to capture that enthusiasm by means of the printed 
book and spirited illustration, an enthusiasm which, after it is once infused, never dies, but is presently led into one of the three channels of the navy, the merchant marine, or the sport of yachting.

It is hoped that these pages may do something to inspire such an enthusiasm or to invigorate it where it already exists. 


\section{CHAPTER II}

THE ORIGIN OF THE FORE-AND-AFT RIG

TF we were to examine all the different rigs of the 1 different ships of the world, of whatsoever size and nationality, we should find that they divide themselves broadly into two separate classes. Firstly, there are the ships which are with yards and rectangular canvas, or, as we should say, with square-sails; and secondly, there are those, usually smaller craft, which are rigged foreand-aft wise. 'That is to say, instead of having their sails set athwart the mast they are affixed longitudinally, in line with the keel.

To the former class belong of course the full-rigged ships and barques. To the latter belong the sloops, cutters, ketches, yawls, and luggers of the coasting trader, the fisherman, the pilots, and the yachts. And of course there are, as in other spheres of activity, certain compromises between the two distinct classes. The topsail schooner, for example, is, strictly speaking, neither a square-rigged ship nor a fore-and-after, but possesses features akin to both. So, in like manner, might we affirm of the barquentine and brigantine. In the history of sailing rigs the square-sail comes first. It was the original form of the sail-plan adopted by the Egyptians, the Phonicians, the Greeks, and the Romans; it was, no doubt, if only records existed to demonstrate the supposition, the actual rig of the first man who ever dared to set a sail on his frail and primitive boat or ship.

In another volume I have already shown, from unimpeachable evidence, that the large square-sail was 


\section{ORIGIN OF THE FORE-AND-AFT RIG}

employed on the ancient ships of Egypt not only for navigating the Nile, but even for sailing in the Red Sea. For deep-sea work there is, of course, nothing to equal it; and even when light winds occur, and the heave of the ocean's bosom causes so much damage to gear and spars and canvas through incessant chafing, it is the square-sails which suffer less than the fore-andaft cut-sails. There was also a special reason why the large square-sail should be retained for so many centuries in the navigation of the national river of Egypt. The stream flows out in a northerly direction, yet the prevailing wind blows from north to south. Consequently, though sail and mast could be lowered and the oarsmen set to work when bound down-stream, the return journey could be made with the utmost ease. The craft was sure of a favourable breeze from due aft, and there was little need to worry about the possibilities of having to close-haul. 'The simplicity of using the squaresail for running before the wind, and, by the employment of this form of sail, never having to gybe, caused the rig to be invaluable. Even in bad weather, in quite a small craft I have run for many miles in comfort under a square-sail dead before the wind, knowing that whereas the fore-and-aft canvas needs immediate attention every time a gybe occurs, the square-sail will look after itself and accommodate its nature, no matter whether the wind comes from the starboard or port quarter.

But nevertheless, as every sailing-man knows, or as every experimenter will quickly discover for himself, the square-sail has its limitations no less than its virtues. It will not hold so good a wind as the fore-and-after : in other words, the square-rigged vessel will not sail as close to the wind by at least one if not two points. Thus in the case of a ship beating to windward, the square-rigger has further to go than the fore-and-after. Now, in such confined waters as rivers this unhandiness is a serious matter, and has, indeed, to be remedied. It 
was after the art of tacking or beating to windward had been discovered that the square-sail underwent certain modifications, which were to bring about what we know as the fore-and-aft rig. So the Egyptians, becoming weary, no doubt, of eternally rowing their craft down the Nile against the northerly wind, at length sought some means of harnessing that same wind. By going in a zigzag fashion from side to side between the two banks of the river they discovered that progress could be made without continuous rowing. For a time the method was not wholly satisfactory, because the squaresail was still used in its original shape. But presently it was found that by tilting the yard so that the peak of the sail pointed much higher and well above the mast: by bringing the foot also down almost to the deck, a much better effect was produced. Forward of the mast there now projected a certain amount of canvas, and whilst the actual cut and shape of the sail, its yard as well as its boom, were retained, yet the real character of the sail was totally different. Bear in mind that the Egyptian sail of the Nile ships was square, but much wider than it was deep. Imagine in your mind, or, better still, depict the same for yourself by taking paper and pencil, a rectangular expanse of canvas about three times wider than it was deep; place this across the mast, not horizontally, but in such a manner that the yard and boom being parallel to each other they make with the deck an angle of about 45 degrees, and you have roughly the sail-plan of the first fore-and-aft rigged vessel.

With this improvement the Egyptians can now get to windward. In itself it does not appear to be a vital change, but the alteration of the angle which the boom and yard make with the mast or deck is something revolutionary in character. For a new power has been put into the sailing-ship; she can do something which she has never before attempted successfully. The Egyptian nuggar of to-day has her sail-plan exactly in 
accordance with the diagram which you have just drawn on your paper, and is still to be seen on the waters of Egypt below the third cataract, though it is being slowly replaced by the all-prevailing lateen. Practically the sail is what we should call nowadays a balance-lug, which many a yachtsman places in his sailing dinghy or canoe.

But this useful modification, this new form of sail, was not to remain the exclusive possession of Egypt. As the influence of Egypt spread to the eastward, so this form of sail, together with even the Egyptian form of hull, followed and continued to be employed. Just how old this ancient balance-lug is no one can say, but it is at least several centuries older than the birth of our Lord.

The accompanying illustration (Fig. 8), which is taken from an old Dutch book of travels published in the year 1598, shows a Javanese vessel with the Egyptian influence all over her. Not merely the shape of the hull, but the sails are directly traceable to the customs which obtained on the Nile. The two sails show that the Egyptian nuggar influence was accepted without question and allowed to remain undeveloped, except that two sails are employed instead of one. But apart from that, here is the very early form of the primitive fore-and-aft rig: the tilted square-sail utilised to give to the ship increased handiness and greater ability for sailing in narrow and confined channels. The peak is high, the foot low, and yet the sails are shallow and wide.

That is the first stage in the inquiry on which we are focussing our attention. As all civilisation sprang from the East, as the ship herself, and even the squaresail came from that quarter of the globe, so also did the fore-and-aft rig in embryo. It was an Oriental and not a Northern development at the first, although, as we shall see later on in this book, it was the Northern nations that were to take it in hand, improve it, and 


\section{ORIGIN OF THE FORE-AND-AFT RIG 31}

make it specially serviceable for local uses. Now this nuggar-lug was itself capable of improvements, and the lines on which the sail became modified may be seen in the familiar sailing craft of the Red Sea, the Persian Gulf, and the Indian Ocean. For the dhow is the lineal descendant of the nuggar, and especially so in the matter of rig. Her sail is called a lateen, and embodies the nuggar-lug, but the idea has been considerably developed so that it changes from a rectangular shape to triangular. Although the yard is retained, it is made of immense length, and Mr. Warington Smyth mentions that he remembers measuring the mainyard of a dahabia and finding it 134 feet long. But with this increased length of yard the boom disappears, the sail becomes peaked even higher still, and it also becomes deeper instead of the shallow feature of the nuggar-lug. Furthermore, instead of only a small portion of the sail extending forward of the mast, the lateen allows quite a considerable part of its area to be there.

Thus the gaiassas and dahabias of Egypt, the dhow and baggaras of the Arabs, the gehazi of Zanzibar, the pattamar of Bombay are, next to the nuggar, the world's earliest fore-and-aft rigged vessels. Omitting small differences as to detail, we may conveniently refer to the rig common to them all as the dhow, and to the sail as the lateen. Now, in spite of the advance of years, this lateen-rig has continued in the East, and still remains, not only east of Suez, but in the Mediterranean. When the Venetians, the Genoese, the Spaniards, and the Portuguese became so civilised that by the time of the early Middle Ages they were the greatest maritime nations of Europe, their ships were rigged according to the historic Mediterranean custom with enormous spreading lateen-sails, triangular in shape and very highly peaked. 'The Vikings of the North, on the contrary, were all this time employing the square-sail exclusively, thanks, as I firmly believe, 


\section{ORIGIN OF THE FORE-AND-AFT RIG}

to the advent of early Phœnician voyagers centuries before. But since the Mediterranean was situated in such close proximity to early civilisation, since it actually received into it the very waters of the Nile, and, further, since its many harbours and land-locked creeks were peculiarly fitted for the dhow-rig, it was but natural that the lateen-sail should become established as the standard rig. It was still further encouraged by the retention from the times of the ancient Greeks and Romans of that long, low-lying craft we call the galley, which in itself is a peculiarity and a characteristic feature of those southern waters. The galley was primarily made for speed and to be rowed, but with a fair breeze the canvas was set. Although for some centuries the square-sail was retained, yet about the year 1500 it was discarded and the Oriental rig used instead, because for her the high-peaked lateen was especially suitable. As we can see for ourselves from existing pictures of early masters, when any sail was set at all the craft were literally smothered in canvas, and with the small displacement which these vessels possessed, with their lightness and great length, their speed before the wind must have been something enormous.

And even when the Venetians, Genoese, the Spaniards, and the Portuguese took to building bigbellied cargo craft, and left the galley type merely for warlike purposes, the lateen-sail was still employed. No matter whether the merchant craft carried one or three masts they were fitted with the triangular lateen and not the square-sail. Thus it was that Moorish pirates, Italian cargo-carriers, or Spanish galleys swore by the excellencies of the lateen fore-and-aft rig. It spread everywhere in the south, and still prevails even to this day. Even the Swiss lakes retain it, as the tourist is well aware. The resemblance of this lateenrig to the Arabian dhows is very marked. But actual experience shows that these Swiss craft embody all the disadvantages of the dhow-rig, for the high peak whilst 


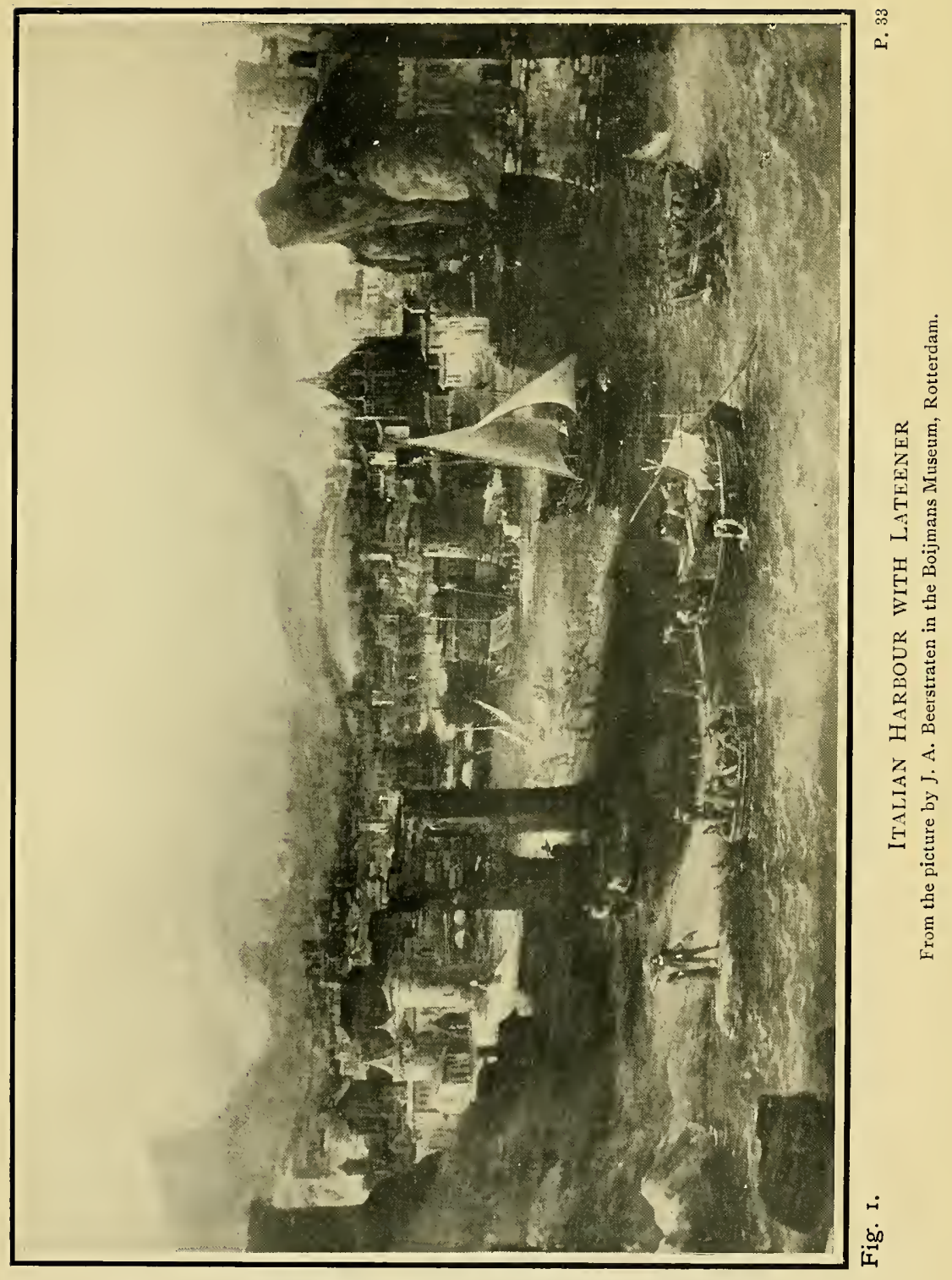




\section{ORIGIN OF THE FORE-AND-AF'T RIG 33}

of unquestionable benefit in light winds, is the most unsuitable of all in sudden squalls. These Swiss ships have wonderful reputations for "ghosting," yet when those sudden and hard winds blow down on to the surface of the lake from the mountains above, these sails are positively dangerous. But for all that, so powerful is the conservative spirit of sailors, whether on sea or fresh water, that the rig has never been discarded.

To-day the lateen-rig is to be found from one end of the Mediterranean to the other. You will note all sorts of modifications, you may notice three masts instead of one, and even in the " one-sticker " you will occasionally find that, not content with its lateen canvas projecting both forward and abaft the mast, other sails have been sometimes added. A moderate instance of this is to be found in such a craft as the Marseilles fishing-boat, which has added a foresail. The accompanying photograph (Fig. 1), taken from a picture in the Boijman's Museum, Rotterdam, by Jan Abrahams Beerstraten, painted in 1654 , shows an Italian harbour with a vessel so rigged running before the wind. The most extreme example, however, is to be found in that singularly curious craft of Portugal known by the name of the muletta. But with each of these we shall deal later. Our immediate object is to insist that the fore-and-aft rig as we have it in northern Europe is of much later development as compared with the Mediterranean lateen. In its original purity the latter is just a large triangular sail, of which a good portion is forward of the mast. The addition of jib and staysail, of topsail, of even "watersails" as well ; the multiplication of masts so that one or two of them may carry square-rigged canvas-all such things as these are accretions and do not properly belong to the native Mediterranean rig. Rather they have been adopted owing to the northern influence exercised through the medium of English, Dutch, or French ships voyaging so frequently backwards and 
forwards to the Middle Sea. It is, indeed, quite amusing to notice that whereas both the square rig and the fore-and-aft came to northern Europe entirely owing to the Mediterranean ships, yet the former, at a later date, actually had a most potent influence in fashioning the southern rigs as we know them to-day. Those curious additions of triangular headsails and topsails actually give to the ships of the south the character of a mongrel. They have an effect about as incongruous as those offences to the eye when one occasionally espies coming down the main street of some old town of the Netherlands a Dutch woman clad not merely in the attractive costume of North Holland, but capped by a black bonnet and strings of the dowdiest nineteenth-century cut placed over the national headgear.

It is essential to our study that we should possess some general idea of the different varieties of the lateen-rig of the south before we proceed to study the manner in which the Mediterranean cast its spell over the north. Our task, however, is not by any means exclusively confined to the lateeners, but rather to show how, given a certain theme, different nations in different periods have elaborated the same. If, then, we run very briefly through the modifications of the descendant of the nuggar lateen-sail, and in the following chapter proceed to show the different aims which actuated those dwellers by the side of the North Sea, we shall be enabled to see the intimate connection which exists between, say, the Lowestoft drifter of to-day and the Nile nuggar both of the present and the past. In the illustration of the Marseilles fishing-boat (Fig. 129) which is given in our final chapter it will be seen that the raking mast of the Oriental craft is retained, and that the headsail is not set on a bowsprit; but among the Mediterranean trading coasters a bowsprit is common enough together with a topmast and topsail.

If we examine some of those interesting prints of 


\section{ORIGIN OF THE FORE-AND-AFT RIG 35}

the sixteenth century we shall find frequently a species of Mediterranean galley called the tartana, and the accompanying illustration (Fig. 2) will show that she carried a couple of lateen-sails. The galleasses were a later development of the galley, the aim being to preserve the handiness of the latter, yet to combine some of the better sea-keeping qualities

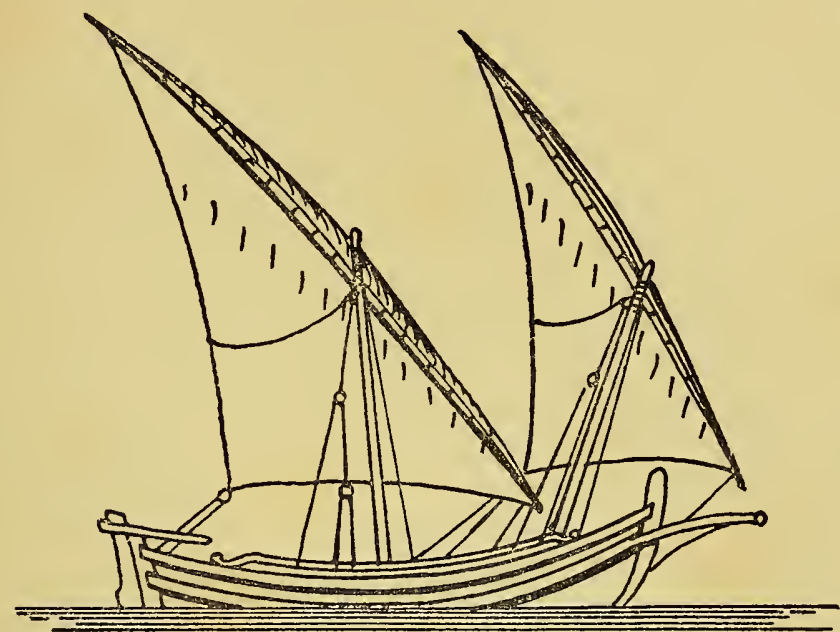

Fig. 2.-Mediterranean Tartana.

She has a couple of the southern lateen-sails, and on each sail has a brailingline for shortening in canvas when necessary. ('Taken from Chapman's Architectura Navalis.)

of the bigger-bodied ship. Contemporary illustrations of the Spanish Armada show such craft rigged with three masts, on each a lateen, but some of the craft have their foremast rigged entirely with a couple of square-sails, the two other masts having each a lateen. In the nineteenth century sometimes the lateener, not content with carrying a jib and bowsprit, added to herself also a square topsail and a lateen mizzen. Even when the southern ship had so forgotten her national characteristics as to rig herself after the 
manner of a northern brigantine, yet she would sometimes retain the loftily peaked yard and sail of the lateen on the mizzen.

Another characteristic to be noted is that whereas the lateen of the Orient tends to become practically a rectangular shape, the Spanish fishing craft retain their strictly triangular form. But it is the Portuguese moletta or muletta which, though a lateener by descent and nationality, does her very best to disguise herself from any other vessel afloat in any part of the world. Looked at for the first time, it seems impossible to place her in any category of sailing craft. Her sailplan seems less like that of any rational vessel than a terrible nightmare of a geometrician. Everywhere it seems all angles and squares; the number of straight lines is bewildering and apparently utterly meaningless. You would put her down at the best as a freak of an exceptional type and past the wit of any sailingman to comprehend, let alone the average layman accustomed only to pleasure craft or the picture of full-rigged ships. But it is when we begin to examine the muletta that we find out her true nature. In the main she is still a lateener, as her biggest sail shows. Forward she carries those square "water-sails" which belonged to the first full-rigged ships of the Middle Ages, and handed down to us through the Tudor and Elizabethan periods even to the early part of the nineteenth century, when our sailor-men used to call them "Jimmy Green's." Right aft a jigger projects over the stern something after the manner of a West of England lugger, and thus additional aftercanvas can be set. Forward of the lateen a staysail is set, which reaches from the top of the mast to the bowsprit or sometimes to the stem-head. Forward of that, again, comes the jib, and besides the lower water-sail there is also an upper small square-sail which extends from a small foremast with considerable rake forward, after the manner, and a survival of, of the 
classical artemon which existed even in St. Paul's time.

What is the meaning of all this complication, do you ask? The answer is very simple. These mulettas are employed in the trawling industry, and the intention is to balance the sail of the bows against that of the stern, so that they may easily regulate the speed of the ship when the trawl is down. These beamy, black-hulled craft are about fifty feet in length and carry a crew of ten men, their home being up the Tagus. The muletta is evidently very proud of her ancestry, for she still paints eyes on her bows, still fits those curious spikes forward above the waterline, features which are curious but interesting survivals from the time when the Roman galleys used to ram each other on the waters of the Mediterranean. The smallest of these craft measure forty-five feet long, and the largest have sixty feet, with ample beam. The greatest number of crew does not exceed eighteen men, but excessive as that amount of hands seems to us they are necessary when so many different sections of canvas have to be handled, and a sudden squall requires all these amazing kites to be got in smartly. 'The lines of the muletta are not less curious than her rig, for instead of having a keel coming down lower than the hull, the converse is the case and her bottom is quite hollow, so that when she is beached she can take the ground without heeling. Furthermore, when she heels under her canvas she thus has a greater draught listed than when exactly upright. The fishing is done with a kind of beamless trawl, ropes from the net being fastened to the projecting spars seen at either end of the craft, the latter being allowed to drift sideways, her after-sails balancing her head-sails, and a leeboard controls her drifting to some extent. The chief cruising ground of these craft is in the vicinity of the Burlings, a group of rocks lying off the Portuguese coast near the bar 
of the Tagus. The spikes, though chiefly ornamental, have their uses, for they are fitted with fairleads for the sheets of the water-sails, and are sometimes also used for carrying creels of fish.

But it is when we pass eastwards to the waters of the Adriatic that we come to another development of the nuggar-rig. We have now not the lateen of Spain or Portugal, but the lugsail, that is so typical of Italy, which Turner and a thousand other artists have made so familiar to us in their brightly coloured paintings of the Adriatic. 'The fore-and-aft rig may best be studied by confining our attention to the two main types of craft, called respectively the trabaccolo and the braggozzi. The decorations, striking and contrasting in their hues of the sails, can be left out of our immediate consideration, for these are but details, and serve only to confuse the study of the rig itself. The trabaccolo is to be met with in most of the Adriatic ports, brilliant in paint and sails, though the latter are much better cut than a casual critic might suspect. The trabaccolo is rigged with a standing lug on each of her two masts and a jib on her bowsprit. Occasionally the mainmast carries a gaff mainsail instead of the lug, but this is not frequent. Usually painted some combination of yellow and crimson, the sails are sometimes left white. Their ground tackle consists of enormous grapnels and hempen cables. The jib is cut very low, and set on a bowsprit steeved high. These ships have a bold sheer, are almost flat-bottomed, and, as in the Marseilles fishing and pilot craft, the rudder descends some distance below the keel. Good seaboats, weatherly, they carry the cargoes of the Adriatic up and down the coast. The sail-spread is not excessive, but the lines of the vessel herself are beautiful, giving with the high bow and the rounded stern a singularly able ship, suitable for the heavy blows and seas for which the Adriatic is famous.

The braggozzi rig is another type of the standing lug 


\section{ORIGIN OF THE FORE-AND-AFT RIG 39}

carrying two masts, whose home port is Chioggia. In size the braggozzi is inferior when compared with many of our British fishing craft. She is a kind of distant cousin of some of our fishing luggers, but the foremast and foresail of the Italian are much smaller than the main. Beamy and bluff-bowed, with an enormous rudder which can be triced up when approaching shallow water, the mainmast is stepped well aft. The braggozzi, with its two lugsails, both of which are distinctly well cut, is anything but a slow craft in a breeze, and can hold a good wind. Flat-bottomed, with a gracefully curved bow, somewhat heavily built, especially by the stern, they are among the most interesting of all developments of the fore-and-aft rig.

The Italian lugsail has also spread to the waters of Greece, where in ancient times the old galleys were never rigged except with square-sails. But in spite of the fact that the lugsail has much its own way in the near East (and this, as the legitimate descendant of the lateen, is but natural), yet it is strange to find that in Turkish waters the spritsail-a distinctly northern and Dutch-like rig-should have become so conspicuous a favourite. Thus there is, by the most curious coincidence, a kinship between the modern Thames barge and the coaster of the Dardanelles, although the latter carries a couple of square-sails on his mast as well. The adoption of the spritsail arose through the facility which the latter possesses of being quickly brailed when one of those not infrequent squalls peculiar to the Mediterranean comes rushing down on the sailingship. And it was almost certainly from the ships of the Netherlands during the seventeenth century, when the Dutch were at their highest point of maritime power, that this spritsail plan was introduced into a corner of the world where we should least have expected to have encountered it. It is only when we realise how far-travelled were the Dutch "waggoners of the sea" in those days, how great a trade 


\section{ORIGIN OF THE FORE-AND-AFT RIG}

they carried on by means of their ships between the Low Countries and the Levant, that the explanation becomes perfectly simple. Here was just the quarter where the old Mahommedan galleys were wont to use the ample canvas of the lateen, but its long yard and its great expanse of sail-area made it an unwieldy thing to handle in a squall or a hard blow. The spritsail, on the contrary, could be brailed up both quickly and effectively, and so it has continued.

After we have left the Mediterranean and pursued our way eastwards to China, we are again confronted with a strange surprise. For whilst the Egyptian influence spread itself thither, and is to this day but thinly veiled in the general lines of the Chinese junks, yet the original square-sail of the Nile has, in Chinese waters, become a lug of a most effective and serviceable kind. Stiffened by battens, hoisted on a pole-mast, bent to both yard and boom, kept to the mast by a hauling parrel, fitted with topping-lifts on both sides of the sail, the sail can be lowered instantaneously in a squall, and it is the handiness of the Chinese rig which is one of its greatest virtues. But it is curious to note that Western influence again asserts itself to produce another mongrel type, when we find some of the big Chinese trawlers occasionally setting triangular staysails between their two masts. And as the Italian lugsails have spread to the Grecian Archipelago, so the Chinese have cast their maritime influence over the Malay seamen and elsewhere. Even many of our British sailing canoes owe their rig entirely to the ingenuity of the Chinese junk.

To sum up, then, we trace the origin of the foreand-aft rig to the days when Egypt was in its prime, when the square-sail was the only rig that any nation was acquainted with. Then, because the square-sail had its own defects, which we have already noted, the nuggar-lug followed. Thereafter the influence of Egypt, even after the downfall of its dynasties, spread 
both east and west. The Phœnicians and Greeks and Romans held on to the square-sail for a time, but as civilisation developed the seafaring man could not remain altogether satisfied with his unhandy sail, so the Mediterraneans changed it to the lateen, and, as in Italy and elsewhere, later on to the standing lug. The Chinese, however, attained their own kind of civilisation at one leap, and have been content to remain at that stage with conservative immobility; yet so thorough and reasonable was it that it would seem to have skipped from the square-sail to the lug in one stage: to have seen at once that the square-sail must develop forthwith into the lug without the intermediate stage of the unwieldy lateen.

But our inquiry now is to follow up the development of the fore-and-aft rig along that line of civilisation whose direction throughout history has been roughly north and west: in other words, to the English Channel, the North Sea, and across the Atlantic to North America. To-day the Spanish felucca still carries the triangular lateen-sail, just as Spain always retained this sail even when its big ocean-going vessels of three masts had all but the bonaventure and the main-mizzen as well, when four masts were carried, rigged with square-canvas and yards. So, also, when the English and Dutch and French began to build their deep-sea ships they still followed the Mediterranean custom of setting a lateen on the mizzen-doubtless for the reason that this form of sail held a better wind and materially aided the steering of these big, unhandy vessels-and it was not until even the close of the eighteenth century that the triangular lateen on our own British battleships was so modified that it became the modern spanker and driver of the full-rigged ship, and still survives also on the barque. The process was quite simple; for that portion of the lateen-yard which projected forward of the mizzen-mast was lopped off, 
but already prior to that the forward portion of the lateen-sail had been cut away entirely, leaving only a quadrilateral sail-area on that mast. The point is an interesting one, and whenever we cast our eyes over those few surviving full-rigged ships or barques, either in harbour or at sea, we can look astern and remind ourselves that that spanker is but a modified form of the old lateen of the Mediterranean, and so of the Nile nuggar-lug.

Such briefly is the evolution of the fore-and-aft rig of the south, and this must suffice by way of introduction before we proceed to see how the northerners were to avail themselves of the heritage of those who were fortunate enough to live in closer proximity to the beginnings of civilisation and mental enterprise. It would be interesting to follow the manifold developments which in all sorts of out-of-the-way places south of the Equator have occurred in connection with the lateen and lug; but that is not our purpose, and is of only minor importance compared with what has happened in the northern hemisphere. The rulers of the earth are the rulers of the sea, and always have been, and no nation can be lord of the sea without being responsible for much progress in the evolution of the rigs and ships that traverse the sea. Whilst the Scandinavians have been responsible chiefly for the propagation of the square-sail in northern waters it is owing to England, Holland, France, and America that the evolution of the fore-and-aft rig has made such wonderful progress, and especially to the first two.

It is now to be our pleasant task to look into this progress, to examine one by one the alterations in rig, the improvements in gear, and the general modifications which have occurred to the hulls in connection with the evolution and spread of this rig. We shall find the theme of unending interest alike for its history and for its connection with the unremitting endeavours 


\section{ORIGIN OF THE FORE-AND-AFT RIG 43}

of mankind to beat the sea at its own game. We shall love our ships none the less for knowing more about their varied careers, but rather in learning to appreciate some of the difficulties which our ancestors had to contend with in order to bring about a satisfactory rig, we shall find instruction for ourselves that may not be utterly worthless when we turn our minds to the direction of improving some feature of the modern expression of the fore-and-aft rig. 


\section{CHAPTER III}

ORIGIN OF THE FORE-AND-AFT RIG IN NORTHERN EUROPE

TAVING regard to the importance, the prevalence, 11 and the varieties of the fore-and-aft rig in Europe, America, and elsewhere, it is unfortunate that no trace can be found of any record of the date when this rig was introduced into northern Europe. I have myself made most careful and extensive researches, yet have failed after years of inquiry to arrive at any definite date, and it is extremely unlikely that we shall ever be able to obtain such information. But the date at which I have succeeded in fixing the actual existence of the fore-and-aft rig is many years earlier than has been assigned hitherto, and will be dealt with in due course. And notwithstanding that there are gaps in the historical sequence just at points where we can least afford to dispense with them, yet in spite of this it will not be impossible to place before the reader a clear idea of the manner in which the transition occurred. With the material that has happily been preserved to us, we cannot remain entirely in ignorance of one of the most notable evolutions in the history of human activity and progress.

Now we must remember that in the north as in the south of Europe the square-sail comes first in historical sequence. In my previous history of the sailingship, I suggested that the Scandinavians and Vikings succeeded to this heritage from the Phœnicians, and subsequent study of the subject has only tended to strengthen my belief in this theory. From the North- 
men the Viking shape of hull, plus their square-sail, came to be the standard type of British craft. There were, of course, certain modifications as time went on, and new ideas occurred; but, roughly speaking, till the time the 'Tudor dynasty arrived the Viking square-sail ship obtained in the fishing, the trading, and the fighting craft of our country, and not merely here, but in France, as well as the Low Countries. It was but natural that this should be, for the Norsemen had overrun the sea-girt countries of the German Ocean, and not only dominated the very liberties of these nations, but instilled into them the Scandinavian ideas in regard to nautical matters, as the conquering race usually and forcibly instructs its vanquished. The minds of those dwellers by the sea were too little sharpened to allow of much possibility of originality. They acted mostly according to precedent, and continued to repeat types rather than create new models. Thus it was, then, that the Scandinavian ideal was followed. Thus it was, also, that for centuries the fore-and-aft rig never reached, or at any rate was never accepted by, the seamen of northern Europe. 'They had-some of themseen the lateen when they voyaged to the Mediterranean at the time of the Crusades or for purposes of trade.

But seamen are the most conservative and obstinate human beings which ever trod the earth; though, as we know from existing records, the big ships of the Mediterranean did most certainly impress them, yet it ended at that. Doubtless their own craft they considered to be better for their own work; no doubt they reasoned, in much the same manner as many a fisherman or ship's hand argues to-day when they come to see some strange rig for the first time, some improvement in gear, some novel form of hull. They "didn't hold with it," just because it was something which hitherto had never come within their experience. The case is analogous to the fisherman and sailing 


\section{ORIGIN OF THE FORE-AND-AF'T RIG}

coaster who a few years ago scorned and derided the mere thought and mention of the marine motor. $\mathrm{He}$ "didn't hold" with that either, simply because he had never had experience of them. But now that he finds that a motor-auxiliary gets the fish home to port more quickly, enables the topsail schooner to enter harbour regardless of the tide and to make her trading voyages with a regularity rivalled only by the small coasting steamer, he has changed his mind. He recognises, in spite of himself, the obvious advantages of this new departure, for it gives to the sailing-ship an efficiency and a handiness which she never possessed before.

In much the same way the fore-and-aft rig had to fight its way into adoption, yet it was more difficult, because it had to fight against even more stubborn ignorance than the motor engine has had to contend with to-day. But then there occurred in Europe that wonderful, far-reaching movement which we call the Renaissance. It sent a kind of electric shock through the mediæval intellects; it roused them from their stupor, caused them to think for themselves instead of remaining mere copyists, simply reproducers of other people's ideas. It was a movement that produced results as soon as it got going. It did more: it produced revolutions, not merely in politics and ecclesiastical jurisdiction, with none of which our present inquiry has to deal; but in art, in science, in literature, using each of these words in its widest sense, it inspired a breath of originality.

Take the subject with which we are entirely concerned. Notwithstanding that the lateen had been in use on the Mediterranean ships of the size large enough to carry cargoes, usually (but not always) in conjunction with the square-sail, yet until the time of the Renaissance, or just after, the galleys of Venice had continued to be rigged with square-sails in a manner almost identical with that of the ancient galleys of Rome and Greece. But, at any rate, by the time of the sixteenth 
century, as we know from existing illustrations, the lateen replaced the old square-sail, and became the recognised rig of the long ship or galley. It was the spirit of the Renaissance, the desire for considering things as they are and not as they have always been regarded, that caused the Venetian seaman to weigh up the advantages respectively of the lateen and the square-sail, just as later on he estimated the worth of the former again, and decided in favour of the lug.

The Renaissance began in Italy, as was only natural seeing what its past history had been and having regard to its progress in civilisation. But gradually this new influence spread northwards, and in England as well as in other countries it set afoot a new movement of energy. Amongst other results it caused even seafaring men to pause and think independently. Was the square-sail, after all, the most suitable rig for their craft? They had never wondered before, but had taken it for granted. And the answer to their inquiry is shown by their actual results. For they had room for their square-rigged craft differing but little from the Viking vessels, and yet they wanted something handier and more suitable for their rivers and inland navigation. 'The fishermen and traders naturally still held to the practice of using the square-sail, for the reason that the North Sea, with its hard blows, its general freedom, during most of the days of the year, from soft, gentle winds, made the lateen-rig utterly undesirable. It was quite out of the question. Unhandy as the square-sail might be, especially when entering harbour, yet it was a more seaworthy arrangement. ${ }^{1}$

For inland sailing, or even for estuary work, for the

1 Leslie, in his Old Sea Wings, Ways, and Words, makes the suggestion that the origin of the cutter or sloop was when the lateener was noticed to bave the fore part of her sail aback, and thus it may have occurred to some ancient sailmaker to cut a lateen-sail vertically by the mast, and so make two sails out of one, giving the fore part a sheet to itself. This, of course, is pure supposition, but it is a likely theory. 
wide reaches of the Scheldt, with its strong tides and tricky channels, its shoals and sandbanks ever ready to pick up an unhandy ship, there was certainly room for a better rig, and so tentatively, at first, it was adopted. Before long it was universally accepted for inland work, for ocean-going ships' boats, and finally was used for large craft which made voyages across the North Sea and down the English Channel and elsewhere. We shall deal in detail presently with the earliest fore-andaft rigs that can be traced, but as to the question whether the north Europeans created their fore-andaft rig out of their own brains by adapting the squaresail of their sea-going craft to suit inland navigation, or whether they copied slavishly something seen in the Mediterranean or Adriatic, cannot be asserted definitely. What seems, from the evidence, most plausible is that the suggestion and certain of the details were obtained from the south, but that the actual carrying out of the idea, together with most of the methods employed, were of northern rather than southern origin. 'To be precise, it would seem that the seaman of the north realised that his present ships were unhandy, but at the same time he realised that the southern craft were to a certain extent superior to his fishing "busses," because the former could hold a better wind and were quicker in stays. At the same time, that high peak and enormous length of yard in the lateen convinced him that however suitable these might be in fair weather they were not convenient for the north of Europe, and would be highly dangerous in a strong tideway and a hard wind. But, as all ships and all rigs in all times and countries have ever been a compromise, so some happy medium had to be discovered between the seaworthy but clumsy square-sail on the one hand and the speedy but dangerous lateen on the other. As an attempt to weld into one conformation the virtues of these two dissimilar types you have the fore-and-aft rig of 
northern Europe to-day if you first make a certain allowance for the modifications and improvements which only can result from time and actual experience of the rig. The earliest date at which $I$ have been able to find any evidence of the existence of the fore-and-aft rig in northern Europe is the year 1475 , and since the golden summer of the Renaissance is covered by the dates $1450-1500$, it is more than likely that this year, which happens to be midway between these two dates, was just about the time when the new idea had its first opportunity of taking definite shape. To sum up, then, it is reasonable to suppose that the fore-and-aft rig in northern Europe was first introduced somewhere about the year 1475 .

But it must not be supposed for one moment that the square-sail was discarded by the fisherman or the trader either then or centuries after. We have shown that in spite of its defects it was far too valuable to be left ashore. A vessel that has to put to sea or to lie to her nets in all kinds of weather must primarily be not fast or handy but seaworthy. Thus the squaresail still remained in the North Sea as it had done since the times when the Scandinavians first introduced it there. We have ample pictorial evidence that the herring - drifters of the Low Countries were rigged with square-sails, and it is from these that the north European fishing luggers evolved and continued until the ketch-rigged smacks began to oust them. But Scotland, Sussex, Cornwall, and the Isle of Man in the United Kingdom, and the chasse-marées of France still bear witness to the fact that not all fishermen prefer the cutter or ketch to the lugger. We alluded just now to the common bond between the Oriental lugger and the north European, but the resemblance is not so much through the latter copying directly from the former as owing to different seamen arriving at the same conclusion in the presence of similar problems. In other words, just as the 
Egyptians found they required something better than the square-sail, and evolved such a sail; and as the Chinese also became possessors of the lugsail, so the English, the Dutch, and the French fishermen gradually effected-quite apart from the cutter, the sloop, the ketch, the yawl, and the schooner rig-an improvement on the square-sail which they call the lug; and since it preserves some of the defects and some of the virtues of the square-sail, it is yet another instance of the law of compromise.

If the reader will now turn to the illustration in Fig. 3, after an artist of the name of Elandts, we will begin to show the kinship between the square-sail and lug of the North Sea fishermen before we return to discuss in detail the evolution of that other branch of the fore-and-aft rig which has among its descendants the cutters and ketches of to-day. The painting from which this craft is drawn hangs in the Municipal Museum at the Hague. The Hague picture itself is not an original, but a copy made by Cornelis Elandts as far back as the year 1664. The original was formerly in a Scheveningen church, but was found to be in so bad a condition that it was impossible to restore it, and was therefore copied as stated. The subject, which was painted by a contemporary artist, shows the sea and shore off Scheveningen in the year 1570 , just before a memorable and historic tempest. On the beach a vessel is being repaired which shows the unmistakable relation that exists between the hull design of the Dutchman's ship and that of the Vikings. The stem of this sixteenth - century craft being repaired is especially akin to that of the modern Dutch tjalk which one encounters everywhere in Holland.

But to return to the sketch before us, which is the most interesting portion of the painting, we have here a sixteenth - century "haring buys," or rather the prototype of the "busche" of the following century. 


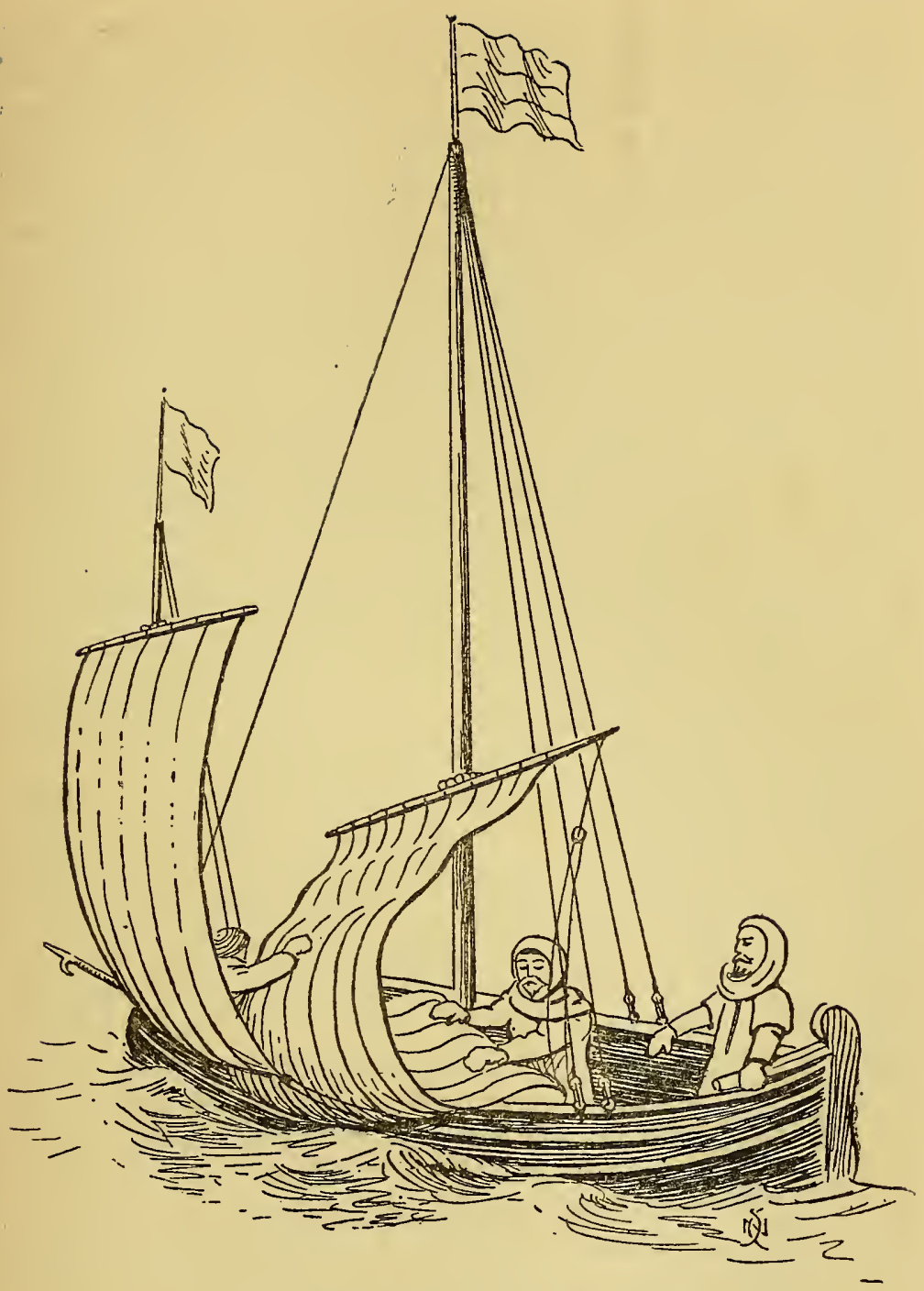

Fig. 3.-Scheveningen HerRing-Buss.

This shows a sixteenth-century type of Dutch fishing craft in which the squaresail was still used previous to the employment of the lugsail. (After the picture by Elandts in the Municipal Museum at the Hague.) 


\section{ORIGIN OF THE FORE-AND-AFT RIG}

The herring industry was one of the most remunerative enterprises of the Dutch even during its prosperous seventeenth century: so remunerative indeed that any interference attempted by England made naval warfare immediately a possibility. The reader may be perhaps reminded in passing that one of the prime causes of the first Anglo-Dutch war was the fact that our Charles I. had enforced his prerogative as Sovereign of the Seas by demanding the sum of $£ 30,000$ annually from the Dutch for licences to fish in the Narrow Seas. This will give some idea of the vast amount of wealth that the Hollanders must have found in the harvest of the sea every year, and of the large fleets of herring-drifters that put to sea from the Dutch ports. And it was in the summer of the year 1652, when the first real beginning of the Dutch war took place, that Blake, who had sailed northwards to Scotland, came upon a big fleet of these herring-men fishing off Buchan Ness and captured a hundred of these buss-ships.

This sixteenth-century buss-ship which we are now considering was of a smaller type than those that were to follow, but it exhibits just those transitional features between the square-sail and the lugsail of which we are speaking. The ship has two masts, consisting of a mainmast and foremast, the former being the smaller of the two, and the main being stepped a long way forward of the stern. On each mast is set a square-sail with sheets and braces as on a full-rigged ship, the yard being kept to the mast by wooden parrels.

In Elandts' picture one of the three men is at the helm whilst the other two are busy lowering away canvas preparatory to beaching their craft on the sandy shore. It will be noticed that these busses have shrouds to support the masts, and that a forestay extends from the top of the mainmast. In the Elandts picture the artist has been so anxious to 
show the men in the act of stowing the mainsail that he has not been able to work into the drawing the shrouds on the port side, although he has been careful to show that the boathook in the bows is all ready for use as soon as the vessel bumps on the shallows. In the picture in Fig. 4, which was sketched in the Boijmans Museum, Rotterdam, from the painting by Jacob Bellevois, we see a couple of seventeenth-century busses, of greater size and power than those of the preceding picture. Bellevois was born in 1621, and was buried in September of 1676 , so that if we suggest that this picture was painted about the year 1652 we shall not be far wrong, and shall have an accurate conception of the kind of vessels which Blake surprised off Scotland. There is additional probability that this picture was painted about the year 1652, for at that time Bellevois was living at Rotterdam, and five years later moved inland to Gouda.

It will be noticed that the busses have now become more powerful ships, and that they carry a mizzen as well as main and fore. If we were to take away the fore and mizzen we should have in respect of rig and hull almost an exact replica of the Humber keel which is so familiar a sight to Yorkshiremen and those who live near the Trent. The buss-she spelled her name with all sorts of variations that included buys, busche, buze, and buis-was sometimes called a fibot though, strictly speaking, the vlie-boot or flibot was a small "flute" of a size not exceeding 100 tons and of a round stern. The flibot proper was a deep, bigbodied craft lacking both foremast and topgallant-sail. A flute, or as she was sometimes called, a pink, was also a big-bellied craft, used as a storeship or for transport purposes. She was a three-masted ship and square-rigged, except, of course, for the lateen on her mizzen.

But the buss-ship as we here see her was square- 


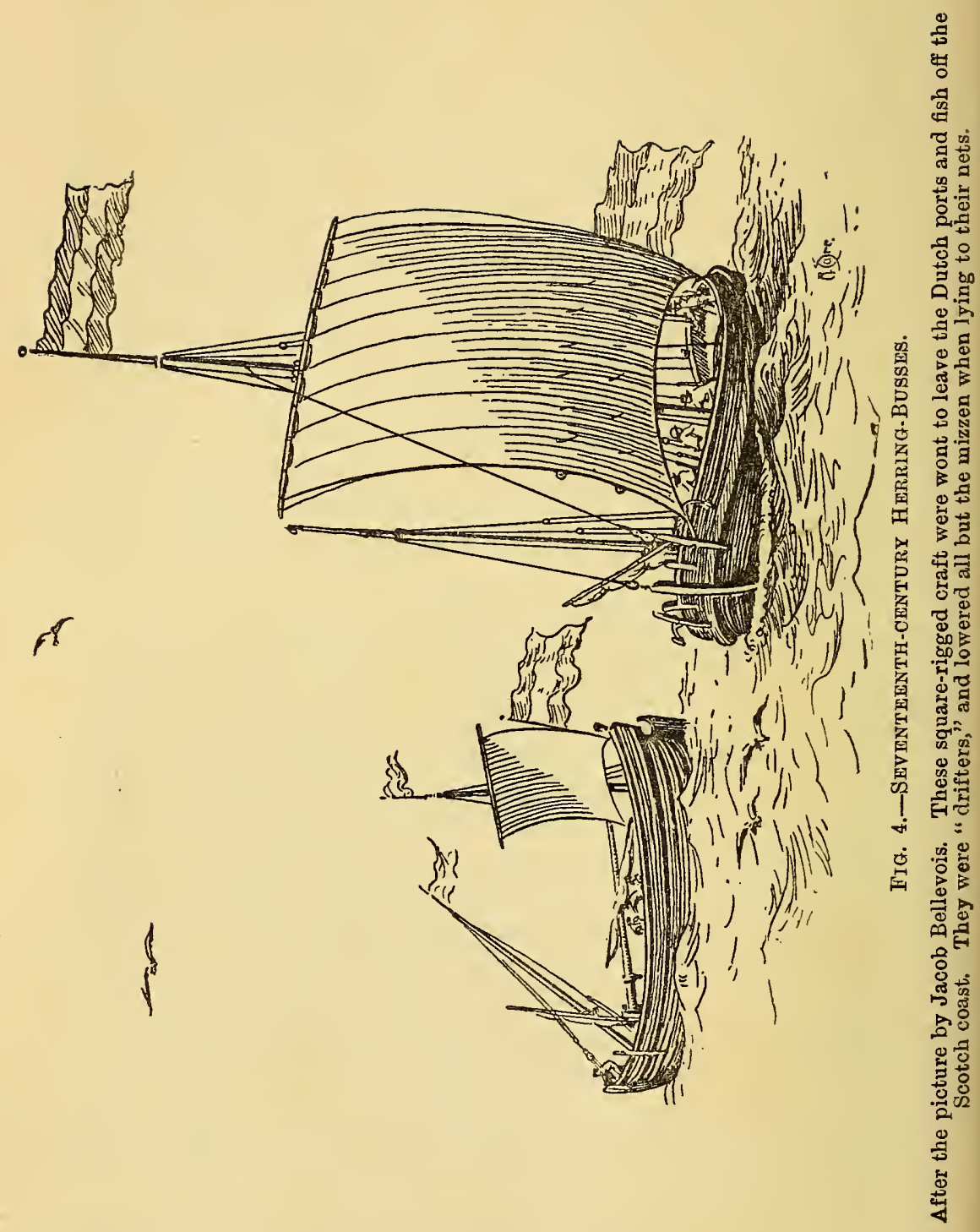


rigged without topsails or topgallants or lateen. She was usually of about 62 feet long and 13 feet beam and 8 feet deep. She had cabins both forward and aft, the former serving for the galley. These ships were commanded by a master or "patron"-as the French to-day call their skippers, if you care to look at the memorial stones to those fishermen or pilots who have lost their lives off Calais-and the crews of the busses were provided with food in the form of biscuits, dried fish, salt butter, and oatmeal. Some of the bigger busses measured 71 feet long, and cost $£ 2325$ to build, not including the heavy ironwork. The sails were of Holland cloth, the mainsail with its bonnets-which were laced according to mediæval fashion along the foot of the sail after the manner of the modern Norfolk wherry-measuring 15 ells long and 13 ells wide. The foresail with its bonnets was 12 ells long and 10 ells wide, whilst the mizzen with its bonnets was of the same length as the foresail but one ell less in width. It will be observed that neither in this nor the Elandts picture are leeboards shown to belong to these craft. The usual custom for the buss was to sail out to her fishing-grounds using her three sails, or, if a two-master, with her main and foresail only. Then lowering both foremast and foresail, but keeping her main or mizzen up, according as to whether she was a three-sticker or two, she rode to her herring-net, precisely as a Lowestoft drifter to-day, though ketch-rigged, lowers her main and rides to her nets, or the Sussex lugger to hers. The photograph of the picture in Fig. 5 by Abraham Storck, who died about the year 1710, shows a couple of small busses of the year 1683. In the foreground one is lying at anchor with foresail lowered and mainsail up, whilst astern of her another buss is running before the wind under mainsail only. This picture is hung in the Mauritshuis at the Hague.

Now, looking at these buss-ships, and especially at 


\section{ORIGIN OF THE FORE-AND-AF'T RIG}

the mainsail of the vessel to the right of the picture by Bellevois, one can readily see how easy was the transition from the square-sail to the lug. The two sails have a very great deal in common. Neither has a boom, and both have a yard which is slung from the mast. But there is this important difference, that whereas the square-sail is slung from the centre, the yard of the lugsail is suspended at a point about onethird or a quarter of its length forward of the mast. The yard also, instead of being at right angles to the mast, as in the square-sail, makes a much smaller angle with the mast, varying from about forty degrees. Furthermore, as in the case of the dipping-lug, which is much used by our fishermen, the tack of the sail is made fast some distance forward of the mast. And since the sail has to be hoisted on the lee-side of the ship in order to get the best advantage, it has to be lowered on each tack and set again on the other side. In the Bellevois picture the tack of the mainsail has been sheeted forward so that the vessel will get as close to the wind as possible, but so long as it remains a square-sail and has not those features of the lug just mentioned, there will be a difference of at least one point in the sailing qualities of the square-sail and the lug, and the advantage will be in favour of the latter. 'Therefore, by the not very elaborate process the yard of the square-sail is braced round, the tack is hauled down, and the after end of the yard becomes peaked. Thus the squire-sail becomes a fore-and-after.

I have not thought it necessary to reproduce more than these accompanying illustrations to explain how small in reality is the alteration, but the reader who cares to pursue the subject will find ample pictorial evidence in the works of the great Dutch painters of the seventeenth century, especially of such men as those already mentioned, as well as Van der Velde and Bakhuyzen. The Dutch museums teem with such paintings, and the galleries of London and Paris will 


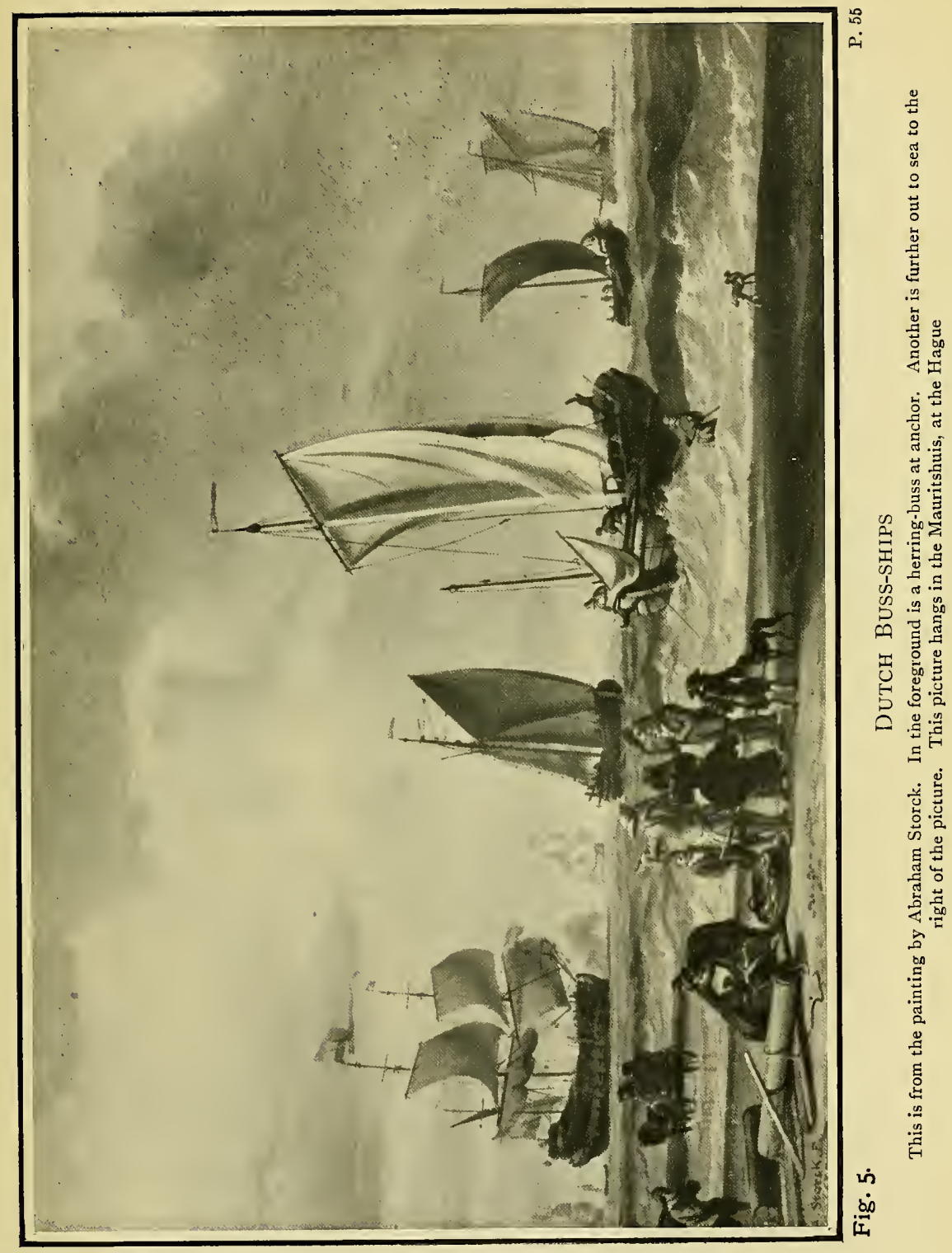



afford probably as many examples as will be required. In the next sketch in Fig. 6, which is taken from a model in the Rijks Museum, Amsterdam, we see the Dutch equivalent of the Mediterranean lateen galley. Here there is no hesitation as to the rig, and the lugsail has entirely replaced the square-sail, but a mizzen has been added as a kind of afterthought, and a jib too. Very characteristic are the pair of leeboards on each side and the unique arrangement of topsails. So as to clear the mast the topsail is divided into half, and the little yard on the afterhalf is very characteristic of the Dutchman, who loves these small spars and employs them whenever he has an opportunity - as, for instance, for bending the halyard to his foresail on a hoogarts, as we shall note later on. It cannot be denied that this model before us, with her guns, her chase-piece, and her beak, betrays the influence of the Mediterranean galley, even though the lugsail is different from the lateen. Hundreds of the Mediterranean galleys rounded Ushant and came up the English Channel in the sixteenth century. But they were never popular with our own seamen, notwithstanding that Henry VIII. had some built for his navy and fitted out by imported Venetians. As the galley contingent of the Armada found, the chops of the Channel and a capful of wind made them singularly unpleasant craft for those who had to work in them. But it is not too much to claim for the Dutch craft in front of us, for the Deal galley, the Sussex, Cornish, Manx, Scotch, and French luggers, that there is found in these the best forms of craft to correspond with the galley of the Mediterranean and of southern history.

We have thus witnessed one branch of the development of the fore-and-aft rig in northern waters, and we can now proceed to watch the evolution of a still more interesting type which eventually brought about the cutter, the sloop, the ketch, the yawl, and the 


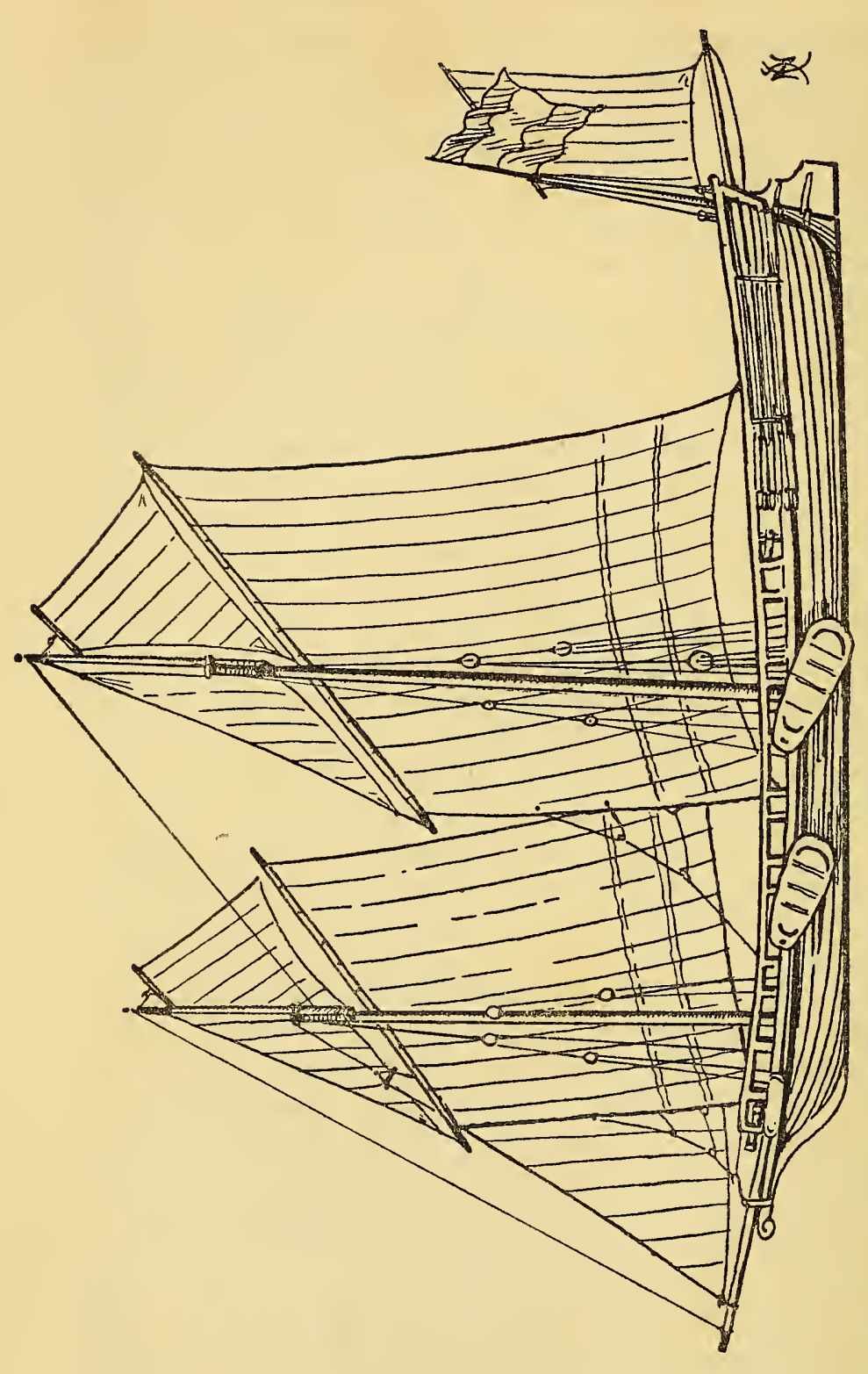

$\frac{9}{0}$

密

㦰

은 몀

它采

수

刃ํㅀ

马्త్ㅂㅇㅇ

武 喝

ह

0 .

몬

방 章

म

औ

공

I

罗

봉 용

P

$\because$ ह

- 国웅

ठं 둉

ध

号

.

.

텅

구

믈

㤩先

龸

in

寻产

害总

묘 क्

휴

용용

ه

용 
schooner. Just now we referred to the date 1475 as being in all probability the time of the first fore-andafters in the north. I have arrived at this date through the evidence of an illustration seen in the Island of Walcheren. The cutter and sloop did not come about with one step. There was a curious intermediate stage in an endeavour to obtain a comparatively handy rig that was more seaworthy than the lateen. The reader is invited to examine closely

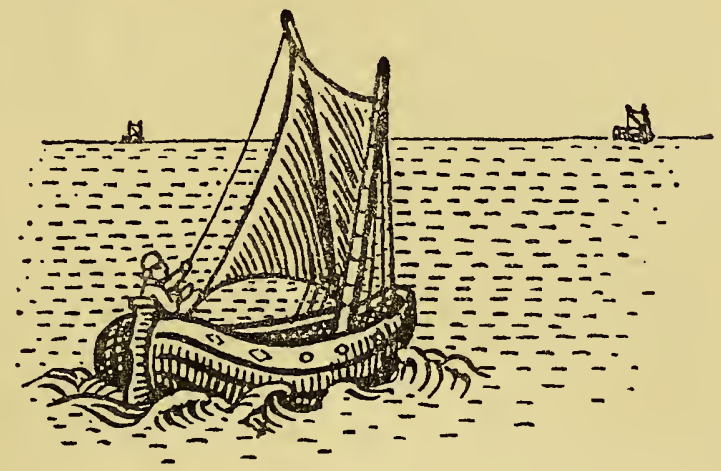

Fig. 7.-AN EARLY Sixteenth-Century Fore-AND-After.

This vessel had a spritsail, as seen, but no headsail. On the horizon will be seen other contemporary craft similarly rigged.

the curious little illustration which is herewith presented in Fig. 7. The craft in the foreground has been copied faithfully from a map of the year 1527 , but it is practically identical as to rig with the pictorial evidence belonging to 1475 . A similar craft, with exactly the same rig, is to be found on the horizon of a printed illustration to an Elizabethan book printed in 1587 recording the pomp and ceremony of the homecoming and burial of Sir Philip Sydney, and this has been inserted in the accompanying sketch. Furthermore, in the Rijks Museum, Amsterdam, there is hidden away in an obscure, dark 


\section{ORIGIN OF THE FORE-AND-AF'T RIG}

corner a picture which bears very closely on our inquiry, and still further strengthens our testimony that about the time we are speaking of there had come into being a new kind of fore-and-aft rig, which consisted, as will be observed, simply and solely of one spritsail. There was no jib, there was no boom, no gaff. 'The mast was placed very far forward in the eyes of the ship, and the one sail was very similar to the mainsail of a modern 'Thames barge. It had a sheet as well as a vang leading from the peak, and the steersman will be seen to hold both these in his hand. The shape of the rudder and of the hull suggests very strongly Holland and her craft, and the spritsail is essentially Dutch by origin.

This rig, then, was a kind of una-rig, as we should nowadays call it, and with the sail placed so far forward no doubt the vessel would beat to windward after a fashion. On the inland waters of Holland one still finds small craft rigged like this vessel, and I remember to have seen such boats on the Hollandische Deep near Dordrecht, and also on the Amstel a few miles south of Amsterdam; but in the latter case, whilst the same idea was carried out, the sprit had been dispensed with and, instead, a gaff and boom added.

We can readily understand how popular this rig of 1475-1527 and onwards became for small craft, because in hard squalls, by withdrawing the sprit, the sail can be at once taken off the ship, and that is the reason why along our coast, especially on the south and west, for open sailing-boats the sprit has been so long retained. 'I'o take the two first instances that occur to my mind, it is the rig of the Portsmouth wherry, as well as of nine-tenths of those little craft which go running in and out of Salcombe, either in connection with the lobster-pots or solely for pleasure. The only difference is that to the primitive spritsail there have been added a jib as well as a mizzen, which, most people would 
agree, form a considerable improvement without detracting from the value of the rig in other respects.

But to come back for a moment to the obscure painting in the Rijks Museum. The incident belongs to the 2nd of January 1565, when an enormous block of ice was carried by the current in a quarter of an hour to the mole of Delfshaven. In this picture will be seen, brought up, a perfect fleet of these one-sail vessels, but with canvas stowed. They are evidently weather-bound, and are anxious to put to sea. The picture is well worth the careful study of any sailingman, because it shows that in the olden days there was in active use a rig that is snugger but not altogether unlike the wherry-rig of the Norfolk Broads, if we gave to it a sprit, a lower peak, and less expanse of canvas.

Thus, then, we have a chain of evidence beginning in 1475 and extending through the years 1527,1565 , and 1587 , to show that a kind of una-rig was in vogue, and that the triangular headsail was not yet used in conjunction therewith, though before the end of the century it had been adopted, as we shall presently see. It was obvious that this addition should be made sooner or later, for when beating to windward the necessity for some canvas forward to pull the ship's head round on to the other tack would impress itself on the mind of the sailor; and in order that it might be of such a size and shape as not to foul the forestay supporting the mast, it was made identical with that fore-triangle in the bows of the boat. Thus a halyard was fitted and the sail was hoisted up the forestay just as we have it to-day on our cutters. The addition of the bowsprit and jib came as a later development, and these we shall deal with in due time; but what we are trying to impress on the reader for the moment is the fact that primarily the fore-and-after was a una-rig, and that it was only as an afterthought that the triangular foresail was added thereto. The sketch of this original rig 


\section{ORIGIN OF THE FORE-AND-AFT RIG}

that we have alluded to is from a map of the world by Robert Thorne. The inscription reads that "This is the forme of a Mappe sent in 1527 from Siuill in Spayne by maister Robert 'Thorne, marchaunt, to Doctor Ley, Embassadour for King Henry the 8, to Charles the Emperour. The imperfection of which mappe may be excused by that tyme : the knowledge of Cosmographie not then beyng entred among our Marchauntes, as nowe it is."

In the Abbey at Middleburg there hang on the walls of the Grand Hall, where the Provincials of Zeeland meet twice annually, some magnificent examples of sixteenth-century tapestry, which show certain interesting naval battles, including the defeat of the Spaniards by the Dutch at Bergen-op-Zoom, and the defeat of the Spaniards at Flushing. The date of the latter incident was April 23, 1573; and we are able to see from these designs that the fore-and-aft rig was employed by the Dutch in their naval warfare of that time. Here again we find ships rigged una-wise with the mast placed right in the eyes of the vessel and no headsails whatsoever. In the battle of Bergen-op-Zoom some of the Dutchmen are ketch-rigged, the mizzen being a lateen, but these, of course, are bigger craft. The Spaniards are ship-rigged. As regards the former, the rig was as follows: Forward of the lateen-mizzen came the sprit-mainsail, then the staysail, then a highly steeved bowsprit; but as yet the jib has not been introduced, for the bowsprit is still used for the convenience of making fast the foretopmast-stay by means of spreaders, into which the lower end of the forestay separates. It was only after the bowsprit had been in vogue on fore-and-afters for some time that it occurred to the seventeenth-century sailors that they might make use of it by setting another sail thereon, outboard, of a shape similar to the staysail. The mizzenlateen and the bowsprit were of course copied from the contemporary full-rigged ships, and it is curious to 
find that although there was no jib, yet below the bowsprit there was carried a square water-sail of the "Jimmy Green" type. Some of these ketches were given square - sails, square - topsails, and square - topgallants on the mainmast.

From yet another source in Middleburg, depicting a naval fight of February 28, 1573, I find the same details as to rig, namely, the una-rig of the one type and the spritsail ketch of the other, amply confirmed. At times, even when a ship was not provided with a staysail, but remained still una-rigged, the bowsprit, steeved up into the air at much the same angle as the later Mary seen in our frontispiece has it, was employed solely for the above-mentioned purpose of spanning out the foretopmast-stay, so as to stay the mast more effectively. But from numerous pictures and prints which I have carefully examined, it would seem that when these una-rigged craft were brought up the sprit still remained aloft, though the sail itself was taken off entirely, and not brailed up as the modern Thames barge retains it when at anchor or by the quayside. And even in Turner's early drawings this same practice will be found to be continued.

Among the Dutch at the end of the sixteenth century and the early part of the seventeenth it was quite a favourite rig for the smaller sailing craft to have this spritsail and staysail, with a bowsprit sticking its nose high up into the air. 'The forestay was employed for setting the foresail, and the bare foretopmast-stay led down not to the extreme outer end of the bowsprit, as we should naturally have expected; but when it was about two-thirds of the way down it ended in a block, and thence proceeded a pair of spreaders, one of which was made fast several feet from the outer end of the " bolte-sprit," whilst the other was affixed somewhere about the centre of that spar. Sometimes one finds the spreaders are more elaborate, and instead of being merely a pair below the block, they become pairs of 


\section{ORIGIN OF THE FORE-AND-AF'T RIG}

three each, or six altogether. But the smallest craft of all, whilst they necessarily retain the forestay, the staysail, and sprit-mainsail, dispense with bowsprit and foretopmast-stay. For how many years the una-like rig survived I cannot say, but I have found that as late as the date 1674 it was not yet discarded, although, of course, the staysail was then employed in many other craft; and by this time, since leeboards had begun to be employed, they were found of assistance in making the una type a better sailer on a wind.

Let us now turn our attention for a while to consider a matter connected with a daring Dutch enterprise belonging to the end of the sixteenth century. Europe had got the exploration fever pretty badly, and since Holland by its long years of the fishery industry, as well as over-seas trading, had gradually raised up a fine race of seamen and an equally fine fleet of ships, it was certain that sooner or later the Dutch would become great explorers and voyagers. They had it in mind that instead of going through the Bay of Biscay, down the southern Atlantic, round the Cape of Good Hope or the Horn, a way through to China could be effected by the Nort-east Passage. A society was formed by the enthusiasts of Zeeland for the purpose of undertaking this voyage, and permission was received from the States-General and Prince Maurice. A squadron of four ships was fitted out under the command of William Barentsz, one of the most experienced of Dutch seamen.

A very great impetus had been given to maritime enterprise by the publication of a book dealing with the East by Jan Huygen von Linschoten. The latter, while resident at Lisbon, had amassed a large number of invaluable data regarding the East-its harbours, trade winds, configuration, and so on. He also produced a number of charts and maps for the benefit of those intent on voyaging thither. 'There is a very interesting copy of this work in the British Museum 


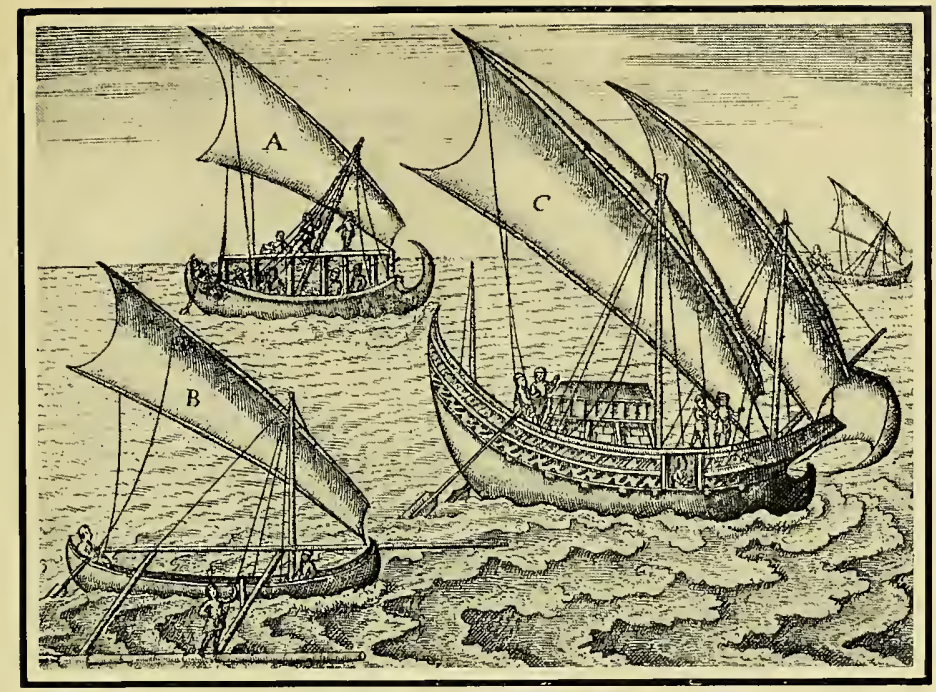

Fig. 8.

FORE-AND-AFTERS

P. 30

This illustration is taken from a Dutch volume of travels published in the year 1598 , and shows the influence of the Egyptian nuggar with the old square sail so modified as to become a kind of lugsail.

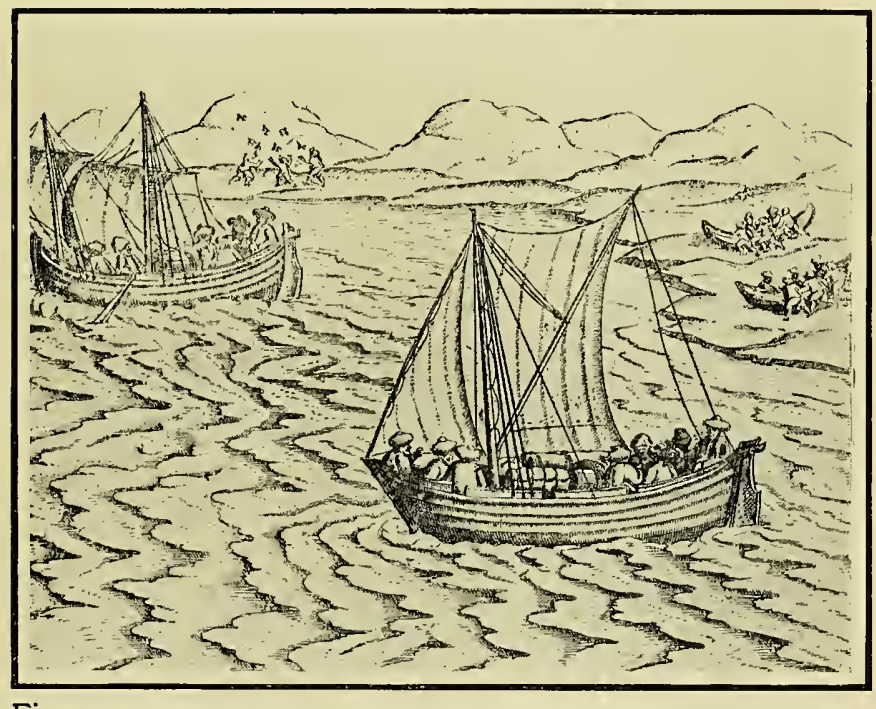

Fig. 9.

The Dutch POLAR Expedition

P. 66

In this illustration, which belongs to the year I599, will be seen the two craft belonging to Barentsz's ship. The sloop is seen in the foreground and rigged with sprit-mainsail and staysail. She has a bonnet laced to the foot of the former, and has vangs from the peak. 

printed in 1596, and an English translation of two years later. The first northern expedition was, however, fruitless, and returned home. A second was fitted out, and that came back to the Maas also a failure. But in the year 1596 a third enterprise was undertaken again under Barentsz. The squadron consisted of only two ships this time, which were equipped not by any Government but by the munificence of the citizens of Amsterdam. On the 10th of May the two vessels set forth, crossed over the North Sea, passed by the Faroe Isles, and eventually discovered Spitzbergen. In due time they arrived at Nova Zembla, which had been already discovered by our English navigator Willoughby in 1553. One of the two Dutch ships became separated from the other, and presently Barentsz's vessel became embayed in the drifting ice, nor could she be released.

We need not waste the reader's time by detailing all the troubles and trials which now followed. They have been happily preserved for posterity by one who accompanied the party. Winter was approaching, and finally the crew, despairing of ever saving the ship, which was groaning and heaving ominously under the pressure of the ice, forsook her, and with the driftwood which they were lucky enough to discover, built themselves a large hut ashore, with many an exciting time in between through the too eager intrusions of the Polar bears, and with much toil consequent on having to drag their stores up from the ship by hand-sleds.

The cold was terrible; their clock refused to go, so that they could only tell the time by means of their hour-glass, and thus distinguish day from night in the darkness of the north. 'Their beer froze solid in the casks, and with many an inconvenience and hardship they continued to inhabit their dwelling from the middle of October to the following June. It was now that they determined to make a fierce effort to get to the south once more. Daylight having returned, and their big ship being still held fast by the ice, they had 


\section{ORIGIN OF THE FORE-AND-AFT RIG}

only the opportunity left to them of putting to sea in the two open boats which they had carried on board the vessel that had brought them north. One of these boats, then, was forthwith dug out of the snow, but she was frail enough in all conscience for her forthcoming voyage, so the men set to work with axes, saws, hammers, and, with the planks taken from the roof of their hut, raised the craft's gunwales so as to give her greater freeboard and cause her to be more seaworthy. This was the larger of the two boats, and was rigged after the manner of the busses-that is to say, with two masts, the one right forward in the bows of the ship, the other about midships, and on each mast one squaresail.

The second boat was a smaller craft-a shallop or sloop, as the Dutchmen called this type-and this, too, was strengthened and given an increased amount of freeboard. But-and this is the point to which I wish to call especial attention-she was not rigged like a buss, but with one mast, a sprit-mainsail and a foresail working up and down the forestay. The illustration (Fig. 9), which is taken from the account printed at Frankfort in the year 1599, shows these two ships' boats under way. The sloop has, it will be noticed, a bonnet laced on to the foot of the mainsail, and vangs leading down from the peak. The craft herself has a transom stern, a cut-away bow, and she has also been decked over and a cabin top given her before leaving the Arctic regions, for prior to this the craft, as is noticeable from one of the earlier pictures in the Dutch book, was a mere open boat and in general character almost identical, at any rate above water-line, with the Yorkshire cobble of to-day, about which craft we shall speak on a later page.

These two small craft succeeded in effecting the explorers' escape. Unhappily Barentsz died before reaching home, but after enduring many more hardships-after having occasionally to drag their craft over 
fields of ice, and to fight with Polar bears-they arrived at Kola in Lapland, where the following day they found that other Dutch ship which had started out originally from Amsterdam in their company. They went on board, and having no further use for the two boats that had brought them so well, they carried them with due ceremony and veneration to the Merchant's House, or Town Hall, where they dedicated them to the memory of their long voyage of 400 leagues, over a tract never traversed before by such tiny craft. They then started for home in the big ship, and reached Amsterdam again on 1st November, by which time they had been long since given up for dead. Their arrival was a most dramatic and welcome surprise, and roused the liveliest enthusiasm among the citizens of this northern capital.

The little sloop, or sloepe, in front of us was clinker built, and had no leeboards. She had three shrouds to her mast on either side, as well as lee-runners. The sprit to the mainsail was supported by block and tackle, very much as in the modern Thames barge, one block being on the sprit and another at the mast-head. But before we proceed any further, let us endeavour to clear up any misconception that may exist in the mind of the reader in regard to the terms employed. It is an unfortunate historical fact that, throughout the history of most ships from very early times, sailor-men have been remarkably careless in nautical nomenclature. Such words as barks, gallies, wherries, galleasses, and brigantines have been regularly applied to totally different types of vessels. So also pinnaces, cutters, and sloops may mean either sailing craft of good size or merely ships' boats. Therefore we shall do well to clear the ground in regard to the fore-and-aft sloop before we proceed any further.

I am led to the conclusion that there can be little doubt but that the Dutch sloepe originally signified a ship's boat such as was used for laying out a kedge 
anchor, and for keeping up communication between the big ship and the shore when there was no harbour for the vessel to enter. The Dutch masters of painting give us plenty of instances of such ships arriving home off a sandy beach from the Dutch Indies or elsewhere, dowsing topsails, and landing their distinguished passengers on to the beach in the vessel's sloop. But as the big ocean-going ships became bigger still, so the size of the sloop increased, until they were something far from insignificant. Instead of being mere oared craft, they were so heavy that they were fitted with mast and sail (as seen in the accompanying Polar illustration of Barentsz's sloop), and were thus an independent type of sailing craft. 'Thus it was that the word sloop was transferred from designating the boat to signify the rig, and thanks to the early colonisation by the Dutch of that portion of America which we speak of nowadays as New England, the word sloop took firm root in America, and is still used even when an English sailing man would use the word cutter. Into this point of distinction we shall look at a later stage. But for the present we may content ourselves with remarking that the English cutters and the American sloops of this twentieth century are directly descended from the Dutch ex-ships' boats, which were called sloepes.

The Dutch referred to the craft also as a "chaloep" or "boot," and an early seventeenth-century authority, written in French and printed at Amsterdam, gives the dimensions of a sloop as 42 feet long, with 9 feet beam. In the case of a two-masted square-rigged sloop, as in the larger sloop seen in the Barentsz illustration, the mainmast was 24 feet high, the yard $12 \frac{1}{2}$ feet long, and the sail had 21 feet in hoist. The foremast was $15 \frac{1}{2}$ feet, the foreyard 11 feet, and the hoist of the foresail $10 \frac{1}{2}$ feet. This same authority also defines the sloops as small vessels, some of which have decks, whilst others had not. 
Partly, then, owing to the many miles of inland waterways, of such important thoroughfares as the rivers Maas, Scheldt, and Rhine: partly because of the number of ports on the Zuyder Zee and North Sea, and the immense amount of traffic which could be carried on solely by means of water-borne conveyances: partly because of the incentive given by the sloops of the great ships of the Dutch Indies, there was every encouragement to build numbers of craft of a moderate size that could carry market-produce and passengers from the outlying villages to such towns as Amsterdam, Dordrecht, and the Zuyder Zee ports, which could be capable of surviving the nasty, short, steep waves which are characteristic of the broad estuaries and contingent seas of the Low Countries.

There is an interesting print in the Rijks Museum, Amsterdam, which is dated 1565, and contains a fullrigged ship, on whose stern is the date of 1564. To the right of this big vessel is a fore-and-after, which is rigged as follows. She has the usual fore (stay) sail, the mainsail has a sprit, and she has also a square topsail as in the full-rigged ships. She also shows a bobstay to support her bowsprit. 'The staysail just mentioned is set as a spinnaker, for she is seen running before the wind. Her mainmast is placed well forward in the ship, and the sprit-mainsail has the usual sheet and vangs. But she is ketch-rigged, for she has a mizzenmast on which a lateen is set. The hull is entirely different from those sloops we have been considering, for it resembles, as far as ever a fore-and-after could, the contemporary naval architecture of the ocean-going, full-rigged vessels. Thus the high-charged stern, with its towering poop-deck, through which the mizzen-mast passes, strikes the modern eye as very peculiar with such a rig as this. But it shows that a date over twenty years before the Armada there were in existence not merely fairly small sloops for coasting and inland purposes, but fore-and-aft ketches of consider- 


\section{ORIGIN OF THE FORE-AND-AF'T RIG}

able size, which could keep the sea independent of the shore for a long period, and be able to ride out bad weather with impunity. There was still no jib to this type of craft, although the steeved bowsprit is very clearly shown; but we can sympathise with the Dutchmen of that time, and appreciate their point of view when they found that for such moderate voyages as across the North Sea to England, and for trade between the Hanseatic ports, and a good deal of intricate navigation in and out of harbours and rivers, a bold foreand-aft rigged vessel of moderate tonnage, so as to be able to carry large cargoes, was in many ways superior to the three or four-masted full-rigged ship with her ultra-seaworthiness but accompanying unhandiness.

Some idea of the fore-and-aft ships in vogue about the year 1600 may be obtained from an old Dutch print of about that date, which is here reproduced in Fig. 10. At one time the authorship was attributed to Johannes Saenredam, who lived at Zaandam from 1565 to 1607 . Recent criticism has cast some doubt on this supposition, but if it is not Saenredam's work it is by one who flourished about the end of the sixteenth century. In the foreground will be seen a characteristic Mediterranean galley with her long, low-lying hull, her beak and enormous yards, on which were set the lateen sails. You may perhaps wonder for the moment what a Southern galley was doing in the port of Amsterdam, until you recollect the years when Spain and Holland were so closely bound together. 'The galley was not beloved by the Dutchmen, or they would have continued to build this type, but for a long time Holland was under Spanish tyranny, and so, naturally enough, the Spanish galley came northwards from its own sunny waters to the fogs and cold of the Low Countries.

Sailing about in the same picture, in wonderful contrast to this slim, narrow type of vessel, are to be seen the Dutch fore-and-afters with their ample beam 


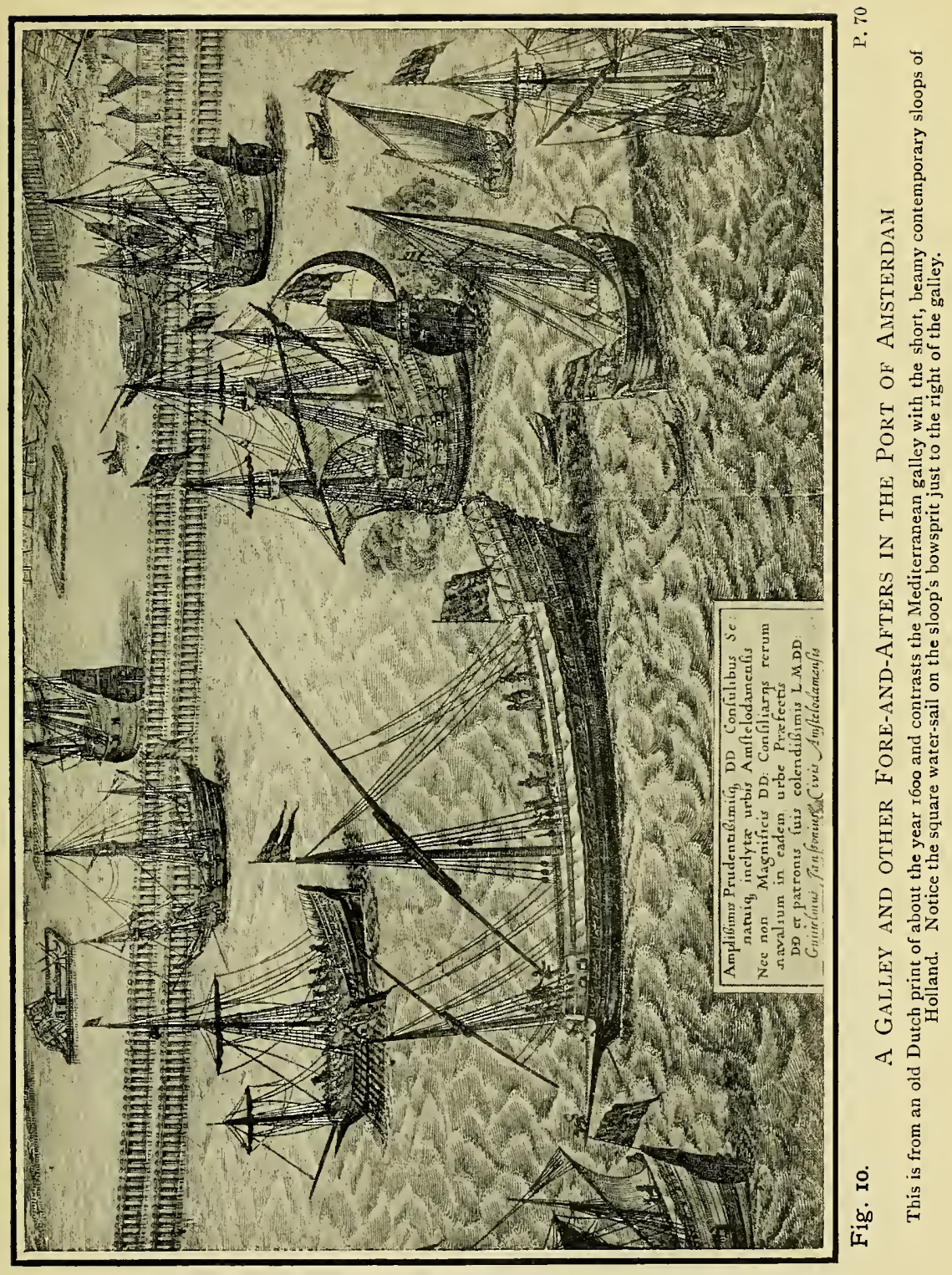





\section{IN NORTHERN EUROPE}

but comparatively short length. To the right of the galley, also in the foreground, is to be seen a large sloop, the staysail of which is just visible. It will be noticed that the outermost end of the bowsprit is clear of any foretopmast stay, as we remarked on another page was the custom, and the square water-sail, with its yard and sheets, as in the full-rigged ships, will be observed below the bowsprit of this sloop. It is noticeable that three out of the four sloops are fitted with leeboards, so we have the fact established that these date back at any rate to about the year 1600 . As to when they first came into use cannot be ascertained, though it is possible that it was sometime during the sixteenth century. An authoritative work published in Amsterdam about a century later furnishes us with some interesting details as to the leeboards, which undoubtedly had their origin in Holland, whence they were adopted eventually in England, and still survive in that Dutch-like creature the Thames barge, to which we have alluded more than once. The Dutch word for leeboard is zwaard, which also means a sword for military purposes. The Dutch word zwaar is an adjective, signifying heavy.

The French word for leeboard then in use was semelle, which means a shoe. The French verb, deriver, means to drift, as in the case of a ship. Consequently the French synonym for leeboard is still to this day semelle de derive, which exactly explains the use of the leeboard, as being for the prevention of a ship's drifting to leeward. The Dutch authority just mentioned says that the zwaard is an assemblage of three planks placed the one over the other and "cut in the shape of the sole of a shoe"; and in many of the Dutch craft of to-day that is exactly the shape in which the leeboard has remained, the "heel" or narrow part of the "shoe" being the part which is pivoted at the side of the hull, while the broad or "toe" end is let down into 


\section{ORIGIN OF THE FORE-AND-AFT RIG}

the water. That straight form of the leeboard with which we are most familiar, and is especially noticeable in the modern botter, is of later evolution.

We learn from our authority that these zwaards or swords were used by such craft as the belanders (i.e. coasters by the land) and hulks so as to enable them to sail on a wind, the usual custom in those days, as to-day, being to have one suspended on each side of the vessel. When they wish to sail on a wind, continues the same explanation, whether to starboard or port, the zwatard which is to leeward, sous le vent, is lowered into the water, and so prevents the ship from driftingderiver-while the other leeboard remains hanging on the opposite side. The belanders, it may be explained, were a species of small craft, very flat on the floor, and in respect of sails and masts resembled the English hulk or "heu." 'The belander's deck began to rise at the bows and continued up to the poop. 'The largest belanders were of eighty tons, and were manned by a crew of three or four, being chiefly used as cargo carriers, and their leeboards thus enabled these bulky creatures to sail à la bouline-that is to say, on a wind. After the close of the seventeenth century leeboards were seldom seen at sea, except on a few boiers, a few light galiots, and some small herring busses, although during the eighteenth century they were in general use for the navigation of internal waterways. And I have myself been aboard a Dutch topsail sea-going schooner of about a hundred tons which carries a pair of enormous zwaards, though there are plenty of modern craft of greater tonnage using these "shoes" up and down the canals of Holland. As to the length of the leeboard, the old rule was that it should be twice the depth of the ship, but the Zeland and Frisian leeboards were somewhat long and straight.

It is a little curious at first sight that the Dutch, with all their inventive ability for matters connected 
with the ship, with all their wonderful labour-saving devices, never seemed to adopt the centreboard as it has been used in both England and America for shallow waters. It was not the case that the centreboard had not been thought of in those days, for I have read in an entertaining little book, published in England in the year 1578, a suggestion for " a thing to be letten downe, and to be wound up againe" through the ship's keel, so as "to make a ship to draw or goe but a little way into the water, and yet to saile well by the wind," and so "not suffer the Ship to fall to Leewardes." If that is not the exact idea of the centreboard I know not what it can be. But it is most probable that the Dutch never heard of this English idea, and that if they did they preferred not to approve thereof, for the sufficient reason that they did not wish to interfere with the internal arrangement of the hull or diminish its cargocarrying capacities. And there is the further probability that in navigating such waters as the Scheldt, where shoals are plentiful and there was every chance of getting picked up by the sand now and again, they would rather not risk the nuisance of having the centreboard jammed in the case. My own opinion on the matter is that this centreboard suggestion of 1578 was rather a theory than a usage, and it seems to me most likely that the whole idea of leeboards came to Holland through some traveller who had noticed them on the Chinese craft, where they had been in use for centuries.

The interesting picture which we have now to consider (Fig. 11) was painted by Arent Arentzen, who was born in Amsterdam in 1586, and died in that city somewhere before October of 1635 . We may suggest, therefore, that the painting was made soon after the beginning of the seventeenth century. In the foreground a couple of fishermen are hauling in to the shore their seine net, as I have seen them 


\section{ORIGIN OF THE FORE-AND-AFT RIG}

doing on the river Maas, when they blow a little horn to warn passing craft from getting foul of the meshes. Those curious caps are still worn by that fine race of seamen, who come in their botters from the Zuyder Zee, from the Island of Marken or Urk, and after passing through the great Orange Locks into the Eye, sail through Amsterdam and out again into the North Sea at Ymuiden, and go to gather the harvest of the deep where waves are frequently treacherous and short, and bad weather comes rolling up with all too little warning.

But the most interesting feature of the picture consists in the two sloops which are seen in the background. The draughtsmanship of these is a little crude, but it is none the less intelligible. The illustration is a little difficult also to reproduce, but in the original one can clearly see the lacing which keeps the mainsail to the mast. This is another feature which is very Dutch, and after looking at some hundreds of modern Dutch fore-and-afters, I do not remember to have seen a single one that used the hoops we use in England and America for keeping the luff of the mainsail to the mast. The advantage quickly manifests itself when leaving a crowded lock, and you want to get a little way on the ship, but not too much You can easily trice up the tack, and, furthermore, instead of allowing one hoop to be doing more work than the others, and so pulling the sail out of shape, you can by means of the lacing distribute the strain evenly over the whole luff.

A yacht's trysail is laced to the mast in much the same way as the Dutchmen of yesterday and to-day lace their mainsails. It will be noticed, however, from this picture that there is a good deal of "drift" between the luff of the sail and the mast, and this defect will be found also in the Dutch hoogarts when we come to speak of her. On the contrary, the Dutch barge has the luff of her mainsail right close up to 


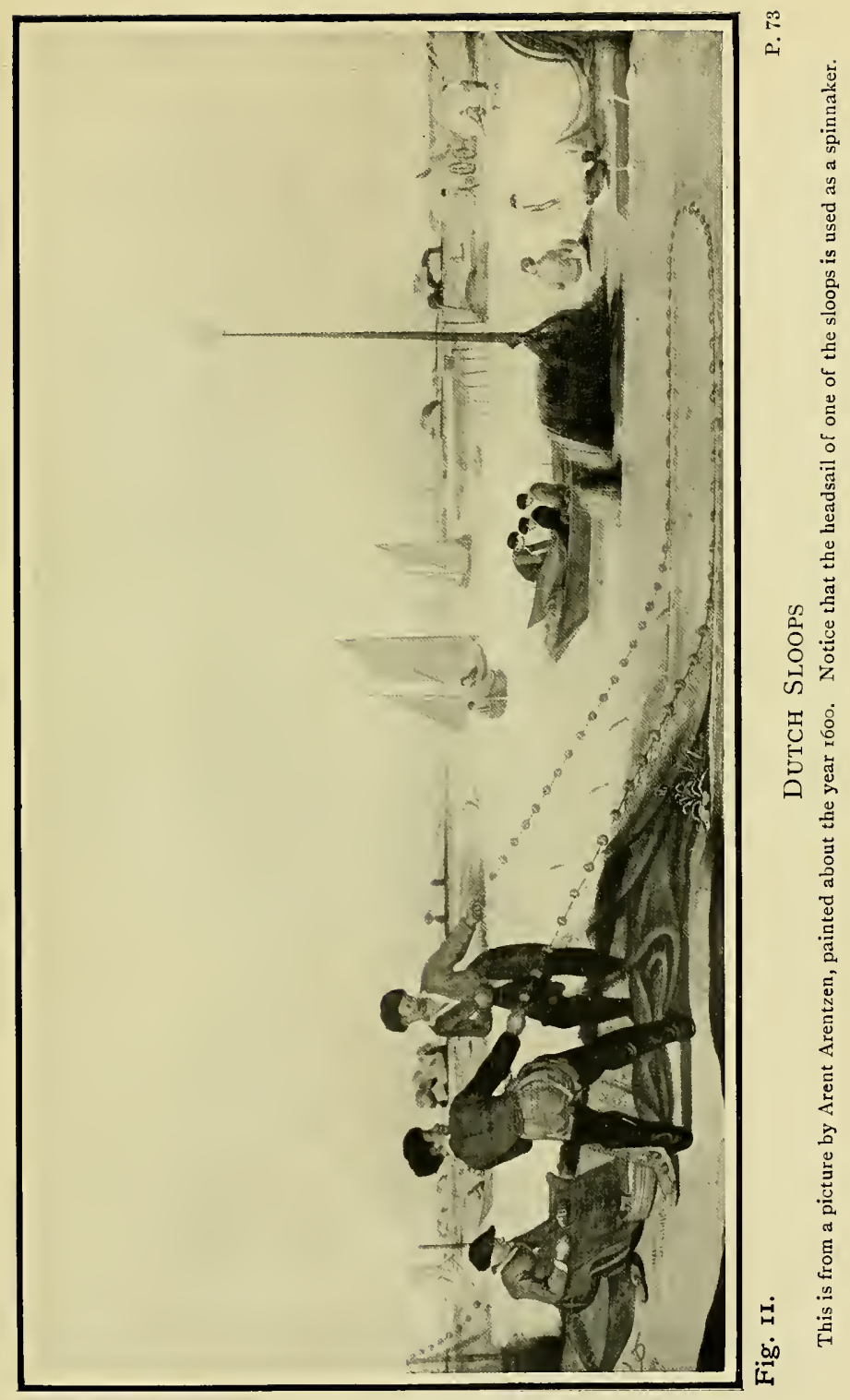



the mast. Very interesting, too, is the foremost ship in Arentzen's picture, which shows that even in those days the germ of the modern spinnaker idea was prevalent. The little sloop is running dead before the wind, and the mainsail has been eased off in the usual manner. But the headsail has been let go at the tack, and brought aft so as to "goose-wing" the craft. Your modern rater does much the same thing when she is racing without spinnaker, with the exception that she usually has a light boom along the foot of the foresail.

We come now to another interesting development of the fore-and-aft rig which is well worth our attention. It is generally but erroneously thought that the schooner developed directly from the cutter by merely causing the addition of another mast. This is not so. The schooner really existed before the cutter, and contemporary with, or but little later, than the advent of the sloop. But there was just this difference, that, whereas the schooner of to-day has triangular headsails, the first schooners had not. In the illustration (Fig. 12) will be found a somewhat curious looking craft of the third decade of the seventeenth century. This has been sketched from the large picture on the staircase of the Dordrecht Museum, which was painted by Adam Willaerts in the year 1629. It shows in a curious way a survival of the former Spanish influence; for practically here are a couple of lateen sails, but without masts, since the lateen yards are used to serve the dual purpose of mast and yard.

By the employment of the two sails we have the germ of the schooner idea-the expressed desire to produce a handy rig for a lengthy vessel without having recourse to the square-sail. In the present instance this is little more than an open boat, but under the contemporary influence there is a high transom stern, with its typical decoration and the 


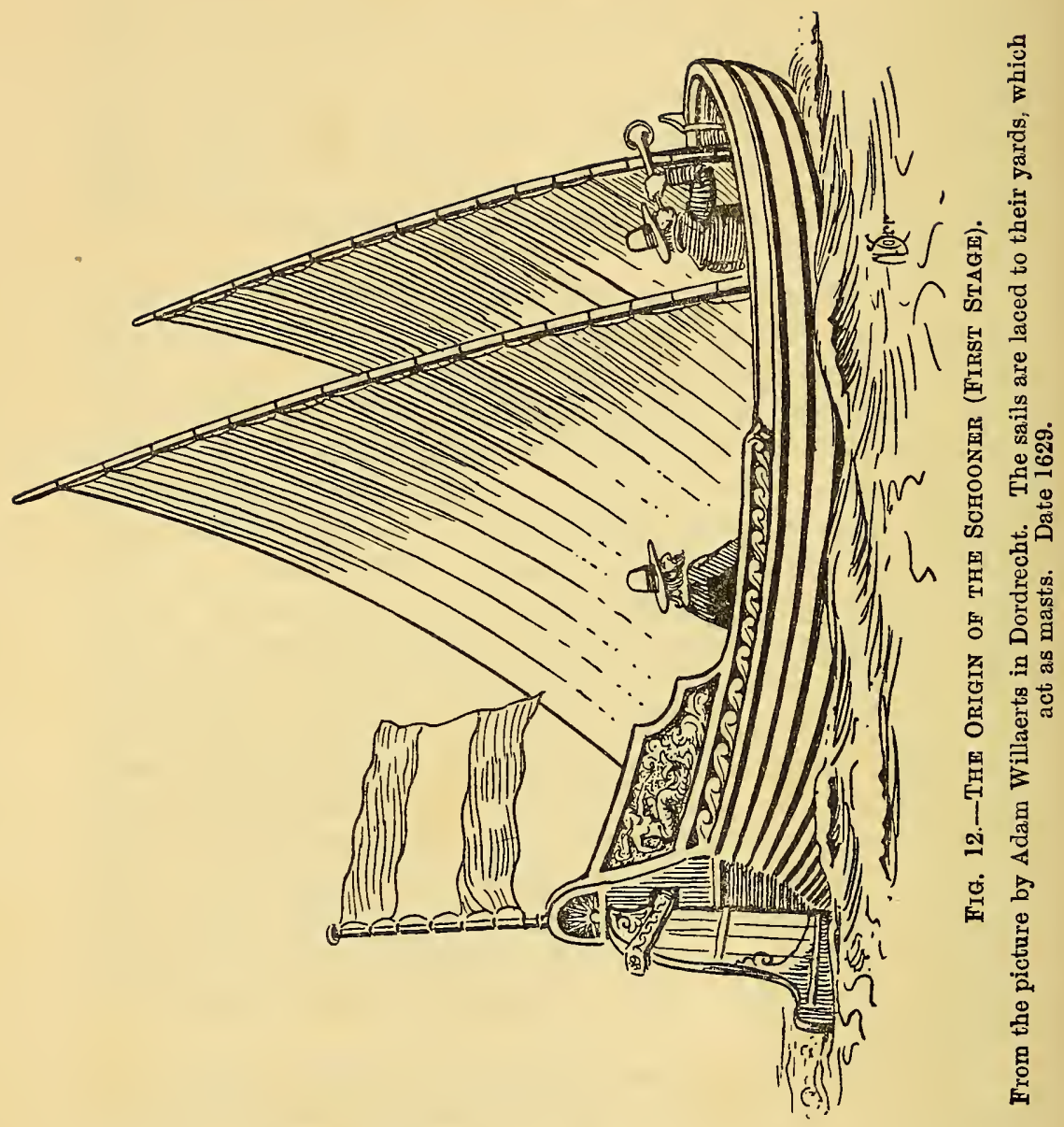




\section{ORIGIN OF THE FORE-AND-AFT RIG 77}

very Dutch-like hatchet rudder, to say nothing of the large-sized ensign, which never seems absent from these ancient and many of the modern craft of the Netherlands. I do not know that such a craft as this is used to-day in Holland. Certainly the stern would be quite different, but it is curious that in the same port of Dordrecht I chanced one day to see coming in out of the strong tideway of the Oude Maas into the Wollewevers Haven an open boat with half this rig. That is to say, she had her one sail bent to the one spar which acted as mast and yard combined. I watched her subsequently turn to windward, and she seemed to sail remarkably well.

But a decided advance on the schooner idea is to be seen in the illustration in Fig. 13, which has been sketched from a picture by a master of the Dutch School in the Boijman's Museum, Rotterdam. The whole picture is entitled "The Arrival at Rotterdam of the Market-Barge between Dordrecht and Rotterdam." The market-barge itself will be shown in another illustration, since it has been deemed better, for the purpose of enabling us to get at the detail, to detach each of these ships from the composition of the original, and to study them separately. From the character of the Rotterdam buildings seen in the picture it has been thought that the date is 1642 , but the name of the artist is not known.

This strange-looking craft is a yacht. She has a couple of masts, one of which is stepped as far forward as ever it could be placed. It has no shrouds, but is supported by means of a forestay, which is sweated home tight by means of a purchase. The sail is a peculiar one. It has no boom on its foot, which is cut more like a forestaysail of a sloop. Both this and the mainsail have a bonnet laced to the canvas for fine weather, as will be observed. 'The foresail is laced to the mast in the usual manner and is hoisted by means of a halyard, but I cannot ascertain exactly 


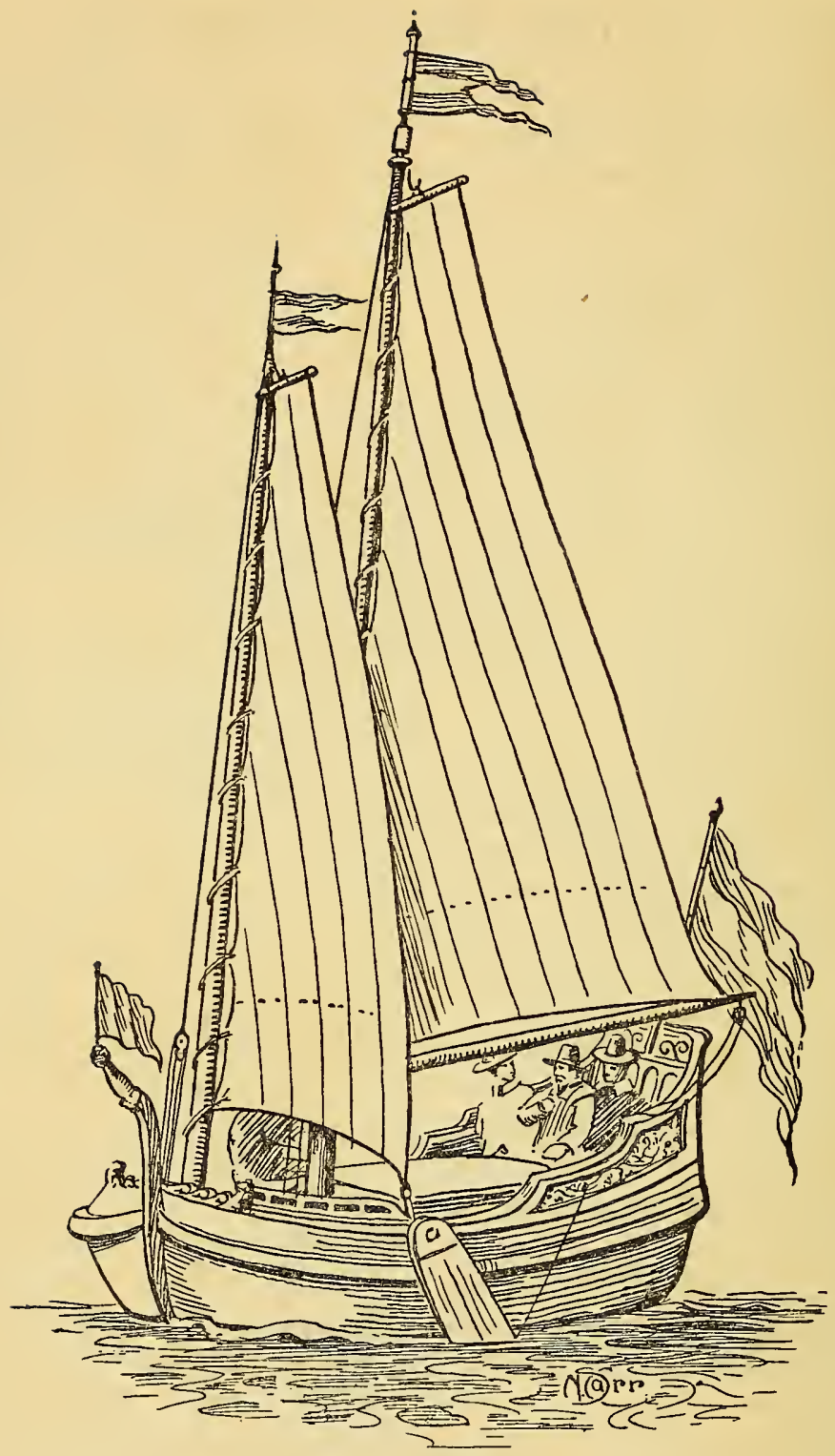

Frg. 13.-The Origin of the Schooner (Second Stage).

This is from a Dutch picture of about 1642 and shows a yacht of that period. From this rig there was to evolve later-in America-by the addition of a triangular head-sail, the modern schooner rig. 
whether the forestay and the halyard are not one and the same in this case. It seems very probable that the one arrangement has been made to serve both purposes. Those who are familiar with the well-known Bermuda rig will be interested to notice the extraordinarily small gaff which both sails in this yacht possess. Even in the Dutch craft of to-day the gaff is usually much smaller than the length we are accustomed to in England, though some of the more modern craft of the Lowland waterways, as for example the trading tjalks, seem to be discarding the older idea.

Many a sailing man has often expressed wonderment why the Dutchman who favours the short gaff has done so for hundreds of years. After sailing through Holland in an English yacht, after experiencing the different kinds of navigation which these Hollanders have regularly to undergo; after watching their craft sailing for trade, racing for pleasure, in fair weather and foul, I fully realise now that reason which has actuated the Dutch skipper to favour the short gaff so enthusiastically. It is just one detail in that whole scheme which tempted him to adopt the fore-and-aft rig at all. The advantage of the short gaff is not that it will give him increased speed : on the contrary, he is diminishing his sail area very considerably. But that is not such an essential in canals and narrow waterways as handiness. Suppose it is a squally day or the wind is steadily strong as it comes over the long stretches of low-lying land. As you sail along through an avenue of short trees, or perhaps through the centre of a little town or village with stumpy houses on either side, the lower part of your sail is blanketed while the upper part catches the full force of the squall or strong breeze that comes rushing across over the windmilldotted country. The consequence is that your ship becomes less handy, is not under proper control; and 
at the most awkward moment, when the narrow space of an opened bridge is being negotiated, or when passing other vessels in a confined bend of the river where the strong tide runs stronger still, you may find that the long gaff will receive a little puff and give the steersman a sudden anxiety.

Again, during his voyage from one town to another - say perhaps he is carrying a cargo from Amsterdam that has come into that port from the Dutch colonies - the inland-sailing tjalk loads up from the steamer and is bound for some town in the south of Holland, or even further still, perhaps to Antwerp. On the way he will have all sorts of seamanship to perform and different kinds of navigation along narrow canals, broad rivers, perhaps up an estuary four miles in width, and a fog to make his work the more difficult. But during these trips one regular activity will consist in negotiating the locks along part of the route. Now, to take a heavy sailing craft inside properly, to carry just enough way on as "would not break even an eggshell," as the saying is ; to enter quietly these crowded basins, perhaps full of sailing botters, haaks, tjalks, a couple of steel motor cargo-carriers or a steamship-all this requires not merely a great deal of skill to avoid doing damage, but necessitates a certain amount of handiness in rig. It is just here, then, that the short gaff is so useful. The greatest sail area is at the lower half of the mainsail and the smallest is at the top; and when the time comes to lower away, the canvas comes down with a run, there is no heavy gaff to go swinging and swaying about. It just comes plumb down, and the sail stows itself in parallel lines. Even on the modern Dutch yachts a mainsail is not stowed, as the English yacht's hand performs his work by first taking the leach and laying it forward along the boom. On the contrary, the Dutchman's mainsail piles itself up in so many layers when the halyard is let go. 
'To come back to our illustration, it will be noticed that instead of having shackles the halyards are attached by means of curved hooks. The mainsail is loosefooted and is sheeted in the usual way with a block at the end of the boom, but the foresail will have to be trimmed at each tack, though it is possible that sooner or later a wooden or iron horse was used, just as in our present-day barges. The solid rubbing-strake which is seen here as on most of the craft of the Netherlands is very necessary when the vessels have frequently to squeeze their way into crowded locks or to spend much of their time alongside quays and wharves. The high stern is again copied from the ocean-going craft, a fashion that took centuries to die out; and among other details it will be seen that the vessel boasts of cabin and a cabin-top. As this is one of the earliest records of a yacht-a "sloepe" as she would have been called in those days, regardless of her rig - she is well worthy of the amount of attention which the reader has been asked to devote to her. One need only add that it required but a very mild form of transition for the subsequent alteration to turn this two-masted vessel into a schooner by providing her first with a big jib and by stepping the masts further aft; secondly, and later on, by giving her a smaller jib but also a staysail in place of one large headsail. How this came about we shall describe in another chapter.

But in the same seventeenth-century original from which this sloepe has been copied there is another foreand-after of that time, which has also been sketched and here reproduced in Fig. 14. This shows the Dordrecht-to-Rotterdam market-barge with her passengers coming in. The wind not being favourable, two of her crew are quanting while the helmsman carefully keeps the rudder amidships. The details of the running-gear and the sails are easily discernible. There is of course 


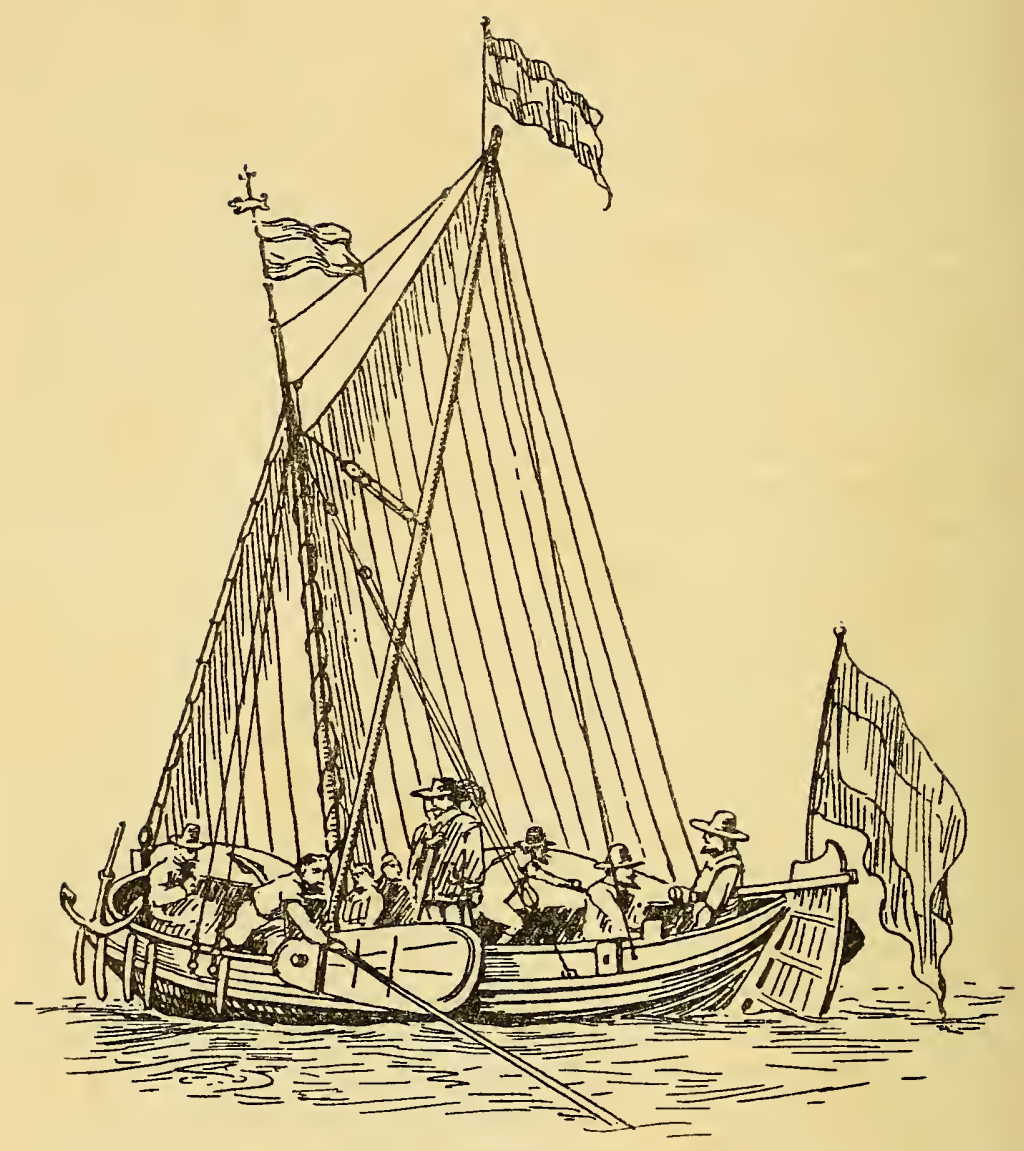

Fig. 14.-DUTCh MARKeT-BARGE.

This also belongs to the 1642. There is no bowsprit to this sloepe-rigged craft, but she has a sprit, mainsail, and staysail. 
no bowsprit; and in a country where so much lockwork and intricate sailing has to be done, who would blame the Dutch for dispensing with the bowsprit? To-day it is true that this spar is much more frequent, but it is fitted with suitable gear to enable it quickly to be hauled up out of harm's way. Nevertheless, it is always getting damaged from one reason or another. The worst accident I saw was when a big steel sailingcraft was emerging from Gouda sluis into the river Ijsel, that flows south for a few miles and then joins the Maas, to find its way through Rotterdam into the North Sea. This barge was unable to check her way enough as she came out of the lock, but took charge, narrowly avoided colliding with the heavy traffic waiting to lock in, and crashed into the opposite shore where the bowsprit ended its life's work.

The other accident which comes back to me was when a cluster of most a dozen different kinds of craft, including ourselves, a couple of Dutch yachts, several big haaks, and some tjalks, had taken shelter in a bottlenecked little harbour between Dordrecht and the North Sea. By the time we had all found berths in this little haven there was no more room for any other craft to get much shelter. Those big bowsprits became a terrible nuisance as one vessel after another came running in and let go his anchor prior to swinging round; and before we were all squared up in an orderly manner at least one Dutchman had suffered damage. The bigger vessels must, of course, set jibs, and so cannot dispense with these great spars, but we cannot be surprised that the smaller craft of the hoogarts and botter types hesitate to set their bowsprit until outside of the inland waterways and in the sea.

The staying of the mast in this market-barge before us is a little strange and contrary to custom: for the shrouds of the rigging, instead of being abaft the mast, are a long way forward. The runner which comes down from the throat of the sail and leads through a 


\section{ORIGIN OF THE FORE-AND-AF' RIG}

hole on the quarter just forward of the hole where the vang comes through is fitted with a purchase and has three blocks. The forestay is tightened to the stem-head by means of a purchase also. 'The sprit is supported in its centre by a tackle from the throat, but the peak is also sustained, as will be seen. A short line from the latter ends in a block. 'Through this is rove another line, one end of which is made fast to the mast-head, while the other leads through another block fastened to the mast some distance above the throat, and so leads down to the deck. The luff of the sail is again observed to be laced to the mast.

One very curious feature of Dutch craft, which still survives, is the curved ensign staff. Other countries usually set them at an angle leaning over the stern, but the staff itself is a perfectly straight spar. In Holland the yachts almost always have them curving outwards, sometimes even in a more exaggerated manner than is seen in the present picture. But although a flag is here seen at the peak, and is so shown in innumerable old masters and existing prints, yet this practice is now chiefly confined to the Dutch yachts. Three other minor points are worth pointing out. The leeboards are somewhat shoe-shaped in this sketch, though not unduly; and following the accepted practice on the contemporary ocean-going ships, the anchors are stowed outboard and not on deck. Notwithstanding that the barge has a good rubbing-strake, she has got out those sausage-shaped wooden fend-offs which were such wellknown features of this time. In regard to the hull in this picture, as in many another: in the Dutch hulls of yesterday and of to-day no one can fail to recognise the obvious descent of the Dutch naval architecture from that of the Viking ship. The bows, the stern, and the under-water lines of the Lowland craft have indeed been modified to suit local conditions and special purposes, but there is still obvious the very near relationship; and when we compare the Scandinavian pilot 


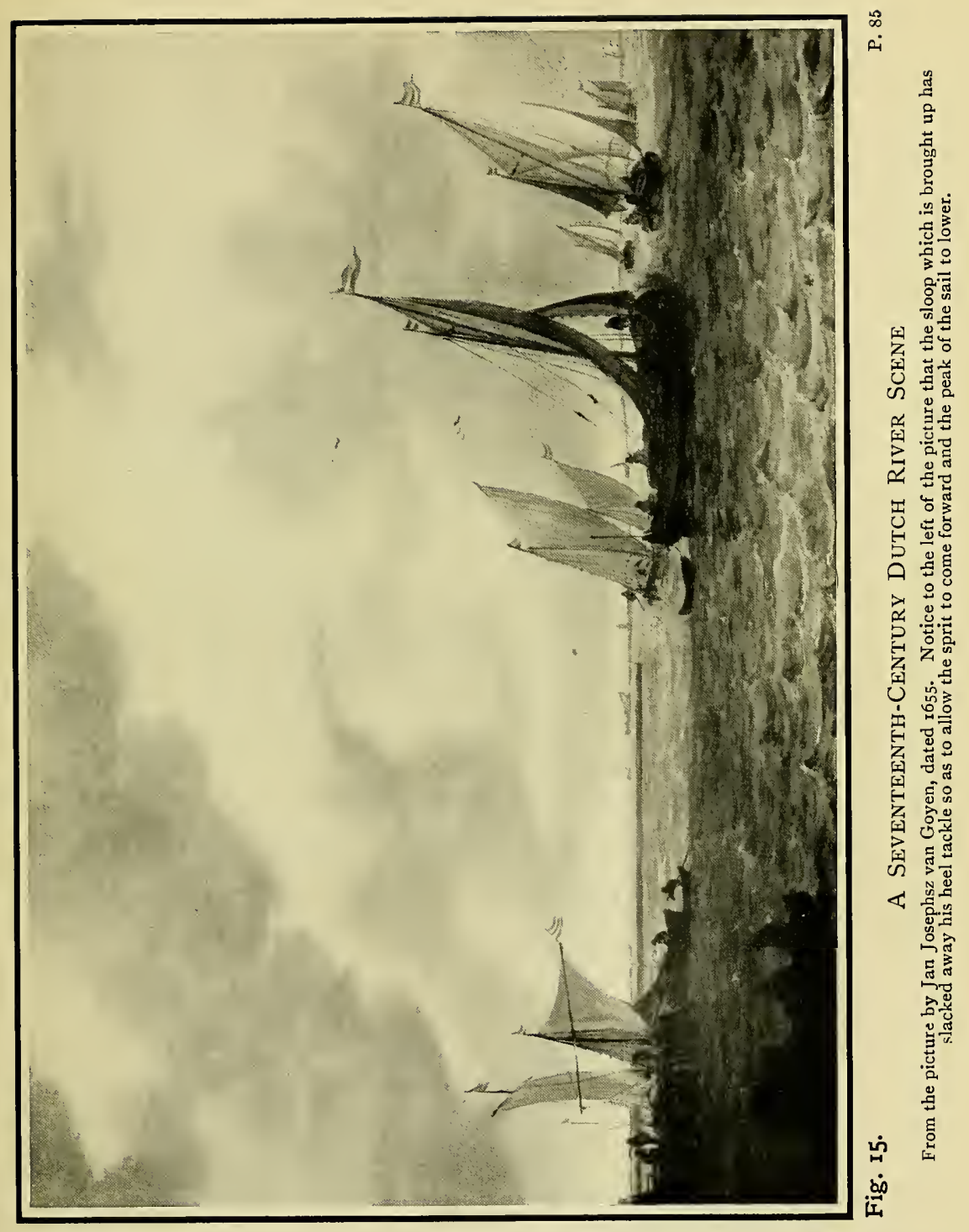



craft of to-day with a contemporary Dutch tjalk the family likeness is no less apparent.

The manner of lowering the mainsail in case of a squall or when brought up is well shown in Fig. 15. This is a reproduction of the picture by Jan Josephsz van Goyen which hangs in the Mauritshuis at the Hague. Van Goyen, who was about sixty years old at the time, painted this in the year 1655, the year before his death. To the left of the picture there is a fore-andafter by the quay. From this we see that, to stow mainsail, brails were not employed as the Thames barge has them to-day, but the sprit was fitted with a block at its heel through which a line was led. By slacking away this line the sprit was allowed to swing up, and the peak could be lowered-partially in case of a temporary squall, or altogether for taking sail off the ship. A fleet of tjalks is seen running up one of the Dutch rivers on the right of the picture. 'The flags just now noted will be seen conspicuous at both masthead and peak. The vangs and other details have already been alluded to, so that we need not now refer to these.

We have, then, been able to witness not merely the evolution of the early fore-and-aft rig in the south, but its firm adoption in the north of Europe. We have seen the inauguration and propagation of a species of rig infinitely more suited for the sea that touches the shores of the Netherlands as well as for traversing its inland waters. We have observed the Hollander gradually feeling his way towards producing the ideal rig for smaller sailing craft, and we have watched step by step the improved devices which he has invented as time and experience suggested to him new ideas and improved methods. We have been able to adduce actual confirmation of this from existing pictorial evidence. All the time both the hull and the rig were under the influence of the full-rigged ship. But this was only natural, and cannot be wondered at; for the sea experi- 


\section{ORIGIN OF THE FORE-AND-AFT RIG}

ence of these sailor-men had been gained either from those big vessels which fought with the Spaniards and voyaged to the Dutch colonies, or else it had been obtained from those fleets of herring-busses which from time immemorial had been fishing in the waters of the North Sea. But as soon as they devoted their serious attention to a consideration of the ideal type of craft required, firstly for the canals and rivers, and secondly for short sea voyages, these sixteenth and seventeenth century seamen and shipbuilders brought into being a rig and type of craft that were not far from ideal for the service that was required of them. It is sufficient proof how reasonable and effective these creations were, how nearly perfect they were in character, by the fact that our cutters, our ketches, our yawls, our yachts, fishing-smacks and pilot craft have continued all this time to follow the lines first enunciated. Even if we make allowances for the modification of a good many small details, yet it is surprising to find how much we owe to the shipmen of the Low Countries.

But we have not yet seen the full extent of our indebtedness, and must now proceed to watch the further development of the rig in the hands of those ingenious people who rose in so short a time to become such a mighty maritime nation that they had none to rival them. Comparatively brief though the Dutch pre-eminence was, yet it was a brilliant period in nautical matters and in the production of great masters of painting. England had too many domestic troubles of her own during that period to think much of the new rig. She had barely settled down after the Spanish wars than the anxieties of the time of James I. culminated in the Civil Wars and the beheading of Charles. All this time the Hollanders had been going ahead in their triumphal march of maritime progress, until the time came for them to clash with England, and eventually to suffer by the encounter. But before their retrogression occurred the Dutch had done much for the 
science of naval architecture, and brought into being a type that was destined to be applauded by generations of seamen, professional and amateur, in many parts of the world, but especially in those ports which touch the North Sea, the English Channel, and the North Atlantic.

It is highly probable that even before the end of the sixteenth century there were some fore-and-afters built in England, though I have not been able to find any definite and detailed records of this. Brixham, which was to become famous for its fore-and-aft rigged fishing fleet, has been instanced. But England was far too busy with her bigger fleet to pay any great attention or to lend much encouragement to such vessels. She had not the same personal interest that Holland with her many miles of inland waters possessed. She was much more concerned with the building and fitting out of those vessels which went sea-roving to lay in wait for the Spanish treasure ships, and so enable the English promoters to return home with their wealth, purchase fine houses and estates, and lay the foundations for future family prestige. Some others were content to follow the more peaceful pursuit of fishing off our coasts or off Newfoundland; but, as we know from contemporary documents, this was sometimes anything but a paying job.

Holland, however, had no choice in her destiny. She had to find some sort of small, handy vessel for her home waters, and thus she did so. 


\section{CHAPTER IV}

THE DEVELOPMENT OF THE FORE-ANI)-AFT RIG IN HOLLAND

$\mathrm{T}^{\prime} \mathrm{T}$ is a curious fact that the subject of the sea and 1 its ships figures with a much rarer frequence in the history of painting than we should have imagined. Historically speaking, marine painting is but an inferior branch of seascape art. If one goes back through the centuries and traces the progress of painting and sculpture, it is only on the rarest occasions that one finds any allusion to the sea. Here and there on some existing Roman reliefs the subject is occasionally found, and further back still in Egyptian art there are even numerous representations of their contemporary craft : yet these were in most cases rather connected with religious manifestations than exhibiting intentionally æsthetic pleasure.

When we come to the birth and growth of art in Italy, and examine the schools of painting in that and other countries, we find a keen disappointment that the sea should have been so thoroughly neglected. Occasionally such inland waters as lakes and rivers are introduced merely as backgrounds for the main subject of the picture, and here and there will be found in the distance a suggestion of the sea and of a ship, often but crudely depicted, and that by an artist who obviously had neither the knowledge of nor any sympathy with the sea. It is, indeed, not until we come to Holland, and not until the end of the sixteenth century, that we find the sea obtaining that recognition at the hands of 
art which it undoubtedly deserves as one of the greatest forces which nature manifests in a visible and pictorial form. That marine painting should spring from Holland is explicable when we remember that it arose contemporaneous with the rise of the Dutch as a great marine power. 'Those interesting and, to every sailingman, fascinating galleries full of Van der Veldes, Van Goyens, Beijerens, Verschuiers, Storcks, Pompes, Van der Capelles, Bakhuizens, and many another marine artist are invaluable, not merely as works of art that can never be repeated, not merely for their subtleties of atmosphere and light and shade, but for the careful details which are preserved to us of the shipping of the period. No one can dare to express opinions on the ships of those days unless he has taken the trouble to study them as depicted in these wonderful old masters. There are some who cannot resist the temptation to underrate the Dutch school, and certainly it is but natural that the mind should revolt against the depressing influence, the dullness, and even the coarseness of many a Teniers and his fellow craftsmen. But in regard to the painting of portraits and of marine subjects it is different. Here was a nation of seamen encouraging the best of its artists to find their inspiration in the sea and those ships which had made Holland so powerful and so wealthy. And as we can see from the admirable examples which time has handed down to us, these gifted masters did their best to commemorate on canvas the achievements of the naval architects and shipbuilders of the time. The fishing craft, the yachts, the trading ships, the men-of-war: at anchor, under way, in a flat calm, in a nasty short, choppy sea, in gales of wind, in whole-sail breezes : with strong light effects, with delicate reflections on the placid water, with terrible storms and shipwrecks and high seas and perilous waves: in harbour, on canals, on meres, with rich golden sunsets flooding the whole composition, in early morning light-in fact in every aspect the Hollanders 
depicted every kind of floating vessel, from the open boat to the man-of-war.

And so, just because when Holland was at its highest stage of worldly power her artists and her shipping were also at their best, so in this chapter we shall continue to draw upon these pictorial representations in order to assist us in our study. In spite of Ruskin's well-known antipathy to Dutch painting, we shall yet find both instruction and interest in these masters. "It is not easily understood," wrote Ruskin, "considering how many there are who love the sea, and look at it, that Van der Velde and such others should be tolerated. Foam appears to me to curdle and cream on the wave sides, and to fly flashing from their crests, and not to be set astride upon them like a peruke; and waves appear to me to fall, and plunge, and toss, and nod, and crash over, and not to curl up like shavings; and water appears to me, when it is grey, to have the grey of stormy air mixed with its own deep, heavy, thunderous, threatening blue, and not the grey of the first coat of cheap paint on a deal floor."

But in defence of Van der Velde and his brother marine artists, in defence of the very pictures which are essential to our present theme, it may be urged in reply that at any rate these artists were sincere, that they painted the sea and the ships as they appeared to themselves, and not according to any existing convention. They interpreted the subject through the medium of their own personality, and not by any thumb-rule. They went to nature with great equipment, but with an open mind. Bakhuizen used to put to sea in all weathers so as to gain accurate impressions for his pictures, and therefore we must regard his works as trustworthy. Van der Velde also-and this ought to be quite obvious from a mere examination of his paintings-spared himself no trouble and inconvenience to get at marine truth. He studied the ship in all her ways, and even went into battle in his yacht 
amid great danger so as to be able to sketch the incident, not from survivors' narrations, but from actual evidence seen with his own eyes. Quite recently I was examining a number of his rough sketches done on the spot. Perhaps Ruskin might not have liked them, but at any rate the information which they convey to a mind not accustomed to the sea is very far from negligible. And as to the "curdling" and "creaming" of the waves, that point does not matter when we are less concerned with wave effects than with rigging and hulls. It is even amazing to find that to-day there are art critics who soberly affirm that "the storms of Van der Velde are certainly unattractive." Perhaps it would have been better had the critic qualified his statement by remarking that such pictures are unattractive only to the man who knows nothing about ships. On the contrary, most sailing-men find the keenest enjoyment in regarding the ship in these trying conditions-in watching her behaviour in wind and sea, in noting the methods which her crew have taken to make her snug.

For these Dutch masters knew what they were painting. They lived and worked surrounded by seamen and children of seafaring people. 'There were so many candid critics about that had these artists begun to paint the ship as they imagined her and not as they saw her, they would very quickly have been corrected by their fellow-men. Even Ruskin, in spite of his prejudice, admitted that the Dutch painters " attained considerably greater dexterity than the Italian in mere delineation of nautical incident." If he complains that these same Dutchmen had "never in all their lives seen the sea, but only a shallow mixture of sea-water and sand, and also never in all their lives seen the sky, but only a lower element between them and it, composed of marsh exhalation and fog-bank," then let us not discredit them for painting only what they saw, whereas 
the Italians did not always do so much; but let us rather value the Dutch paintings because whatever else they may or might be they are based on sincerity and truth, a basis, one would have thought, that was as essential to art as secure foundations are to any art critic's dwelling-house.

We may, then, now proceed to gather our harvest of information from these much maligned masters. Even if we discover them erring occasionally, we shall find them on the whole reliable guides in our investigation. The first (Fig. 16) is by Abraham Hendricksz van Beijeren, a well-known marine painter, who lived all his life in the neighbourhood of the sea. Born in 1620, he had fifty years' experience of the contemporary craft of his country, and the accompanying picture, which hangs in the Boijmans Museum, shows in sincerity and truth one of those confused seas which are so characteristic of Dutch waters. But most important of all detail is the confirmation of the evidence which we adduced in the preceding chapter. The support of the peak of the spritsail by a line to the mast above the throat, the total absence of jib, the flag at the peak, and the tumble-home of the vessel's hull, the vangs, the leeboards, and so on, are all well worth remarking. No definite designation is given to the geography of this picture, yet the church in the background, the jobble of a sea, the broken breakwater, the little tjalks thrashing to windward, will revive a hundred familiar memories in the minds of those who have sailed in Holland.

But it is when we come to Ruskin's Van der Velde that we find a perfect feast of delight. Those misty flat-calms, so peculiar to Holland, happily do not detract from the value and enjoyment of the picture. On the contrary, they enable us to study with greater ease the types and rigs of the different vessels. If we remember that this William van der Velde, the 


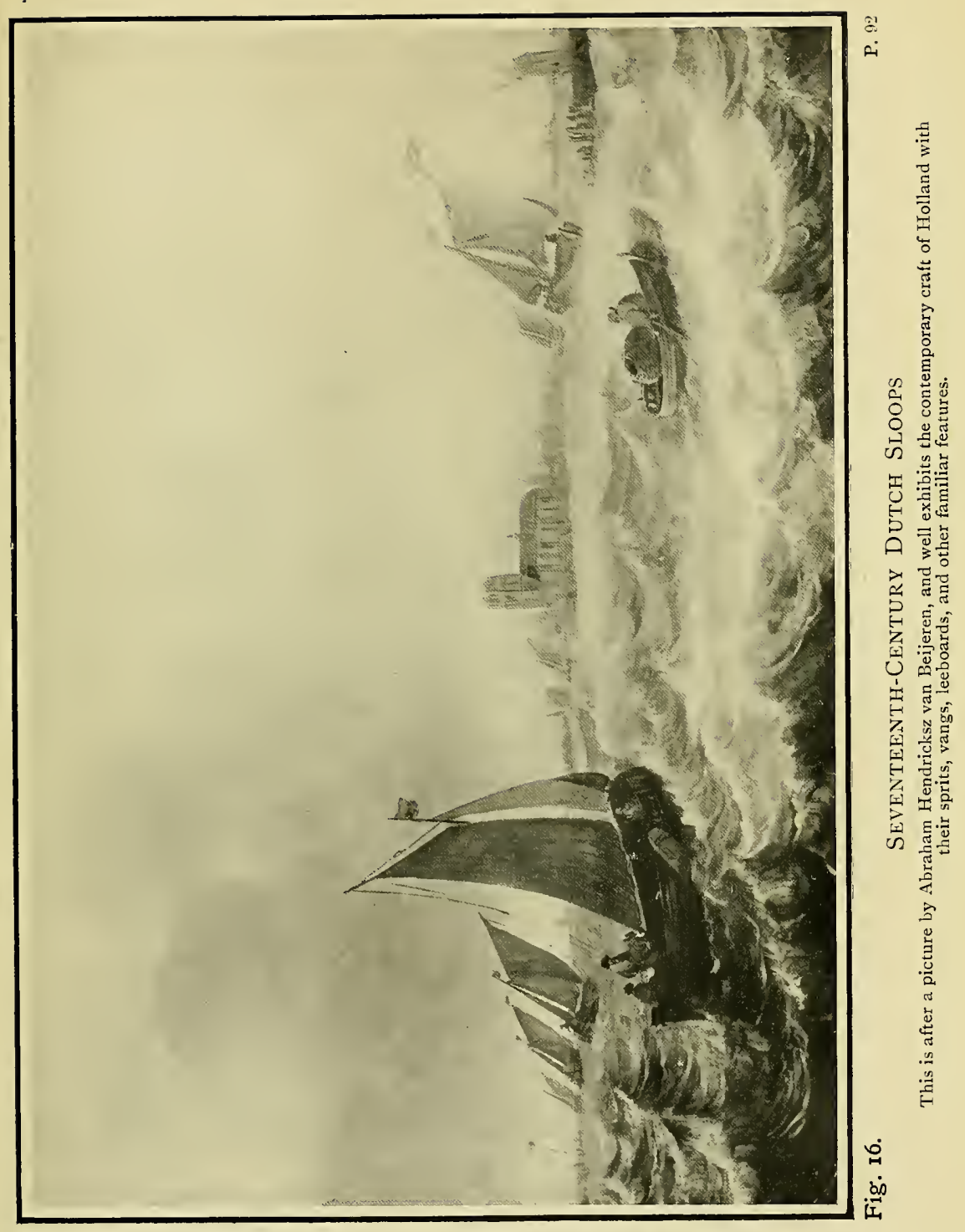



younger, lived from 1633 to 1707 we shall realise how important a relation he bears to our subject. Speaking roughly, the Dutch were at the topmost rung in their ladder of progress and prosperity about the year 1663. At that time also Van der Velde was in his prime as an artist. 'The best types of Dutch ships belonging to the golden age of that country were everywhere to be seen by him. Consequently we find in his paintings records which are simply invaluable to us. In this first picture (Fig. 17) it will be seen that a great advance both in architecture and rig has taken place. In the foreground, stern on to us, is seen one of those magnificent Dutch yachts of which we shall have more to say presently. The gilded stern with its lantern is expressive of the wealth that was at this time a feature of Dutch life. Beautifully carved, it rises to a great height from the water, and is in many respects similar to the sterns of the contemporary men-of-war and East Indiamen. The rig, also, we shall discuss in detail later on, but for the moment we may content ourselves with remarking that the spritsail is still at that time used for a mainsail, and that it is peaked very high. To the left of the picture will be noticed a vessel that has sprit mainsail, but sets a square topsail above. For headsails not merely does she carry the usual foresail working on the forestay, but by now she sets a jib. True, the bowsprit is steeved at a somewhat considerable angle, but at any rate by about this time - the late seventeenth century - the general appearance of what we call the cutter-rig had begun to take definite shape. The fore-and-after close to her has slacked away the heel-rope of her spritsail, and by thus allowing the spar to swing up and forward has caused the peak of the sail to be dropped. To the right of the picture will be seen a curious hybrid kind of rig consisting of a high square-sail and a staysail. This arrangement would seem to have evolved from 


\section{THE DEVELOPMEN'T OF THE}

the buss herring-ships which we discussed on an earlier page. 'There is but one square-sail, and that is set on the mast stepped amidships. No doubt it was because the sloops had found the triangular headsail so valuable for handiness that at last even the pinks with their great, heavy, clinker-built bodies and their leeboards at last decided to adopt this triangular sail for use when on a wind, whilst yet retaining the lofty squaresail, which would be especially serviceable for running before a free wind. Handiness in the pink was not a greatly desired virtue. Most of her time was spent as to-day in lying to her nets off Scheveningen, in the North Sea; but doubtless there were times when running out to, or home from, the fishing grounds that the staysail would be found very convenient. Thus, for the present, the fisherman did not see his way to "go the whole hog" and have a true foreand-after while he was about it, for he had been brought up to using the old-time square-sail, and he had no wish for the big spar of the spritsail up aloft, swinging its heavy weight backwards and forwards across the ship as the latter rose and fell to the waves. Any one who has had experience of riding to nets or anchor with a spritsail rig in bad weather will agree that in such cases the sprit-rig is an abomination. I have never heard of a spritsail-rigged vessel being employed in the fishing industry, with the exception of the small hoogarts of Walcheren, and it is significant that the bawley rig, which is the nearest of all British fishing craft to the Dutch rig, has for her boomless mainsail not a sprit but a gaff. But I have been told by the owner of an English barge yacht what it feels like to be in bad weather, even at anchor, with such a spar as shipmate. He had been compelled to run back for shelter to the Dutch coast, and anchored. There came a shift of wind, and the sea got up. Presently this developed into a gale, the force of which I well remember, for I was tied up in the snuggest of Dutch 


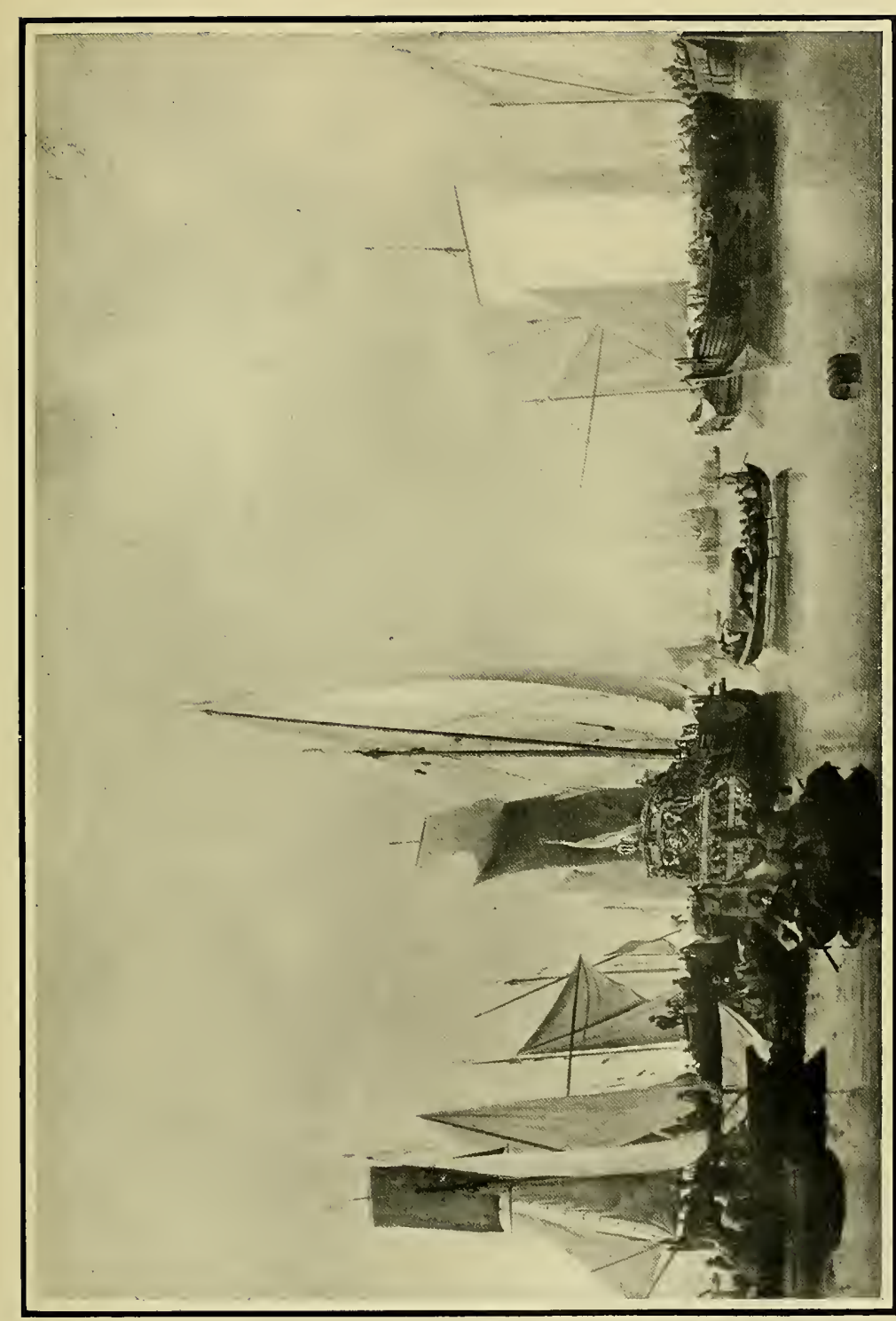

용

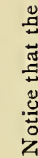

马ु

+ 苛

帒

出

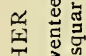

局

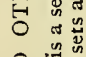

(2)

究焉

$\rightarrow$ 过

矛 홍

प

$>$ च्ञ

年

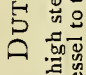

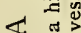

声

$\stackrel{1}{*}$

$\dot{\infty}$ 

harbours a few miles away, and felt much of its power even then. A terribly anxious night was spent, my friend told me, as the barge viciously snubbed at her anchor, but the greatest anxiety was whether that swaying sprit would break adrift and drop down, killing some of them, and perhaps crashing through the ship. This is not the place to tell the whole story, but it may be added that after burning flares for a while during the night the barge had eventually to be abandoned, and was wrecked, though, I believe, subsequently salvaged, yet much damaged.

I mention this experience, which occurred only as recently as the end of last summer, for it shows that whatever virtues this almost universal rig in Holland possessed in the seventeenth century, yet emphatically it was not suitable for vessels that were not keen on making a quick passage. Thus, if we turn now to the next Van der Velde (Fig. 18), we shall see that the Dutch did away with the sprit on some of their mainsails. They were so prosperous at this time, they were so full of energy, they had so many incentives to alter their vessels that they were ready to use every ingenious idea for improving their craft. Consider for a moment what was in their minds. The old lateen was really a large triangular sail, of which one part was set forward of the mast. Now that part had found itself reproduced in the staysail of the sixteenth and seventeenth centuries. But the afterpart had to be peaked up, and since the lateen yard had been done away with the sprit took its place, was placed diagonally across the sail, and thus the main (sprit) sail, together with the staysail, made up practically the same thing as the original lateen. And now when the time came to improve on the sprit the chief point which had to be aimed at was some arrangement for keeping the peak as high as before. This was achieved-after discarding the sprit-by lacing a shorter spar along the head of the sail, following the line which the sail made in its 
extension from peak to mast. In order to support, to raise and lower this spar, a halyard was rove through blocks, as will be seen from the vessel on the extreme left. Thus we get the origin of the gaff. But it must not be supposed that the boom was also at this time added, for that did not come till later on-not till the Dutch found that they could improve the set of the sail, whether staysail or mainsail, when running by attaching a light spar to boom the Holland canvas out. But ordinarily the gaff was left aloft when at anchor, and the sail was stowed in a manner very similar to the Thames barge of to-day by brailing it into the mast, as will be seen in the present illustration. And of course the practice on modern full-rigged ships of brailing up the spanker is exactly the same method, although the trysail is becoming nowadays more common than the spanker or driver.

'The vessel before us, then, had we seen her under way would have been rigged as follows: Forward she would have a bowsprit steeved high out above the water. On this spar she would set a jib. On the forestay she would carry a staysail, and above this a square topsail, as on the full-rigged ships. Abaft the mast was set her mainsail, quadrilateral in shape, with a gaff at the top and no boom. There are so many illustrations of these vessels rigged as above that there is no possible suggestion that they were mere freaks. One can see how from this the modern cutter has sprung, and by what interesting stages so many of her important features have been adopted. In the act of reproducing this picture the ship alongside that which we have been discussing has suffered so much in detail that it cannot easily be recognised, but it is well to mention, for the prevention of confusion, that the sprit which is seen belongs not to the ship with a topsail that we have been considering, but the more obscure vessel alongside. In the same picture, to the right, will be seen another of those yachts or "vessels of state and pleasure," with 


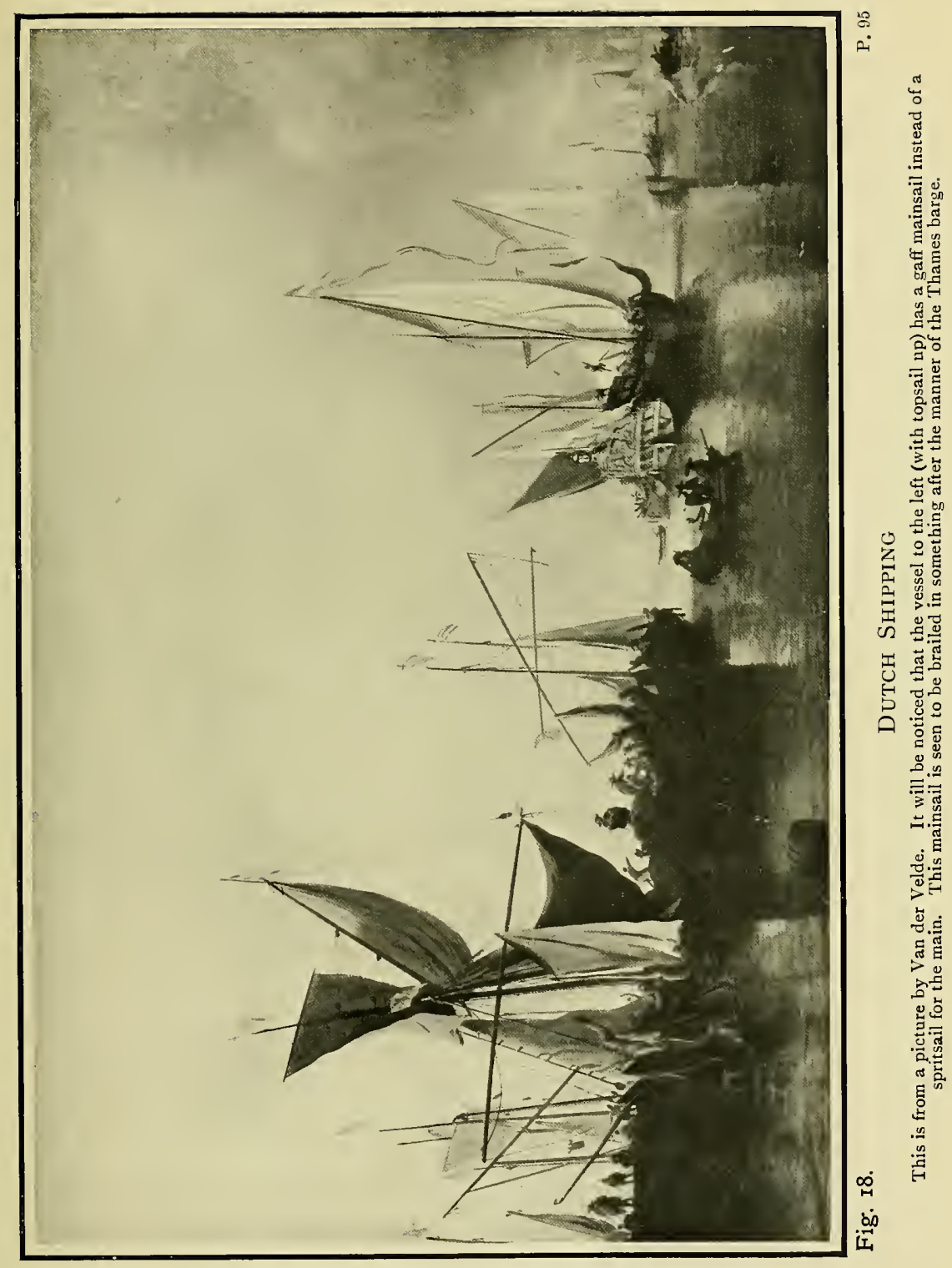



gilded stern and lantern over the poop. Many an artist of this time loved to depict these yachts, for they found that the decoration of the stern especially appealed to them, but no one has depicted them with greater ability than Van der Velde, the man who understood ships if ever a painter did.

And now let us stop to look into the origin of the yacht, about whose beginnings a good deal of confusion seems to have centred. One hears a good deal of careless talk that our Queen Elizabeth possessed a yacht, and that even sovereigns before her time had such a ship. To make such an assertion necessitates a very clear definition of terms. To begin with, it is certain that not Elizabeth nor any of her preceding sovereigns, nor any of her crew, nor any of the shipbuilders ever spoke of the vessel as such. From the time of Edgar the English kings, and sometimes queens, had indulged their love of pleasure by sailing on the sea. But that does not make a vessel a yacht any more than if his present Majesty King George were to cruise in the Dreadnought she would be entitled to such a term. The Rat o' Wight, which belonged to Elizabeth, is sometimes referred to as being a yacht, whereas it would be truer to speak of her as a royal ship. Not only was the word yacht not in use in England at that time, but even the Dutch, who created the word, had not then begun to use it. At any rate, in a Dutch dictionary of the year $\mathbf{1 5 7 3}$ it is not included. In olden times, when the Cinque Ports were at their prime, there were specially fitted up ships for the kings and queens of England to cross the Channel, but these were not yachts. They were a modified type of Vikingshaped ships, with cabins and a square-sail. Even the Rat o' Wight was most probably a smaller ship-rigged vessel and not a fore-and-after at all. But if the evidence of Holland is not enough, let us anticipate a point that we shall come to later, and quote the remark made by Sir Anthony Deane in the time of Charles II. to Pepys, 
when Deane told the genial Secretary of the Admiralty

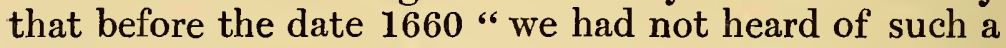
name [as 'yacht'] in England."

I have searched through whatever books on seamanship were published about this time, together with contemporary dictionaries, and I am convinced that by the close of the sixteenth century the word "yacht" had not originated even in Holland. But the derivation of the word will throw some light on our subject. There is an old Dutch word, jager, which means a hunter or sportsman. A secondary, meaning is "the rider of the horse that draws a boat." Even in the sixteenth century the word jager meant the equivalent of the French chasseur, and the verb is jagen, to hunt. Thus jaght means hunting or chasing. From this there comes the synonym jaghtschip, which might mean (1) either a vessel employed in the service of sportsmen, or (2) a ship that would sail very quickly, like the chasing of an animal. As to which of these actually caused the word jaght to be applied to schip it is not possible to determine. Another origin of derivation is based on the fact that jagen also means to draw, especially in the case of a boat: as, for instance, a horse towing a boat from the bank of a canal. Thus the towed craft became known as the jaght-schip. By colloquial abbreviation this vessel would soon become known merely as the jaght. There is in the Rijks Museum an interesting painting of about this time which shows a yacht being towed through the Middleburg Canal, having on board a gentleman of distinction. To-day on many of the canals, as, for instance, between Gouda and Gouwe, when the wind fails or gets ahead, a man with a horse will come along and offer to tow the sailing vessel, whether trader or yacht. I have seen a 100-ton haak in a scant fair-wind in a hurry to get to Amsterdam adopt this method. The horse that is so employed is called a trek-paard. 
The suggestions of these three propositions cannot definitely be set at rest. It may be that the word came from the fact that she was a towed vessel, or from the fact that she was speedy in comparison with the other prevailing craft. Considering that she was built not to carry cargo, but for sailing as well as possible, consistent with seaworthiness and passenger accommodation, it seems far more probable that the jaght-schip was originally so called because she was a "chaser" or " hunter" for speed. The Dictionnaire de Marine, printed in Amsterdam in the year 1736, gives the dimensions of a small sailing yacht - " un petit yacht de promenade"-as $42 \mathrm{ft}$. long from stem to stern, $9 \mathrm{ft}$. 4 in. wide, and $3 \mathrm{ft}$. $8 \frac{1}{4}$ in. deep. Her keel is $30 \mathrm{ft}$. long. (These are Rhenish feet.) The bigger yachts are of similar build than the smacks, says the author. They have hatchways and a raised deck aft, as well as a room forward, and the vessel has glass windows. The tiller was made of iron and bent a little. There were two lead pumps in these old yachts, and to-day the Dutchman wisely still retains the custom of having such an essential article in duplicate, as you will find if you examine the equipment of a Zuyder Zee botter. This excellent habit is the very reverse of that which is found on many English yachts, wherein the pump is placed on one side of the craft only, so that in bad weather-the very time when you are most likely to need the service of the pump-the deck on which you would wish to pump is the lee-side and awash. But according to the Dutch idea it matters not which tack the ships may be on, for there is always an available pump on the windward side. This was a fact that was clearly appreciated in those days, for the authority just cited adds that the advantage of having two pumps was "so as to be able to pump from whatever side the vessel leans."

The bowsprit of these yachts was usually not fixed, and could be run in and out, in order, doubtless, to 
give additional convenience in entering harbours or locks. And it is because the Dutch adapted the bowsprit, made it capable of being run in and out, that the English cutters of the old-fashioned type were thus provided, not with fixed bowsprits, but spars that could be reefed when necessary. 'That was the real origin of the matter-the crowded havens and locks-though in actual practice it was found convenient to run the spar in when bad weather came down. It was customary for the mast of the yachts of Holland to lean forward and not be quite vertical. Windlasses were fitted close to the mast for hoisting sail, and in the bigger yachts, as, for instance, the "great yacht of the West Indies" belonging to the year 1671, the deck at a point thirty-three feet from the stem was raised eighteen inches so as to form "la chambre du capitaine." The length over all of such a yacht as the last mentioned was sixty-six feet, her width being nineteen feet, the planking being very thick and varying from three inches to four and a half.

There were also yachts for different purposes now that the fore-and-afters had for so many years shown themselves to be so useful and convenient. There were thus Government yachts, passenger yachts for communication between the different towns of Holland, and there were "advys-jaghts" or despatch-boats. This form of yacht was known as "a kind of galleot," which was used for carrying army orders, and even to make big passages. She measured usually $115 \mathrm{ft}$. long, $27 \mathrm{ft}$. $5 \frac{1}{2}$ in. beam, and $11 \mathrm{ft}$. $5 \frac{1}{2}$ in. deep, yet she was not fore-and-aft rigged but square rigged. Even to-day, though in most other navies there are no sailing vessels fore-and-aft rigged still employed, yet in Holland there still survive some sailing cutters which one comes across occasionally. With their varnished hulls, their old-fashioned lines, the Dutch State yachts of to-day seem curiously out of their 
element alongside the very modern Dutch steel motor cargo-carriers.

Nowadays these yachts are employed, as centuries ago, for the purpose of preventing smuggling and for looking after the fishing; but no longer does one certain custom continue. Meagre as is Holland's collection of warships to-day, yet it is not still customary, as in the seventeenth century, to attach a sailing yacht to the fleet. But at that age which is covered by the Dutch wars, Admiralty yachts were so employed and used by the admiral in command. With the State yachts, then, employed for protecting the Revenue and the fisheries; with the Admiralty yachts employed in the service of the navy; with the "advys" yachts used for carrying despatches; and with, finally, the numerous cutters that belonged to the wealthy citizens of Amsterdam, Dordrecht, Rotterdam, and other cities, and the hulls of these yachts magnificent in gold, yellow, and blue, with high bowsprits and lofty resplendent sternsthere would have been plenty of detail for us to have admired and criticised had we been able to take a cruise two and a half centuries ago through Holland.

But it is significant that the influence of the Dutch navy over these fore-and-aft yachts was very great. Their sides were pierced for guns, and these latter were carried, usually eight in number; and so, whilst as far as one can find, there was no such thing as yacht-racing among the Dutch, yet there were plenty of sham-fights. As one examines the existing pictures and old prints which have been handed down from the seventeenth century, one can see these naval manœuvres being carried out by the Dutch yachts. For it was a century when there was always a naval war ending, beginning, or threatened. There was a strong naval enthusiasm in the Dutch people at that time, and so it was but natural that the yachts should exhibit this characteristic. Thus we see pictures of naval reviews undertaken entirely by yachts, of mock battles and yachts' cannon blazing 
away. We see fleets of these vessels sailing in the naval formation of line-ahead, each unit keeping her station like a squadron of ducks with head to stern and sails bellying out. In the event of distinguished foreign visitors the Dutch would entertain them with these spectacular sham-fights and water-parades, much as nowadays we organise a naval review at Spithead. Detailed sailing instructions were issued, and under the command of their admiral these lines of fore-and-afters would come sweeping down, firing their guns as they came, in the most impressive manner. They would practise mimic warfare by boarding each other, and exhibiting their abilities in the arts of naval tactics. The admiral flung out his orders by signals just exactly as in actual battle, ordering them to turn, to attack the enemy, to cease fire, to come alongside for instructions, and so on. A terrible thunder these yachts made with their guns, and shook the houses of the city of Amsterdam down to their very mud-driven piles. To-day, where wharves and great warehouses have been erected to deal with the commerce of great steam liners, the good people of Amsterdam were wont to stand on the green banks of the Eye and watch the striking evolutions of these fleets of yachts.

In the reproduction (Fig. 19) of a Van der Velde a nearer view will be gained of one of these yachts to the right of the picture. There she is with her guns projecting from her hull, with her leeboards, her brave display of bunting, and her rowing-boat tied up astern. The heel-rope of the sprit has been slacked off, as the vessel is at anchor, thus allowing the peak to drop; but the sail itself is kept to the mast by the usual lacing. In the foreground and centre of the picture is an early type of the smallest of the Dutch yachts, known as a boier, which were usually about eighteen or twenty feet long. It will be observed that this type of craft was rigged with a small spritsail like the bigger vessels, and forward she set a staysail. Both this little ship and the 


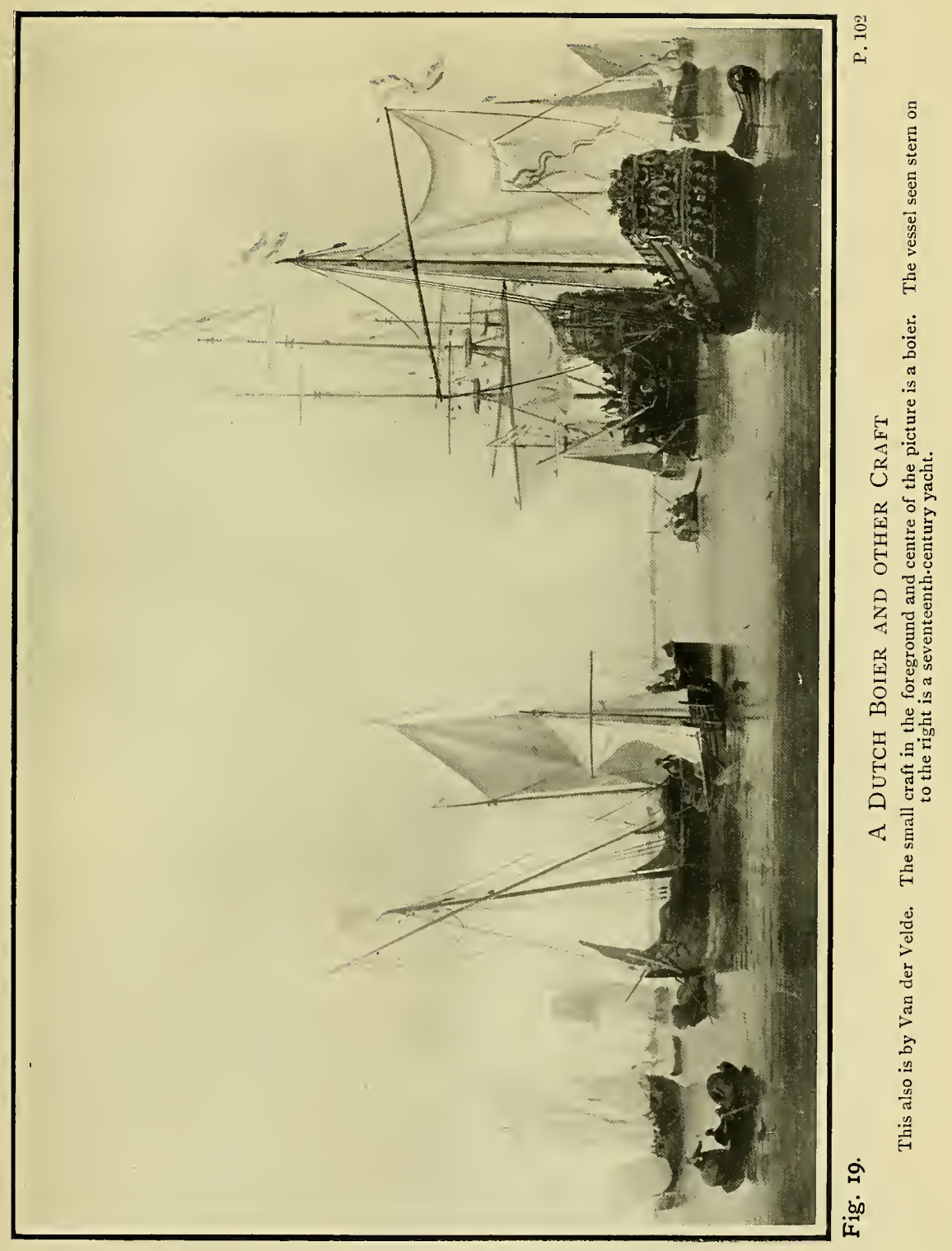



bigger one behind her are seen to stow their anchors over the bows after the manner of the full-rigged sailing ships. We alluded just now to the great rake forward which was possessed by the mast of some of the Dutch vessels of the time. This is especially noticeable in the ship alongside the boier. One other point we might call attention to in connection with the yacht at the right hand side. It was the practice in the case of the big, full-rigged vessels to cruise with a boat towing astern, so that if any of the crew fell overboard he might have a chance of being picked up. In contemporary pictures one always finds the painter of the boat leading to the bigger ship through one of the stern portholes. Now, in the case of these high-pooped yachts a similar practice was followed, and though the photograph in this instance has suffered through being reduced, yet in the original one can clearly see the painter of the boat leading up to the port-hole where it was belayed. Even the yacht's boat apes her bigger sister by having a stern raised as high as she dare, and in the older-fashioned Thames skiffs, and to an extent in those of to-day, there is a kinship with the open boats of the seventeenth century and so with the high-sterned sailing-ships of the early Tudor times. No doubt the unhappy man whose lot it was to be towed in the small boat must have been glad of this little protection at the stern, but we cannot exactly envy his experiences when a following sea kept rolling up and the boat viciously kept charging first to one side and then the other. At the extreme left of this picture will be noticed a threemasted fishing-pink, very similar in hull to the pink we discussed in our first Van der Velde. This time, instead of being rigged with one square-sail and staysail, she is three-masted, her fore and main masts setting squaresails, but her stern has adopted the raised poop of the bigger ships, and like the latter she sets a lateen on her mizzen.

In Fig. 20, the artist (Van der Velde) again affords 


\section{THE DEVELOPMENT OF THE}

us an opportunity of studying the craft of his time. The fore-and-after with the white sails in the centre of the picture has just come out from the harbour. She has been standing on the starboard tack, but cannot on that board clear the end of the pier, so, as we just see her, she is going about, and is in the very act of coming on to the port tack. The man in the bows is backing the staysail, and we can see the helmsman pushing his tiller over to port, so as to enable the vessel to pay off. The reader will find that it is worth his while to study the similarity which exists between the rig of this vessel and of the modern Dutch hoogarts, as reproduced in a later chapter. There is no gaff, there is no boom; the mainsail is fitted with a sprit as usual, though we cannot see it, since it is the other side of the sail, and would have interfered in Van der Velde's composition with the vertical line of the mast in the small craft in the foreground. But though the mainsail is laced to the mast, there is still permitted quite a considerable drift between luff and spar. The small sailing-boat in the foreground has dropped her staysail, in readiness for coming to her anchorage or entering a lock. That, at least, is what seems likely, and the canvas seen in the bows of the boat would be the lowered staysail. But it is also possible that this is one of those small fishing-craft such as one comes across in Hollands Deep, one of those broad tidal estuaries which lead inland from the North Sea. These are open boats, and are rigged with spritsail just as this, but have a curved canvas tent placed forward so that the fisherman while at anchor may turn in and sleep. And if this is the kind of craft which Van der Velde wishes us to see, then that arrangement forward is not the lowered staysail but the canvas forecastle. It is impossible to say for which it is meant, but it is significant that in such quiet little havens as Willemstadt and Strijensas just such boats as this, measuring perhaps sixteen feet in length, are to be seen, or anchored out of the fairway, 


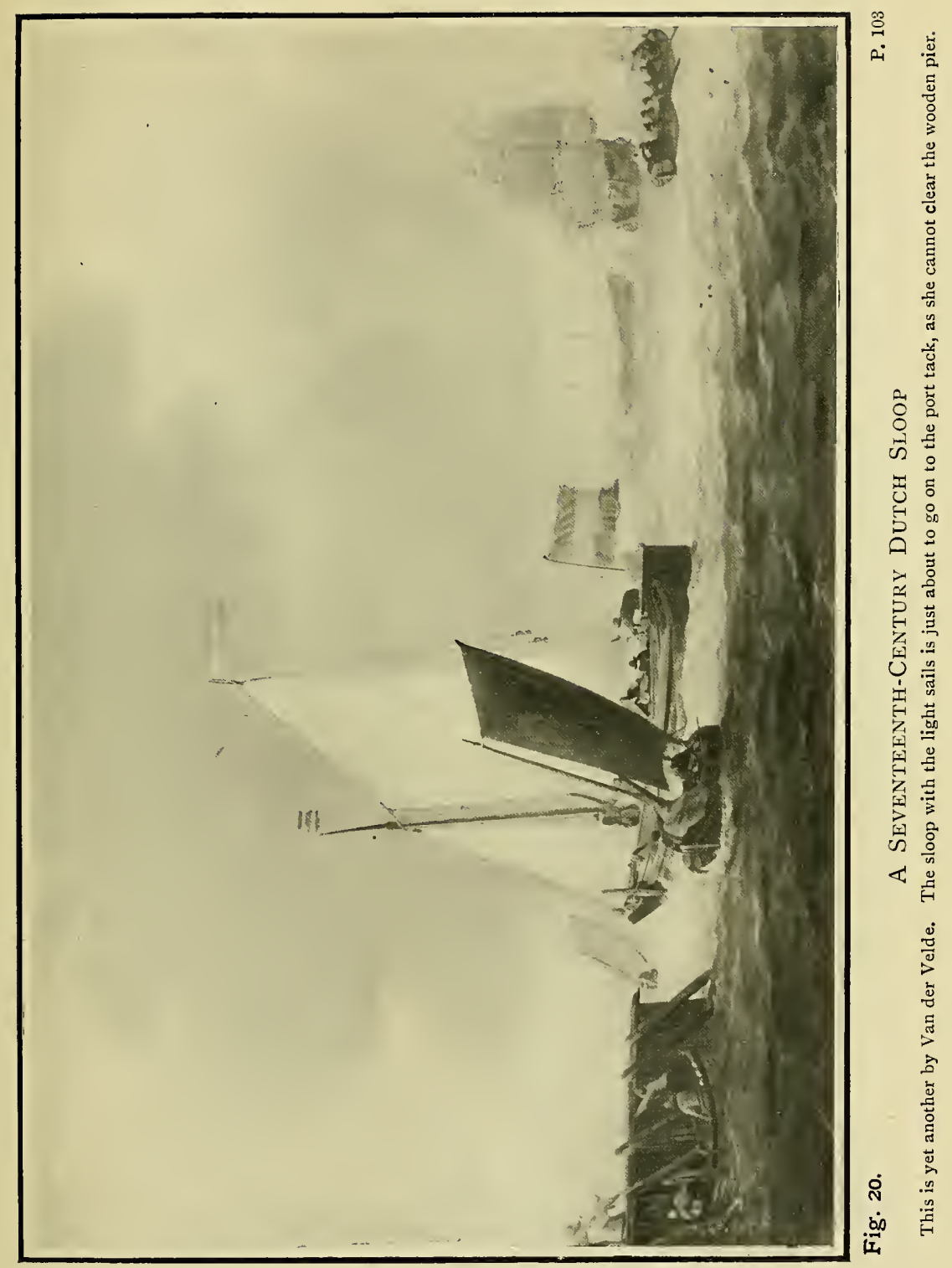



pursuing their calling with canvas hood, spritsail, and everything exactly as in this picture.

In the striking line-drawing (Fig. 21) we have a good opportunity of remarking the lines of an Admiralty Dutch yacht. This has been drawn from the model in the Rijks Museum, and shows a somewhat later type, as would be in use about the end of the eighteenth century. The bows of the ship are exceedingly similar to those of the war-ships of that time, with figurehead and high poop. She has a nice sheer which comes up to the typical high stern, with its rich carvings and the conventional Neptune. Copying the big ships also, it will be observed that a balcony has been extended from the quarter, which was fitted with glass windows. This yacht is very straight on the keel, as was the practice, and her bulwarks have been pierced for six guns aside. That does not necessarily mean that she carried twelve cannon plus the two which would be in the stern and point aft-in all fourteen. For the practice was sometimes to provide more port-holes than were required for all the guns, so that a full broadside could be given by transferring those across the deck from the side that was not in action. The object aimed at was to avoid any possibility of the ship becoming top-heavy by so much upper weight. It will be seen at the channel-plates that five shrouds would be set on either side, which also was the prevailing number, and many a time was copied subsequently in British Revenue-cutters. The rudder is somewhat big, but with the straight stern-post would doubtless be necessarily so large in order to control a vessel of such length.

In the next illustration-this time by Abraham Storck-we have (Fig. 22) yet another insight into the fore-and-aft shipping of the seventeenth century. This picture, like the other Storck, was painted in 1683, and hangs in the Mauritshuis at the Hague. On the extreme left will be seen an interesting but somewhat strangely rigged vessel. She has a good deal of free- 


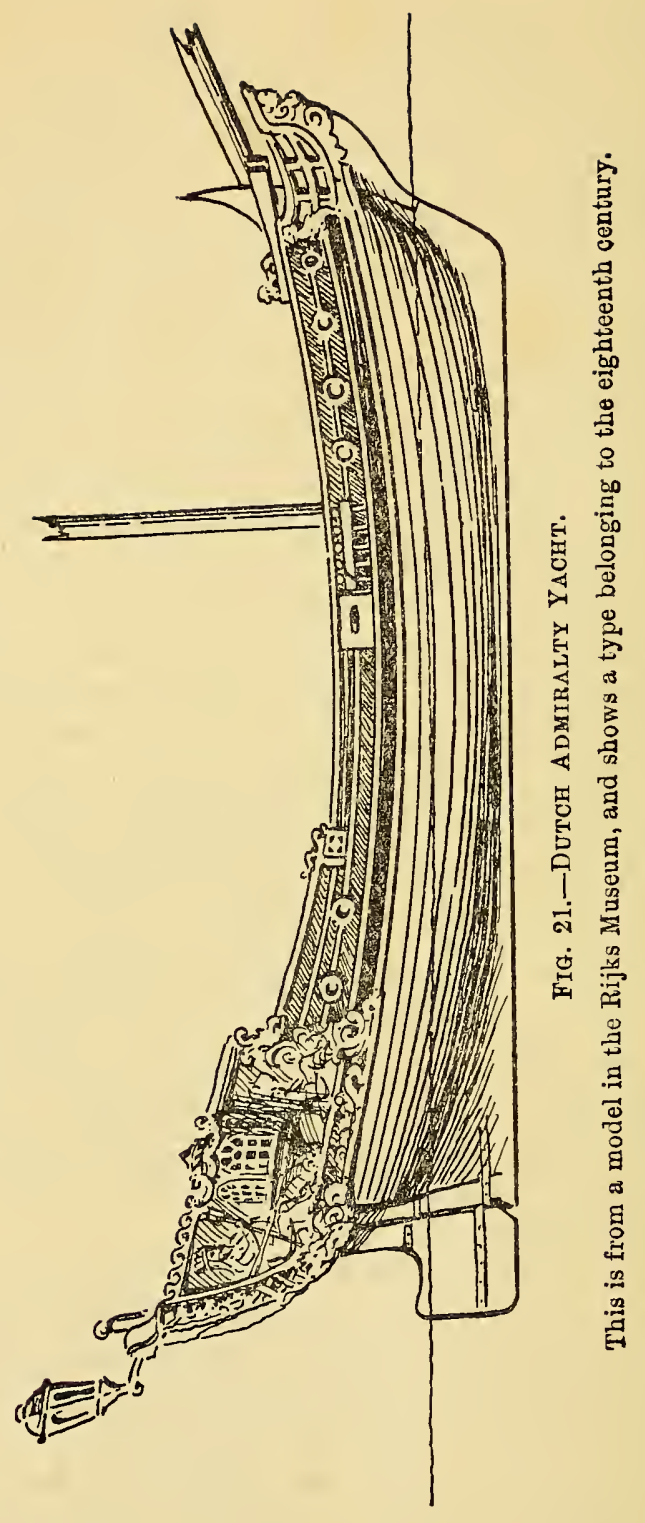


board, and is of good size. The breeze, although free, is so very light that she has had to send out her boat ahead with some of her crew to tow her. This is a seventeenth-century Dutch galleot, and the precursor of the ketch. On her mizzen she sets a lateen-sail ; on the main she is square-rigged, forward of which come a staysail, and then on the bowsprit a jib, working on the foretopmast-stay. Below the bowsprit she would also probably set a water-sail. We have here in one ship a most extraordinary mixture of the north and south, of the fore-and-aft rig as well as the square. The applestern is characteristic of the modern Dutch galleot, and I have seen this type in English waters as far west as Poole in Dorsetshire. It will be noticed that the hull, with its large amount of tumble-home, is not unpleasing, even if the vessel seems to us somewhat unnecessarily ponderous. Still, again, is the close kinship to the ocean-going ship displayed in the stern and the poop-deck. No doubt this old galleot would not distinguish herself to windward, but in a hard wind, running free or well on the quarter, she would be able to render a pretty good account of herself.

From this galleot type there descended firstly the bomb-ketch. 'The latter was adapted by the English and French naval powers towards the end of the seventeenth century. The French called these vessels, in fact, "galiotes à bombe," and so preserved the old Dutch relationship. The bomb-ketch was of about two hundred tons burthen and built of exceptional strength, for she had to endure the downward recoil of the mortar, which was placed forward of the mainmast. And it was for this reason that the mast was stepped nothing forward of amidships so as to allow plenty of space between itself and the stemhead for firing this mortar. She is, according to existing prints, rigged in a manner very similar to the Dutch galleot in Storck's painting, except that the bomb-ketch carries a square topsail above her 
lateen, and both topsail and topgallant above her main, a water-sail being also shown below the bowsprit.

From this the galleot in the course of the next few decades altered her character by changing her lateen to a gaff sail with boom, and by doing the same with the mainsail, but setting the square-sail when running. At the same time, since the foreand-aft rig was being adopted so thoroughly, it also overcame the galleot, and the somewhat diminutive mizzen was stepped further inboard and its sail area increased, in order, doubtless, to spread the canvas over the spars with greater evenness, and prevent the mainsail from being of a size that might be too unhandy. With this seventeenth-century galleot must be compared the early nineteenth-century galleots of the same country shown in the engraving (Fig. 23) by $\mathbf{E}$. W. Cooke. In a hundred and fifty years the change that has taken place has been less in respect of hull than of rig. Gone are the lateen and the water-sails. For the loose-footed mainsail that of the contemporary cutter with its boom and gaff has been borrowed, and so also with regard to the ketch; but it is curious to find that the vangs of those seventeenth-century Dutch yachts that used to besport themselves in naval reviews are still retained on the mainsail, as will be immediately noticed. In the galleot to the left of Cooke's picture the sails are set, but in that of the foreground of the illustration the sails have been stowed and the gaff has been detached from the head of the sail and hoisted, possibly to act as a derrick, in handling the cargo. But notice that the lower yard is cock-a-billed and is used for setting a high square-sail. 'This sail, as in the Revenue-cutters of the eighteenth and nineteenth centuries, was not kept bent to the yard as we should have expected, but when in disuse was taken off, so that the yard was quite bare. For our convenience Cooke has shown the square-sail hanging 


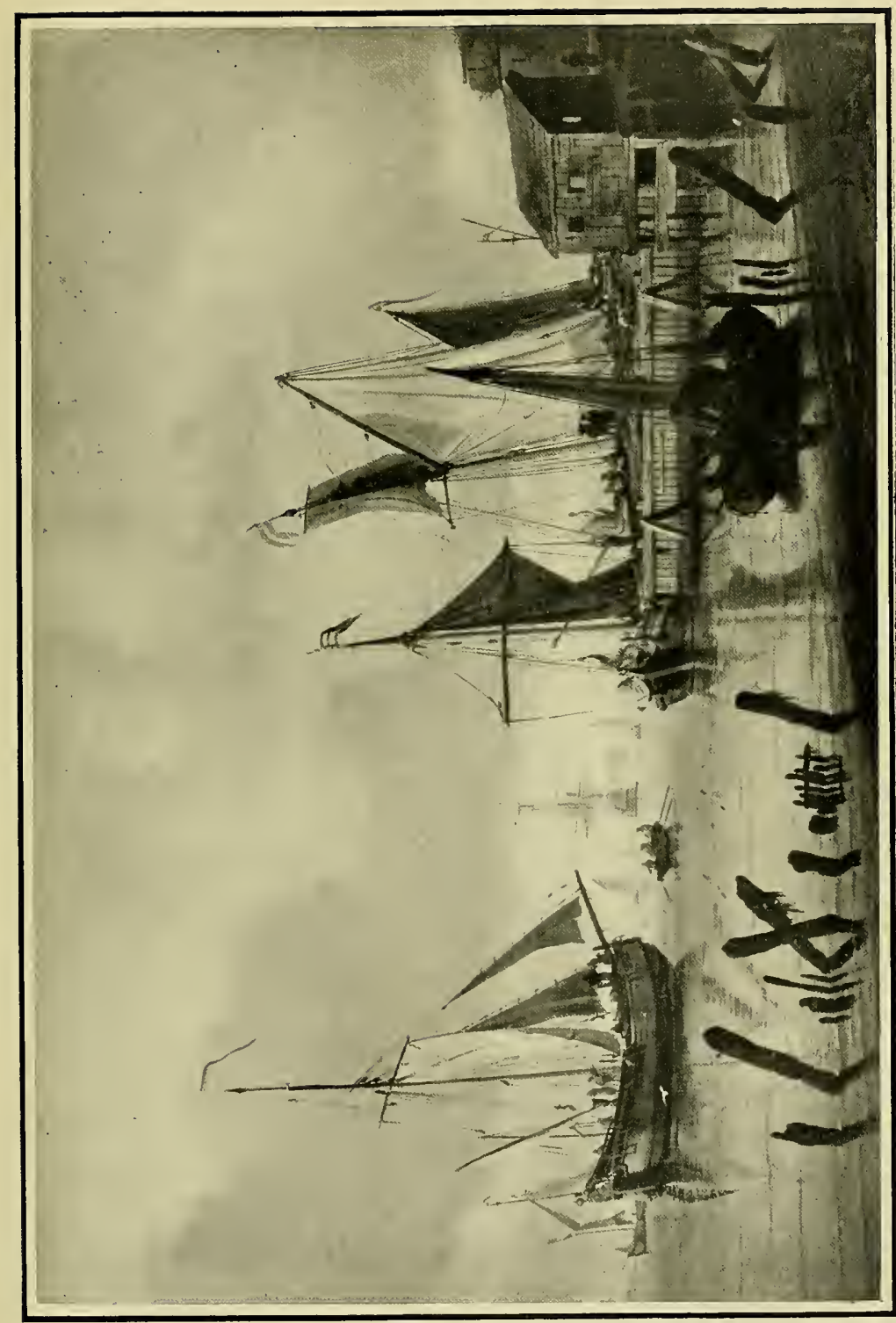

움

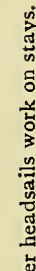

岁

营

5

凷密.

ن

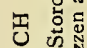

$\rightarrow$ की

吕䲿

$>$ 题

骂 츌

实

武

亲

$z$

됟 ․ㅡㄹ들

क

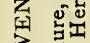

红

这

岕

$=$

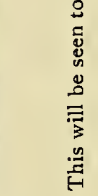

สู่

is 

up to dry in the background behind the galleot which is nearest to us. Observe, too, that in addition to this course and its yard the early nineteenthcentury galleot sets a square topsail, and for convenience this is not detached from its yard, but the crew when sent aloft to stow get into the foot-ropes and slack away the sail so that it runs along after the manner of the contemporary stunsail. A neat stow is then made of it in the centre of the yard, close to the mast, and the sail can be run out along its yard again when desired. The foresail has been stowed to the forestay, and the bowsprit, after the chain bobstay and tackle have been slacked off, has been hauled up. We have repeatedly referred, during the course of these pages, to the extraordinarily close relationship existing between the modern Thames barge and the Dutchmen, so that here we shall not wonder that our countrymen have copied the Hollanders in another item.

Those two stern windows seen in these galleots, or ketches as we should call them in our country, are very characteristic of the Netherlands craft, as also is the hatchet-shaped rudder. In another of Cooke's etchings a Dutch galleot is seen not merely with course and square topsail but even with topgallant as well. And so much space has been left at the yardarms that it would appear that stunsails were also set thereon during suitable winds, for about this time1829-the studding-sails of the ocean-going sailing vessel were very much in vogue.

I have digressed a little from our period, because I was anxious to show at once how important an influence the old Dutch galleots have had on our fore-and-aft ketches. Among our fishing fleets and coasters the ketch rig is so plentiful that one cannot deny that Holland has laid us as a maritime nation under a very heavy debt of gratitude by showing us the right way to go about our business, by imparting 
to us ingenious ideas that we had never thought of. And if we may go back for a moment and look again at the Storck picture before we pass on, the reader will perhaps be interested to notice that even before the end of the seventeenth century the galleot had, whilst retaining the lateen mizzen, adopted the gaff mainsail-without boom-but with bonnet laced along the foot and an arrangement of brails for shortening in or stowing the sail. These points will be observed by looking at the white-sailed vessel to the right of the picture in the middle distance, but partially hidden by the wooden quay. Her square topsail is hollowed out along the foot- "goared" is the correct expression-so as not to chafe against the forestay, and in the later fore-and-afters of the Revenue-cutter time we shall find that this "goaring" was carried to great extremes.

In the illustration (Fig. 24) we have a view of the Maas near Rotterdam. This is from the painting by Gerrit Pompe, who is believed to have lived in that city about the year 1690. The fore-and-after to the left of the picture shows a yacht of this period with gaff mainsail, but without boom. And Pompe had been very careful to show us that the yacht carried a square-sail for running, as in the case of the galleots that we discussed just now, for part of it is seen cock-abilled and projecting from the vessel to windward. That this was no singular feature is seen from an examination of other Dutch masters. In the National Gallery there is a painting by Jan van der Capelle, who was alive in 1680, which shows a smaller vessel than this, but with gaff mainsail, bonnet, and no boom, no jib, but staysail, and a square-sail set forward of the latter boomed out with a light spar. And there is a similar subject by Ruysdael in the Boijmans' Museum. We cannot blame the seventeenth-century Dutchmen for their love of this squaresail. It is a most useful article when the wind is fair 


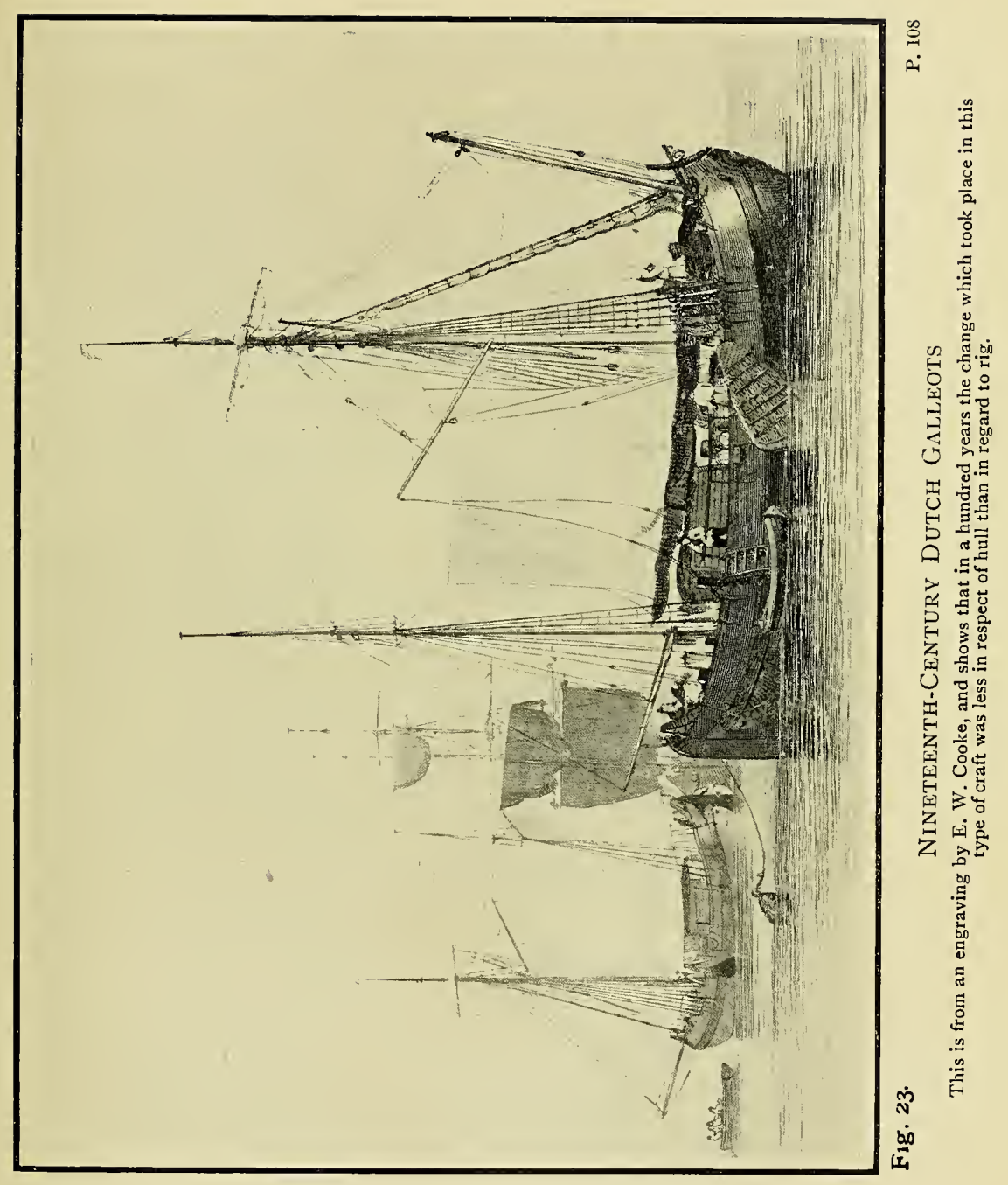



and it is surprising that its modern employment on British fore-and-afters is the exception rather than the rule. True, one does see it set on coasting ketches and sometimes on yachts, though very rarely in the case of the latter, especially when cutter-rigged. I have myself used it with that rig, and found it of the very greatest utility when a long run was being undertaken with the wind dead aft or nearly so. It can be set above a reefed mainsail, and itself reefed and hoisted again, so that it becomes practically a square topsail. 'The old Revenue-cutters found this sail so useful, the Dutch inland vessels to-day sometimes set it-as, for instance, when they have a fair wind along the North Sea Canal-our coasting ketches and schooners also employ it, that one wonders that smaller fore-andafters are so slow to prove its value. It is certainly not so conducive to speed as that modern invention the spinnaker. But it is as a cruising-sail that the square-sail is invaluable for the yachtsman. It is much handier, and can be carried for a much longer time than the spinnaker-in fact for as long as it is safe to run at all.

'The line-drawing in Fig. 25 has been sketched from a Dutch print of the year 1770 , which is preserved in the Water 'Tower Museum at Dordrecht. This craft is a kof-tjalk. She has the older spritsail laced to the mast as well as staysail, but as she is running free the jib has not been set. It will be observed that one brailing-line is shown from the leach of the mainsail to its throat in order to shorten in canvas. The square topsail is there, well-goared this time for the reason that we explained just now, and the barren-yard below, as it used to be called at this period on English fullrigged ships, is employed so that the topsail may set the better. But notice also that in the light, free air the Dutchman recognises that he needs a boom: for one of the crew has taken one of those very long boathooks which are found on every sailing craft of Holland, 


\section{THE DEVELOPMENT OF THE}

and are used with so much skill for entering or leaving a lock, or for getting alongside a quay. In this picture the man has sought to improvise a boom by thrusting

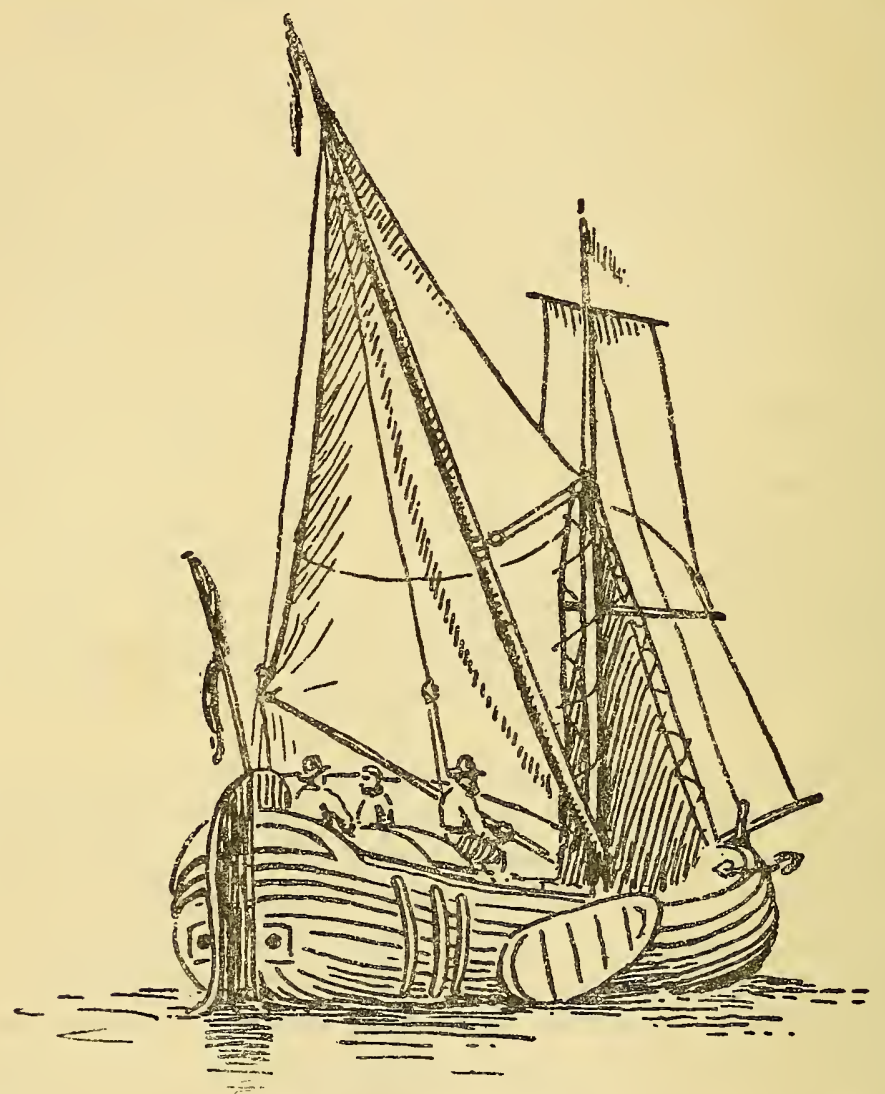

FIG. 25.-KOF-TJALK.

This was sketched from an old print of the year 1770, preserved in the Water Tower Museum, Dordrecht. Notice the light spar used to keep out the boom. less mainsail.

the boathook into one of the reef cringles on the leach of the sail.

Perhaps a better idea of the sail-plan may be 


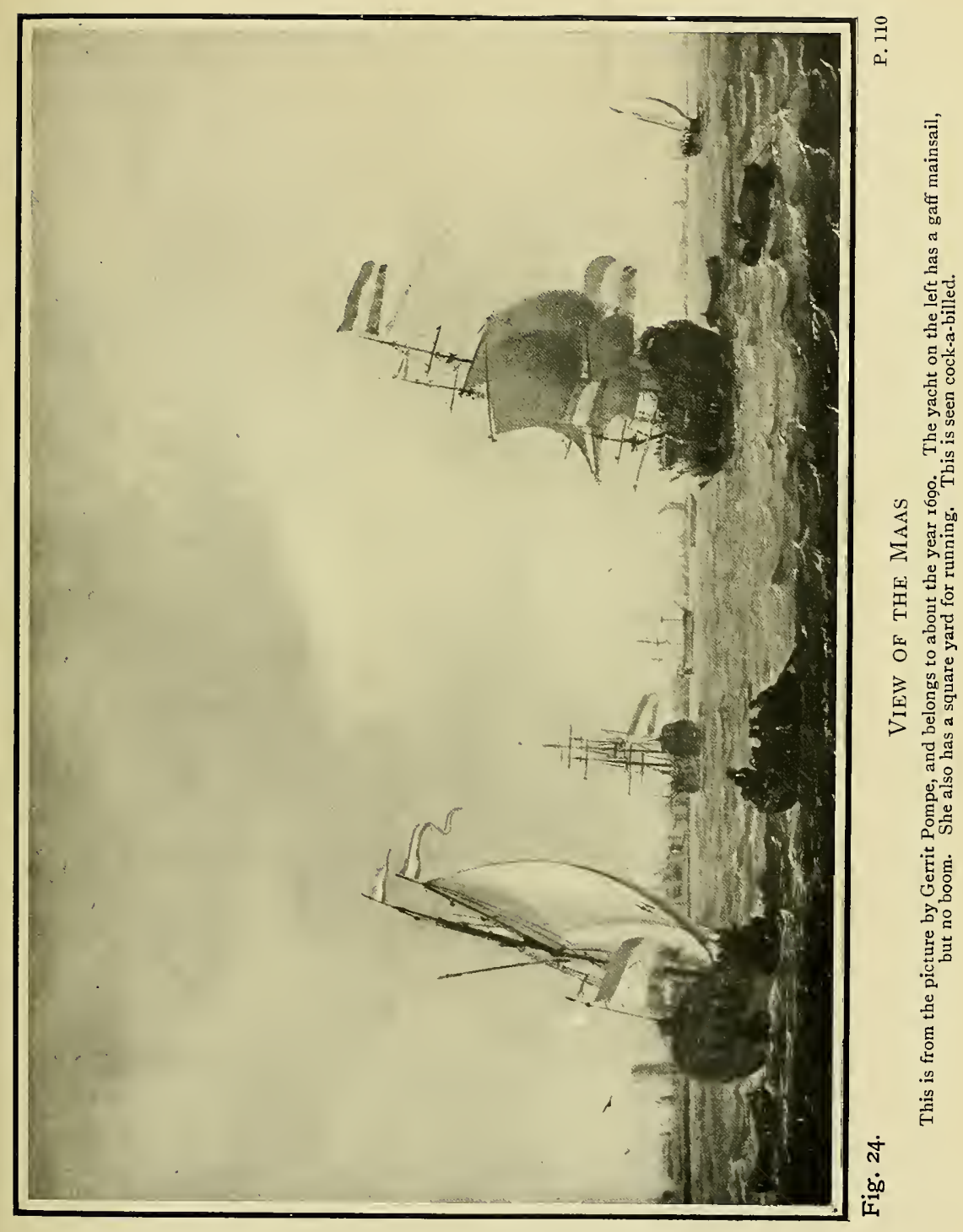



FORE-AND-AF'T RIG IN HOLLAND 113 gathered from the illustration (Fig. 26), which has been faithfully copied from the celebrated volume published in the year 1768 by Frederick Hennik Af. Chapman, entitled Architectura Navalis Mercatoria, and was one of the most important and authoritative

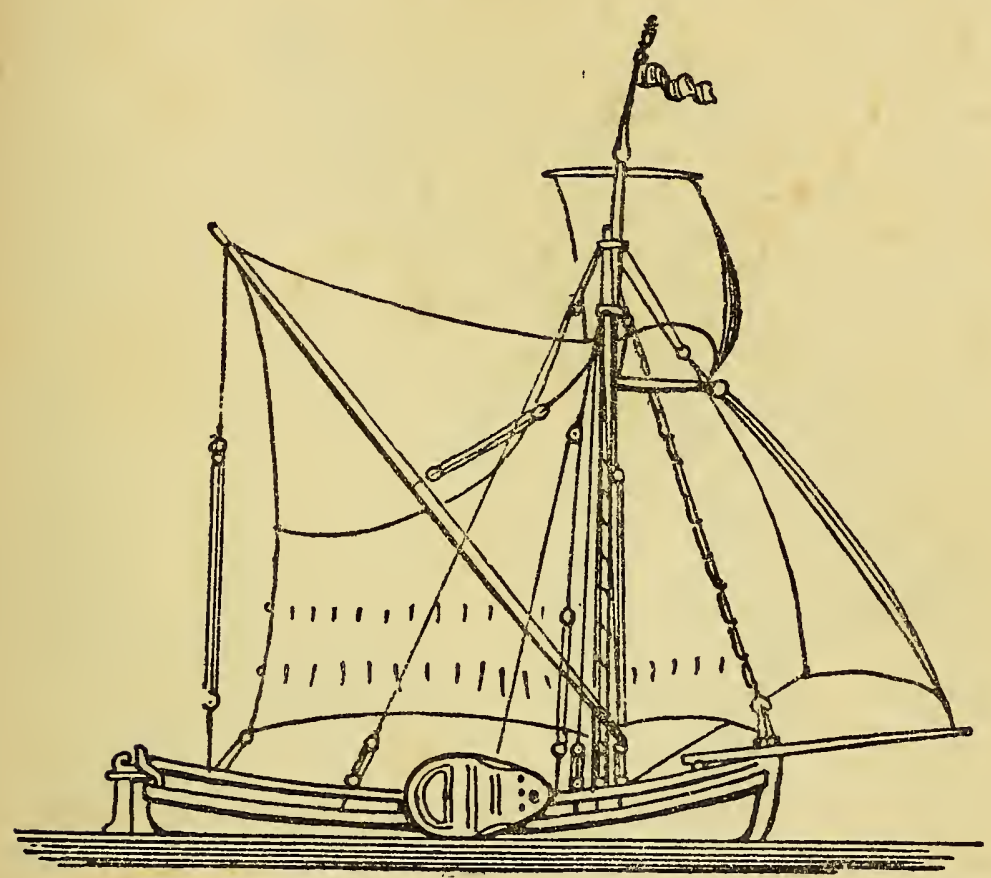

Fig. 26.-Sall Plan of Kof-TJalk.

Taken from Chapman's Architectura Navalis, published in 1768.

Obserre the single brailing-line to the mainsail.

works on naval architecture which the eighteenth century produced. It will be seen that it is no accident that there is only a single brailing-line, but that this was the custom of the time, and that two rows of reef points were provided, as well as one on the staysail. The other features, when compared with this present 


\section{THE DEVELOPMEN'T OF THE}

tjalk, are so apparent that we need not detain the reader's attention in this connection, but may pass on.

We have (Fig. 27) an interesting sketch that was made in the Rijks Museum of a beautiful little model that must appeal unmistakably to all who have the

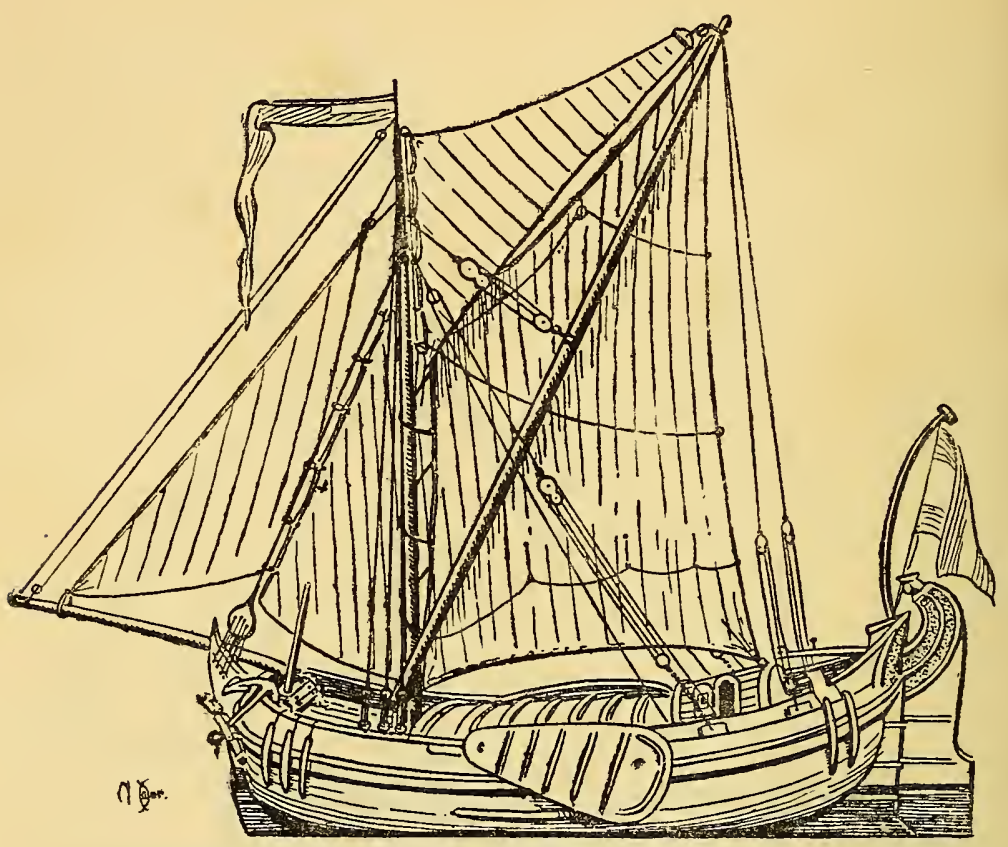

Fig. 27.-Enkhuizen BeURtman.

From a model in the Rijks Museum. A "beurtman" is a cargo-carrier, and Enkhuizen is on the Zuyder Zee.

slightest affection for ships. This represents an Enkhuizen "beurtman," or freight-carrier, regularly employed in traffic to and from the little port in that north-east corner of North Holland on the Zuyder Zee facing Friesland. Nowadays many a beurtman is propelled by Kromhout motors belching forth their paraffin exhaust, and certainly less beautiful if more 
useful to commerce than their older sisters. But happily there are still plenty of these sailing traders doing their useful work in connecting the ports of the Zuyder Zee with Amsterdam.

They must needs be strong and seaworthy so as to stand the dangerous waves which soon get up on this shallow tidal water which has hollowed out the "South Sea" (so called in comparison with the Noord Zee). They must be so designed that they may take the ground without heeling over, and they must be bigbellied because they have to carry all the cargo possible. And they must have a shallow draught because of the few feet in the harbour. Thus we get in this vessel a modification based on the existing Dutch tjalk. The date of this model is about that of Cooke's etchings, within eleven years. To be precise, this vessel here reproduced belongs to the year 1818, and shows the sprit-rig at its fullest development for comparatively smaller craft. Fiddle-blocks are seen to be used in connection with the runners, the vangs, and the sprittackle. There is a more complicated and more efficient arrangement of the brailing-line than in the kof-tjalk of some years earlier, so that the sail can be shortened in quickly and effectively. But a topsail is now set, and not a square one nor of the hybrid type which a Thames barge to-day sets. On the contrary, so far have improvements advanced that it is indeed a foreand-aft sail in every sense, and triangular in shape. The topsail ends at the peak just as the head of our modern spinnakers, and this triangular addition to the sail-area of the craft makes the general shape of the mainsail thus to approximate very closely to the original, almost square, form of the sail which existed before ever a staysail was employed and the old una-like rig was in vogue.

On deck forward will be seen the windlass and handspike which are still used on the botters, tjalks, and other Dutch sailing craft, though in the most 


\section{THE DEVELOPMEN'T OF 'THE}

modern types an iron windlass, with a large handle and wheel on either side-much resembling the arrangement which is employed for pumping air down a diver's pipe-are more common. The mast is placed well ahead, so as to leave plenty of room for the hatches and cargo space, abaft of which comes the cabin for the skipper and his wife and family. The curve of the ensign staff is in no way exaggerated, though I have not been able to discover the reason for this preference for a straight staff. Notice also below the rubbing strake that there is a ridge which projects from the hull and continues fore and aft for a short distance amidships. This is a contrivance, still employed, on which to rest the weather leeboard when on a wind, or both leeboards can rest, each on its own ridge, when the tjalk is not under way. The reader will be struck by the high stern and the considerable amount of sheer. It is now many a long year from the days of mediævalism, yet the Dutchman of even the twentieth century cannot get away from this custom entirely. It still shows itself in the steel tjalks and haaks as it did in the highly pooped ships of the early sixteenth century and the sailing craft of a few years later. For, above all things, the Dutch are a conservative race, and the seamen are the least susceptible to change of any living people. The tiller has a cleat and a block fixed at its end, so that a line may be rove when the wind is strong or the skipper wants to run forward, perhaps, to lend a hand in getting up the anchor. I have watched a whole fleet of about thirty of these sailing craft getting under way in the weird darkness just before dawn. 'There is one continuous clanking of windlasses and cables until the anchor is broken out, and then with silent, ghost-like effect the whole fleet one by one goes sailing down the river in the cool morning breeze and the fastswishing ebb. Perhaps an occasional shout from the skipper to the hands forward, or the thud of the 
FORE-AND-AFT RIG IN HOLLAND 117

muddy chain on the damp decks, and that is all the sound one hears. In a few minutes the anchorage, which last night was a forest of masts and weathervanes, is now empty, and there is nothing but the tide.

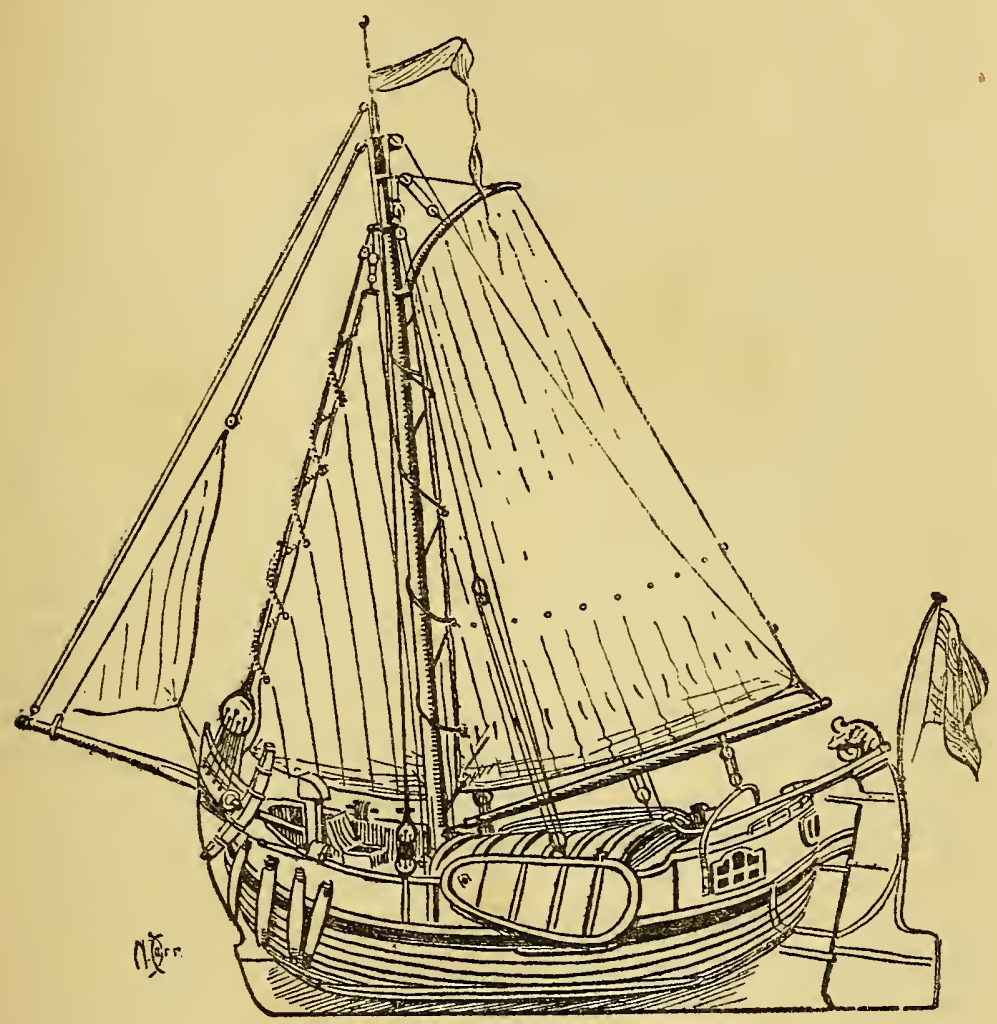

Fig. 28.-PAVILJOEN-Poм.

From a model in the Rijks Museum.

In the next model seen in Fig. 28, which belongs to the year 1784, and is one of the exhibits in the Rijks Museum, we have a paviljoen-pom called the Prince of Orange. Here, though the date is earlier than the 
last-mentioned model, we have the fore-and-aft rig in almost its final Dutch development-final, that is to say, in everything except a few minor alterations that have come through the most recent years. The sprit has gone altogether, but the long gaff of the Admiralty yachts has been shortened and curved. A boom is added to the loose-footed mainsail, and there is also a topping-lift as well.

In many a respect this vessel resembles the Enkhuizen craft, and yet there are differences. The word "paviljoen" signifies "tent" or "pavilion," and the characteristic of this ship is her captain's "pavilion" or cabin placed right aft, formed by the poop deck, with its windows at the side and the stern. The chimney in the fore-deck, with its cowl, is of the prevailing Dutch type, and can be seen any day on the two or three Dutch eel craft which are always to be found at their moorings off Billingsgate. Observe that the head of the foresail ends not in a cringle but in a diminutive yard. The foresail also works up and down the stay, not by means of hanks but like the mainsail with a lacing. The decoration on the top of the rudder-head is not unusual, and one frequently finds some such device as a gilded lion there placed. It may seem not a little extraordinary that only a single shroud should be given on either side to support the mast; but it should be noticed that the runners are stout and provide a good deal of aid in taking off the strain. The main sheet works on an iron horse, and has a couple of blocks. There is a lower line of reef points on the mainsail, whilst the upper row consists of holes for lacing. The deadeyes, far from being any modern development, are among the oldest of the ship's equipment; for on the largest mediæval sailing craft "dead men's eyne," as they were called, were in regular use, and are so named in many a ship's inventory of Tudor times. 'The forehatch is much like a box in shape, and the lid, which 
is fixed, works on hinges, so that it cannot get adrift. The pair of substantial bollards, one of which is seen on either bow, are typically Dutch, and essential when so much work has to be done warping in and out of dock or checking the vessel's way when coming alongside a quay. It will be observed that, contrary to a custom which obtained on many of the bigger foreand-afters, the jib does not work on a stay. It is hoisted by a halyard in the usual manner, and has a traveller on the bowsprit. The word "paviljoen" we have already explained, but the word "bom" or "pom" is given in Holland to various kinds of craft. For instance, in addition to the type before us, one finds it applied to such sailing vessels as the Scheveningen pinks. As to the origin of this expression I cannot obtain any definite information, though I suspect that it may have come into use with the time when the " bombe" or "bomb-ketches" were in their glory. Remembering the historic prerogative which the sailor-man has always possessed for confusing nautical terminology, one can easily imagine that even a cutter-rigged craft might have certain peculiar features which would cause her to be designated by a title which rightly belonged only to a galleot or ketch.

A very interesting type of cutter will be found in Fig. 29, which has also been sketched from a delightful little model in the Rijks Museum. She is a very beamy, big-bellied craft, with bluff rounded bows and stern. The ledge on which to rest the leeboard is here again seen, and fixed cat-heads are discernible on either bow for the anchor work. It should be remarked that at this time the hempen cable was still employed for the big ships of war, and so the custom obtained on the smaller craft. This cutter is well supplied with cannon, including a heavy chasing-piece and a quick-firer on the port gunwale, and was probably employed in protecting the Revenues, although her bulky hull would have been anything but speedy. Her gear is 


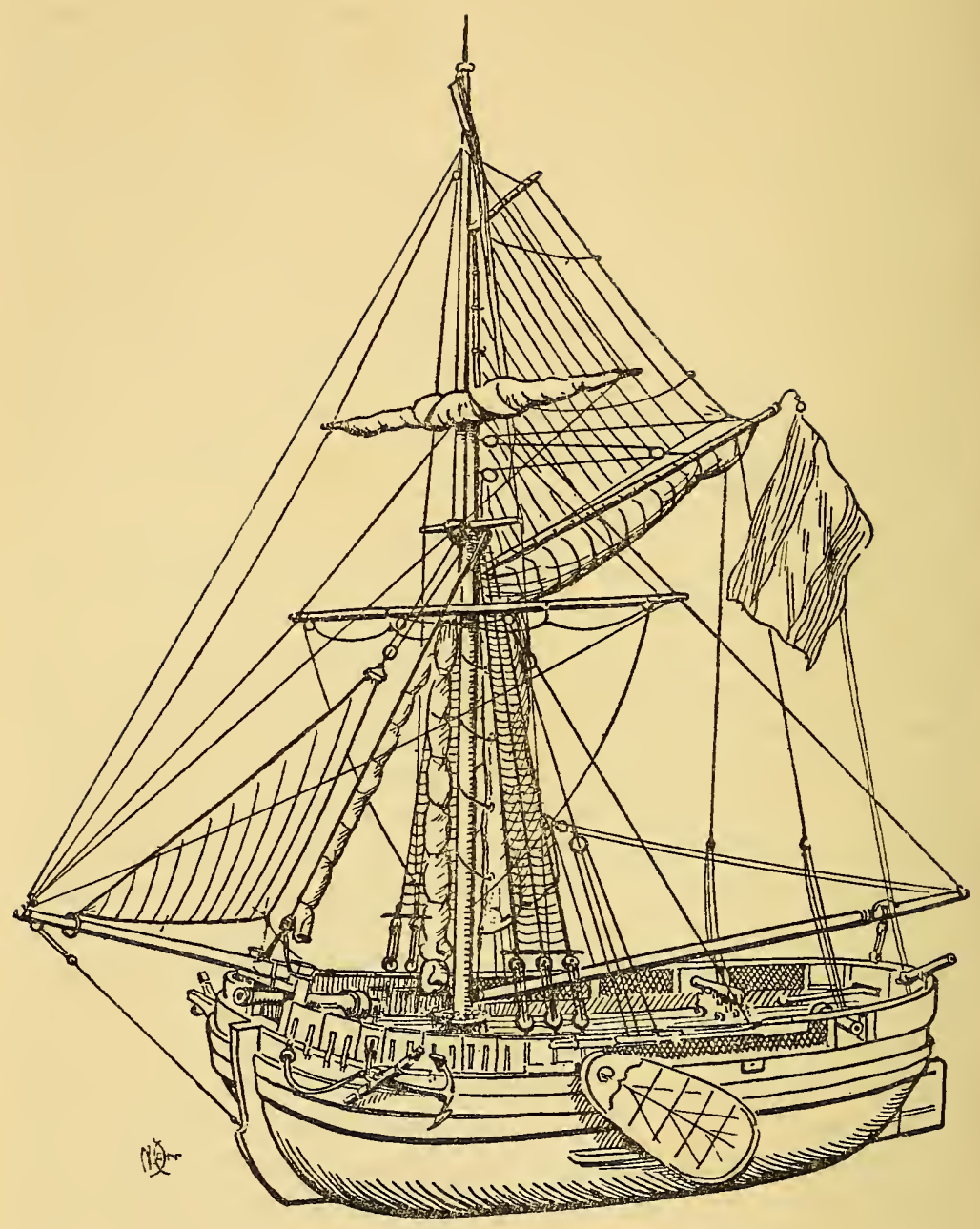

Fig. 29.-DutCh Cutter.

From the model in the Rijks Musenm. Notice the method of stowing the lower course up and down the mast. 
deserving of attention. She is indeed cutter-rigged, but she carries not merely a square-topsail, but one also that has a gaff. The former is stowed to the yard, as we saw in Cooke's picture of the Dutch galleots. The course which is set on the lower yard when a fair wind favoured the ship is not stowed to the yard, but is rolled up and laid up and down the mast forward. By a system of blocks and lines it can be readily hauled out along the yard when required. As we said above, it was the same method which was employed in the case of the English Revenue-cutters, and the practice is still continued to this day on some of the Dutch steam tugs which are found in the neighbourhood of Rotterdam and Dordrecht.

The staysail of this model is equally neatly stowed to the stay, and the mainsail, which has its gaff and boom, is stowed by brailing the sail to the mast after the manner of the big ships' driver. There is no ensign staff shown on this model, but the Dutchman cannot resist an opportunity for showing his love of a curve in the manner he has attached the ensign to the peak. One very curious feature, which is rare, should be noticed in the gaff-topsail. We are accustomed to seeing a mainsail brailed, yet never a topsail. However, in this example a couple of brailing-lines are shown, so that in the advent of a sudden squall or when stowing canvas immediately if coming alongside a smuggler, the upper no less than the lower sail-area can be diminished to nothing at all. It is just such details as these which make the craft of Holland of such enormous interest. The Dutch have never been water-shy. 'They live and die on their craft, they take their families with them; their sympathies are with ships and the things connected therewith, and have no yearning for the shore. Their women-folk acquire the ship-sense; the smallest child when he sees you sailing up to a tjalk or quay knows what is expected of him. He or his mother is ready to catch your line and 
to make fast. He will watch your manœuvres with the eye of a critic, for his mind is moulded by such experience. And so, because all through his life the Dutch shipman is ever concentrating his thoughts on his floating home, and how he can improve her, how he can make her more useful for all the services for which she was intended, she is, in spite of her conservatism in hull and the main features of her gear, always being made better by the addition of articles of apparently small import. If there is a device that is good for labour-saving the Dutchman adopts it, whether it is an improved winch or a novel arrangement for his main-sheet. He goes on getting the last ounce of value from his craft, because whilst he is always improving his ship he has never got her to ultimate perfection.

The prejudice in England, for instance, against building sailing craft of steel does not hold good in Holland. Nor does he always feel it necessary to send to Rotterdam or Dordrecht to have his new steel tjalk built. He has enough space at the end of his garden between his cottage and the river, so two or three men will go on hammering in rivets until at length the vessel is built, and one day she will be launched broadside on at the top of the spring tide. She has been built far more cheaply than we in England could make such a craft, and she will go on steadily year after year doing her work up and down the waterways of the Netherlands, carrying hay, vegetables, or whatever cargoes may be intended for her. To any one outside Holland there is always something new to examine in the Dutchman, always some new "gadget" to admire and take note of, for Holland has done more for the development of the fore-and-after than all the other nations of the world put together. She has given the lead, and others have followed after.

"To no man," says Mr. Warington Smyth in his delightful Mast and Sail, "to no man is the greatness 
of our debt to the Dutch more forcibly brought home than to him who has widely used the sea, in whom something akin to reverence springs up as he roams, and finds everywhere about the globe the footprints of this steadfast sailor race. The very sea-terms in everyday use all across the seven seas, alike by Briton, Yankee, and every northern race, were in the mouths of De Ruyter and those other great admirals who fought against us in the seventeenth century. Certainly no western race is so amphibious as the Dutch, and no land animal except the duck takes so readily to navigation."

Although, as we shall see presently, the yacht came to us in England from Holland in the seventeenth century, yet it cannot be said that from that time onwards without a break the fore-and-aft pleasure vessel steadily improved until now. There followed before long a decided slump, which continued for some time, and all the good that our own nation has done in the service of the fore-and-aft yacht has been within the space of about sixty years-from about the year 1850 to the present day; whereas the Dutch, as far back as the late sixteenth century, began to give us the proper data on which to base our improvements in naval architecture and rig in so far as they affect the fore-and-after. For most of two hundred years we were content to follow blindly and without question along the lines which the Dutch had laid down for us. There was little or no contribution on our part in regard to the science and art of the fore-and-after. We accepted the facts as they came to us from the other side of the North Sea, and we remained content at that. When the reaction set in sixty years ago there was little to work upon except the Dutch heritage. You can easily see what is meant if you examine the sea-pictures of the early nineteenth century. Bluff-bowed, cumbrous, heavily constructed vessels they were, lacking the natural beauty of the original Dutch types, and often as not 


\section{THE DEVELOPMENT OF THE}

employed for general purposes, whereas the prototypes had been designed to suit special objects, special waters, and special harbours. When you look into the improvements of lines, sails, and gear of the fishing fleets, pilot craft, and yachts of Great Britain as they are to-day, you will find that these superiorities are scarcely more than sixty years old, and not always that. The Hollander began at the beginning, because he found that with his canals and rivers he was not making the best of his opportunities. He began by improving the rig of southern Europe. England years after began only where the Dutch left off, and commenced her work not as in any sense a creator but as adapter; and that, if you are a careful observer of English history in general, has been our great characteristic for the whole of our national career. From the time when the Dutch seven provinces had united themselves into a powerful republic their prosperity seems properly to have begun. In place of being a mere inferior to Spain, she became the latter's rival. The low-lying land between the North and Zuyder Seas was all too small to contain the energies of its inhabitants, and so they spread themselves, roamed over the seas, fought, traded, and colonised ; trained a magnificent race of admirals, seamen, and fishermen; looked to their own internal water-traffic, and did wonders in the perfecting of the most suitable means of transport.

Before we close this chapter we must not omit to mention the origin of the smack. The subsequent alteration of the English smack's rig we shall deal with in due course. But in the early eighteenth century a "smak-schip" or "semaque" was similar to a "semale" or "smal-schip." 'The smal-schip was a narrower craft, whereas the smak-schip was so large, that she was known in Flanders as the "wydt-schip." 'These two vessels differed in size, but they were similar in build. The accompanying illustration in Fig. 31, which is taken from a volume published in Amsterdam 
in 1736, will indicate the general appearance of the smal-schip. She was made intentionally narrow in order that she might be able to pass through Gouda (pronounced "Hooda") lock. Gouda, it may be mentioned, is a few miles to the north-east of Rotterdam at the junction of the canal which joins the Ijssel, and is on the regular line of water patronised by the traffic between Amsterdam and Rotterdam. For some distance after emerging from the lock when bound towards Amsterdam the canal is exceedingly narrow as it passes through the town. On both sides the houses rise up without a break, so that it is utterly impossible to sail, and one has either to quant or be towed through by trek-paard or perhaps by hand. To make matters still more unpleasant the modern motor cargo craft come running round the bend and leave little enough room to squeeze through. Altogether for a mile or so it is a trying time for the helmsman.

But there is also a duplicate and wider, though less direct canal running outside by the walls of the town, and, says the eighteenth century authority, the semaques have to pass along that canal by the other lock. Thus the smal-schip went one way and the smack the other. These craft in the times of which we are speaking used often to find their way from Amsterdam as far south as Antwerp and other places in Flanders. They carried merchandise to the big ships, and brought other cargoes in return. The rudder of this type of vessel was very wide and heavy, because these craft were not very fine, and drew little water, and this small quantity of water was not capable of doing much to move the rudder. The more water the rudder moves, continues this description, so much the better is the vessel controlled. 'Thus the rudder of the smal-schip is made very wide, so as to move more water. The illustration which is here reproduced represents a smal-schip 
of $58 \mathrm{ft}$. long, $15 \mathrm{ft}$. 8 in. wide, the hold varying from $4 \mathrm{ft}$. to $6 \mathrm{ft}$. 4 in. deep. But in these measurements which have been given of Dutch vessels it should be remembered that the foot was the equivalent of eleven Rhenish inches. The keel of this vessel was $1 \mathrm{ft} .1 \mathrm{in}$. wide and 5 in. thick. She was rigged with a spritmainsail and staysail, but no bowsprit is shown. There is an old Dutch print in the British Museum that shows a smak-schip rigged as a fore-and-aft ketch, and is very similar to the Dutch galleot which we saw on an earlier page. She has jib and foresail, a gaff mainsail which has no boom, but is brailed in like some of those other vessels we have been looking at. Her mizzen, however, has both gaff and boom. She is seen with course and square topsail set on her mainmast. A hooy-schip seen in a print of the same date as the latter is shown as a ketch-rigged vessel, also being used for carrying hay, and in many points resembles the previously mentioned ketch. But in almost each suceeeding generation the same name is used so frequently for different types of craft that it is better to be able to recognise them by their rig and general appearance than to rely solely on the nautical term that happened to be applied at a particular date. We call some of those vessels which go forth from Great Yarmouth and other North Sea ports to gather the harvest of the sea by the name of smacks. And yet if we compare them with the smak-schips of Holland in the eighteenth century there is precious little in common between them.

Thus have we endeavoured to show alike the origin and the development of the fore-and-aft rig in Holland. It was essential that we should devote so much space to that country and her craft, because she is the true mother of our fore-and-afters of to-day. But we are not devoting ourselves exclusively to Dutch shipping, and may now pass on to show the influence which Holland was to exercise over the vessels of other 


\section{FORE-AND-AFT RIG IN HOLLAND 127}

nations during the seventeenth, eighteenth, and the early part of the twentieth centuries. And we shall seek to substantiate this influence by the evidence of contemporary literature and contemporary illustrations, for it is a period that is full of interest, even though the interest is spread over a number of types rather than centred on one or two. 


\section{CHAPTER V}

THE INTRODUCTION OF YACHTS INTO ENGLAND

WE showed briefly in the previous chapter that during the seventeenth century the time came when the "persons of rank" in the Low Countries began to adapt the fore-and-aft rig to their own special convenience for use both on the North and Zuyder Seas, as well as for the rivers and canals. For those who had business that took them to Amsterdam, Rotterdam, Dordrecht, or other cities the yacht was a convenient and commodious means of transport; and as the nation had rapidly increased in wealth, so the number of the yachts became, before long, considerable. They were now firmly established among the usual possessions of the rich of that country.

Now the young man who was presently to become Charles II. of England had been living on the Continent ever since he was twenty-one, and a part of this time had been passed in Holland. It was on May 8, 1660, that he was proclaimed King of England in Westminster Hall. At that time he was still in the Low Countries, at Breda ; and, attended by his courtiers, proceeded to set forth from Breda to get to the Hague and thence take ship to England. To accomplish this journey it was essential to proceed by canal and tidal river, so a number of those gilded yachts with their high sterns and cutter rigs were got together and courteously placed at the disposal of Charles, his brother and suite. During his stay abroad the new king had made himself a great favourite, and his sendoff was in every way hearty and sincere. So soon as 


\section{THE INTRODUCTION OF YACH'TS}

the news of his proclamation had been made known the Prince of Orange placed the finest yacht in Holland at Charles' convenience, and Charles went aboard her. This vessel had been built in that same year for the Prince of Orange, but at this time belonged to the Board of Admiralty of Rotterdam. She was most beautifully carved and gilded at the stern, over which a single lantern was hung just by the ensign staff. There was a roomy cabin here, with adequate head-room for the accommodation of the royal exiles, and there was plenty of deck-room for this monarch to walk about during the inland voyage. The yacht was rigged with a sprit mainsail and staysail. She doubtless set a jib also, though in Verschuier's painting, while the bowsprit is most clearly shown the jib is not depicted at all, because it had no doubt just been stowed. Two portholes are provided in the stern, which was of the old-fashioned square shape, while both sides of the ship were pierced with the more modern circular ports, through which the guns are seen projecting. The yacht also had leeboards and carried a burgee on her jack-staff, as it was called in England, at the end of the bowsprit.

We can imagine this royal fleet of yachts, then, making their way from Breda and out into the Hollandsch Diep, then turning northward past the delightfully peaceful and sylvan Willemsdorp and up the Dordtsche Kil, where to-day there is a never-ceasing stream of all sorts of sailing, steam, and motor vessels. Each of these yachts had its own steward, cooks, and men who were responsible for the efficiency of the pantry, the wines, and the cooking. And those vessels which had not suitable kitchens on board were accompanied by other vessels that carried ovens, stoves, and other culinary necessities. Captain Clark, in his History of Yachting, quotes a contemporary who remarks that "the stewards of the English lords, though accustomed to abundance, were astonished thereat, and confessed 


\section{0 \\ THE INTRODUCTION OF YACH'TS}

that they could not conceive by what means twenty or twenty-five great dishes for each table could be prepared on board the yachts and with the motion of the water." Altogether the Dutch were leaving nothing undone to make the king's voyage pleasant.

We do not know where the wind was on that May day, but it is very probable that it was northerly. Now it is hardly likely that these yachts would not avail themselves of a fair tide. And about the month of May northerly winds are more prevalent than southerly over this part of Holland. But when wind is against tide the Hollandsch Diep is not pleasant. The two forces working against each other kick up an unpleasant sea, so that this broad water is notorious under such conditions. Thus the Princess Royal, we learn, was unable to endure the motion of the yacht, but was compelled to retire, the captain stating that they could not expect to have better conditions until Dordrecht should have been reached, where there would be shelter. And so on they sailed until at last they arrived at Rotterdam, where they were to remain for a short time. In the Rijks Museum there has happily been preserved a very fine painting of this incident by Lieve Verschuier, who was born and buried in Rotterdam, and was thirty years old when Charles II. arrived. In this picture we see the Maas studded with all kinds of craft to welcome the young king. It is from this picture that the accompanying sketch (Fig. 30) has been made, which shows in greater detail than is possible by means of photograph the yacht on which Charles was proceeding on his inland voyage. There is a full-rigged ship seen in the original which is firing a salute, and the yacht is replying with the cannon at the bow. In the Rijks original some of the other yachts of the fleet are shown also; and numerous small rowing-boats, boiers, and other craft full of eager sightseers are coming forth to manœuvre round the yacht.

With their mingled splashes of gold, of blue, orange, 


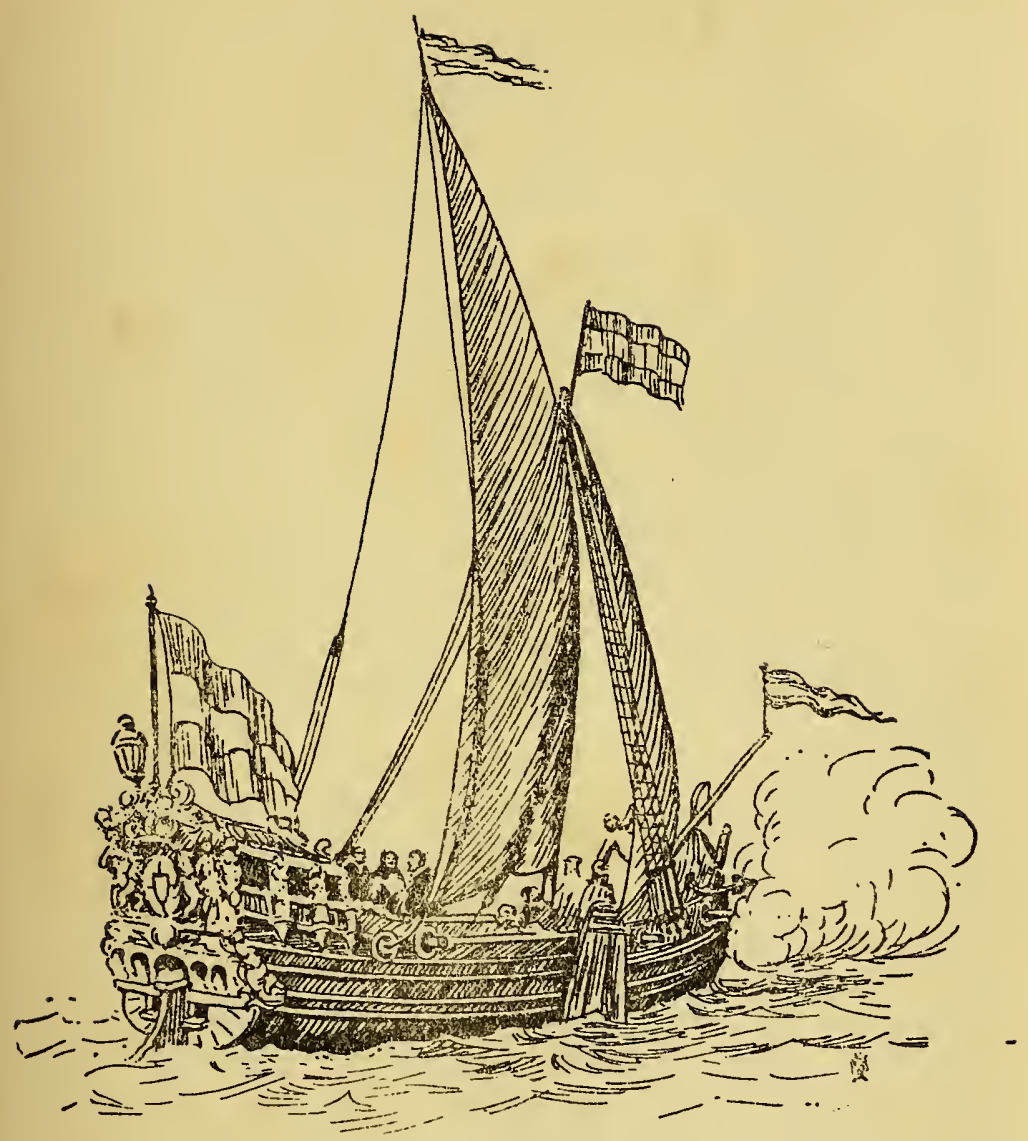

Fig. 30.-THe Yacht in which ChaRles II. SaILed.

This was the vessel which carried his Majesty from Breda to Rotterdam after bis proclamation in England as king. The sketch is taken from Verschuier's painting in the Rijks Museum, Amsterdam. 


\section{2 'THE INTRODUCTION OF YACH'TS}

and red, this fleet of yachts with its English royalty, their courtiers, attendants, cooks, and servants must have looked striking even to the citizens of Rotterdam. At length the yacht passed from the waters of the Maas and its powerful tide through the lock into the canal which connects this river with Delft, and presently she continued her voyage and arrived at the latter town, which is but a short distance from the Hague. Just outside the Hague lies the North Sea village of Scheveningen, though to-day it is a village no longer, but a cosmopolitan tourist resort. Charles proceeded to Scheveningen, was rowed off from the sandy beach in a boat, and went on board the English warship Naseby on May 22. With the rest of the fleet this vessel had arrived off the Dutch coast a few days earlier. She was now re-named the Royal Charles, and on May 24, sixteen days after Charles' proclamation, she set sail for England with her king on board, and on May 26 landed him safely at Dover. Thus, briefly, had been the royal progress by yacht and warship from Breda to England.

Now this is no place to examine the personal character of him who has ever been best known to posterity as the gay king. Apart from one consideration we are not concerned with his failings or virtues in this present volume. But among his pleasures there stands out conspicuously that which can only be obtained from ships and the sea. With him sailing was as great a passion as were any of his unfortunate amours. When he was sixteen years old and was staying in the Channel Isles but three years before his father's execution, he displayed his affection for this sport, and used to go sailing in a boat about those rocky islands. Whilst he was in Holland he must have often been struck by the little fore-and-afters dodging in and out, and his enthusiasm keenly aroused, as it is in the case of every man who is born with that ineradicable attraction towards nautical things, which neither time nor cir- 
cumstance can modify, but will continue even till the grave.

The cruise from Breda to Delft had especially impressed this enthusiast. He had both enjoyed the trip itself and intensely admired the yacht which had carried him in such surprising comfort and luxury. "The king found his yacht so convenient and comfortable," writes the contemporary we have just quoted, "that he remarked, while discoursing with the deputies, that he might order one of the same style, so soon as he should arrive in England, to use on the river Thames. Mr. Van Vlooswyck, Burgermaster of Amsterdam, and one of the deputies of the province of Holland, taking occasion to do a considerable service to his fatherland, said to the king that lately a yacht has been built in Amsterdam which was almost of the same size, and at least as handsome, and he took the liberty of presenting it to his Majesty, praying him to do a favour to the Magistrate by accepting it."

Thus it came about that before the winter of that same year of his accession a yacht was purchased by the Hollanders from the Dutch East India Company; was taken in hand and made fit for a king, her cabins being decorated, her stern beautifully gilded, and the best artists of the day employed to paint magnificent pictures or to carve sculpture both within and without the yacht. This, then, was the Mary, the first yacht that England ever possessed, the ancestor of that long line of descendants which include the Alarm, the Thistles, Meteors, Valkyries, White Heathers, Shamrocks, and many another famous craft within living memory.

The Mary measured $52 \mathrm{ft}$. long, $19 \mathrm{ft}$. beam, $7 \mathrm{ft}$. $7 \mathrm{in}$. deep, drew $10 \mathrm{ft}$. of water, and worked out at 100 tons burthen, though we must not forget that the tonnage reckoning of those days was a little erratic. She had leeboards, carried eight guns and a crew of twenty. Now, so far no one has ever succeeded in finding a design or picture that could truthfully be said to repre- 


\section{THE INTRODUCTION OF YACHTS}

sent this first Mary, although Mary $\boldsymbol{I I}$. is reproduced in this volume. But we need not be in doubt as to the appearance of this first Anglo-Dutch craft ; for remembering that we saw in a preceding paragraph just now that "lately a yacht has been built in Amsterdam which was almost of the same size, and at least as handsome" as the vessel in which the Breda to Delft trip was taken, and that in the Verschuier picture we have a detailed idea of her lines and rig, we cannot go far wrong if we say that the Mary was practically the counterpart of this yacht which has been reproduced from the Verschuier painting. She has leeboards and four guns each side like the Mary, and would seem to be about the dimensions just given.

Just exactly when the Mary crossed the North Sea I cannot ascertain, but it would seem that by the middle of August she had arrived in the London river, for under date of August 15, 1660, Pepys gives the following in his Diary:-

"To the office, and after dinner by water to White Hall, where I found the King gone this morning by 5 of the clock to see a Dutch pleasure-boat below bridge."

If that is not the Mary that Charles got up at daybreak to go and see, then she was certainly here by November, for on the eighth of that month the same genial diarist has the entry which shows that he himself went aboard the new yacht at Deptford :-

" November 8, 1660.

"In the afternoon Commissioner Pett and I went aboard the yacht, which indeed is one of the finest things that ever I saw for neatness and room in so small a vessel. Mr. Pett is to make one to outdo this for the honour of his country, which I fear he will scarce better."

But under date of January 13 of the next year Pepys was inclined to alter his mind, for he came to the conclusion that Pett's yacht which he was building for the king "will be a pretty thing and much beyond the 


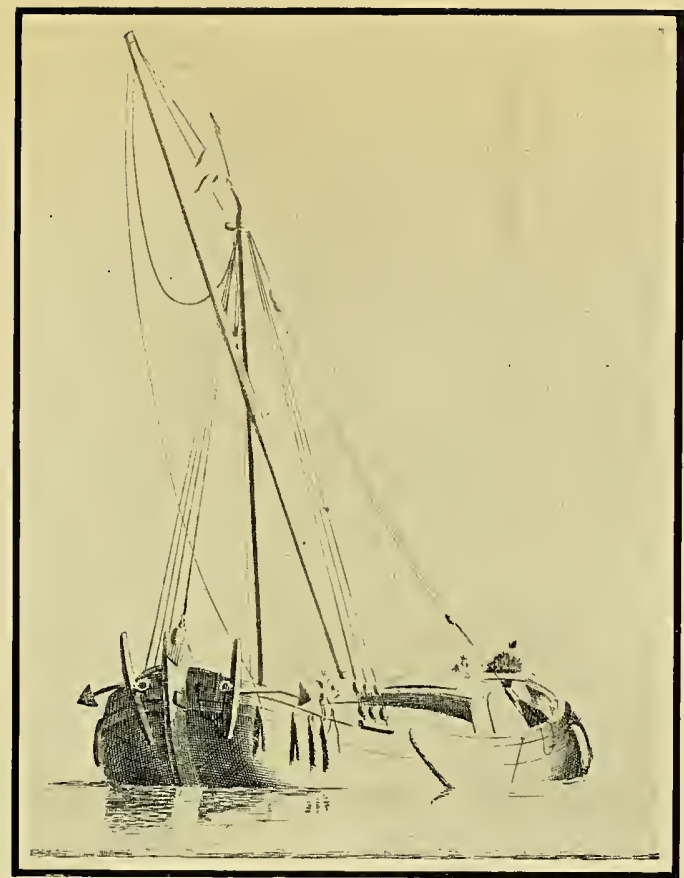

Fig. 3r.

\section{Semale Ship}

In the eighteenth century the semaque or smack was similar to the above craft, but the smak-schip was somewhat wider than the semale-schip.

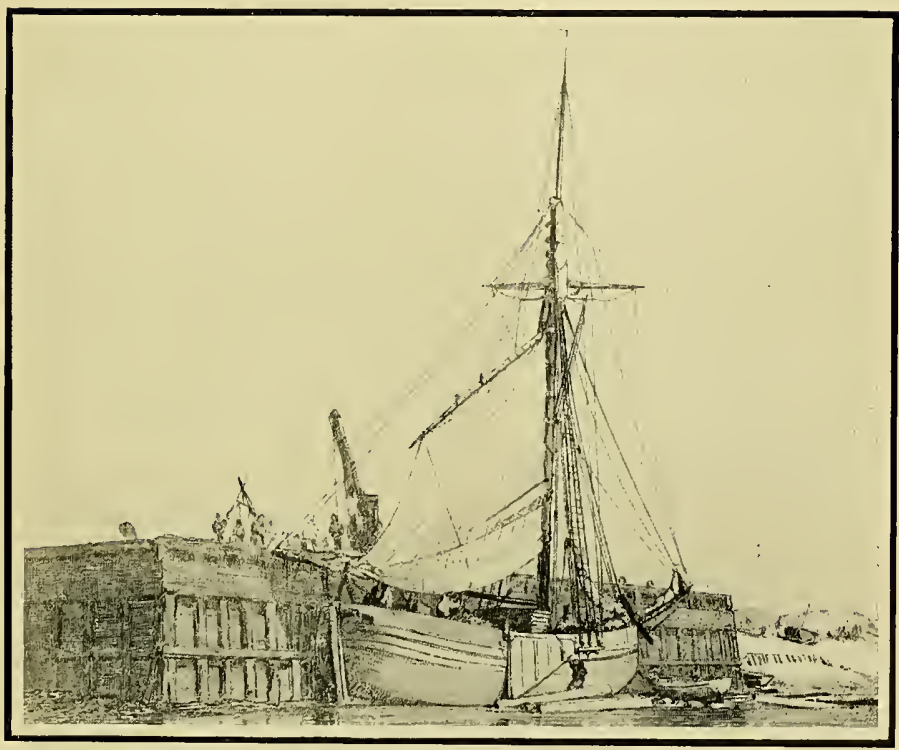

Fig. 32.

YORKSHIRE BILLY-BOY

P. 167

After the engraving by E. W. Cooke. Few British craft exhibit their Dutch ancestry so clearly as this type of vessel. 

Dutchman's." She was to have sails made of Holland duck, and was ballasted with lead shot brought from the Tower of London. The Petts were a family of shipbuilders which were employed in the service of the English sovereigns from the time of Henry VIII. even to the reign of William III. and Mary. In their day and country the different generations of this family were supreme for the science and art of naval construction. Battleships of unheard-of size the family had been building through half-a-dozen reigns, and they had had all sorts of difficult and unprecedented tasks to perform. But a yacht not one of them had ever constructed or designed. So great was Charles' delight in his Dutch Mary that both he and his brother the Duke of York resolved to have an English yacht. Thus Peter Pett was entrusted with the building at Deptford of one for the king, whilst his younger brother Christopher was to construct the Anne at Woolwich for the Duke of York. The name of the king's yacht was to be the Jenny, and a keen rivalry was started as to which shipbuilding brother should turn out the better yacht for one of the two royal brothers.

Already as early as November of the year in which the Mary came over, we have seen the elder Pett instructed to build something better; and two months later we have seen Pepys going to look at her on the stocks and much admiring her. That was in January, and from a State Paper Domestic of the 12th of April in that same year, 1661, we find that the other brother Christopher is busily engaged with the finishing touches to the Anne. He has had some anxiety in his yard, for he informs the Navy Commissioners that a gunner of the Mary - not the yacht but a man-of-war of the same name-whilst entering the powder-room of that ship with a cracked candle, caused the loose powder to take fire, which burnt the man much but did not harm the ship. Then he goes on to say that the Duke of York has ordered his yacht to be launched on Thursday, 


\section{THE INTRODUC'TION OF YACHTS}

although the joiners and carvers have not yet completed their jobs. Perhaps, like many another sailing-man, it was the first dawn of spring, and an occasional bright day of sunshine after the winter which caused the royal yachtsman during that April to hurry along the shipbuilder and get the yacht into the water with the utmost speed.

But at last both yachts were launched, and the two pairs of brothers were able to make their comparisons. Let us turn to Pepys' Diary again and look at his remarks dated May 21, 1661 :-

"And then we took boat to Woolwich, where we staid and gave order for the fitting out of some more ships presently. And then to Deptford, where we staid and did the same; and so took barge again, and were overtaken by the King in his barge, he having been down the river with his yacht this day for pleasure to try it; and, as I hear, Commissioner Pett's do prove better than the Dutch one, and than that his brother built."

Thus Peter had beaten Christopher and the king had beaten the Duke of York. Up till then English shipbuilding had been indebted to foreign influences in regard to ship-design and building. Just as in times long past Scandinavia, then Italy, and Spain had taught the English shipmen much of what they knew : just, too, as the French in the following century were to give them many more ideas, so Holland had imparted some of her knowledge of shipbuilding and design of menof-war, so she had taught the Petts how to design and build the first English yacht. We can almost see the Secretary of the Admiralty and Commissioner Pett climbing in and out of the Mary, taking up boards to examine her fastenings, tapping the beams here and there, examining the planking with the eyes of experts. We can imagine Pepys admiring the Dutch workmanship, criticising some novel idea that English shipwrights had never yet contemplated, and then poor vexed Peter Pett scratching his head and wondering 
whether his own capacity, the capacities of his men and the yard, would be capable of turning out a craft as good, let alone superior to the Dutch Mary of the East India Company. However, he applied his mind to it, and he was spurred on as well by national pride as by the competition of his brother a few miles down the river, and in the end, as we have seen, Deptford not only beat Woolwich but Amsterdam as well.

The Mary had created a sensation among those who interested themselves in shipping matters. She was something distinctly sui generis. The year 1660 was memorable not merely for the king's accession, for the Restoration of the Stuarts, but for the innovation of the first yacht. "In the year '60," Sir Anthony Deane told Pepys, "the Dutch gave his Majesty the yacht called the Mary, from whence came the improvement of our present yachts ; for until that time we had not heard of such a name in England." And yet it is certain that the word, if not the type of craft, had been heard of in this country some years before; for in a Collection of Voyages and Travels it was used in 1642 in reference to the Dutch East India Company's yachts, yet these were more likely to have been full-rigged ships than cutters or sloops.

The Mary was the first yacht which was ever on any of the navy lists of England, and she remained there until the year 1675 , when she was cast away near to Holyhead. The Duke of York's Anne, which had the Mary as model, was identical with the Mary in regard to tonnage, beam, and length of keel, but the Anne was seven inches less in depth, and drew seven feet of water as against the Mary's ten. She also carried twenty men like her prototype. It was in this year (1661) that the Dutch again presented Charles with a Dutch yacht. No doubt they were flattered by the amount of appreciation which their gift had aroused, and this time they sent a smaller vessel of 35 tons named the Bezan, which seems, as we shall see presently, to have 
been used by no one so much as our friend Mr. Pepys, who was accustomed to spend enjoyable week-ends cruising in her down the Thames, leaving her somewhere up the Medway and then returning by land.

For Pepys was as much attached to the new sport of yachting as was his sovereign. And here is a little picture he gives of an incident, dated June 13, 1661 : "I went down with my lord in the barge to Deptford," he writes, "and there went on board the Dutch yacht, and staid there a good while, W. Howe not being come with my lord's things, which made my lord very angry. By-and-by he comes, and so we set sayle, and anon went to dinner, my lord and we very merry; and after dinner I went down below, and there sang, and took leave of W. Howe, Captain Rolt, and the rest of my friends ; then went up and took leave of my lord, who gave me his hand, and parted with great respect. So went, and Captain Ferrers with me, into our wherry; and my lord did give five guns, all they had charged, which was the greatest respect my lord could do me, and of which I was not a little proud. So, with a sad and merry heart, I left them, sailing pleasantly from Erith, hoping to be in the Downs to-morrow early."

There were, then, by the summer of 1661 , or the year following Charles' accession, four royal yachts: the two Dutch yachts, Mary and Bezan, as well as the two English yachts, Jenny and Anne. As this little fleet lay in the "Thames they were the sights of the London river. "Before we had dined," writes Pepys on September 14, 1661, "comes Sir R. Slingsby and his lady, and a great deal of company, to take my wife and I out by barge to show them the King's and Duke's yachts .... and we had great pleasure, seeing all four yachts, viz. these two, and the two Dutch ones."

We mentioned in a previous chapter that in spite of their large fleets of yachts, their sham-fights and reviews, the Dutch do not seem to have been interested 
in yacht-racing ; for these vessels were built rather for dignity and comfort, for stateliness, and as a means of transport, than for racing purposes. But knowing Charles' type of character as we do, with its intense love of pleasure, of excitement and novelty, we are not surprised to find that he instituted the new sport of yacht-racing as soon as he had got together this little fleet of yachts. Whatever else may be said to his credit or discredit in an age that was notorious for its general laxity reacting on the Puritanism of the Commonwealth period, at any rate the Merry Monarch was the father of that which we are accustomed to call the queen of sports. We read just now that Pepys, on his way':back to town from Deptford, was overtaken by the king in his rowed barge after the sovereign had been down the river trying his new yacht against the Duke of York's. Four months later there was a more definite and decided race, as we may see from Evelyn, who, like his contemporary, kept and bequeathed to posterity a diary that is a reflection of the social life in England during the latter part of the seventeenth century. On October 1, 1661, Evelyn writes :-

"I sailed this morning with his Majesty in one of his yachts (or pleasure-boats), vessels not known among us till the Dutch East India Company presented that curious piece to the King; being very excellent sailingvessels. It was on a wager between his other new pleasure-boat, built frigate-like, and one of the Duke of York's-the wager 100l.; the race from Greenwich to Gravesend and back. The King lost it going, the wind being contrary, but saved stakes in returning. There were divers noble persons and lords on board, his Majesty sometimes steering himself. His barge and kitchen-boat attended. I brake fast this morning with the King at return in his smaller vessel, he being pleased to take me and only four more, who were noblemen, with him; but dined in his yacht, where we all eat together with his Majesty." 


\section{THE INTRODUCTION OF YACHTS}

Thus we have here from one who was an actual eye-witness a brief but reliable account of the first of those yachting contests which to-day take place throughout the summer, week by week, around our coasts, wherever local conditions permit. From this first race has descended indirectly the important series of contests for the America Cup, the still longer races across the Atlantic from America to England, to say nothing of the annual races on the Solent, and especially with Cowes as the starting and finishing point. I say "indirectly," because there follows a hiatus, as we shall see presently. But the revival was to follow a few decades after, and so to connect the yachting of Charles II. with that of to-day.

With the dimensions of the Mary that we have given, with the Verschuier sketch before us of an admittedly similar craft, we have been enabled to visualise the first Mary. Her glass windows let into the poop, her gilt, her carvings and interior paintings we can well imagine, knowing that they actually existed. Of the life on board Pepys and Evelyn have left us glimpses, and the State Papers Domestic of this period lend their aid by adding an occasional item to complete the picture that we are endeavouring to compose. There is, for instance, still preserved under date of February 27, 1662, an order for a warrant to pay John Goulding, captain of the yacht Mary, the sum of $£ 500$ in lieu of 5000 guilders voluntarily lent by him to the King at Antwerp in 1657, "during the time of his necessities"; and there is another warrant of March 11 in the same year to the same effect. It is just an amusing detail that the royal exile should be seen borrowing from his future skipper a sum of money which apparently was not paid back for at any rate five years. Belonging to November 27 of the same year, 1662, there is also a State Paper wherein Captain James Lambert recommends Edw. Janson to be mate of the Duke of York's yacht. 
The second Dutch yacht, the Bezan, which, we saw, was received as a present also, was of 35 tons burthen. In length she was as much as 18 feet shorter than the Mary, and drew less than half the Mary's draught of water. The Bezan's exact dimension's were: Length, 34 ft.; breadth, $14 \mathrm{ft}$; d depth, $7 \mathrm{ft}$; d draught, $3 \mathrm{ft}$. 6 in.; and her crew consisted of four men. More than this we do not know, but I am inclined to think she was probably of the boier type. Illustrations of this species of craft will be found later on in this volume.

So pleased had Charles II. become with his two Dutch and two English yachts, that in the year 1662 we find him anxious for another. Just as his Deptford Jenny had been built to beat the Amsterdam Mary, so now he evidently wanted an English-built Bezan. Since Peter Pett had done better than his brother with the Jenny, so now he was commissioned to build the Jamaie. This craft measured $31 \mathrm{ft}$. long, $12 \frac{1}{2} \mathrm{ft}$. wide, drew $3 \frac{1}{2} \mathrm{ft}$. of water, was of 25 tons burthen, and carried a crew of four. She was slightly smaller than the Bezan, but otherwise so similar that we cannot resist the temptation to believe that she was built to show herself the superior of the Dutchman.

Perhaps this is the craft of which Pepys speaks in the following account belonging to September 5, $1662:-$

“ Up by break of day at 5 o'clock, and down by water to Woolwich ; in my way saw the yacht lately built by our virtuosoes (my Lord Brunkard and others with the help of Commissioner Pett also) set out from Greenwich with the little Dutch Bezan to try for master ; and before they got to Woolwich the Dutch beat them half-a-mile (and I hear this afternoon that, in coming home, it got above three miles) : which all our people are glad of."

The Jamaie, it should be added, was built at Lambeth and was designed by Charles himself. 


\section{THE INTRODUCTION OF YACHTS}

For it must be remembered that apart from his personal keenness for sailing he possessed for that time a really great amount of knowledge in matters connected with ships and the sea. To a natural instinct for such matters he brought a mind that was ever receptive of new ideas, and during his sojourn in Holland he could scarcely help assimilating some of the theories and practice of the then greatest maritime power in existence.

The popular mind is nowadays so much interested in that king's follies and weaknesses that it forgets the other side to his character. He showed a true zeal for his navy, over which his brother the Duke of York and the future James II., a real fighting seaman as well as yachtsman, was head. No English sovereign had taken such a personal interest in the service. It was during his reign that the Greenwich Royal Observatory and the Nautical Almanac were founded, and a new impulse given to astronomy, to navigation, and to naval architecture, and the beginning of scientific inquiry instead of a mere blind following of existing conventions. Fresh types of craft were introduced into the navy, and in general the foundations were being laid for the next generations to build upon.

From the incentive which had been given during the first couple of years of his reign, yachts of various sizes began to be built in the English yards, and a complete list of these can be found in the navy lists of the time which still exist. The smaller types, such as the two just mentioned, were now rarer than those of bigger tonnage. It is true that in 1673 another 25-tonner named the Isle of Wight was built at Portsmouth, her dimensions being $31 \mathrm{ft}$. long, $12 \frac{1}{2} \mathrm{ft}$. beam, and drawing $6 \mathrm{ft}$. of water. And two years prior to that a yacht called the Queenborough was built by Pett at Chatham, with a tonnage of twenty-nine; and there was even the Minion, smaller 
still, whose burthen was only 22 tons; length, $28 \mathrm{ft}$; beam, $12 \mathrm{ft}$. 4 in.; depth, 4 ft. 9 in.; and draught $4 \mathrm{ft}$. But it must not be imagined that all these yachts were mere pleasure-boats. The bigger ones, at any rate, carried guns as we have seen, and were reckoned as small units of the navy, which at that time included in its list such craft as ketches, sloops, pinks, hoys, and hulks. The Minion even carried a couple of guns and a crew of four. 'The ketches were of about 60 tons, had a crew of thirty-five, and carried six or eight guns.

There is a sloop, for instance, of the name Dunkirk which has a burthen of 33 tons, carries a crew of five and a couple of guns. There were also galleots varying from 108 to 33 tons measurement, the pinks varying from 55 to 123 tons, and the sloops from 22 to 68 tons. 'The sloop Bonetta, for example, built by Phineas Pett in 1673 , measured $61 \mathrm{ft}$. long, $13 \mathrm{ft}$. wide, was $5 \mathrm{ft}$. deep, drew $4 \frac{1}{2} \mathrm{ft}$. of water, had a burthen of 57 tons, and carried a crew of ten and four guns. Between the dates of the accession and end of Charles' reign there were altogether twenty-six yachts numbered in the navy lists, which, additional to those we have already mentioned, include the Merlin, the Charlotte, Navy, Monmouth,' Mary II., Kitchen, Cleaveland, Fubbs, Henrietta, Charlotte, Isabella, Katherine, Portsmouth, Greyhound. We have not space to deal with all of these separately, but in most of the larger craft there was a close resemblance to the yacht in the Verschuier sketch. After the close of his reign the list of yachts diminishes in number, and on Lady Day of 1686 there were only sixteen of these in our navy.

The Katherine is mentioned in a State Paper of January 22, 1662-3, wherein Christopher Pett and Jonas Shish write to the Navy Commissioners giving the dimensions of the three chimneys which are being placed in this royal vessel. Five days later matters were being taken in hand to get a crew for the new 


\section{THE INTRODUCTION OF YACHTS}

yacht, and Captain William Badiley writes to the Navy Commissioners from Deptford wishing to appoint a second master to this yacht, and recommends a man of the name Garner. And so these yachts multiplied. On May 19, 1663, Christopher Pett again writes to the Commissioners in respect of the latest yacht that he is constructing. He says that the charge for building a yacht like the Anne will be $£ 1850$, but that sum would not include the cost of the guns. And the next day he writes again to say that with regard to the timber required for the new yacht the carters have spoiled some by cutting it for their own convenience; but Captain Taylor of Wapping, he mentions, has some very good planks in his yard. And then there is a little touch which illustrates once again how keen an enthusiast Charles II. was; for Pett adds the information that yesterday the king paid a visit to Woolwich and was inquiring for the "keel-piece." This is significant, and the impetuous monarch was doubtless anxious to see Pett make a beginning and get the keel laid without delay.

But some delay still continued, probably owing to the scarcity of timber, for a few weeks later, on June 2, Pett writes again to the Commissioners, sending an estimate "of the charge for building a new yacht for the King," the total cost of which is to be as in the estimate above. Pett mentions that he has abated the charge from what was allowed for the king's yacht Katherine and the Duke's yacht Anne, because his Majesty intends to have the cabins hung with gilded leather instead of carved work on the sides. There is yet another reference in these State Papers three months later when Christopher Pett again writes to the Commissioners to say that repairs are needed to the glass windows of the Duke of York's yacht Anne, which is ordered to sail for France on Monday.

On September 6, 1663, Captain James Lambert 
of the Anne yacht writes to inform the Commissioners that he cannot land Madame Fiennes before Friday or Saturday, but will take her on board at Dover on Thursday. He has been with the QueenMother, but, he adds with a distinctly human touch, her commands are too tedious to write. He begs orders to Master Sheppard to set off with all despatch to attend the Duke of York at Southampton, and to William Fasby, master of the hoy Kitchen, to sail with him, as there will be want of the Kitchen there. This last-mentioned vessel was doubtless used as tender. There is also an Admiralty Paper of December 9 in the same year, sent from Deptford, in which we are furnished with the list of gunners and cooks entered on board the Katharine and the Anne.

In the year 1906 two interesting historical documents were sold in London which are of sufficient bearing on the subject to merit quoting here in full. The first is dated July 3, 1674, from Hampton Court, and is addressed by Charles to the Navy Commissioners with reference to the appointment of a new Master Gunner to "our yacht the Mary." In addition to the royal signature it is countersigned by our friend Samuel Pepys, and reads as follows :-

"Charles R.

"Our will and pleasure is that you cause Rowland Roberts to be entred $\mathbf{M a}^{\mathrm{r}}$ Gunner of our Yacht the Mary in the roome of [hiatus] Soshley whom Wee thinke fitting to discharge from that Employm together with such allowance of Wages \& Victualls for himselfe \& servant as is proper \& usuall for $\mathrm{y}^{\mathrm{e}}$ $\mathrm{Ma}^{\mathrm{r}}$ Gunner of our said Yacht. Given at Our Honor of Hampton Court this $3^{\mathrm{d}}$ of July 1674 .

"To the Principall Officers and $\mathrm{Com}^{\mathrm{rs}}$ of Our Navy.

"By his Mats Comand,
"S. Pepys." 


\section{THE INTRODUCTION OF YACH'TS}

Another of the yachts in Charles' service was named the Fubbs, which also was the familiar royal nickname for the somewhat beamy Duchess of Portsmouth, of whom the king was notoriously fond. The yacht was also beamy, being of the three beams to length type, and her measurements worked out at $63 \mathrm{ft}$. long, $21 \mathrm{ft}$. wide, her draught being nearly $8 \mathrm{ft}$., her burthen 148 tons, and her depth $9 \frac{1}{2} \mathrm{ft}$. She was built in 1682 by Phineas Pett at Greenwich. If we may for a moment pass out of Charles' reign into the following we shall be able to adduce this other royal document in connection with the seventeenth-century royal yachts of our nation. This order is dated from Whitehall to the Commissioners, directing them to pay the wages of the officers and crews of the yachts Fubbs and Navy. It is signed by James II. and again countersigned by Pepys, and reads thus :-

"JAMES R.

"Our will and pleasure is, That you cause the Wages due to the Officers and Company of Our Yachts the Fubbs and Navy to the 25 ${ }^{\text {th }}$ of March 1686 , to be paid as fast as you shall be enabled thereto, by moneys to be specially appointed to that purpose, by the Lords Commissioners of our Treasy. For which this shall be your Warrant. Given at Our Court at Whitehall this $7^{\text {th }}$ Aprill, 1687.

"To Our Trusty \& Welbeloved

$$
\text { "By His Mats Comand, }
$$

$\mathrm{S}^{\mathrm{r}}$ John Tippetts \& $\mathbf{S}^{\mathrm{r}}$ Rich $^{\mathrm{d}}$ Haddock

$\mathrm{Kn}^{\text {ts }} \&$ James Sotherne $\mathrm{Esq}^{\text {re }}$

Commiss ${ }^{8}$ of Our Navy."

The Navy, it may be mentioned, was a 74-tonner, and was built by Sir Anthony Deane at Portsmouth in 1671. She measured $48 \mathrm{ft}$. long, $17 \frac{1}{2} \mathrm{ft}$. beam, and 
drew just over $7 \mathrm{ft}$. of water. The appellation seems to our mind somewhat strange to give to a yacht. The origin of the Fubbs we have already explained. The Katherine was named, of course, after Charles' wife, Katherine of Portugal. The Dunkirk was also a reasonable name, for that port was at one time an English possession, and was only sold to the French in the year 1662. It will be recollected that this transaction made Clarendon very unpopular, for it was said that he had been bribed, and a new house that he was building was nicknamed "Dunkirk House." And so we might go on and find the cause of the names that were given to the various other yachts. But there are two other references about this time in Pepys' Diary which we must not omit. The first belongs to July 26, 1662, and reads :-

"This afternoon I had a letter from Mr. Creed, who hath escaped narrowly in the King's yacht, and got safe to the Downs after the late storm; and that there the King do tell him that he is sure that my Lord is landed at Callis safe."

As to which of these yachts is here referred to we know not, but she was most probably one of the larger craft. We called attention just now to the fact that the king was contemplating building a new yacht, and that Pett had been asked to send in estimates for the cost thereof. Her name was the Henrietta, after Charles' mother. From the following extract in Pepys' Diary we see another instance that the king was content not only to be an amateur helmsman, but had certain ideas of his own in respect of naval architecture, and was wishful to give to these a concrete shape. "For," writes the Secretary of the Admiralty, "we walked to White Hall, and meeting the King, we followed him into the Park, where Mr. Coventry and he talked of building a new yacht, which the King is resolved to have built out of his privy purse, he having some contrivance of his own." 


\section{THE INTRODUCTION OF YACH'TS}

This "contrivance" consisted of lead sheathing, as we shall mention presently. It is possible that Charles may have also been anxious to minimise the excessive sheer of the day, and to diminish the amount of tophamper, for it was no rare custom about this time to cut one of the ships of the navy down a deck and make her less top-heavy. On the other hand, it is also possible that Charles realised that he could get an improvement to the hull if he gave his yachts less beam and a proportionately greater length. It is indeed evident enough that the royal mind was ever occupied with the welfare of his yachts and their possible improvements. And here let us redeem our promise made a few pages back in reference to the Bezan. For some reason or other this little ship seems to have taken a back place in Charles' interest before long. Either he got tired of her as he did of some of his lady friends, or his newer craft showed themselves so much superior to the Dutch yacht that she became outclassed. At any rate, the only person who seems to have used her was Pepys, to whom she was to all intents and purposes his own private property.

This gay bon viveur, as devoted an apostle of hedonism as his royal master, found the Bezan a delightful means of recreation. He was able to get away from the cares and worries of the Admiralty, which in those days of political corruption, bribery, and dockyard theft were innumerable and incessant, and could forget his troubles as the wind and tide carried him pleasantly down the Thames. For in those days the London river was indeed enjoyable. The Thames mud was there as it shows up to-day, but there was comparatively little traffic, and of course it was many a long day before the eternal stream of steam liners, tramps, and every kind of mechanically propelled craft took away the peace and pleasure of sailing on the lower reaches.

As we can see from contemporary sketches, the 
banks of the Thames were indeed beautiful, and the sun shed its rays not on the unsympathetic lines of chimneys, dilapidated wharves, cement works, gasometers, or other offences to the eye, but the wind blew true across the green grass and bellowed the Holland duck of the sails with which these bluff-bowed State craft were rigged. It came laden with no foul gases from factory or refuse-heap ; there was no ceaseless churning of the river by thrashing propellers, and the certainty of a collision looming up at every bend of the river. On the contrary, it was scarcely less a pleasure than the Solent to-day is to the sailing-man who is worn out with the rush and work of the big city. Thus we must think of Pepys comfortably placed on board the Bezan, with the sun pouring down on the yacht, well-victualled as she certainly was ere Mr. Pepys ever put to sea. He was very fond of sailing down to the Nore, there to admire the crack man-of-war of that time, for it was a pleasant way of combining business with recreation, and of giving Mrs. Pepys an opportunity of showing her sympathy in her husband's interests.

"A A gust 12, 1665.-I down to Greenwich and sent away the Bezan, thinking to go with my wife to-night, to come back again to-morrow night to the Soveraigne at the buoy off the Nore."

The Soveraigne, of course, was the famous battleship Sovereign of the Seas, a great creature of 1652 tons, which was not merely the pride of England, but the admiration and envy of both France and Holland. She was the first three-decker which the English navy ever possessed, but was afterwards cut down a deck. Originally she had four masts, but one was afterwards taken out of her. With her beak and figurehead, her great spars, and her 100 guns, she made a fine objective for Pepys' aquatic excursions as she lay to her buoy or swinging to her anchor near the mouth of the Medway. She had been built as far back as the year 
1637, and though now nearly thirty years old, she was still a source of keen interest, her alterations, which we noted above, having taken place in 1652. She had been designed by Phineas Pett and built under the supervision of Peter Pett, but was practically rebuilt in 1684 .

And so with a suitable yacht in which to run down the Nore on nice summer days, with plenty to eat and drink, and plenty of good fellowship, with the authority of his office to ensure every attention, the Bezan was a very considerable convenience to Mr. Pepys.

"We down to the water," he writes on August 17, 1665, "and by boat to Greenwich to the Bezan yacht, where Sir W. Batten, Sir J. Minnes, my Lord Bruncker, and myself, with some servants (among others $\mathrm{Mr}$. Carcasse, my Lord's clerk, a very civil gentleman), embarked in the yacht, and down we went most pleasantly. . . . Short of Gravesend it grew calm, and so we come to an anchor, and the supper mighty merry ; and after it, being moonshine, we out of the cabin to laugh and talk, and then, as we grew sleepy, went in, and upon velvet cushions of the King's that belong to the yacht fell to sleep, which we all did pretty well till 3 or 4 of the clock, having risen in the night to look for a new comet. . .."

"18th.-Up about 5 o'clock and dressed ourselves, and to sayle again down to the Soveraigne at the buoy of the Nore, a noble ship, now rigged and fitted and manned . . . thence to Sheerness. . . Thence with great pleasure up the Meadeway, our yacht contending with Commissioner Pett's, wherein he met us from Chatham, and he had the best of it. Here I come by, but had not tide enough to stop at Quinborough."

And again, exactly a month later, he was out for another little cruise. "I walked to Woolwich," he writes, ". . . and by the time I was ready they come 
down in the Bezan yacht, and so I aboard and my boy Tom, and there very merrily we sailed to below Gravesend, and there came to anchor for all night, and supped and talked, and with much pleasure at last settled ourselves to sleep, having very good lodging upon cushions in the cabin." The next day they continued their cruise, and called on the Prince Royal, which had been built by Phineas Pett in the year 1610. She was, when first commissioned, the largest and finest man-ofwar in the world, though there was an unfortunate contretemps at the time of her launching. So it was but natural that the Secretary of the Admiralty should take his boy down the river to admire one of the three finest ships in the English navy. Arrived near this big vessel, the Bezan let go anchor some distance astern of her, and a ship's boat was sent out from the Prince Royal to tow the Bezan against wind and tide, which were so strong that had not the Prince thrown them a line to the Bezan the yacht would have been compelled to wait where she was. Remembering the strength of the Medway tide coming in and out by the Nore, we cannot wonder that the Dutch craft with her bluff lines was unable to turn to windward against it. Mr. Pepys, being now brought alongside, went aboard, and passed the hours pleasantly in professional conversation until the time came to get under way again.

"So to our yacht again," he continues. . . " No sooner come into the yacht, though overjoyed with the good work we have done to-day, but I was overcome with sea sickness so that I begun to spue soundly, and so continued a good while, till at last I went into the cabbin, and, shutting my eyes, my troubles did cease that I fell asleep, which continued till we come into Chatham river, where the water was smooth, and then I rose and was very well."

Doubtless the tide had changed whilst he had been paying his call on the warship, so that when he returned to the Bezan she was a little lively with wind against 


\section{THE INTRODUCTION OF YACH'TS}

tide. This, together with the excellent hospitality which would be dispensed while on board the Prince Royal, caused even a Secretary of the Admiralty to have unpleasant qualms. But that did not kill his enthusiasm, for a few days later, on the last day of September, we find him off again in the same craft to spend another week-end. "“. . . And we three and two companions of his in the evening by agreement took ship in the Bezan, and the tide carried us no further than Woolwich about 8 at night." So Pepys goes ashore to sleep, and early the next morning comes aboard again. "October 1 st (Lord's Day).Called up about 4 of the clock, and so dressed myself and so on board the Bezan, and there finding all my company asleep I would not wake them, but it beginning to be break of day I did stay upon the decke walking, and then into the Maister's cabbin, and there laid and slept a little."

Presently they get under way and sail down to have a look at the fleet as usual, and then sail up the Medway. "So after supper Captain Cocke and I and 'Temple on board the Bezan . . . we having sailed all night (and I do wonder how they in the dark could find the way), we got by morning to Gillingham, and thence all walked to Chatham," after which they "took horses to Gravesend," and so back to town. This, then, seems to have been Pepys' favourite cruise, down the Thames and up the Medway, and then home by land, the crew apparently sailing the yacht back to her buoy during the course of the week. And there are still other extracts that we could quote to show Pepys' love of the new sport and the manner in which yachting was indulged in during this reign. Three more instances belong to the same year, and one sees that Pepys was so keenly attached to sailing that he kept up his weekends until five weeks before Christmas. Thus :-

"October 25, 1665.-After dinner my Lord by a ketch down to Erith, where the Bezan was." 
“November 3, 1665.-Was called up about four o'clock, and in the darke by lanthorne, took boat and to the ketch and set sayle, sleeping a little in the Cabbin till day."

"November 17, 1665.-And so away to my Bezan againe ... and sayled all night, and came to Erith before break of day."

Thus from this time onwards yachts of various sizes continued to be built in the English yards at Deptford and Chatham, Portsmouth, Rotherhithe, and so on, the tendency being to turn out craft of larger tonnage. There were various minds at work on the problem of designing a faster type of craft. We have already seen Charles introducing to Pett a new type of vessel; we have seen the king fanning the rivalry between the two brothers in order that the best possible yacht should be evolved to beat the Mary; we have seen that Charles even went so far as to help to design, or at any rate to give the bare outline for a new and improved type. He also insisted that what was commonly supposed to be a new device (of which we spoke earlier in this chapter) should be applied to the Henrietta, by having her under-water body sheathed with lead, the precursor of the later development of giving yachts copper sheathing, but owing to the corrosion which set up, this lead system, which was also tried on some of the ships of war, was abandoned.

In truth, this was not a new idea but a revival of a very old nautical custom, as I have already explained in the pages of another volume. And in the year 1662 -the year before the king was busy with his device for the Henrietta-Sir William Petty had designed and launched a wonderful craft which much interested Charles, insomuch that the latter was present to see her enter the water for the first time, and named her the Experiment. This vessel consisted of two bottoms or keels, as she was described. She was practically a catamaran, and it is probable that Sir William had 


\section{THE INTRODUCTION OF YACH'TS}

received the idea from some one who had travelled abroad. It was five days before Christmas when the launch took place, and Pepys also was present. She was practically a freak, and has no historical value in regard to the evolution of the yacht, but it is illustrative of the enthusiasm which had been aroused within a year or two owing to the gift from the Dutch East India Company.

Certainly the Experiment was not slow. A match was arranged for a wager of $£ 50$ to race from Dublin to Holyhead next year between her and the " packettboat," and the Experiment won easily. Add to this the fact that there was a gale blowing at the time, and it is proof of the seaworthy qualities which this craft must have possessed. She had a burthen of thirty tons, carried thirty men, had good accommodation, and ten guns. This is an interesting contest, as having been the first ocean race on record. Eventually the Experiment foundered with all hands in the Bay of Biscay. But her designer, who was one of the most intellectual men of his time and one of the founders of the Royal Society, spent a good deal of time and work on this double-bottom idea, and devised a number of other craft so arranged.

It is now time to speak of the second yacht Mary, which belongs to this reign, which has been, so to speak, brought to life again in our frontispiece. The first Mary, it will be remembered, foundered, and it is clear that the second Mary was built on very similar lines, but somewhat larger. In his interesting History of Yachting, to which I am indebted for certain facts and suggestions, Captain A. H. Clark asserts that " it is rather strange that there should be only one portrait of English yachts at this period," and he proceeds to refer to a painting in a private collection.

But this is an error. It certainly would be strange when we recollect that the Van der Veldes, both father and son, came over to England specially to depict sea- 


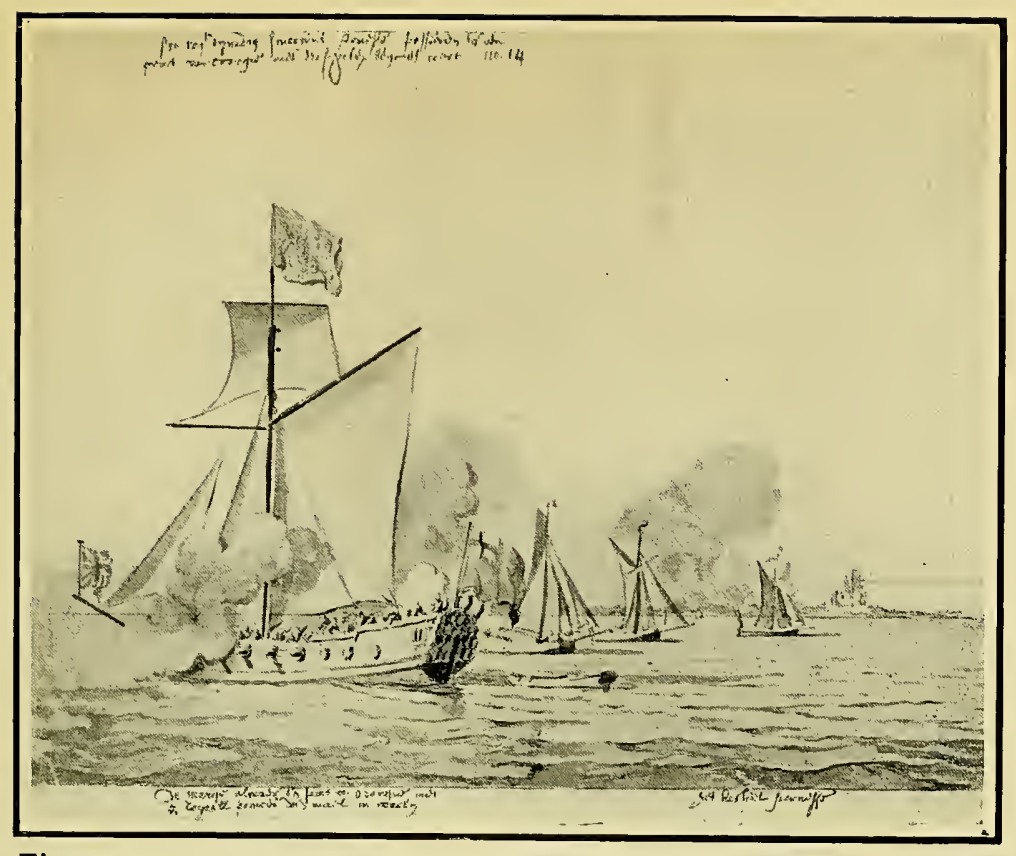

Fig. 33 .

The English Yacht, The Second "Mary"

P. 155

From a contemporary sketch by Van der Velds. Notice the absence of leeboards. Sheerness is seen to the right of the picture.

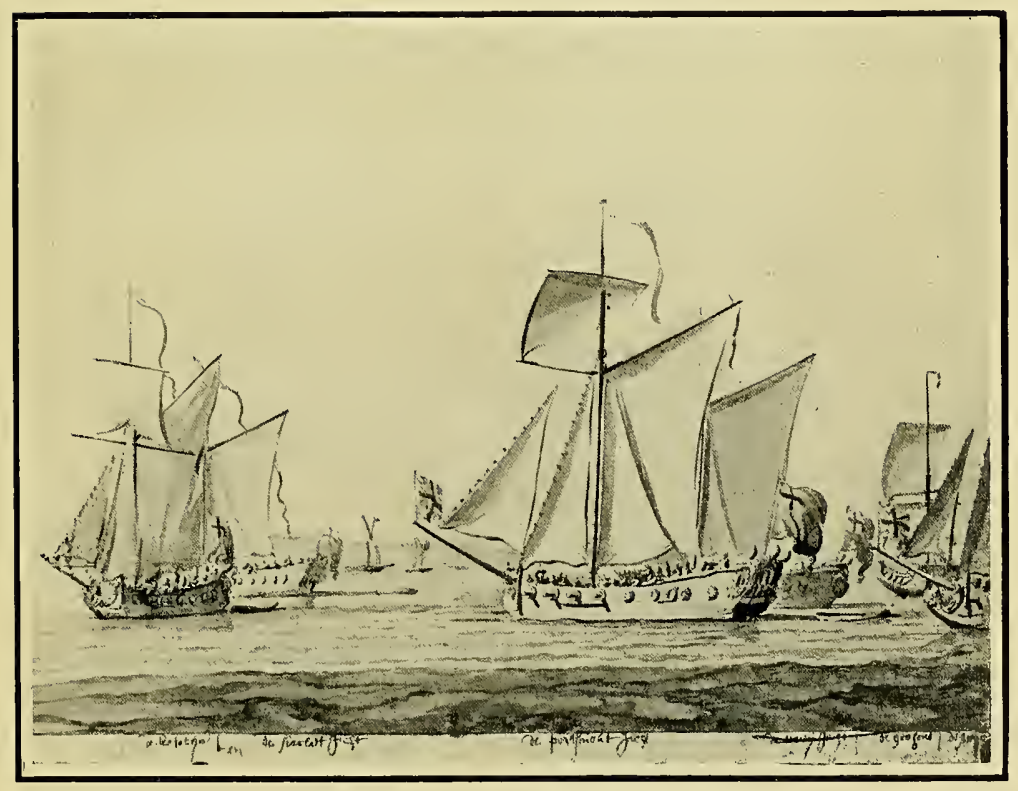

Fig. 34 .

Some of Charles II'S Yachts

P. 155

Reading from left to right these are the " Katherine," "Charlotte," "Portsmouth," "Navy," "Greyhound," and "Anne." (From a contemporary sketch by Van der Verde.) 

pictures, and were established at Greenwich by Charles II. There are still preserved some delightful pictures in pencil and Indian ink of all sorts of marine subjects by Van der Velde, depicting the shipping of the time. Our present study is concerned only with the fore-andafters which appear in these drawings, and in order to rivet the attention of the reader, and to prove that contemporary illustrations of the Mary and other yachts that we have mentioned do exist, the two accompanying pictures by $V$ an der Velde (Figs. 33 and 34 ) are here reproduced. It is not possible to assert the exact year when these two painters arrived in England. It was not earlier than 1673, and was probably 1675 . The son's work is so similar to his father's that art critics admit that it is practically impossible to distinguish the one from the other. But those which are here reproduced are thought to be by the son.

In Holland the Dutch States had provided him with a yacht specially to draw marine subjects and sea-fights, and there is still extant a drawing of the Battle of Solebay, in the composition of which he has actually depicted not only the warships, but his yacht as well in the foreground. Now, in the first of the drawings which the reader will find interest in perusing there will be noticed on the extreme left the English yacht Mary the second. Her dimensions were : length, $66 \frac{1}{2}$ ft. ; beam, $21 \frac{1}{2} \mathrm{ft}$.; depth, $8 \frac{3}{4} \mathrm{ft}$. ; draught, $7 \frac{1}{2} \mathrm{ft}$. Her tonnage worked out at 166 , so that she was exactly sixty-six tons larger than her prototype. She carried twenty men and six guns. This yacht was built in the year 1677 at Chatham by Phineas Pett, and this Van der Velde sketch was drawn in November of that year, so that we see the yacht probably at her best. The incident here depicted is the starting of the Prince and Princess of Orange on November 20, 1677, bound for Holland.

It will be recollected that their marriage had taken 


\section{THE INTRODUCTION OF YACHTS}

place on November 4. The royal pair are on board the Mary, which is just sailing away, and the fort at Sheerness is firing a royal salute, which the Mary is answering. The similarity between this yacht and that in the Verschuier sketch (and so between the first and the second Mary) will be immediately remarked. But this Mary $I I$., instead of the spritsail has a gaff mainsail, and no boom. The jib works on the foretopmaststay as the foresail works on the forestay, so that both sails can be easily lowered and stowed. There is a Jack flying at the outer end of the bowsprit and an ensign at the stern, as well as a royal standard at the masthead. It is clear from the other shipping, which is seen in the background of this picture, that there certainly were by this date fore-and-aft craft in English waters that were not yachts.

'The reader will observe that they resemble Dutch tjalks, and if they are not foreign vessels, then they are English trading craft based on Dutch models. One has a boom, a second has a gaff but no boom, and so also the third. It is extremely interesting to notice this point, for it shows that the fore-and-aft rig was more frequently seen in our waters than is generally suspected. There is no question that Van der Velde was drawing an imaginary picture, for he has recorded the fact that he did this picture on the morning of the date here given, and those other fore-and-afters must have been there as shown.

The other illustrations in Fig. 34 is the second half of this Van der Velde original. The picture has been reproduced in two sections so as to preserve the details as much as possible. In addition to the Mary, the reader will find, reading from left to right, some of the other yachts that we have been talking of. These are the Katherine, the Charlotte (nearly out of sight), the Portsmouth, the Navy (nearly out of sight), the Greyhound, and the Anne, the two last-mentioned just showing their bows and figureheads. It is possible, 
while looking at these drawings, and bearing in mind the sea-pictures which Pepys and Evelyn have drawn for us by their pens, to gain an impression not very different from that which would have been received had we been present to see these craft in the latter half of the seventeenth century. And these drawings form some of the most valuable evidence which exists in respect of our subject.

There is another drawing by the same artist made the previous day which we do not reproduce. It shows an earlier stage of this royal voyage on November 19. In that delightfully sunny picture we see the Mary getting under way from Erith. There are other craft in the picture as well, including the yacht Portsmouth, which in size, in rig, in general appearance, with her three poop-lanterns, is very similar to the Mary. The men on the latter are seen getting up anchor. There is some bunting at the jack-staff at the end of the bowsprit. The jib is already set, so is the square-topsail, which is provided with leather chafing-pieces and the usual barren yard below. The staysail has been hoisted, but is stowed to the stay according to the Dutch custom. The gaff-boomless-mainsail is up, of course, and the brail-line is being slacked off so as to allow the full spread of canvas. The yacht carries two anchors, one on either side, and has also a cathead on either bow. One anchor is up, the other is being broken out, and it is a flat calm as one not infrequently has it in the month of November. The Mary displays four of her guns through her port-holes. Erith shore is seen glistening in the sunlight at the back of the picture, and the yachts Anne and Katherine are both again shown.

Thanks, then, to Charles II., to his previous exile in the Low Countries, to the historic present from the Dutch, to the excitement and interest which the first Mary aroused alike among shipbuilders and gossips, and thanks also to the continued enthusiasm of Charles 


\section{THE INTRODUCTION OF YACH'TS}

himself, yacht building and racing had made a sure beginning in England. Society displayed their interest, and, in addition to Petty, it was not long before Queen Katherine and the Duke of Richmond had become yacht-owners. The enthusiasm even spread to France, and Charles permitted Sir Anthony Deane to go to France to build a couple of yachts for Louis XV. There is a brief mention in Pepys' Diary which shows that yachting in these fore-and-afters was becoming fashionable under Charles' influence. On September 3, 1663, writes the diarist :-

"Up betimes, and for an hour at my viall before my people rise. Then up to the office a while, and then to Sir W. Batten, who is going this day for pleasure down to the Downes. I eat a breakfast with them, and at my Lady's desire with them by coach to Greenwich, where I went aboard with them on the Charlotte yacht. The wind very fresh, and I believe they will be all sicke enough, besides that she is mighty troublesome on the water. . . . I left them under sayle, and I to Deptford."

Pepys' prognostications came true, for on September 5 he adds :-

"I hear this day that Sir W. Batten was fain to put ashore at Queenborough with my Lady, who has been so sick she swears never to go to sea again. But it happens well that Holmes is come home into the Downes, where he will meet my Lady, and it may do her more good than she looked for."

Thus to the existing list the name of Sir W. Batten must be added as a seventeenth-century yachtsman. But there was much to interfere with the progress of this sport during this reign. Most of all, there were the Anglo-Dutch wars, which made it impossible to cruise round to the Downs and across to France. For when the Dutch were frequently hovering about the North Foreland, the mouth of the Thames, and even-scandalous to remember-were allowed to sail up the Medway 
and burn our warships, it was more than enough to stifle the sport for a good time. But the yachts themselves were none the less used even if the sport was suspended. Just as the Dutch had been wont to use yachts in naval warfare, so the English navy did not hesitate so to employ them. And, additional to the Dutch warfare, we must not forget that first the Plague of London and secondly the Great Fire had a terribly depressing influence on even the pleasure-seeking people of Charles' reign.

Thus there followed a depression in the sport which had begun so well, in the development of the rig which had been introduced with such appreciation, in the building of a new type of hull which had immediately been improved upon by the Petts and others. Domestic peace is essential for the enjoyment of sports as well as the arts and sciences, and a new sport can suffer violent shocks with less ability than one which has existed for a century or more. However, it is evident that the yachting idea did not die utterly during the time of trouble and national anxiety when the war was draining the financial resources of the country in the most serious manner. For, at any rate, not more than thirty-five years after Charles' death there were enough yachts in existence to found the first yachting club which our nation possessed. And this, if you please, was not on the 'Thames, nor on the south coast. It was in a quarter where it would have been least expected.

Not England nor Scotland, but Ireland had been building and sailing these craft, and in the year $\mathbf{1 7 2 0}$ the existing yachts and yachtsmen were the cause of the inauguration of the Cork Water Club, which to-day still continues under the title of the Royal Cork Yacht Club. And as to the effect which this had on the yachts of the time, as to the relation which Cork bears to Amsterdam, and the rig of its yachts to the foreand-afters of Holland, we shall inquire in the following chapter. 


\section{THE INTRODUC'TION OF YACH'TS}

But let this be remembered, that there was no such sport as what is known to-day as Corinthian yachting. It was as formal as a minuet, as ceremonious as the prevailing insincerities of the life and epistles during that time. It was an age when pompousness was respected, and a similar spirit manifested itself, as we shall see, in the style of yachting then in vogue. Today there is a democratic spirit not merely on land but afloat. Yachts put to sea when they like and separately, whereas in the early eighteenth century they cruised in fleets and were under discipline all the time. The love of the sea and of ships must necessarily have been present, otherwise the Irish noblemen and gentlemen would have preferred some other form of sport in which to interest themselves. But there were other considerations as well.

'The yacht or sailing club of those days was somewhat different from such institutions to-day. Formerly there was a kind of semi-naval dignity and distinction attached thereto, there was all the saluting to which an admiral is entitled, there was the display of tactics, and so on. Finally, after an interesting day had been spent in signalling and manœuvring, the fleet returned to harbour, the crew stowed the sails, and the gallant owners went ashore to enjoy a hearty dinner and their bottles of port. Yachting was thus rather a series of exercises than of races; rather an occasional event of social importance than a voyage of discovery round the coast, entering harbours never visited before, or stealing into those snug creeks which the yachtsman of to-day loves to choose as his quiet anchorage for the night. Moreover, the style of the yachts was modified in such a way as to show their close relationship to the great ships of the English navy, and, further back still, to the vessels which had come from Holland. The influence of the first Mary was indeed restrained, yet it was not altogether obliterated in the designs of the eighteenthcentury pleasure fore-and-afters. 


\section{CHAPTER VI}

THE INFLUENCE OF HOLLAND ON THE DEVELOPMENT OF THE FORE-AND-AFT RIG

NOW that we have seen the development of the fore-and-aft rig in Holland, as well as the introduction of the first fore-and-afters, or at any rate of the first fore-and-aft yachts into England, we are in a position to follow the development of this new rig, and to observe how from the time when Holland had reached her grand climax the history of the rig passes away from the Low Countries.

We have seen that it is certain that until the advent of the Mary there was no such thing as a yacht in English life. Whether there were, prior to this, any fore-and-afters for trading or fishing purposes is extremely doubtful and impossible to say definitely. If they existed at all they were only in isolated instances, and were not the rule but the exception. I am confident that the herring fishermen did not employ the fore-andaft rig, but, following the example of their Dutch rivals, put to see in buss-ships. Now, from an interesting little book, whose folios are not numbered, and published in London in the year 1615, we are able to gain a pretty exact idea of these craft, the counterpart of those other vessels which put forth from the Dutch ports to catch the herrings of the North Sea. They were rigged in a similar manner to the Dutch herringdrifters with three masts and one square-sail on eachfrom which rig there was to evolve the three-masted lugger which is so familiar a feature in many of the 161 
old illustrations of the eighteenth and early nineteenth centuries.

'Therefore, as the immediate forerunner of the Deal lugger, the old Yarmouth "yawl," the French chassemarée, and the armed lugger-each of these having originally three masts with lugsail on each-we may see briefly the character of the English buss-ship which was to give to English craft that development of the foreand-aft rig that is of all examples one most akin to the original square-sail. Although in England the lugsail is being replaced by the ketch, yet in Scotland and France the rig seems to hold its own among the fishermen, but in some ports the lug is vanishing. At one time it was a favourite rig for the smugglers which the Revenue-cutters of our Government went forth to chase, but the lugger is wonderfully fast on a wind, as any one who has ever matched an average cutter against one must know. And it was because of their speed, because they so often succeeded in showing a clean pair of heels to the Revenue-cruisers, that ultimately the British Government had to follow their example and to build armed luggers to cope with them; but, like the old Yarmouth yawls, besides the lug on each of the three masts they carried a jib, and in addition the armed lugger carried a topsail on her fore and main.

But to come back to the seventeenth-century English busses : these were of about seventy tons burthen and measured fifty feet on the keel, with seventeen feet beam, and had hold enough to carry thirty-five lasts of fish. These vessels, according to the contemporary, record, had cabins, "cooks' roomes," and other "roomes." The cost of building such a buss as this, together with the "ruther" (rudder), the ironwork, the bolts, the "chane-bolts" for the rigging, the "shroud-chaines," "nailes," \&c., as well as her cock-boat and "oares," amounted to the sum of $\$ 260$ as a maximum. Her mainsail and bonnet, which was laced along the foot 
after the manner of some of the North Sea fishermen and the Norfolk wherries to-day, measured eleven yards deep and was "sixteen cloaths" broad, the material being known as "Ipswich Poledauis." Over this mainsail she also set a topsail. Her foresail was likewise a square-sail, and with its two bonnets measured ten yards deep and twelve cloths broad. Also she had a " mizen or backsaile," which was four cloths broad and five yards deep. In addition the buss was furnished with all the necessary articles for sailing and fishing, boatswain's stores, and nets and barrels, \&c. She was also to have "two flagges or fannes [whence the word "vanes"] to obserue the winde by," and these "fannes" were also to be mounted on their "staues" or staves. The total estimated cost of a new buss, together with her new nets, her gear, the first year's charges for salt, casks, as well as victuals and wages for the crew, amounted to £934 5s. 8d.

But, having seen something of the character of the English busses and the manner in which they were destined to affect the later development of the fishing craft of our coasts, until to-day they are at their very best in the Scotch and Cornish luggers, we may now turn from this species to consider the further evolution of the sloop and cutter rig. The influence of Holland was to be exercised in respect of the yacht, the Revenuecutter, the sailing-barge, the trader, the packet-boat, and the fisherman as well. The period which we have in view for the present is the eighteenth century and the beginning of the nineteenth.

Let us commence by showing that the English naval architecture was content for many a year to follow along the lines which Holland had laid down. It was a dull age this eighteenth century, as barren in art as it was in architecture. Depressing and uninventive, without sparkle of originality, it needed the great national revival during the middle of its epoch to stir men's minds to enthusiasm, and to bring about all those 


\section{INFLUENCE OF HOLLAND ON}

beneficial changes which we in this country have been enjoying for so many years past. 'The marvellous awakening of industrial development, of improved methods of transport, the discovery of the latent powers of steam which was to lead to the invention of the locomotive and the steamship, and so to revolutionise the world by hurrying forward civilisation and development-all this did not come till late in the day, and after a period of mere copying had been followed. And when the time for the new order of things did arrive it was to change altogether the character and appearance of the sailing fore-and-after: it was to transform a more or less barrel-shaped object into a delicately fashioned wedge that would cleave and leave the water as undisturbed as possible. Instead of driving a hull through the water by the mere force of the wind pressing on to unduly bellying canvas, the fore-and-after was to slip through the water with the minimum of effort. The resistance was to be diminished as much as practicable, the sails were not to be windbags but more like flexible boards. The ship herself was not to seek battle with every single wave, but, so to speak, coax her own way through the water with the least fuss.

But before we arrive at the time when this was brought about, we have first to see what conditions had to be contended with. First of all, consider the actual rig of such a Dutch craft as the "hoeker." In the accompanying illustration (Fig. 35), which has been taken from Chapman's Architectura Navalis Merca-

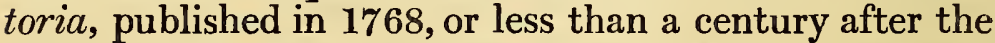
death of Charles II., we have the hoeker in her most refined aspect, for this is a hoeker-yacht. She is to all intents and purposes a development of the galleot, and, as she now appears, is virtually a ketch. In her original form, the hoeker, "houcre," or " hoek-boot," was square-rigged, with one course on the main and another on the mizzen. Afterwards there was added a 
bowsprit, with staysail and jib, and there were also given to her a fore-and-aft mizzen and a fore-and-aft mainsail. The lower course, the square-topsail, and topgallant were retained, nevertheless, on the mainmast, and thus there was an admixture of both the

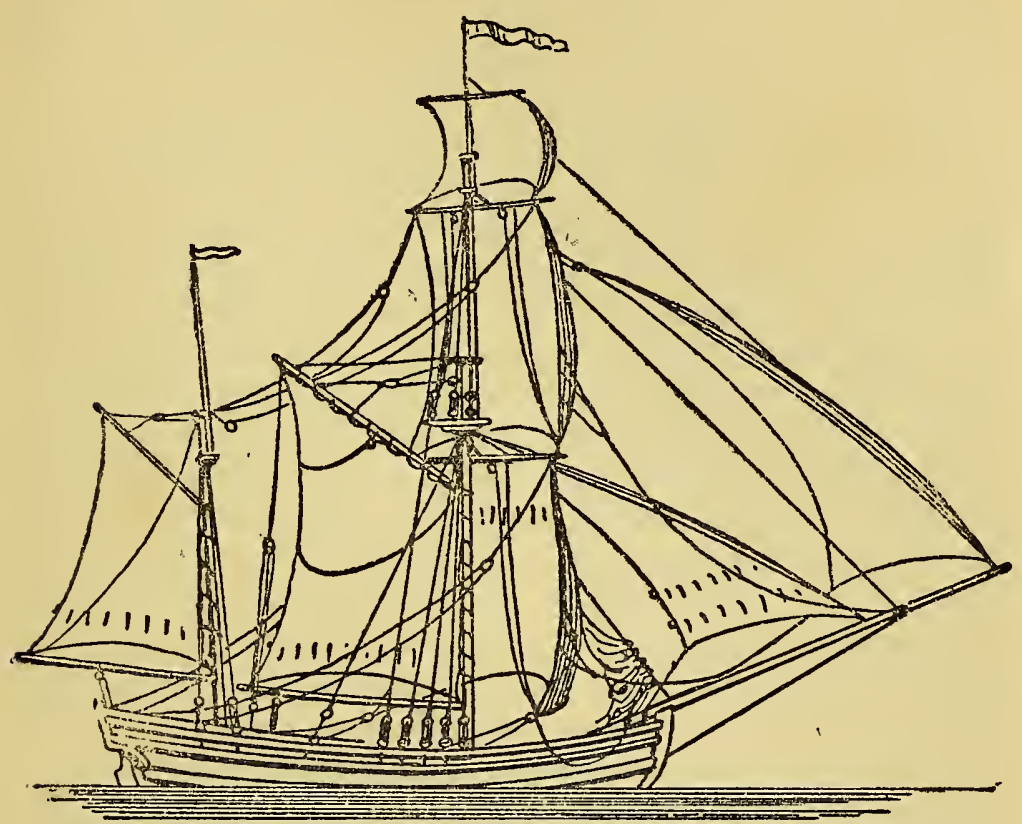

Fig. 35.-Eighteenth Century Dutch Hoeker-Yacht.

Taken from Chapman's Architectura Navalis. This shows the later development of the old galleot. It will be noticed that she carries three square-sails on her mainmast.

original square-sail and the more recent fore-and-aft rig.

It will be observed from the accompanying diagram that there are braces to the lower and topsail yards, and that in order to make the sail set better when on a wind the old idea of a bowline was still employed. This will be seen with its three-part spreader attached 
to the leach of the topsail, and the line leads away down to the bowsprit. The high-steeved bowsprit is seen still to be retained. The mainsail has both gaff and boom. It has one row of reef-points near the foot, whilst the upper half of the sail can be brailed in. The boom has its mainsheet, and there is a vang with its purchase shown. The mizzen is also a gaffsail. 'The brailing arrangement is not here used, and by this date it will be seen that the topping-lift is in vogue.

From this diagram let us turn to the etching of E. W. Cooke (Fig. 36), which shows some Dutch craft turning to windward. We miss here the colour which this marine artist put into his paintings, but the picture is none the less lacking in life, and few artists of his time had such a sympathetic interest in the shipping of his day nor understood so well how to depict what he saw. If any British artist ever understood Dutch craft it was Cooke. He was of Dutch descent, and he visited Holland as many as fifteen times. He was constantly producing paintings of these bluff-bowed Dutchmen, and he has shown us, for future and present interest, that which Van der Velde bequeathed to us from his day. Cooke's life was covered by the dates 1811 and 1880. His father was so skilled an engraver as to be chosen to reproduce Turner's seascapes, and the son was also employed for a time on such work. His output was enormous, yet it is rarely that he disappoints us.

This illustration before us, together with the others of Cooke, belongs to the year 1829, but during the time between this date and the death of Charles II. there had been but little alteration in the Dutch galleots hulls. True, there is far more of the fore-and-aft rig than of the square-sail in this time, but in the ketch or galleot seen in the foreground of the picture to the left we have many an item to remind us of her descent. The lower course, which is set on the mainmast, may seem of unusual shape, but it is quite correct, and 
exactly as the Dutch had it at this time. Strictly speaking, it is not a square-sail at all, for the head is of triangular shape. Why was this? The answer is quite simple. Look at the topsail. That has to be goared-that is to say, its foot has to be hollowed out -so as to clear the forestay. But in cutting the topsail of this shape a great deal of sail-area is wasted. It is to make up for this deficiency, therefore, that the lower course comes up in a triangular form.

And now compare this Dutch craft with that English one in Fig. 32, which is also from Cooke. Here we have a craft which is well known to all who are familiar with the coasters along the east of England. Cooke has happily made his sketch at low-water, so that we can see the under-body of this ship. It is true that she is cutter-rigged in this instance, but they are more usually ketch-rigged. If you compare them hull for hull you will find that Holland is far more manifest in the billy-boy than England. Like the Dutchman she still carries leeboards; the mast is still stepped in a tabernacle for convenience in lowering; and though the square-topsail is retained in the sketch before us, it has to-day gone, but the modern billy-boy still retains the lower course for use when running before the wind. Big-bellied, rounded as to her stern, the billy-boy of yesterday and to-day announces to any one who has eyes that she possessed Dutch parents.

But it was not merely the trading-coaster, but practically every other kind of fore-and-after belonging to the eighteenth and the early part of the nineteenth centuries that was destined to be moulded by the Dutch custom. The yacht, the Revenue-cutter, the pilot-boat, the fishing-smack, the herring and mackerel boats, the barge-these were all to show their submission to the country which had taught the world the value of the fore-and-aft rig. If we examine the work of such marine painters as existed during the eighteenth and early nineteenth centuries we may not always find a 


\section{INFLUENCE OF HOLLAND ON}

high level of art, but we scarcely ever come away disappointed in respect of nautical information. This is not the place to give a complete catalogue of such seapainters, but it is possible from the works of such men as Brooking (1723-1759), Bonington (1801-1828), Serres (1759-1825), Monamy (1670-1749), Clarkson Stanfield (1793-1867), Constable (1776-1837), E. W. Cooke (1811-1880), Turner (1775-1851), and others, to gain an accurate idea as to the kind of vessels the foreand-afters of the time had become.

Among the accumulation of inartistic trifles which are stored up in Kensington Palace are a number of badly painted sea-pieces. But we can look over these defects and feel quite thankful that these paintings have been preserved, for they illustrate just what we should wish to know. The collection is so accessible to many people that we do not feel called upon to examine each picture in detail. Omitting from our purview those which are battle-pieces and strictly concerned with the Royal Navy we see that late on into the eighteenth century the first Mary type appeared to be the standard for the yachts of this country. After that, whilst preserving those highsteeved bowsprits and the general bagginess as to the sails, there is added a boom to the gaff-mainsail, the sail being loose-footed.

The great loftiness of the stern also begins to disappear, until by the end of the century there is many a pleasure-yacht with her poop no higher than her bows. There is an effort being made to get away from the transom stern and to approximate to the counter stern that was to follow. Those who are familiar with the sterns of many of the Sussex beach craft such as are seen at Brighton and Hastings, will find a great similarity between these existing sterns and those which obtained at the end of the eighteenth century. The evolution of the counter has been just this: The transom stern was taken from the con- 


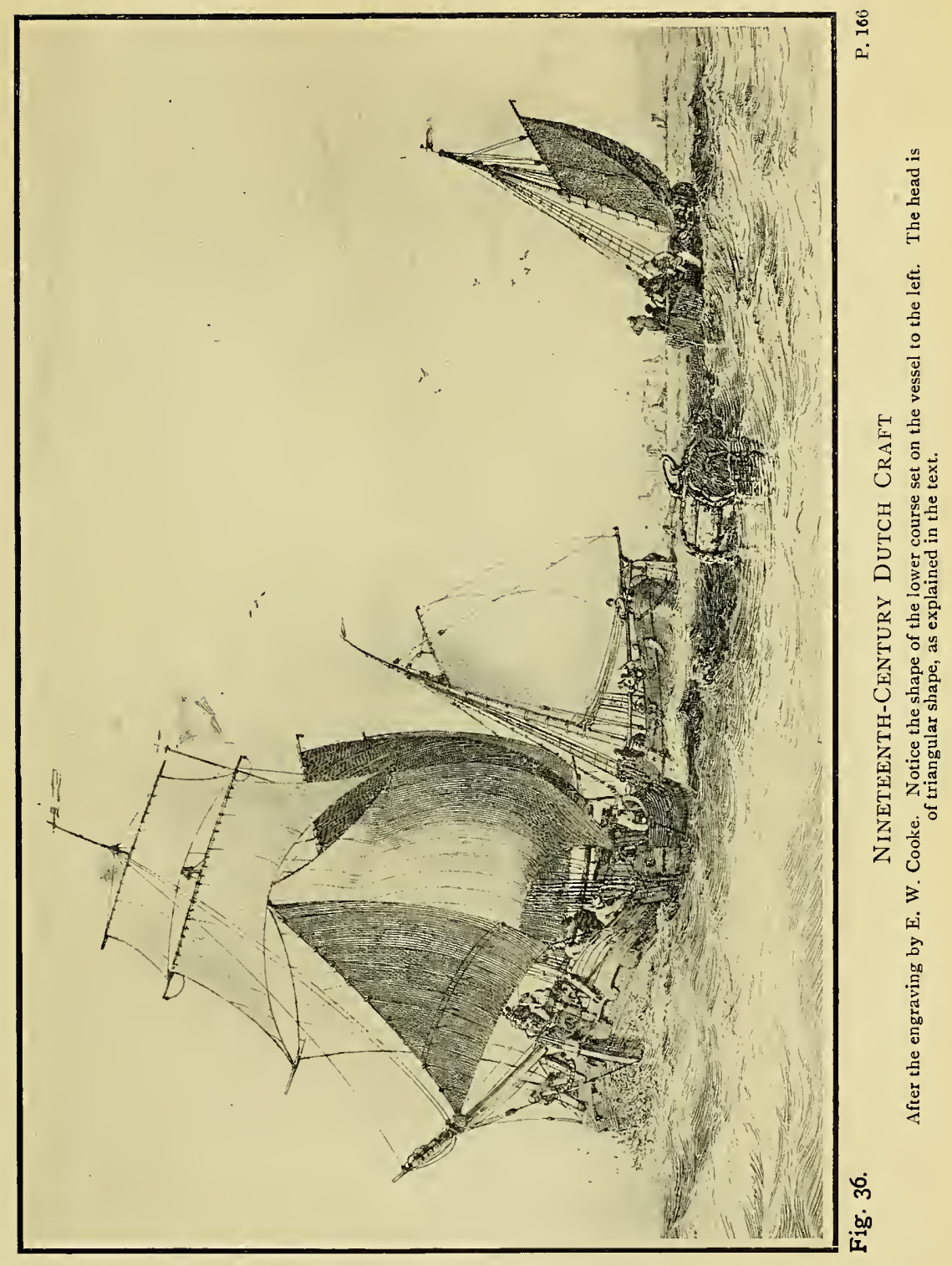



temporary Dutch warships. Then the poop-deck was, later on, made to project well over the stern. The stern-post was now at practically right angles with the keel. But the transition thence was only a slight one, for the stern-post was given a much greater rake, the after-end of the ship was made to project further astern, the transom vanished, and thus there came about the modern counter.

But in the late eighteenth-century craft of which we are speaking there was a stout rail which ran round the stern, as if the loss of the high poop were really felt and some protection were needed. The modern life-lines which run round many of our yachts are but the survival of these strong rails. There were sloops, cutters, yawls, and luggers afloat and dodging about the water with lords and ladies to witness a naval review. 'The bluff bows, the beamy proportions, the timber colour for painting the hulls-these traditions of the Dutch were still held on to rigidly. The sails are usually white, but occasionally one comes across a pleasure craft with canvas striped like a window blind, yet this is exceptional. But before we pass on to deal more minutely with the eighteenth-century fore-and-afters, let us give some idea of the appearance of a Dutch yacht belonging to this epoch.

Such a yacht has, according to an old Dutch volume printed in Amsterdam, no sprit but a gaffmainsail, and the latter is brailed to the mast. There is a tackle to the tack of this sail, and there are four vangs to the peak. There is also a yard for the square-sail. 'The Dutch love of bunting is seen at the masthead, the peak, and the ensign-staff; and no doubt there would be another flag of some sort at the end of the bowsprit. The foretopmast-stay is not at the end of the bowsprit, but at a point between the stempost and the beakhead. No jib is shown, though it was in all probability set.

The lion and figurehead and the beak are of 


\section{INFLUENCE OF HOLLAND ON}

course copied from the contemporary full-rigged ships. There are two backstays on either side, and there is a big chimney shown forward of the mast coming up from the "cooke-roome." There is also a curious additional backstay which appears to lead from the throat to the end of the poop-deck. One would have thought that it would have chafed the sail a good deal, although it must certainly have given an additional support to the mast. Those sausage-shaped wooden fend-offs which we noted on another Dutch vessel are in the case of this print here seen again. They are placed as well at the bows as at the stern. She has leeboards, a couple of guns are seen projecting from rounded ports on either side, and she has the conspicuous stern lantern at the extremity of the poopdeck.

We mentioned in the previous chapter that by the year 1720, at any rate, there were sufficient yachts in the south of Ireland to form the first of our yacht clubs. Now here again the Dutch influence continued down to the minutest details. Laying aside, for the moment, any question of rig, the Cork yachtsmen adopted the very ideals of those Amsterdam yachtsmen whom we considered in another chapter, not racing but engaging in sham fights and naval manœuvres under the command of an admiral. Now the Cork club busied themselves in just the same manner. We must remember that this was a time when naval affairs were wonderfully prominent. It was not so long since the Anglo-Dutch wars had at last come to an end, and now from the year 1689 till the battle of Trafalgar, with but slight intermissions, there were the wearisome wars with France. Additional to this there was ever a good deal of smuggling going on and the corresponding activity of the Government craft to catch the delinquents. If, then, we bear these facts in mind, it comes quite natural to find the first yacht club in the second decade of the eighteenth 
century based on semi-naval principles, although it must be understood that the precedent was Dutch and not English. The Netherlands had been such an ensample of everything that was correct in nautical matters that those Irish gentlemen doubtless thought that they were following the best ideals when they drew up the sailing instructions for their fleet of pleasure vessels.

As to its constitution, this club had its admiral, its chaplain, and officers, and to-day every yacht and sailing club, with its commodore, vice-commodore, its rear-commodore, known as the club's officers, is unconsciously following the example of the Dutch yachtsmen in the seventeenth century by adopting a kind of naval atmosphere and appellation in its organisation. In his interesting article in the second of the "Badminton" yachting volumes, Mr. R. T. Pritchett quotes from a book published in the year 1748, wherein it is stated that these Cork yachts "for painting and guilding exceed the King's yacht at Greenwich and Deptford." Mr. Pritchett also gives the rules and sailing regulations which were in vogue among these Cork enthusiasts, and may be summarised as follows: The yachts did not get under way until the admiral signalled to this effect by firing a gun and throwing out his flag signals as in the Royal Navy. It was the admiral who led the van, who received the honours of the flag, and, with his vessel as leader, the rest of the craft fell into their proper stations and "keep their line in the same manner as the King's ships." With colours flying, drums beating, trumpets sounding, and guns bellowing forth, the occasional cruises of the Cork Water Club were indeed impressive ceremonies. Following the contemporary practice in the service, there was a good deal of gunpowder wasted during these cruises. Sometimes the admiral would give the fleet a chance of playing at Revenue-cutters, sometimes he would also give his 
fleet the signal to chase an imaginary foe; in which case "he will hoist Dutch colours under his flag and fire a gun from each quarter." Under Rule IX., if any of the fleet had not guns to salute the admiral they were to give three cheers, which are to be returned by the admiral, and one cheer is to be returned by the captain so saluting.

The sailing orders, after the manner of the Dutch yachtsmen, included the instructions for rendezvous, for getting under way, for communicating with the fleet, for coming to an anchor, for chasing, and so on. This club flourished until the year 1765, after which there seems occasionally to have been a dearth of enthusiasm, although it was eventually revived, and now exists as stated. We have already drawn attention to the marine paintings of Peter Monamy, some of which are to be found in Kensington Palace and the Dulwich Gallery. But there are still preserved in the Royal Cork Yacht Club other paintings by this artist, which show the Cork yachts of about 1720 to 1750 under way. They are seen to be rigged with mainsail, staysail, and jib. They set no topsails, because the throat of the mainsail is exceptionally high, and is hoisted nearly to the truck. The staysail is also very big, and the jib likewise. The bowsprit as usual is steeved at a considerable angle. The mast has its shrouds and lee-runners, and at the end of the bowsprit there is the customary Union Jack. It is possible and even probable that some of these yachts set a watersail below the bowsprit. But the sails are very baggy, and possessed nothing like the efficiency which our modern cut affords. Each yacht flies a large ensign at his stern, but the admiral flies a large Union Jack at his masthead, charged with a gold harp and crown on a green field in the centre of the flag. Other yachts, instead of this distinction, fly streamers or pennants from the masthead. The hulls are of the Dutchlike, bluff-bowed type of which we have already spoken, 
and the sheer of the hulls rises up from the bows towards the stern, but the poops have been very considerably lowered by this time. The spritsail is used no longer in these vessels, but a gaff and boom.

It must not, however, be thought that yachting on the Thames was dead. Certainly it suffered a relapse, but at any rate by the year 1749 there were many small sailing pleasure craft on the London river. The sport of sailing matches was now becoming commoner, and in the year mentioned a dozen of these craft started from Greenwich to race to the Nore and back for a silver cup presented by Prince George. In the year 1775 there was held at Battersea a regatta for sailing craft, and a sailing match for pleasure craft of a size from two to five tons was held from Westminster to Putney Bridge. It was thus that the famous Cumberland fleet came that year into being, whence there was eventually to evolve the present Royal Thames Yacht Club. The yacht which in the following year won the cup was named the King's Fisher. She was a clinker-built craft, as was the fashion in those days, and had a straight stem and a long straight keel. The lofty poop of other days was absolutely gone, and only the very slightest resemblance to the Dutch craft was preserved by a stern that was raised just a little. But ample beam and a flat body were still ideals which remained rooted in the minds of the designers. Those were the days, of course, when yacht races were started not by a flying start and an imaginary line as to-day: the vessels rode to their anchors with sails furled, and had to break out their hook, hoist their canvas, and hurry off as best they might. And the semi-naval ceremony was still adhered to even now. For the use of the Commodore of the famous Cumberland fleet a special code of signals was printed, so that he might manœuvre his fleet as if commanding men-of-war. Indeed there were times when yachts were actually chased into port by privateers. 


\section{INFLUENCE OF HOLLAND ON}

In July of 1793, for example, a yacht that was cruising round the Isle of Wight was captured by the Dagomar, a French privateer. It is not known what became of the yacht, but the yachtsmen were taken into Dunkirk, stripped of everything valuable, and then released.

By the close of the eighteenth century the great national revival and the universal awakening of England had reached the industry of yacht building. As we know from contemporary prints and from the contemporary works on naval architecture, there began to be introduced a greater originality with better designs, giving the yacht an increase of speed. The illustration, which includes more than one of the prevailing types, as well as the Atalanta, a famous craft in her day (Fig. 37), will afford a better idea of the yachts at the commencement of the nineteenth century. But in the year $\mathbf{1 7 9 6}$ there was launched at Rotherhithe a celebrated yacht of the name Ann Sarah. It is said that she " was formed pretty much after the old school, and is certainly a very clever thing. All floor from end to end, shallow body, deep keel, very full bow, straight sheer, a pretty airy stern. Her extreme breadth is before the mast." 'The "straight sheer" was certainly representative of the effort to get away from the old Dutch model, but the retention of the "full bow" showed how difficult it was to break away from the conservatism of many years' standing. But it was not till the years following 1851, when the famous America came as such a surprise, that the final cleavage between the old and the new ideas as to the lines of the ideal craft was to come about. Of this we shall speak in due place.

Many of even the smallest sailing craft on the Thames at the beginning of the nineteenth century still retained the spritsail of the Dutchman, the mast being placed very far forward, the sail being brailed for stowing as usual. The staysail formed not a large triangle, and most frequently there was no bowsprit. 


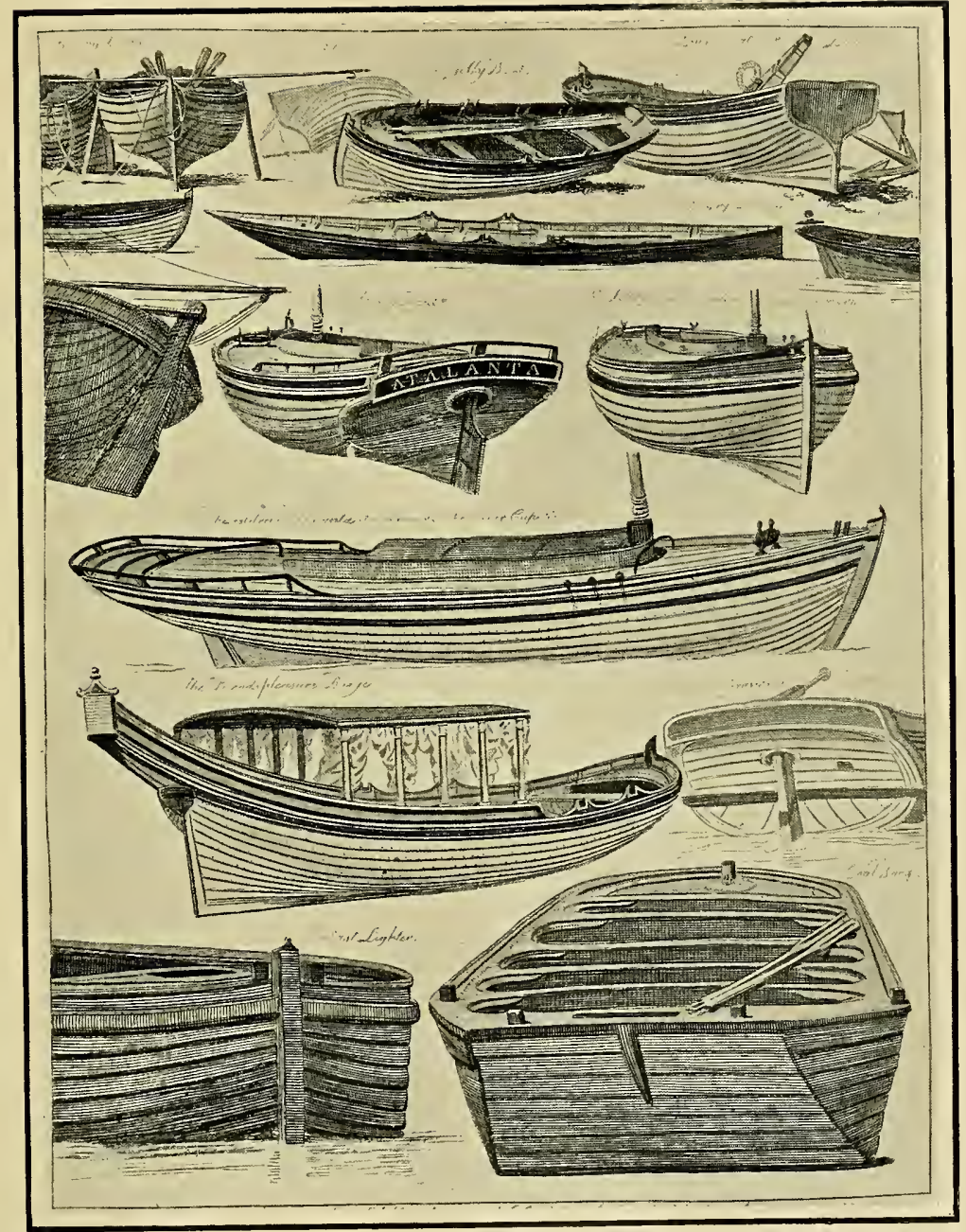

Fig. 37.

P. 174

Eighteenth Century Craft

This contemporary print affords an idea of the lines of yachts, fishing boats, sailing boats and other craft belonging to the close of the eighteenth century. Especially to be noticed is the famous "Atalanta." 

If the reader will examine the accompanying reproduction (Fig. 38) of one of Cooke's etchings he will find much to interest him, and will be enabled to get a good idea of some of the early nineteenth-century small fry. In the background are some of the Billingsgate oyster boats, which are cutter-rigged with gaff, boom, staysail, bowsprit, and jib. The mainsail is loosefooted, and it will be noticed that the topping-lift is not single, but it works through a block not merely at the masthead, but at the end of the boom, and then returns to the mast again. If one remembers the uninventive period wherein this type of vessel was evolved, one can readily understand that the designers and shipbuilders had remained content to accept the Dutch influence without much argument. We have only to look at this next Cooke etching (Fig. 39), showing a Dutch "schuyt" in Blackwall Reach, to see that the Dutch model has only been adapted just as much as was necessary for local purposes.

But to come back to the Billingsgate picture, it is important to notice two other characteristic types of craft which at one time were features of the 'Thames estuary, but now are among the obsoletes. These are the Peter-boat and the hatch-boat respectively. The former will be seen on the extreme left and the latter on the extreme right of this illustration. Sometimes both Peter-boats and hatch-boats used to race on the Thames in the early 'twenties, and they were then rigged as cutters. But the Peter-boat is indebted to Holland only for her rig. Her double-ended, canoe-shaped hull dates back to the times when the Viking-form was the recognised hull for England, and a beautiful legend connects her name with the consecration of St. Peter's, Westminster, which was to be replaced later by the Westminster Abbey. And it was almost under the shadow of this abbey, just above the Houses of Parliament, that one might see such craft some time since.

According to old prints these craft were decked in 


\section{INFLUENCE OF HOLLAND ON}

at the bows and the stern much like a lifeboat, except that the decks were flat and not convex. They were essentially fishing craft, and the old illustrations show them with a well for their fish running athwart the craft amidships. Strongly built, with plenty of freeboard, they were able to encounter the hollow seas which get up in the Thames estuary when wind is against tide. If there are a few semi-decayed hulls of these craft still to be seen anywhere on the Thames, they are really worthy of being taken ashore and preserved in one of our museums, for they are the only English craft which can trace, in a direct line, an ancestry that reaches right back to those times when the Vikings overran our land, but left to us a knowledge of shipbuilding that formed the basis on which the Tudors were to build their men-of-war. Excepting the Norwegian, the Baltic, and the Dutch craft of to-day, there are no craft in northern Europe that have had such a career with such few modifications from the original design.

But the hatch-boat, as seen in this picture and, better still, in the Gravesend picture, represents an attempt to get away from the Dutch influence. In a certain degree it is an improved and larger Peterboat, and in the early part of last century was the typical Thames estuary fisherman's craft. In the Billingsgate picture one of the smaller type is shown, but in the spirited illustration seen in Fig. 40, depicting Gravesend Reach, a bigger species of this craft is seen. In the present instance the hatch-boat is doublereefed. Although not discernible, such a craft set a bowsprit; and in this case it will be seen that a gaffmainsail has been adopted in lieu of the spritsail. The rudder is worked by a yoke-lifeboat fashionand the mainsheet worked on a horse. The retention of a couple of vangs, and the lacing to keep the sail to the mast, instead of using hoops, are survivals of the Dutch influence. 


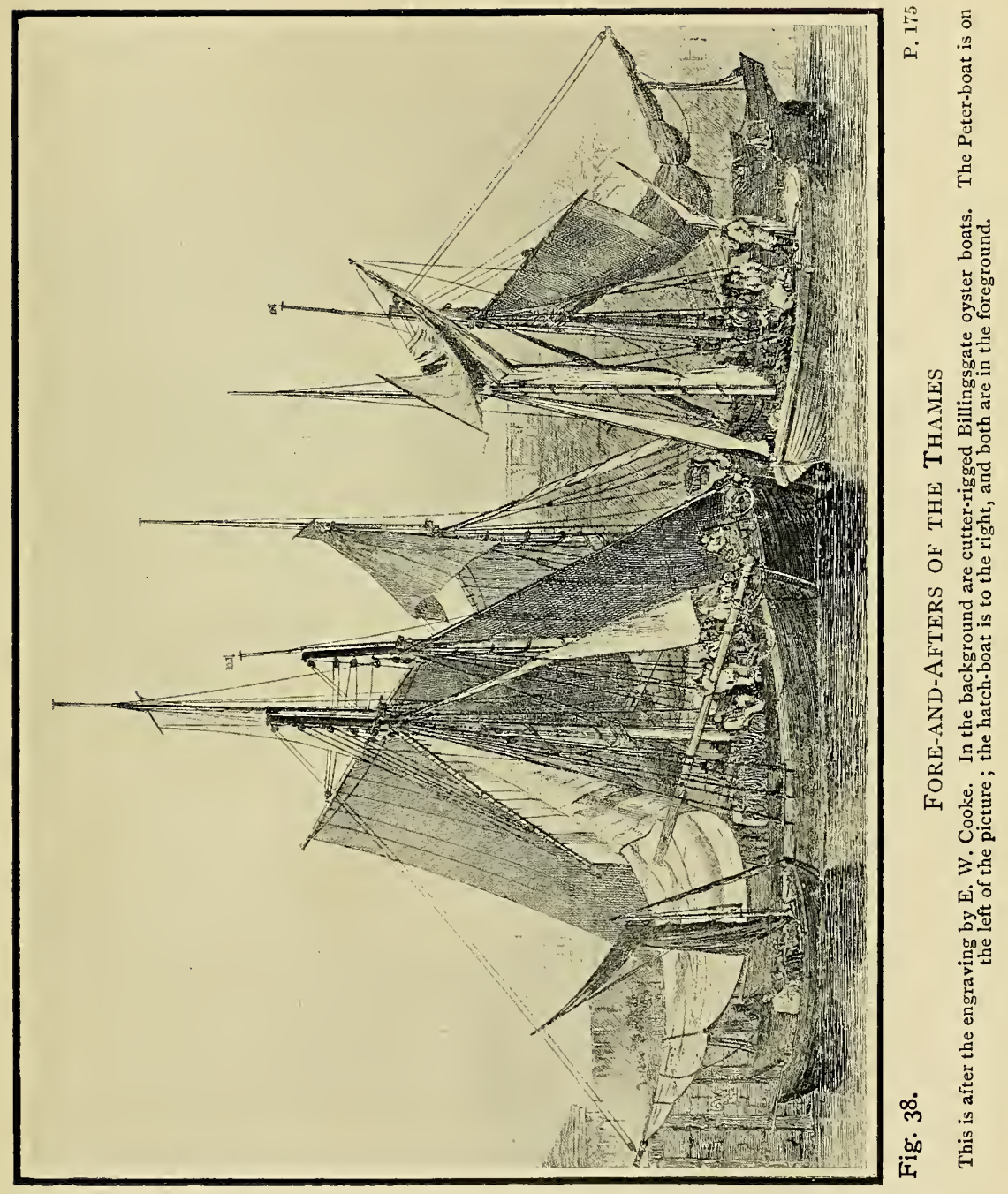



It was in these later developed types of the hatchboat that the topmast was added as seen. The boom was not employed-at least I have never seen any representation of that-but the mizzen still kept its sprit. To-day, as we shall see later on, the Bawley has kept some of the essential features of this mainsail, although with the addition of the brailing-lines. It was because the Thames watermen required something a little larger and capable of having the shelter which a small cabin afforded that the hatch-boat attained such popularity. The topmast, as shown, was rather in the nature of an addition to the original rig of this boat. The connection of Billingsgate with the different types of vessels it has witnessed throughout the centuries would make an interesting essay, and those oyster craft that we have just examined had their counterpart in the early seventeenth century. Even Manwayring, who lived in Elizabeth's reign, speaks of the ketch as "a small boate such as uses to come to Belingsgate with mackrell, oisters, \&c." To-day, if the steam fish-carrier may seem to have taken away some of the former romance from this quayside, at any rate the historic custom of the Dutch eel-carrying schuyts is still kept up, as any one who has ever looked over the side of London Bridge is aware.

The pleasure craft and the fishing vessels, the smuggler and the King's Revenue vessels have reacted on each other in regard to development to an extraordinary degree. Sometimes it has been the one which has led, sometimes the other, according to whether the yacht, the smuggler, the Revenue craft, or the fisherman has at a particular period been the most developed.

At the beginning of the nineteenth century it used to happen that, when there were not enough suitable craft to be obtained, the yachtsman purchased some vessel that had earned both fame and notoriety in the 
smuggling industry : fame for her speed in getting away from the King's cutters, notoriety for her nefarious occupation. So also there have been times when the fisherman has at last grown discontented, in spite of himself, with the bluff, old lines, the old-fashioned gear, the badly cut sails, and been willing to learn from the more scientific appliances on board the yacht. The hulls, for instance, the sails and other details of the Poole fishing-cutters to-day are far more akin to yachts than to the vessels which one might associate with the work of fishing. So also in the olden days, a cutter might be built for the purpose of preventing contraband traffic and end her days a yacht. And there are plenty of so-called yachts to-day which were designed, built for, and for years employed in fishing or pilot work. Some of the novelties which have long since found their way into yachts, which were despised and ridiculed at one time by the old fishermen who "didn't hold" with such ideas (as, for instance, improved methods of reefing), have been accepted by the old school, and would not be given up without regret. And so in the most natural manner the different types of the fore-and-aft rig have acted and reacted the one on the other for the mutual improvement of the rig as a whole.

If we except the fleet of quite pleasure craft which were accustomed to sail, and sometimes race, between Blackfriars Bridge and Putney, it may be asserted that whatever yachting was indulged in about this time belonged to the wealthy alone. Those noblemen, for instance, who had their places along, or not far from, the coast, found their yachts highly useful for crossing to the Continent, and more convenient than the packet-boat. The Duke of Richmond, for instance, is reported to have had a large yacht launched at Itchen on May 17, 1783, and on July 5 to have "set sail in his new yacht for France" accompanied by members of his family. And it was rather as a means of transport that down to the beginning of the nineteenth century these big 


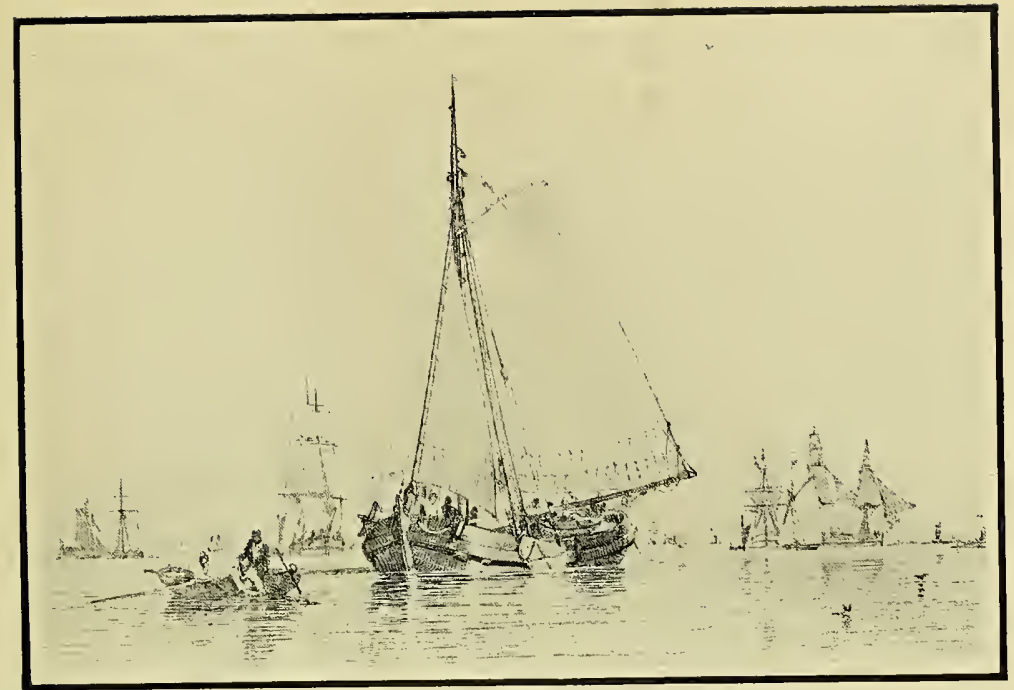

Fig. 39.

DUTCH SCHUYT

P. 175

After the engraving by E. W. Cooke. The influence of the Dutch hull and rig over English craft persisted in a most marked manner till nearly the middle of the nineteenth century.

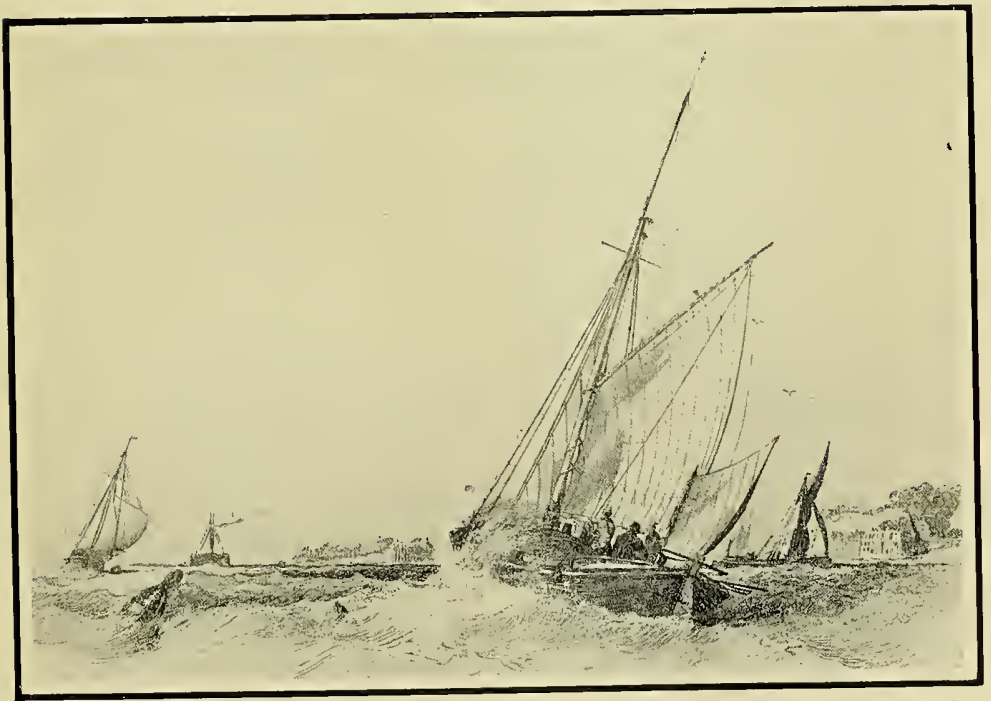

Fig. 40.

HATCH-BOAT in GRAVESEND REACH

P. 176

This is after the engraving by $\mathrm{E}$. W. Cooke. In the early part ot the nineteenth century this was the typical craft of the Thames Estuary fishermen. 

yachts were employed, instead of being either racing or pleasure craft. It is also on record that a new yacht belonging to Lord Ferrers, in turning to windward from the Downs to Blackwall, beat everything else. That was in 1773 , but the same year she was in turn beaten by two "shallops" in a race from Dover to the French coast and back.

We may now pass on to examine more closely the character of the cutters and sloops that were prevalent at this time; and first, with regard to that exceedingly interesting creature the Revenue cruiser. As her mission in life was to get along with the utmost despatch so as to overtake the wily smuggler, it was of prime importance that she should be given the fastest hull that the contemporary designer could give her, together with an exceptionally large sail-area. First of all, then, consider the noble peaceful English cutter as she was at the time of about 1810 to 1830 . Every one is familiar with 'Turner's celebrated picture in the National Gallery entitled " Calais Pier," which shows the English packet coming into the harbour and a French fisherman clearing out. It is blowing a strong breeze from the westward, with the nasty sea which is familiar to those who have sailed along this coast, where a smart wind against tide makes a sea sufficiently unpleasant for moderate-sized sailing craft. The war with France had prevented Englishmen for many years from travelling abroad, but in the year 1802 Turner took advantage of the Peace of Amiens and crossed to France. It was while entering Calais harbour that he had at hand a subject for his picture that was to be exhibited at the next year's Academy, and was entitled as mentioned. 'The English packet and the French fisherman are a study in contrasts, and the picture shows that in this year 1802 the former had begun to be less beamy, more distinctive, more original, while the French vessel was yet as tubby and big-bellied as the old-fashioned Dutch craft; in short, the English craft is a long way the 
superior. For, ever since about the middle of the eighteenth century, our own countrymen had begun to improve on their Dutch inheritance, and in no respect more than in the development of the cutter. It is to the English that this development was especially due.

In a French nautical work published in Paris in the year 1783, the cutter is referred to as a craft whose construction comes to the French from the English. After remarking that in respect of its rigging and its sail-plan the cutter resembles a sloop or "bateau d'Amérique," except that the cutter usually has her mast inclined more aft and has also a longer mast and greater sailarea, this authority goes on to say that the cutter also sets a kind of bonnet which is bent to the foot of the mainsail, and adds that the cutter differs from the sloop in that she has little freeboard, but that she draws more water so as to carry sail the better.

"'The cutters," continues this explanation, "have many uses, especially being employed by the smugglers of the English Channel, for the reason that these craft being very fine sailers, and being able to carry a good deal of sail, they can easily escape from the guardships. The English Government for the same reason maintain a good many of these craft so as to stop these smugglers; they are manned by a crew of thirty, and carry from six to eight cannon as well as some swivel-guns. Recently some have been constructed for the Department of Brest."

Thus we see that it was England that originated this special type of vessel. Falconer in his authoritative dictionary defines the cutter as "a small vessel commonly navigated in the Channel of England, furnished with one mast and a straight-running bowsprit that can be run in on the deck occasionally; except which, and the largeness of the sails, they are rigged much like sloops. Many of these vessels are used on an illicit trade, and others employed by the Government to seize them, the 
latter of which are either under the direction of the Admiralty or Custom-house."

In the illustration (Fig. 41) will be seen a sketch of a Revenue-cutter belonging to about 1810 to 1830 . This is from a model in the South Kensington Museum. She carries twelve guns - six a side plus two swivel-guns - viz. two at the bow and two at the stern. Her tonnage would work at about 130, her length $85 \mathrm{ft}$., beam $24 \mathrm{ft}$., depth $13 \cdot 3 \mathrm{ft}$., and draught $11 \mathrm{ft}$. As to her rigging, notice that the square-sail yard has been lowered nearly to the deck. Her bowsprit, as was then the fashion, is very long, and she has five good shrouds a side, with rope-ladders for going aloft to set the square-sail. Above the lower course she would set a much-goared topsail, and a square topsail over that. The square ports are taken from the fashion in the contemporary "wooden walls." 'The mast and gaff are very long, and the topmast seems excessive; but these vessels were made to carry sail and to be hard driven. Notice also that the yard is guyed forward to the end of the bowsprit. The topping-lift was double in the manner we explained a few paragraphs back. The hull was varnished timber-colour, with a black rubbing-strake running around. As to whether the Revenue-cutter broke the rule existing among ships by having her topmast abaft instead of forward of the mast is a point of dispute. In this model the topmast is shown forward, but Leslie, in his Old Sea Wings, states definitely that it was stepped abaft.

Now, the Revenue-cutter, the English packets, and the despatch-boats of Nelson's time were very similar to this model in general respects. They were clinkerbuilt up to the deck, and their stern projected aft for a little way in the nature of a platform, as will be seen, and thus was the forerunner, as we explained above, of the modern counter stern. There were catheads on either bow, and the ship rode to hempen cables. The lines are certainly most pleasing. The bow was 


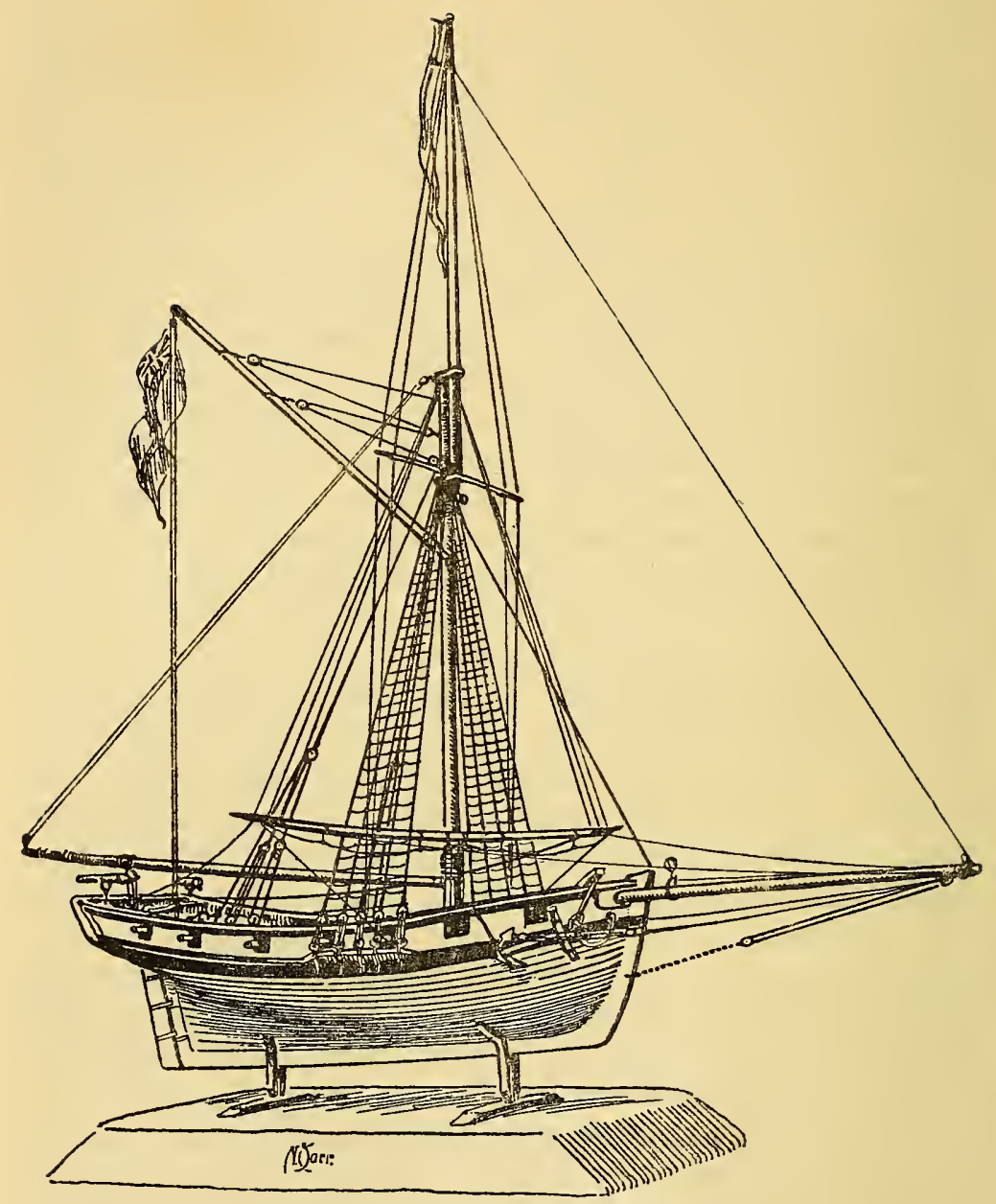

Fig. 41.-English Revenue-CutTer.

From a model in the South Kensington Museum. Her tonnage was 130, and she belongs to the period of about 1810-1830. She was employed against smugglers and was a very fine sailer, being manned by a crew of thirty. 
a great improvement on the old bluff Dutch design, and the stern is very fine. It is especially noticeable that aft is the greatest draught of water, and Leslie points out that this has always been retained as a feature in our English cutters.

From this let us turn to look at another equally interesting model (Fig. 42) which was sketched in the Rijks Museum, Amsterdam. This shows a Dutch Revenue-cutter-oorlogskotter is the Dutch wordDe Vlieg. ("The Fly"), on account, no doubt, of her great speed. Here, in the matter of influence, is England returning thanks to Holland; for, as may immediately be seen, the Dutch have copied the English craft in almost every possible respect. There is the very closest similarity in respect of hulls, though this Dutchman carries eight guns a side, and the sockets in the stern are there all ready for the swivelguns to be placed. The lines are so nearly identical with the English cutter that we need not discuss them further.

But the sail-plan is deserving of every consideration. Notice the bowlines on both topsail and topgallant which lead forward to the end of the bowsprit; also the Dutch way in which the head of the jib ends in a tiny yard. The lower course is shaped in the curious manner that we have already demonstrated, and its yard is of course necessarily short. Above this she sets a much-goared topsail, which is thus made to clear the forestay and both jib and fore halyards, and above the topsail she carries also a topgallant. But as if this canvas were not enough, she carries stunsails, the lower booms being run out along the lower yard, while, above, quite short yards and blocks suffice. In addition even to these the mainsail also sets a ring-tail abaft the leach of the mainsail. Of course the square-sails, the stunsails, and the ring-tail were all copied from the prevailing full-rigged ships. But with all this cloud of canvas and a smart breeze, the smuggler must have 


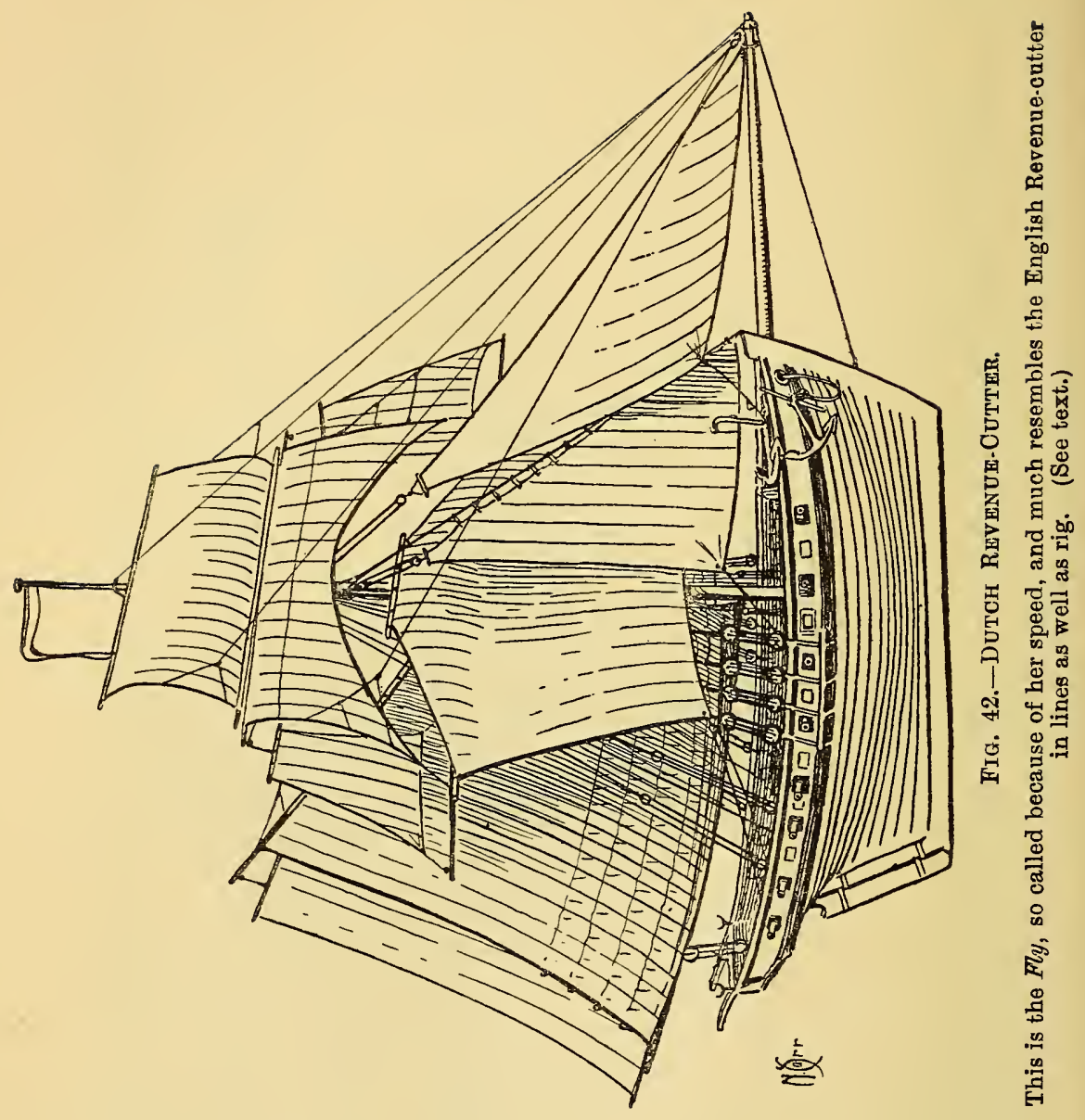


been a mighty smart craft to be able to elude this Government cruiser. As she came foaming along, with all this immense sail-area aloft, she would have presented a magnificent sight for any one possessed of imagination and emotion. Her lines are such that she would undoubtedly be fast; her rigging and runners and backstays are all very strong, and of necessity so. Skilfully handled, with a sufficient and ample crew, the Fly under way must have shown herself capable of doing some wonderful passages and chases. She has set canvas in almost every inch of space, and additional to what is here seen there would be a jib topsail as well. Below the small yard to which the lower course is bent there is another yard. This was known on full-rigged ships as the barren-yard, and was used on the cutters for the purpose of sheeting down the topsail, and in the present instance for running out the stunsail booms. The two davits at the stern are copied from the Scandinavian custom, and are used for carrying the ship's boat. On a later page we shall deal with the famous Captain Schank's invention of the sliding keel, but here, in passing, we may add that this invention was tried on a Revenue-cutter named the Trial.

We have already referred to Chapman's well-known work on naval architecture, which, together with Stalkartt's Naval Architecture, formed two of the greatest authorities on the subject of the eighteenth century. Marmaduke Stalkartt published his book in London in 1781. It was a time when, thanks now not to the Dutch but the scientific French, naval design and construction were being raised to a higher position than had ever obtained before. England had good reason to watch this improvement with great interest. The war-cloud hung so heavily and so threateningly that she had need to keep her sailing warships up to the highest standard, and so all the learned theories and investigations of the French on such subjects as 
resistance of vessels passing through the water, and so on, were examined with great care by our countrymen, and, where they seemed feasible, embodied in English designs. The books printed in England about this time on naval architecture are full of theories and experimental ideas, which, however, we need not stop to look into. But the nett result was that, while in very many cases, especially among the obstinate and old-fashioned, the cutters and sloops still remained more like barrels than scientifically designed ships, yet, as evidenced in the Revenue-cutters and the best yachts, no less than in the smugglers, there had set in since the mid-eighteenth century a decided improvement both in design and build, though it was not till the middle of the nineteenth century that the foreand-after really began to make rapid headway towards the attainment of the ideal design.

Two designs have been here reproduced from Stalkartt, as illustrating the highest point reached in the year 1781 by our designers of this type of vessel. The first (Fig. 43) shows the lines of a cutter, whose length, measured from the foreside of the stem at the upper edge of the wales to the afterpart of the sternpost at the upper edge of the rabbet of the keel, was $60 \mathrm{ft}$. Her breadth was $25 \mathrm{ft}$. 4 in., the length of keel (for tonnage measurement) being $44 \mathrm{ft}$. $9 \frac{5}{8}$ in. Her burthen worked out at $1528 \frac{8}{9}$ tons. With the addition of these plans to the two models of the Revenue-cutters previously alluded to, it is possible to acquire a good working idea as to the degree of advancement in the cutter at the end of the eighteenth and the beginning of the nineteenth centuries.

The second illustration (Fig. 44) from Stalkartt shows a design for a yacht, and she is only slightly smaller. The length from the foreside of the stem to the afterpart of the sternpost at the height of the wing transom measures $75 \mathrm{ft}$. 5 in. The length of the 


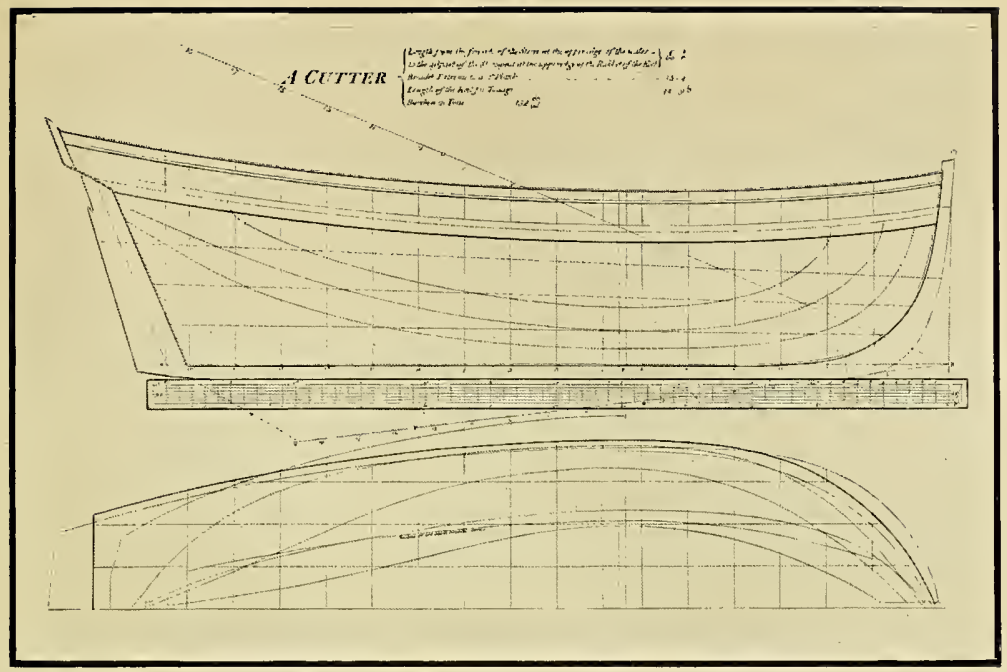

Fig. 43.

Lines OF A CUTTER OF THE YEAR I78I

This shows the design by Stalkartt, the famous eighteenth-century naval architect, for a cutter of about 152 tons.

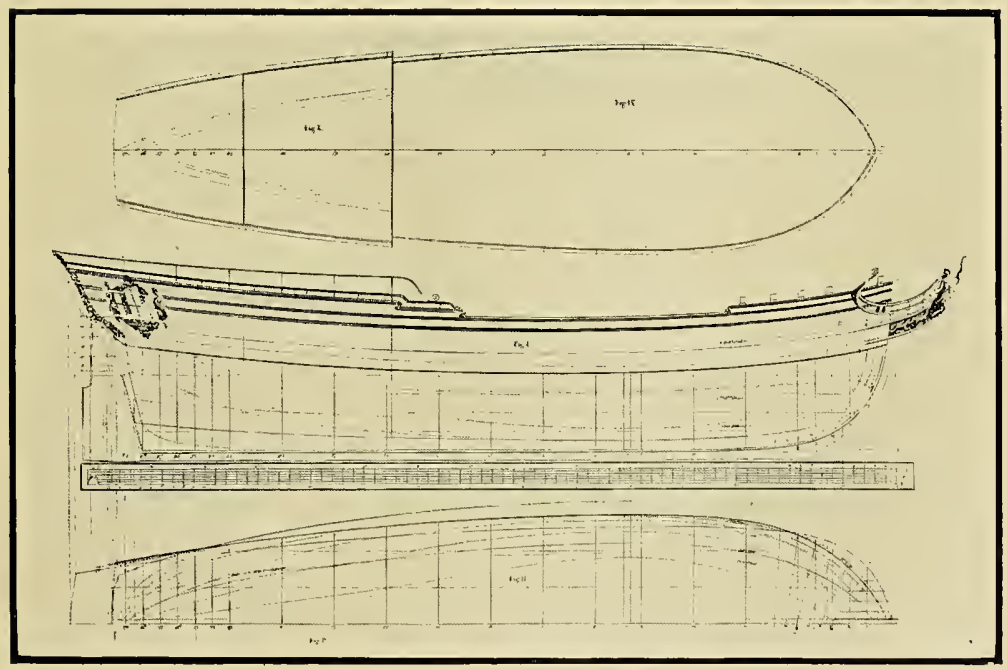

Fig. 44.

DESIGN FOR A YACHT

P. 186

This also is by Stalkartt, the tonnage being about I4r. Notice the influence of the contemporary full-rigged ship on the bow and stern. 

keel for tonnage measurement is $59 \mathrm{ft} .4_{4}^{3}$ in. Her extreme breadth is $21 \mathrm{ft}$. 2 in., and the moulded breadth $20 \mathrm{ft}$. 10 in. Her burthen worked out at $141 \frac{51}{94}$ tons. Stalkartt describes her as having been "designed to be an expeditious sailer, without any other stowage than is actually necessary for accommodation; but which is to be, at the same time, what is termed a stiff sea boat, able to carry sail sufficient to speed her to some place of safety, and to keep her off from a lee-shore. These qualities in a yacht when happily united render her a most useful as well as agreeable appendage to the more noble structures of naval architecture." In short, what he aimed at was, in the words which have been recently employed to describe the modern racing cruiser, "habitability with speed." To-day there is a complete separation between yacht and ship designing, for the obvious reason that the two types are entirely different and need special methods. Nevertheless the yacht is neither despised nor unworthy. It is therefore amusing to note the disposition of the eighteenth century towards these craft as evidenced by Stalkartt as being " a most useful as well as agreeable appendage to the more noble structures," \&c. It was analogous to the pomposity of a period when might was right and the mightiest was the best in matters not necessarily connected with sport or naval architecture.

We gave Falconer's definition just now of a cutter. Let us now add that he speaks of the sloop as "a small vessel furnished with one mast, the mainsail of which is attached to a gaff above, to the mast on its foremost edge, and to a boom below, by which it is occasionally shifted to either quarter. It differs from a cutter by having a fixed steering [sic] bowsprit and a jib-stay, nor are the sails generally so large in proportion to the size of the vessel." "The word "steering" is doubtless a misprint for "steeving," for 
in the sloops of this period it is characteristic that the bowsprit was steeved at a great angle, something after the manner of the early Dutch yachts, which, in turn, had copied the fashion from the older fullrigged ships.

Moore, in his Midshipman's or British Mariner's Vocabulary, written in the year 1801, speaks of Falconer's Marine Dictionary as the only book that has hitherto appeared in the English language as a guide to seamen on which any dependence can be placed. Moore, who professes that he has consulted the best French marine authors of the time, defines the cutter briefly as "a vessel furnished with one mast and a straight running bowsprit, or which can be run in on the deck occasionally; except which, and the largeness of the sails, they are rigged much like sloops." The sloop he defines in almost identically the same language as Falconer, except that he uses the word "steeving" instead of the misprinted "steering" in connection with the bowsprit. "The sloops of war, which formed units in the Royal Navy of this time, were sometimes rigged as cutters, sometimes as schooners, and occasionally even as ships and brigs. They carried from 10 to 18 guns, and were commanded "by officers in a middle rank, between a lieutenant and a post-captain, and stiled masters and commanders." In the accompanying illustration (Fig. 45) has been reproduced a model of a schooner-rigged sloop.

Moore, in his work from which we have quoted, does not so much as mention the word yacht, and this, taken in conjunction with Stalkartt's attitude, well illustrates the insignificant place which the yacht occupied at that time in the mind of the seaman; for it existed in such few numbers that it was not worth reckoning. Falconer, the first edition of whose work was published in 1770 , certainly does allude to this type of craft, but his definition of her "as a vessel of State, usually employed to convey princes, 
ambassadors, or other great personages from one kingdom to another" shows that this species of craft must at that time have necessarily been few in number.

In one of the later editions of this work we are able to gain an accurate idea as to what sort of a vessel the yacht of about 1815 was. We find that she was rigged with a jib, staysail, mainsail, and square topsail set on a yard, but with a barren-yard below. The hull is in many ways influenced by the frigate or corvette type of warship then in service. It had both figurehead and beak, whilst the raised poop shows how closely connected was this vessel with the galleons of 'Tudor times. Along the hull was a line of port-holes, consisting of as many as six each side. The bowsprit was as long as the boom, and below the former she set a square water-sail. At the end of the bowsprit she flew the Union Jack, as was then the custom. The influence of the old bomb-ketch is exceedingly marked in the hull of this yacht, but it belongs rather to the royal type of yacht in use during the eighteenth century than to the improved private yachts seen on the south coast in the second decade of the nineteenth.

The Dutch sloepe, then, had as descendants firstly the British cutters and sloops. Then, owing to the success which the cutter had found in England, France copied this type, and Holland too. At the same time, in America, the sloop had also begun to thrive, and also owing to Holland. For we are aware that the Dutch in the seventeenth century were great colonisers, and that the men who had been bred and born always with some waterway in their close vicinity in that stretch of land between the North Sea and the Zuyder Zee, after having made their new home in America and called it New Netherlands, would most naturally, and actually did, take to the water as ducks which have been transported from one lagoon to another. As they had built and sailed sloops all their lives in old Holland, so they 
began to do in the New Netherlands, and thus the Dutch example and invention in the matter of the fore-and-aft rig were carried not merely to England, and through the latter to France, but to North America as well. And to this day the Americans speak of the sloop when we should use the word cutter.

From a contemporary drawing in the British Museum the measurements of a sloop belonging to the year 1796 are given as: length on keel, $33 \mathrm{ft}$. $4 \frac{1}{4} \mathrm{in.} ;$ extreme beam, $16 \mathrm{ft}$. 6 in., so that they were remarkably beamy craft. But as belonging to the generic rig of cutter there were also other small craft with special designations. 'The hoy, for instance, according to Moore, was a small vessel rigged usually as a sloop, and employed in carrying passengers and goods from one place to another, particularly on the sea-coast, where ordinary lighters cannot be managed with safety or convenience. 'The smack, according to Falconer, was a small vessel commonly rigged as a cutter, and used in the coasting or fishing trade, or as a tender in the king's service. 'That, of course, refers to the smacks belonging to the late eighteenth and the early part of the nineteenth century. But the original type of Dutch semaque we have dealt with in a previous chapter.

As to what these early nineteenth-century smacks were like we may see from the accompanying picture (Fig. 46), which shows some Scotch smacks. In them the old Dutch bluff lines have been retained, and the bows in particular are instantly noticeable. 'The anchors are of course smaller, but of a similar pattern to those which Nelson's Victory carried. Even the yard for the square-sail is still kept, and the rope ladders for climbing aloft. 'The Dutch-like weather-vane is also there. 'These vessels are trading smacks. But in the next illustration, also after Cooke (Fig. 47), we have an excellent presentation of the sail-plan of a fishing smack. The first point which immediately strikes one is the amazingly bad cut of the canvas. It is to our 


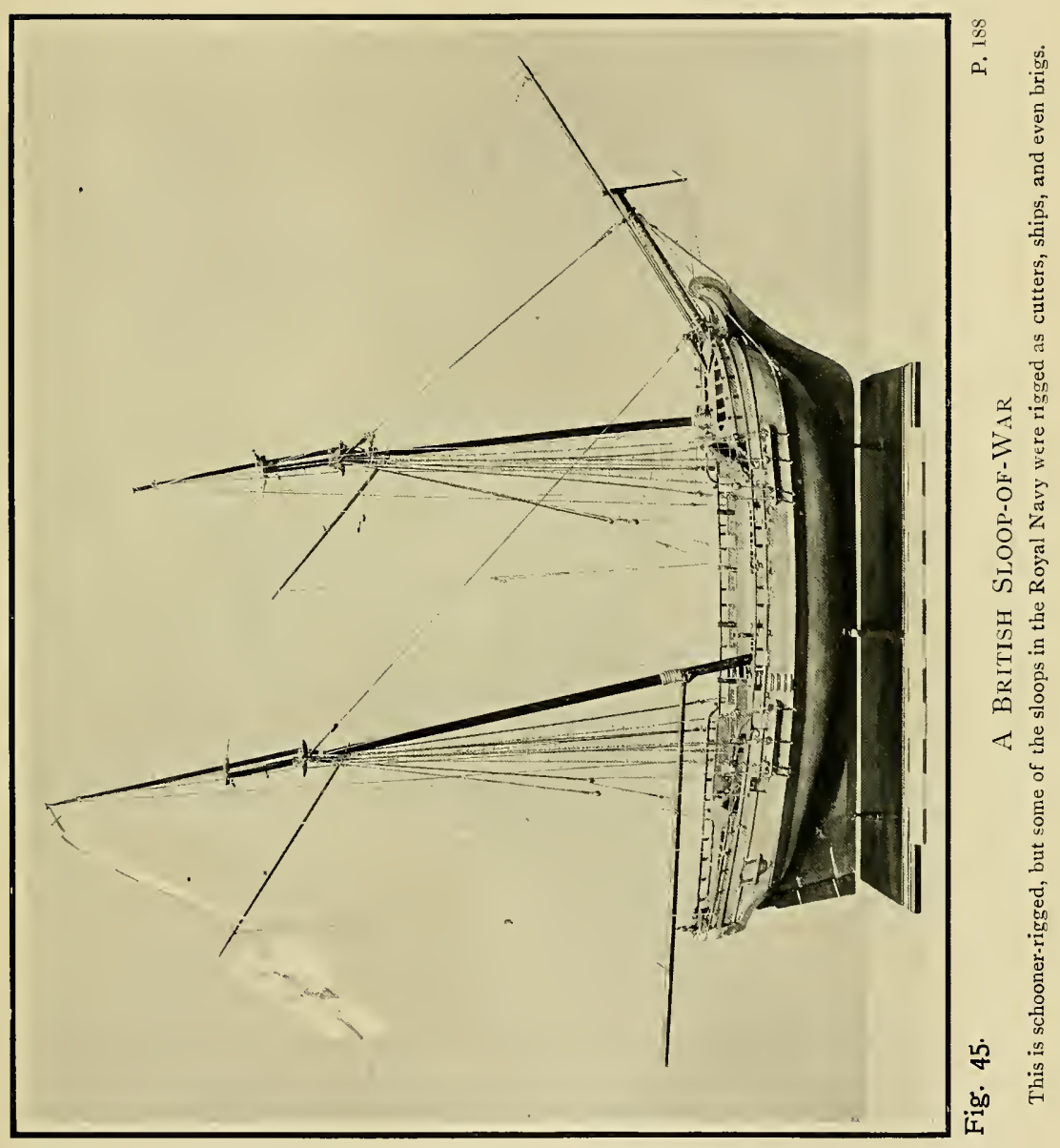



modern eyes slovenly and unnecessarily baggy, but this was the custom till after the mid-nineteenth century. The length of the boom and the bowsprit is enormous, and the whole effect is not one to rouse enthusiasm. The topsail, however, bad as it is, must interest us ; for with a part of it projecting forward of the mast something like a lugsail, and the angle which the head makes with the topmast, we see this sail in its state of transition. The square topsail of the full-rigged ship and the Revenue-cutter is vanishing, but not yet has come that perfect shape which we are accustomed to use on our cutters to-day. The only instance where nowadays there still clings tenaciously a resemblance to the transitional topsail is in the case of the 'Thames barge.

Cooke, of course, knew his business far too well to fall into any inaccuracy in regard to a vessel's rig; but lest the reader should imagine that in this particular example the sails seen are of an unusually bad cut and have not been sweated up to their full hoist, let us be allowed to refer him to other illustrations of about this date that depict this kind of craft. There are plenty of instances to be noticed in the prints and paintings of the time. It was just as bad on one part of the coast as any other, and I have examined a very considerable number of contemporary illustrations of the subject.

If any reader should happen to be cruising on the south coast of England and find himself in the vicinity of Chichester harbour he may find it interesting to run up to Bosham, in whose churchyard, near to the gate, he will find on a tombstone an inscription and illustration belonging to this period that are well worth examining. At the top of the stone is carved, somewhat crudely, but with a good deal of truth, a sloop belonging to the middle of the eighteenth century, or almost exactly a hundred years after that day when the first yacht Mary came over from Holland. This sloop has jib and staysail as well as mainsail, with the Jack 
flying on the jack-staff forward, and the legend reads thus :-

\section{"IN Memory of}

Thomas, son of Richard and Ann Barrow, master of the ship Two Brothers,

who by the breaking of the horse fell into the

sea and was drowned,

October the 13th, 1759, aged 23 years."

This is the only instance I know of which shows a fore-and-aft sculpture of that period. The "breaking of the horse" has nothing to do with a refractory steed, but, as the quaint illustration depicts, the bobstay has carried away, and the body of the unfortunate mariner is seen tumbling headlong into the water, a conventional shark or fish eagerly awaiting him at the stern. In the Elizabethan times the word "hawse" signified the bows of the ship; hence the nautical expression "athwart hawse." But two hundred years later, whilst the word hawse was retained to speak of the ship's cables, yet "horse" signified a rope, usually that which reached from the middle of a yard to both its extremities, and depended some two or three feet from that yard for the sailors to tread, while aloft setting the square-sail on a cutter. But it was also employed to describe a thick rope which was used for hoisting a yard or extending a sail thereon. The yard of the square-sail, for example, was attached to the horse by means of a traveller which slid up and down. But in the sculpture alluded to it is clear that the use of the word was also applied to the bobstay, which is seen to have broken, and so in some way caused the decease of the young master of the Troo Brothers.

We shall see presently how it came about that the yacht was to influence the Government vessel, but before so doing we may run briefly through the early period of the nineteenth century, so that we may have clearly in our mind the different processes through 


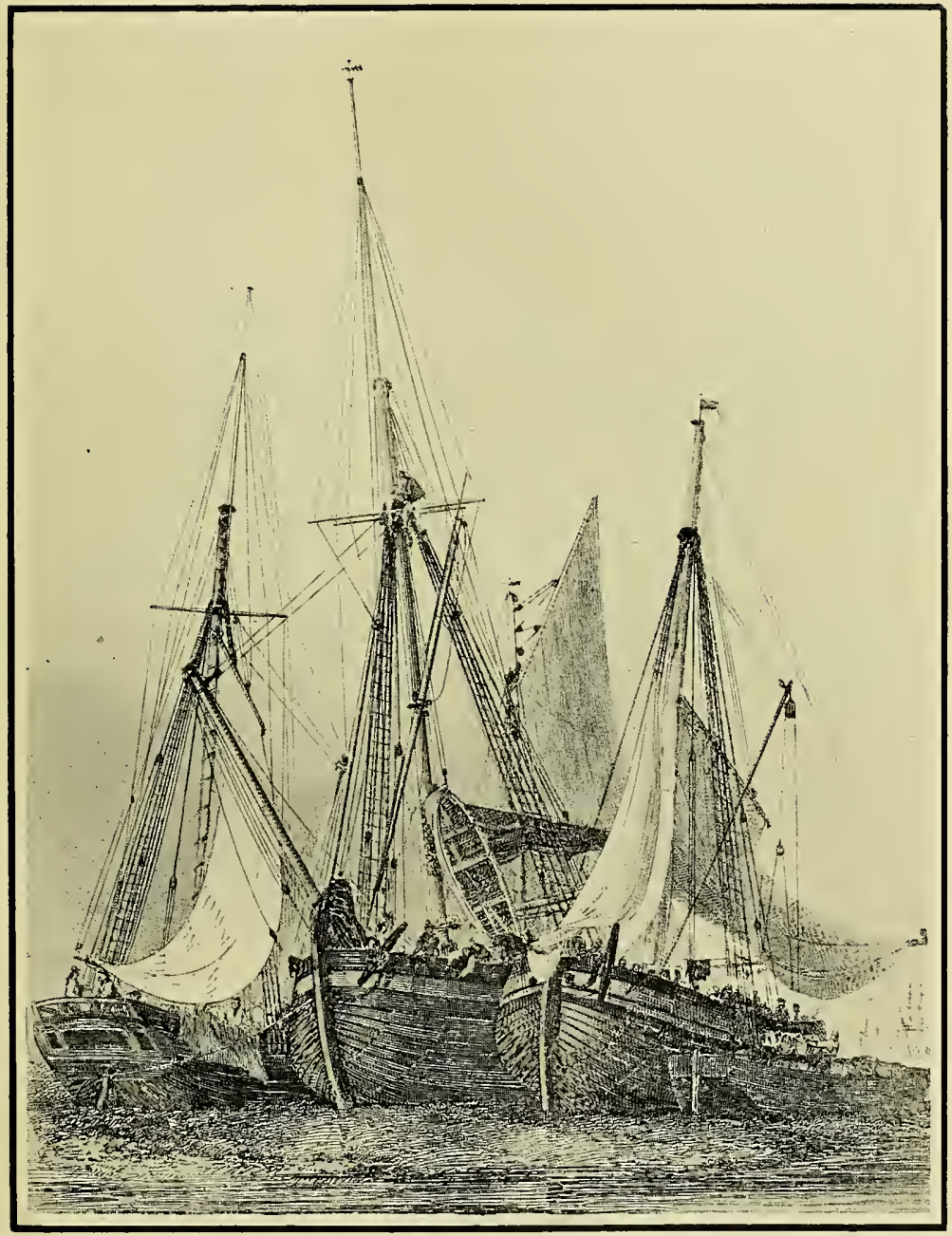

Fig. 46.

P. 190

Scotch Trading Smack.

After the engraving by E. W. Cooke. These craft show how persistently the old Dutch bluff lines continued into the nineteenth century. 

which the fore-and-aft yacht had to pass. The reader is already in possession of a good many facts, and has in his mind, thanks to the illustrations which have been put before him, a working knowledge of many of the fore-and-afters as they are descended from the time of Charles to about the time of the battle of Trafalgar. In order to make our meaning clear, and to be allowed to fill in details at once, it has been necessary to digress more than once. What we now propose to do is not so much to go into minute details of rigging and sail, which we have already attempted, as to give cohesion to the progress of the cutter and sloop, and to carry on that evolution from the days of ignorance to the time when experiment and knowledge were to bring about a complete revolution in the design and equipment of the fore-and-after.

In order to effect any radical series of improvements in ships it is essential that there should be sufficient financial encouragement. The shipbuilding industry is carried along on business lines, and must pay its way. It is true that in this progressive twentieth century big shipbuilding firms can afford to employ a part of their staff in experimental work, and to sink part of their capital in making models and tanks to ascertain certain laws and theories. But matters were not so prosperous at the beginning of the nineteenth century. The long wars had been a serious financial loss to the country, and there was nothing like that amount of wealth and prosperity in our land which were to follow from increased trade caused by better facilities of transportation, such as have been brought about by the steamship and the railway.

Therefore, the men whose work it was to build ships either had to follow the acknowledged types which would readily be purchased, if not by the Government, at any rate by the fishermen, the pilot, or the smuggler. To depart largely from the models already recognised was a risky matter. True, the encouragement during 


\section{INFLUENCE OF HOLLAND ON}

the first two decades of the nineteenth century given by the Government to build the fastest seaworthy craft to deal with the contraband traffic was more than helpful to the shipbuilder; but it was the wealthy gentleman of leisure who could afford to spend lavishly on the building of a pleasure craft that came as a great incentive force to the shipman. At first he wanted a craft something like himself-stately, dignified, impressive. But after a while, when racing became a fashion, and wagers were frequently made, and handsome cups and prizes offered, his yacht was to be something better than a miniature floating palace.

One owner this summer might bring out a yacht that would sweep the board, and continue to be talked about for the whole of the winter. The following year would see other owners in the field with something better-superior lines, increased tonnage, and a much larger sail-area. These new craft, in their turn, would wrest the laurels from the yacht of last year; and so the competition went on. Now all this was very good for the sport; for the development of the cutter and sloop gave the highest encouragement to the builder, and generally helped forward the right kind of enthusiasm. The yacht was to become something more than a nonentity: she was destined actually to influence some of the naval craft.

We have seen that from its earliest days yachting in Holland was connected with the navy by the adoption of naval tactics, sailing instructions, and signals. We have seen the same custom continued in the first yacht club in Cork; and we have remarked that even on the Thames the commodore of the Cumberland fleet commanded his ships like a naval commander-inchief. So it was to be on the south coast. In the year 1812 there were so many yachts and yachtsmen that fifty of the latter determined to establish at Cowes an institution which was called the Yacht Club. Eight years later the name was changed to the Royal Yacht 
Club. There was, as yet, no regular regatta held. That was to come several years later; but these comfortable and slow craft used annually to give a wonderfully impressive demonstration or naval review after the manner of the Dutch and the Irish. Under the command of the commodore the fleet would collect and process round the Brambles buoys, then cruise to the westward, down the Solent as far as Hurst Castle, and so back to Cowes, where thousands of awed spectators would look on and applaud this pompous spectacle.

The yachts had to keep their station after the manner of ships-of-the-line, and, like the other associations, signalling was indulged in. During the year 1816 a new code of signals had come into the navy, thanks to Sir Home Popham, and it was that new code which this fleet of yachts loved to practice. Every year, then, the great event off Cowes was this pageant of yachts parading after the naval manner. What an owner wanted, then, was not a fast ship, but one that would look imposing as she took her place in that annual procession. And if we are to judge by the yachts which attended the royal naval reviews, as depicted in contemporary paintings, we can surmise that the owners got what they had ordered from the shipbuilders. There was, in addition to this, a certain amount of ocean cruising to be done northwards to Russia and the Baltic, or southwards to the Mediterranean. And the late Mr. Montague Guest, in his history of the Royal Yacht Squadron, which was to evolve from this Royal Yacht Club, related that often an owner would take his yacht down to Lisbon and load up with wine to replenish his English cellars.

But after a while it began to be realised that this water pageant was but a limited form of sport, and racing began. So the element of speed entered into the recreation, and the "impressive" type of yachts became obsolete, and, instead, something that would hurry through the water was wanted. Where could they be obtained? Obviously the only men to go to 
were those who had been accustomed to build the fast Revenue-cutters and smuggling craft; or, failing these, some lesser men who had made successes of their pilot and fishing craft. It happened sometimes that smuggler craft and Revenue-cutters were being built simultaneously in the same yard, side by side. If after launching it was found that the ship which had been intended for the contraband industry proved herself to be the faster, then the Government was not unwilling to pay a handsome premium and take that instead of the other vessel.

To begin with, then, the yachtsman who wanted a fast craft had either to purchase an ex-smuggler or Revenue craft, or he had to have a ship built on those lines. It is thus that in some of the racing yachts of the early 'twenties we find the water-sail, stunsails, and ring-tails carried just like a Revenue-cutter. The rating, such as it was, was based on the tonnage, which in turn was estimated from the supposed cargo capacity that the yacht possessed. And between the yacht, the packet-boat, the Revenue-cutter, and the pilot-boat there was little externally to choose. The accompanying illustration (Fig. 48), which belongs to the year 1823, will show the nature of these craft. It is entitled "Pier at Little Hampton," and forms one of the beautiful pictures engraved by William Daniell and collected in a volume entitled $\boldsymbol{A}$ Voyage Round Great Britain. These vessels were extraordinarily strong and heavy. Full in the bows they fined away aft, as we saw in the two models just now. But gradually, as a result of the competitive sport of yachting, it began to be realised that there was no point in making these yachts of such heavy materials. Their timbers and planking could be made lighter without unduly sacrificing strength, but at the same time giving a welcome lightness to the vessel. They were therefore improved in this direction.

The cutter rig was retained for the reason that it 


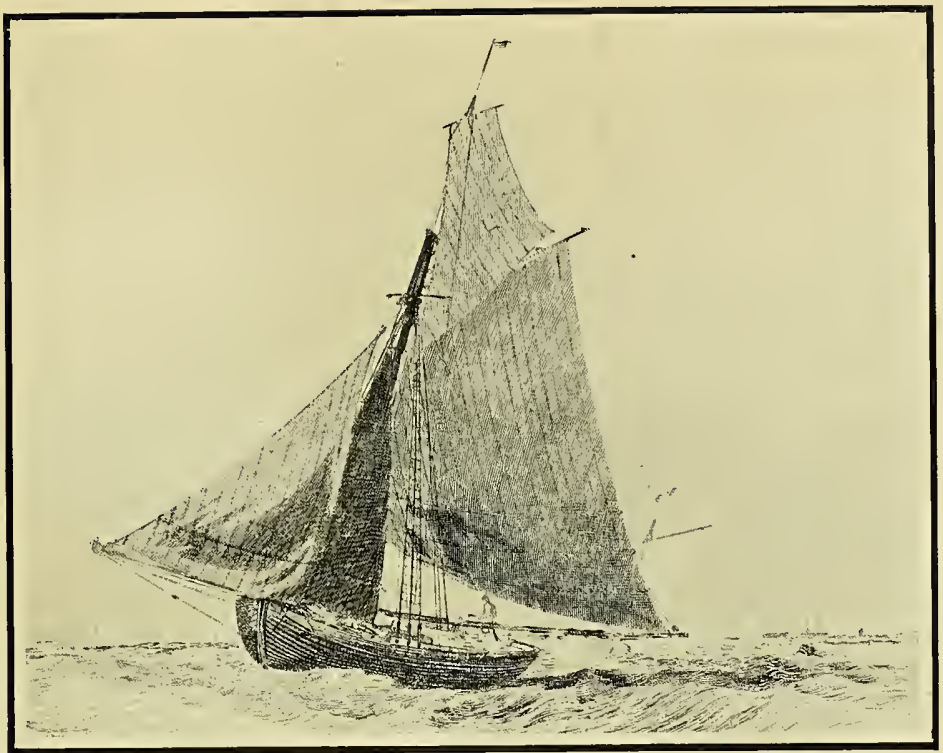

Fig. 47 .

Fishing SMACK

P. 190

Of the early nineteenth century. This shows how bad was the cut of the sails in those days, which are in nowise here exaggerated. (After the engraving by E. W. Cooke.)

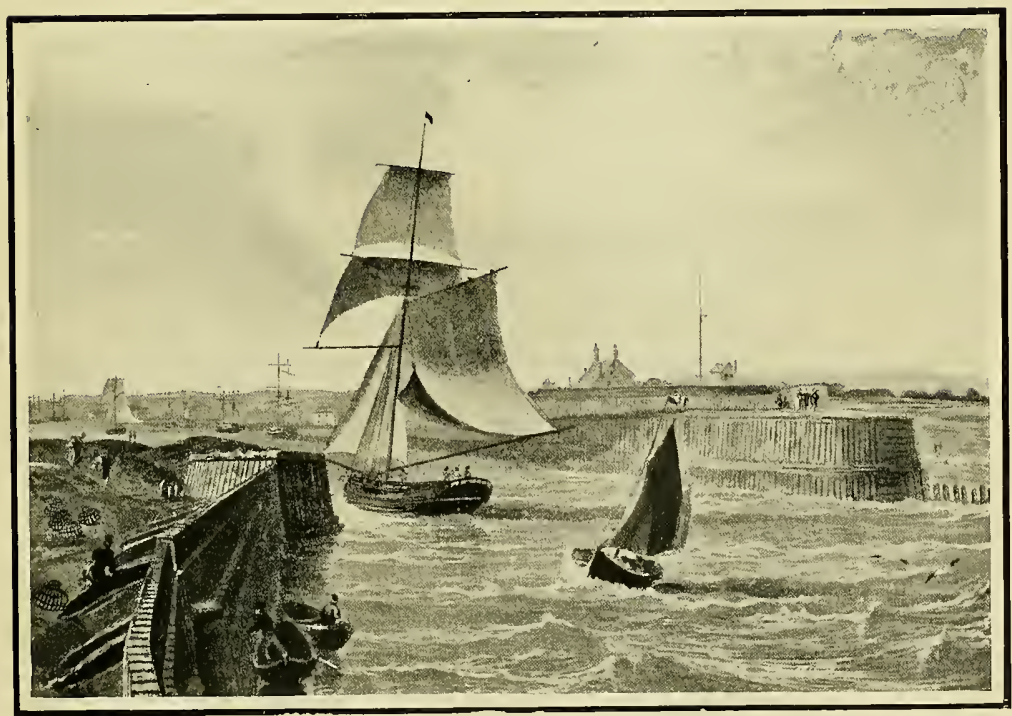

Fig. 48 .

P. 196

CUtTer Entering LitTlehamp'TON HARBour

This illustration, which is after William Daniell and belongs to the year 1823 , shows the strong, heavy, full.bowed type of cutter of that time, with square topsail and t'gallant. 

was the handiest for manœuvring in confined waters, and especially suitable when harbours had frequently to be entered. Furthermore, it afforded the greatest amount of sail-area with the minimum amount of weight in spars. And lastly, as every one knows, the cutter will sail at least one, if not two points nearer the wind than the square-rigger. A typical fast yacht of about the year 1815 was cutter-rigged, copper-fastened, and sometimes copper-sheathed. Having a burthen of 60 or 70 tons, with a saloon $10 \frac{1}{2} \mathrm{ft}$. by $15 \mathrm{ft}$., she had also three smaller bed-cabins and a steward's room, as well as forecastle. She was ballasted with 5 tons of lead and 25 tons of iron, the blocks being moulded to fit the hold.

It is true that as far back as the year $\mathbf{1 7 8 0}$ there had been sailing matches off Cowes, but these were exceptional, and not regular annual affairs of importance. Up to the close of the eighteenth century it was rare to find a yacht exceeding 35 tons burthen, but by about the year 1826 some of the Royal Yacht Club cutters, thanks to the new influence of racing, had reached the exceptional size of 180 tons. For a " singlesticker" this is simply enormous, and it is not surprising that these yachts whenever during their cruises they came across any of the king's cutters beat the latter easily. Each year the tendency of the cutter yacht was to get longer and longer, and increased tonnage went on till it reached the figure mentioned. One of the most famous cutters of the big class was the Atalanta, belonging to about the year 1815, but she was not by any means the largest, and worked out at 116 tons. Owners insisted on gigantic sail-areas, and thus larger hulls had to be built to meet these requirements. As we shall see, the evolution of the fore-and-aft yacht ever since the sport was founded on a secure basis has been regulated and modified by the laws laid down by the yacht clubs and racing associations. Even as far back as the year 1826 this force had begun to operate, for it was enacted that the use of extra sails was forbidden. 


\section{INFLUENCE OF HOLLAND ON}

That being so, there was nothing for it but to increase the size of the ordinary sails. To meet this, not merely had the size of the hulls to be made greater, but very drastic means had to be effected that the vessels should be able to sustain such a spread of canvas. Additional ballast had to be carried, and a certain amount of heavy-weight lifting took place to shift great blocks of metal to the windward side of the vessel on each tack. This was, of course, a false method of working towards the attainment of the ideal racer; but it was in these days legitimate, and so for a time continued. But at this time the line of separation between the old and new types is most marked. Thanks to the prevailing rules for racing, the Revenue-cutter type had ceased to be the model for the cutter yacht. Something finer with lighter scantlings was required as to hull, and in the matter of the rig those square courses, square topsails and topgallants, stunsails and ring-tails, which were regarded as extra or fancy sails, were scrapped and omitted from future designs.

But though the square-topsail had gone, a gafftopsail was employed, and thus there was laid down the general lines of the cutter rig for futurity. It was not altogether fortunate that some of these undoubtedly useful square-sails should have been abolished. For the cruiser in certain winds they are most useful, and so easily handled that it was a pity to do away with them entirely. But for years the new convention was followed owing to the element of racing which remained as a potent influence, and it is only comparatively recently that cruising men have begun to bring back the square-sail into the inventory which should be found on a yacht intended not exclusively nor especially for winning cups.

Even in the 'twenties, after the wars had ceased, and it was safe to cruise up and down Channel, some of the big cutters still went about with a few four and six-pounders on their decks, and even with a complete 
armoury below consisting of rifles, pistols, and cutlasses. But this was not so much from the necessity of having arms on board as resulting from that semi-naval tradition which still clung to the yacht. Besides the cutters, both large and small, there were a number of yawls, and, from about the year 1820, the schooner began to increase in popularity, but she was usually a topsail schooner, and just prior to her time the brig, with guns and discipline resembling that of the Royal Navy, was popular among wealthy owners. There were also, thanks to the influence which certain fast smugglercraft had exercised on naval architecture, a certain number of luggers used as yachts, as well as yawls; but for the reasons already given the cutter remained the most popular. Long before ever Cowes was a great yachting resort, that town had become connected with the fore-and-after by its build of Revenuecutters; but after the design and rig of the yacht began to improve, the old-fashioned clinker-build was superseded, and yachts were made carvel-built instead.

It was because the smugglers were so frequently able to get away from the Government craft, and because the big yachts were able to show the king's cutters a clean pair of heels, that at last an outcry was made, and the Government was urged to bring about an improvement. They were to sink their pride and be content to learn from the amateur pleasure yachts which had shown themselves to possess qualities that the king's ships did not. It was apparent to every one that the cutter yachts had far outstripped the naval architecture which the Government had favoured, and the amateur had, by his sporting enthusiasm and his purse, encouraged the science and art of cutter-building to an extent which previously had not been attained.

Thus it came about, then, that the Government took the matter up, set its experts to work, and even arranged a match between a cutter yacht and a king's cutter. The result was so much in favour of the yacht 


\section{0 \\ INFLUENCE OF HOLLAND ON}

that the matter was settled beyond all possibility of dispute. There was not room for any opinion on a matter which was as clear as could be. And thus at length not only did it come about that some of the new Revenue-cutters were built on the lines of the fast yachts, but in some occasions were even built on the same stocks where the yachts had been laid down. The smaller type of sailing-ships had developed to such an extent that it had become a special branch of shipbuilding, requiring a particular knowledge which the maker of ships-of-the-line, frigates, and corvettes did not necessarily possess. Even the two last-mentioned types were dominated by their structural strength in spite of their superiority of speed as compared with the battleship. But in the case of the cutter finer work, more scientific, and of a different nature was required.

To an experience gained originally by the building of the older types of fore-and-afters, and improved subsequently by the demands of racing, there had been applied mathematical science, and all the laws which had been discovered by French and other naval architects. For about the close of the great Anglo-French wars the Gallic ability in naval design and construction was pre-eminent. Had the human element always been of a similar excellence, perhaps the Napoleonic wars might have ended differently. But at any rate England was now beginning to wake up, and to learn from the French as in previous times she had learned from the Dutch.

We alluded just now to the increasing popularity of the schooner in the early 'twenties in this country. For bigger vessels anxious to retain the fore-and-aft rig, this type had much to commend it. But as to its evolution it is interesting to note that here again can the Dutch origin be traced. The reader will recollect two sketches which we considered in an earlier chapter, to which we called special attention owing to the peculiarity of their rig. One of these (Fig. 12) was from a 
painting by Willaerts, and now hangs in the Dordrecht Museum; the other was by an artist of the Dutch school, and hangs in the Boijmans' Museum, Rotterdam. Virtually these two craft were a kind of schooner, but without either jib or staysail. Their Dutch designation was, in spite of the fact that there was no staysail, that of sloepe. These paintings, it will be recollected, belonged respectively to the years 1629 and 1642.

Some of these so-called sloepes were about $24 \mathrm{ft}$. long in the mainmast, $42 \mathrm{ft}$. in length over all, with a beam of $9 \mathrm{ft}$. Now we referred some pages back to the colonisation of northern America by the Dutch, who called their territory the New Netherlands, and that which is now known as New York was called by them New Amsterdam. Along that Atlantic shore, stretching northwards to Gloucester and Boston, are to be seen to this day perhaps the very finest class of schooners in existence, or ever conceived by the mind of designer. The reason is to be found in the fact that the Dutch colonists took over the Atlantic not merely their ideas of cutters and single-masted sloops, but also the other notions of craft, including this kind of vessel depicted in the Boijmans' Museum.

It was in 1664 that, during the Anglo-Dutch War, the British seized New Netherlands, but that did not mean that the whole Dutch colony vanished, nor that the Dutch-American shipping was instantly to be swept out of sight. Undoubtedly this two-masted sloepe held on. But in the year 1713 there came a change: there was seen to be room for an improvement, for it was realised that this "two-sticker" could be made a better craft by adding a triangular jib as in the single-masted sloops. And so this was done. The foremast was was already very far forward in the eyes of the ship, and so a broeksprit, or bowsprit, had to be added also on which to set the jib, and so with this the schooner as belonging to the years 1800 to 1850 came into being. 
It was then distinctly a Dutch-American craft, and not British, and the date of the first of this new type was, as stated, 1713. Captain Clark relates that as she was leaving the launching ways some one exclaimed, "See how she scoons," and from that day this prototype and her descendants have been called schooners. ${ }^{1}$

The place where this vessel originated was Gloucester, and this early reputation for the two-masted fore-and-after has been since continuously maintained by that port. Two separate reasons have contributed to the development of the Gloucester schooner. Firstly, there was a demand for an able type of vessel that should be capable of riding out bad weather in the Atlantic; and, secondly, the type that was required must also have a good turn of speed, for two separate kinds of people needed just such a vessel as possessed these qualifications. In the first place, there was the brotherhood of pilots, who were so keen on getting to the incoming ship that they would race for many a long mile out into the ocean so as to arrive first. Secondly, there were the fishermen who earned their living by going to fish off the Grand Banks. Having filled up with the spoil of the sea, it was their duty to hurry back to market and obtain the best prices for their catch.

Thus, owing to the demand for these two qualities, the Gloucester designers and builders set to work to provide the supply, and this they did with the utmost success. The coasters of the North Atlantic seaboard in northern America also took to the schooner and gave her additional masts until as many as seven have been seen on one of these ships. It is characteristic that the American prefers a plain fore-and-aft schooner and not a topsail schooner which the English coaster utilises. These American multiple-masted schooners

1 Against this origin of the word the Dutch adjective "schoon" might be employed by those who disagree with Captain Clark. "Schoon," in Holland, means " beantiful," "handsome," "fine," and "schoone" means "a beauty.' The latter is just the expression which fits this craft. 
need small crews, and the sheets work on horses, so they are comparatively handy. I believe that the largest fore-and-aft schooner, and indeed the largest wooden sailing-ship in existence, was built last year-in 1910-at Bath, U.S.A. Her name is the Wyoming, and she carries six masts, on which she sets the abnormal amount of 12,000 square yards of canvas, every sail being a fore-and-after. The hull is $350 \mathrm{ft}$. long, and she has only $50 \mathrm{ft}$. beam-or seven beams to the length, the old idea having been three beams to the length. The tonnage works out at $\mathbf{3 7 3 0}$ gross. The length of her keel is $304 \mathrm{ft}$., and the depth of her hold $30 \mathrm{ft}$. The thickness of her planking, which is of yellow pine, is six inches. The lower masts are $126 \mathrm{ft}$. long, the topmasts are $56 \mathrm{ft}$. Steel girders are used in the ship's construction, which would seem to be very necessary in the case of a wooden ship of such enormous length. Here, indeed, is a fore-andaft-rigged schooner which is able to carry 6000 tons of coal, or as much as a good-sized steam tramp.

Although the Wyoming is not illustrative of the rule of schooners, but rather the exception, yet there are plenty of three and four-masted fore-and-afters employed in the coasting trade of North America. In the early years of the nineteenth century the famous Baltimore clippers were rigged as topsail schooners. Their two masts raked aft, and their hulls were long, lean, and fast. They were of about the same size as the Gloucester schooners-roughly 50 tons-and their successes as speedmakers caused them to be copied by English shipbuilders, especially those of the Royal Yacht Club and the Royal Navy.

How soon after that year 1713 the schooner was introduced into England it is impossible to say; but in his British Mariner's Vocabulary, written in 1801, Moore defines the schooner as " a small vessel with two masts, whose mainsail and foresail are both suspended by gaffs, like a sloop's mainsail." What an 


\section{INFLUENCE OF HOLLAND ON}

English schooner of the early 'twenties of the nineteenth century looked like may be seen from the accompanying reproduction after Cooke (Fig. 49). It will be recognised that she is a topsail schooner, and her hull is not unlike the collier brigs of that day.

But to return to the subject of the cutters, the rig which has been more developed in this country since the time of Charles II. than any other species of the fore-and-after: there were sloops which in the early eighteenth century were of such a size and seaworthiness as to cross the Atlantic and bring back to the mother country supplies of timber which the American colonies afforded. That was a long time before the Revolution occurred. The American colonists at that time also largely employed the sloop for fishing and trading purposes. Captain Clark quotes the interesting instance of the sloop Union, a vessel of only 98 tons. This fore-and-after set forth from Newport, on the Atlantic coast, in August of 1794. Twenty-two and a half months later she returned from an eventful voyage, in which time she had circumnavigated the world. She proved herself to be an excellent sea-boat, and is believed to be the first sloop-rigged craft that ever sailed around the world. She had the speed of most modern sailingships, and averaged 130 knots a day.

Many readers will immediately be put in mind of the recent famous voyage of Captain Slocum round the world, also in a fore-and-after. This, indeed, must reckon as a much finer achievement, since he was single-handed and had a far smaller ship, but that does not detract from the highly meritorious cruise of the Union. There have been a number of English cutters which have crossed the Atlantic to race for the America Cup, but all these, or some of them, have crossed as yawls, being specially jury-rigged for the trip. And there have been numbers of schooner yachts which have sailed and even raced from America 


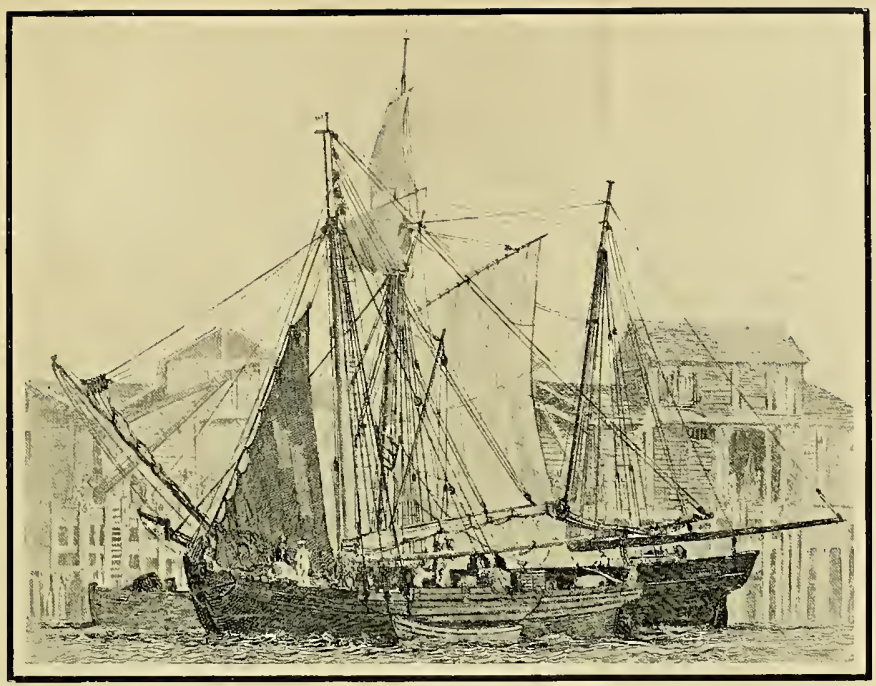

Fig. 49 .

P. 204

Early Nineteenth Century Topsall Schooner

The schooner is in the background, and her type was much influenced by the contemporary collier brig. Notice the rake of the mainmast. (From an engraving by E. W. Cooke.)

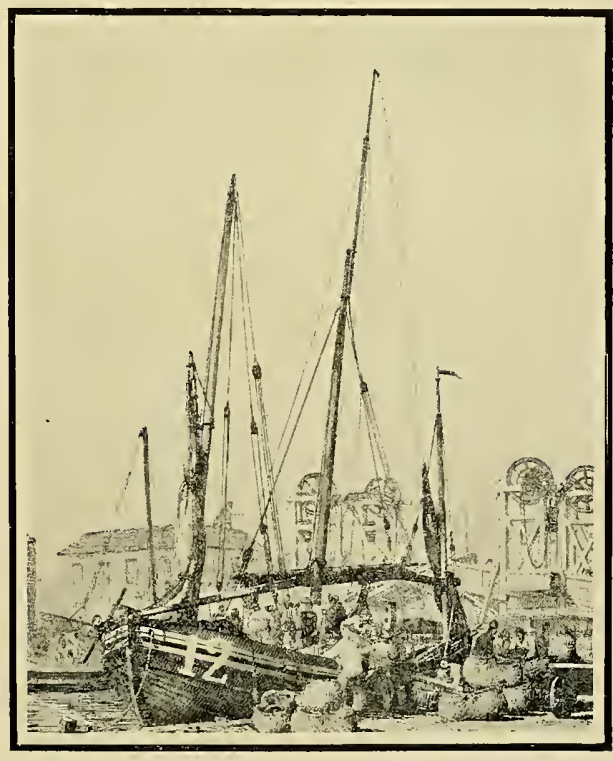

Fig. 50.

A YARMOUTH YAWL

P. 220

This shows the old-fashioned North Sea herring-fishing craft with three masts and three lugsails. It was in use in the time of $\mathrm{E}$. W. Cooke, but is now long since superseded by the sailing ketch and the steam drifter and trawler. 

to England which have been fore-and-aft rigged, but these were at least in the position of having two masts and would not be utterly helpless if one carried away. In the case of the Union, she had her mast stepped about midships, had a long hull and an exceptionally lengthy bowsprit, which was well steeved so as to be as high as possible above the water, somewhat after the manner of a full-rigged ship. And whilst we are on this subject let us not forget that Captain Amundsen's ship the Gjöa, which set forth from Christiania in June 1903, and three and a half years later had proved for the first time the existence of the North-West passage and arrived at San Francisco, was also cutter-rigged. It is true that she was fitted with a motor giving the ship a speed of four knots, but she was a smaller vessel than the Union by some 28 tons.

Among the famous English yachts of the 'twenties must be mentioned the Pearl, the Arrore, and the Alarm. These were all built as cutters. The Peart was launched in 1820 at Wyvenhoe, and was of 95 tons. The Arrow was 84 tons. She was altered and rebuilt many times since she first appeared in $\mathbf{1 8 2 2}$. The Alarm, which came out in 1830, was only seven tons short of two hundred, and was one of the very largest cutters ever built. What a gybe must have been like round a mark-boat in a smart breeze we can well wonder. Her origin is not without interest, for she was designed from the lines of a celebrated smuggler that was captured off the Isle of Wight.

It was owing to the fact that no time allowance was granted that the development of size in yachts had gone on unchecked: otherwise such a monstrosity as the Alarm would not have appeared. Right away as far back as the time of Charles II. the English yachts had been ballasted with shot. It was suggested to Christopher Pett that stones should be used for this purpose, but he wisely declined to entertain such an idea on the 


\section{INFLUENCE OF HOLLAND ON}

ground that it took up too much room. In this respect Pett was more ahead of his times than might appear, for the ocean-going ships had for centuries had a considerable amount of their valuable internal space taken up by gravel ballast, which left but little room for the ship's stores.

In some of the early nineteenth-century English yachts gravel or stone blocks were still used, just as one still finds to this day in the case of some of the open fishing craft which go out from the shore to their lobster-pots. After that iron blocks were introduced, and finally a reversion to the idea of lead. Bags of shot were employed in the last century so that they could easily be moved up to windward at each tack. In 1846 lead pigs were used, and finally, ten years later, in spite of the frownings of the pessimists, the lead instead of being used as inside ballast was transferred to the keel outside. After the battle of Waterloo the sport of yachting, and so the development of yacht architecture and everything connected with the yacht from ballast to running gear, received the advantage of an enthusiasm which had never previously been granted; and both immediately before and immediately after the Crimean War this enthusiasm and interest had been increased tenfold. It was because there had been so little personal interest on the part of the owner, such scant encouragement given to the builder, such universal ignorance extant in regard to problems of naval design, such infrequent races for testing certain types of hull and rigs, that the progress since the introduction of the first Mary into our own country had been slow.

But then from about the close of the first half of the nineteenth century a new order of things came in owing to the opposite of those defects which we have just noted. The peace of nations was now an assured thing. That long era of battles which had continued for centuries, almost since the times of our own internal Wars of the Roses, had come to an end. For three 
hundred years we had been fighting Spain, Holland, France, or two or more of these allied. It was therefore impossible that the smaller types of sailing craftthe yacht and the small trader-should have a chance of development except in short intervals of peace ; for all the enthusiasm and workmanship had to be guided into that channel which would bring about a ship-ofwar instead of a ship-of-trade or ship-of-pleasure.

But now all this was changed. 'The Victorian sovereignty had brought about peace and contentment, and the effects of the great industrial revival of the previous century had already caused so much increased wealth to our countrymen that there was an unprecedented army of rich sportsmen from whose ranks to draw a large band of yachtsmen. Here then was the needful force of encouragement to builders. This was intensified by the formation of powerful yacht clubs having for their object, as the preamble to almost every sailing and yacht club reads, "the improvement of yacht building and the encouragement of yacht sailing," "giving the greatest latitude in the construction, rigging, and sailing of vessels, consistent with their aptitude to yachting."

Between the years 1823 and 1844 the Royal Thames, Royal Northern, Royal Western, Royal Eastern, Royal St. George's, Royal Southern, Royal Harwich, Royal Mersey, and Royal Victoria Yacht Clubs had been established, additional of course to the Royal Yacht Squadron. Thus, in all parts of the country the builders and designers of the fore-and-aft craft received every incentive to create the best which materials and existing knowledge could bring about. Presently these clubs were to be added to by the instituting of many more similar organisations in almost every suitable harbour or estuary in the United Kingdom. Royal patronage had also helped, and the first royal cup was given by William IV. to the Royal Yacht Squadron in the year 1834 . 


\section{INFLUENCE OF HOLLAND ON}

All sorts of theories had for the previous hundred years been advanced in connection with the resistance of water in the progress of a vessel, and many an attempt had been made to design such a hull as would offer the least possible resistance compatible with seaworthiness. Of these theories many were of Gallic origin. But in the 'forties Scott Russell made very valuable contributions to this science, suggested certain theories for dealing with resistance, and advocated a wave-like system. Others have since increased this body of information by further experiments. It was during the 'forties that designers began to realise thoroughly that the old "cod's head and mackerel's tail" was a long way from the ideal design. So in the year 1848 there was built on the Thames a cutter named the Mosquito, which was entirely original in that she possessed a long hollow bow, and a short after-body of great beam, and generally was in conformity with the lines advocated by Scott Russell. She was of 70 tons displacement, and built not of wood but of iron. However, so great was the existing blind prejudice that she was not popularly received.

But in the meantime the Americans had developed the schooner and improved on the pilots and fishermen until they were able to produce a schooner yacht. During the early 'forties the yachtsmen of the United States had been engaged in racing both in sloop and schooner. In 1844 a memorable race took place between two American yachts, of which one was the 178 ton centre-board sloop Maria, which had a clipper bow, and the other was the schooner-rigged Coquette, of 74 tons. The result was that the schooner won, for, thanks to the influence of the Gloucester fishermen and pilots, this type of vessel had been brought very close to perfection considering the amount of knowledge then extant.

There was a man in New York of the name of George Steers, who had obtained a first-rate reputa- 
tion for the building of crack pilot schooners, and to him now came the commission to build a racing schooner yacht that was to cross the Atlantic on her own bottom and see what she could do in English waters against English craft. We are not writing a history of the sport of yachting, but only of the developments of rig and hull as that sport has affected the same. Therefore we need not follow this yacht into all her activities over here. But when we say that she was the famous America, after which the historic races for the America Cup have been named, the reader will not feel himself disinterested.

We may add briefly that after being built at a cost of $£ 4000$ she reached Cowes in August of 1851, and on the 22nd of that month won the special cup offered by the Royal Yacht Squadron. She beat the best of our crack cutters and schooners so handsomely, and was so great a departure in many of her features from the existing British convention, that it did not take our fellow-countrymen long to realise that the America was mostly right and we were mostly wrong. 'To begin with, the America had similar lines to the despised Mosquito of a few years earlier, and the characteristics of the Yankee were, briefly, small displacement, small midships sectional area, and her hull was distinctly small in proportion to her dimensions. Her water-lines were also much sharper than had previously been attempted in the case of large yachts.

She was also a contrast in other respects as compared with the best contemporary English yachts. Firstly, she was a schooner, whereas most of our yachts were cutters. Secondly, her sails, unlike those horrible-looking windbags which we have seen from Daniell and Cooke, were cut so that when set they were tight and flat. Consequently, with the fine entrance lines of the hull and the well-fitting sails to propel her the America went to windward in a splendid manner. 


\section{0}

\section{INFLUENCE OF HOLLAND ON}

After her departure there remained her influence. As the America had been a schooner, the Alarm (193 tons) was in 1852 lengthened by 20 feet at the bow and rigged as a schooner, which made her to be of 248 tons. As the America had the newer type of close-fitting, flat sails, so the Alarm copied her example, and she subsequently appeared with one enormous triangular jib but no staysail, the foresail having a gaff but no boom, and the mainsail with both boom and gaff. In other words, she was very similar to the prevailing pilot schooners of North America. Furthermore, instead of the old idea which England had copied from the Dutch, to which she still clung, in having the loose-footed mainsail, the latter was laced to the spar, the jib worked on the forestay and was laced along the foot to a boom also.

The net result of all this was that English sailmakers began to cut better sails and English designers began to evolve better hulls. For a time, from about 1852 to 1865, there was a craze for American centreboard craft, but there was also a craze for schooners, thanks to the America's success. In the 'sixties the yawl rig also became the fashion, following the popularity of the schooner, for it provided a half-way stage between the schooner and the single-masted cutter.

But it is when we come to study the ten years that are covered by the dates 1870 and 1880 that we begin to see a still greater activity. It had been preceded by a fine fleet of cutter yachts that included the famous Oimara, built in 1867, and still used, but as a houseboat in Poole Harbour, above bridge. Her spars were all big, and her great topmast and lengthy bowsprit were characteristic of that period. The tonnage of this vessel is 135. The Aline and Egeria also belong to this period, the former being historic as having been the first yacht to discard the rake which was always given to the mast previously. 


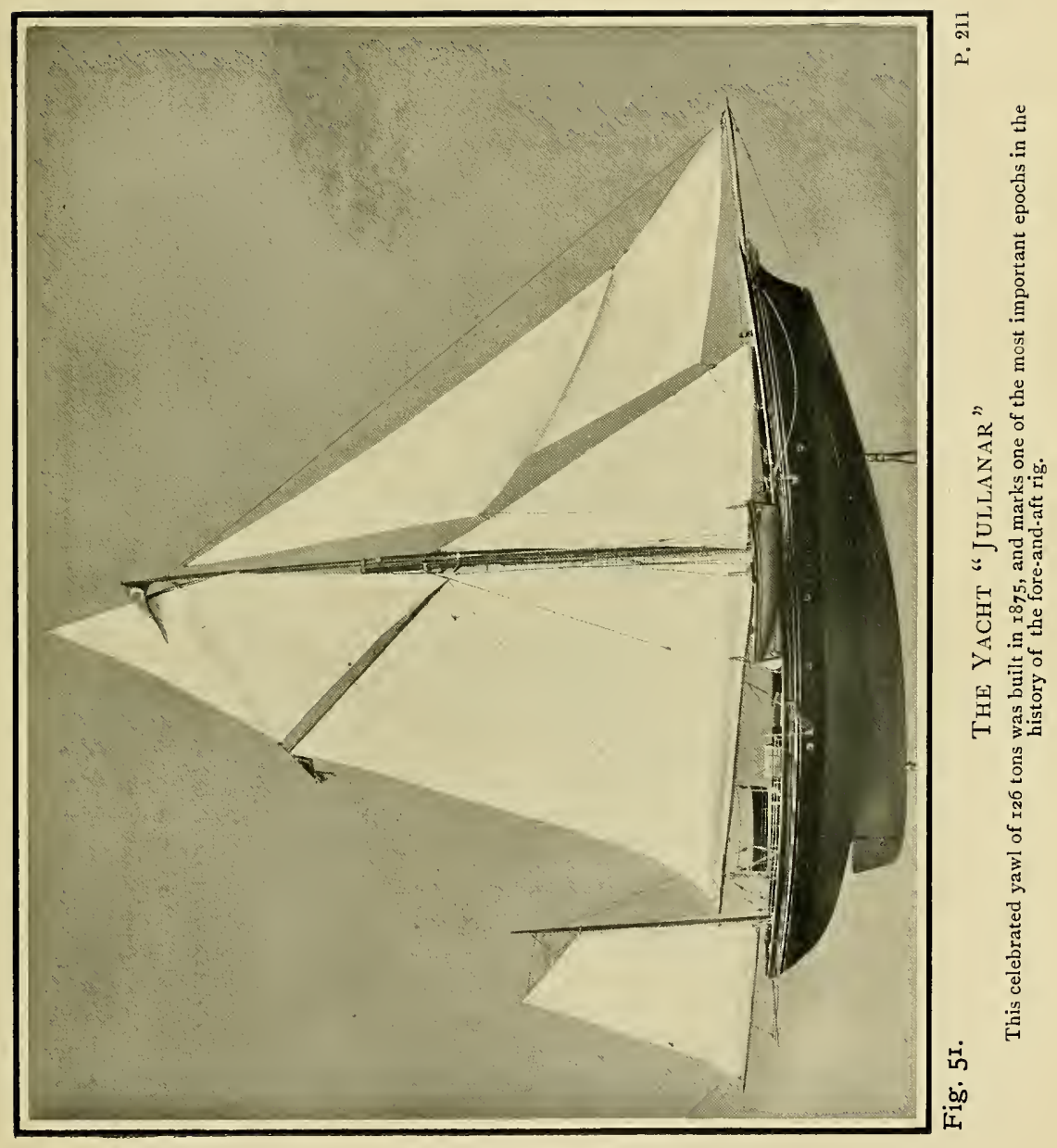



The 'seventies saw a real awakening in yachtinga new birth as it were. There were big schooners, cutters, and yawls, and yacht-building yards were busily employed. It was during this period that the famous forty-tonners came into being that numbered in their class among others the well-known Foxhound and Bloodhound. The last mentioned has attracted an increased amount of attention by her return to racing during this twentieth century. She was recently altered by Fife, and has done remarkably well in handicap races when we recollect her great age as compared with modern flyers. Under the new modification the Bloodhound was given a raised sail-plan, and the ballast was brought lower down. In addition to this the forefoot was cut away, and she was thus made quicker in stays.

But besides these celebrated forty-tonners we must call attention to the equally famous Jullanar, which was representative not of a class but as a special and original creation. The Jullanar, which we have here reproduced in Fig. 51, from the model in the South Kensington Museum, is indeed a milestone on the road which begins in the late sixteenth century and reaches on to the present day. Perhaps there was no designer of the fore-and-aft rig of our own time that did so much for this development as the late Mr. G. L. Watson. His name was associated with a fleet of crack yachts that is too numerous to give here. And when it is remembered that Mr. Watson frankly admitted that he himself was considerably influenced in his designing by the lines of the Jullanar, we have every right to regard this vessel as one of the highest importance. To some extent the excellent illustration will here speak for itself, and the fewest words will suffice to demonstrate her especial features. Her birthplace was in Essex, that county which has brought forth so many famous craft and equally famous sailor-men. 
Designed by a Mr. E. H. Benthall, the Jullanar, of 126 tons, was built in the year 1875. In this model the old-fashioned straight stem and the old-time stern have vanished altogether. There is not a trace-in detail at least-of the former Dutch influence. Her bow, however, shows some connection with the prevailing schooner of that period, and so with the clipperships which were then fast coming to the end of their limit of usefulness. This yacht showed herself such a success, and possessed of io great a speed, that Mr. Watson based his design for the famous Thistle on the lessons to be learned from the Essex craft, although the Thistle did not actually appear till the year 1887 .

It was in the year 1875 that the Yacht Racing Association was established, and it is important to bear in mind the existence of that society, for it has been a powerful controlling agent ever since that date in determining the trend of the architecture of our yachts. The object aimed at throughout the history of these measurement rules has been to cause, if possible, the winning boat to attain victory not by reason of her size, but owing to her superiority of model. This of course eliminates for the moment the important question of the human element, which, after all, is frequently the means of separating a loss from a win. But it is impossible to legislate for such uncertainties as human ability, though the aim of the rules being as indicated, it throws a very heavy onus on the designer. It is only reasonable and fair that the yacht which wins should be the fastest for her size, and that her victory should go not to the millionaire necessarily, but to the most scientific creation. In both cases, the small and the large, the element of good seamanship, of nerve, of personal daring and mental ability, are entirely essential. Given equal chances, and two vessels of almost equally good design, the winning gun will go almost certainly to the better helmsman, even if his crew is slightly the inferior of his rival. 
It cannot be denied that the different measurement rules in some years have retarded rather than assisted the progress of a sound, healthy type. But this was almost inevitable in the case of a comparatively undeveloped sport in which science and the knowledge only to be obtained from experience enter so much. Perhaps it was necessary to make mistakes in order to learn for future years what was necessarily to be avoided. For whenever it is announced by the authority that such and such a feature will be taxed, it becomes the duty of the designer to bring about such a yacht as will be able to suffer least by those restrictions. His duty is to cheat the rule as far as possible, so that the yacht will not be penalised unduly.

We have no intention to try the reader's attention by placing before him a number of mathematical formulæ, which belong to the more detailed consideration of the subject and would detract from the clearness of our vista. But we may say at once that the first method of finding the common denominator was by means of the Thames measurement, a system that was found wanting and subsequently altered.

This newest arrangement led to the production of a type of yacht that was altogether unhappy and a mistake. The new rule had the effect of encouraging the designers to make a craft extremely long, very deep, and excessively narrow, so that they were familiarly known as "planks-on-edge." It was a thoroughly unwholesome type, and required a perfect lead mine to keep them upright. The reader will remember that in the olden days the principle was three beams to the length. So far had the reaction now set in that the case of a craft having a length six times that of her beam actually occurred. She had on her keel an amount equal to about one-half of her displacement tonnage, whilst she could not carry the full amount of sail that a vessel of that tonnage should have been expected to carry. The fact was that the 


\section{INFLUENCE OF HOLLAND ON}

measurement rules penalised all yachts with beam, and so the designers were driven to make vessels deeper, but, so to speak, as narrow as a plank when set on its edge.

In the year 1877 the plank-on-edge became obsolete, the system of measuring yachts by their tonnage was discarded, and a system of rating by length on the water-line and sail-area was adopted. The effect of this was to penalise only the yacht's water-line and her sail-area. The designer's object, therefore, was not to bring out a narrow, deep craft, but it was left to him to give her as short a water-line length as he liked, and to cut down her sail-area. Now it is evident that this did not put a tax on the length-over-all, so consequently one of the ideas demonstrated in the Jullanar was here at hand waiting to be developed, and the design permitted long overhangs at bow and stern, which were not penalised. Through this a much better type of yacht was evolved, for her overhangs made her a drier and better boat altogether. Beam was not penalised, and there was an opportunity to build a type that was healthy and sensible, and thus it became possible for such excellent craft as the Creole, Queen $M a b$, Corsair, and others to come into being, yachts whose names and hulls are still fresh in the memory of many yachtsmen.

Thus at last, after centuries of learning and experiment, after much ignorance and many a mistake, the cutter had become very nearly perfect, a fast yet good sea-boat, handy yet comfortable, stiff yet not unduly ballasted, a real ship and not a racing machine. Cotton and silk sails had been adopted, and about the year 1866 a new sail, the spinnaker, had been brought into use, and utilised to enormous areas on the racing yachts especially. The first occasion in which a yacht carried this sail was, I believe, the Niobe. Its derivation can easily be traced to the studding-sail, which was still in use during the 'sixties on the clippers and 
the auxiliary men-of-war in the service. But there was evidently a desire for such a sail many years before this, for there is on record an incident belonging to the year 1797. In that year the yacht Blue Dragon was racing in a match on the Thames, and was disqualified for having boomed out her jib during the race.

It is, then, from the 'nineties of the nineteenth century that the next awakening comes in the development of the fore-and-aft yacht. In the early stages yachting was exclusively a rich man's recreation. Even up till the 'seventies it was still a close preserve, and owed its success almost as much to its social connection as for pure sport. But from, at any rate, the 'nineties, yachting - the enthusiasm for the fore-and-after-began to receive adherents in tens where previously it had been only by units. It was not merely the nobleman nor the millionaire who now put to sea in his own craft. It was the comparatively poor man who, content to dispense with the expensive crew, and happy to cruise or race in smaller craft, swelled the ranks of the keen yachtsmen. The 'eighties had seen him coming, but the 'nineties saw him fully arrived. The consequence is that a whole army of designers and builders have arisen intent on creating, not hundred-ton racing machines, but anything from a dinghy to twenty tons. All sorts of improvements as to design, internal accommodation, rigging, and so on, have been evolved for the "poor" man's benefit. In short, as the democratic spirit was spreading on land, so it was to manifest itself afloat.

Having now traced the evolution of the fore-and-aft yacht up to the commencement of the last decade of the nineteenth century, we may leave that branch of our subject for a little and pass on. It has intentionally been our purpose to deal with the development of the yacht to such an extent, for that is the craft which has done more for the evolution of the fore-and-aft rig than the pilot or the fisherman, reckoned as an historic whole. 
Even in the early days of the nineteenth century, an erstwhile yacht was often to end her life as a fisherman. Gradually both fishermen and pilots-especially when stationed at some yachting resort-have now begun to adopt some improvement first seen and developed on the yacht. It is true that the yachtsman has had much to learn from both these two classes of seamen, but the converse is also true if we look at the matter as a period and not in any particular year.

There are certain types of the fore-and-aft rig, as, for instance, the luggers, which can have but little attraction for the amateur sailor-man except for quite small craft. This rig he cannot be said, then, to have assisted in developing. But most certainly he has helped to convince the fisherman that to be a good, sound seaworthy, sea-keeping craft, the fishing-vessel need not necessarily be bluff or clumsy, need not even be slow. On the other hand, the yachtsman has learned from the professional the value of strong but simple gear, of not overburdening his ship with too many "patents." He has learned, too, that while "putty and paint cover a multitude of blemishes," yet there is something to be said for having a vessel decorated as if she were meant for service and not for show. It is this delightful spirit, in fact, of mutual improvement and mutual sympathy - I dare not say admiration-which has done and is doing much for the amelioration of the fore-and-after. Most of those able hands on our crack racing-yachts go back to their fishing-boats during the winter. They bring to their work on the yacht a knowledge of seamanship, a sea-sense that could not be excelled. But they go back to their clumsier craft with some reverence and respect for science as applied to the ship.

Similarly the yachting enthusiast, from his association with the fisherman or the coaster, unlearns a good deal of fancy theory and acquires a new standard by which to work. Time has wrought many changes on 
both yachts and fishing vessels during the last sixty years-since 1850 -and we have already been enabled to watch some of the main causes which have been at the origin of these. The old-fashioned methods were found wanting, and it was high time that a new order of things should come about. Whilst we can never be too grateful to the Dutch for having shown us the broad essentials at first, yet we have not rested content with that. America has given us ideas, as we saw just now in regard to the two-master, the design of hulls, and the cut of sails. But these Dutch and American ideas have been assimilated and improved on-they have been mingled with those scientific ideas which we learnt direct from the French, so that finally an English foreand-after is something distinct, something characteristic of its nationality, something which actually reacts on Holland, America, and France that were its own teachers in part.

But we have dealt only with a portion of this development of the fore-and-aft rig. Before we have finished our task we must needs see to what stages of development northern Europe of to-day has attained in its fore-and-afters. We have closely studied the past; let us now look into the present. And for this purpose we shall examine the fore-and-afters of this twentieth century as we find them in Scandinavian waters, in Holland, Belgium, France, the waters of the United Kingdom, as well in yachts as in traders, fishermen, and pilot craft. By this means we shall have made our picture as complete as we can hope to paint it.

Types are themselves most interesting, but one sacrifices half the pleasure and interest if we know not why and how such types have evolved. The mind is not satisfied to consider a phenomenon; it aspires to know the cause thereof. It is in this spirit, then, that we may now proceed with confidence to see the modern expressions of that rig whose first beginnings we have 
endeavoured to trace. And we shall illustrate these types from sketches of the actual craft, from photographs, from models, and from the plans of those designers who have been accustomed to design these vessels, whose names as experts in these particular craft are recognised by those who have the duty of sailing in them. It shall be our endeavour by these means to put all doubt beyond possibility of occurring. 


\section{CHAP'TER VII}

\section{THE FORE-AND-AFT RIG TO-DAY IN GREAT BRITAIN}

AND AMERICA

TT is not to be expected that every single variation 1 of the fore-and-aft rig can possibly be minutely examined within the number of pages here allotted. Such a demand would take up more space than we have at our disposal, And yet as we look through the material which is here gathered together, it will be found that the most representative and the most interesting examples of the fore-and-aft rig as to-day it manifests itself in different localities have been brought under our gaze. As we pursue our way through our own country, through the countries of northern Europe and America; as we stop to note first in one region and then in another the different ways in which the shipman has seen fit to modify the rig for local usage and his own especial purposes, we shall encompass practically the whole of the subject.

And if we should feel inclined to wonder that there should be so many species of the genus, it is not difficult to find a reason. It will generally be found that the local craft employed in any particular district is that which is best suited for that region. There are special inducements, for example, that influence the fisherman in some parts of the country to put to sea in the lugger, whilst another kind of fishing work, with the home harbours of a different character and the fishing grounds many miles further out, demands a type of rig totally different from the lug, It may be 


\section{THE FORE-AND-AFT RIG TO-DAY}

the ketch or it may be the cutter, but as a general rule the fisherman knows what is best for his own branch of the industry.

We say generally, for some allowance must be made for human nature-for ignorance, conservatism, and pig-headedness. It is proof of his fallibility that in many an instance he has seen fit to change from the lugsail to the cutter or ketch. Had the lug really been the ideal rig there would have been no reason for changing. In some cases it is true that certain new conditions, such as the formation of new channels, the constructing of new harbour-works, the discovery of other fishing grounds, have made it more convenient to adopt, it may be, a handier rig for beating to windward, for working short tacks, for carrying a good deal of way on so as to shoot well inside the entrance to the haven, or for making longer passages. But these are rather in the nature of exceptions. In the olden days, for instance, the herring-fishing craft of Great Yarmouth were still three-masted luggers, with a rig that was akin to the old Dutch three-masted buss-ships, except that the latter were square-rigged, and with a hull that was highly reminiscent of the Scheveningen pink. That was so as late as about 1830. Such hulls as remain of these old Yarmouth "yawl" type are now cutter-rigged and employed as pleasure boats during the summer from the beach. A glance at the reproduction here given (Fig. 50) from Cooke should be followed by reference to the hull of the Dutch pink (Fig. 107) to be found on another page.

We may take it as a general law that when two coasts, irrespective of nationality, are separated by not more than about a hundred miles of sea, the differing craft of those two nations will influence each other. The reason is not far to seek. The fishermen go out to the open sea from both sides. They even run into each others' ports sometimes through stress of weather or other cause. You see Lowestoft drifters in Ostend 


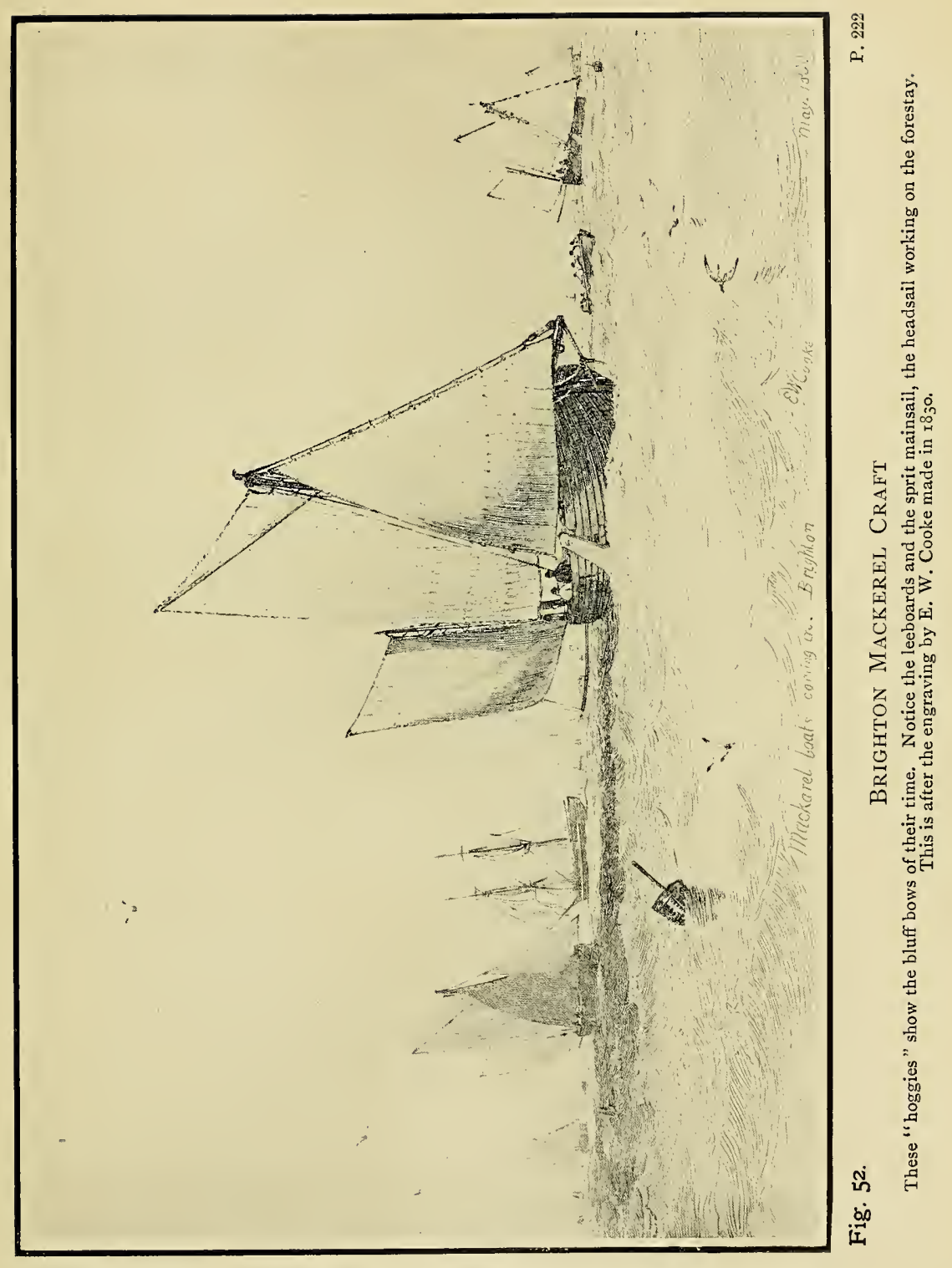





\section{IN GREAT BRITAIN AND AMERICA 221}

harbour, and you see Frenchmen, Dutchmen, and Belgians in Lowestoft. You see French fishermen off the Scillies and in Falmouth harbour; you see English fishermen in the French ports. And as the progress of time has gone on an opportunity has been afforded of mutual appreciation or criticism of the craft of other nationalities.

And this has not unnaturally occurred with greatest frequence in the case of those fishing ports which more or less directly face each other. For instance, Great Yarmouth and Scheveningen, Sussex and the French coast, Scotland and Norway, have each other for opposite neighbours, and we are not surprised to find that the pink resembles the old-fashioned Yarmouth herring-lugger, and that the Hastings, Brighton, and other Sussex luggers have a bond of relationship which binds them to the luggers of the north French coast, while the hulls of many of the older-fashioned Scotch fishing craft are allied by a similar influence to the craft of Norway. Just as it was the custom for the smugglers to run across from France to the ports on the southern English shore that were in a direct line, so in the same way has the influence of rig come along the shortest route and requiring the least effort.

As it was yesterday, so it is to-day. Years ago our south-coast fishermen copied the lugsails of the French: that was in the eighteenth century, and not anterior to the year 1770. To-day the French luggers are slowly but surely being replaced by the English type of ketch. In the olden days the English used to look to Holland for improvements in fishing gear; but whilst these pages were being written a Dutch ship came over, entered Great Yarmouth, and loaded up with a large cargo of English-made nets for the fisheries of the Low Countries.

It is obvious, then, that the bald statement that whatever craft may be found in use in any particular locality is therefore the best for such a region, must be 
modified by an additional assertion that it is the best only until something better is tried. Otherwise the lugger would not have been supplanted by the ketch, and the ketch by the steam trawler. There was a time when the bluff-bowed craft was thought to be ideal for sea-work, but no one would to-day make such an assertion in the face of the cleaner, finer lines which are accepted by yacht as well as fishing-boat.

We spoke just now of the Sussex luggers. They are still to be seen in the English Channel. One meets them at work in Dungeness Bay, or off Fairlight, or between Newhaven and Selsey Bill, and at night the sea is dotted with a pattern of small yellow lights as they pursue their calling, looking at a distance for all the world like so many glow-worms. Like the Scotchman, the Cornishman, and the Manxman, the Sussex fisherman still sticks to the lug because he has not yet advanced to the belief which is shared by Yarmouth, Lowestoft, the Thames estuary, Ramsgate, Spithead, Poole, Brixham, Plymouth, and Lancashire that the cutter or ketch is the better type of rig. According as to whether these luggers have to be beached, to keep afloat in deep harbours, or to take the ground at low tide, so the lines of their hull have been modified, but the lugsail as a rig has continued.

In the illustration (Fig. 52) Cooke gives us a type of the Brighton mackerel craft of the year 1830. These boats were known as hoggies. With their round, bluff bows, their foresail working on the forestay, with their sprit-mainsail and their leeboards, they showed a curious exception to the all-prevailing French lugger. On one of these boats astern to the left of the picture it will be seen that, additional to the foresail, main, and mizzen, there was sometimes also set a jib, for which purpose a bowsprit was run out.

The same artist in other of his pictures, both colour and etchings, shows us these craft hauled up on the beach (Fig. 53). They had transom sterns, were very 


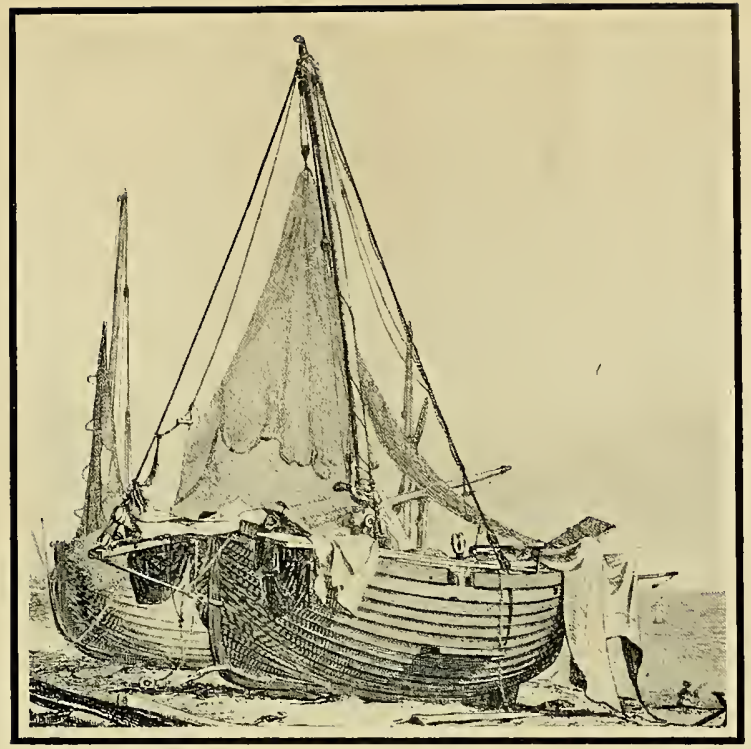

Fig. 53 .

BRIGHTON HOGGIES

P. 222

Notice the ledge on which the leeboard can rest. The bumpkin was always sweated well down as here shown. (After E. W. Cooke.)

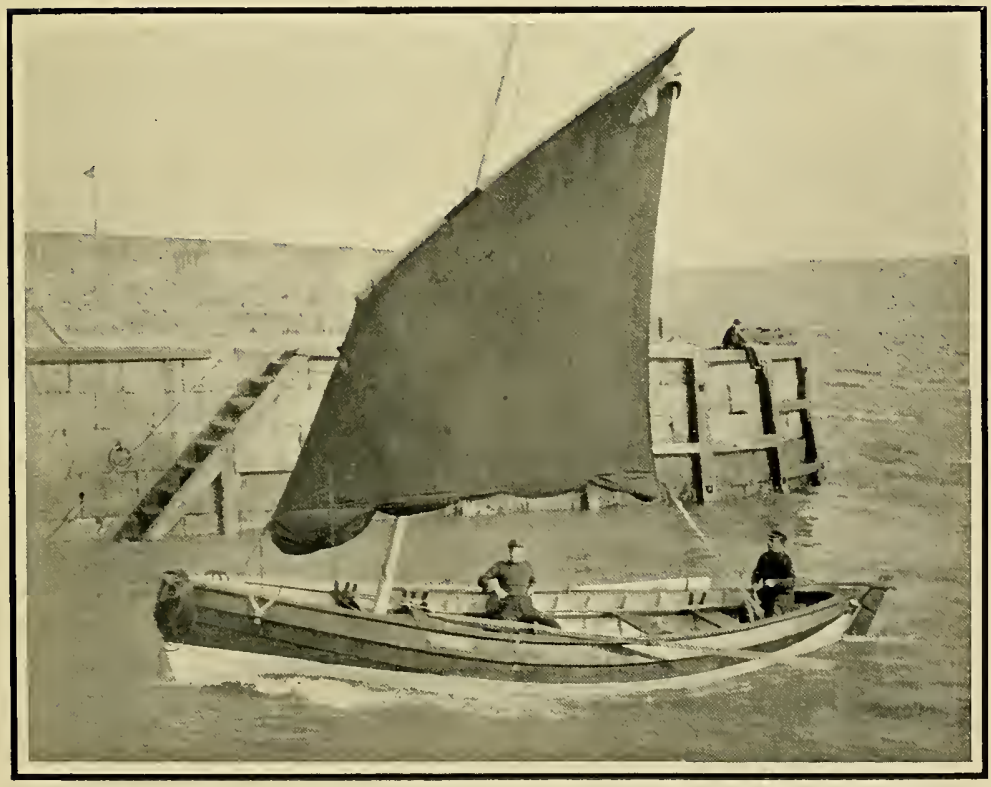

Fig. 54 .

Scarborough "Mule"

P. 222

This type of Yorkshire cobble has a whaler stern instead of the older transom stern. 



\section{GREAT BRITAIN AND AMERICA 223}

tubby, clinker-built, and had a couple of bilge-keeis on either side of the hull. They were given a half-deck from forward to the mast. 'The bobstay led out to the end of the bumpkin, which was bowsed down to such an extent that the bumpkin pointed its nose down to the water instead of up to the sky as in the old-fashioned Dutch craft. The forestay, which led to the outer end of this bumpkin, was secured by means of a couple of blocks. The mast was supported by a single shroud on either side, which could be tightened by means of a couple of blocks, and the mainsheet worked on a horse.

Some, but not all, of these craft carried a mizzen, and very interesting to note is that very Dutch-like ledge we demonstrated in an earlier chapter, which is used for resting the leeboard when not in use for windward work, and is also seen in these craft. But simultaneous with the existence of these boats were the Brighton luggers as well. They were two-stickers, one mast being placed in the very eyes of the boat, the little mizzen being stepped as far astern as it could be placed, and given an outrigger for working the mizzensheet. Having arrived at the fishing grounds, the big mast was lowered down into a substantial crutch, while the little mizzen helped to keep the craft's head to wind. The bilge-rest, as in the Dutchmen and the hoggies, was also retained. It was useful when these somewhat deep-bodied boats were beached, but its origin would seem to have come from Holland, whence certain other of the features of its hull most certainly originated. More correctly stated, we might remark that the hoggie was the bearer of the Dutch influence, and that this boat conveyed certain of her foreign features to the Brighton lugger.

We may well be proud as a nation that we have done what we have for the cause of ship development. But as soon as we begin to examine into the evolution of any craft, large or small, fore-and-aft or square- 
rigged that hail from any of our ports, we forthwith realise that there is, strictly speaking, no such thing as a pure-bred English sailing vessel. Every craft that is of English registration, build, or design is a mongrel. She is in part Scandinavian, in part Dutch, in part French, and as regards sails, especially in the case of the schooner-rig, partly American. And, as we have seen, further back still these craft are Mediterranean and even Oriental. It is as an adapter, as an improver on other nations' ideas that we have excelled, rather than as real originators.

It is just and proper that we should exult in our pride of country, in our record as sailor-men and shipmen, but we must not let our enthusiasm carry us away so that we forget the measure of our indebtedness to other countries. Only in the steamship, both for war and for peace, can we be said to have been the prime cause, to have led the way, and even this triumph would never have come about but for the data which sailing vessels of previous ages had provided for the construction of the hulis.

We referred just now to the relation of Norway to Scotland in the matter of the fore-and-after. This is no fanciful but a real relation. Up to about the year 1860 the Scotch fishing craft were altogether influenced by the boats across the North Sea, and to-day there is still a strong family likeness in the hulls. It is only because bigger, decked, and generally more seaworthy craft were required so as to ply the industry further out from the shore that the Norwegian model began to be greatly modified. Carvel-built boats replaced the old clinker type, which had existed right from the time when the Vikings used to construct ships; the old square-sail of the Norse kings had become a lug, and because of the Scottish national characteristic for stubbornness the lug has been continued since it has been in use for so long a period and every man and boy brought up to using it. There was a brief interval 


\section{IN GREAT BRITAIN AND AMERICA 225}

when the smack-rig was employed, but to-day the lugsail is doing much more than holding its own.

It would be an interesting study to discuss separately the varying qualities of the " nabbies," "skiffs," "zulus," and other species of these Scotch craft did our space permit. But underlying them is the broad influence of the whale-boat, and so of the Norwegian and the Viking craft. The influence of Holland in relation to the Scotch craft is practically nil, and this is surprising when we consider that in the early seventeenth century, and earlier still, great fleets of herring-busses used to cross the North Sea from the Netherlands and fish off the north-east Scottish coast. Certainly as regards influence Scotland has always been much nearer to Scandinavia than to Holland. No one who has been to the Orkneys and Shetlands can have failed to have been struck with the existence of certain characteristics common to the two peoples on either side of the sea; and this similarity is confined not merely to the people, but it manifests itself in even some of the smallest rowing-boats. The skiffs and herring-boats of Denmark, of Norway, and the Baltic have clearly cast their spell over the Scotch fisherman. In Norway the old historic square-sail of the Vikings has not vanished utterly, but it has in many species of craft been turned into a lugsail, and this lugsail came over not unnaturally to Scotland as well.

The use of bowlines to cause the square-cut sail to set better is one of the oldest customs of European seamanship. This has been in vogue in Norway, Holland, France, and England for many a long year. In England the bowlines were employed at any rate during the early 'Tudor period, and their origin was in all probability due to the Norse seamen of the Middle Ages. The Blankenberg luggers-only but recently obsolete - used bowlines for the better set of their sails when on a wind, just as we saw in another chapter the Dutchmen so acted. And it is another proof of the close 
connection between Norway and Scotland that until comparatively recently the Scotch "skaffies" followed this Norse custom also.

Forty years ago the Loch Fyne skiffs were small open craft of about five-and-twenty fect over all. They were undecked, and they were towed, a couple at a time, by the smacks to engage in the seine-net trawling. The next step was to be independent of the smack, so instead of the hands sleeping on board the latter they had huts on shore. From that it came about that the skiffs developed into a larger size, and so the crew were able to live on board. The bigger type of skiff was found generally more advantageous, and could hurry ahead very quickly and much faster than the oared boats as soon as a shoal of fish was descried. The smaller examples of this boat are still used for white fishing.

As we leave Scotland with its Norse-like hulls and its lugs, we do not instantly get away from the Norwegian influence. The coast of Yorkshire is famous for its special breed of boats, although to be correct this type belongs to a region that reaches as far north as Northumberland and as far south as Great Yarmouth. The cobble has been called the most peculiar type of craft to be seen anywhere on our English coasts, but she is peculiar only, relatively speaking, just as the Viking ship to-day would be called curious among modern vessels. Like the Scotch fishing-boat, and for the same reason, the Yorkshire cobble is of Norwegian descent. Time has brought about sundry modifications as to detail, which is inevitable; but as a whole the cobble, even as seen to-day, is very Scandinavian in her appearance. They are not the type of craft to suit every one, for they have such special peculiarities of their own that only the expert can handle them. They have been called incomprehensible craft, but as one who has known them for over a quarter of a century and watched them out in all 


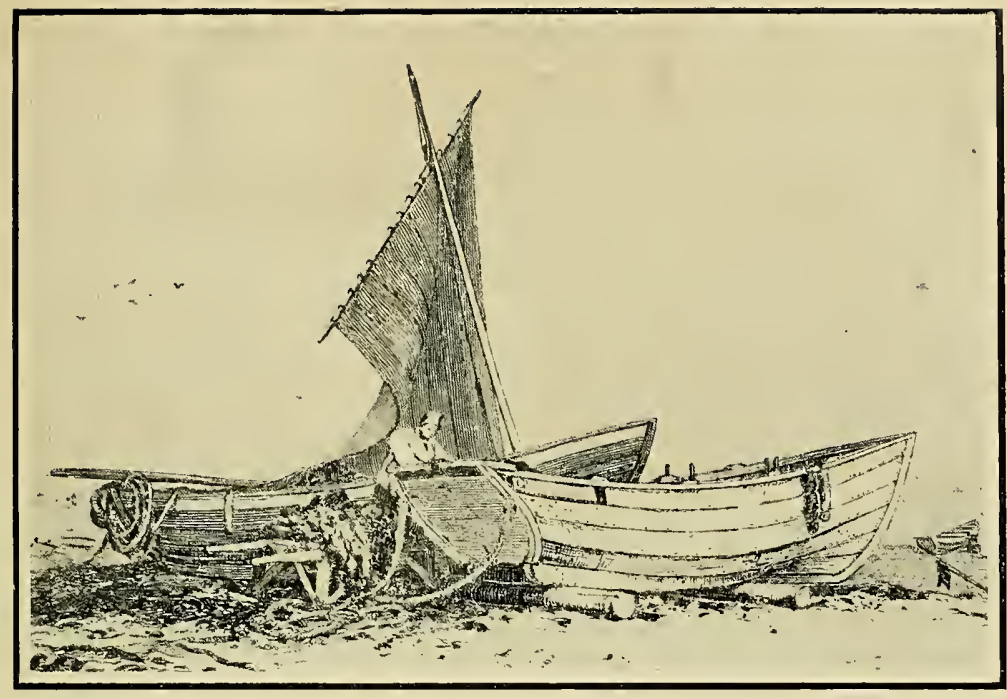

Fig. 55.

\section{Old Yarmouth COBble}

P. 229

This is now an obsolete Norfolk type, but it was in use during E. W. Cooke's time. With its transom stern and its lugsail and bilge keels it much resembles the older type of Yorkshire cobble.

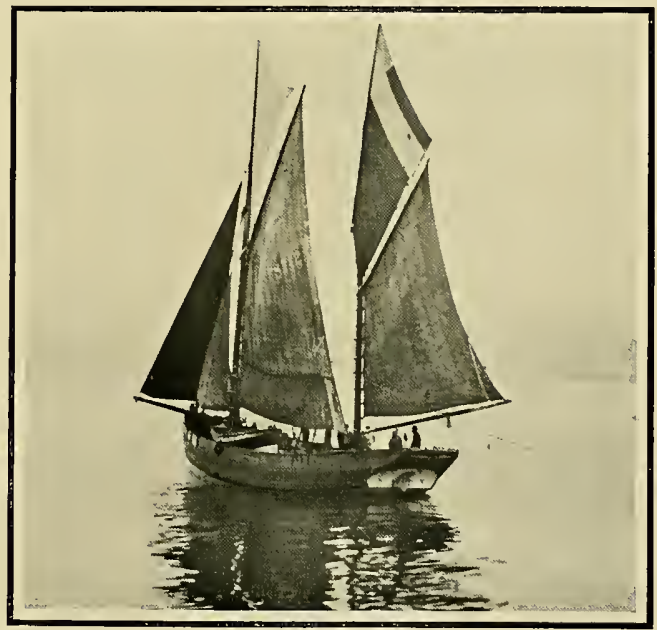

Fig. 56.

SCARBorough KeTCH

P. 229

This is one of the vessels engaged in North Sea line-fishing. Like the Lowestoft dritters she has no boom to her mainsail. 



\section{IN GREAT BRITAIN AND AMERICA}

weathers, it seems difficult to realise that this stigma should attach to them.

They are indeed crotchetty creatures if not handled in the right way, but their existence is reasonable if we remember firstly their Norwegian ancestry, and secondly the purposes for which they have always been intended. They date back before the time when deep harbours began to be made, and they are practically a kind of whale-boat, but designed specially for beaching. Like the ships of the time of ancient Greece, they are beached stern first, and for this reason the floor runs aft very flat, bilge-keels being below that so as to keep them upright on the sand. Their greatest draught is forward, where the keel is able to get a good grip on the water. The stern of the pure type of cobble is broad and square, and the entrance is fine, while the bows have plenty of freeboard. They go to windward, but when running free they are very erratic and dangerous craft except to the man who has been brought up in these boats ; and along the coast-line of Northumberland, Durham, and Yorkshire many a disaster to these craft has come in spite of the hereditary ability of their crew. They tend to run along too fast and to gripe very badly and then broach-to. $\mathbf{A}$ wave then fills them up, and before long the cliffs of Flamborough look down and see yet another addition to the long list of cobble casualties.

If she is out in bad weather and seems to be taking charge, a hand is sent forward to stand by the halyards of the lugsail ready to lower instantly if need be. On a wind these craft are no dull sailers, and it is a treat to watch them running along near the land in a nice off-shore breeze. The rudder of these boats comes down a good four feet below the keel, and herein north would seem to meet south. For it is this same peculiarity of deep rudder which is noticeable in the sailing vessels of Venice and the pilot and fishing craft of Marseilles. The rig of the cobble consists of a lug, 
but sometimes a jib is carried on a temporary bowsprit. In effect the deep rudder acts as a centreboard aft to make up for the lack of grip which only the forefoot possesses. The cobble is poled off from the beach just as was the custom of the old Greek ships, and as soon as deep water has been reached the rudder is placed in situ and the sail is quickly hoisted.

The harbours of Whitby, Scarborough, Bridlington, and the beaches of Filey and elsewhere on this part of the coast afford plenty of opportunities for studying this Norse-like craft. 'Their lines are not displeasing to the eye, and the sheer is especially attractive. Clinkerbuilt, like the old Norse craft, with a raking transomstern and a raking mast on which a dipping lugsail is set, a long tiller is provided for the helmsman. The smaller type of cobble measures about $28 \mathrm{ft}$. long, $5 \frac{1}{2} \mathrm{ft}$. beam, and is $2 \frac{1}{4} \mathrm{ft}$. in depth, the capacity being three tons; whilst the larger type, capable of carrying nine tons, is just under $34 \mathrm{ft}$. long by $10 \mathrm{ft}$. wide and $4 \frac{3}{4} \mathrm{ft}$. deep.

But at Filey and Scarborough there is now built a slightly different type of cobble called a "mule," and it is this species which is here illustrated in the accompanying photograph of a Yorkshire cobble running into Scarborough harbour under reefed canvas (Fig. 54). These "mules" have not the transom but a whaler stern, as will be noticed, the reason being that this whaler-ending is better for running before a big sea and wind. These boats are rowed not by means of the usual pattern of oars and metal rowlocks. Instead, there is a single thole-pin, and a kind of cringle is attached to the oar, which broadens out at its centre. The cringle slips over the thole-pin, and thus the oars can be immediately let go and allowed to float on the water without any fear of their breaking adrift. The only part of the country where I remember to have seen these oars on the south coast is in Lulworth Cove.

As to the now obsolete Yarmouth cobble, the 


\section{IN GREAT BRITAIN AND AMERICA 229}

accompanying illustration (Fig. 55) after Cooke, done in 1828, will afford a good idea, and show the kinship between the transom-sterned Yorkshire and the transom-sterned Norfolk types. In the latter, as in the former, the bilge-keels for beach work are seen here to exist. The rudder came down several feet below the keel, and the other features of the flat floor aft and the deep forefoot were also preserved in the Yarmouth type as long as it lasted. Recent years have made many changes in the vessels of Great Yarmouth, but it is worth noting that by reason of its double proximity both to Norway and to Holland there should have continued till well into the middle of the nineteenth century a type of the Scandinavian craft as seen in the cobble, and of the Dutch craft as seen in the beach-yawl.

As late as the 'seventies the rig of the North Sea fisherman was the lug, but, as we saw in the case of the yacht's evolution, the tendency of the fore-andafter throughout her history has ever been to increase in size, and if in size then in sail-area. Now there comes a point when the lugsail is found to be of too great a measurement to be handled either conveniently or with safety. Therefore the ketch rig with all its handiness-its sail-area cut up so as to be capable of being managed with the smallest crew and with the minimum of effort, its convenience for working into narrow harbours and through narrow channels-was adopted. In the accompanying photograph (Fig. 56) is seen a Scarborough ketch of a somewhat old-fashioned type engaged in line-fishing. Like her the Lowestoft drifter has no boom to her mainsail, though she carries one on her mizzen.

It is a fine sight to witness the harbours of Yarmouth, Lowestoft, and Ramsgate when the fleet of fishing craft are in port. It is fine to regard the forest of masts representing so many able fore-and-afters that can face almost any North Sea gale with pluck and 


\section{THE FORE-AND-AFT RIG TO-DAY}

endurance, confident of riding out the worst weather in a manner that brings credit to a fine breed of ships and men. But, sentimentally, it is sad to find that the steam trawler is causing these ships rapidly to become obsolete. In some parts of the coast, notably in Scotland and Cornwall, the auxiliary motor is fast becoming recognised as the handmaid of the sail; yet the stress and hurry of shore life are having their effect on the fishing trade, and so on the ships themselves and their means of propulsion. But Ramsgate still sticks to its sailing fleet; its harbour is not exactly suitable for steam fishing vessels, and they who would be sorry to see such fine craft as those which put to sea from the Kentish port will not be sorry that local conditions are unfavourable to the mechanically propelled ships.

One of the most interesting features of the busy Thames estuary is the bawley, some idea of which is to be obtained from the photographs (Figs. 57 and 58). Of these, one (Fig. 58) is a pilot craft, the other a fisherman. In this rig we come back again to find something of the Dutch influence still preserved; for, with her gaff-but boomless-mainsail (which is shortened. by means of brails) we have the identical principle which the second Mary yacht of Charles II. possessed in her rig.

What especially strike the eye are the very long bowsprit and gaff which these bawleys are given. And yet they are both fast and handy, and the brailing arrangement enables them quickly to get snug when bad weather comes up. For the seas of the Thames estuary, with their deep hollows and short, steep waves, are sometimes as much as a small craft can tolerate. Dodging in and out among the shallows and sandbanks these craft must needs be both handy and good sea-boats. The topmast is a long one, but as soon as it is housed the bawley is able, with her shortened canvas, to render a very good account of herself. She can quickly trice up her tack, brail in her main, set a small 


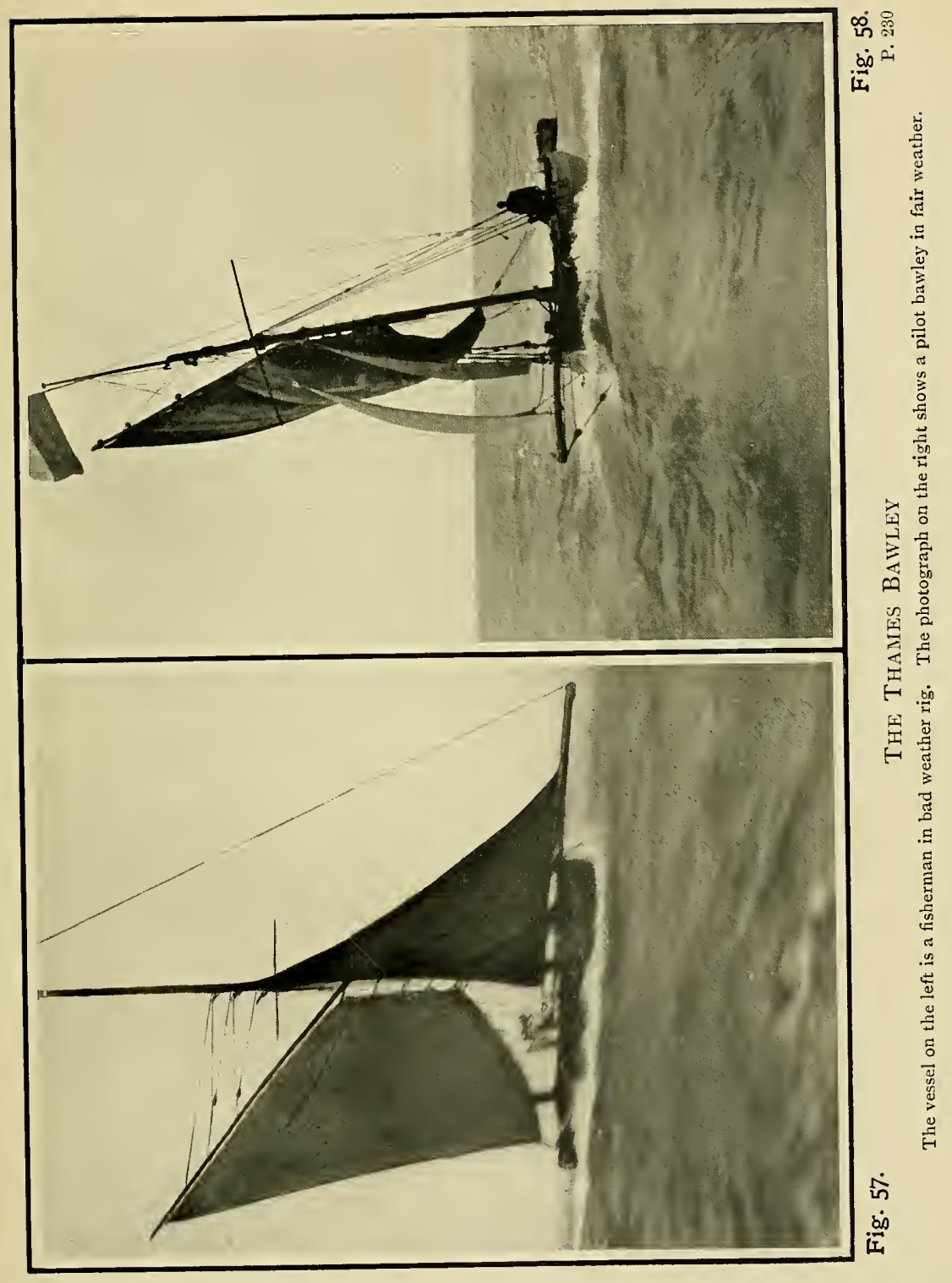



storm-jib, and she is ready to fight her way through the bad weather which is breaking over her. Frankly, she is not a pretty craft, but handsome is as handsome does. Her topmast is actually several feet longer than the mast, and in fine weather she sets a topsail of considerable size. But whatever her merits as a seakeeping craft, as a wage-earner; whatever her defects may be as a sightly craft, she is to us, who have watched the evolution of the fore-and-aft rig, of special interest owing to her resemblance to the seventeenth-century rig of Holland. She wisely does not yearn for a sprit, though in other respects she has many similarities to the Thames barge. Not in hull but in the style of her rig she is the one example of the cutter, which is very like the sloops that were seen in Holland and England three hundred years ago.

It is highly probable that her origin may be traced directly to the time when the Thames estuary was accustomed to seeing much more clumsy craft, yet with a rig that survives to this day in the same waters. We may compare these photographs with the frontispiece and the Van der Velde sketches of this book, and we shall find that though in the modern craft the bowsprit is not steeved as it was, and that the square topsail has disappeared, yet otherwise the principle is the same. That this seventeenth-century rig should in the twentieth century be still found satisfactory, and so little modified as in these bawleys, is proof enough of the high rank of perfection to which the Dutch shipman of yesterday should have attained. He, indeed, was living at a time when invention was neither as rapid nor as easy as to-day. And yet when put face to face with similar problems as confront our modern shipmen, he was able to evolve a very satisfactory and useful solution.

And whilst we are in the Thames estuary and are speaking of Holland, let us not forget to mention the Thames barge, to whose characteristics we have been 


\section{THE FORE-AND-AF' RIG TO-DAY}

compelled to allude on several occasions above. It was because the set of conditions that obtained in the Dutch waterways was in many respects reproduced over here in the Thames and Medway that a similarity of rig, modified for local peculiarities, should also be adopted. Consider for a moment what these conditions are. The Dutch cargo-carrier had to be not too big to be able to pass into the locks. She had to be sufficiently handy to work short tacks, and she could not draw much water. But since wind against tide in the Maas and the Scheldt quickly raise a nasty sea, these vessels had to be fit for something more than mere smoothwater sailing. In order to render them capable of being worked by a small crew, and to facilitate shortening canvas immediately, some system had to be employed that would not ruin her speed too much. Thus, to satisfy all these requirements, the Dutch created a big-bellied, round, shallow craft, with staysail and spritmainsail, with leeboards, with adequate freeboard, with decks, with brails, and so on.

The Dutchman was given a flat floor so that she could take the ground. The Thames barge is flat for the same reason - so that she may be able at high water to get right alongside the wharf and, when the tide ebbs, she may be able to sit upright and load or discharge her cargo. The barge also must be both handy and seaworthy: she must be able to turn to windward in narrow, and nowadays exceedingly crowded, reaches. And she must be able to go through the amount of sea-work for which she is intended. The Scheldt and the Thames have much in common in so far as the conditions of sailing are concerned, and a good, strong, weatherly type of ship is essential for either waters. Therefore, it is not surprising that a similar rig and the employment of those Dutch leeboards should have been chosen. The vangs to prevent the peak from sagging too far to leeward, and even some of those crude but pleasing colour contrasts are also preserved, 


\section{IN GREAT BRITAIN AND AMERICA 233}

as, for instance, where the tackle comes down from the throat to support the sprit.

But there are certain qualities of the Thames barge which do not belong to the Dutch prototype. The former is more angular than her chubby sister, and she sets a small mizzen to assist her steering. And the Thames skipper is glad to have this sprit rig, for the reason that it gives him a clear space on his deck and hatches when brought up. His cargo can be discharged or stowed without any impediment. There is no gaff or boom to get in the way, and he can even rig up at the end of his peak a big pulley-wheel to aid in hauling out the contents of his hold. She has all her canvas tanned with the exception of her jib staysail, which her skipper calls a "spinnaker." It is only when he is in a bad sea, as we stated in an earlier chapter, that the barge's sprit, with its heavy weight swinging from side to side, causes the crew grave anxiety. Otherwise for estuary work in fine weather and river sailing there is no more suitable kind of craft or rig. 'The average size of the Medway barge is 40 tons (registered), length $78 \mathrm{ft}$., beam $17 \mathrm{ft}$., draught $6 \mathrm{ft}$. She is an adept at "ditch-crawling" and tide-cheating, and her high topsail enables her to catch the breeze as it filters through between the high wharves and chimney-pots on either bank; but her full sail-area is about 400 square yards. At the back of your mind you may despise the Thames barges, but when once you have turned to windward in their company you begin to have a respect for them no less than for their skippers. The Dutch fore-and-aft sailor-men who are wont to visit the Thames have an undisguised admiration for these our craft and seamen, and that tribute from a nation of such thorough seamen is worth having. There are roughly three types of the Thames barge, one of which is intended solely for her work on the Thames, the Medway, and such short trips as northwards to Yarmouth and Harwich, 


\section{THE FORE-AND-AFT RIG TO-DAY}

and southwards to Ramsgate and Pegwell Bay. This is the type of barge which carries a topsail that is still evidence of the days that are gone. It is not a jackyarder nor a square topsail, but somewhere between the two-another of the numerous British compromises.

The second type of Thames barge is the stumpy, which carries no topsail, has a short pole mast, has no bowsprit nor jib. But the third type is a larger development of the first, a craft that is capable of doing quite long coasting voyages down Channel, across to France and the Low Countries, northwards to the Wash, and so on. In them the diminutive mizzen which one sees on the vessels that come swinging down with the tide under London Bridge has become of considerable size, so that the rig is practically ketch, and the mizzen is as important to the barge as to the fishing-smack. The type of hull in these sea-going craft is also a bolder and more powerful type than that of the Medway class. It is wonderful what weather they will stand-up to a certain point. When once that point is transgressed there is trouble. It is not so very long since two of these bigger barges actually sailed on their own bottoms across the Atlantic from England to South America, but about the same time also two others foundered in a winter's gale off Newhaven.

We can see by comparison of the drawings of Cooke and others how much the modern type of Thames barge has improved during the last hundred years. The lines of the "stumpy" of that time were practically those of the modern dumb barge which one sees being rowed down with the tide through the bridges of the metropolis. The cut-away bow and the stern with its deadwood are very similar to the barges of to-day, except that in those days they were of wood and not of steel. Some of the sailing barges, according to Cooke, were cutter-rigged, with gaff and 


\section{IN GREAT BRITAIN AND AMERICA 235}

loose-footed mainsail, staysail, and sometimes a jib set on a bowsprit capable of being triced up, the aforesaid bowsprit being steeved at a considerable angle as in the old Revenue cutters. The topsail was quadrilateral, the head being laced to a very short yard. They had no mizzen whatever, and their hulls were also very similar to those of the old stumpies. These were known as sloop-rigged barges (Fig. 59), but nowadays since the little mizzen is so useful in assisting the steering, the sloop-rig is not found in the barge class of vessels.

Sometimes the yawl-rigged barges of a hundred years ago are shown with two square-sails additional to the ordinary rig. That is to say, they would carry a jib on the bowsprit, a staysail, a spritsail, and the tiny mizzen; but for running free a large square-sail with sheets as well as braces was set, and above this also a square topsail as well as a fore-and-aft topsail set over the spritsail and laced to the topmast. Cooke shows (Fig. 60) just such a vessel and just such a rig as this in Northfleet Reach, the only minute difference being that as the wind is so free the bowsprit has been triced up and the jib stowed, but the other sails are all set as mentioned.

We have to pass down half the length of the English Channel before we come to the western type of the barge. Portsmouth has in its time seen practically every kind of vessel that has been afloat. It has seen the Viking ships of the Norsemen as well as even the Mediterranean galleys in the time of Henry VIII.; and we could go through time enumerating a plethora of other classes which have been floating in the waters of Spithead. But the Portsmouth type of barge such as trades up and down Spithead, the Solent, and Southampton Water, Chichester and Langstone and Bembridge harbours - fetching gravel from the Shingles off Hurst Point to help to build break waters or the like, and carrying cargo between Portsmouth and South- 
ampton-is a somewhat inferior species of that class which the Thames has evolved owing to the influence of Holland and the peculiarity of the London river and Medway.

But there is another type of two-master which is familiar to all who cruise along between the Isle of Wight and the mainland. She is becoming obsolete in these days of steam and motor cargo-carriers, but she is not quite extinct. I refer to those tubby blackhulled vessels to be seen in Cowes and Southampton and other ports of this district. They are a kind of south-country type of the billy-boy, and with their rails running around the deck are reminiscent both of the Humber "keels" and the Mersey lighters. In the accompanying illustration (Fig. 61) Cooke shows one of these Solent vessels coming out of Cowes harbour.

The origin of the Deal lugger I am inclined to attribute to the close proximity of this coast to Belgium and France. More strictly speaking this applies to the rig rather than the hull, for the latter is really the outcome of certain essentials demanded by the peculiar nature of the work which they are called upon to undertake. She must be able to sail well and be fairly light to row. She must be suitable for hauling up the beach, for running out to the Goodwins in all sorts of weather, or for bringing off pilots from outward-bound steamships. The story of the Deal luggers would alone furnish one of the most interesting and exciting of true romances ever written, and it is remarkable the amount of weather these small craft can endure. It is, indeed, owing partly to the nature of the little ships themselves, but it is still more due to the human element-the skilful handling of an exceptionally skilful breed of seafaring men.

In olden times - that is to say, in the eighteenth century-these Deal "cutters," as they were then known, were rigged with three spritsails, the mizzen 


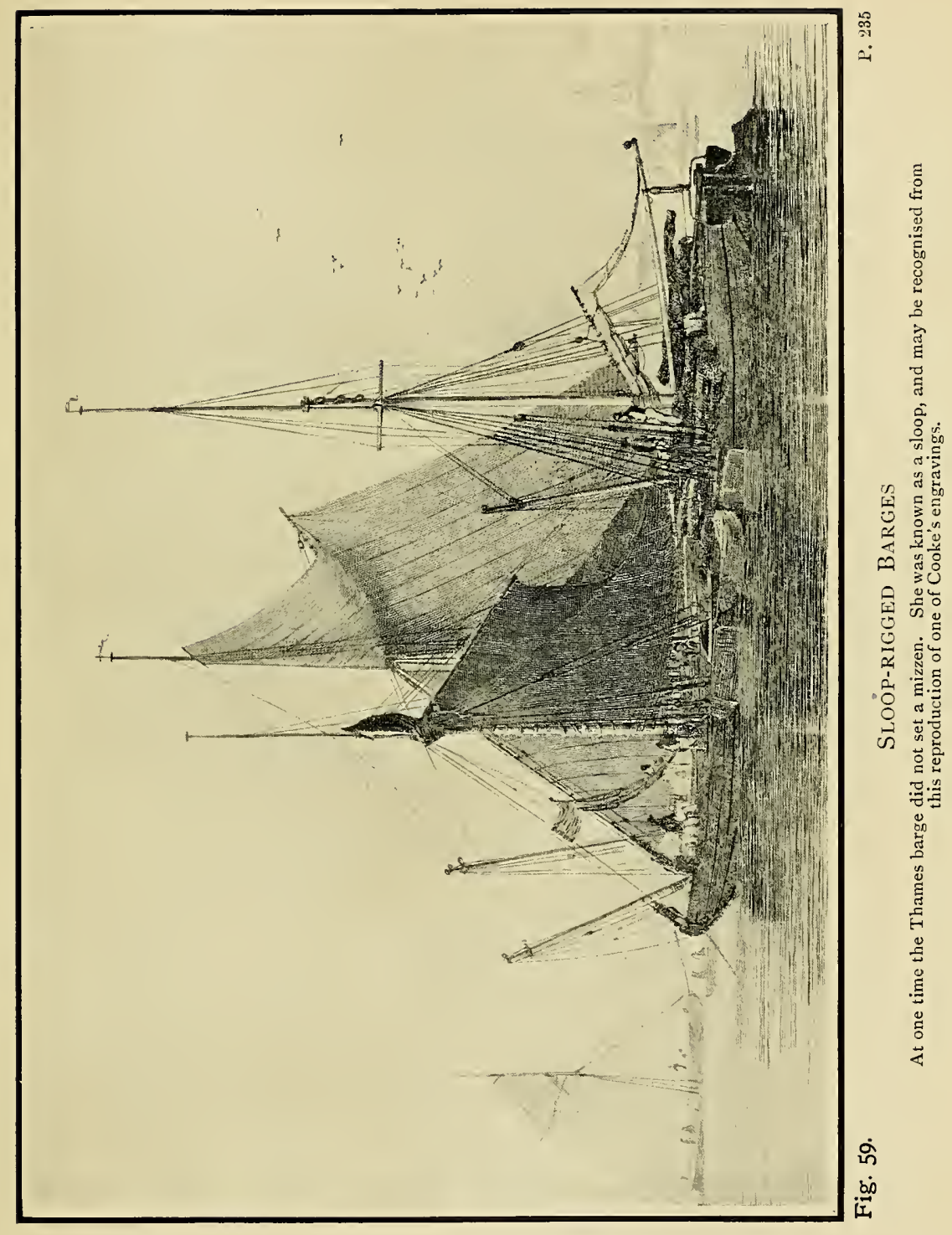





\section{IN GREAT BRITAIN AND AMERICA 237}

having a bumpkin, whilst a jib was set forward. But for the sprits, therefore, these craft were somewhat like the small fishing-boats of the French coast, which were afterwards to develop into the larger chassemarées. Nowadays this type has disappeared, and the demand is for a smaller and handier type that goes "hovelling" anywhere between Dungeness and the Forelands.

Pilots tell you that it is wonderful how much sea these craft will go through, manned by a crew of two or perhaps three "knock-toes" (so called because of the well-known habit of these men of standing, hands in pockets, knocking their feet against the boat on the shore while they yarn and gaze out seawards), but with the strong tides in the vicinity of the Goodwins and the ferocious seas which can get up here in no very long space of time it may be hours before the galley has covered the distance between the liner and the shore, and the pilot has at last been enabled to land. The remuneration for this service is certainly not bad, and the occasional salvage work which the Goodwins bring them and the attention, which weather-bound sailing-ships brought up in the Downs sometimes need, enable the Deal men to keep going.

These craft are of two kinds. Firstly there is the larger lugger with two masts and lugs, and secondly there is the smaller galley-punt, in length somewhere between twenty and thirty feet. The lug is very square-headed, they seldom reef unless the weather is exceptionally bad, and they sail remarkably close to the wind. Long, deep, and narrow, the bigger class is rivalled only by the shorter, heavier, and beamier galley-punt. There is another type of galley to be seen across the water, in Flushing, where the Dutch and Belgian pilots are stationed and keep continual watch from their two club-houses side by side. This Dutch galley is very similar to the Deal class, and 
we shall speak of her when we come to discuss the fore-and-aft rig abroad.

We pass on now to discuss the west country and its characteristic fore-and-aft ships. We run across West Bay after rounding the Bill of Portland, and look into the little fishing harbour of Brixham, just inside Berry Head, and here we find none of the steam trawlers of the North Sea ports, but an entire fleet of sailing vessels. In the evolution of the fishing craft and of trawling gear the port of Brixham occupies a most important place. It has raised up a haidy race of seamen from the time of the 'Tudors and earlier to the present day. And its vessels are like its men-hardy, sturdy, strong, and made to wrestle with the sea. I have met them out at sea, studied them in port, watched them at their work by night, seen them thrashing to windward downChannel in a hard blow, and stealthily doing a little poaching where the high cliffs of Devon and the lack of moon assisted them.

There are two types of the Brixham fishing craftone small and the other large. Of these the smaller ones are called "mumble-bees" and are rigged as cutters. They measure about half the size of the other type. The larger size are ketch-rigged like their North Sea sisters, and measure about $70 \mathrm{ft}$. in length over all, and are of about 60 tons. Worked by a crew of four, the ketch carries 900 sq. ft. of sail, has a beam of $18 \mathrm{ft}$., drawing $10 \mathrm{ft}$. of water aft and $9 \mathrm{ft}$. forward. With the long, straight keel and straight stem, these are wonderful craft for reaching. The forefoot is scarcely cut away. They are heavily and massively constructed, and so they carry a great deal of way on them and are remarkably powerful, sea-keeping vessels. The characteristic of these west-country trawlers is the very large staysail, which immediately strikes the sailing-man who has come round from the east coast. Their masts rake 


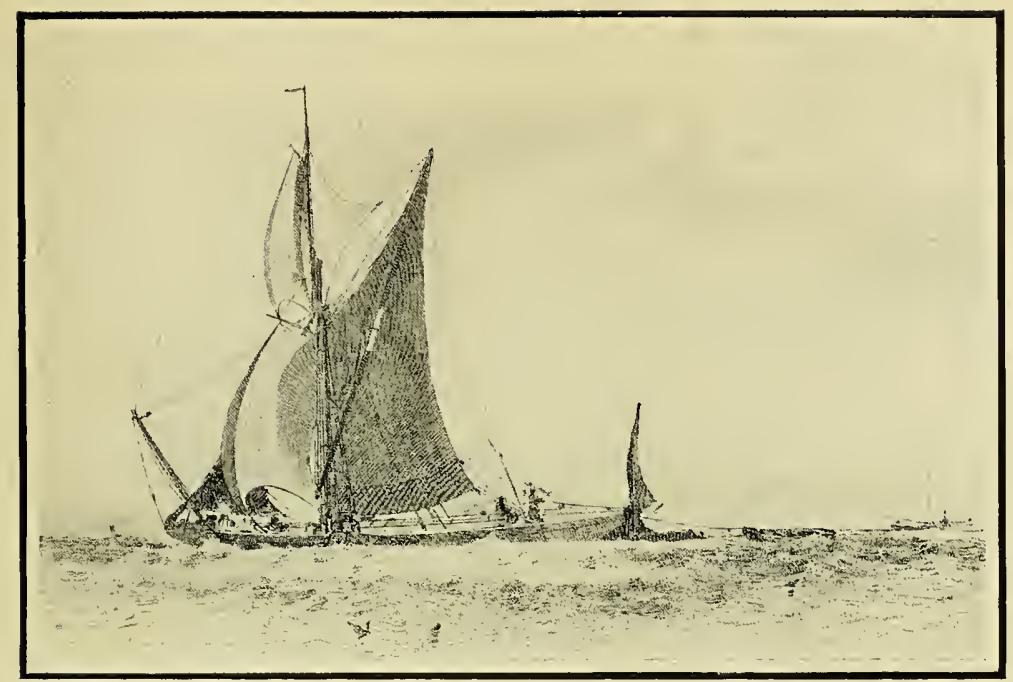

Fig. 60.

Old Thames Barge ivith Squaresails

P. 235

Nowadays the barges of the MIedway and Thames do not set any squaresails when running, but one may see them sometimes bring their jib topsail (which they call a spinnaker) aft and set it like a racing yacht's spinnaker.

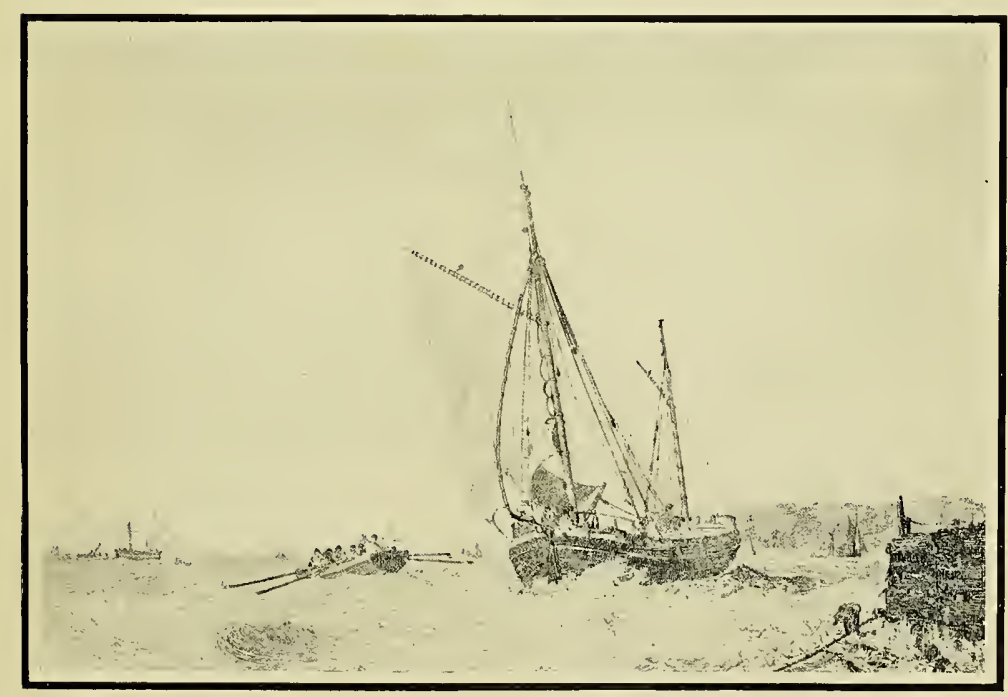

Fig. 61

Cowes KETCH

P. 236

This shows a South Coast counterpart of the Yorkshire Billy-boy. (After E. W. Cooke.) 



\section{IN GREAT BRITAIN AND AMERICA 239}

forward, not aft, and they are very fond of setting their topsails even over double-reefed mainsail, as the men say that the topsail steadies the gaff in a seaway. Historically it is the Brixham men who have influenced Ramsgate, and so Yarmouth and Lowestoft, to use the ketch-rigged fishing vessels.

Although before the time of the Norman Conquest the men of Kent were engaged in the herring-fisheries, yet the men of Devon, especially of Brixham, Dartmouth, and Plymouth, have always been distinguished sons of the sea. It has even been said that Brixham was the first port in this country which ever developed the fore-and-aft rig. Possibly there were here in the sixteenth century some such craft as that shown in the map of Master Robert Thorne alluded to and illustrated in one of our earlier chapters.

Torbay and the proximity of the English Channel were more conducive to an acquisition of the arts of sailing than the strong tidal waters of Kent dotted with innumerable shoals and sand-banks. Consequently a great school of seamen grew up in Devonshire, who married into each others' families and voyaged, fought, and fished together. Nephews and sons were taken out across the Atlantic to fish off the Grand Banks, even in mid-Tudor times, by their uncles and fathers. But for this keen Devonshire race of seafaring men, trained by their life as fishermen, there would have been no Drake, nor a good many other illustrious sailors who saved England and enabled her to retain her independence and liberty. They are still a conservative people, and in spite of the advantages which the motor has been demonstrated to possess, they have decided to have none of it and to hold to the type of sailing fore-and-after which has earned them their living for so long a time. But the fishing industry is not what it used to be, even though nowadays they have to cruise further ahead and go round the land beyond the Bristol 
Channel and the Welsh coast. But it will be a pity if for any circumstance Brixham should ever lose its fine fleet, and still more if it should cease to rear such exceptional seafaring men.

As we proceed further westward we come to the Plymouth hookers, where the old Dutch word is still retained, and some slight Dutch resemblance in their sail. That is to say these cutters, whilst they have not the brailing arrangement of the Thames bawley, have the boomless mainsail and the long gaff which we spoke of above. The sheet is attached to the clew by means of a long hook which cannot shake out of the sail by any amount of flapping.

Naturally, the absence of a spar along the foot of the sail detracts from the latter when the vessel is sailing on a wind, but any one who has had to endure the threshing about of a boomed-sail in the Channel will sometimes have felt inclined to envy those Plymouth hookers. It is quite a vertical cut which is given to the leach, so that the general impression is of a high, narrow sail-the very reverse of the shape of the modern Dutch craft with their short gaffs, and the sail broadening out the nearer it approaches the foot. Far west though Plymouth is, yet nevertheless the hooker has some historical connection with Holland, as its name and sail imply. And this is all the more surprising, because the other craft of the neighbourhood, both in Devon and Cornwall, show no such intimate connection with the Low Countries.

Cornwall, like Scotland, is the country of the lugger, but there is a difference of types. The Cornish craft is, owing to the geographical proximity of her county, more akin to the French type of lugger than is the North British fisherman. We spoke just now of the Scotch zulu, which was really a compromise between the Fifie and the Buckie boats. The latter was a flat-floored craft and sailed exceedingly well. Her sternpost raked aft a good deal. But 


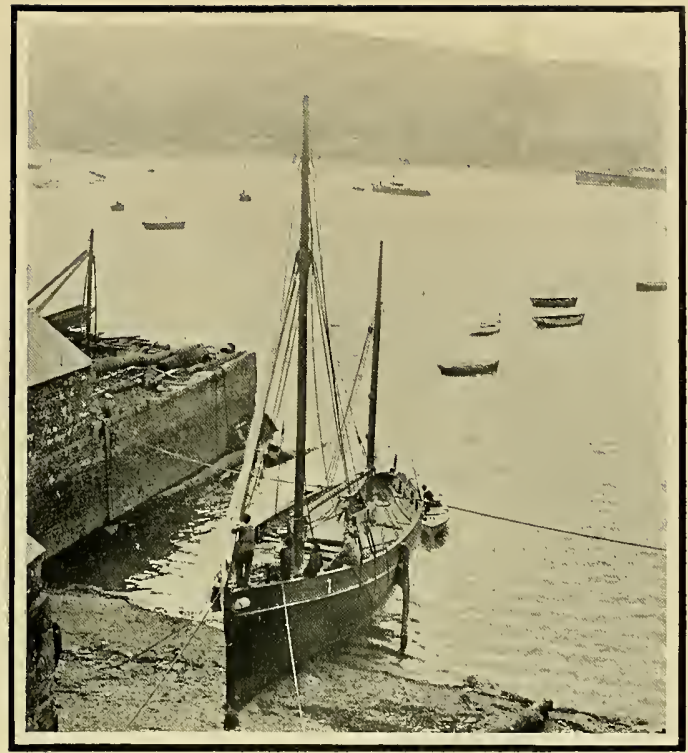

Fig. 62.

CORNISH Fishing CRAFT

P. 241

This shows a West Country craft which has discarded her characteristic lugs for the rig of the ketch.

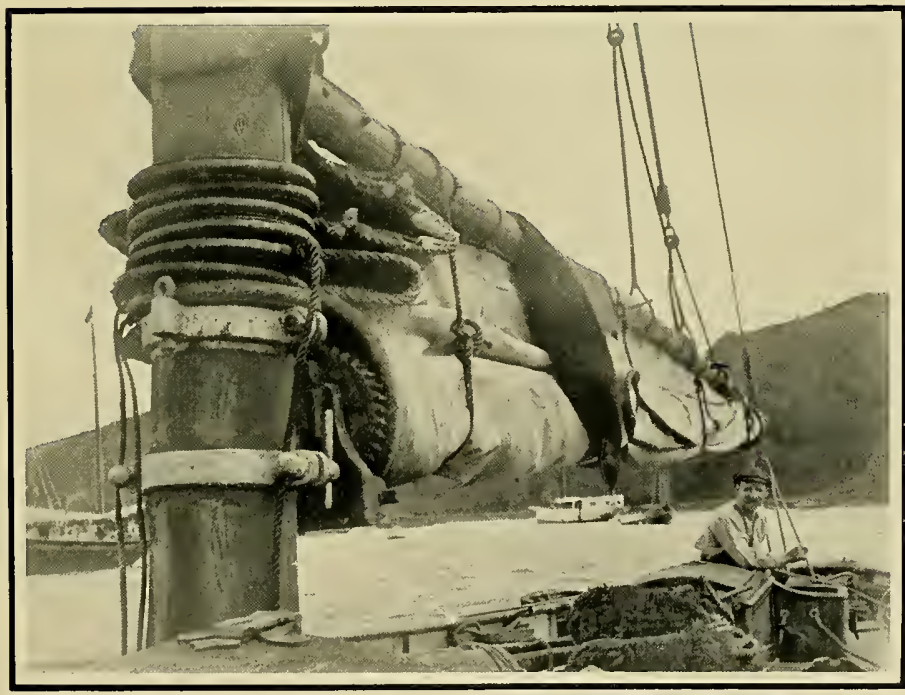

Fig. 63.

P. 243

Reefing Gear of Bristol Channel Pilot Craft

The set of cogs will be seen in the foreground on the boom, and by means of worm gear and handle the boom is revolved and the mainsail reefed. 

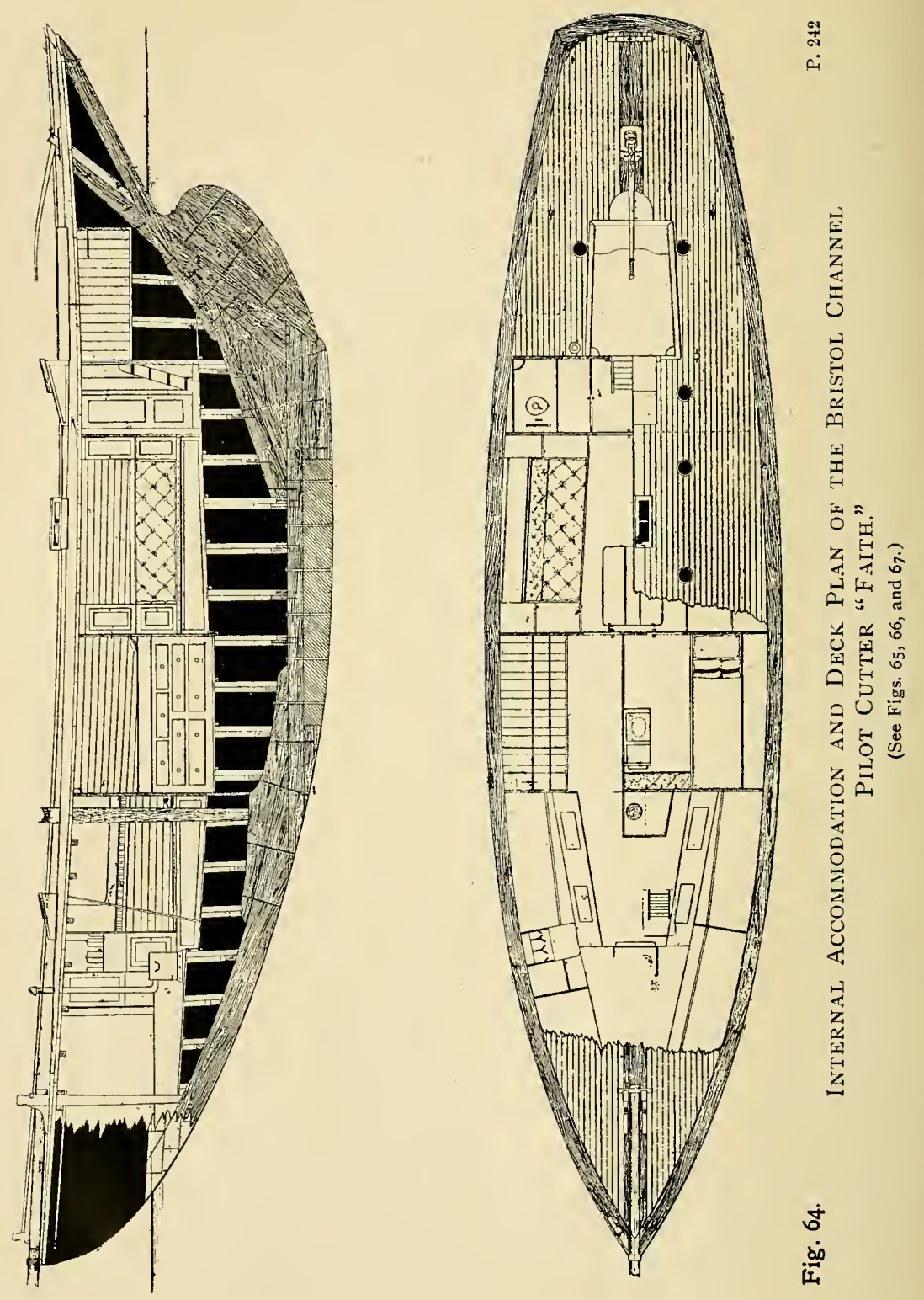


\section{IN GREAT BRITAIN AND AMERICA 241}

the Cornishman draws more water aft than the zulu, and she carries a larger mizzen than her northern sister, over which she sometimes sets a topsail. They have easy lines, these west-country craft, and high bulwarks, together with an exceedingly long outrigger aft for the mizzen, and this spar comes up at an exceptionally high angle, being steeved somewhat after the manner of the old-fashioned bowsprits. These Cornish luggers have both speed and seaworthiness, and their mizzen-mast has more hoist than the Scotchman. Occasionally they set a bowsprit and jib.

There are few more beautiful sights than to watch a fleet of these vessels putting to sea just before sunset, from Mevagissey or some other Cornish port, and though they have the drawback of their lug-rig in having to dip the sail at each tack, yet on a wind they have a speed that is surprisingly fast. Some idea of their speed may be gathered from the achievement of a trio of Penzance drifters, named respectively the Nellie Jane, the Emblem, and the Children's Friend. These on one occasion a couple of years ago sailed in company from Mount's Bay up the whole length of the English Channel, round past the Essex coast, up northwards as far as Scarborough. They were becalmed at the outset in Mount's Bay for some time, and when off the Yorkshire coast in a heavy squall they were compelled to lower sail altogether, but otherwise they scarcely had need to touch tack or sheet the whole trip. But, even including this, the long run from one end of England to the other was accomplished under three days, the actual time being seventy hours.

Nowadays one sometimes finds these west-country luggers have their rig altered to a ketch, and in the accompanying illustration (Fig. 62) such a craft is seen. But they tell you that this transformation is not altogether a success, and that these vessels which are designed for a couple of lugs are better so sailed. The size 
of the Penzance luggers is usually about 27 tons, with a beam of $13 \frac{1}{2} \mathrm{ft}$. and a draught of $7 \mathrm{ft}$.

And now let us run round the land to Bristol Channel, the home of some of the finest fore-andafters in the world, in the shape of the Bristol Channel pilot-cutters. For three things collectively these craft are probably unrivalled by the vessels of any country or indeed any port. These three qualities may be summed up under the heads of speed, seaworthiness, and handiness, and for these reasons this type of pilot-cutter makes one of the soundest models for the modern yachtsman to aim at if he desires a good ship of moderate dimensions. I have watched these splendid craft being manouvred in a crowded harbour with the ease almost of a small rater. And yet they are designed so as to be able to encounter any amount of bad weather.

The Bristol Channel itself is notorious for the alarming strength of its tide; and with a south-west wind against this there rises a sea that may well strike terror into many small craft. But these yacht-like vessels have to go out for many a mile to pick up their job, round Land's End, perhaps half-way up the English Channel. There may be three men on board the cutter, perhaps only two sometimes. One of them gets the dinghy overboard as they come abreast of the big steel-liner, and rows off to the latter. As he climbs up into the great steamship he kicks off the little dinghy, the steamship's telegraph clangs down in the engineroom, and her engines begin to move again. Then when she has gone, the pilot-cutter sails down, heavesto, and hoists the dinghy on board again. Then-all single-handed the while-the one man sails his ship back day and night home.

We may well admire both the craft and her crew able to do these manœurres so well. But of course the cutter is supplied with the best possible devices to increase her handiness and save labour, and it is these 


\section{IN GREAT BRITAIN AND AMERICA 243}

features which make her so extremely interesting. In the accompanying illustrations will be found ample opportunity of examining some of these. We shall deal with her lines presently, but for the moment let us just notice her reefing-gear, which is used for the mainsail. 'This is the arrangement which is in general use among the Bristol Channel pilot-cutters. As will

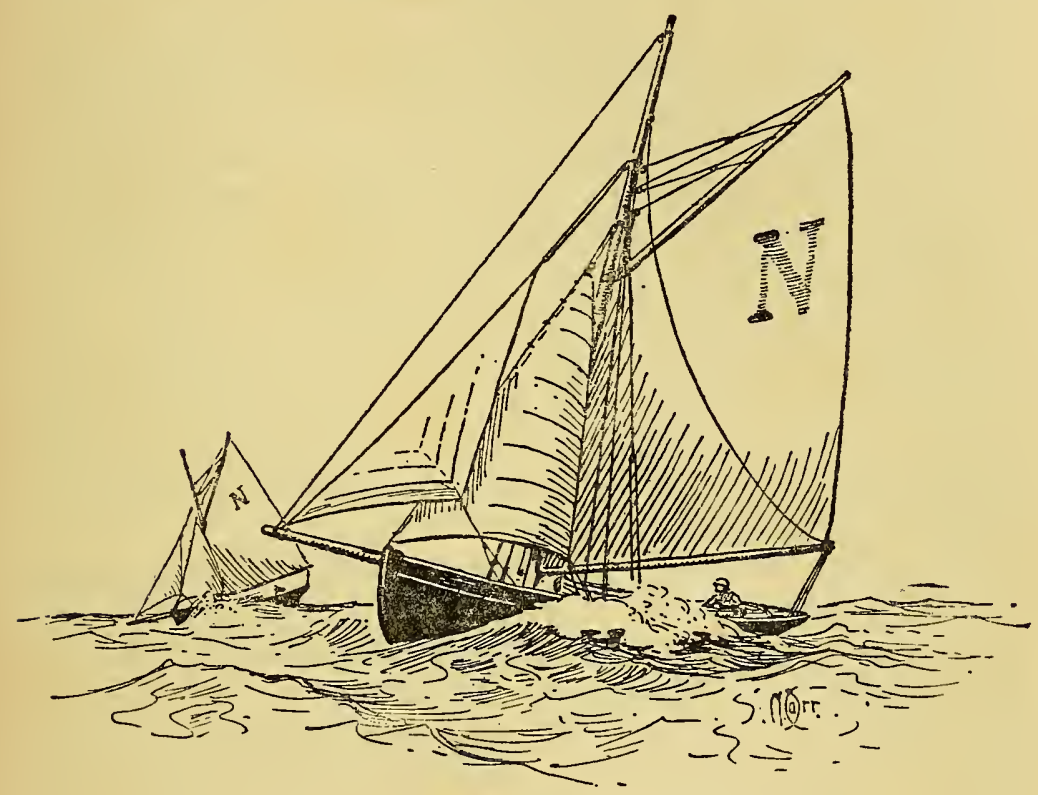

Fig. 65.-Bristol Channel Pilot-Cutter.

This shows two of the smaller type of these craft. Notice that they have no bobstays.

be seen from the accompanying photograph (Fig. 63), taken on one of these vessels, there is at the forward end of the boom a set of cogs. Either below or above these, according to choice, there is fitted into them a worm-gear that is revolved by means of a handle which can be unshipped when not in use. The worm works in the cogs, and thus turns the boom round, and so causes 


\section{THE FORE-AND-AFT RIG TO-DAY}

the sail to roll round the boom after the manner of the domestic window-blind. There is obtained a very considerable power, and the action is immediate; consequently the cutter can hang on to all her sail in a hard blow, and only reef when absolutely compelled so to do.

But it is essential that the boom should not project further aft than the end of the counter, and the pilots tell you that since this reefing-gear was introduced more booms have been broken than formerly, for the reason that the greatest strain occurs in the centre of this spar. But in spite of this the arrangement is both excellent and popular, and a great saving of time and trouble as compared with the old-fashioned method of reefing. I have heard so much praise from actual users-men who were inclined to be prejudiced against it-that it is impossible to think too highly of it. Another excellent practice which these men have is to place two bands instead of one around the mast, though the smaller gears, which are made of gun-metal, fit into an ordinary goose-neck and have but one mast-band.

For further facility in reefing when single-handed, the peak-halyard leads aft; and, as will be seen in this photograph, the sheets of the head-sails lead in through the coaming of the cockpit. The shape of the latter, by the way, as here seen, is very characteristic of these craft. These cutters carry no davits, but they make short work of getting the dinghy on board. This is done as follows : The lee-runner is unhitched and hooked on to lines in the dinghy, and then the crew hoist away on the runner. The result is that the boat comes up with her bow and stern on the same plane. She is then stowed on deck, special chocks being laid down for the reception of her keel, and in the photograph one of these can be noticed at the bottom right-hand corner. The mast is stepped nearly amidships, so that she sets a good-sized staysail, and a smaller jib on a bowsprit of moderate length. 


\section{IN GREAT BRITAIN AND AMERICA 245}

As to the size of these splendid cutters, they vary from $34 \mathrm{ft}$. length over all to $56 \mathrm{ft}$., the beam varying from $11 \mathrm{ft}$. to $14 \mathrm{ft}$., and the draught from $7 \mathrm{ft}$. to $8 \mathrm{ft}$. The newer types have the forefoot curved to a greater extent than the others, which have straight bows. 'The elliptical counters of the more modern class are ideal for sea-work, and the pilots find them less likely to get damaged against the side of the liner in those instances when the dinghy is not launched and the cutter lands her pilot direct. But the older type have square sterns. As I write I have before me the dimensions of the pilotcutter Grace, whose details, taken from an auctioneer's advertisement, are thus: length over all, $50 \mathrm{ft}$. 3 in.; length on water-line, $43 \mathrm{ft}$; ; beam, $13 \mathrm{ft}$. 6 in. ; draught, $8 \mathrm{ft} .6$ in. Like most of this breed she has a flush deck. Her rigging is of steel wire, and she has the patent reefing-gear already described. She has two anchors, about 55 fathoms of cable, punt, "and all necessary fittings appertaining to a pilot-cutter."

For the halyards there are purchases, and in reefing all that one has to do is to slack off the purchase with one hand, after having taken in the slack of the toppinglift, and then turn the handle of the reefing-gear. And it makes no difference whether the ship is running, or on the wind on either tack, the reefing operation being perfectly easy and simple. So easily does the gear work that it is no extraordinary thing for the helmsman, while his mate is enjoying his watch below, to run forward in bad weather and get in the bowsprit, reef the staysail, and roll down the mainsail till it is a mere handkerchief; and all this in the space of but a few minutes. It is not even necessary to disturb the other man below. The cockpits are small and watertight, and there is a leather flap which covers the discharge outlet of the pipe.

'The motion of the ship through the water keeps this flap pressed against the side of the hull, and so prevents any water running up. From the cockpit one steps 


\section{THE FORE-AND-AFT RIG TO-DAY}

into a compartment where the sails and "oilies" are stowed, the dimensions of this space being about 6 to $10 \mathrm{ft}$. long. The saloon has either two or four bunks according to size, with a coal stove in the middle, and on some cutters there is a sleeping cabin forward of this, with the pantry and store in the alleyway. The cooking is done in the large forecastle.

It is a strenuous life, and there is keen competition between these craft, but those which are fitted with auxiliary motors have them sealed, and they are, by mutual agreement, not used when the different cutters sight their liner in the distance and set all sail to be the first to get up to her. Nine months out of the twelve these men are afloat, but the pay is good, for the pilot is worthy of his hire. These vessels, in addition to their virtues of speed, handiness, and seaworthiness, have also the quality of being able to heave-to "like ducks," as it has been said. Forward, the hulls of these splendid cutters have fine high shoulders, and they have a good sheer.

It is asserted that, as indicative of the excellent seakeeping qualities of these cutters, whilst many of them have been run down, yet not one of them has been known to founder owing to bad weather merely. In ordinary weather they carry a small jib, the foresail being as stated a large one; but when it comes on to blow, the jib is stowed and the large foresail does the work. Very interesting and thoroughly sound is the Bristol Channel pilot's idea as to ballast. He does not want a ship that is a brute for rolling: when he is alongside some gigantic liner at night in the swell of the Atlantic, he does not want his brave little craft to kick herself about more than need be. So, additional to the ballast on the keel outside he believes very strongly in placing inside ballast to steady her. It is piled up almost to the water-line, and though the cutter may pitch somewhat, yet she will be very steady with a nice easy roll. As an instance of how steady these 


\section{IN GREAT BRITAIN AND AMERICA 247}

craft are, one authority recently asserted that a pilot told him that when hove-to in half a gale off Lundy, the match-box on a polished table in the cabin had never moved.

In order to minimise the shock of a gybe these cutters are sometimes fitted with special buffers for the mainsheet, and made either of rubber or of a steel spiral spring. Although there is plenty of individuality about the different pilot-cutters of this part of the world, yet they all have a common likeness in respect of the handiness of the rig, the ballasting, the ample beam, and so on. So general has the patent reefing apparatus become that about three-quarters of the fleet now possess this device. These vessels have three shrouds on either side, and some of them have no runners. Bobstays are not universal, and one often finds them discarded, for the jib is small and the spar may have to be run in before long. We spoke just now of the inside ballast, but whilst all have quantities of this, yet there are some which have no external ballast at all. It is rare to provide these cutters with skylights, for some of the seas off the Longships would burst through in a short time, so the usual practice is to insert decklights.

'The shapes of these vessels' hulls differ a good deal, some being very fine forward and full aft, others being very full forward and fine aft, and a few have overhanging bows. Some, again, have rather barrel-shaped hulls, whilst others also have a good deal of hollow. I once came across the Alpha, which with a couple of other Bristol Channel cutters put into Dartmouth. 'This is admittedly one of the crack ships of the class. Although she has a straight stem she is well cut-away at her forefoot. She has turned out to be just what she looks - a fine, able sea-boat. I am able, through the courtesy of Mr. Harold Clayton, the well-known Penarth designer, to include here the design and lines of the Barry pilot-cutter Faith (Figs. 64, 66, and 67). 


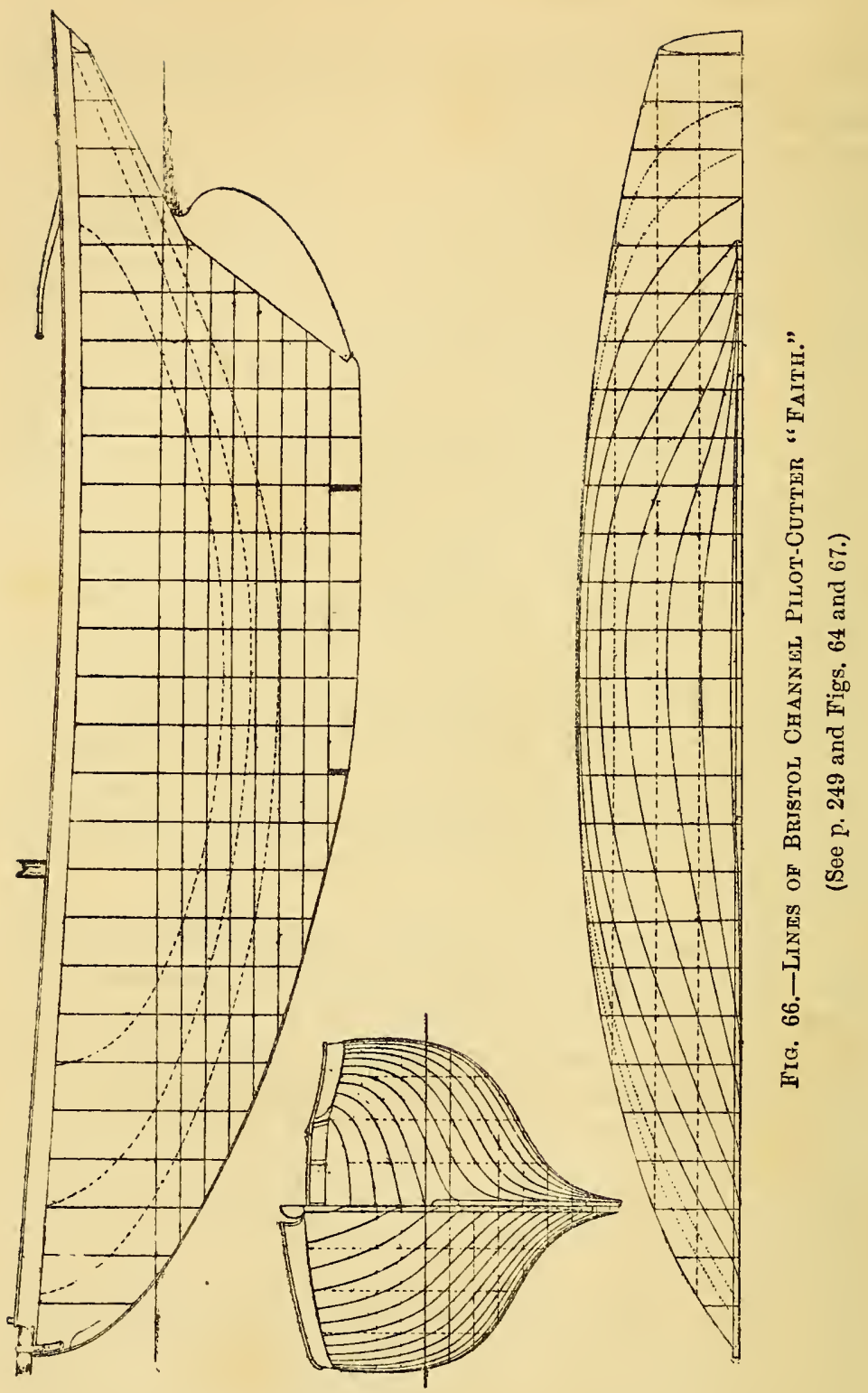


THE FORE-AND-AFT RIG TO-DAY 249

It should be explained that she is not quite in consonance with the general type of these pilot-cutters, although possessing many of their features. Mr Clayton says that she was the first of these craft ever built to paper drawings only, and the one boat which has an

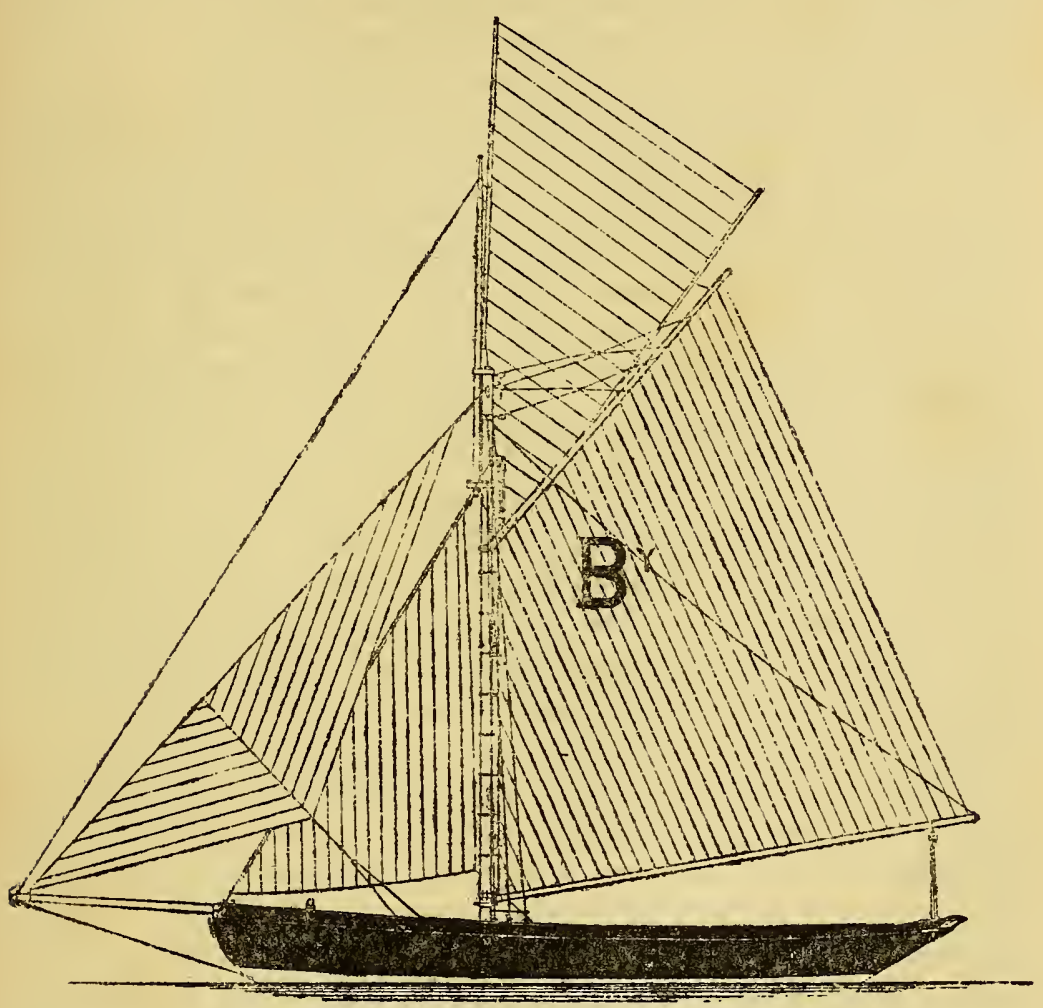

Fig. 67.-Sail-Plan of Bristol Channel Pilot-Cutter "Faith."

(See Figs. 64 and 66.)

owner's cabin. Mr. Clayton also asserts that the Faith has proved herself to be very fast both in light weather and in heavy, being a fine, able sea-boat in a gale of wind. The sail-plan (Fig. 67) shows the characteristic large staysail and the comparatively small jib. 
The mainsheet goes straight down from the boom, and the latter is seen to be plumb with the taffrail of the counter. The forefoot is very much more cut-away than is usual, and it would not be every pilot that would agree to approve of this modification. The accommodation and the construction plans are well worthy of study, and will explain themselves.

I feel that I scarcely need apologise to the reader for having taken up so much of his time to consider this west-country type of cutter, for it is a type which, in spite of its varieties of species, is so healthy and instructive that it is well deserving of being copied. Those of us who have owned or cruised in yachts modelled on the general features which are possessed by these Bristol cutters admit that they make ideal cruisers. But from the Bristol Channel we may now pass round Land's End again and run up the English Channel to have a look at another type of pilot craft, very interesting but totally different from those which we have just been considering. I wish to call attention to the auxiliary motor pilot-ketches Solent and the St. Helen's, which may have been noticed by those whose cruising ground usually includes the neighbourhood of the Isle of Wight.

'These vessels are only about eighteen months old, and were built at Leith to the order of the Trinity House for use in the English Channel. The first remark that rises to one's lips on seeing them is that they are fine, weatherly craft, and able to endure as much wind and sea as even the Channel in its worst mood may feel inclined to put up. They stand as the most modern type of sea-keeping craft, built not for speed but for weatherliness. Constructed of steel, and considerably in excess of Lloyd's yacht rules, 100 A1 class, under the society's special survey, they have a length of $68 \mathrm{ft}$. over all, $59 \mathrm{ft}$. on the load water-line, $18 \mathrm{ft}$. beam, and $11 \frac{1}{2} \mathrm{ft}$. moulded depth. Rigged as ketches they carry a good stretch of canvas, 


\section{IN GREAT BRITAIN AND AMERICA 251}

with jib and foresail for headsails, and a short bowsprit. The stem is straight, but the forefoot is moderately cut-away immediately below where the bobstay shackle is affixed.

The accommodation below is very roomy and comfortable. There is a large forecastle for a crew of four, fitted with table, lockers, and bunks, aft of which is a pantry on one side and a lavatory on the other. Aft again of this are the pilot's quarters, and there is a division by means of a watertight bulkhead. 'This large saloon is well-lighted, the bunks being, of course, on either side, the rest of the contents consisting of table, sofas, stove, and bookcase. Entrance is given to this saloon by means of a teak ladder, whilst on deck the amount of room is very great. Abaft of the saloon comes the engine-room, being divided off by means of a steel bulkhead from the living accommodation. The engine has two cylinders with reverse gear, and is started by means of compressed air, and this latter is also used for blowing the ship's siren. Paraffin is used for fuel, and under power alone these pilot-ketches have obtained a speed of seven knots.

The machinery is controlled from the engine-room, and thus a telegraph communicates from the steeringwheel aft. Such a type as this would afford an excellent model for any one desiring a ketch-rigged yacht that would face any weather that one would have the heart to let her look at. 'These craft have a nice sheer, and the high bows and their plentiful freeboard generally enable them to be dry ships in a seaway. They cruise about under canvas alone, but when they espy their steamship in the distance they lower away and run up under motor-power. With the right kind of amateur crew and given fair average weather it would be difficult to conceive of anything more delightful than an extended cruise in southern seas with such a ship under one as this.

And whilst we are speaking of motors as applied 
to fore-and-afters, we might mention that this new development has been the means of enlarging the earning power of the ships which have received this installation. We could give a number of instances, but we may content ourselves with remarking first the case of a comparatively small vessel, and secondly one of much greater tonnage. 'The former refers to the Gladys, a sailing barge. During the construction of the great lock at Portsmouth dockyard tons of shingle were required that had to be brought from Langstone harbour just to the eastward. This transportation was carried on by means of barges remunerated at so much per load. Although the actual distance is quite small, as the crow flies, yet the strong tides had to be studied and worked.

In the case of light airs it was not easy for the barge to make one trip every day. But in the Gladys there was installed a 5-horse-power engine which enabled her to perform not one daily trip but three, regardless of almost all conditions. 'That meant that her earning power was trebled, although the initial cost of the engine was moderate and the upkeep infinitesimal. Perhaps the time may come when the London river will see the Medway barges coming up over the tide with the motor plugging them along. It is not altogether improbable; but what a contrast between the things of to-day and the old Dutch influence of yesterday!

The second instance has reference to the threemasted twin-screw auxiliary schooner Saevareid. She is a vessel of $112 \mathrm{ft}$. long, $25 \mathrm{ft}$. beam, and $11 \mathrm{ft}$. depth. She is owned in Norway, but was built in Denmark. Her engine is of 30 horse-power, and is installed right aft immediately below the officers' cabin, the tonnage of the ship working out at about 300 tons. She was built for trading between the United Kingdom and Norway. With her sail-power she is able and efficient, but with her twin-screws she is 


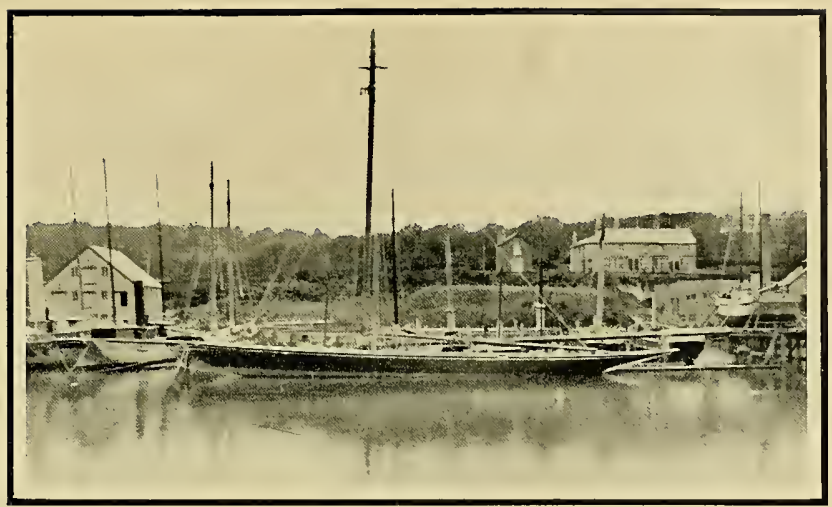

Fig. 68.

"BritanNiA"

P. 253

This royal fore-and-after, designed by G. L. Watson for His late Majesty King Edward VII, when Prince of Wales, is perhaps the finest racing cutter which was ever built. The illustration was taken in the Medina when she was being fitted out at Cowes for her second season.

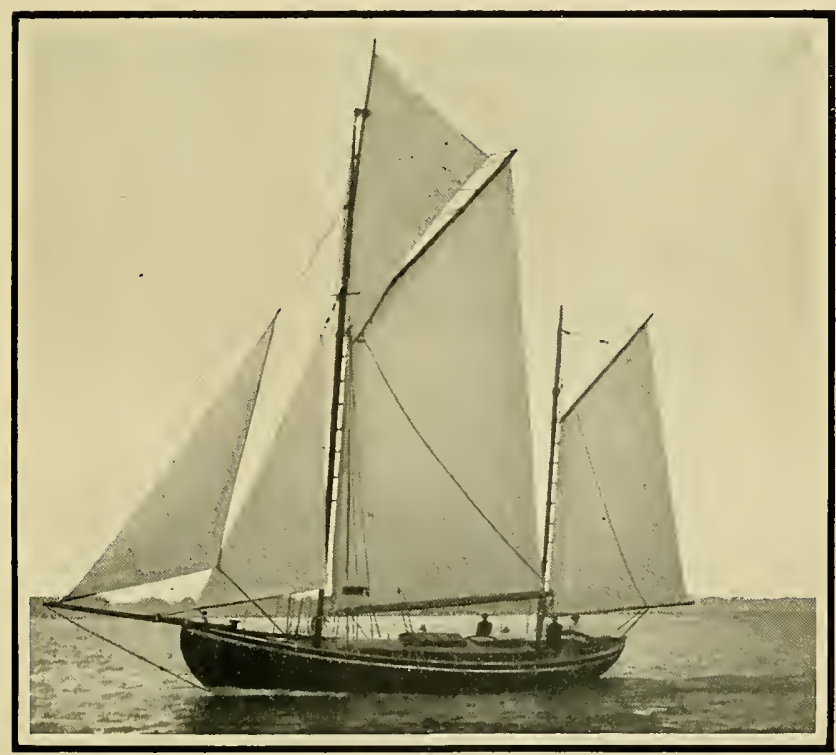

Fig. 69.

"MAUD"

P. 266

This ketch-rigged yacht is one of the best known examples of the attempts to obtain the ideal cruiser. 


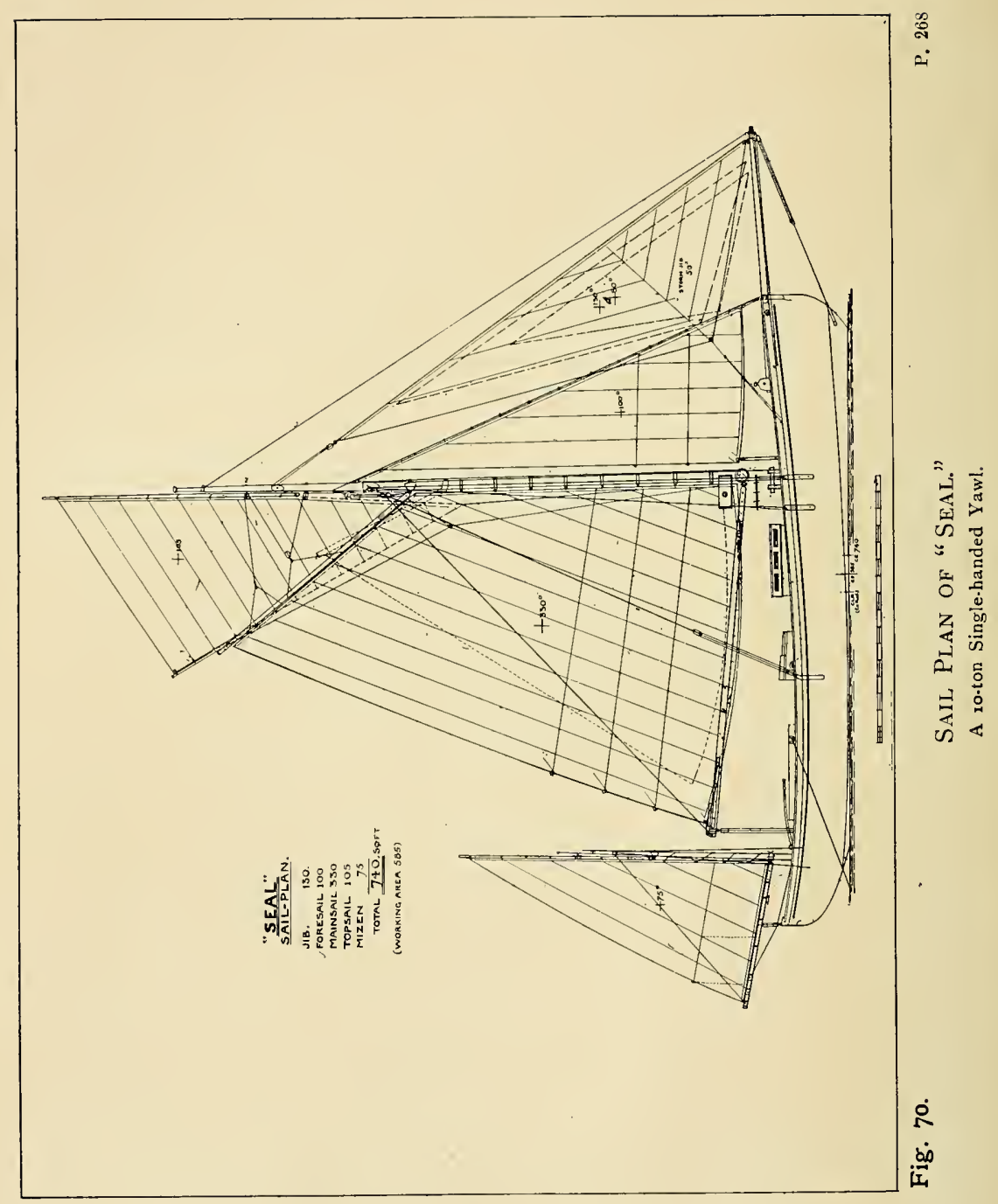




\section{IN GREAT BRITAIN AND AMERICA 253}

both economical and has greater efficiency. In addition to her main engines she has a useful little 4 horsepower motor for driving the anchor windlass, cargo winches, and bilge pumps.

Although we are not writing a history of motor craft, yet I have deemed it worth while to quote these instances as being typical of the way in which the motor is affecting the fore-and-aft sailing-ship. Where regular rather than great speed is required, where economy with greater efficiency and independence are desired, the combination of motor and sail power brings about an ideal state of things. 'There is no such necessity as having to keep steam up and bank fires. Waste is altogether eliminated because the motor is only employed when actually required. It is thus that the motor and the sails are in the position of mutual friends, and instead of the former's advent altogether driving the latter out of existence, it has caused the sailing-ship to take a new lease of life, to the satisfaction of all who retain any affection or sentiment for one of the oldest institutions of the world.

And now that we have seen something of the modern development of the fore-and-afters engaged in fishing, trading, and pilotage, let us go back and take up the threads where we left them in the last chapter. We can proceed to observe the lines on which the foreand-aft yachts have developed during the last twenty years, a period that has produced some most interesting pleasure vessels, not merely for racing but for cruising, not exclusively for the wealthy sportsman but for the man of moderate means.

The most notable racing vessel of the last fifty years, and perhaps the finest all-round cutter that was ever launched, is the Britannia, which was built for the Prince of Wales, his late Majesty King Edward VII. (see Fig. 68). She was one of those wonderful racing craft which flourished so exceedingly during the 'nineties, and included in their list such famous vessels as the 
Valkyrie I., the Satanita, the American Herreshoffdesigned Navahoe, the American Vigilant, and many another. But even in such distinguished company the Britannia was herself distinguished. She showed herself not only to be beautiful to the eye, but a consistent and reliable craft, with considerable speed possibilities. Handled to perfection as she was by the late Captain Carter, brilliantly as she fought her way in some really strenuous contests both at home and abroad, she is to-day perfectly strong and unstrained. Unlike the 52-footers and many other racing yachts which exhibit to-day the undoubted signs of serious strains, the Britannia still remains a good sound ship. Designed by the late Mr. G. L. Watson and built by Hendersons, she was from the first a vessel of distinction.

Her first appearance was made in 1893, and she stood for the finest combination of British skill in design and construction as to hull, and equally so in regard to the cut of her sails. Her dimensions are: length over all, $121.5 \mathrm{ft}$. ; length on water-line, $87 \cdot 8 \mathrm{ft}$.; beam, 23.66 ft.; depth, $15 \mathrm{ft}$. According to the rating of the Yacht Racing Association, she worked out at $151 \cdot 13$ tons. Her sail-area was no less than 10,328 square feet. She did so well in the waters of the United Kingdom and the Mediterranean that every one must regret she had no opportunity of crossing the Atlantic and trying her powers against some of the America Cup defenders. However, in England she beat the American Navahoe thrice out of five starts, and the Vigilant twelve times out of eighteen starts, and it must be remembered that the Vigilant had beaten Valkyrie in American waters for the America Cup.

But the Britannia was not built to any classification rule. She represented Watson's idea for an ideal racingcutter of great size. Most readers will remember to have seen her in her prime, and to have noted the singular beauty of her lines. The amount of overhang at bow and stern is tremendous: well over thirty odd 


\section{IN GREAT BRITAIN AND AMERICA 255}

feet, or as long as many a smaller yacht measures over all.

As one looks at her one sees summed up all the lessons of the past and the present. In essentials there is the teaching which Holland gave forth as to the wisdom of the cutter (or, as they would have termed it, the sloepe) rig. But additional to that must be recognised in her all the experiences of nearly two and a half centuries, all the increased science of the designer on the one hand and the better workmanship of the builder on the other.

In actual length the Britannia is about double that of the second Mary of our frontispiece, though the Britannia, without being any the less worthy a seacraft, is only an odd couple of feet beamier than the seventeenth-century English-built yacht. But the modern vessel will be noticed to be nearly twice as deep as Charles the Second's pleasure-craft. And as to the comparative merits of speed, it would be almost ridiculous to question. For Britannia, whilst sacrificing nothing that would make her a better sea-boat, has eliminated everything, both in design and construction, that would in any way detract from her being a greyhound of the sea.

It was the influence of such handsome craft as the Queen Mab, forty-rater, that is to be recognised in the evolution of the Britannia, the Valkyrie II., Satanita, and so on. The latter was also launched in the year 1893. She had rather more on the water-line than Britannia by about ten feet, and her beam was about another foot greater than in the case of the royal yacht. Nevertheless the Satanita's sail-area was slightly less. The exact dimensions of this vessel were: sail-area, 9923 sq. ft.; length on water-line, $97 \cdot 7 \mathrm{ft}$. ; extreme beam, 24.7 ft.; draught, $16.5 \mathrm{ft}$. These modern craft of the 'nineties had discarded the fiddle or clipper stem which had been so popular about the year 1887, and instead there had come into being the 
spoon-like, overhanging bow as shown in such yachts as Britannia and Satanita. 'This newer type was also given a deeper keel which was destined practically to become a fin.

Instead of the old idea of having a vessel that hammered and plunged the waves, instead of even "clipping" or cleaving them, the newest type of all skimmed over the sea and left it as clean as possible with the smallest amount of fuss and friction. Thanks to the fact that yacht designing and building had become an exact science, the racing yacht was a model of seaworthiness, of speed, of weatherliness and handiness, having regard always to the great size. Britannia has spent some years in retirement, though during this present year (1911) she was fitted out again not as a racer but as a cruiser on which the sons of King George might be able to acquire a knowledge of practical fore-and-aft seamanship. For greater safety her eightinch bulwarks were raised very considerably, and her old racing spars were also replaced by some of more moderate dimensions. Possibly we shall never see the Britannia race again, but she has done magnificently, and between the time when she first hoisted her racing flag up to the end of the season of 1897 she had won 122 firsts out of 219 starts, and prizes amounting to just under $£ 10,000$. Her fame will go down to posterity along with the two Marys, the Alarm, and other fine ships of the fore-and-aft rig.

The spoon-shaped bow had now become a definite fashion for racing craft, and as it was in the bigger yachts so it was in the small fry: the straight stem and the later fiddle-bow had gone. Every one remembers that the type of the small racing yacht now became a slim-hulled vessel with a fin that ended in a cigarshaped keel, the latter being of lead. To a certain extent this example was followed in fast cruisers. But one great disadvantage resulting from this method of ballasting a craft is that in a seaway she has the motion 


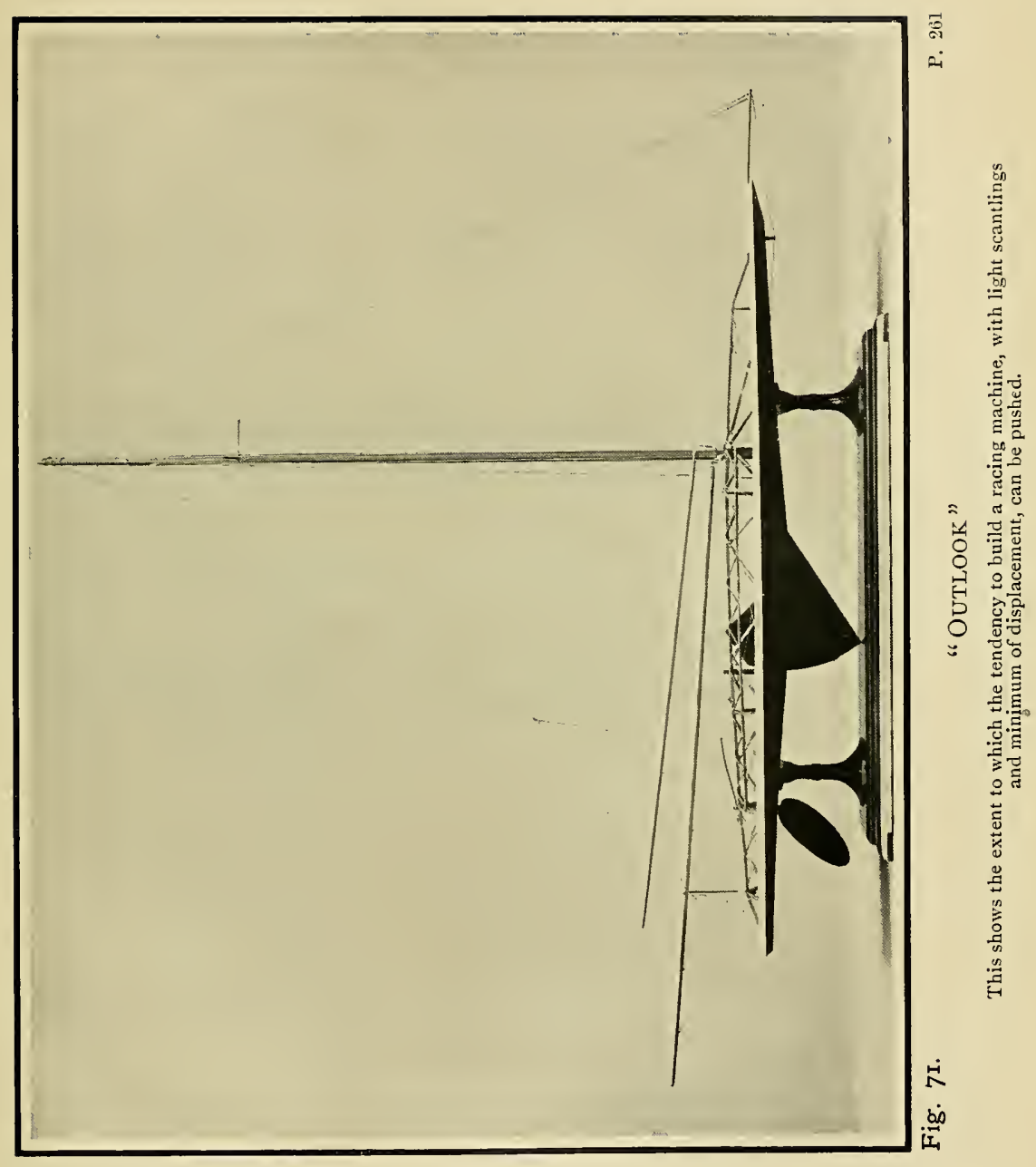




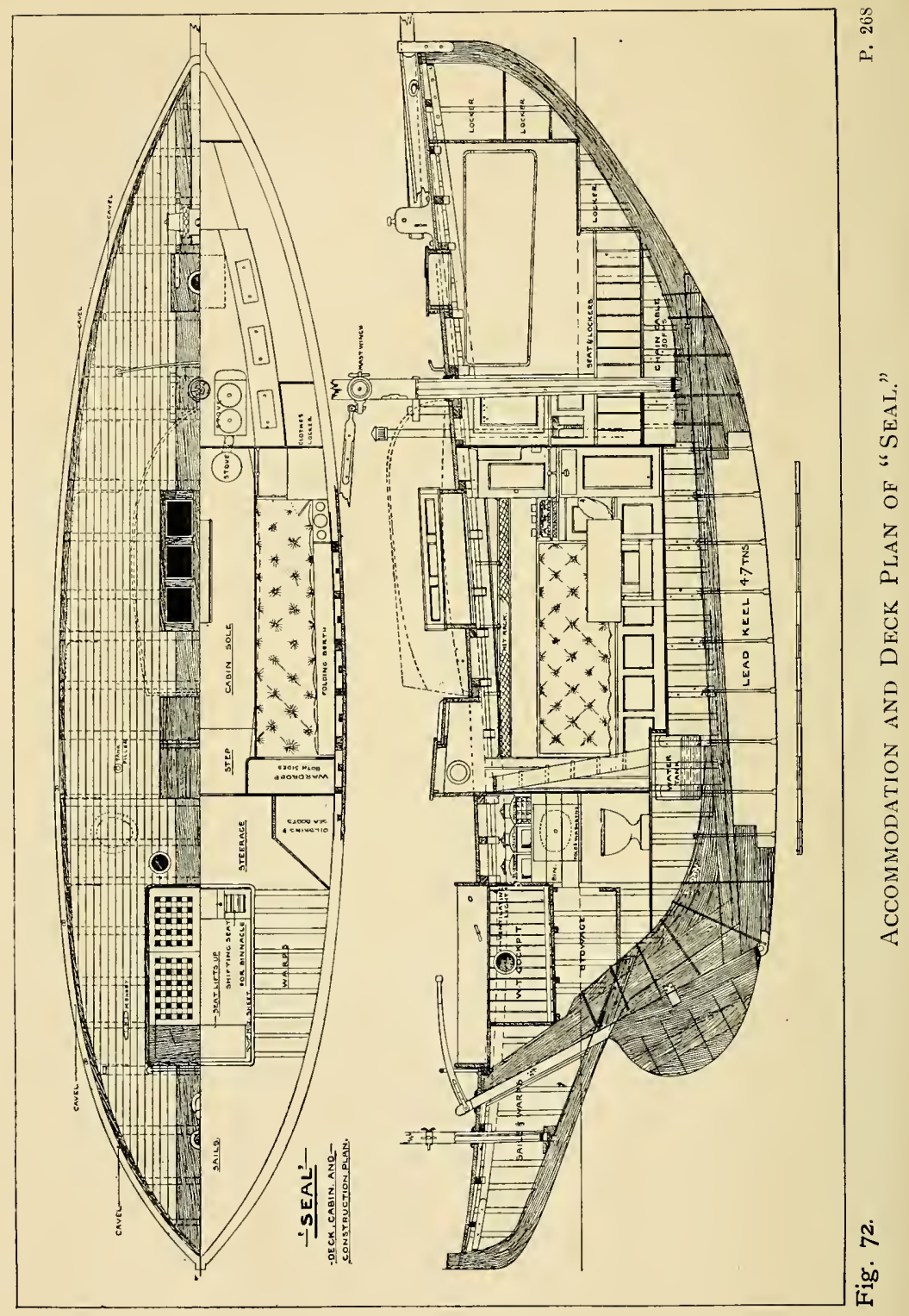




\section{IN GREAT BRITAIN AND AMERICA 257}

of a pendulum with the weight at the very lowest possible point. Many modern cruisers therefore nowadays prefer to effect a compromise by having part of the weight outside with part internal ballast, so as to produce a steadier and less lively craft.

But in the small classes of racing craft the era became known as that of the "skimming dishes," as they were nicknamed. It was the exact reaction from the time when vessels of great displacement were driven through instead of over the water. To thwart this tendency of building mere racing machines the Yacht Racing Association introduced a new rule at the beginning of 1896, and this was supplemented five years later. But the tendency to exaggerate the overhanging bow still continued. In small craft this was not of great concern, but in the case of the big classes the reader can readily imagine that this continual pounding of the "spoon" against even a moderate sea when turning to windward in a breeze caused severe strains to the ship.

But in the year 1908 an entirely new departure was made in the history of yachting, for in that year came into force an international rule for the measurement and rating of racing craft. This was agreed to by all the nations of Europe, but not by the United States of America. The object which measurement rules have had in view has been-according to the existing knowledge of the time-the evolution of an ideal craft. Previous years had seen various extremes at different dates. There had been the revulsion from big displacement craft towards the plank-on-edge. 'There had been the exaggerated fin-and-bulb type and the excessive overhangs. But now there was to be the death-knell of the racing machine, for it was resolved that she should aim at being both a ship as well as a racer. She was to make a good cruiser on which her owner, his friends, and crew could live in comfort, but she was also to be strong and fast. Whether this inter- 
national ideal has been attained by the yachts which have been built under this rule is a matter of dispute. Inasmuch as a compromise can never be altogether satisfactory, so it is natural that this case should present difficulties.

But it may be said that the object aimed at-the creating of a ship rather than a racing machine built merely as a "pothunter"-was in itself sound enough. By this rule the light scantling was abolished, and all yachts had to be built under survey, the authority for our own country being Lloyd's, that for Germany being the Germanischere Lloyd, that for France the Bureau Veritas. But prior to this there had been evolved in such craft as the first White Heather, built by Fife in 1904, and in the Nyria, built by Camper \& Nicholson in 1906, a type of cruiser-racer which became the forerunner of the new order of things. To-day Shamrock $I V$., White Heather II., and many other fine craft show the outcome of the international rule. These latter belong to the 23-metre class, and their duels have produced some of the best competitions in the annals of yacht racing. But the present year has seen the introduction of the 19-metre class, in addition to which there are the smaller types of vessels included under the 15-metres, 6-metres, and so on.

It is only but characteristic of Britain that although she was not the first to introduce either the fore-andaft rig or its later development the yacht, yet she has certainly done more for the sport than any other country. The influence of our nationality on Germany, France, Belgium, Spain, and even Holland is undeniable. The well-known admiration of the German Emperor for the achievements of our countrymen on the sea, whether of the navy, the mercantile marine, or the yachting organisations, has expressed itself in no form more striking than in the impetus which has been given to German water-sport. It 


\section{IN GREAT BRITAIN AND AMERICA 259}

was in the 'eighties that this British influence was first deeply felt, and Kiel has much for which to thank our country. Later on the Germans also began to assimilate ideas learned from the United States, but none the less the British influence was not by any means dead.

Nowadays the Germans are able to design, build, and race their own yachts without British aid, though it was not always thus. They have recently shown themselves able to produce well-cut sails for their racing craft. The sensation which the German schooner Germania made in the summer of 1908, when she broke the record for the Queen's course in the waters of the Isle of Wight, has not been forgotten, her average speed for the whole course being over thirteen knots. Had it not been, we may pertinently suggest, for such designers as Fife in Britain, Herreshoff in America, for such sailmakers as Ratsey and Lapthorne of Britain, and for what had been learned from German-employed British racing crews, it is pretty certain that German yachting would not have advanced either so rapidly or with such signal success.

We spoke some time back of the influence in America of the pilot and fishing schooners, and went on to show how this rig was adopted for the famous yacht America. The American yachtsmen have shown themselves much attached to the schooner-rig and to the centre-board sloop, or cutter as we should call her in this country. (The word sloop has been retained in the former country, owing its ancestry straight back to the time of the Dutch colonists, whereas in England the influence of the Revenue-cutters on yachting caused the retention of the word cutter instead of sloop.) We might date American yachting from the time when the little Dutch sloops were wont to sail about the harbour of New Amsterdam, but as an organised sport it is not as old as in our own 
country. It is only from the year 1844 that the New York Yacht Club dates, but it is really after the year 1851 that American yachting began in any way to flourish. The line of separation between the past and the present is formed by the famous America. Because she had done so wonderfully in English waters, and because she was also a schooner, so the Americans from the early 'fifties began both to enthuse over yachts as a whole and over schooners in particular. It was but natural, also, that the American pilot and fishing craft should continue to be the models for the new enthusiasts.

But because of the nature of the eastern coast of the United States, our cousins have shown a great liking for the centre-board even in the biggest yachts, schooners no less than in sloops. This is the exact opposite of British ideas. About the time when the plank-on-edge craze was at its summit in England the Americans chose a beamier type of craft, and because they wanted a shallow-draught boat they employed the centre-board in contradistinction to our narrow, deep-keeled craft of that time; but during the eighties they began to modify the lines of their yachts so that they actually approximated more to the contemporary British yachts.

The efforts to win back the America Cup have also acted as a great inducement to American yachting, and one has only to name such famous craft as the Defender and Columbia and Vigilant of the 'nineties, and the Constitution and Reliance of the present century, to call to mind the finest racing sloops of the United States. But the excessive amount of sailarea and the exceedingly light scantlings which these American racing craft possess make them indeed marvellous racing machines for their own waters in fine, fair weather, though strictly speaking they are not sea yachts. As an instance of the degree to which an idea may be pushed, let us call attention to the accompanying illustration of the Outlook in 


\section{IN GREAT BRITAIN AND AMERICA 261}

Fig. 71. This shows a model of a very much smaller craft-a mere small-rater in fact-but it well illustrates the tendency towards the attainment of a fast boat in light weather. The Outlook is not a ship in any sense of the word; she is a very clever and ingenious racing machine for skimming along the water, with the minimum of displacement and a deep rudder and centre-board. She has neither strength nor beauty, and speed is her only justification for existence.

Among the small craft the Americans have shown themselves also fond of the cat-boat type of craft. In the sketch (Fig. 73) this type of boat is here represented. Such a specimen would measure about $26 \mathrm{ft}$. over all, $10 \mathrm{ft}$. beam, and with $3 \mathrm{ft}$. draught. In this cat-boat type we have a clear descendant of the Dutch influence, with no jib, but the mast stepped right in the eyes of the boat. In England we can see her counterpart in the Una-rigged craft, but historically she is related to the Norfolk wherry (by reason of her connection with Holland), and she must also justly lay claim to being related to that type of vessel, with one sail and mast but no headsail, that we saw in existence in the sixteenth century. To-day, as we shall see in the following chapter, the inland waters of Holland still preserve the Dutch equivalent, or rather prototype, of this cat-boat craft. Because of their well-known bad proclivities when running before a moderate breeze this rig is not popular in England; and even when it is proposed to give a small open boat a simple rig, the balance lugsail is infinitely preferred in our country. It should be added that even in America, where the cat-boat prospers most, there is a decided tendency to modify it by the addition of a jib and bowsprit, so as to make her a sloop. But for all that the mast remains in the same position as before-just as far forward as it is possible to have it placed. For landlocked waters these craft have certain advantages, but 


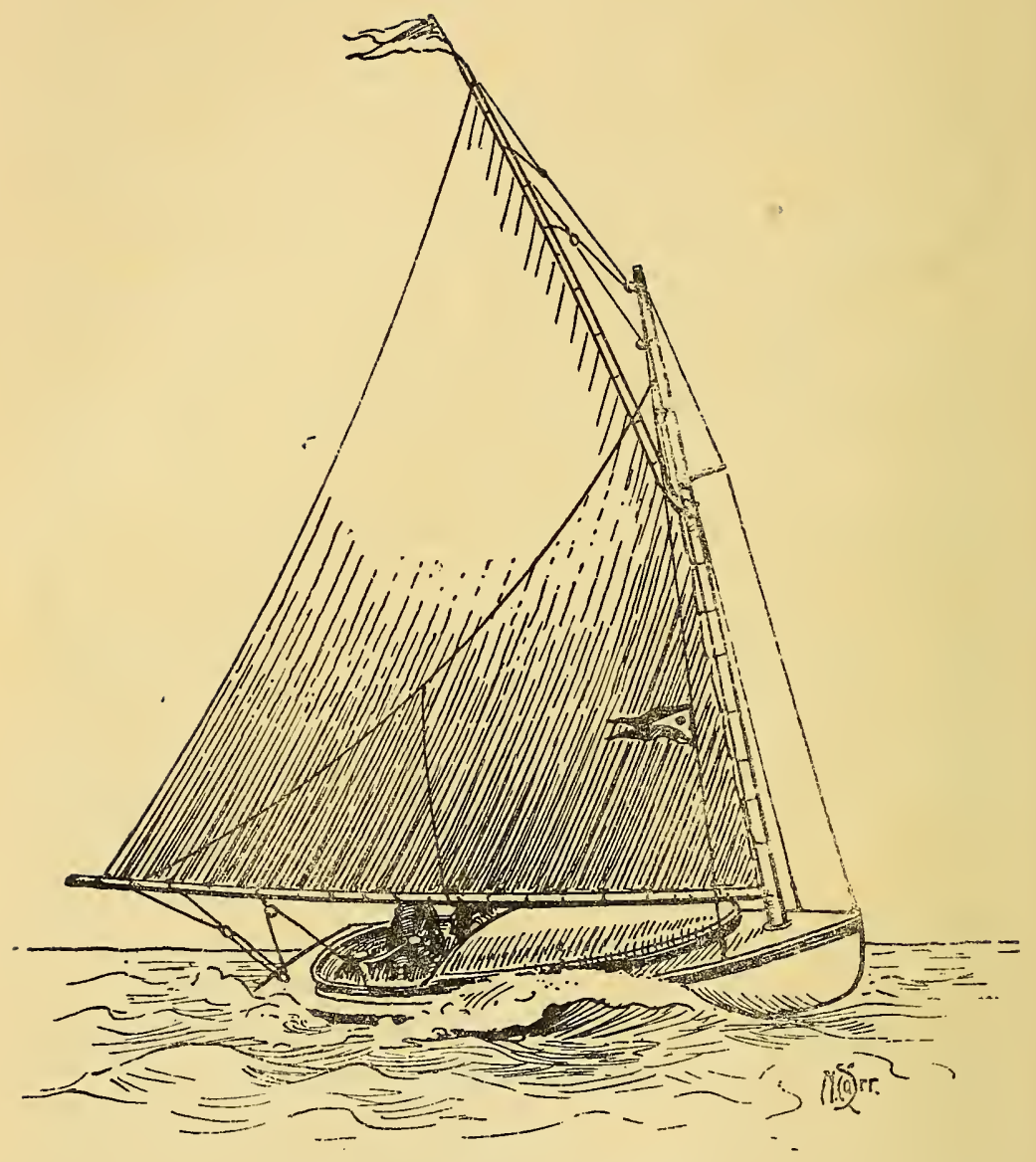

Fig. 73.-AMERICAN CAT-BoAT.

The mast is stepped rery far forward as in the Dutch-American sloops of the seventeenth century. 
there are not many who would call the rig suitable for actual sea-work.

Recently in England the 15-metre cutters have practically superseded the $\mathbf{5 2}$-footers, except in handicap racing; but in America a somewhat similar class to these, though larger, was found in the 70-footers, which have been the most popular large yachts, within recent times, of the New York Yacht Club. In America the same difficulty which has confronted ourselves in regard to finding a suitable rule for the measurement and rating of yachts has also existed. The problem has been, as with us, to find some satisfactory method for the prevention of an exaggerated, unhealthy type. It is a matter for regret that America did not see her way to joining the other yachting nations in agreeing to the international rule, but last summer-in 1910-Herreshoff, the greatest naval architect across the Atlantic, designed the schooner Westward specially to compete with the yachts built under the international rules, and she sailed on her own bottom across to the Solent last summer. She raced with consummate success, and showed herself to be the finest schooner ever built. The accompanying sketch (Fig. 74) shows her with topsails, all lower canvas, and spinnaker set, as she was seen cruising one day last July in the Solent.

Westward is practically the modern America in regard to the sensational success which she won for herself at Cowes in 1910. She was designed and built for the one purpose of sailing as fast as the wind would send her. To that end everything else, so far as possible, was sacrificed, but on the Atlantic she showed herself to be a good sea-boat. She was spoken of as a racing machine, but it is hardly fair so to speak of a vessel with such sea-keeping qualities. In the great race on August 1, 1910, with the German schooner Germania as scratch boat, and the German Emperor's schooner Meteor also scratch, the Westward 


\section{4 'THE FORE-AND-AF'T RIG TO-DAY}

won handsomely, the British cutter Shamrock IV. being second, followed by the Germania and Meteor in the order named.

But not all the representatives of the fore-andaft rig either in Great Britain or America are traders, fisher-craft, pilots, or racing yachts. There is that

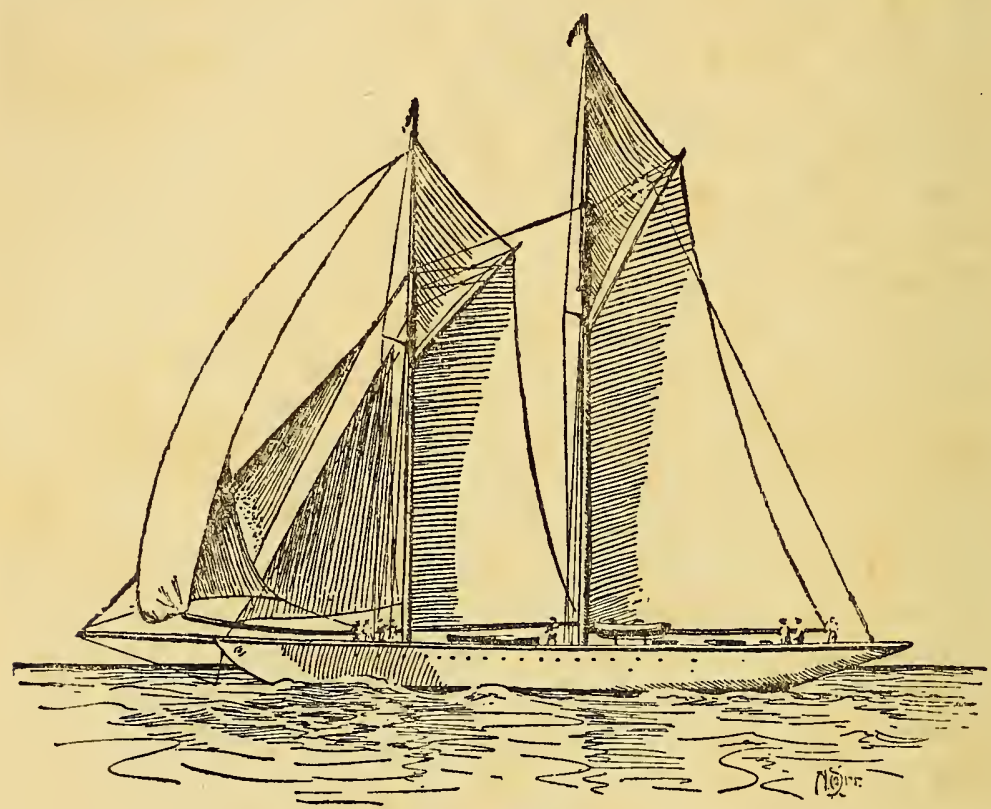

FIG. 74.-“"W ESTWARD."

This American schooner was the sensation of the yacht-racing season of 1910, when, like her predecessor the famous America, she showed herself to be the finest schooner afloat.

not inconsiderable class to be reckoned which includes the cruisers, and about these we propose now to say something. It is undeniable that for a time the cruiser, after she had been for so long a period designed on the lines of the king's cutters, was influenced by the racing yacht. To an extent this is so to-day; but there is not that wild fanaticism 
IN GREA'T BRITAIN AND AMERICA 265

which fails to draw a separating line between the requirements of the one and the other. Speed is absolutely the first essential in the racing yacht; in the cruiser it is merely highly desirable.

The first virtues which the cruiser should possess are comfort, the ability to keep the sea in most weathers, handiness for entering harbours or navigating narrow channels, simplicity of gear, requiring the fewest possible hands to work her; and then, when these qualities have been obtained, the best turn of speed that her designer and builder can endow her with. She is intended to win for her owner not fame but pleasure-the two things are not necessarily the same-and she is to be a ship before she is a greyhound. To this end the owner may choose a vessel of any rig or any tonnage. With those few but fine ship- or barque-rigged craft such as one meets with occasionally in different ports and in different seas we have no need here to speak. Of the mediumsized cruisers, the topsail schooner was at one time a favourite rig, though the fore-and-aft schooner and the yawl are now more common. For some unexplained reason the ketch-rig, notwithstanding that it was found serviceable by the fisherman, was until fairly recently not adopted by the yachtsman, though it is in many ways suitable for vessels of anything above eleven or twelve tons; and by splitting up the canvas into such dimensions as enable it to be handled easily it has much to commend itself. Otherwise, with the exception of a few vessels, the yawl and cutter rigs have been chiefly employed for cruisers.

But as democracy has gradually superseded aristocracy, as wealth has spread from the few to the many; so when the sport of yachting became, comparatively speaking, universal, it followed that there was the man of moderate means to be catered for quite as much as the man who could afford to commission his fine big schooner, or yawl, or cutter year 
by year. But there was this difference: the former wished to dispense with the paid hand altogether, or at any rate as far as possible. This not only allowed of greater improvement as to internal accommodation, inasmuch as it left the crew's quarters available, but it gave room for such devices as would minimise labour in different ways. And to-day, if we omit from our purview the big, crack racing yachts, it is the keen amateur who, either alone or in company with a few kindred spirits, makes up the largest proportion of membership in the many yacht and sailing clubs that exist in all parts of the globe where the fore-and-aft yacht is in vogue.

For a time the old ideals were followed, the ideals which belonged rather to the bigger craft with ample paid assistance. But comparatively recently the moderate-sized yacht has been given the attention which she deserves. It is because many an owner has found to his cost that whilst sometimes a paid hand is more than worthy of his hire, yet there is so much uncertainty about him as a class, there are so many unsatisfactory members of his vocation, that it were best to try and do without him. Added to which there would also thereby be a considerable saving in wages, and the much-increased joy of being independent of all professional help.

Vessels of 18 or 20 tons are now designed and built and rigged with so much skill that they can be taken anywhere along the coast without a professional crew. Of these perhaps the most famous is the ketch-rigged Maud, a photograph of which is seen in Fig. 69, which I mention especially owing to the fact that she has already shown herself to be an influence on the development of the Corinthian cruiser. By common consent there are summed up in her many of the virtues which the largest class of yachtsmen believe to be essential for a cruiser. She is not a species of a type, but has an originality which demands criticism at once. There 


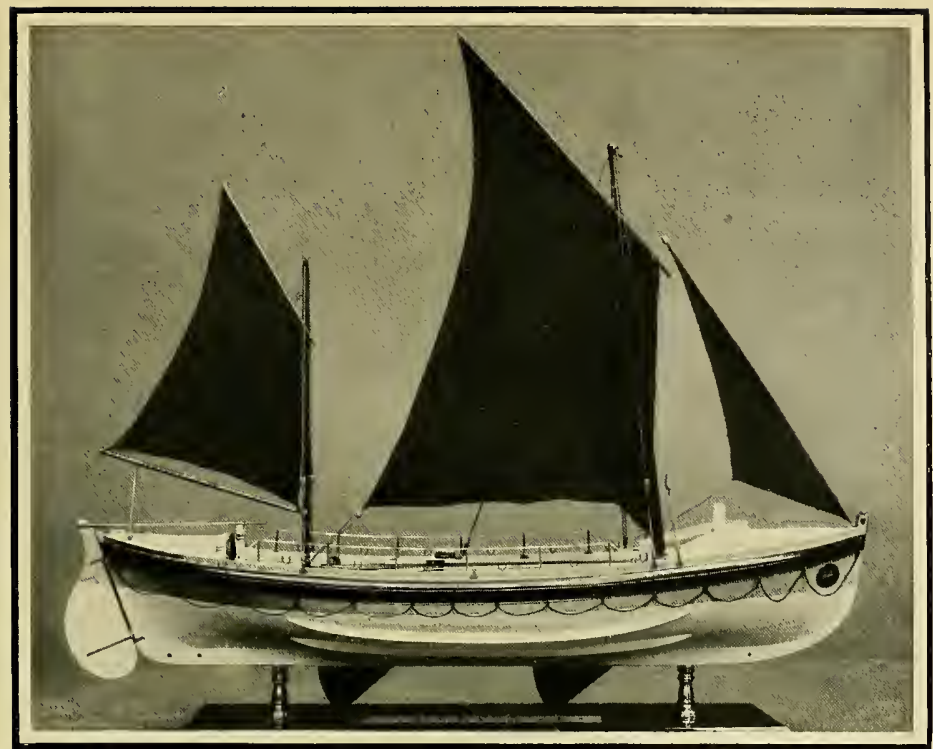

Fig. 75 .

SAILING LIFEBOAT

P. 268

The modern so-called "canoe-stern" whicb forms part of the design ot some cruisers is nowhere better exhibited than in the Scotch fishing craft, the Norwegian fore-and-afters, and the lifeboat.

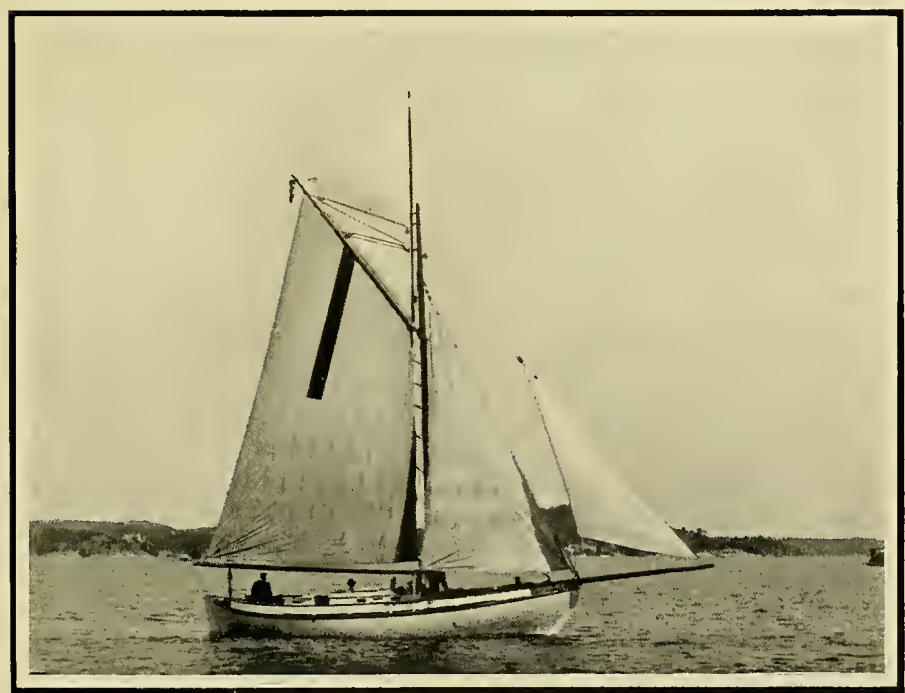

Fig. 76.

NORWEGIAN PILOT CUTTER

P. 290

Notice the large staysail. These craft measure about $38 \mathrm{ft}$. to $40 \mathrm{ft}$. in length over all. 


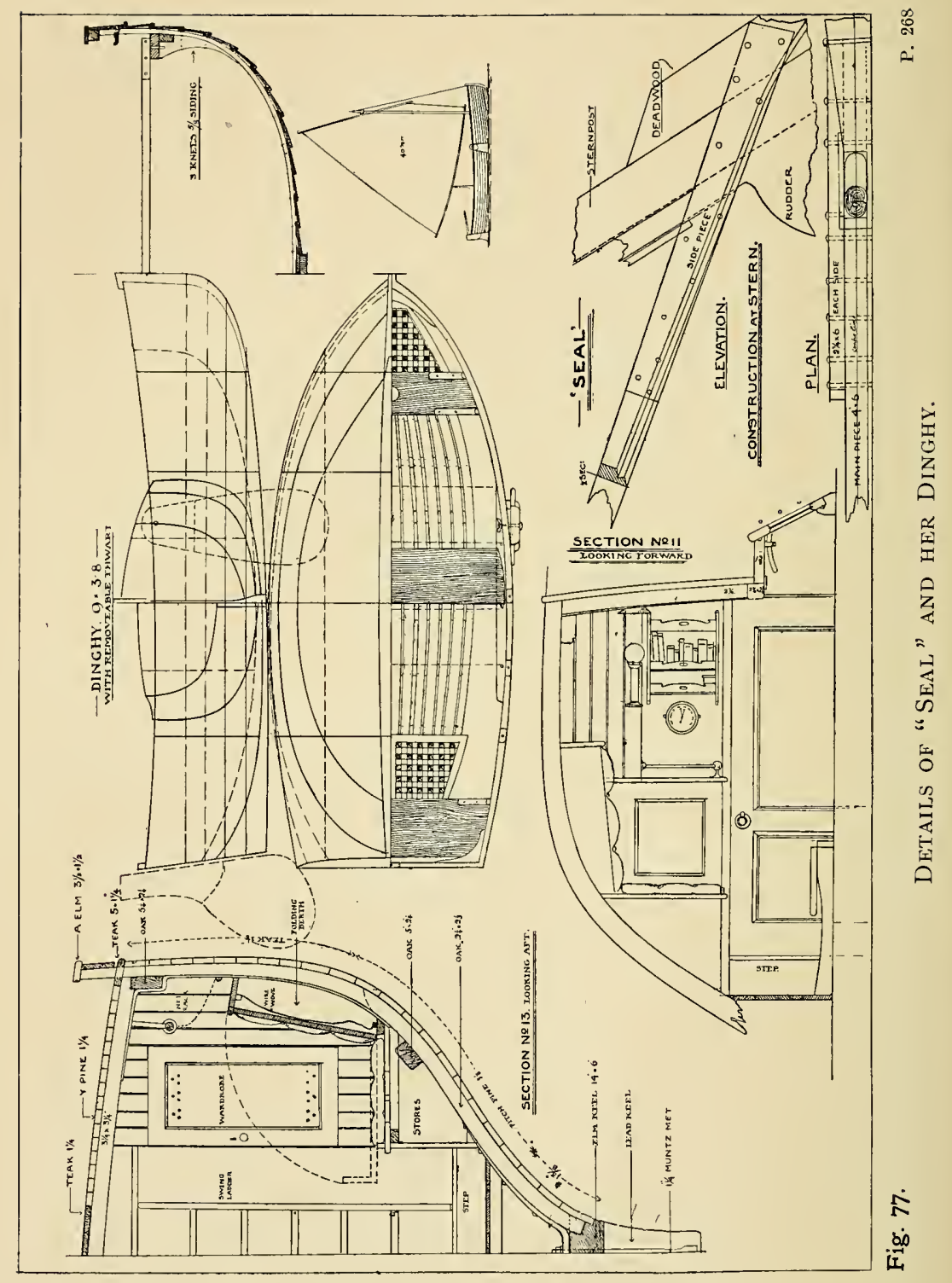




\section{IN GREAT BRITAIN AND AMERICA 267}

is nothing of the old-fashioned, unhandy, heavily-rigged cruiser in her character, but everything has been thought out to the smallest details. And therefore, though she will be familiar to many readers of these pages, one may legitimately call attention to her now.

Originally intended for a long ocean cruise, she was made of great strength. She was designed and built by Fife of Fairlie in 1899 , and has a Thames tonnage of 21, her length over all being $41 \mathrm{ft} .9$ in., her draught $6 \mathrm{ft} .8$ in. After being purchased by Mr. Claud Worth and $\mathrm{Mr}$. C. D. Marshall (of whom the latter is still part owner), she was considerably improved as to her equipment, and in spite of her size is acknowledged to be one of the handiest craft afloat. Those who have sailed in her say that Maud is a splendid sea-boat, and the fact that she has been handled on any ordinary cruise by the owner and his wife must be taken as sufficient proof of her virtues as a convenient craft. Built with oak frames and pitch-pine planking, with seven tons of ballast on her keel and a couple of tons of lead inside, she has a canoe stern, a moderately cutaway bow, and a bold sheer with fine high shoulders. The mainboom is fitted with a reefing-gear, and the jib has the Wykeham-Martin furling gear.

For running before the wind a square-sail is used as a better cruising sail than the spinnaker, the yard being hoisted by the fore-halyards. A shackle is made fast to the yard at the slings, and travels up and down the jackstay, the fall of the halyard being bent to the yard as a down-haul. Of course no one can expect a ketch to go to windward as well as a cutter, but since Maud has had her gaff shortened she has been considerably improved, and she is certainly fast on all points of sailing. A little time since she was fitted with a small auxiliary motor, which has been found to add to her already considerable efficiency. The very many interesting details that compose her personality, with the numerous ingenious devices, space will not allow 
of being discussed here, but those who are interested may be referred to an entertaining and full description of this vessel given by her late owner, Mr. Claud Worth, in the Yachting Monthly for April of 1908, to which issue, as well as to Mr. C. D. Marshall, I am myself indebted for certain information here gathered.

The Maud has cruised all round England from the south coast, east about and back again, and is still one of the most admirable cruisers on the south coast. For here is a yacht that has a good turn of speed, as well as sea-keeping qualities; that can be managed without paid assistance, that is handy as well as comfortable, habitable as well as handsome. These are among the most notable qualifications which the ideal cruiser of modern dimensions demand, and accordingly Maud is likely to be an influence for some time to come. There are those who object to the canoe stern, either because it is unsightly or that it leaves very little deck-room right aft. The latter may be a drawback, but the former criticism is rather a matter of personal taste. At any rate, this form of stern makes an ideal one for bad weather in a following sea, and the fact that it is the same principle which is to be seen in the old Viking ships, the whalers, and the modern Scotch fishing craft must instantly commend itself as having very considerable merits. It is the same principle, is it not, which is always seen in the lifeboat, as the accompanying illustration (Fig. 75) shows; and it is more natural that a vessel should be so-called "double-ended," and thereby better balanced as to its ends, than that it should be given a long, overhanging counter, or the ugly transom stern of the Itchen Ferry type of craft.

From the 21-ton ketch-rigged Maud we pass on to consider the designs of the 10-ton yawl Seal (Figs. 70, $72,77)$, which, through the courtesy of their creator, Mr. Albert Strange, are here reproduced. I have included the Seal for several reasons. In a recent de- 


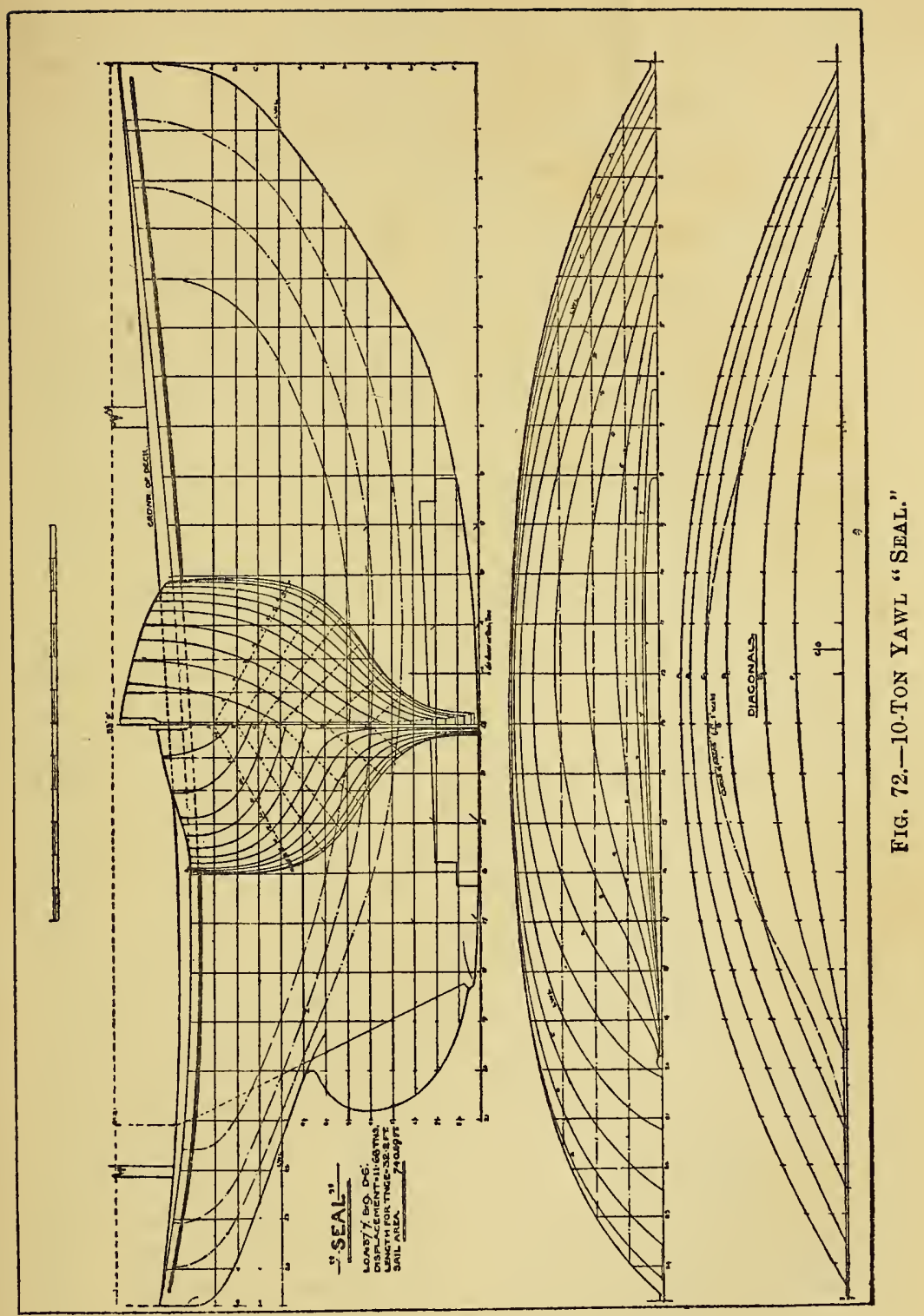


signing competition she won for herself a great deal of praise both because of her originality and the features which she exhibits as the outcome of actual sea-experience. Whilst many a man may feel inclined to hesitate before he would tackle a vessel of the size of Maud, yet in the Seal there is attempted a somewhat similar type of craft, but of inferior tonnage. In many ways the Seal is the ideal cruiser to a man of moderate means seeking a vessel that will give him a comfortable home as long as he is afloat, but possessing those necessary qualities of good speed and ability to endure weather up to a summer gale. Such a craft as this would be able to be independent of the shore for a week, would be able to go through a fair amount of dirty weather, and would be dry in a seaway, plucky and strong. And yet she is pleasing to the eye, easy to handle, and without complicated devices. As she is intended to be sailed without paid hands, the forecastle gives an additional cabin.

The Seal measures in length over all $37 \mathrm{ft} .7$ in., extreme beam $9 \mathrm{ft}$., draught $6 \mathrm{ft}$., length on water-line $30 \mathrm{ft} .7$ in., so that her overhang is exactly $7 \mathrm{ft}$. At the bow she has $4 \mathrm{ft} .10 \mathrm{in}$. of freeboard, and at the stern $3 \mathrm{ft} .8 \frac{1}{4}$ in., her displacement being $11^{\cdot 68}$ tons. It will be noticed that on her keel she has over four tons of lead, and her sail-area is $\mathbf{7 4 0} \mathrm{sq}$. ft.; that is to say, with jib, foresail, mainsail, topsail, and mizzen set. According to the specification of her designer, this little vessel would be built with timbers of English oak and floors of galvanised wrought-iron, the fastenings to be of muntz metal and copper. The planking would vary in thickness from $1 \frac{3}{8}$ to $1 \frac{1}{8}$ inches. A winch with brake is to be placed forward for the anchor-work, and both the mainand fore-sheet are to work on galvanised-iron horses. In the after-cabin will be seen a slow-combustion stove, and this connects with the flue which comes from the galley-stove, the latter having also an oven. The cockpit is lined with lead and made watertight, with a couple of pipes placed aft for discharging into the sea. 


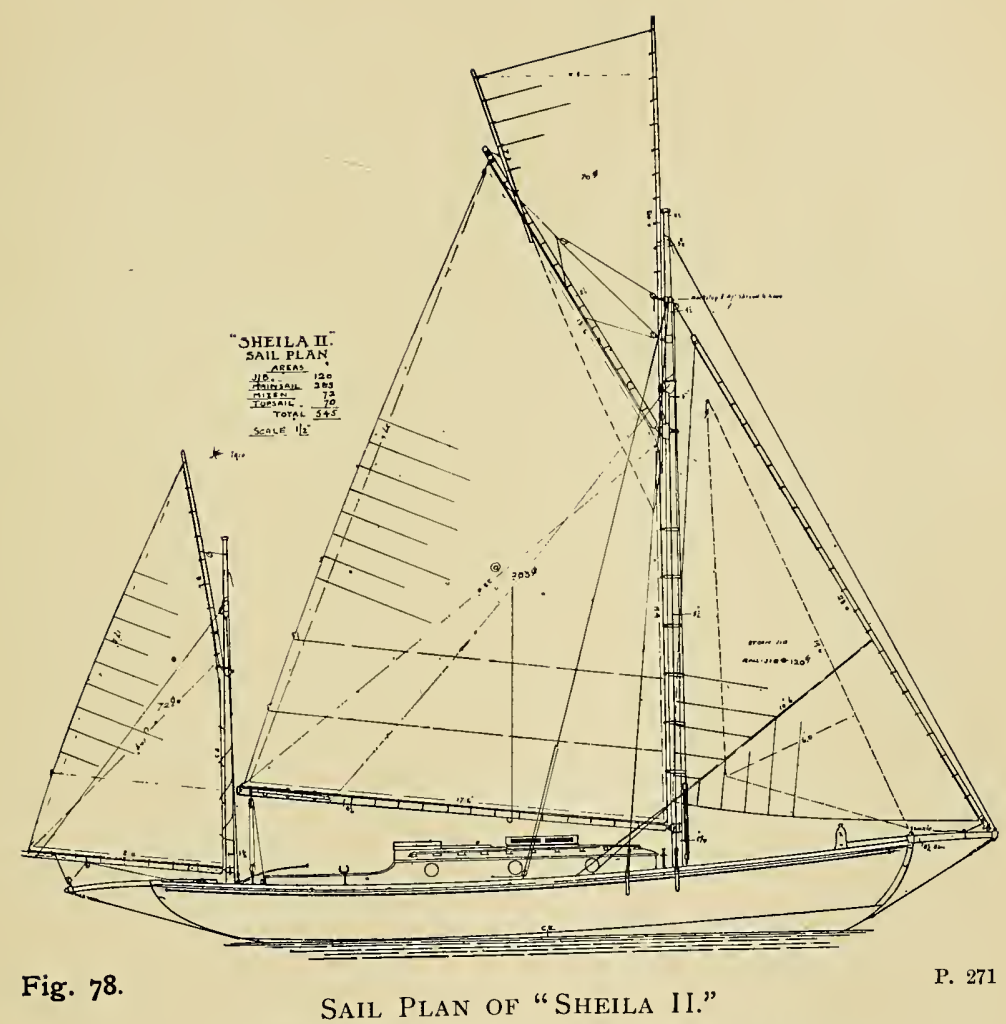

Fig. 78

This is an 8-tonner, measuring $3 \mathrm{r}$ fi. 7 in. in length over all. 


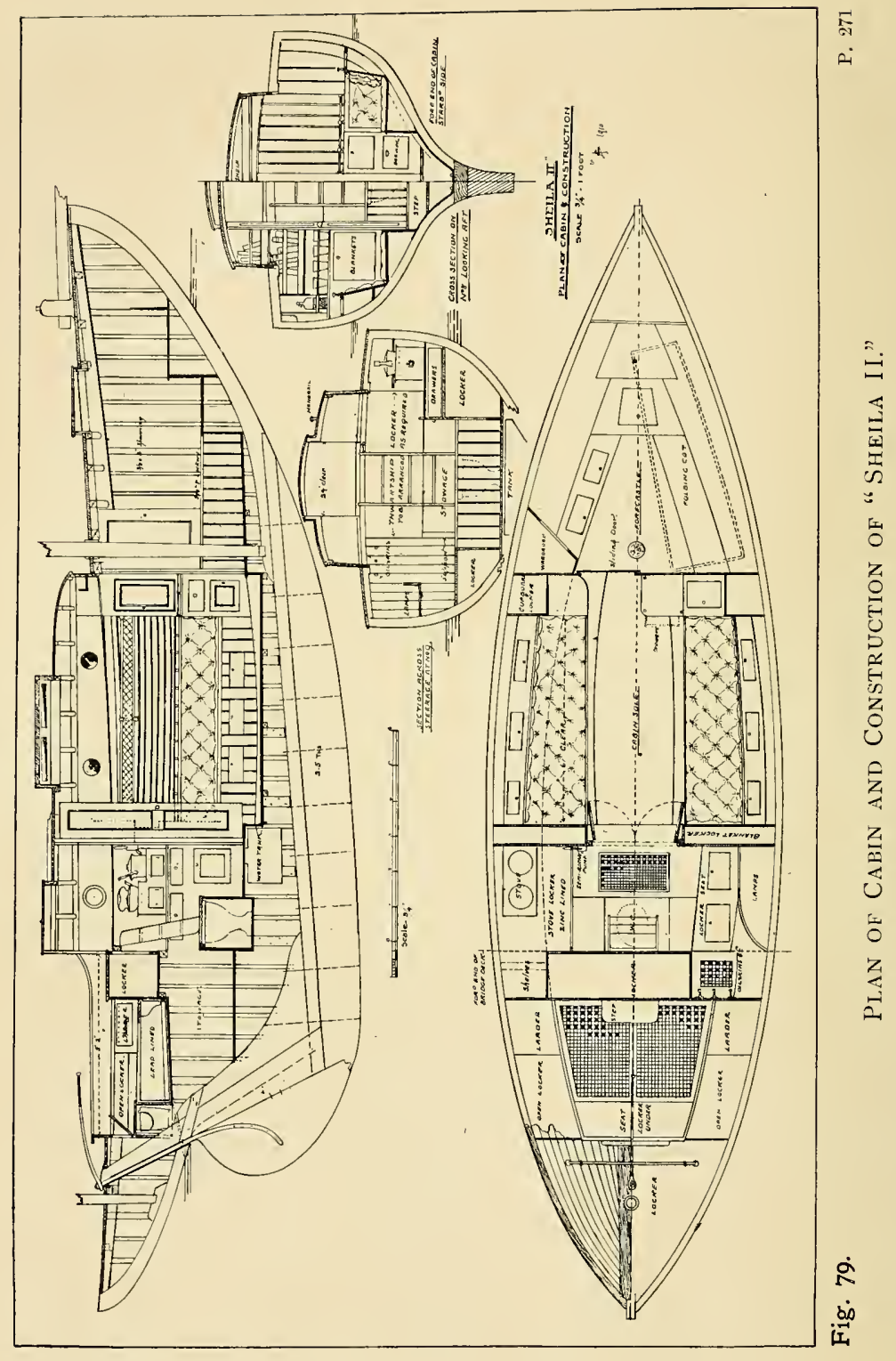




\section{IN GREAT BRITAIN AND AMERICA 271}

All the rigging is to be of wire, the running-gear to be of best manila. The internal accommodation plan shows how much comfort can be easily worked into even a ten-tonner. Immediately below the cockpit there is a nice space for storage-room, forward of which is the steerage, with a patent w.c., folding washstand, and cupboard for oilskins and sea-boots. The side- and anchor-lights are handily placed on a shelf in the steerage ready for immediate use. The saloon is fitted up with berths, which can be lowered at night-time and folded back out of sight during the day. Ample care has been bestowed on such conveniences as net-racks, wardrobe, cupboards, and lockers.

In the forecastle the sides are lined with pitch-pine and varnished, the locker-doors and cupboard-doors being of the same material. By an ingenious arrangement the nuisance of the dinghy is overcome. Every one knows how very tiresome she can make herself when being towed, and how awkward she is to stow on deck. But in the accompanying illustrations it will be seen that the suggestion is made for her central thwart to be unshipped, so that she can, after being capsized, rest comfortably over the skylight. True, this would make the cabin dark during the voyage, but that is inevitable and could be endured, especially as one is mostly on deck during daylight, and when it is night the presence of the dinghy on the top would not matter during a passage. In harbour, of course, it would be usually afloat. As the dinghy is meant to sail, and the movable central thwart prevents the use of a centre-board, leeboards, after the Dutch fashion, are provided.

The Seal has so much by which to commend her to all who are interested in the evolution of the small, handy, comfortable cruiser that she is well deserving of careful consideration. But a slightly smaller craft, also yawl-rigged, and in many ways resembling the Seal, is to be found in the Sheila $I I$., whose lines are here 
reproduced (Figs. 78, 79, 80). This is an eight-tonner, and measures $31 \mathrm{ft} .7 \mathrm{in}$. in length over all, 24. ft. on the water-line, beam $8 \mathrm{ft} .6$ in., draught $4 \mathrm{ft} .11$ in., sail-area $545 \mathrm{sq}$. $\mathrm{ft}$. At the moment of writing this craft is being constructed, and she promises to be a very sturdy little yawl. She is a veritable singlehander, with single headsail, a moderate sail-area, and well split-up. She has plenty of accommodation, good forecastle, and a number of interesting and ingenious devices for making the best of every inch of room. She has $5 \mathrm{ft} .7 \frac{1}{2}$ in. of head-room under the beams, so that for an eight-tonner she is by no means ill-provided in this respect. The bowsprit, as is the modern custom in contradistinction to the ideas of the early nineteenth century, is quite short.

In a hard blow, when the storm-jib will be set, the tack of the latter will be made fast by means of a shackle to the stem-head so that the whole of this sail would be inboard. Her internal accommodation is especially interesting and comfortable for a vessel of this tonnage. In the steerage, after descending the companion, there is on the port hand a convenient place for cooking, so that the single-hander can keep an eye on this domestic department whilst he is still at the helm. Furthermore, this steerage is a convenient place for taking off one's oilies and leaving behind any dampness that might otherwise come into the cabin. On the starboard hand are seats and lockers, with a place for the lamps above. Undoubtedly this is the right part of the ship for these details. There are times when in a seaway, and the little craft is endeavouring to stand first on her head and then on her tail, it is trying even to the most hardened to have to go forward either to attend to the stove or to get out the side-lights. Many a professional seaman succumbs under these circumstances. But with such an arrangement as is here shown, everything is at hand and where it is most likely to be wanted. The fresh-water tank is placed immedi- 


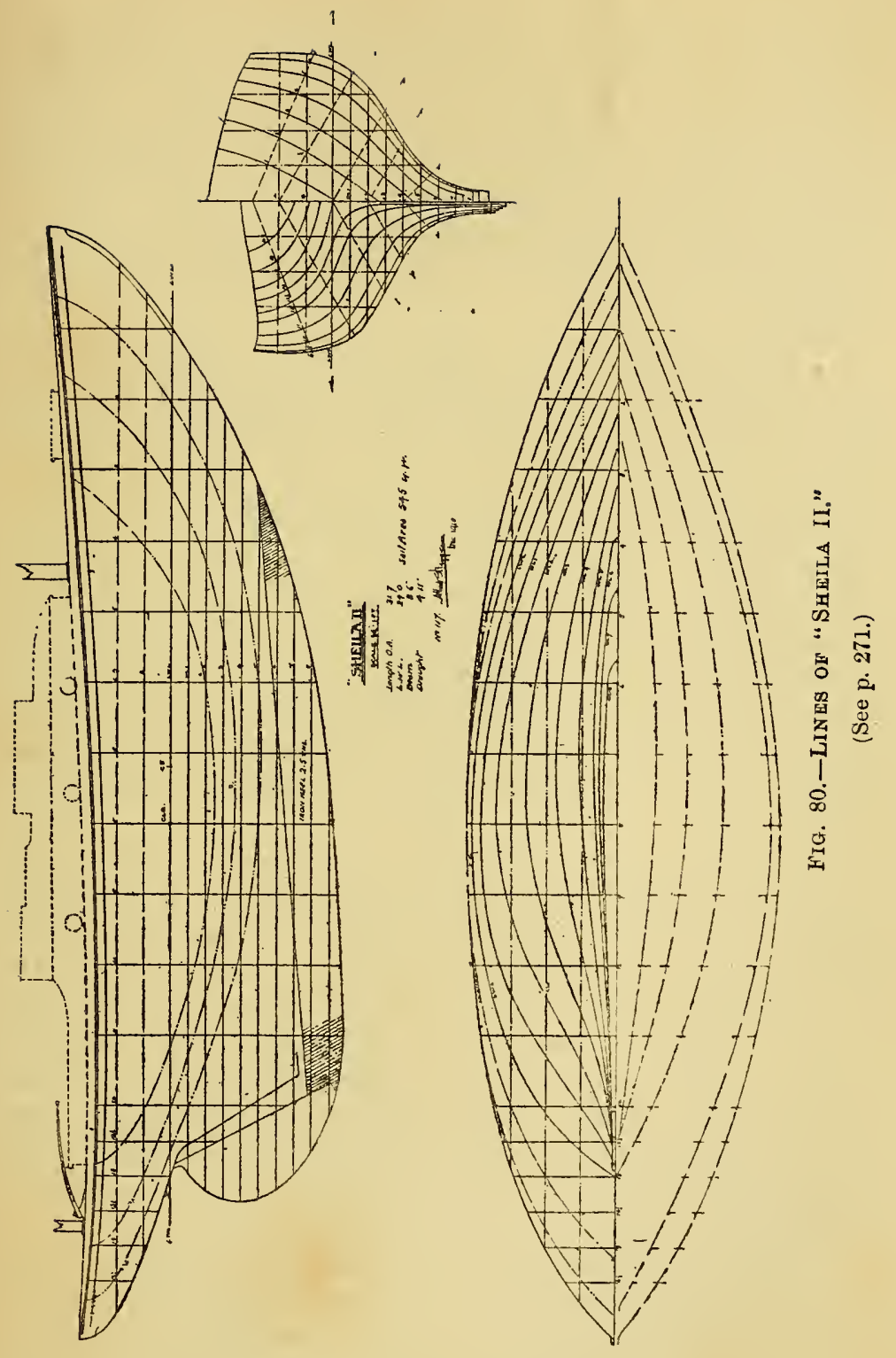




\section{THE FORE-AND-AFT RIG TO-DAY}

ately below, and the water is raised by a semi-rotary pump to the part of the steerage where it is required. In the cabin a couple of lockers have been cleverly worked into the plan for the purpose of keeping the blankets quite dry and out of the way. A sliding door gives access to the forecastle, which is fitted with a folding cot. The other details are so well shown in the accompanying plans that they need not be explained further.

Smaller still comes the Cherub III. (Figs. 81, 82, and 87), designed also by Mr. Strange and for his own use. She is a six-tonner with a displacement of 4.6 tons, measuring $28 \mathrm{ft}$. 6 in. over all, 22.95 on the waterline, and draws $3 \mathrm{ft}$. 10 in. of water. Her owner describes her as very able, a splendid sea-boat, and very comfortable. Again we have the yawl rig and again the single headsail. With her $8 \mathrm{ft}$. beam, her sailarea of 483 sq. $\mathrm{ft}$., her excellent accommodation below with plenty of locker space and room for stowage of ropes, \&c., and with many of the features on a smaller scale which the Sheila II. possesses, this craft will appeal to the amateur sailor who does his cruising in small craft.

In the Norma (Figs. 83, 84, and 85) we have the canoe-yacht type of vessel worked out to give a displacement of $3 \cdot 35$ tons on a length over all of $25 \cdot 4 \mathrm{ft}$., with $20 \mathrm{ft}$. on the water-line, and a beam of $7 \mathrm{ft}$. $2 \mathrm{in}$., the draught being $3 \mathrm{ft}$. 4 in., and the sail-area 365 sq. ft. Extreme convenience in getting up sails is made possible with this split-up sail-plan, though for so small a craft many people would prefer the cutter rig. She has a good amount of freeboard at the bows and a nice sheer, whilst below, as will be readily seen, her accommodation is compact and well thought out.

And so we might go on to add other instances, and show how the fore-and-aft rig has adapted itself even to the smallest possible raters, to the dinghies, to canoes, and even to the model yachts. But we have already 

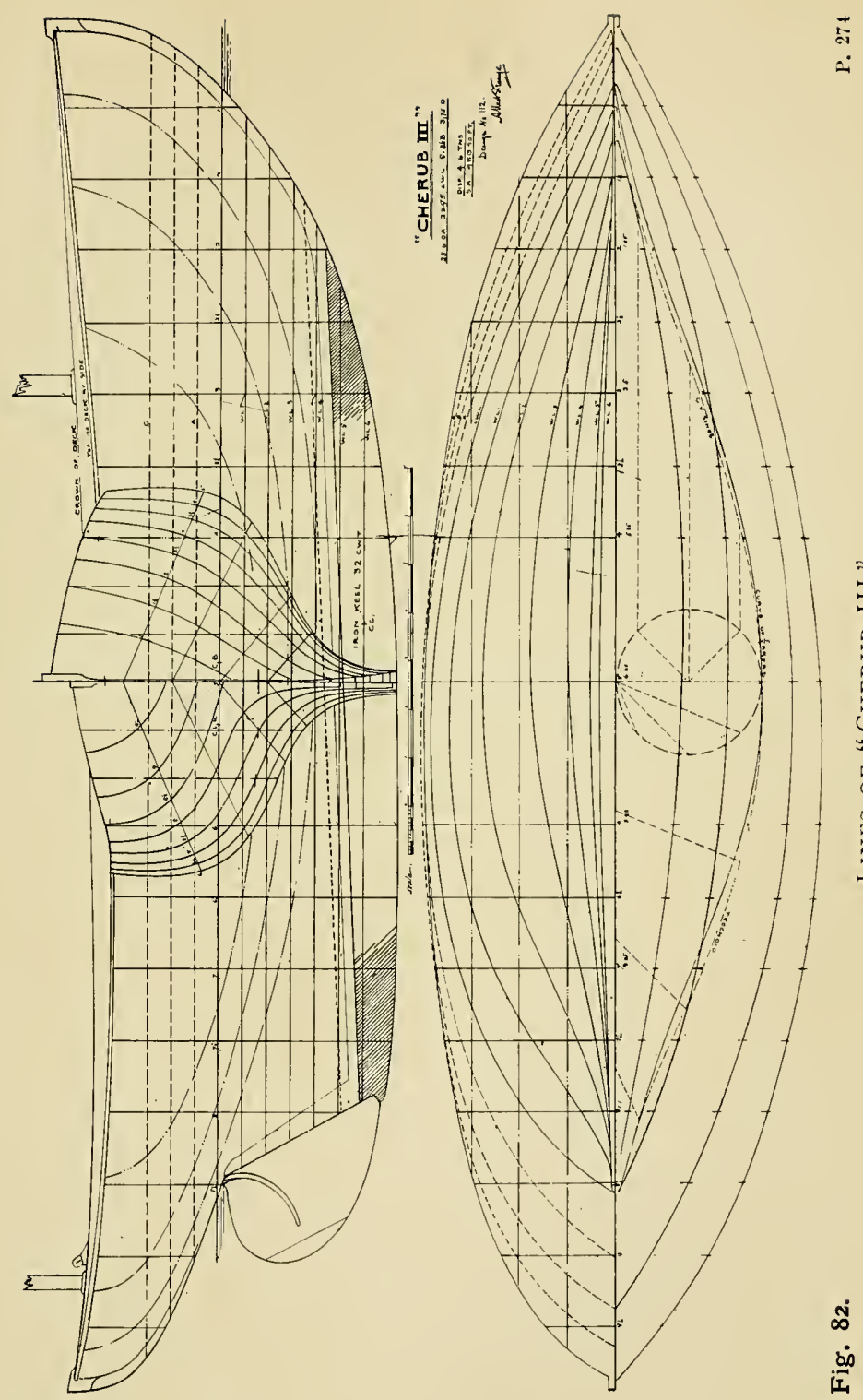

$\dot{5}$

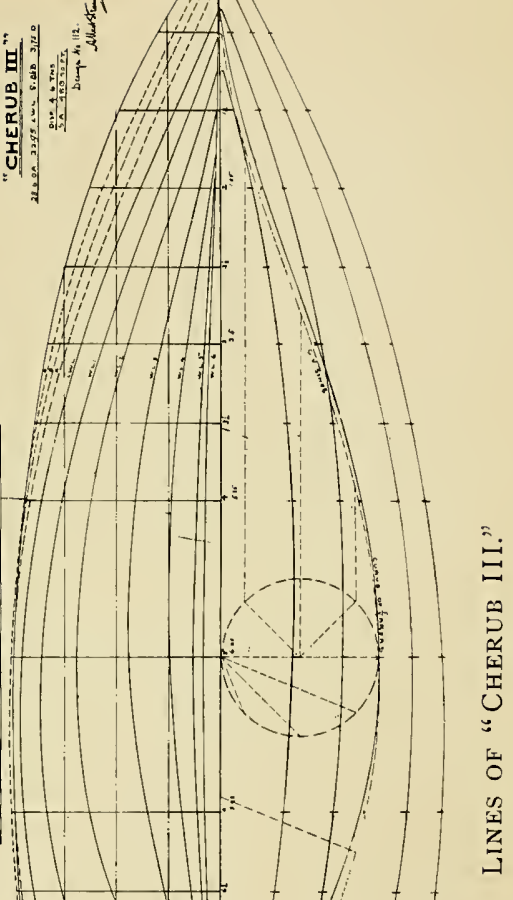




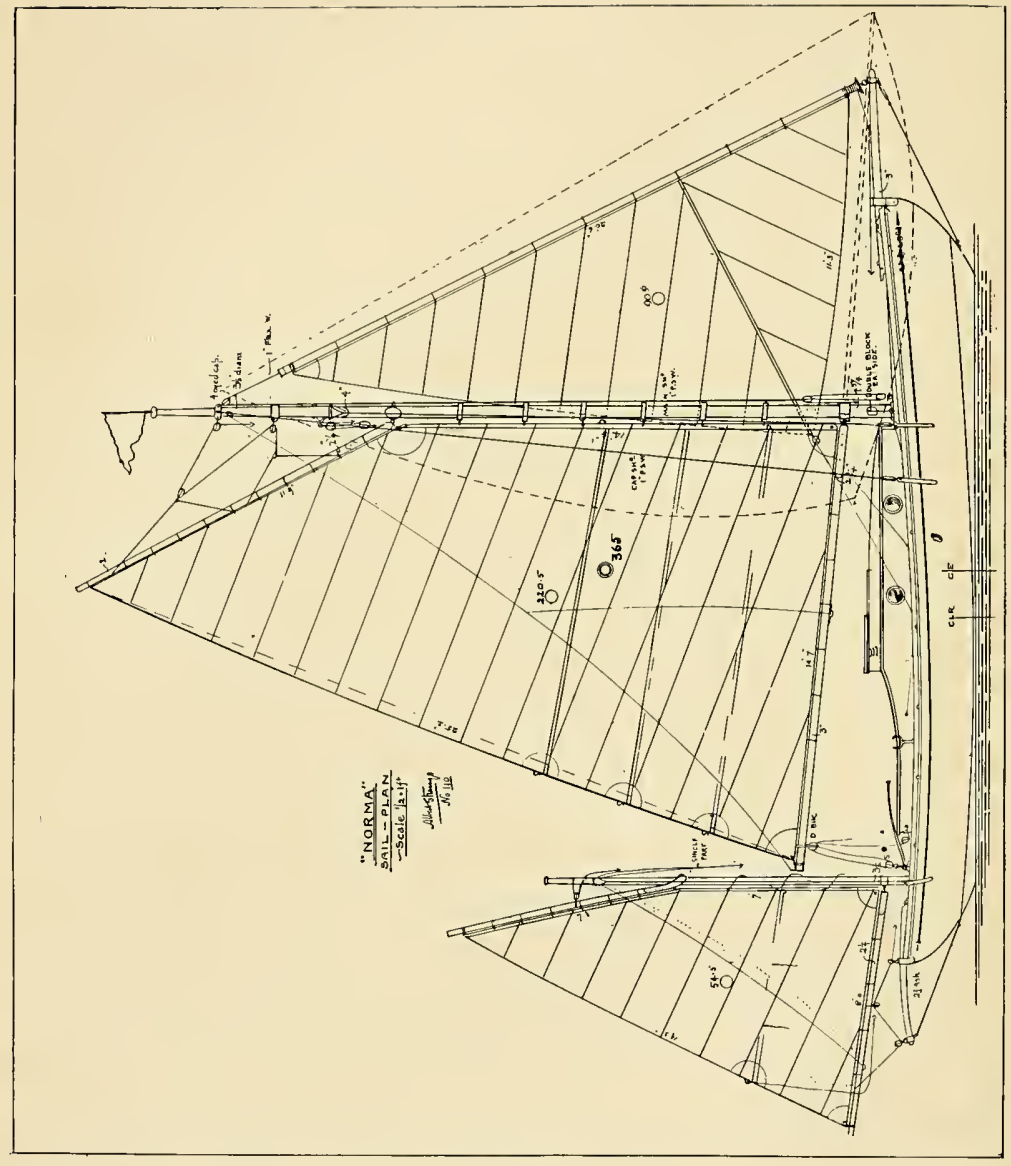




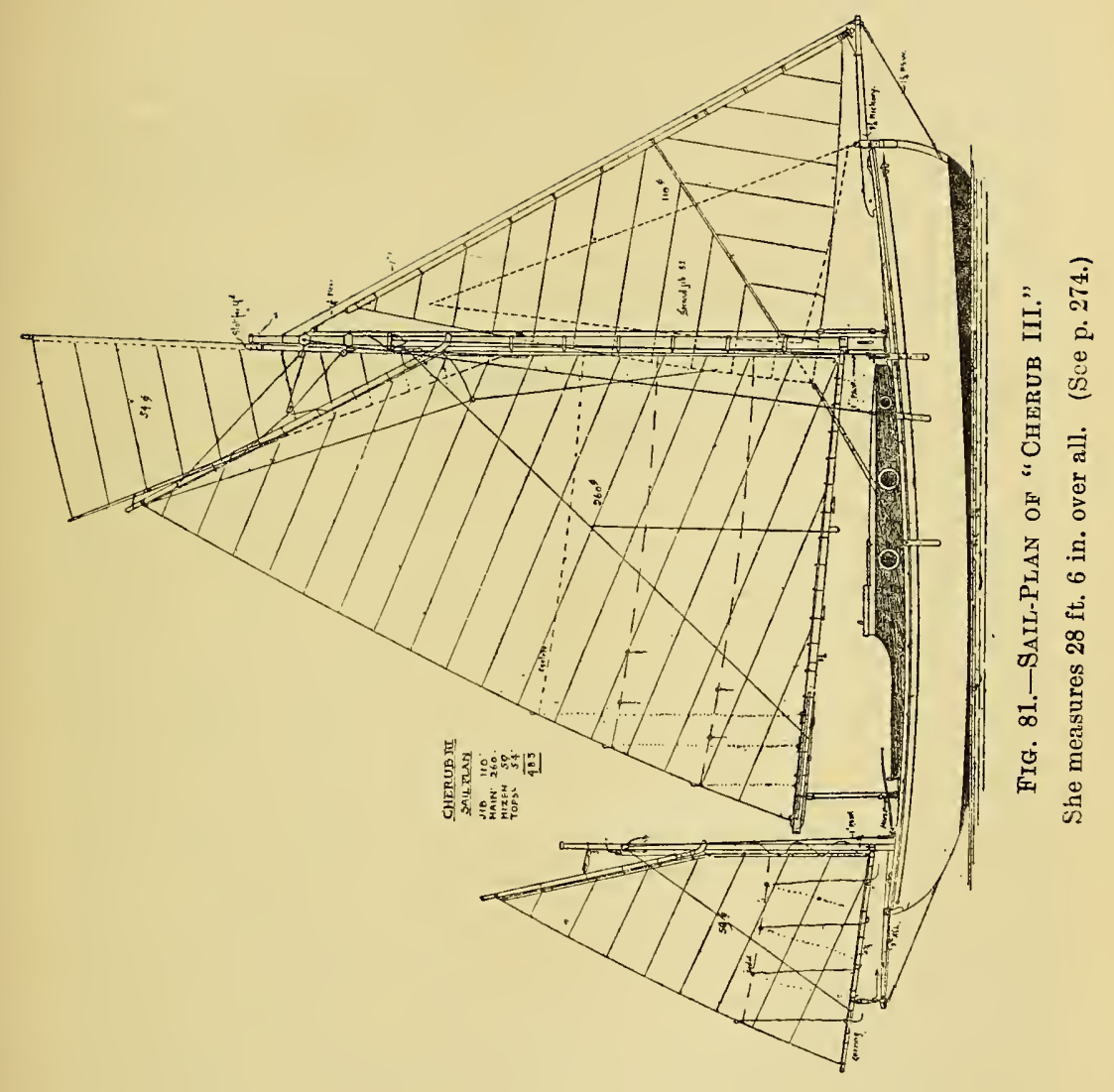


shown in what manner and under what influences the various main developments of the rig have taken place within our own times by the Anglo-Saxon people. It has been, and still continues to be, a blessing and a boon to sailor-men, whether professional or amateur, and with the addition of the motor within the last few years it has shown itself far too valuable to be discarded for many long years to come. It has been the means of keeping alive that spirit which is one of the most valuable possessions of our race, the love of the sea; for the square rig means a large craft, and that means increased expense and fewer numbers.

But the fore-and-aft rig, because it is applicable even to the smallest craft, is at once a training institution for the learner and an economical teacher. Whatever changes our shipping and craft may in the years to come be destined to suffer, at least it is to be desired that so wholesome a lurer to the healthy enjoyment of the sea life will not be allowed to be withdrawn. Today the development of this rig owes more than is usually admitted to the yachtsman, who remains, as has been well said, the only educated sailing-man at a time when the remaining sailors are, if not marine engineers, at any rate nautical chauffeurs who look upon a ship rather as a convenient creature for housing their wonderfully complex machinery than as a being of infinite character, infinite beauty, and of incredible charm. So long as the ship is allowed to retain her sails-not as auxiliaries but as essentials-she can only be improved by the addition of a motor as her secondary power. But as soon as she gives herself over entirely to steam or oil she sacrifices that simplicity which is, and always has been, the most charming part of her character.

And now, having seen the modern developments of this rig among our own people, let us pass on to note the conditions which prevail in other European countries where the fore-and-aft rig flourishes to-day. 


\section{CHAP'TER VIII}

THE MODERN FORE-AND-AFT RIG IN SCANDINAVIA, HOLLAND, BELGIUM, FRANCE, AND SOUTHERN EUROPE

SCANDINAVIA and the Baltic have been the $D$ dominating influence throughout the history of north European naval architecture, and so we shall, in our survey of the modern fore-and-aft rig in foreign countries, begin in the north, and thence on our southward journey take note of all that Holland, Belgium, France, and southern Europe may have to show us in regard to our study. We have again to emphasise the fact that it is impossible within the space allotted to us to take every species of craft and discuss it in detail. Our object throughout the course of this book has been rather to show the connected narrative of the fore-and-aft rig as exemplified in different waters than to form a list of every kind of sailing vessel which each nation possesses. The Norwegian "jaegt," for instance, with its single mast, square-sail, square topsail, and bonnet to the former sail, does not belong to the fore-and-aft rig, and therefore need not detain us ; and there are other smaller Norwegian craft which, with their single mast, square-sail, and double-ended hull, still keep alive the ancient characteristics of the Viking craft.

From the use through centuries of that square-sail there has come gradually and in the most natural manner the lugsail of varying patterns carried on these double-ended fishing-boats. Who shall say how it was that the square-sail in northern Europe as in 


\section{THE MODERN FORE-AND-AFT RIG}

Egypt was to give way to, or rather be merged into, the lug of some sort? Most probably it was for the same reason that compelled the Egyptian to adopt the nuggar rig-because of handiness for windward work. It always seems to me that the transition from the Viking square-sail to the lug really began with the use of bowlines. After that the transformation of the canvas from a square to a fore-and-aft sail came fairly easily. But whatever was the exact cause of the transition, the lug spread from Norway to Scotland, as we saw just now, and thither also crossed the Norselike fashion in naval architecture which has given those double ends to the Scotch fishing craft.

The pure descent, then, from the square-rigged Viking ship in Scandinavia to-day is one of those so-called "yawls" with double ends, the mast stepped about midships, no decks, and one large square-sail as our forefathers beheld it when the enemies of our land swept down in fleets from their country across the North Sea. And first cousin to this "yawl" is that other kind of craft similar in most respects save for the fact that the square-sail has changed itself into a lug. These are the first two classes to be borne in mind. But the north was to be influenced by the south; and as Holland, at the height of her maritime power, was to affect the rig of England's small craft, so this Dutch influence was to spread to Scandinavia.

And thus we find to-day in Norway, in Sweden, in Denmark, and along the German coast in the Baltic, that the spritsail of Holland is used just as it was by the Dutch of the sixteenth century. That is to say, the sail is not peaked as it is in the modern Thames barge, but the peak is no higher, and sometimes even slightly lower, than the throat of the sail. This is the third type-the application of a characteristically Dutch rig on to a typically Scandinavian type of hull. And there is the fourth type which shows the further influence of the later development of the fore-and-aft 


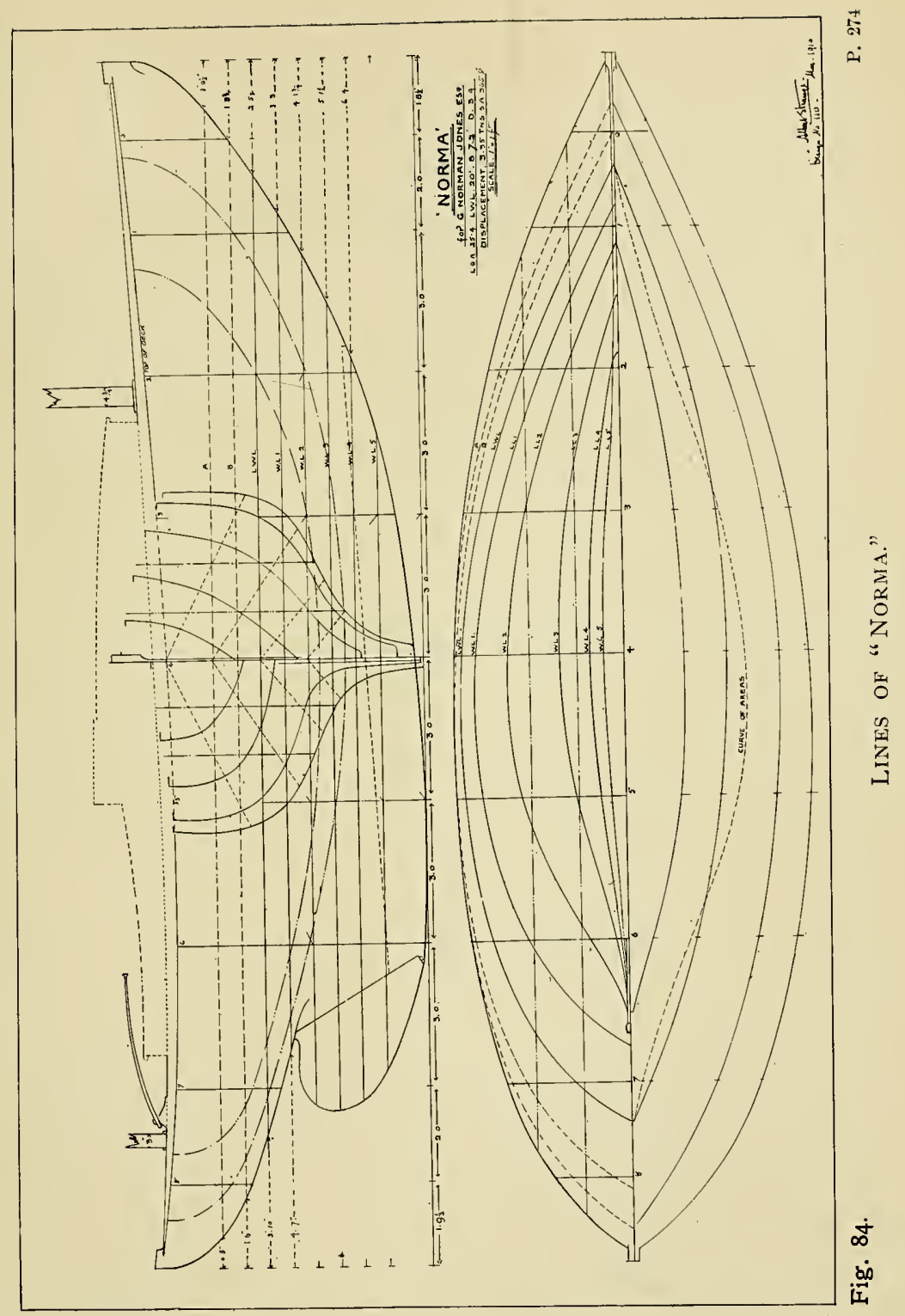




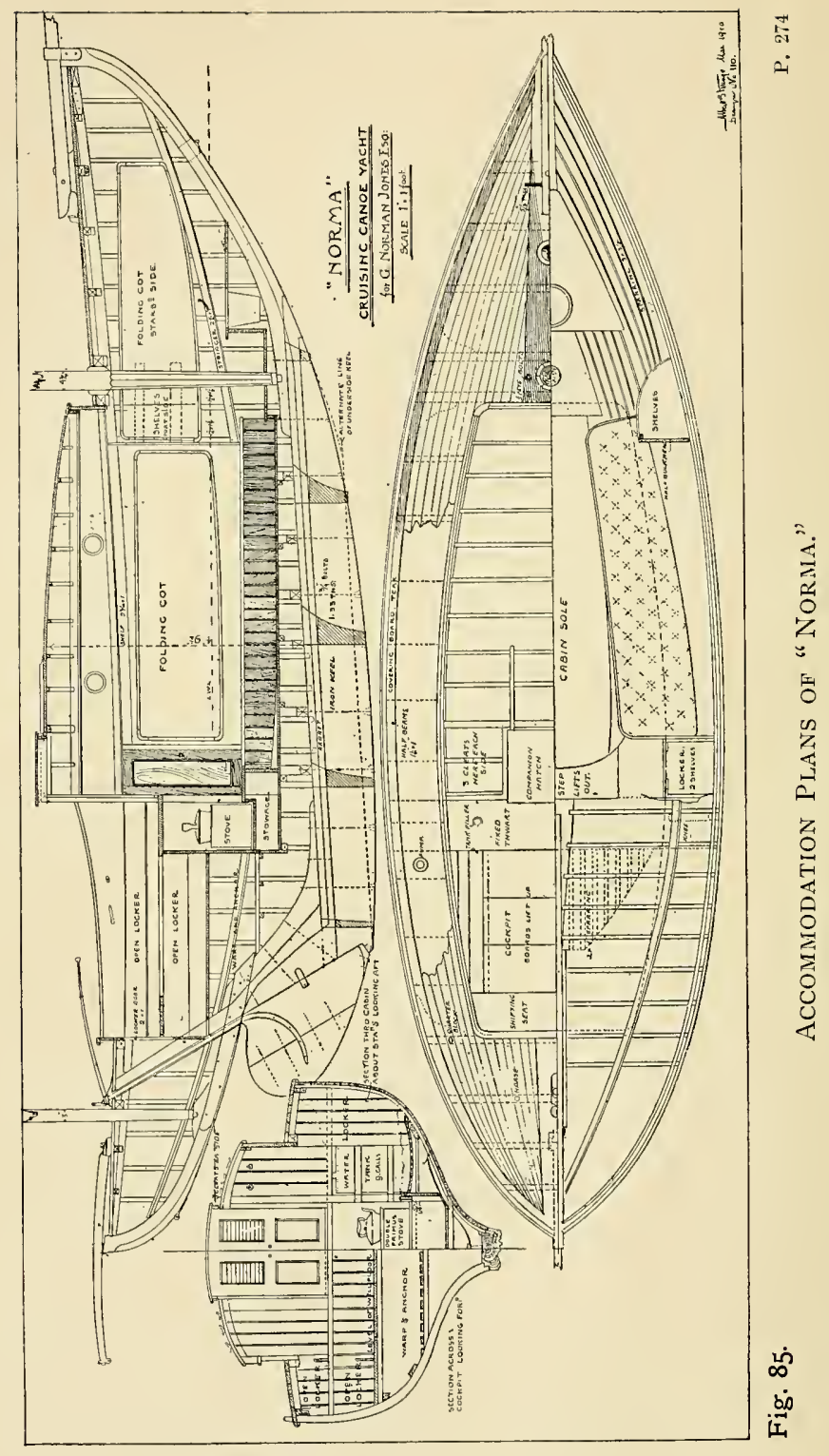


rig, which has done away with the sprit, and instead added a boom and gaff, added also another mastbrought about the galliot, in fact, also like the Dutch. And lastly, did our limits permit us, we could go on to show the land of the Vikings yielding to English influence and going in for steamships.

Now it is remarkable that the people of the north, notwithstanding the fact that they have shown themselves willing to accept the cutter and the ketch rigs, have nevertheless held on to a more or less Viking shape of hull. The same motive that prompted the old Norsemen to choose a double-ended craft, that to-day influences the design of lifeboats, whale-boats, and Scotch fishing craft-namely, the desire to get the best design for the worst weather-is still at work in the fashioning of the craft of the Baltic and Norway. We have in our last chapter seen this influence coming back again in the latest type of the best British cruisers-in Maud, in Seal, and so on. For magna est veritas et pravvalebit. You may suppress truth for centuries, but by its own power it will raise itself into recognition again in due course. You may forsake all the lessons which evolved from the Norse period, you may banish their designs from appearing in your craft from the beginning of the sixteenth century, but here in the twentieth you are going back to them. The fact is that history is emphatically not one long procession of progress: rather it is a series of progressions and regressions. At the time of the Vikings it was progression indeed, and naval architects to-day of the highest standing, who have gone carefully over the lines of these Viking ships which have been unearthed and still exist in Norway, tell you that their design could not be excelled even by our best men of modern times.

But thereafter all sorts of side-influences came in to modify the straight course of development. The demand for big-bellied cargo-carriers, the growth of 
the sterncastle and the forecastle, the wild, eccentric influence of the towering poop of the sixteenth and seventeenth centuries, the craze for ships of great tonnage, the influence of artillery on ship designs, the addition of a kind of stern platform to the transom stern, and so the transition to the later counterthese separate forces caused the natural-the Vikingends of a ship to be developed beyond all recognition. Therefore, in the present, which is an age rather of inquiry than of blind convention, it is but natural that we should go back to first principles. If we have in mind the desire for a vessel of moderate size, that is not to be hampered by any considerations of cargo accommodation, warfare, enormous tonnage for the carrying of large crews and soldiery, or racing: if, in short, we are looking for that which the old Vikings -the first great seafaring people of northern Europewanted, viz. a good sea-craft, then it is only reasonable that we should cast our eyes in the direction of the Norse region and study the type which generation after generation has happily preserved.

The history of any country is roughly thus, is it not? It begins with utter chaos and absence of rule. Then order enters in, and the country begins steadily to prosper. The next step sees it advancing rapidly to prosperity until it attains a climax. So long as it remains at that pivot it influences the other nations in all sorts of ways, of which shipping is one. Then there sets in the retrogression from that high point; it ceases to be an influence, and some other nation usurps its former proud position. It was so with Rome, it was with the land of the Norsemen, it was with Spain, it was with Holland; and there are those who say that with England the retrogression has begun. The Norsemen rose from insignificance to superiority in northern Europe, and after the climax of their power was reached they dwindled away to nothing. But as a relic of their epoch of supremacy there survives the 


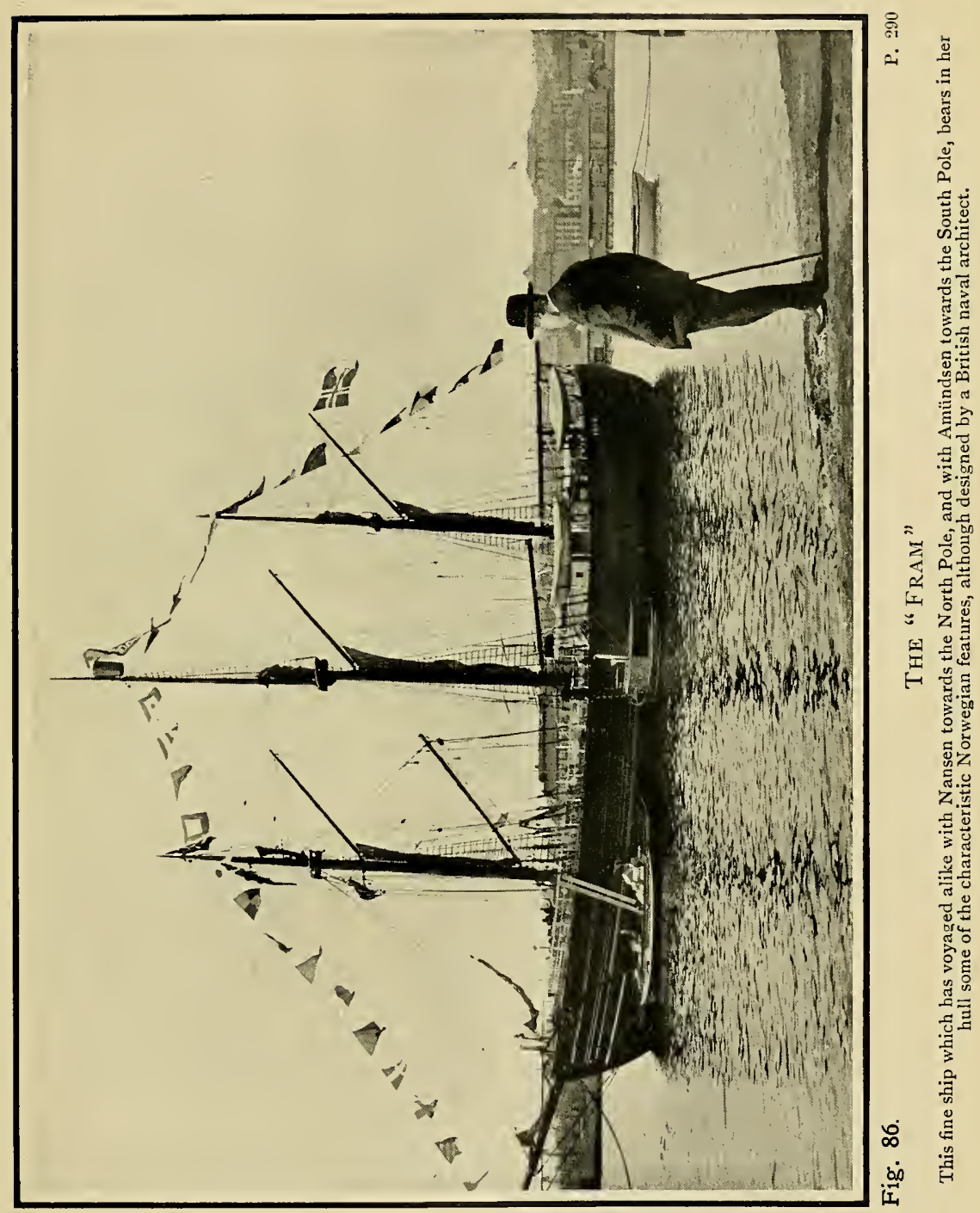



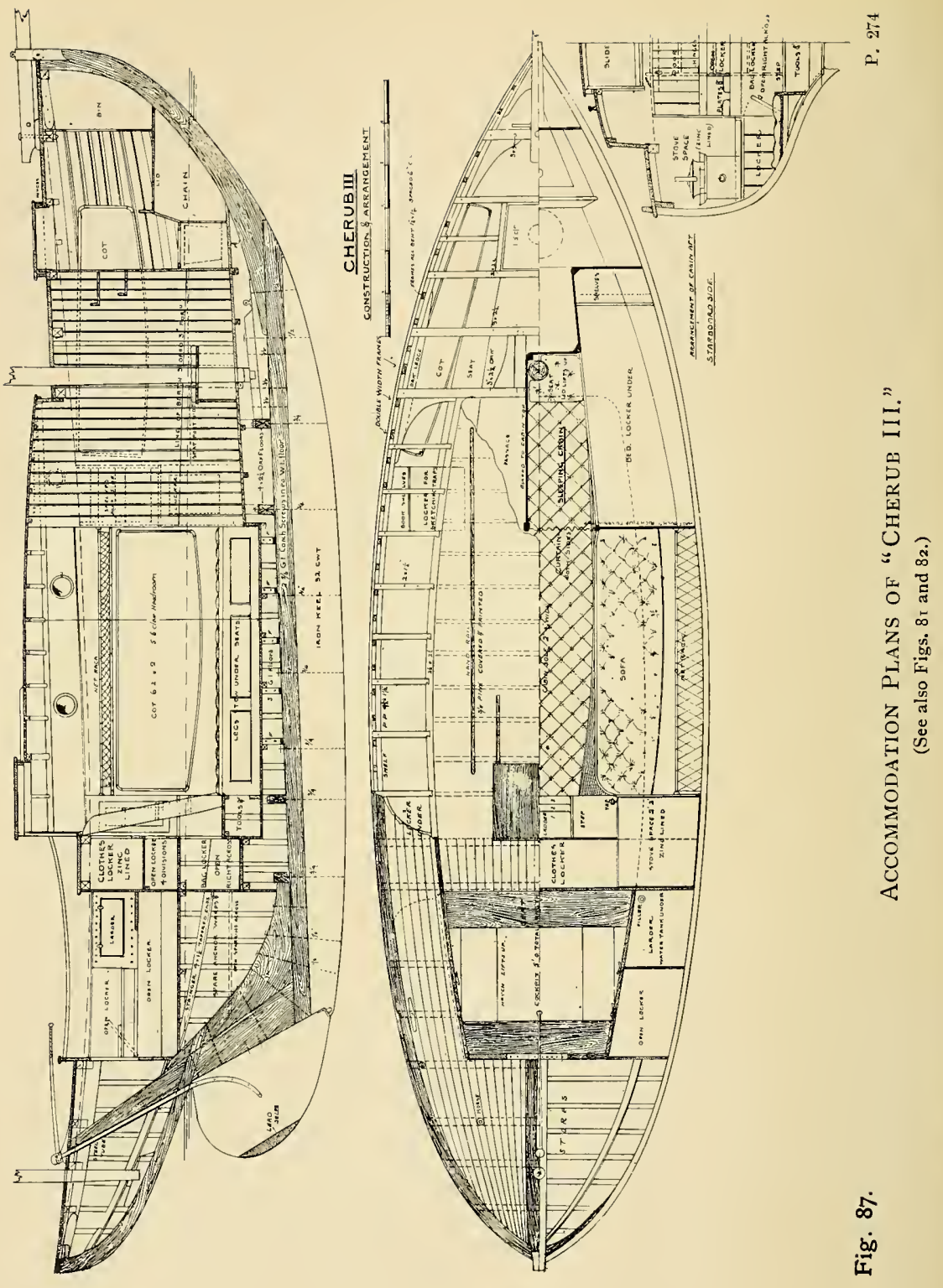
Viking design in ships. The Dutch also bequeathed to us the sloop or cutter rig, just as ancient Rome had, before she declined, left to the world a legacy that is still the basis of all legal systems. Spain rose to supremacy and then fell, but she had unlocked the door of the New World and shown to the East what a wonderful treasure-house the West contained. And if we must apply ourselves strictly to matters of marine interest, let us add that it was the Spanish who bequeathed to posterity the first data for the science and art of navigation.

To come back, then, to our main theme, it would seem to have been the duty of the Vikings to leave for us the right design for a sea-craft, and it is only to-day that after years of cross-purposes and bungling we are beginning to recognise the value of that legacy. We are wont in England to speak of the "canoe-stern," but that is because we have been accustomed to see such an ending to a boat on these frail craft. It would be more correct if we were to describe the type as the Norse stern. The old-fashioned stern is vanishing even from those very different steel walls which compose our modern navies. 'Take the torpedoboats and destroyers: consider the stern even of a modern "Dreadnought," and there is nothing of the square or circular character which belonged to the sterns of the period when the "wooden walls" were in vogue. We need not enter into the very different reasons which have influenced the Admiralty to introduce a stern-formation different from a few years ago. A number of reasons could be adduced connected with warfare, but another reason is found in the progress of modern naval architecture.

And if we pass over those intermediate centuries when architectural truths were forgotten, when the shipman was not able to realise how much his earliest ancestors had taught him, and then come down to the most modern times, we shall find that the curve of 


\section{THE MODERN FORE-AND-AFT RIG}

coincidence begins with the Vikings, bears away for centuries, and then comes back to the epoch in which we are now dwelling. It is indeed no rash prophecy to suggest that the influence of the general lines of the Norse-like bow and stern will in the future be evidenced in such craft as our fishing-boats, pilot craft, and yachts to an extent never before attempted. The fact was that the early Norwegians. grasped an important fact and held on to it. Because they never had reason during the Middle Ages to become a great nation of discoverers, or traders, or fighters, they never had to build great ships, and so never lost hold of their original design. We certainly have lost hold of that formation, but are getting back to it.

As our space is limited, we will content ourselves with four separate types of the north in which this early influence still persists in spite of the different natures of the respective craft. These four will embrace an auxiliary motor fishing craft, a sailing lifeboat, a pilot-craft, and a famous and historic contemporary vessel engaged in Polar exploration. Common to all these, though of different tonnage, is the influence we have just been discussing. The first of these will be seen in Fig. 88, which shows the lines of an auxiliary motor fishingboat of Frederikshaven, Denmark, which is here reproduced through the courtesy of M. Soé, the well-known French naval architect. Almost all the boats of this type are now fitted with paraffin motors and are ketchrigged, and yet practically the old Viking lines of the hull are still retained as will be seen. Of course they have been slightly modified for modern needs; otherwise they are as stated.

It may seem to the mere archæologist that it is almost shameful to debase so old and venerable a type of craft by the addition of a motor propeller and its shaft. But this same species of critic would in Viking times have asserted that it was a shame to spoil those beautiful, long ships by the addition of a mast and sail, 

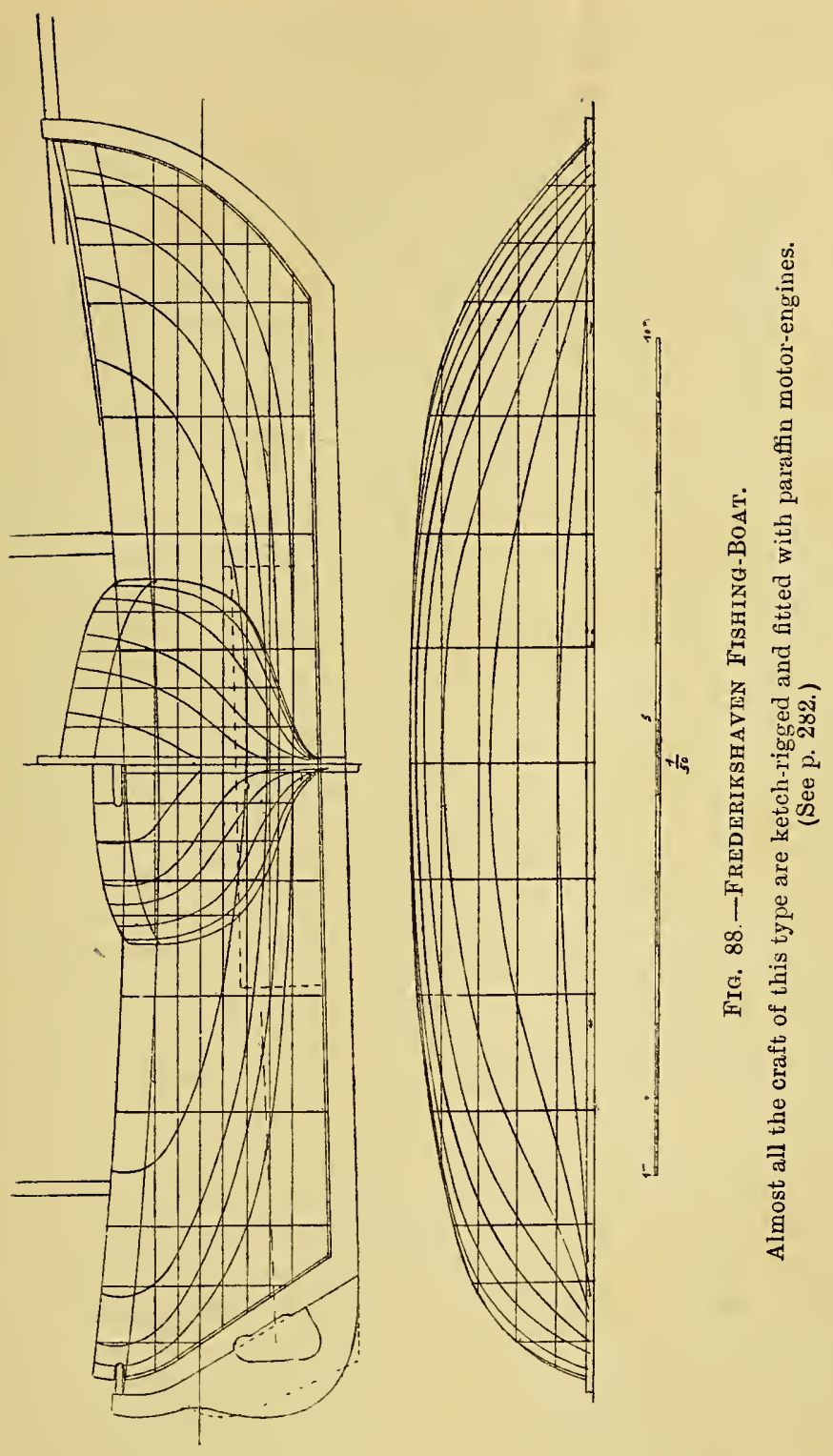


\section{4 'THE MODERN FORE-AND-AFT RIG}

seeing that they could be rowed so well. Surely it is the duty of the shipman, no matter what age he may be living in, to do the best he can to give his craft a greater efficiency, and to avail himself of any and every invention or device towards this end. We can be quite sure that if, say, about the eighth century of our era there had been such things as paraffin motors in Norway the Vikings would most certainly have installed them when once they had convinced themselves of their suitability for the work to be undertaken. The Danish craft before us measures 16.75 metres in length over all, and is driven by an Alpha motor of 20 horse-power.

In the modern "redningskoite," or Norwegian sailing lifeboat, the same important convention that we have noted still survives. The exceedingly interesting plans of this singularly able type of craft (Figs. 89, 92, and 97) have been here reproduced through the courtesy of Mr. Colin Archer, who migrated across the North Sea to settle in the port of Larvik. Here is a most interesting case of a Britisher actually influencing the shipping of Norway, just as Norway in the past has influenced the shipping of Britain. There is in existence a brave little ship whose name is known in every civilised country, which has been north and south from one end of the world to another, and will be remembered throughout history, not merely for the enterprise, the courage, and the important scientific results belonging to those whom she carried, but will, for her own powers of endurance, her strength, and design, be venerated throughout the centuries. Every reader has her name on the tip of his tongue. At the present moment she is away in the South Atlantic making oceanic investigations after having landed Captain Amundsen (the hero of the North-West Passage) preparatory to his attempt to make a dash for the South Pole. A few years ago this Fram carried Nansen northwards on his famous expedition towards the North Pole. We shall call attention to her again and give an illustration of 
her shortly, but for the present one may just note that her designer was not a Norwegian, but Mr. Archer of Larvik.

Now to return to the "redningskoite," let us at once remark that this type of vessel has been taken as the basis for the improved modern fishing and pilot craft of Norway. Furthermore, it is to Mr. Archer that these separate classes have been thus improved. $\mathrm{He}$ would seem to have begun by creating not a new and altogether different kind of craft, but rather to have taken the existing characteristic Norwegian species and to have worked on that model in the direction of improvement. This "redningskoite" is, as a type, different from our British lifeboat. The latter is more a boat, the former is more a ship. The British type is mostly open, being decked only at the ends, whereas the Norwegian type is decked all over. The lifeboat has practically no accommodation, but the " redningskoite" has ample cabin room below, and can keep the sea for days independently of the shore even in the wildest weather which blows on the cruel Norwegian coast. " "This type of boat," says Mr. Archer in a letter to the present writer, " gives perhaps the best idea of my work. Those I have built for pleasure-sailing only are nearly all modifications of the same type, being designed more for good sea-going qualities than for speed. The modern pilot-boat is very like a redningskoite (except the internal fittings) but smaller, being generally 38 to $40 \mathrm{ft}$. over all."

Looking at the accompanying plans, no one can hesitate to admire the admirable sea-keeping qualities which this Norwegian lifeboat type possesses. It is essentially a northern design, and should be compared with the lines of the Frederikshaven fishing-boat we discussed just now. The common influence which is seen in the Gogstad ship and other specimens of the Viking craft now unearthed (and referred to in detail in my Sailing Ships) is here vividly manifest in the essential lines of 
the redningskoite; but the latter has also the improvements which time has brought in the shape of a better rig than the old square-sail, a better form of rudder-at the stern instead of at the side-better internal accommodation, and better methods generally of producing a fine, able sea-boat allied to the qualities of handiness and comfort.

These vessels are built of the greatest possible strength that a wooden ship of their size could possess; oak, as in the case of the old Viking ships, being almost exclusively employed. It is because this redningskoite was built primarily for ability in bad weather that those modern yachtsmen who prefer a ship to a pretty toy, who would choose a healthy and able cruiser before a racing machine, are selecting this type as a basis for the design of their new craft. The Maud we mentioned has certain resemblances, because her pedigree may be summed up thus : she was built in Scotland and influenced by the Loch Fyne type of craft, which in turn was brought about indirectly by the proximity of Norway to Scotland, as already we have observed. The Maud was designed for ocean cruising, not for pottering about the Solent in fine weather The redningskoite, as we have seen, was also designed for bad weather, and so, owing to the two forces respectively of Norway and bad weather operating on these two ships, we get a common similarity which is more than accidental. In the same river Hamble, so well known to most yachtsmen, one has the opportunity of comparing the two types by the most happy circumstance. For besides the Maud there is another yacht of roughly the same tonnage named the Askgard. The latter is owned by Mr. Erskine Childers, internationally famous to many as the author of The Riddle of the Sands. This Askgard was designed by Mr. Colin Archer as a yacht but based on the redningskoite type, and thus notwithstanding the fact that these two yachts were designed and built hundreds of miles away from each 
other and in different countries, yet in their main features the Maud and Askgard exhibit the clear-cut influence of Norway.

The reader will recollect that when speaking of the Bristol Channel pilot craft we referred to the important value of internal ballast. 'This fact is equally appreciated by the craft of the Baltic and Norway which are so distinguished for their easy behaviour in a seaway. Two-thirds of the ballast inside and only one-third outside on the keel is about the proportion. In the accompanying lines of the redningskoite it will be seen that the cut-away bow is totally different from the exaggerated spoon-bow of the racing yacht, and there is no possibility of straining through constant hammering of the waves. The keel is a long straight line so that the vessel will heave-to and keep on her course steadily.

Passing next to the sail-plan of this craft, it will be seen that, like those other sea-keeping craft we have pointed out, the staysail is big, the mizzen being somewhat smaller than is usual in ketches. There are those who insist on what they call a "ketchy-yawl"; in other words, a yawl rig with the mizzen larger than is usual in a yawl. But amongst others I would prefer to have the advantage of a yawl-like ketch, by which you have a good-sized mainsail to drive the ship along, and yet your comparatively small mizzen is mostly inboard and projects but little abaft the stern. And so it will be seen in the sail-plan (Fig. 89). The mainsail and mizzen are loose-footed and no patent reefing-gear is used, but double reefing cringles are attached to the leach of the mainsail. The foot of the staysail is cut rather high, and thus prevents the sail from being so depressing as it might be through driving the wind down on to the deck from the canvas. From a little abaft where the helmsman sits right away to the bows on both sides of the ship a useful and stout rail runs round, which will give ample protection to the crew in bad 


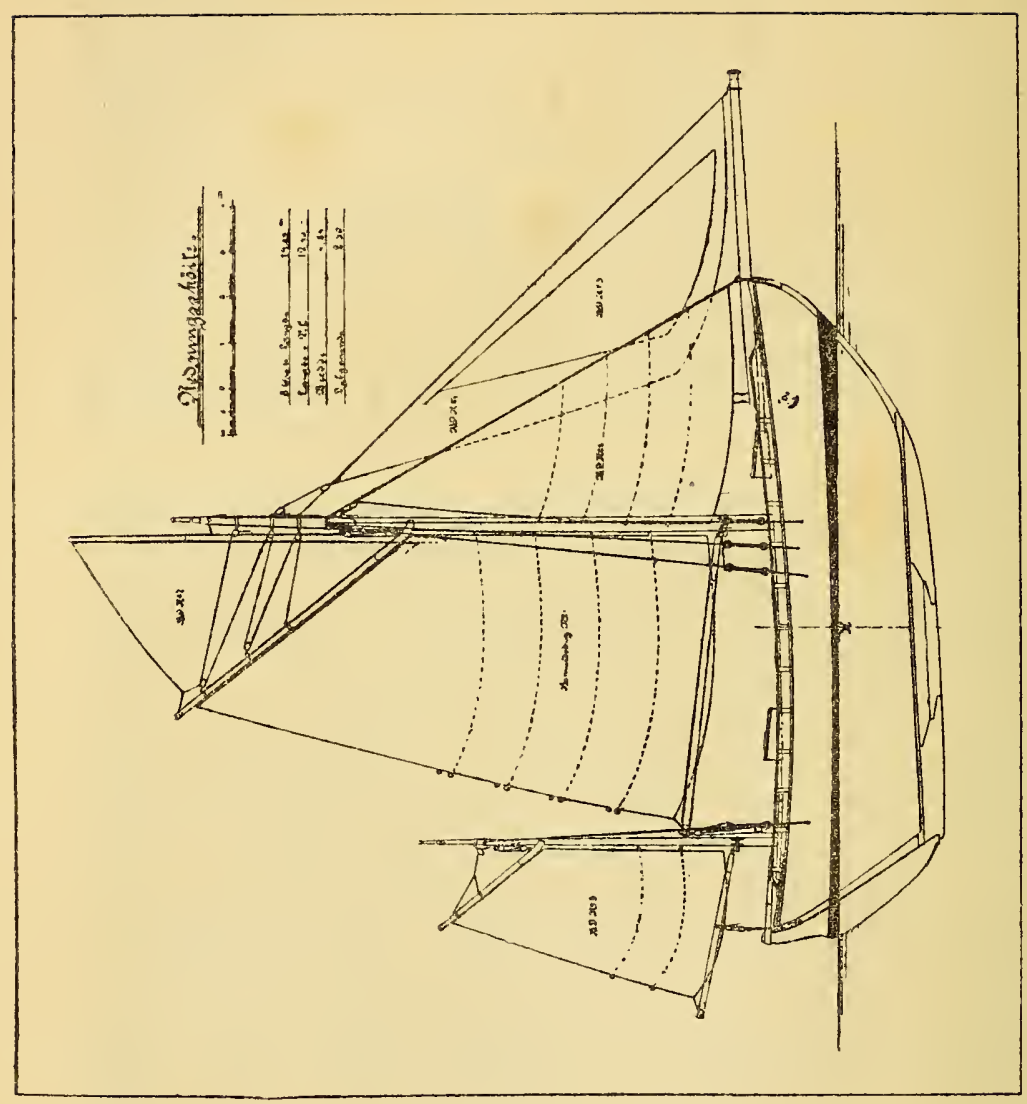

造 


\section{THE MODERN FORE-AND-AFT RIG 289}

weather. Just as secure as a bulwark it has none of the latter's disadvantages, for because of its being open it allows the water to flow off as rapidly as the seas are shipped.

In the old-fashioned type of English craft the high bulwark was really a delusion. True, it did afford some protection, but because it held on its lee-side such quantities of water before the latter could escape through the scuppers it actually detracted from the seaworthiness of the ship quite as proportionately as it added thereto. Three shrouds on either side are seen to support the mainmast, which, by the way, has no spreader. 'There are no runners or backstays at all. The mizzen is supported by a single shroud on either side, but placed well forward of the mast. There are those who would say that the rudder looks unsightly placed as it is in these craft, but that is only because the eye has become so accustomed to seeing a counterstern that it actually misses it when it has disappeared.

The internal accommodation of this redningskoite is so thorough and attractive that it might well form the model from which to design the arrangements below deck of the modern ideal cruiser. Access is given from the deck by the two companion ladders, the one forward, the other aft. 'There is a serviceable cockpit, and some very stout bollards are placed aft. This is because these lifeboats sometimes have to tow home small fishing-craft caught out in bad weather. On either side of the bowsprit will be noticed a kind of cathead with fairlead therein. No one could assert that these add to the beauty of the ship, but they are eminently serviceable and prevent the cable chain from grinding away against the craft's bows. In the steerage there are the sail-locker, the lamp room, provision lockers, \&c.; forward of which comes the saloon, with table in the centre and two beds on either side. A coke stove is placed at the forward end of this saloon, and a door gives access into the forward cabin. 


\section{THE MODERN FORE-AND-AFT RIG}

In the illustration (Fig. 76) will be seen a photograph of a modern Norwegian pilot-craft, which, except for being cutter-rigged and for her internal fittings, is very similar to the redningskoite. She carries a large staysail and a small jib like the Bristol Channel pilot-craft. Like the latter, too, she is a staunch, plucky little vessel, having about thirtyeight to forty feet in length over all. Her mainsail is peaked very high, and she sets a small topsail. But it is her hull which is of such interest to us with its retention of those eminently northern features of which we have spoken already. There are several yachts in England of varying sizes which have been based on these pilot-craft, and if not fast in light winds they have proved themselves to be splendid sea-boats.

Finally we come to the Fram (Fig. 86), which, though a considerably larger vessel than any we have been dealing with in this chapter, bears in her hull the eminently characteristic Norwegian features. She is really double-ended, though this design was adopted less from considerations of weather than as a protection against the ice. Still, it is interesting none the less to note this repetition of type in Norwegian craft irrespective of size or rig. Some means had to be sought by her designer to afford her such a stern as would be able effectually to cheat the ice, and he found no more useful stern for this Polar ship than in that which prevailed in most of the craft of the north. It is now a matter of history that the Fram has shown herself a magnificent sea-craft and able successfully to withstand the attacks of the ice. The accompanying illustration was taken just before she left on her expedition which was to enable Captain Amundsen to make his dash for the South Pole.

We have spoken a good deal of the part which Holland in the past has played in the development of the fore-and-aft rig: we may now pause awhile 


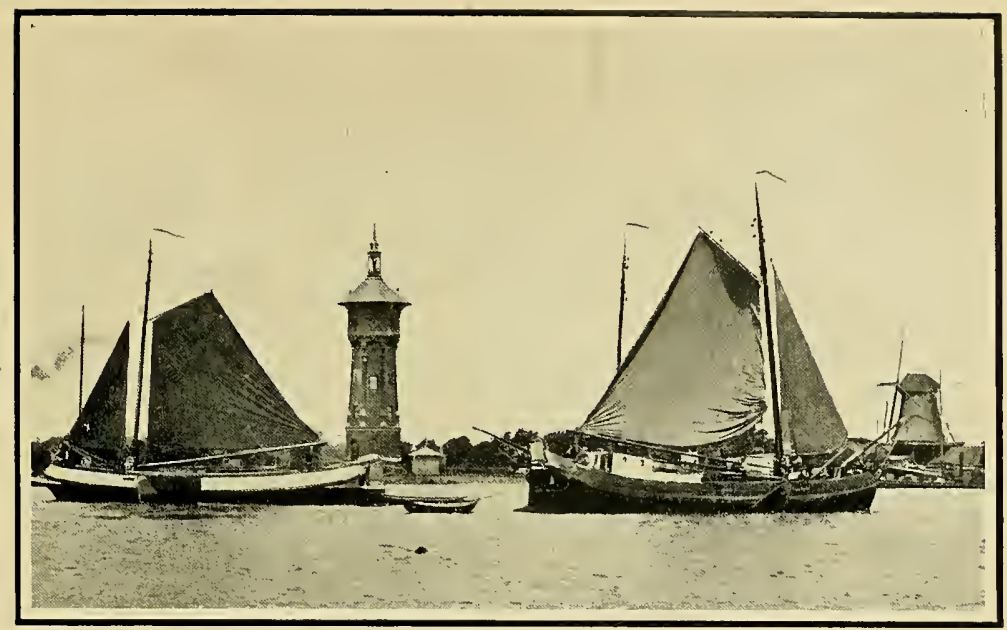

Fig 90.

DUTCH TJALKS

P. 291

Notice the high sterns in these.

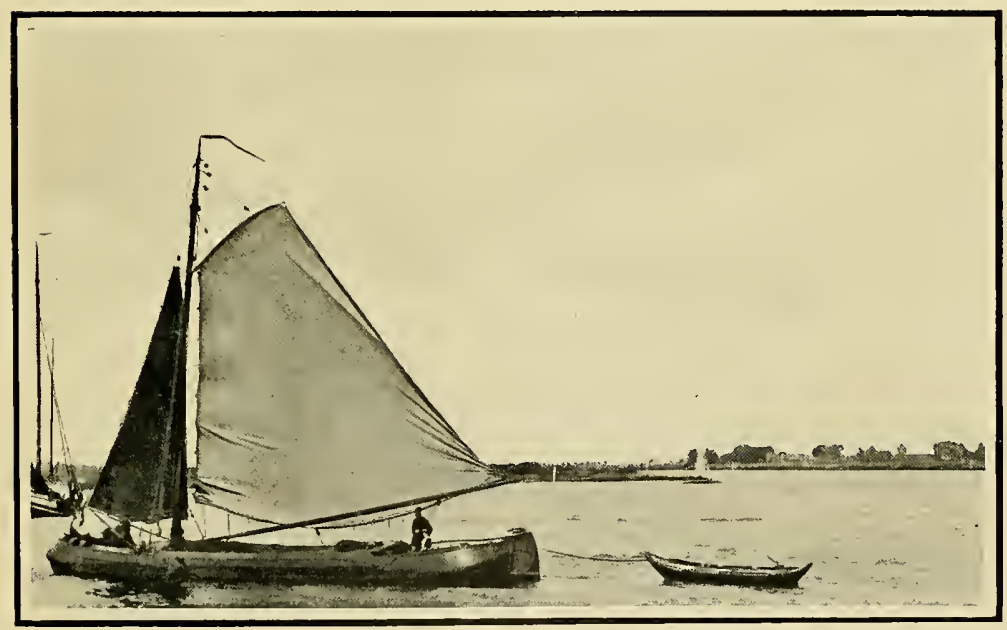

Fig. 9I.

A Smaller Dutch TJalk

P. 291

There is an absence of sheer and the stem is not high. 


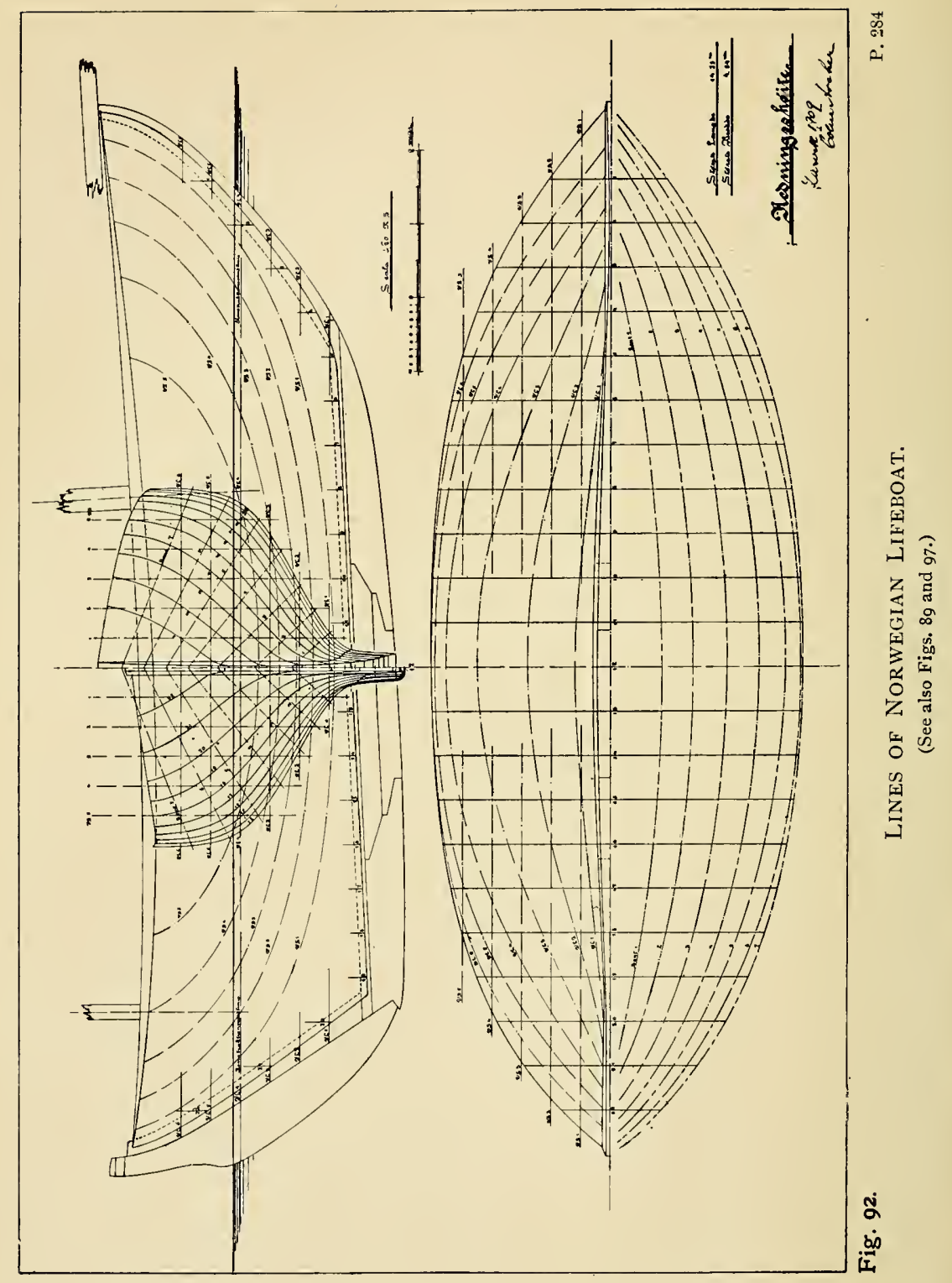


to examine the prevailing types which are in use today. And first let us consider the tjalk, which is the type of sailing-craft that is most frequently met with everywhere on the Dutch waters. Usually she is of about fifty to seventy tons, and is characterised by her round bows and stern, the latter being frequently higher than the bows; such is the persistence of the sixteenth-century precedent. These craft have a flat bottom, and are, of course, fitted with leeboards. You see them everywhere creeping along with their brown sails, perhaps beating up the Engelische Varwater or running into the Orange locks that keep out the Zuyder Zee from Amsterdam. You meet them coming into Rotterdam with their cargoes ready to be put aboard the sea-going liners; you see them threading their way in and out of the tightly packed havens or brought up at night just clear of the fairway in the Schelde, or perhaps sailing stealthily through the night, not with sidelights as is our custom, but with a white light exhibited at the masthead. In the two illustrations (Figs. 90 and 91) one can see three types of the tjalk-the large, the medium, and the small. In the first two the sheer from bow to stern is pronounced; in the last of the three it is altogether vanished. Some of these craft have a single mainsheet of steel wire which is worked by a hand-gear from aft, and some of them have auxiliary motors installed.

Looking for a moment at the illustration (Fig. 91) containing only one tjalk, it will be seen that just below the staysail there is a triangularshaped arrangement consisting of two spars. When the mast is lowered this gradually rises to its feet so that the apex points upwards, and it resembles the letter A. At this apex the forestay passes over, so that an increased assistance is given in the work of raising the mast when the bridge has been passed under. The mainsail is always loose-footed and 
frequently triced up, but the gaff, which is seen to be curved in the case of the smallest tjalk, is straight like our own ships in the bigger ones. Sometimes there is a deck-house aft, and the skipper carries with him his wife, his flaxen-haired little daughters, and a couple of his sons, who work the ship between them. You may sometimes find a smaller tjalk with only the skipper, his wife, his little girl, and his boy of about ten or eleven. In a flat calm as he comes into Amsterdam or along the tidal Maas into Rotterdam you may see the little boy and girl go ahead in the ship's boat and endeavour to tow this hefty vessel. How they have physical strength so to do I know not; all I can say is that I have seen them doing it.

The boat which the smallest tjalk (Fig. 91) is seen to be towing is typical of Holland. Flat-bottomed, with high bows like a botter, varnished outside, with a green gunwale and a white stripe, and both bow and stern alike saving for the addition of some deadwood aft to make her steer better, this is not a light craft but one of the most seaworthy dinghies which time could possibly evolve. They are very strong, and if an English yachtsman were to add a dagger plate they would be as good for sailing, rowing, and towing as the pram dinghy. I asked a Dutch shipbuilder how they described these craft, and he told me the name was a "Boskoop boot," Boskoop being a little waterside town on the canal between Gouda and Amsterdam. The decks of the tjalk seem to an Englishman to be encumbered with too many quants, sounding poles, and lengthy boathooks. And yet these are all required where so much locking in and out of a sluis, so much creeping over short-cuts infested with sand-banks, so much hauling along quays have to be done in the course of the voyage. Nowadays the tjalk is usually built of iron, and retains much of the former shape which has done 
duty for centuries. But the old-fashioned wooden tjalks are so mellow in their appearance, so well taken care of, so deserving of respect, that it is to be hoped that iron will not utterly eradicate them.

In the illustration (Fig. 93) will be seen a sketch of another very familiar Dutch type. This is the klipper, which is a decidedly bigger craft, longer and proportionately narrower. 'They sail well, are usually

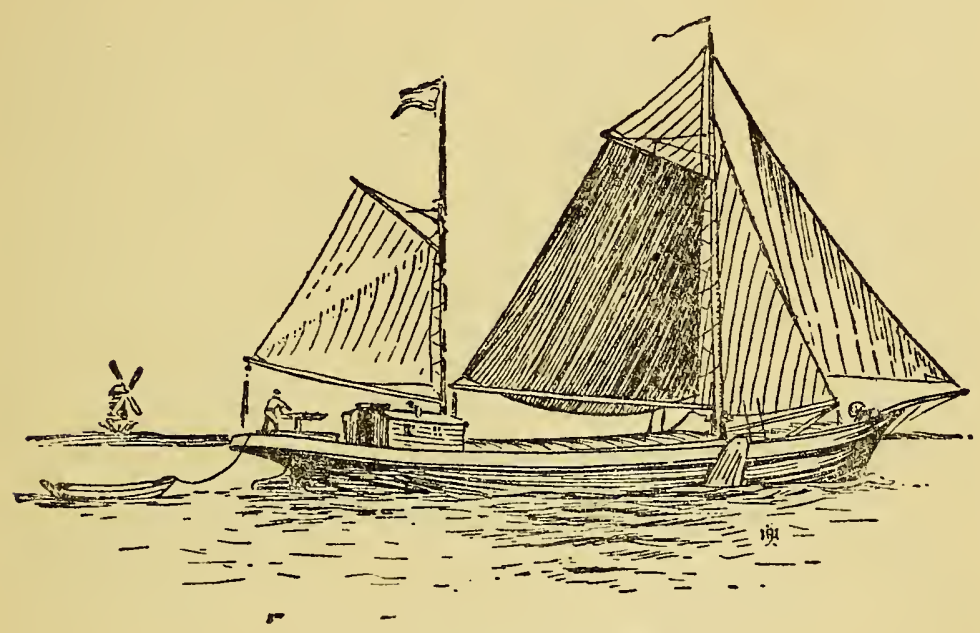

FIG. 93.-DUTCH KLIPPER.

Usually/ketch-rigged, built of iron, with an enormous horizontal steering-wheel and clipper bows, these craft carry much of the cargo from one end of Holland to the other.

ketch-rigged though sometimes cutter-rigged. Built of iron, the larger craft have an enormous steeringwheel, which is placed horizontally and not vertically as in our ships, so that it is possible immediately to alter the large rudders even a quarter of a point when making their voyage through the winding rivers and canals. There is enormous space in the hold for the cargo, and a deck-house is placed aft for the skipper's family. The bipod attachment for raising 


\section{THE MODERN FORE-AND-AFT RIG}

the lowered mast that we spoke of just now will again be seen to be illustrated at the foot of the forestay. These craft have a clipper bow, leeboards, loose-footed mainsail, bowsprit, jib, and staysail, and when rigged as ketches are as seen in this sketch. For getting up the bow-anchor they have a powerful capstan forward which is worked by means of the circular iron wheel and handle just as on a laundress' wringing-machine. Right aft, underneath the counter, there is a hole in which there is a stockless anchor. This is sometimes let go when running into a crowded haven or lock and the ship has too much way on, but is too long to luff up in the narrow confines of these waters. Frankly, the klipper is not a beautiful craft; she is really just a smaller edition of one of those great 2000-ton "Rhine-schiffs," but is driven by her own sail-power instead of being towed by a powerful little steam tug. There are innumerable winches on these modern Dutch craft for the halyards, mainsheets, leeboards, and anchors, which have brought the art of labour-saving down to its finest point.

Most interesting is a totally different species of Dutch craft as seen in the next two of our illustrations (Figs. 94 and 95). 'This is the botter. In the foreground of the sketch is one from the Island of Urk in the Zuyder Zee. Her high, bold bows make her ideal for combatting the nasty, steep seas of the Zuyder Zee and of the North Sea off the Dutch coast. They come on Mondays across the former from the Islands of Urk or Marken, lock through the Orange Sluis, sail along the Eye through Amsterdam, and so out through the Ymuiden locks into the North Sea. The following Saturday will see them again doing the return journey, calling at Amsterdam to take home the Sunday's meat for their families. The ships are like their crews and the latter's costumes-old-world and unique. The men are as fine and stalwart as their craft, and, in their own particular line of sea- 
manship, unsurpassed. These craft seem usually to be handled with a crew of three, perhaps the father and his two sons, of whom the younger is a mere boy in years but has the seaman's instinct born and bred in him as it has been in his family for centuries. Manly, healthy, clear-skinned, flaxen people in their

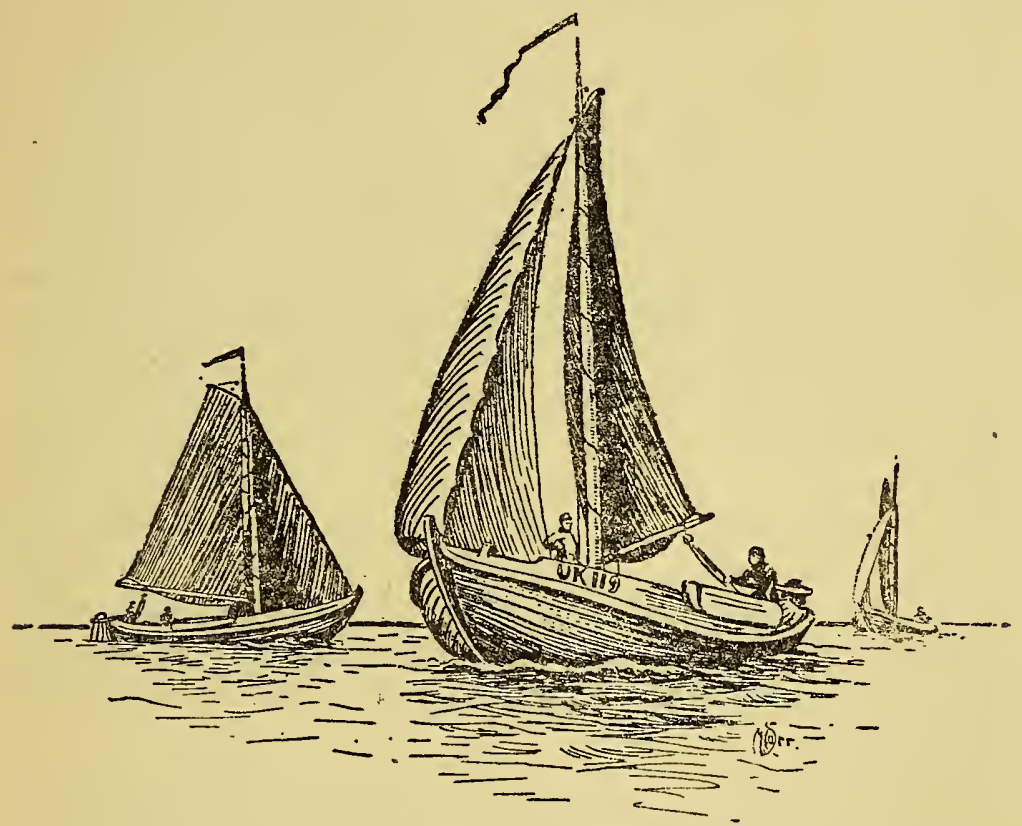

Fig. 94.-Dutch Botters.

These have their home on the Zuyder Zee, and come from such ports as the Isles of Marken and Urk.

baggy knickerbockers (much patched) and stockings and wooden shoes, there is something singularly attractive about them. Usually their craft cruise under staysail and main, the latter being loose-footed and laced to the mast, and the gaff is short; but sometimes they run out a bowsprit and set a jib as well. 


\section{THE MODERN FORE-AND-AFT RIG}

The botter rarely ships any solid water, even when it is blowing hard on the Zuyder Zee, though she throws up a good deal of spray from her high bows. A noticeable feature of these craft is that the mast is stepped well aft and the staysail is very big. From the photograph (Fig. 95), which was taken at Monnikendam, on the Zuyder Zee, just opposite the Isle of Marken, an excellent idea may be formed of the deckplan of the botter. She has a large fore-deck; immediately abaft this is stepped the mast, aft of which, again, is a very large well for working the nets. On either side of the ship, at the break of the fore-deck, is installed a pump. Her leeboards are anything but shoe-shaped, being quite narrow and small. Nevertheless, she goes to windward and points nearer the wind than one would expect. As to size, these craft vary from $30 \mathrm{ft}$. to $50 \mathrm{ft}$. in length, and have the whole of their ballast inside. The danger of these vessels is that they sometimes get pooped, when their great open well soon fills, and they sink. The " hatchet-shaped" rudder is very Dutch-like. 'They are carvel-built, and being quite flat underneath, can take the ground quite easily in tidal harbours. Fitted with open gratings below the water-line, the water can be run in and out so as to keep the fish fresh.

I have had every opportunity for studying themon the slips for repairs, in harbour, under-way, and have examined them carefully on board-and it would be difficult to find a better type of craft for the work they are called upon to perform. Some of the Dutch sportsmen have had their yachts built on these models, in which case they are decked in all over with a fine ample cabin, a forecastle (under the fore-deck), and cockpit. I have seen them turning to windward out of a very narrow harbour (as, for instance, Scheveningen), and noted how handy they are under merely main- and stay-sail. There is a powerful but simple winch foreward just as it was in the sixteenth century, with a 


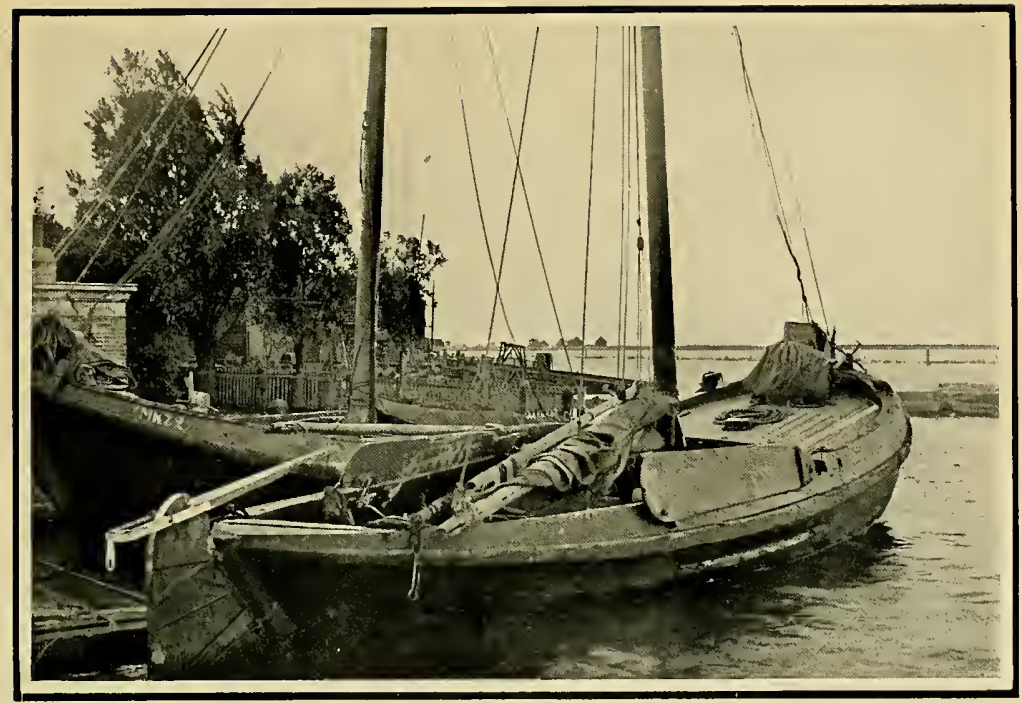

Fig. 95 .

P. 294

ISLE OF MARKEN BOTTERS

The large foredeck of these craft helps to keep them dry and a very large well abaft the mast gives plenty of roam for their nets.

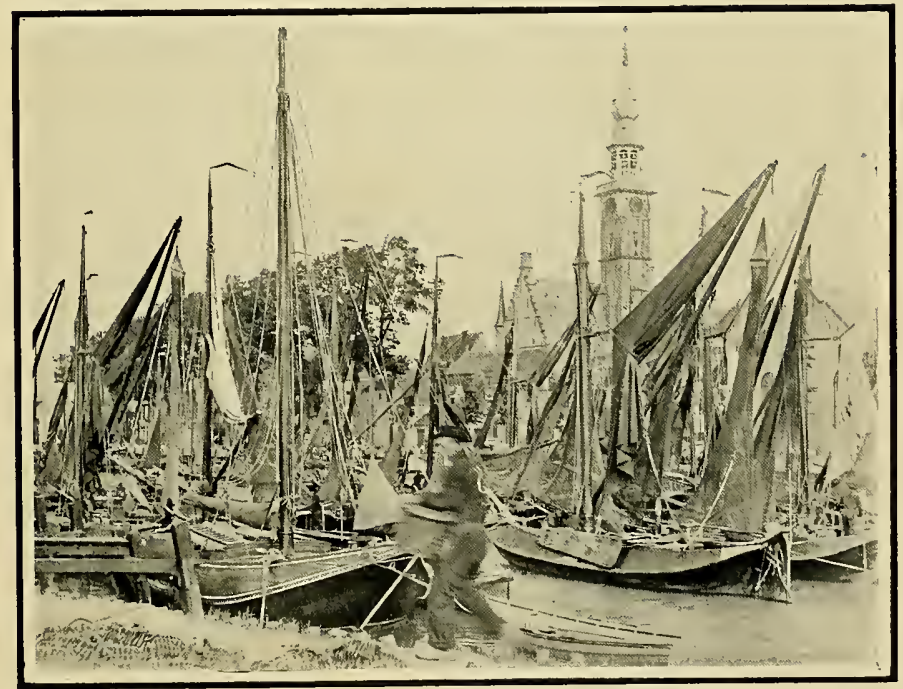

Fig. 96.

HoOgARTS Fishing FLEET

P. 298

Notice the large amount of "drift" between the mast and the throat of the spritsail on the hoogarts to the right of the picture. The craft to the left near the man is more modern and has a mainsail with boom and gaff. (See also Figs. 99 and 10o.) 


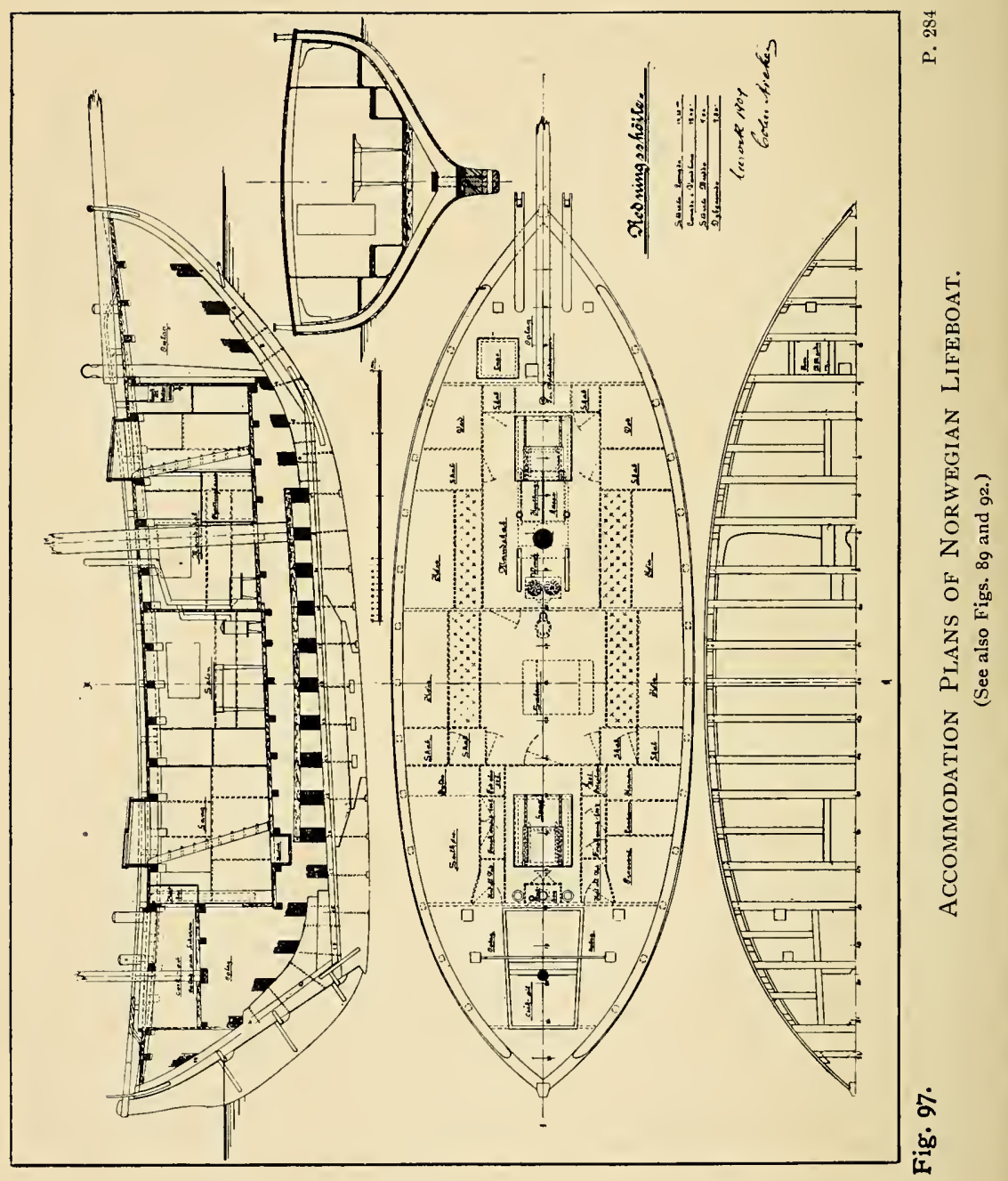


great wooden drum worked by handspikes and provided with pawls.

The schokker is a modified botter, but bigger, and an excellent sea-boat. As will be seen from the sketch in Fig. 98, she has a cleft in her stem-head, in which she stows her anchor, usually a grapnel. The stem-

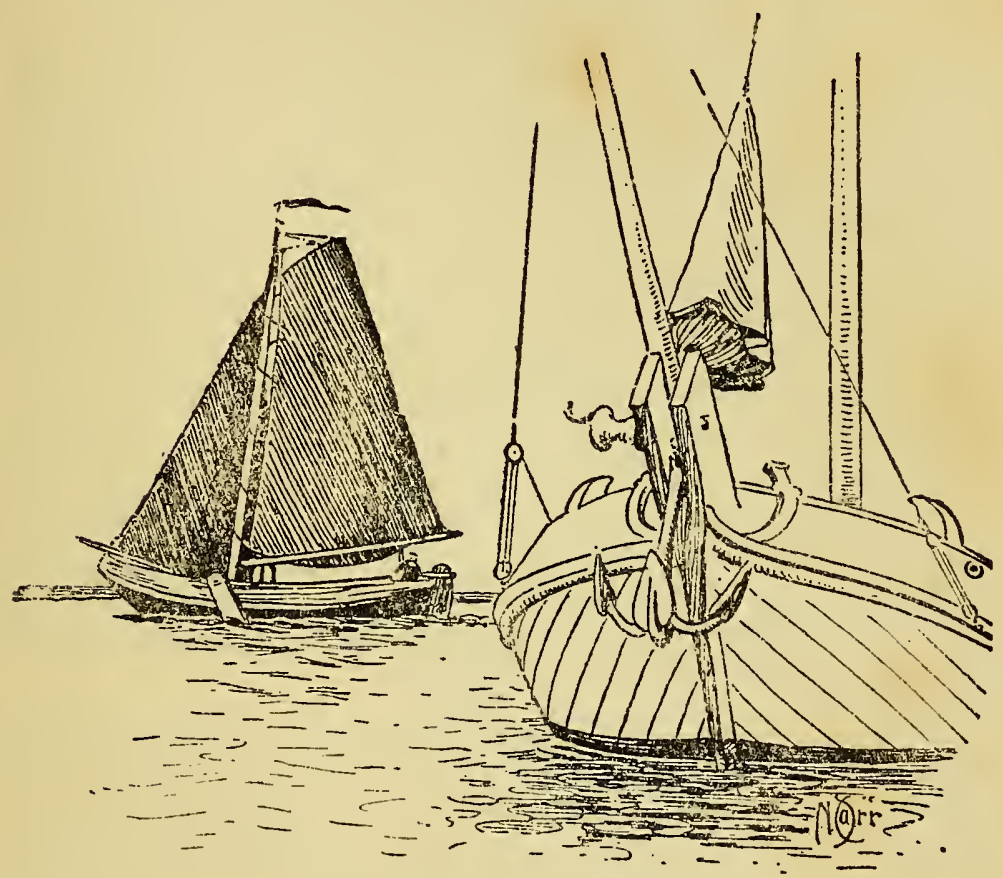

FIG. 98.-DUTCH SCHOKKERg.

The cleft in the stem-head for the grapnel anchor is very characteristic.

post comes down to the keel at an angle of about fortyfive degrees, and the keel is straight and long. The method of coating the foresail, as illustrated, is quite a peculiarity of Holland. The air is able to get from underneath, but the cover keeps off the rain, and looks rather like a gigantic candle-snuffer. This idea is not 


\section{THE MODERN FORE-AND-AFT RIG}

peculiar to the schokker, but is employed on many other kinds of Dutch craft.

The hoogarts are practically small schokkers. In many a respect they are ideal shallow-draught craft. They are rigged with extreme simplicity, and they are wonderfully handy. Most of them are rigged with a spritsail, but some are rigged as sloops. Their real home is the Island of Walcheren, especially at Flushing, the fishing harbour of which on a Saturday is full of these, as two of the illustrations (Figs. 96 and 99) will show. They are flat-bottomed, and the way these craft turn to windward up the Walcheren Canal past Middleburg to the picturesque and quaint little haven at Veere is an inspiriting sight. Single-handed, there may be a couple of them tacking together, and being excellent sportsmen, each skipper races right into the very lock entrance to get there first. 'Then, not content with that, he endeavours to get his craft out first as soon as the gates open the other side, and away they go, tack and tack, with a yard or so to separate them. Handy as a small rater, their work takes them outside, where a rater would not live for many minutes, and it is a fine sight to see the fleet running home before a fair wind into Flushing from the sea.

Their vocation is connected with the mussel-fishery, and they are fitted up as follows. There is a fore-deck, which comes as far aft as the mast. Then there is an open well, in which there is placed a large stove, apparently for boiling the mussels. Aft of this comes the cabin, with a bunk on either side and a hatch above. Then follows an open cockpit, across which is a horse for the mainsheet to work on. The staysail also works on an iron horse. The sketch (Fig. 100) is from a model that was put together by one of the guild of men who build these hoogarts ; it may therefore be regarded as correct. Taken in conjunction with the photographs it will afford an accurate idea of these very interesting vessels. It has been suggested that these little craft 


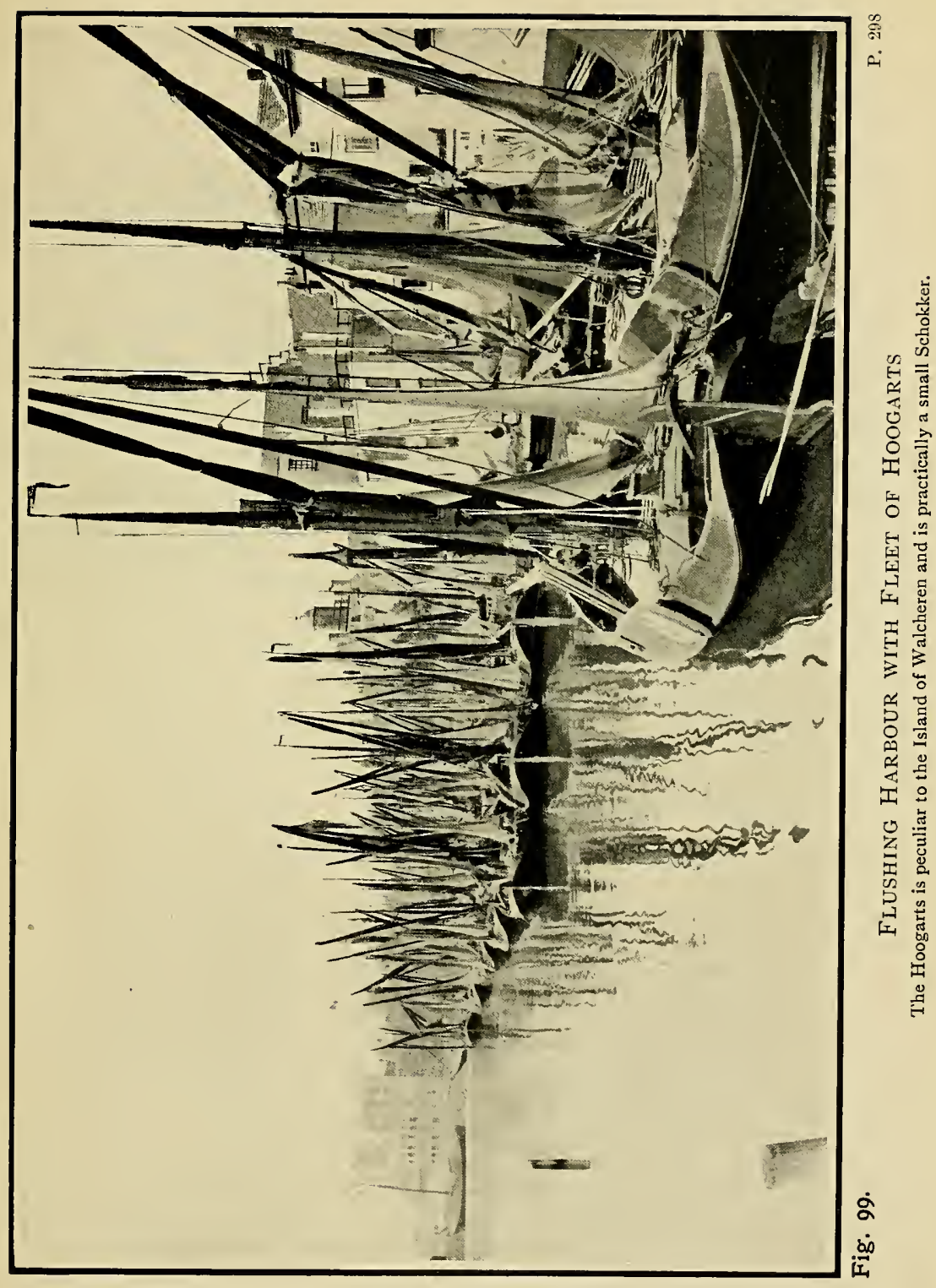





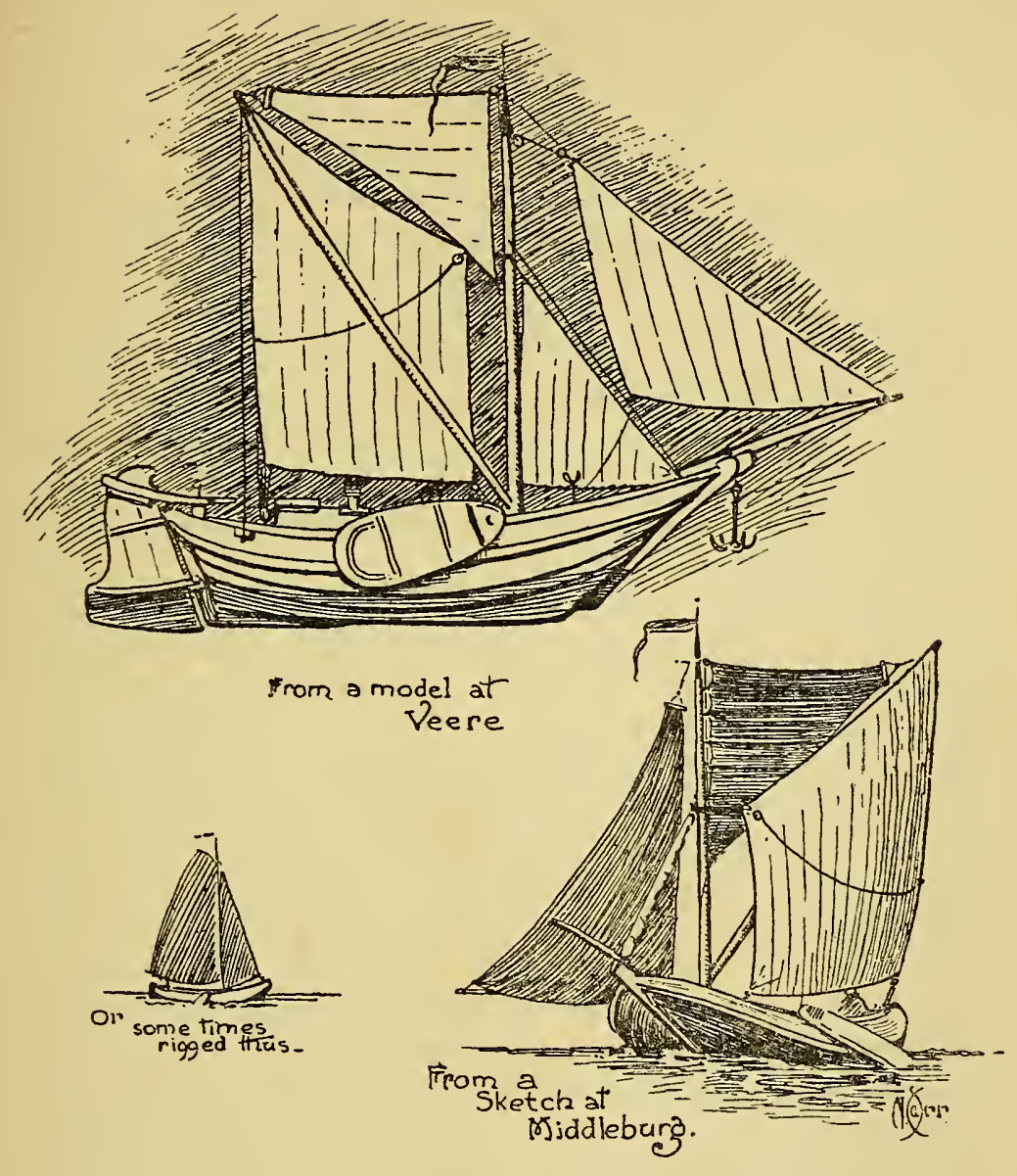

Fig. 100.-HoOgaRTS OF WALChERHA. 
would make ideal boats, if slightly modified, for those English yachtsmen addicted to " ditch-crawling," though the sloop would be preferred to the sprit-rig. All these craft, without exception, carry weather-vanes at the masthead, and have the hatchet-shaped rudders with helms that unship.

It is very curious to notice that in the case of the sprit-rigged hoogarts there is a bracket of iron, shaped something like a magnet, which extends from the mast, to which the throat of the sail is lashed. This will be observed in the accompanying photographs. Thus, instead of the leach of the sail being quite close to the mast, as we in this country are accustomed to find, there is quite a considerable "drift." This will be well seen in the sketch of the model. Inside the hull there is no lining, but, as in the case of the botter, the timbers are all showing.

There is but one brailing-line and there are two vangs, but neither shrouds nor runners; and this fact gives us furiously to think who have always been accustomed to such supports. They carry both jib and foresail, the latter having at its head a tiny yard, and when this foresail is stowed it is rolled round and round itself till it looks as if it had some sort of modern patent reefing-gear, though of course it has no such thing. But this method is one of the oldest Dutch characteristics, as may be seen from examining some of the pictures by the old Dutch masters. The hoogarts is clinker-built, has easy and graceful lines, and a good deal of tumble-home. The bowsprit has no shrouds whatsoever, nor bobstay, nor has she always a forestay. In fact, one begins to wonder how ever any of her spars are supported, until one realises that the sprit and its vangs must be taken into account. When in harbour the hoogarts has its jib lashed to the bowsprit, in readiness for getting under way again.

The heel of the sprit is kept to the mast by a lashing of rope, and there is another lashing higher up to keep 
the throat to the " magnet." To prevent chafing, there is a copper sheathing round the mast at the latter place, the peak of the sprit reaching about as high as the truck of the mast. These craft of course carry leeboards, and their bows have a good deal of overhang, as in the schokker. Like the latter, they also frequently carry a grapnel-anchor, so as to give a better hold in mud than the ordinary pattern. The topsail seen in the sketch is very old-fashioned, and reminiscent of a bygone age. This sail also exhibits the former affection of the Dutch sailor-man for the diminutive yard we spoke about just now.

We come now to the boier, which originally was not a fishing-craft, but a cargo-carrier and yacht. In the sketch (Fig. 101) will be seen a reproduction of a fine little model preserved in the Rijks Museum. The shoe-shaped leeboards are not a bit exaggerated. The very small gaff, the mast stepped in a tabernacle, the curved ensign-staff, the forestay ending in a deadeye and spreaders that are made fast through the stemhead, the single shrouds at either side of the mast, the great horse for the mainsheet, the raised stern, and the bold, curved rudder-these are all typical of their nationality, with the large streamer at the top to crown all. The boier is one of the oldest, if not the very oldest, of all the types of Dutch craft. To-day the type is perpetuated by a large number of boier yachts possessed by the Dutch sportsmen. In fact, there are more Dutch yachts of this type than of any other. They are small, little ships, apparently about twenty-five feet over all, with cabins, varnished hulls, and a lavish display of gold paint, especially at the stern. They are eminently suitable for inland cruising, but after watching a good many of them cruising and racing at regattatime, I am not convinced that they are anything but slow. Their chief charm to an Englishman must lie in their historic interest, for, like the hoogarts, they carry one instantly back into bygone centuries. The repro- 


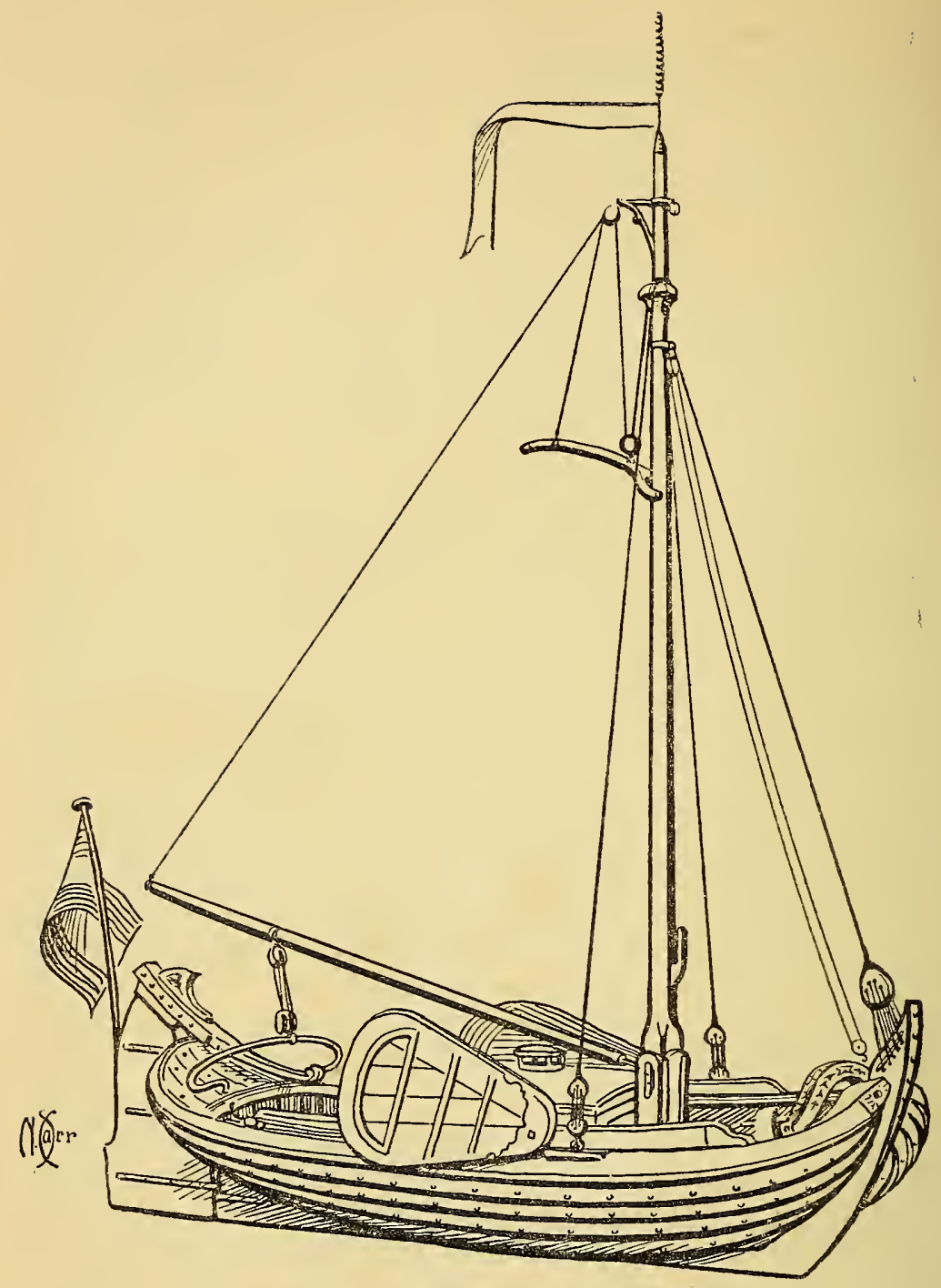

Fig. 101.-DUTCH BoIER.

From a model in the Rijks Museum. 


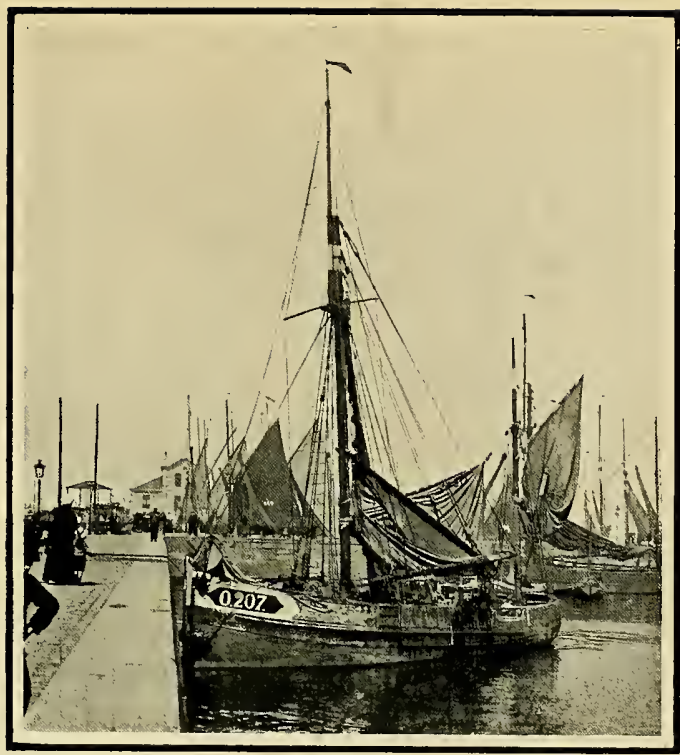

Fig. 102.

OSTEND Fishing SMACK

P. 310

Notice the result of the infuence of the British North Sea Fishing Smacks on this type of craft.

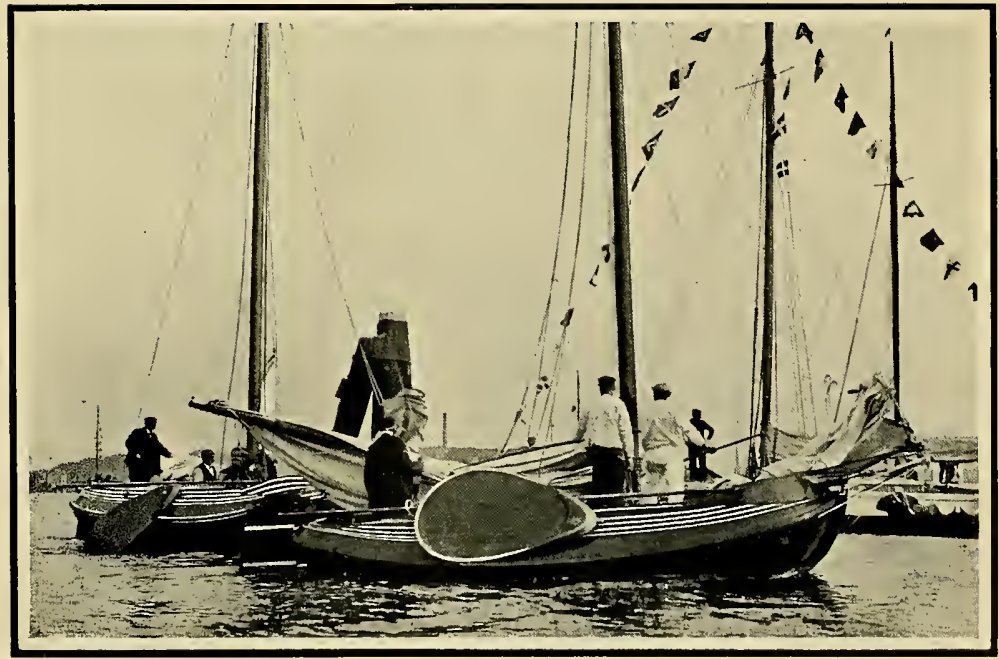

Fig. I03.

MODERN BOIER YACHTS

P. 303

From a photograph taken in Amsterdam at Regatta time on Queen Wilhelmina's birthday. (See also Fig. Iот.) 


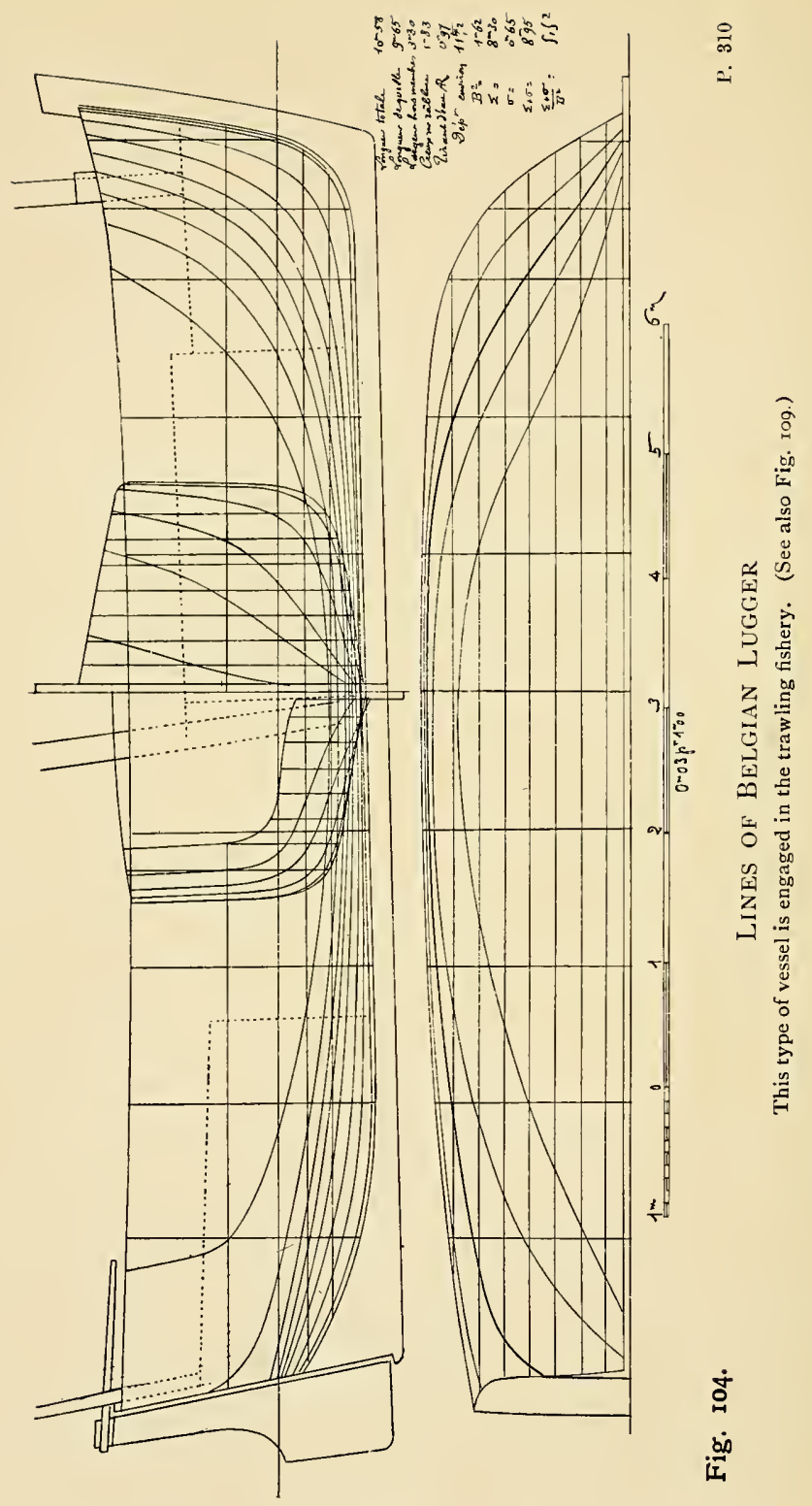


THE MODERN FORE-AND-AFT RIG 303 duction of a modern boier yacht (Fig. 103) is from a photograph taken at regatta-time at Amsterdam on the occasion of Queen Wilhelmina's birthday, but these craft are to be seen in many a port of Holland and Friesland. Some of them nowadays have an iron bumpkin projecting forward of the bows, so as to be able to set

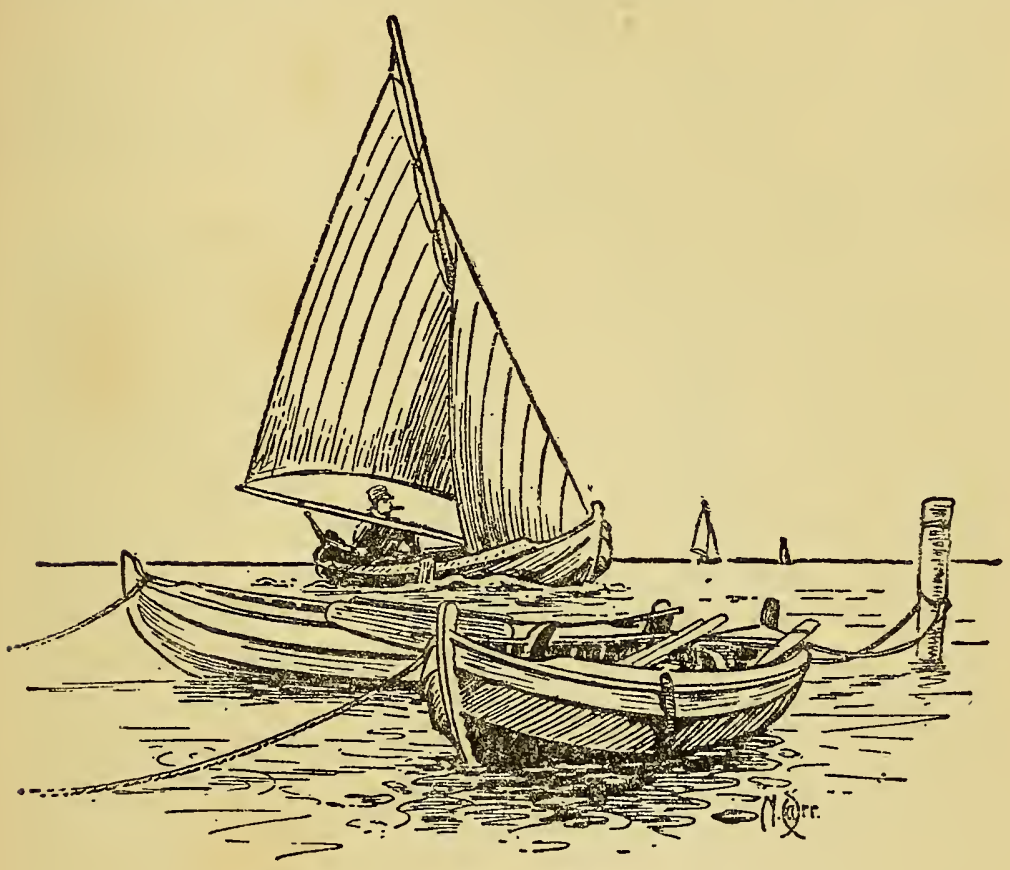

FIG. 105.-ZUYDER ZEE KUb-BOATS.

The rig consists of foresail and triangular mainsail.

a larger foresail, but others even add a bowsprit and carry a jib.

There is a funny little example of the fore-and-aft craft which I have seen nowhere else than on the Zuyder Zee. The natives call her a "kub-boot," and some idea of her appearance may be seen from the sketch which is here reproduced in Fig. 105. The boat 
itself is certainly, considering its size, a plucky kind of craft, and the rig consists of a mast with foresail and a triangular mainsail which is hoisted, of course, by a single halyard, the luff of the sail being kept to the mast by means of lacing. It is loose-footed, and there is a good deal of space between the boom itself and the foot of the sail. The little ship has leeboards like her bigger sisters. Practically this is a trysail, but it is a definite and regular rig which may be seen in Monnikendam. The great advantage which it possesses lies in the fact that it can instantly be lowered by slacking off the lacing and letting go the halyard.

Speaking of the Deal galley in our previous chapter one was reminded that at Flushing there is a foreign counterpart of this type of open sailing-craft. Perhaps there are few spots in the world which contain so many pilots as this little town. Side by side along the seafront are two club-houses where a ceaseless look-out is kept, the one being for the Dutch, the other for the Belgian pilots-loodsreezen is the Dutch word for our English "pilotage, "loods" being a pilot. Originally the loods was the man who hove the lead, and thus navigated the ship safely through the intricate channels, for the Dutch equivalent for the word lead is lood. Now for putting out from the shore to a ship bound up to Antwerp, a "loodssloepe" is employed, and this craft is practically the Deal lugger. In hull she is very like her, and has both length and freeboard to make her able to encounter the choppy waters of the Schelde, where the tides are exceedingly strong and a considerable sea soon gets up when wind is against tide. These "sloepes" are rigged with a lugsail on the mast which is stepped about amidships. At the extreme stern a small mizzen is stepped, practically the whole of that sail being outboard, the sail being sheeted home with the assistance of an outrigger, though not raked at the high angle possessed by the Cornish luggers.

The reader will recollect that we referred some time 
back to the matter of the Una-rig, and besides mentioning the fact that the earliest fore-and-aft rig in England was such, we went on to refer to the present-day rig of the Norfolk wherry and of the American cat-boat. Now in Holland there is still in use the Dutch equi-

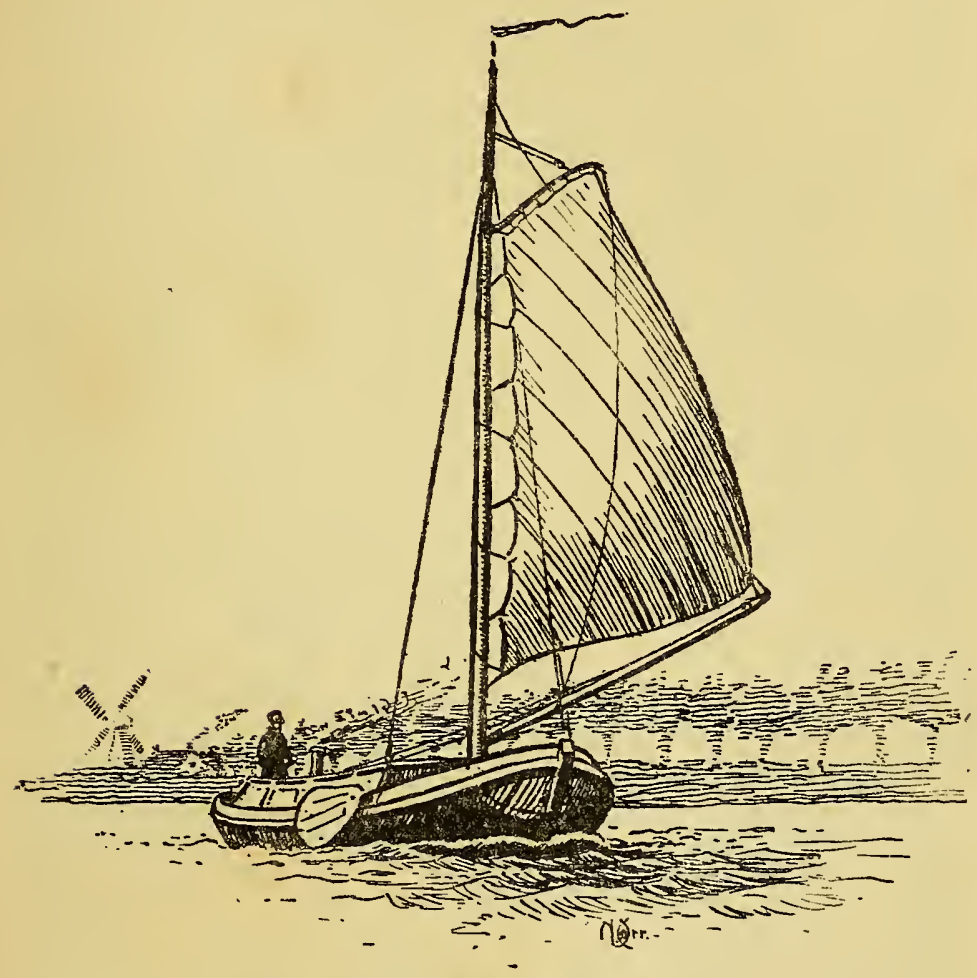

FIG. 106.-MOdern DUtCH Una-RIG.

Seen on the River Amstel near Amsterdam.

valent for this species of a fore-and-after. The sketch in Fig. 106 was made of a vessel seen on the river Amstel a few miles south of Amsterdam. There is no headsail of any kind, and the mast must necessarily be stepped a long way forward. The sail is laced to 
the mast in the usual Dutch fashion, and the vessel also carries leeboards. I have never seen one of these craft except when running free, so cannot say how well she goes to windward. In length the boat here shown would seem to be somewhere about $28 \mathrm{ft}$. over all, and there is a cabin right aft for the skipper and his family. 'They sail quite well before the wind and are not slow, but of course their special virtues are confined to the suitability for inland navigation.

One may wonder how many visitors to the Hague and Scheveningen, with the latter's cosmopolitan crowd and its crude modern pleasure palaces, ever stop to examine those curious old craft which are found on its beach and in its harbour. These pinks are indeed the most interesting features of the place, possessing a history of their own and a conservatism that is unique even in conservative Holland. But to the casual tourist these weather-worn craft may not seem sufficiently attractive to be worth even a glance, and the harbour is at the other end of the sea-front, some distance away from the noisy crowd. Some of the modern Dutch painters, like their predecessors, never weary of depicting these fisher-craft in all weathers, and frequently in storms running back to the Scheveningen beach.

To understand these weird, beamy objects one must first realise the objects for which they were built. Off Scheveningen the water is somewhat shallow for some distance out from the shore, and it is notorious that in even a moderate on-shore wind the seas get very bad. The pink puts forth to sea and expects to ride out this weather to her nets. 'The first aim in building her is to make her of enormous strength, and speed is altogether out of the question. When she has finished her fishing she sails back to the beach about high tide, and then takes the ground, and gradually the tide leaves her high and dry. The beach is all sand, but in bad weather there is, naturally, a 
good deal of bumping before the vessel definitely settles down. It is for this reason that the pink (Fig. 107 ) is built so stoutly. The sea may continually pick her up and drop her down again, yet she can endure

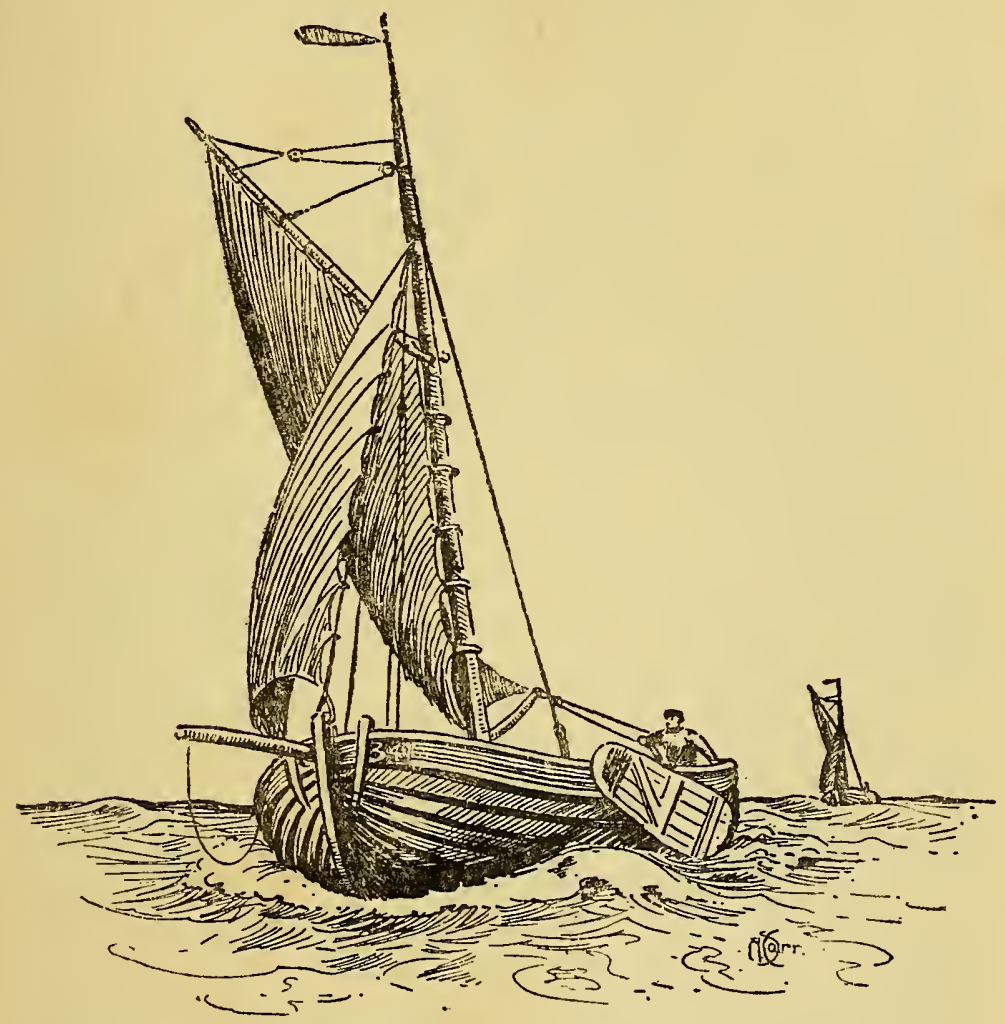

Fig. 107.-Scheveningen Pinks.

They are exactly two beams to their length-and remarkably strong.

all that. She is given also a very broad keel, and in general is so designed that she can take the ground with ease. Contrariwise, she is also given such lines by her keel that she will float as quickly as possible, 
and be able to get off to her work when a few feet of water have risen.

Now that the harbour at Scheveningen has been made what it is, one may find alongside its quays quite big editions of these craft, but even then they are still built with an amount of beam that is almost incredible to eyes that have been accustomed to other craft. Let it be said at once that the pink is only twice as long as she is wide, and looking at her for the first time you would say she was just an oblong box designed by a madman. Clinker-built, she is slooprigged with mainsail, jib, and foresail. Her bluff bows are bluffer than anything else in Holland. Pinks measure $40 \mathrm{ft}$. long and $20 \mathrm{ft}$. wide, being $12 \mathrm{ft}$. deep. It is important to remember that these dimensions are fixed and immutable. They have leeboards, of course, and the inevitable vane at their masthead. In very fine weather they carry a narrow topsail, and sail straight on to the beach with everything up, and wait till the tide ebbs. Like certain other types of Dutch craft, these pinks have frequently no bobstay to their bowsprit.

Frankly the pink does not appeal to one as in any way a beautiful craft. It is because of her antiquity and her natural eccentricities, her ability to stand so much knocking and buffeting about, that she is deserving of so much interest. The furthest south $I$ have seen the pink was in the new Belgian harbour of $Z$ eebrugge, a few miles north of Ostend; but there is a variation of the Scheveningen type a few miles north of this Dutch resort at Katwijk, although Scheveningen, which has been famous throughout the history of Holland for its herring-fisheries, has ever been the home of the pink. In the sketch which is reproduced in Fig. 108 will be seen the Katwijk "pom," as she is called. This represents an interesting model which was recently added to the collection in the Rijks Museum. Although she is a bigger craft and rigged as a yawl rather than a 
sloepe, with three headsails instead of two; although the lines of the hull are slightly finer than in the pure pink of Scheveningen, yet, for all that, any one can see the Scheveningen influence written large all over her. The crutch for the lowered mainmast, the leeboards, the general design of the hull, the rudder, the

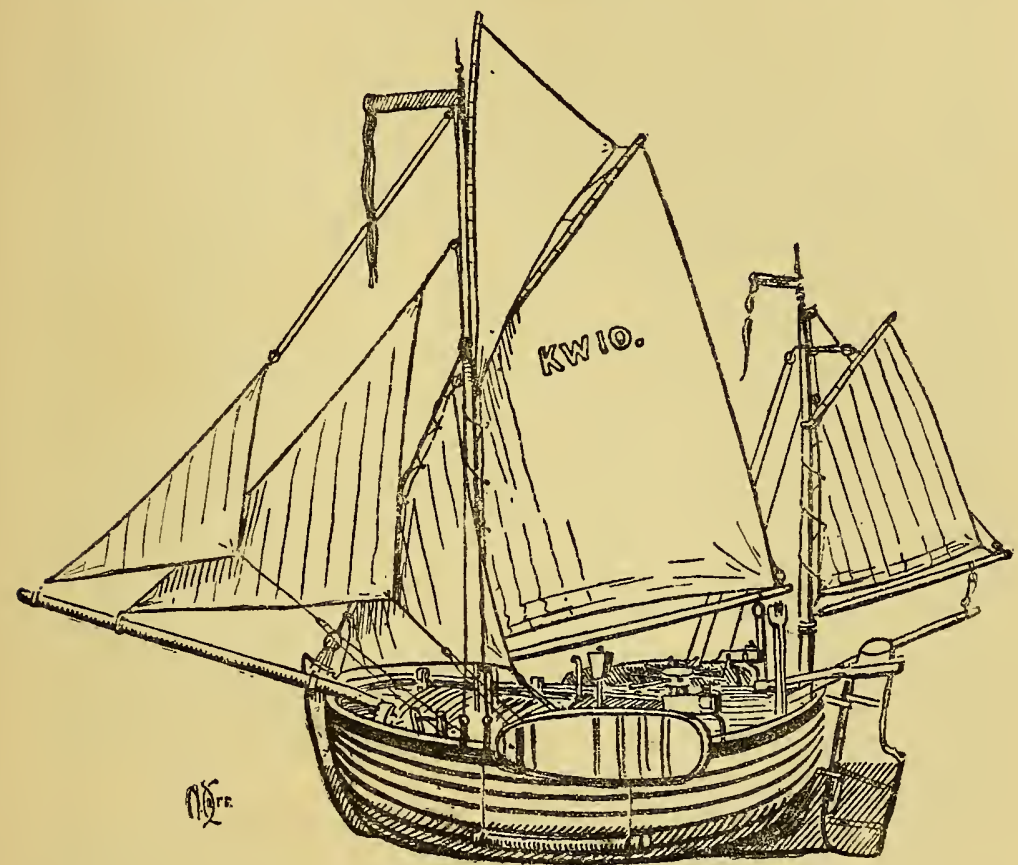

FIG. 108.-KATWIJK-PoM.

This is a somewhat larger edition of the Scheveningen pink, and hails from the port of Katwijk, a few miles north of Scheveningen.

streamers at the masthead, and so on, indicate the near relationship. There is a very powerful capstan with handspikes on the deck for getting in the nets, for these Dutch vessels, unlike the British North Sea fishing-craft, do not carry a boiler for getting in the nets by steam-power. That same interesting little 
feature to which we called attention just now when considering the boier, namely, the deadeye and the spreaders coming down into the stem-post, will also be observed in this Katwijk pom.

And so we leave Holland in our southward trend, and pass to the other side of the Schelde into Belgium. As far south as Blankenberghe the pink influence is still felt. It is a sandy coast, with dunes and coarse grass stretching away as far south as Calais where the cliffs begin. But at Ostend, because the craft are no longer beached and have a good deep harbour to enter, a totally different type of craft obtains ; different, that is to say, on the one hand from the Dutch vessels, and on the other from those of France. In the photograph (Fig. 102) will be seen one of the Ostend fishing fleet, and instantly it will be observed that this resembles the Ramsgate and Yarmouth smacks more than anything on the Continent. The rig, the bows, and the general lines of the hull proclaim English rather than Dutch or French influence. Only the rounded quarters show the proximity of Holland. But if we were to go aboard the Ostend steam trawlers we should find that in practically every instance the build was British and the county Yorkshire. With the exception of Ostend, however, we have done with either Dutch or British influence for the present.

We pass into the sphere of the lugger, into the influence of France. It is perfectly true that to-day the old French lugger is fast disappearing and giving way to the British ketch-rigged type of craft which Brixham, Ramsgate, Yarmouth, and Lowestoft have developed. But nevertheless there are still many large fleets of luggers along the coast of the continent that touches the North Sea and the English Channel, and in the next two designs (Figs. 104 and 109) will be seen the plans of a Belgian lugger. This is one of the smaller trawlers which run out from Dunkirk. As we regard this craft with its mizzen, main, maintopsail, 


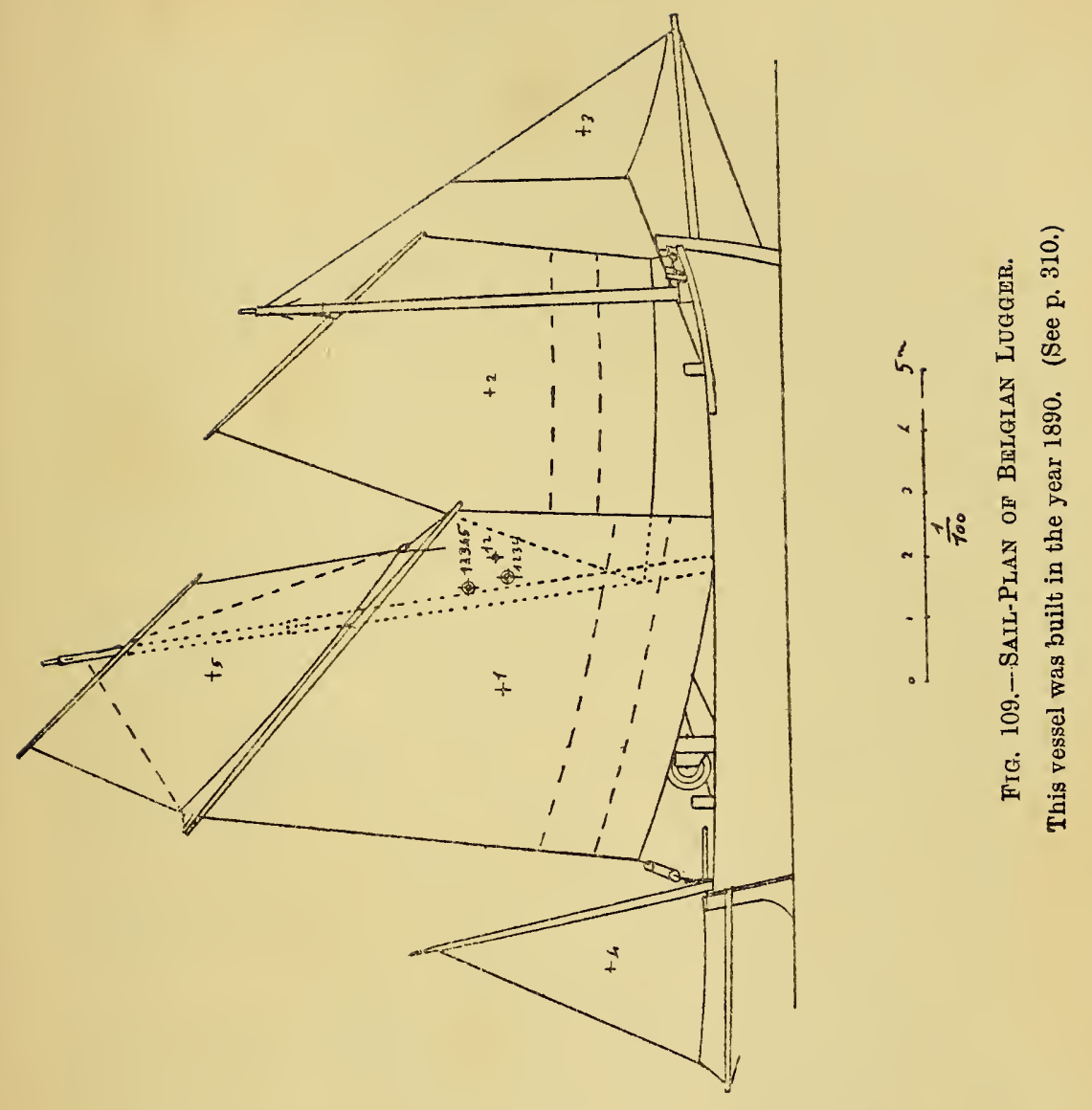


foresail, and small jib, we have the identical rig which France made so popular in the eighteenth century, and was destined to be employed so much by the privateersmen and smugglers. Originally, of course, there was no jib; that is really but a later addition. Nevertheless, in spite of this the foremast will be seen still stepped in its original place, right as far forward as ever it could be placed. These craft, in spite of their curious appearance to British eyes, must not be despised. They look crazy to us, and perhaps their crew do not keep them as smart and clean as one might wish; but for all that they possess the qualities of speed, as the English Revenue-cutters used to find to their cost many years ago. The lines of the hull show rather a box-like craft, with flat floor and wall-sided. In length this type of Belgian lugger works out at between forty and fifty feet. In accordance with the old-fashioned custom of fishermen the masts rake aft a good deal, and especially is this so in the case of the main.

Some idea of the Dunkirk type of ketch may be seen from the design which is given (Figs. 111 and 112). These craft have a total length over all of 26 metres, and they also have very flat floors, though not quite so wall-sided, and have a little tumble-home. 'This Dunkirk ketch goes far away from her home waters to fish for cod in the neighbourhood of Iceland. Her main and mizzen are both loose-footed, and she carries a topsail over the former. With her rig, her straight stem and straight keel, she is in many respects similar to the older type of the Ramsgate trawler.

An excellent instance of a Gravelines lugger may also here be seen in Figs. 110 and 113. As you look at her sail-plan you can see how old-fashioned she is, how close akin to those days before the lugsail began its régime in French waters when the fishing buss-ships were three-masted square-sail craft. For look, as an example, at the mainsail. It is nearly the shape of the old square-sail rather than of the modern lug. It 

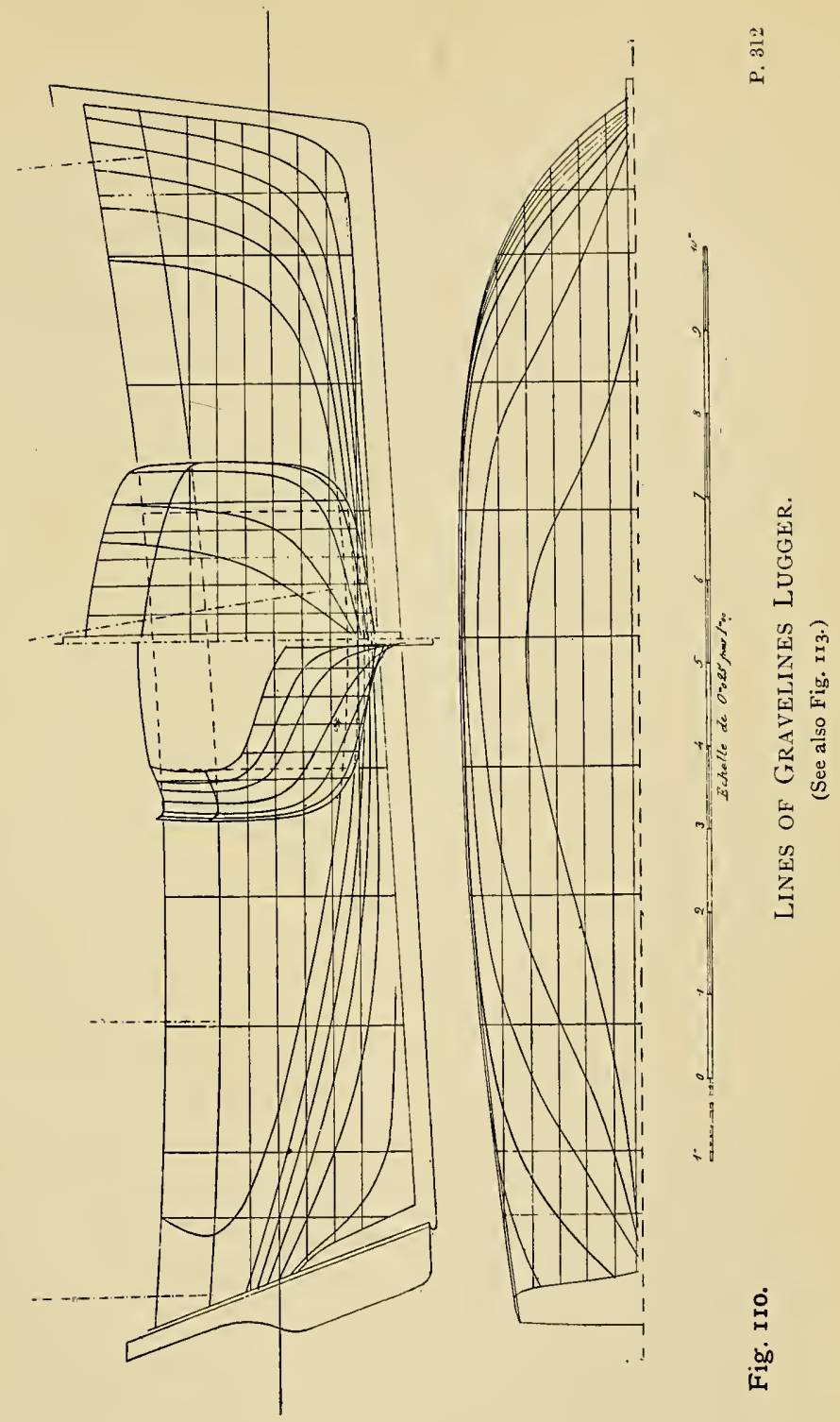

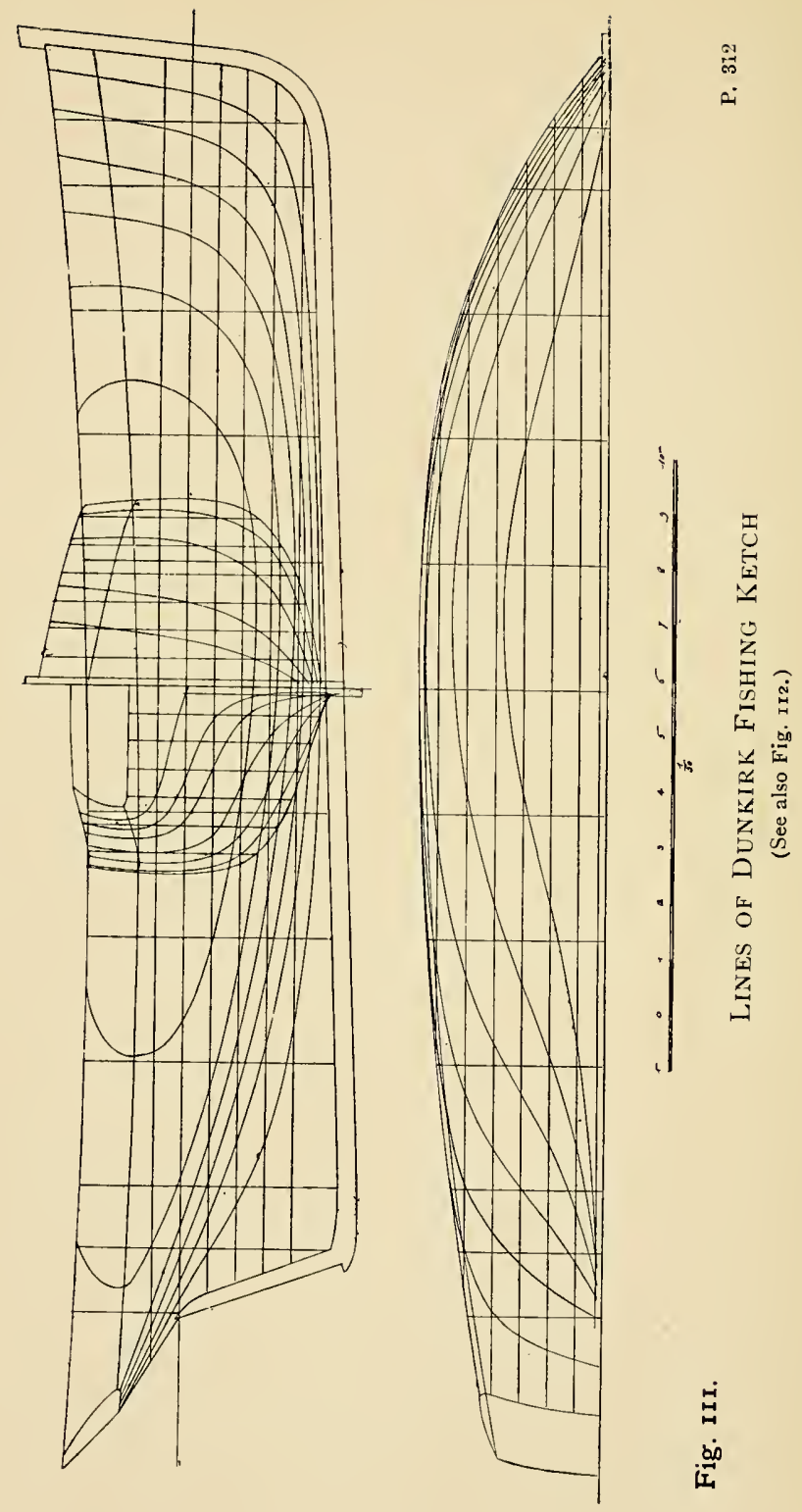


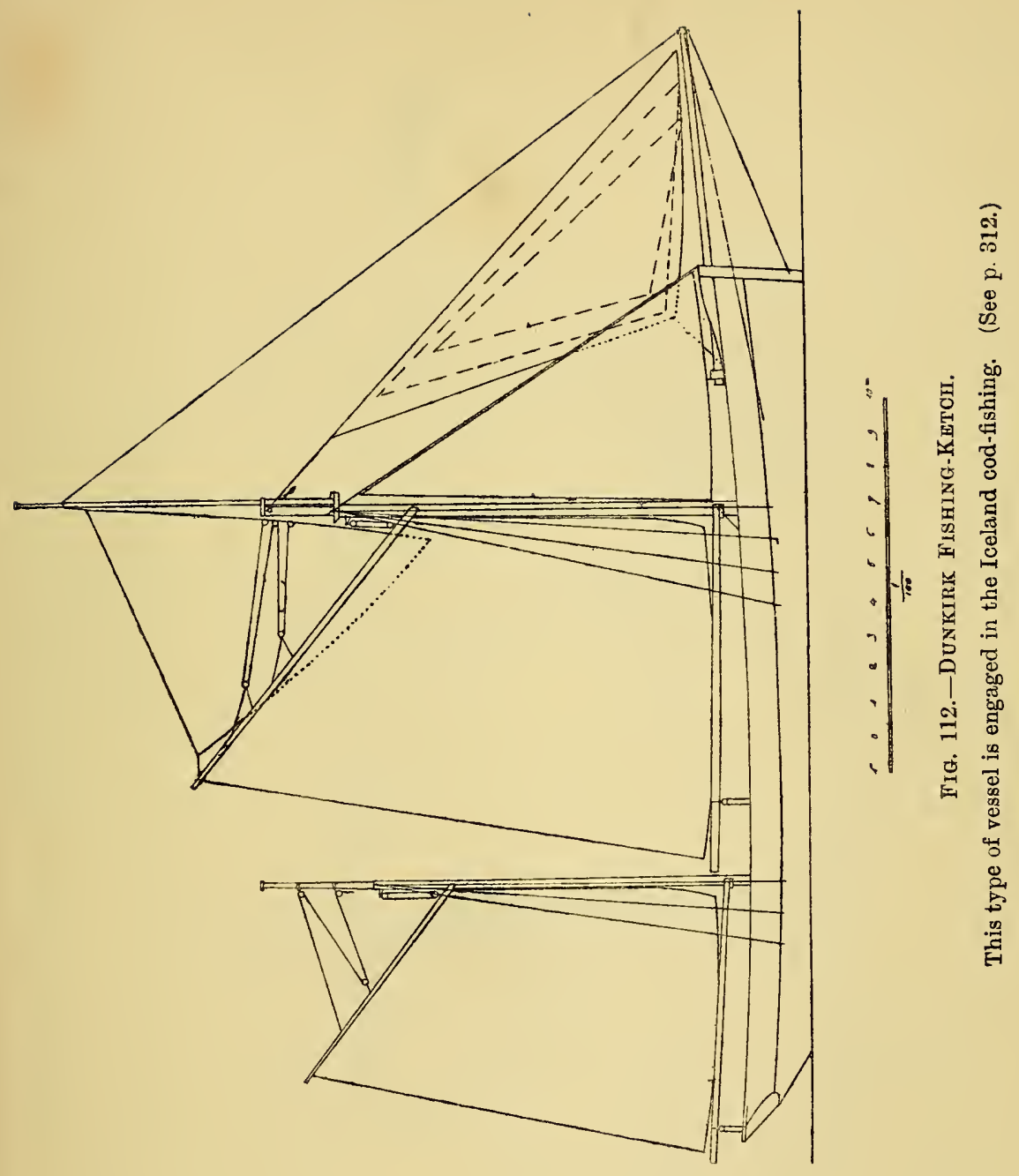



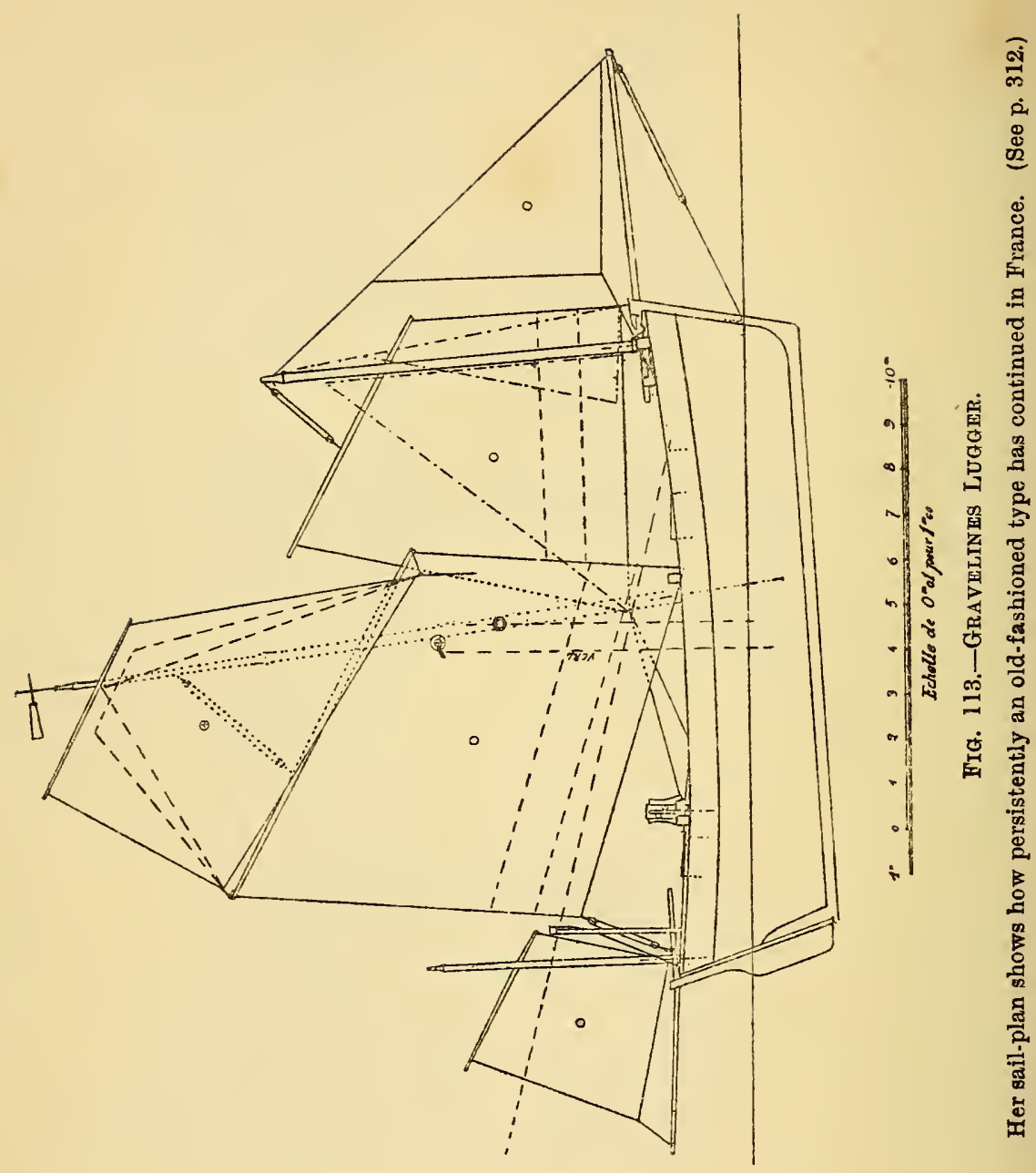


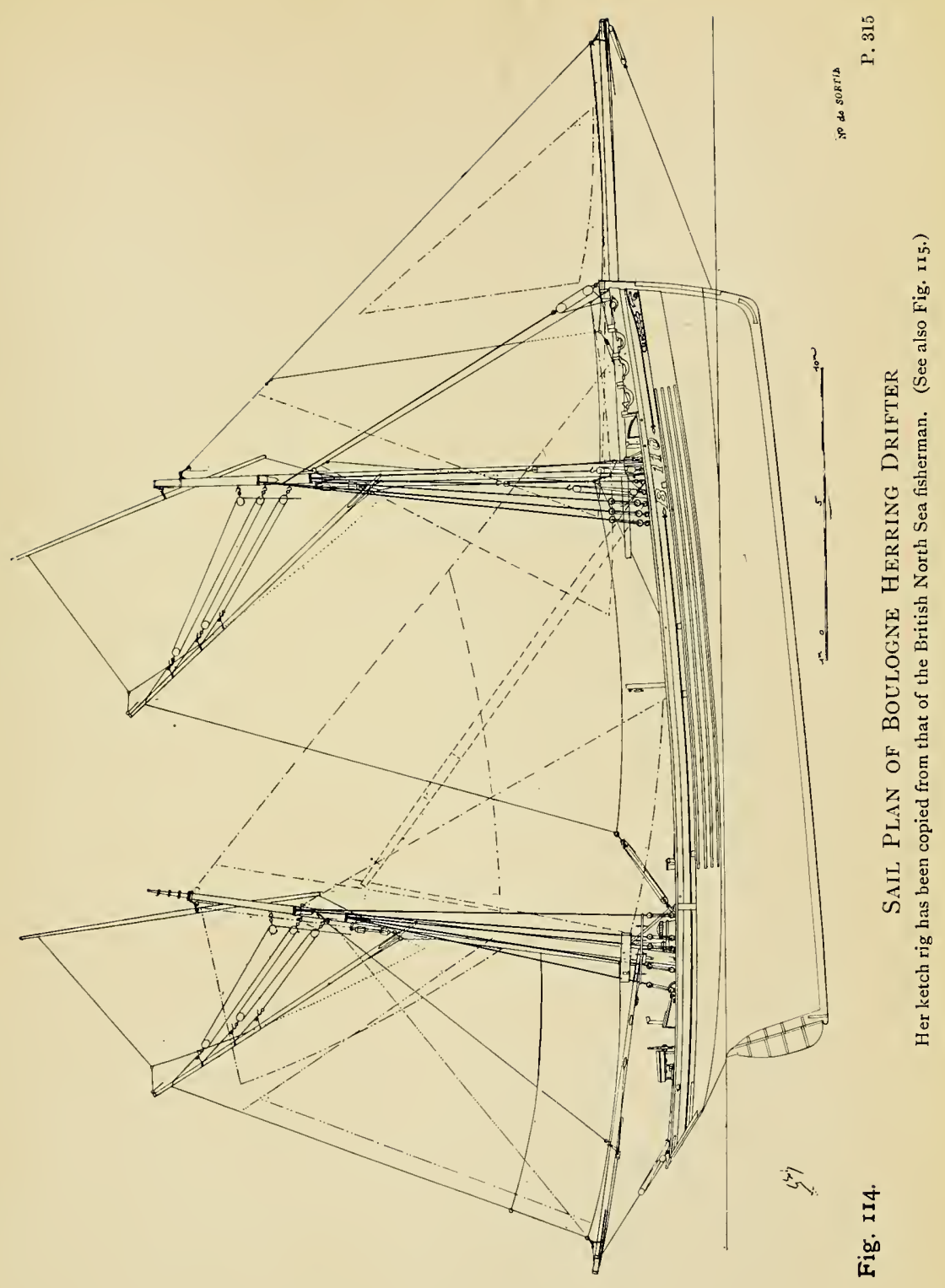



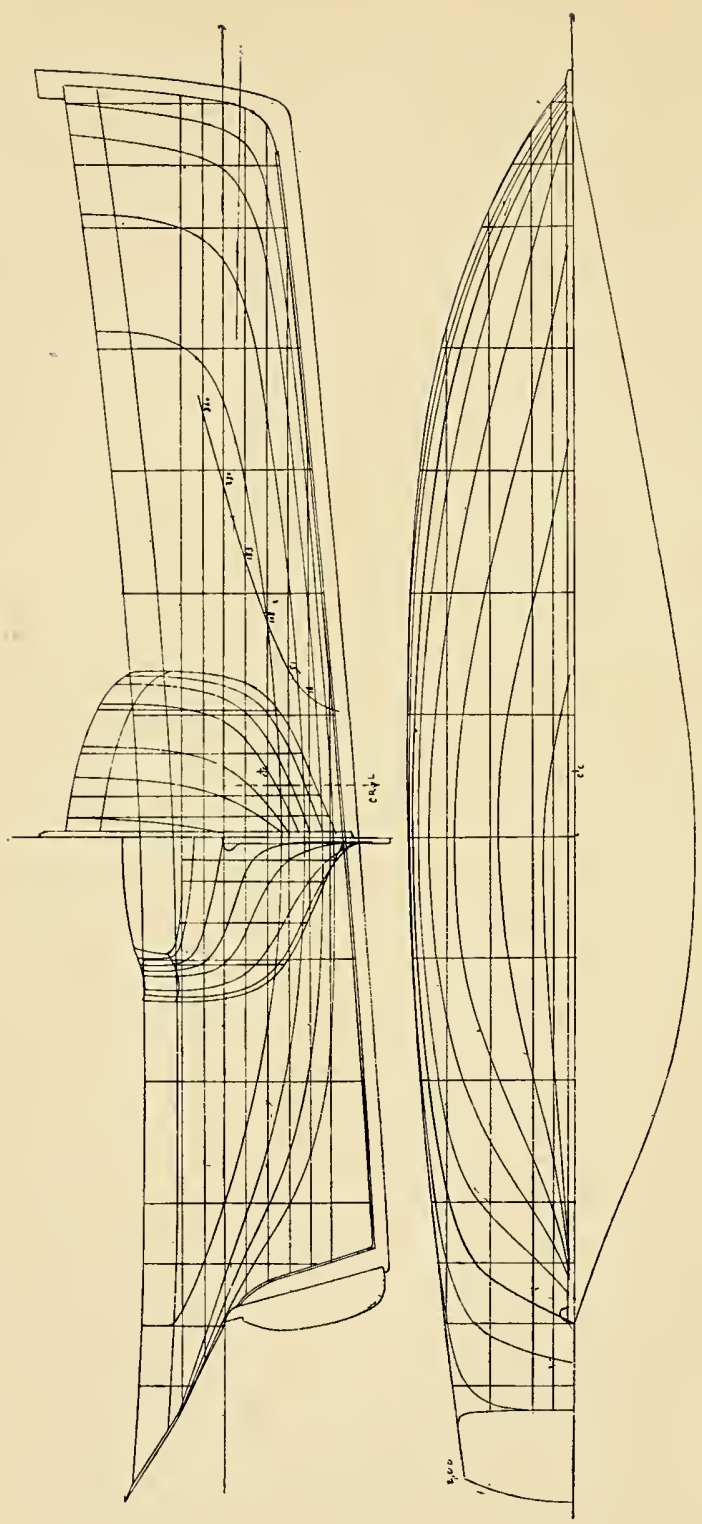

$\frac{19}{80}$

1

4

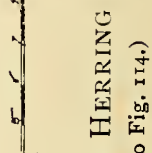

भाष

.

- 5

- 55

i

寽

皇 
has been hauled down by the tack so that the fore part of the yard comes down, and the after part is peaked up. We can indeed observe most clearly from this how the transition from the square-sail began. You still witness this type of craft putting to sea from Gravelines, or sailing about somewhere between the Dyck Lightship and Ostend. But it is fast disappearing, and is being replaced by the more modern craft which are ketch-rigged. It is because the Gravelines and Dunkirk craft frequent the Dogger Bank, where also our British fishing fleets congregate, that the influence of Ramsgate and Yarmouth has begun to be felt. This fact is even more noticeable in the design of the Boulogne herring-drifter seen in Figs. 114 and 115. Notice that she very much resembles the Lowestoft drifter by being ketch-rigged, by having her mizzen-mast stepped leaning forward, by having no boom to her mainsail, and by carrying a topsail over her mizzen.

These Boulogne craft also are engaged in fishing for mackerel during the summer with drift-nets. They pursue the herring on the coast of Scotland and in the North Sea. It is because they have to encounter a good deal of weather and sail long distances, even as far as Ireland, that they are made of good size and strength. They can do their ten knots an hour with a fair wind, and are a great improvement on the older type of French lugger. In this craft there is no necessity for the great capstan that we saw in the Katwijk pom, for they have copied the English North Sea fishing fleets altogether by having steam capstans installed in the newer type for the purpose of hauling in their nets. Such a craft as this measures about $34 \cdot 15$ metres over all, $29 \cdot 30$ metres on the water-line, and $27 \cdot 66$ metres on the keel. They are good sea-boats, and no one can regret that the French have returned the compliment of learning from us who, in previous times, learnt so much from them in matters of naval architecture and 


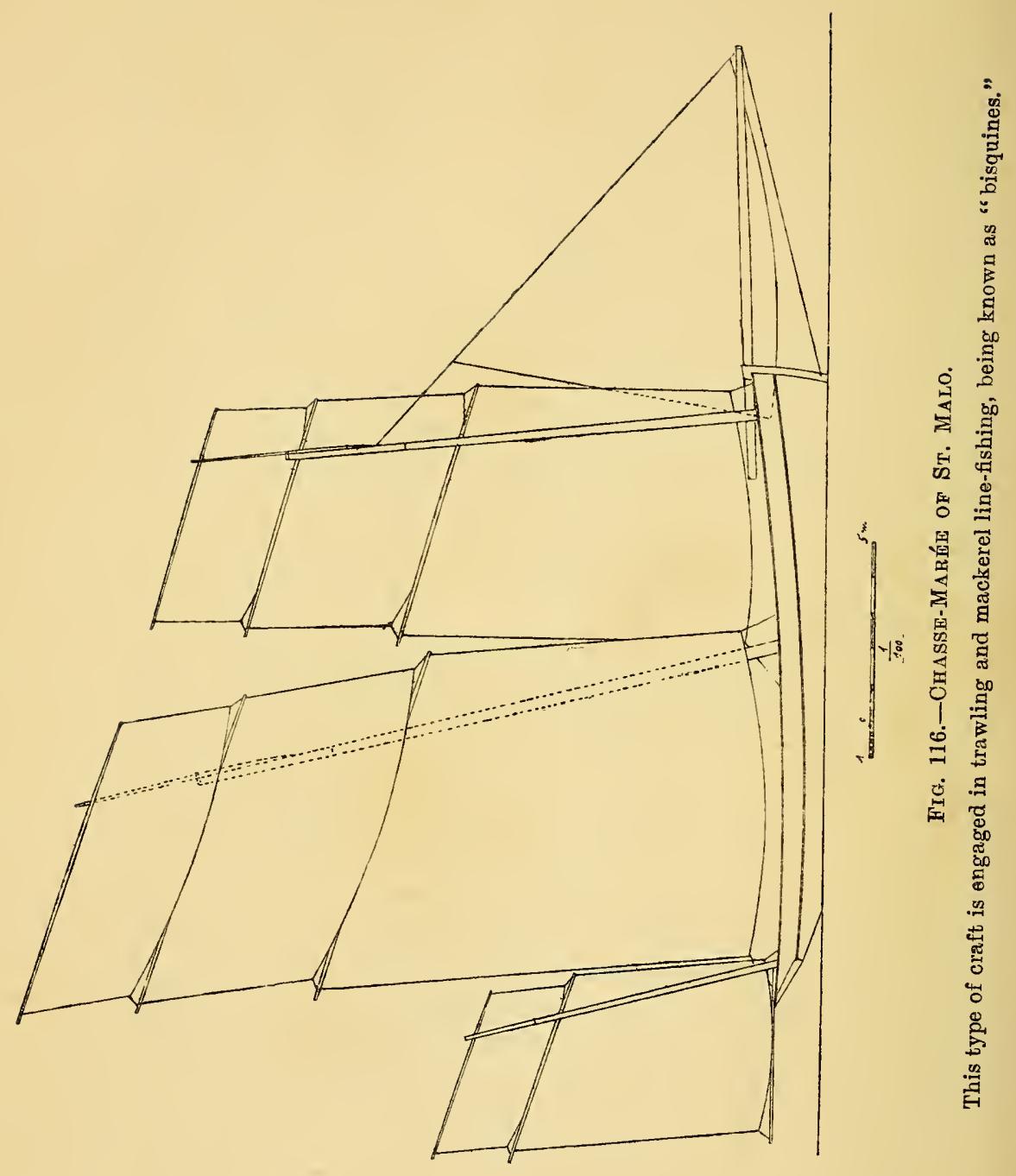



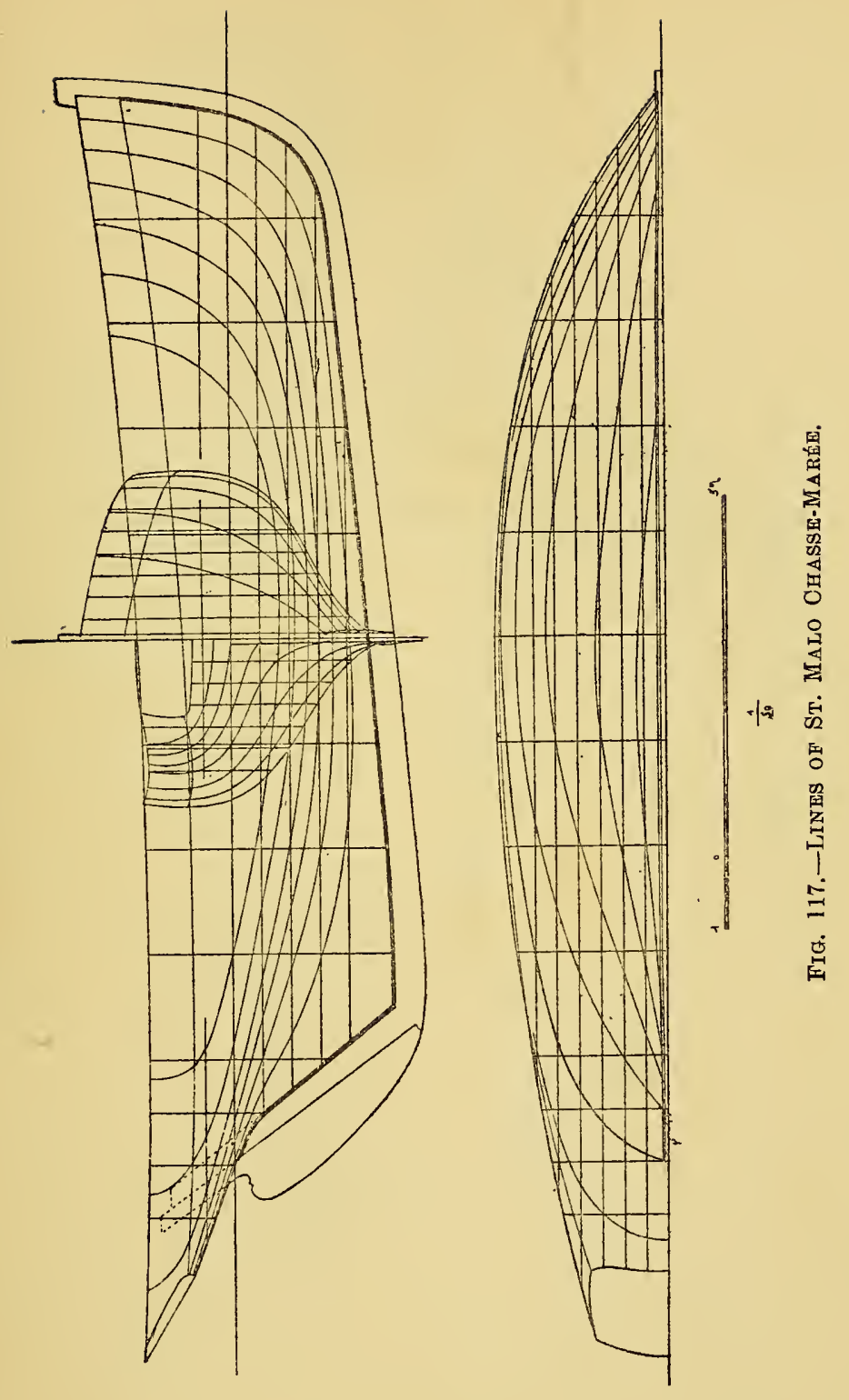


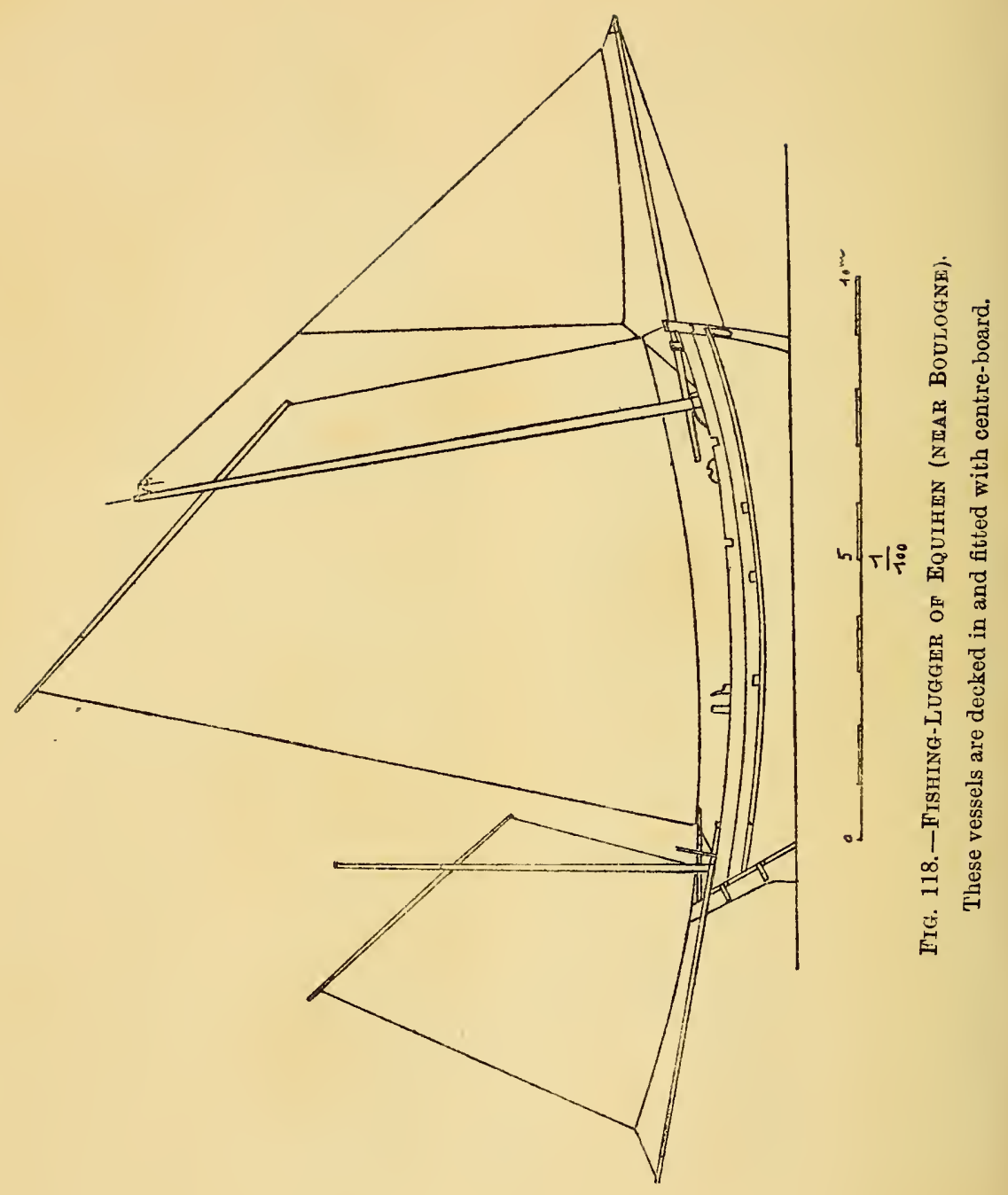




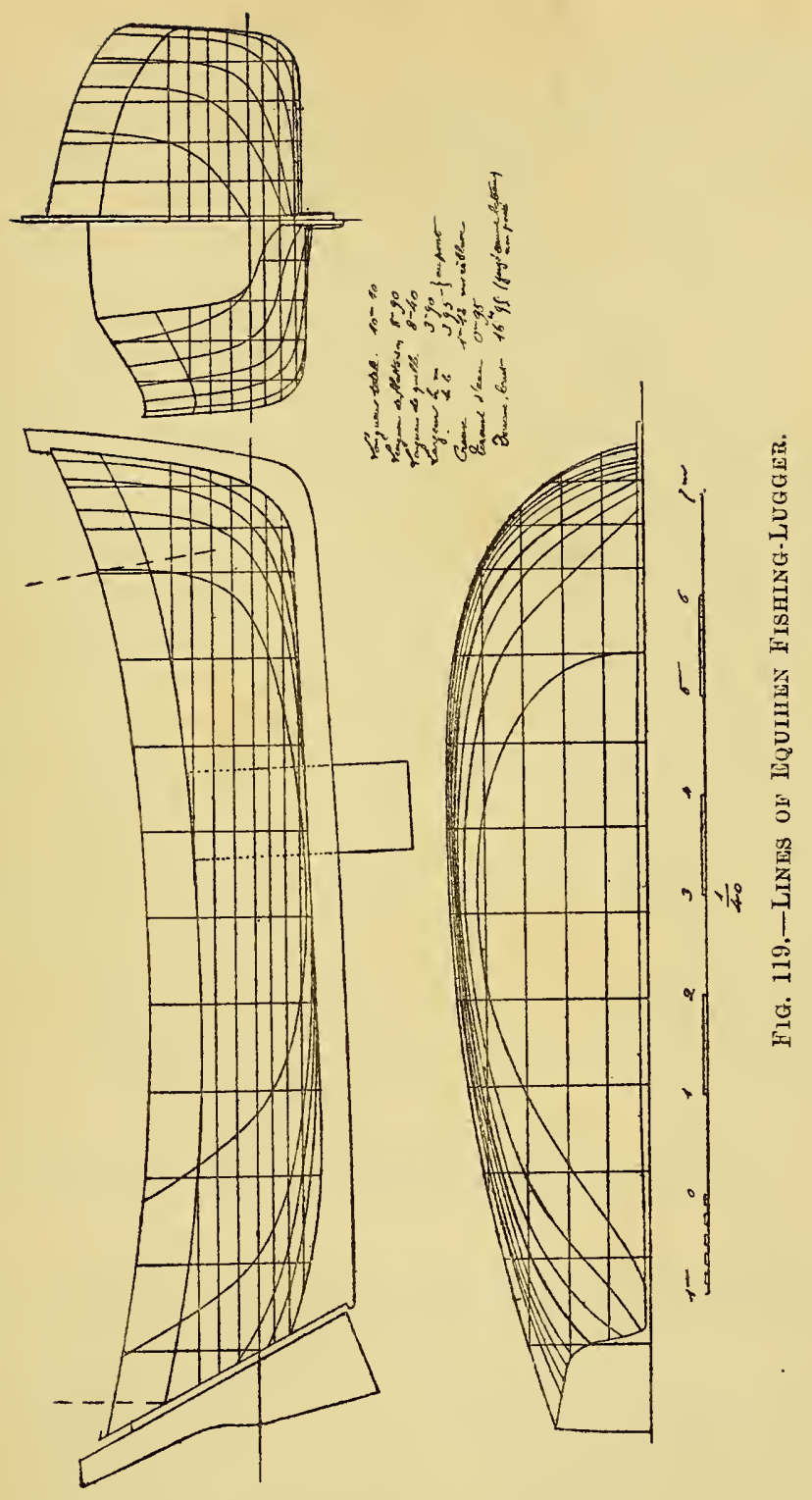




\section{THE MODERN FORE-AND-AFT RIG}

rig. Dunkirk, Gravelines, and Boulogne all bear witness to this fact.

But as representative of the old-fashioned type of chasse-marée we could wish for no clearer example than the fishing-craft of the Bay of St. Malo, of which the designs are here given (Figs. 116 and 117). These craft are engaged in trawling and mackerel line-fishing, and the same kind of boats are found at Cancale and of the same rig. These, as well as those belonging to the Bay of St. Brieuc, are all known as bisquines, but the bisquines of St. Brieuc are not so crowded with sails. The bisquine came to this part of the world with the Basques, as the name suggests. The foremast of these vessels is, as we pointed out in another species of French lugger, stepped right forward, the main being about midships and raking aft at a considerable angle, but the mizzen is only rarely used. The bowsprit carries a large, low jib which is hauled right out. As to the sails of the three masts, these are standing-lugs, one being hoisted to starboard and the other to port, as will be seen. A large square-headed topsail, and sometimes two, can be hoisted above the lugs. The lines of these bisquines are fine, and the scantling is exceedingly strong and heavy, for, like the pinks, they have to take the ground at low water, the range of the tide being something like forty feet. But for this great strength the craft would be bumped to pieces on the sands as the tide fell. They sail remarkably well, especially when the wind is on the quarter, and are very stiff. They measure about $\mathbf{1 7 \cdot 7 0}$ metres over all, and carry large crews.

A handy type of small lugger (Figs. 118 and 119) is seen in the fishing-craft of Equihen, near Boulogne. These are decked in and fitted with a centre-board, which is of the sliding and not of the revolving type. There is a large lug for the main and a smaller one for the mizzen. This craft carries also a long bowsprit, well steeved, on which she sets a jib. At the stern, 
like the Cornish luggers she has an outrigger, also steeved, for the sheet of the mizzen. The hull of the little vessel has a nice sheer, and well she needs this and the protection of her deck; for in this neigh-

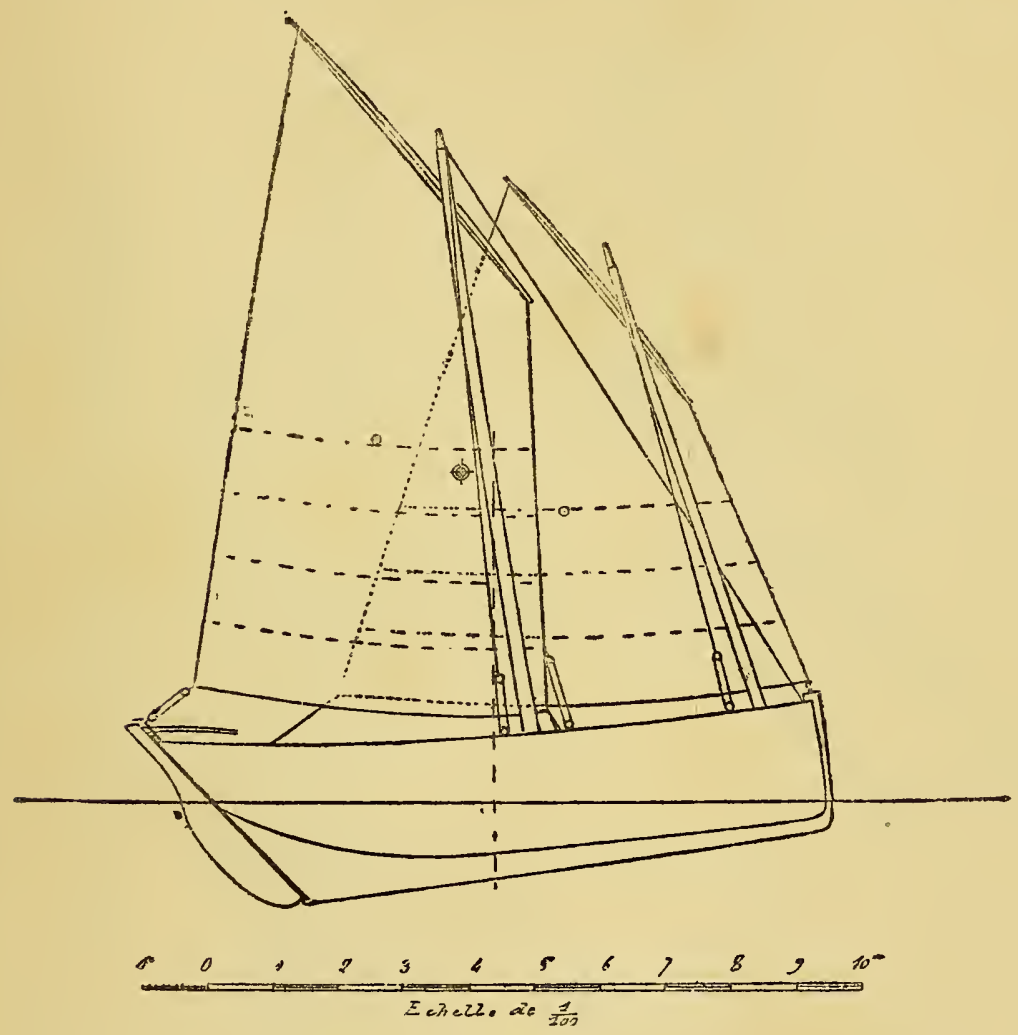

Fig. 120.--SARdine Fishing-LugGer of the CoASt of BrittanY.

She measures roughly 10 metres in length over all.

bourhood the tides are notoriously strong, and the amount of sea that a westerly wind can raise against a west-going tide is as bad as any small craft can do with. In the lines of the hull it will be seen that she 


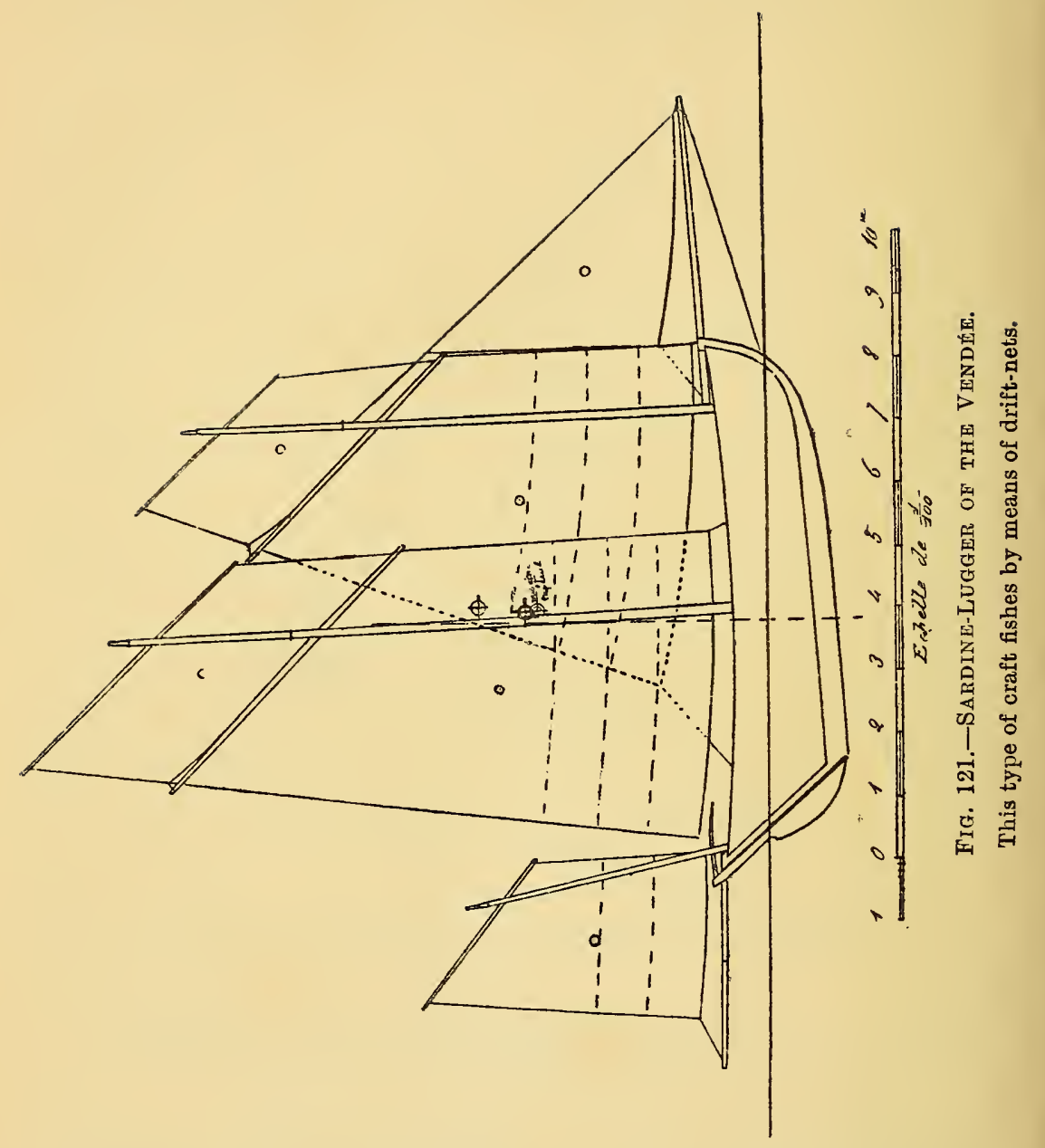




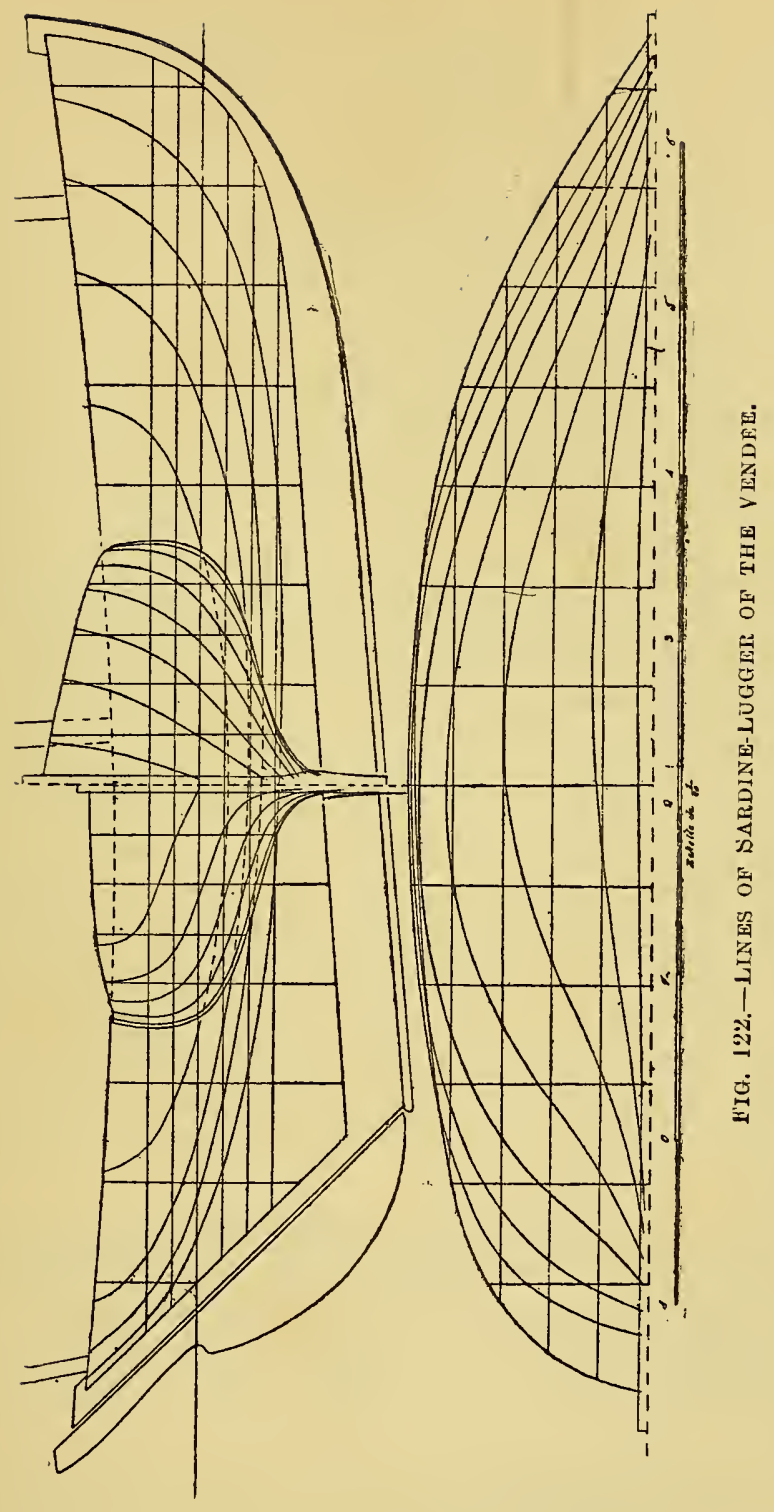


is flat-floored like most of the French craft, and that the centre-board is placed well forward. These craft measure about 10.10 metres over all, and 8.90 metres on the water-line.

Every one knows how throughout history the Bretons have been famous as sailors, perhaps one might say as the most famous of all the French seafaring men, whether as pirates, privateers, fishermen, or as crews of the men-of-war of France. In illustration, p. 321 (Fig. 120), we give the sail-plan of a Breton sardine boat, such as is found in Douarnenez and Concarneau. They measure roughly 10 metres over all in length, and have a total sail-area of 68 square metres, the foresail being 30 square metres in area, and the mizzen 38. In the foregoing plans (Figs. 121 and 122) will be seen another type of the sardine craft. These belong chiefly to the port of Les Sables d'Olonne in the Vendée. Like the previously mentioned craft, they are engaged almost exclusively in fishing for sardines by means of drift-nets. It should be added that in a fresh breeze the Douarnenez craft sail under foresail and a small mizzen. So also the Vendéenne craft, under similar conditions of wind, sail with foresail and mizzen, but with the mainmast lowered. They have a total sail-area of $68 \cdot 30$ square metres. It will be seen that in the general rig, the old-fashioned topsails and the jib, they are entirely influenced by the national craft and rig of France, viz. the chassemarée.

From the lines of the hull (Fig. 122) it will be observed that the stern-post rakes aft at a great angle. These craft measure about 8.50 metres over all, and $7 \cdot 48$ metres on the water-line, their extreme beam being 2.98 metres, and they draw 1.30 metres of water.

In the evil-smelling port of St. Malo there is a wealth of historical incident lying concealed in its shipping. In the eighteenth century it was the port 


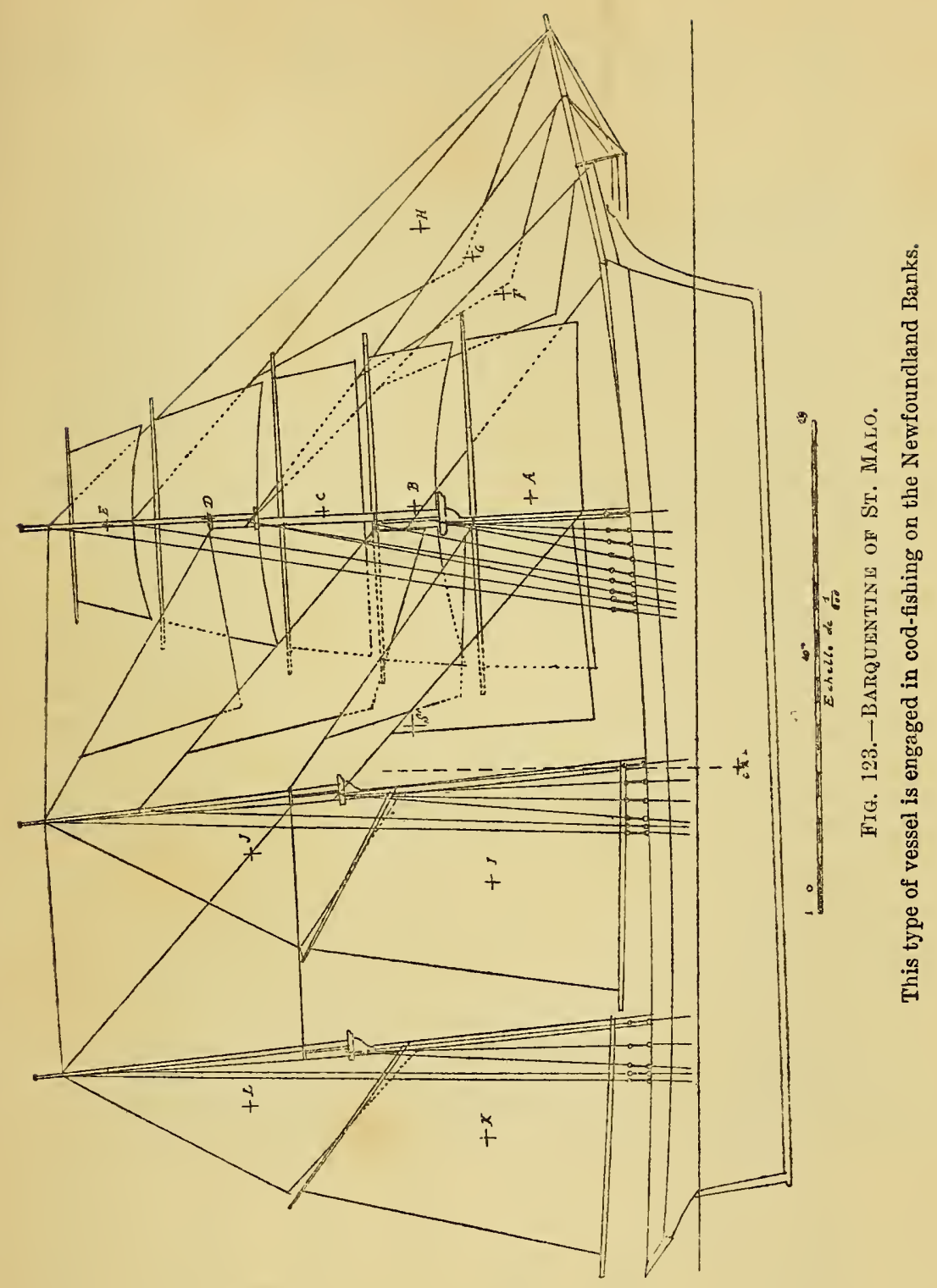




\section{THE MODERN FORE-AND-AFT RIG}

whence the numerous privateers embarked for the purpose of seizing the merchant vessels of England, and it is from here that those big sailing-ships still set forth, as they have done for many a generation, to cross the broad Atlantic and engage in cod-fishing off the Newfoundland Banks. Every one who has read Kipling's Captains Courageous will remember something about these French ships, and those who have visited St. Malo will have realised the depth of sentiment aroused each year as these ships start off from their home port for their long, solitary exile-perhaps to return, perhaps to be run down by some ocean greyhound hurrying on through the Atlantic fog. There are more collisions and disasters off the Grand Banks than ever get into the papers, and many a home in St. Malo has been bereft of its father and sons.

In the illustration (Figs. 123 and 126) will be seen one of the St. Malo barquentines which go out to the Grand Banks. "Terreneuviers" they designate these craft in France, and there are similar vessels which also put forth from Cancale, Granville, and Fécamp. When they arrive off the fishing grounds the vessels anchor, and the fishing is done from dories with long lines ; and as Kipling's or Connolly's readers are aware, the dories sometimes get so far separated in fogs or gales of wind that they are never picked up again, and the men either die of starvation and exhaustion or are mercifully drowned or run down by a steamship. This kind of craft measures $43 \cdot 15$ metres long and 39.35 metres on the water-line, with an extreme beam of 8.72 metres.

The two-masted schooner which is next to be considered (Figs. 124 and 128) is also French. She, too, is engaged in the fishing industry, but she has not so far to wander as the St. Malo craft. True she is a Breton, but she voyages to Iceland after the cod. Besides her lower canvas she carries a square topsail on her fore and a jib-headed topsail on her main, with 


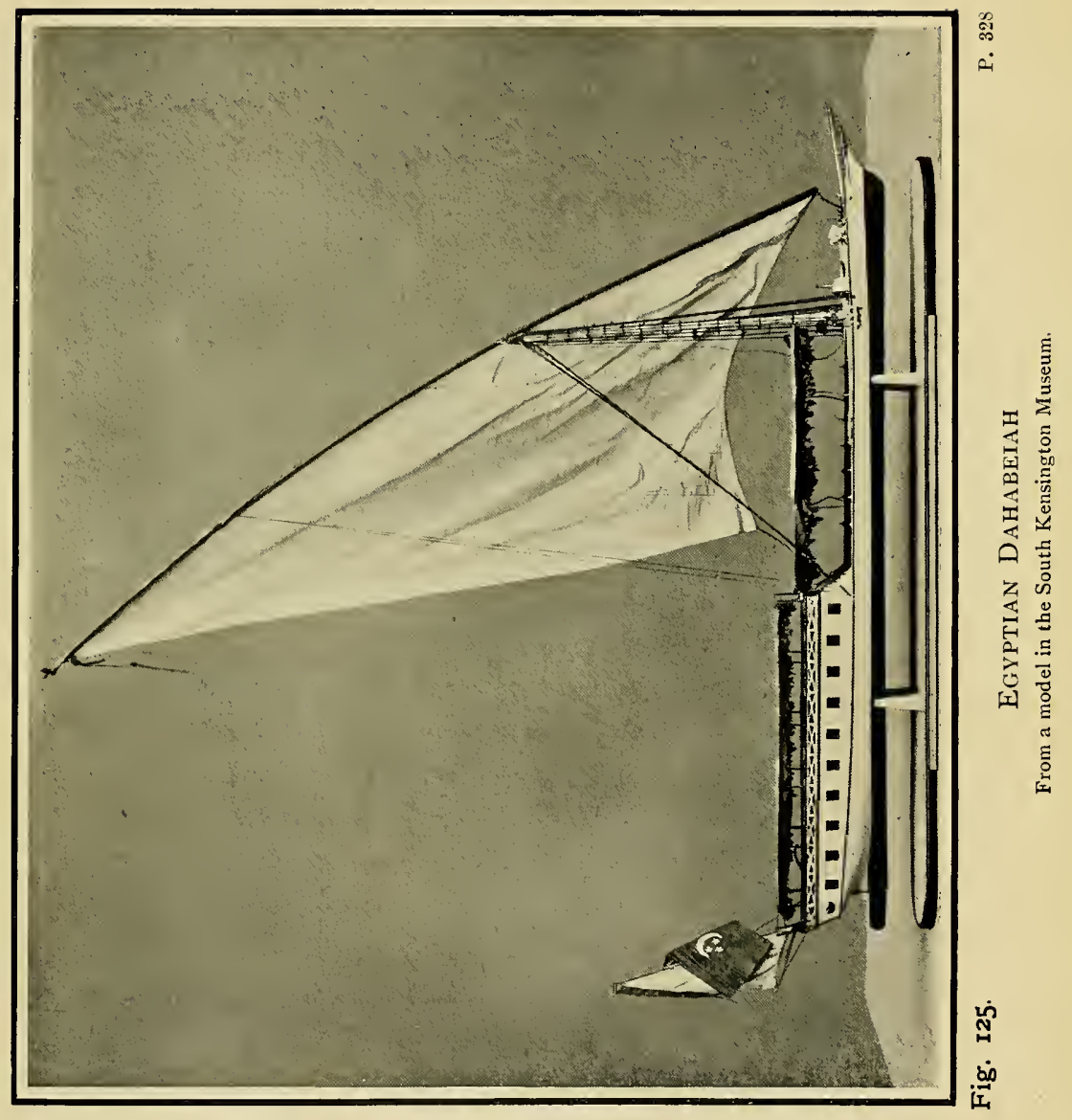



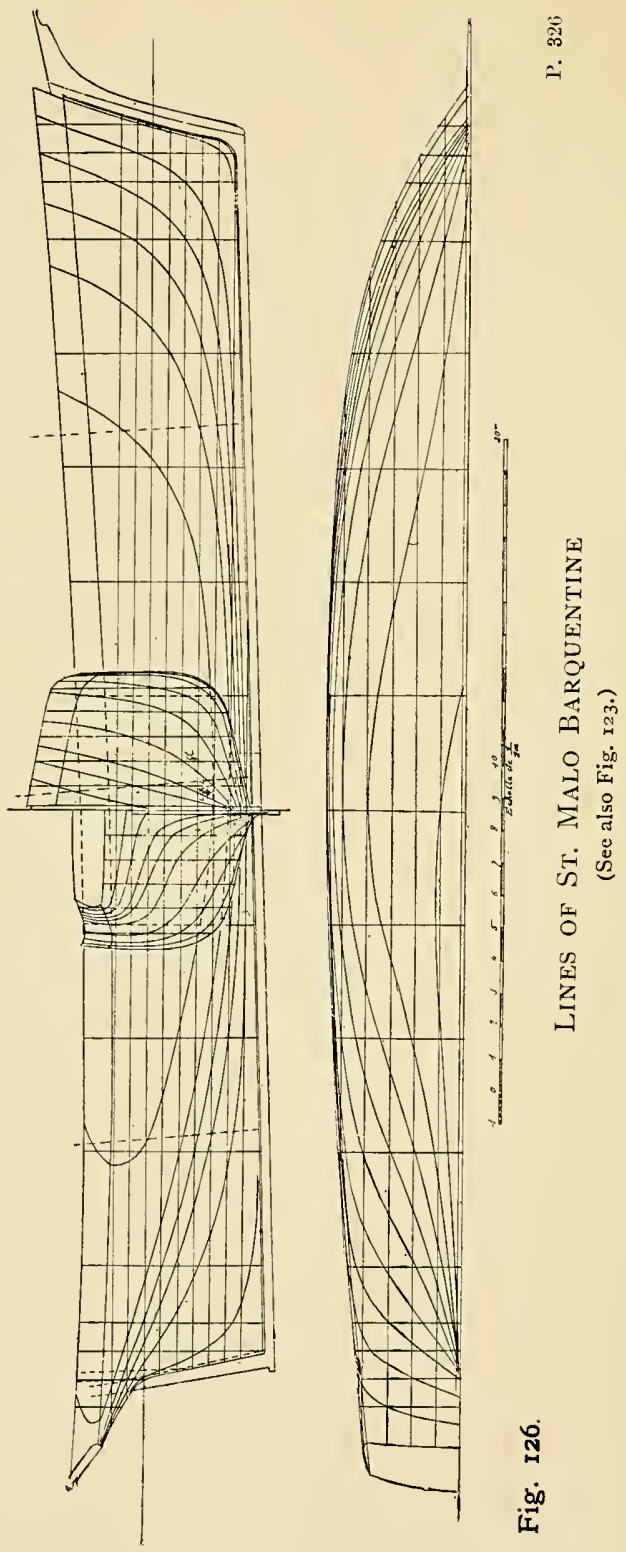


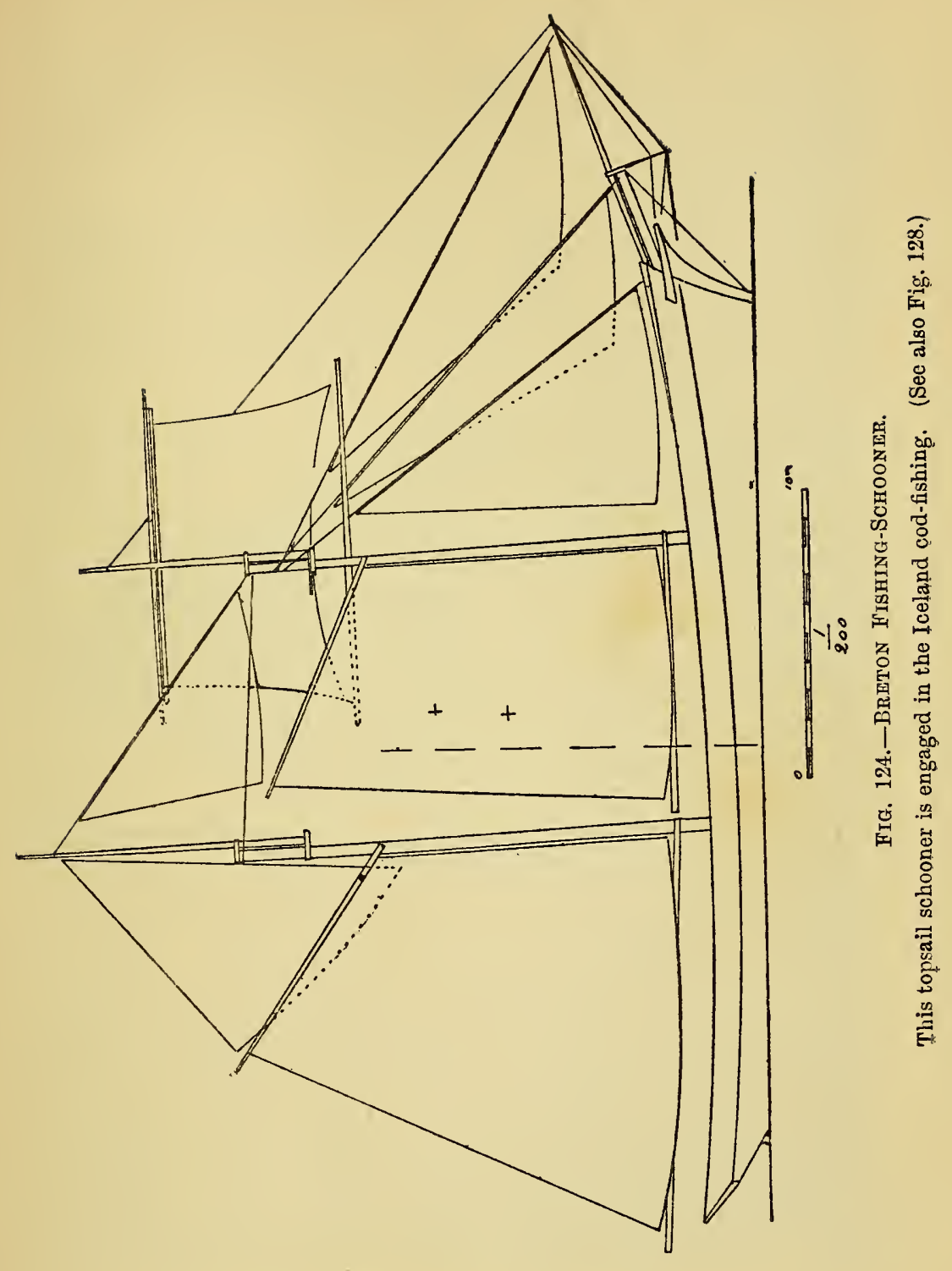


a staysail in between, her total sail-area amounting to 428.60 square metres. Her sail-plan has, however, been since slightly reduced in the case of the craft before us. She has 33.10 metres in length over all, and 28.64 metres on the keel, with an extreme beam of $7 \cdot 20$ metres.

And thus we conclude our survey of the modern types of the fore-and-aft craft as witnessed in northern Europe. But we will end as we began this volume, and show how the old and the new in the Mediterranean and the Nile still meet after the intervention of centuries and centuries.

We spoke at the commencement of this book about the lateen-sail and its influence. It is still in vogue in the Mediterranean, on the Nile, and also east of Suez. The trading craft of the Egyptian river no less than the dahabeiahs for royalty or for carrying the tourist are still rigged with the sail of history. In the illustration (Fig. 125) will be seen this rig employed for the purpose of the Khedive's yacht. The small mast, the huge yard coming almost down to the deck, the hollowed foot of the sail, the high peak, and so on-these features are still preserved regardless of the many species of fore-and-aft rig which have been evolved by the north of Europe. And then compare this with the photograph of a Spanish fore-and-after which is here shown (Fig. 127). This represents a Galician sardine boat seen in Vigo Bay. You remember in the days just preceding the coming of the Armada, when Philip was amassing considerable quantities of provisions for his mighty fleet, that Drake came south to interrupt these great preparations, and captured the fishing craft and nets of the Spanish, thus depriving the Armada, among other details, of the fish supplies which they would have taken on board for the expedition, had it been attempted that year. Well, the rig of the Spanish fisherman has altered but little during the centuries which have 


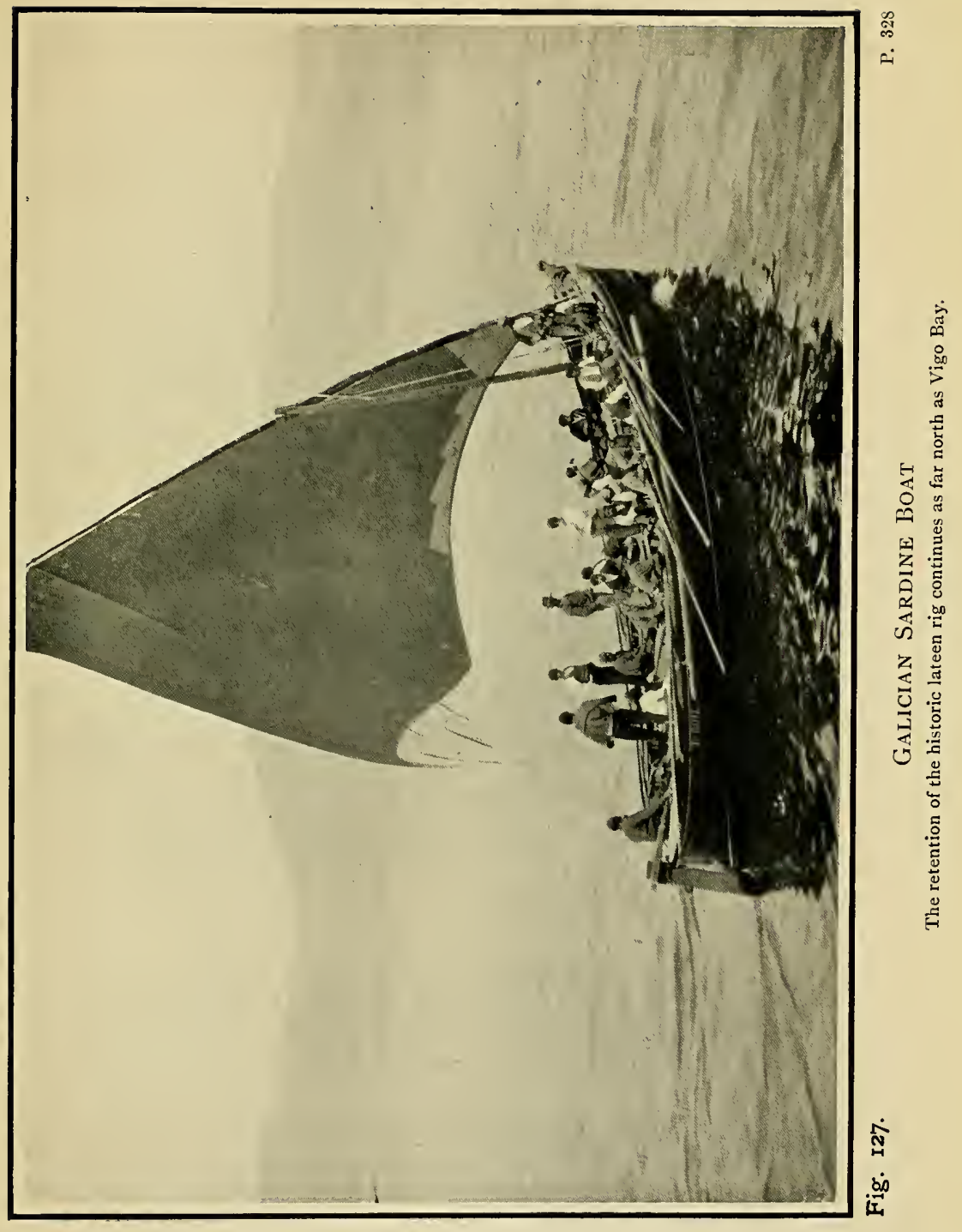



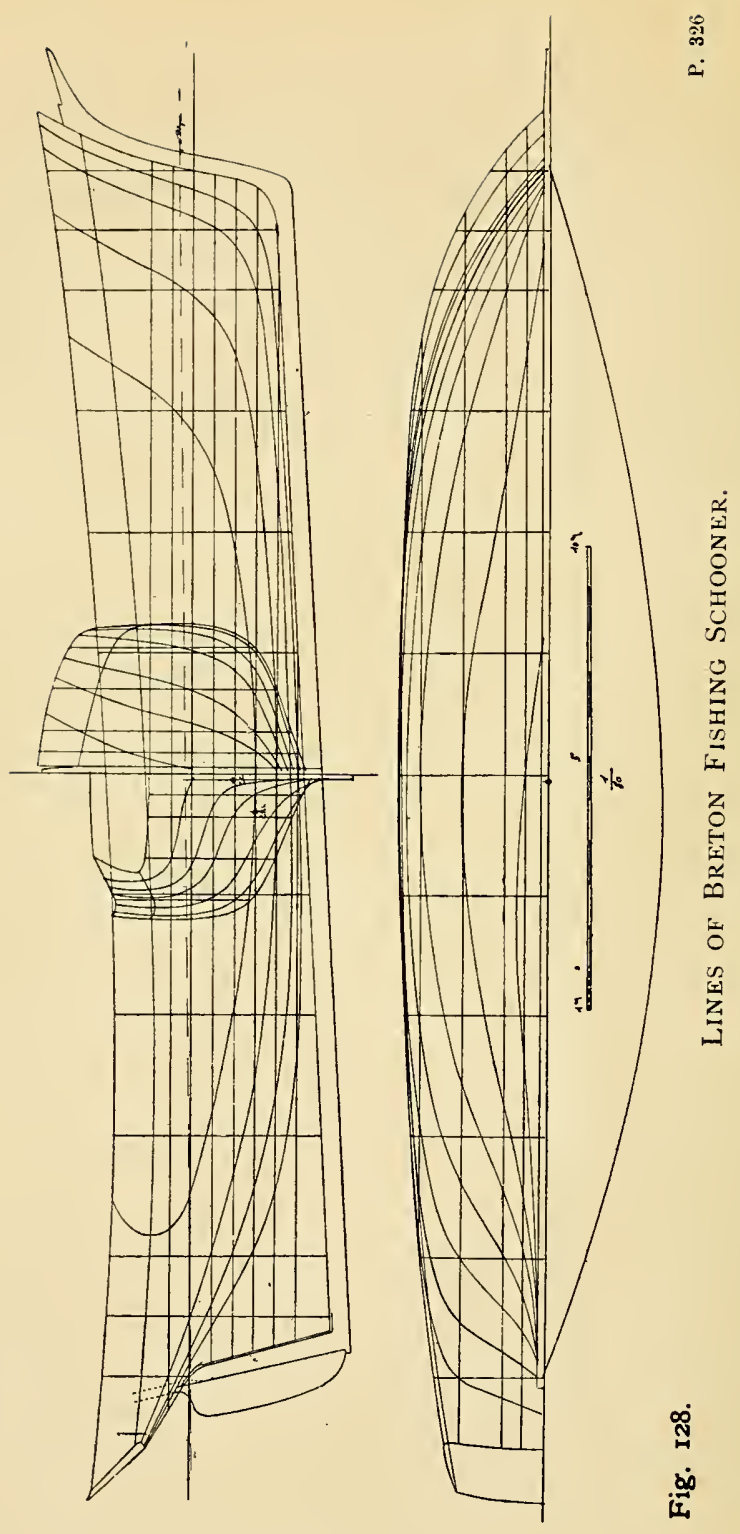
elapsed. Even as far north as Galicia the influence of Egypt is felt, as will be observed from this lateen in the photograph.

In the Marseilles pilot-craft (Figs. 129 and 130) the lateen is still retained also, even with the addition of a foresail, which she has probably acquired from northern Europe. These craft, like the Yorkshire cobbles, have their rudder projecting some distance below the keel. They have two rigs for summer and winter respectively, as will be seen from the dark and the dotted lines in the sail-plan here given. The winter rig gives a sail-area of 25.75 square metres, and the summer area is $\mathbf{3 7 \cdot 4 . 5}$ square metres. A shorter mast is also used for the winter sail-plan, and the lower half of the yard also is smaller. And notice that, as in the days of ancient Greece and Rome, the yard is still made in two pieces, of which the upper half is called the penne and the lower half the car. Even the stemhead shows traces of the beak, as seen in the galley of olden times. This type of pilot-boat is certainly a little old-fashioned now, but it has been thought well to reproduce it, as it shows more clearly the real connection between the things of the present and those of yesterday. At the same time it must be remembered that such craft are still built on these identical lines. They have an extreme length of 8.50 metres, and an extreme beam of 2.96 metres.

And so we bring our story to its close. What we have endeavoured to show throughout these pages, by letterpress as well as by illustration, has been the historical connection of the different types of the foreand-aft rig. We have begun at the beginning, and have tried to show, step by step, how different countries and different localities in those countries have adapted this rig to suit their own requirements. It is not for every ship to engage in trans-oceanic voyaging. The coaster, the fisherman, the pilot, and the yacht are all 


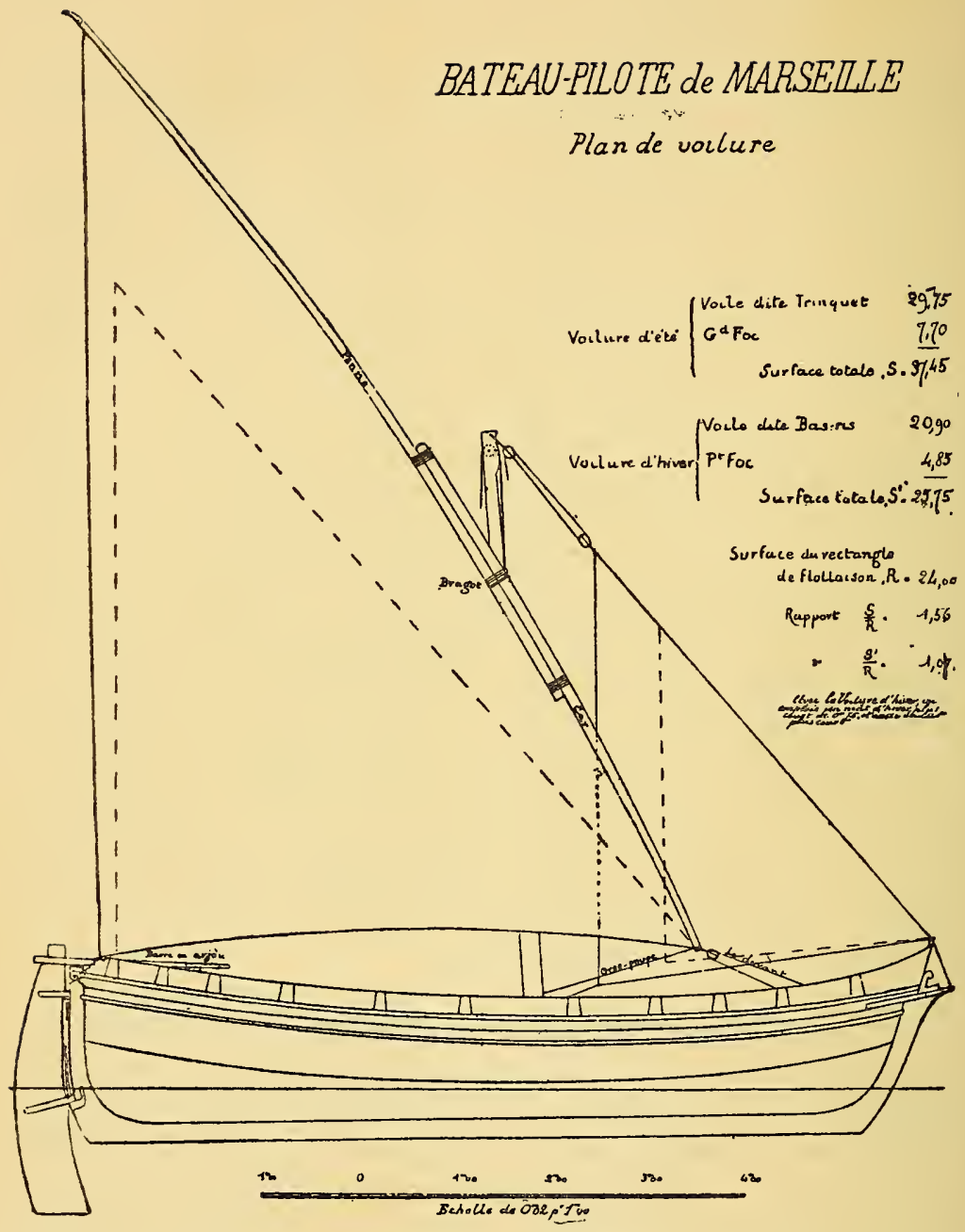

Fig. 129.-SAIL-Plan of MARseilles Pilot-BoAt.

The black lines show the summer rig and the dotted lines the winter rig. 

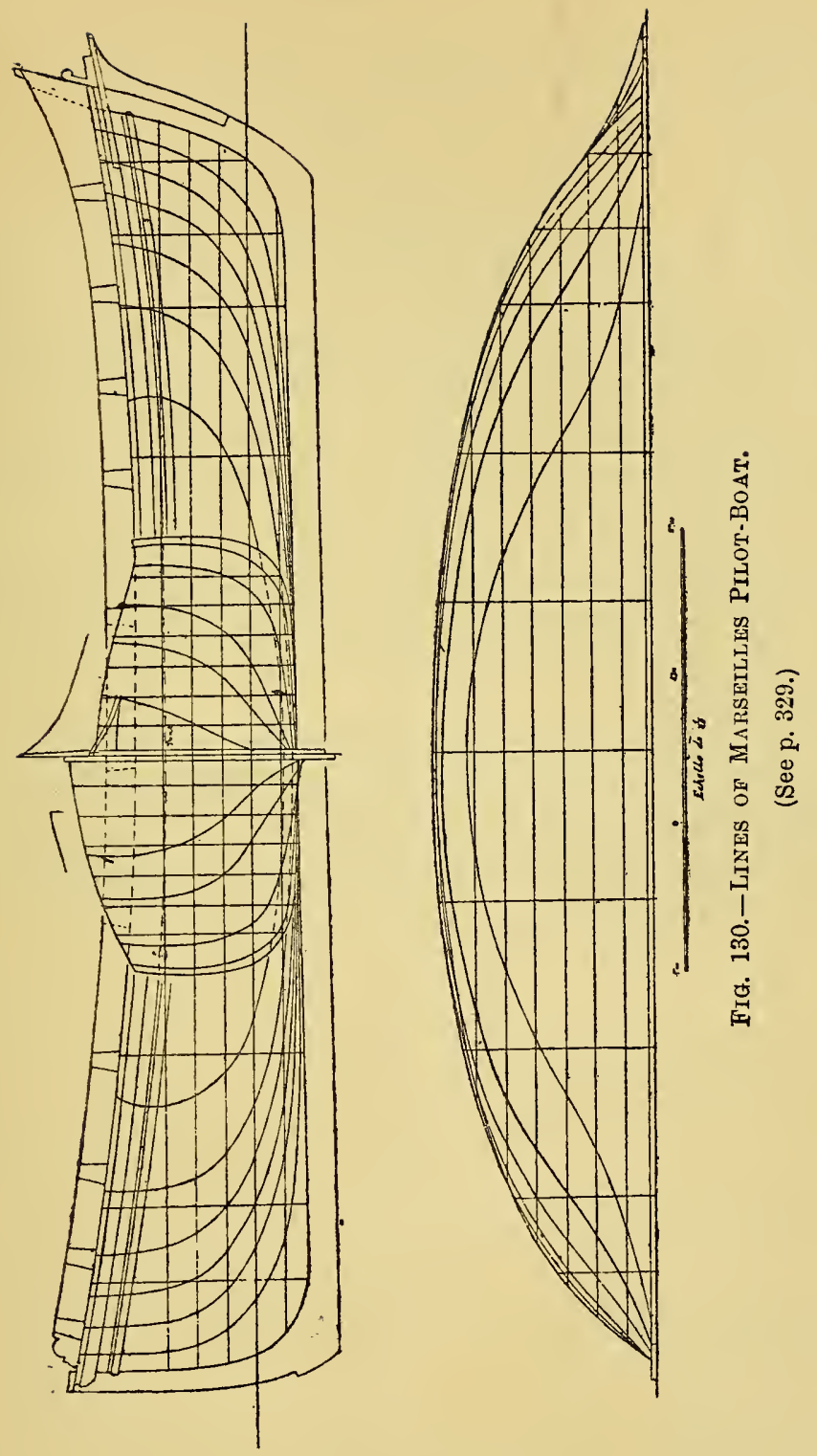
entitled to their existence, and to develop along whatever lines may be found best suited to their needs. They have found that the square-sail, for the reasons which have already been given, was not altogether happy for their requirements, and we cannot but admire the ingenious manner in which they have adapted, modified, and added to the rig that originally came to them from the south. Perhaps the next time we put to sea or loaf round our favourite harbour looking at some poor fisherman's craft we shall feel that in spite of her lack of beauty in form, her want of paint, or her need of a general refit altogether, she is something more than what she looks - that she is one of a long line of interesting personalities which throughout the centuries have been engaged in fishing and fighting, pirating and privateering, or whatever duty she may have been summoned to perform by the call of the sea.

For there is no romance like the real romance of history, and there is among the creations of man nothing which possesses one tithe of the romance that is hidden in the ship, whether large or small, square or fore-and-aft rigged. 


\section{GLOSSARY}

NOTE.-It should be explained that the following is in no sense whatever $x$ complete glossary, but is merely added to make the meaning clearer of certain Nautical terms not always familiar to the general reader.

Apple-Stern.-A name given to such a shaped end as is found in the case of many of the Dutch sailing vessels of to-day and yesterday, with their rounded buttocks.

Batance-Lug.-The balance-lug has both boom and yard. The tack is fixed to the forward end of the boom and made taut. As distinct from a dipping-lug, the balance-lugsail is not dipped at each tack.

BARREN-YARD.-The French in the eighteenth century were wout to speak of the cro'-jack or cross-jack yard as the barren-yard or vergue sec, because in those days no sail was set on that yard of a full-rigged ship. Similarly, fore-and-aft craft of that period carried a yard on which no sail was set.

Bilge.-The broadest part of a ship's bottom.

Boestay.-The stay which is employed for keeping the bowsprit down to counteract the upward tendency.

Bollard.-A strong post used for the purpose of making fast a rope. BONNET.-A strip of canvas which is laced along the foot of the sail to give greater area, as, for instance, in the case of the Lowestoft drifters and the Norfolk wherries.

Bowlines.-Ropes fastened to the luff of a square-sail for the purpose of keeping the weather-edge of the sail tight forward and steady when the vessel is close-hauled.

Braces.-These are ropes employed for the purpose of controlling the yards of square-sails, and are made fast to the extremities of the yards.

BraIls.-Ropes which are used for shortening a vessel's canvas by gathering it up to the mast, as in the case of the Dutchmen of yesterday and the English barges of to-day. 
"BREAK out THE Hook."-An expression to denote the breaking out of the anchor from the ground.

Bumpкin.-A small strong boom for the lead of the mizzen-sheet; also a kind of small bowsprit placed at the bows, usually made of iron, but sometimes of wood, for extending the foot of the foresail.

Chain-Plates. - These are plates of iron bolted to the ship's side beneath the channel (which is a platform bolted to the outside of the vessel to receive the dead-eyes for setting up the rigging). The dead-eyes or rigging screws are made fast either to the chain-plates by means of links led up through the channels, or else secured direct to the channels themselves.

Cleat.-A piece of wood so fashioned as to be convenient for making fast ropes.

Clinker-Built.-The manner of building a vessel so that the planks overlap each other; the exact opposite of carvel-built.

"СосK-A-BILLED." - The expression is used when speaking of an anchor that is suspended perpendicularly from the cat-head ready to be let go at once. The expression is also used in reference to the yard of a ship's square-sail when, the sail having been stowed, the yard is hauled more or less perpendicularly parallel with the mast.

Cringle.-A small hole formed on the bolt-rope of a sail with a brass or iron ring or thimble placed therein.

Drifr.-The distance which a vessel is carried from her course. It is also used in this book metaphorically in speaking of the space between the mast and luff of the mainsail.

Exes.-The eyes of a ship are those parts which are in the extreme forward end of the vessel.

FiddLe-Block.-So called from its similarity in shape to a violin.

ForEFoor.-The foremost part of a vessel's keel.

ForestaY.-The stay on which the foresail is set. This stay is for the support of the mast forward.

FreEbOARD. - The amount of a ship's hull which is between the water-line and the gunwale.

GAFF.-The spar along which the head or upper part of a fore-andaft rectangular sail is laced.

Goose-NECK.-A piece of bent iron or other metal fitted to the end of a boom so as to allow the spar to move easily and yet be secured 
to the mast, as, for instance,' in the case of a spinnaker boom goose-neck.

GrIPE.-A vessel is said to gripe when she carries too much weather helm; that is to say, she has too great a tendency to run up into the wind.

Guys.-Ropes used for the purpose of steadying a spar.

Grie.-When the wind changes from one quarter to another, the vessel running free, the mainsail of a cutter will swing over to the other side, and so be said to gybe.

Halyard. - The rope by which a sail is hoisted.

Horse. - An iron or wooden bar along which the sheet of the sail can travel, as for instance, in the case of a Thames barge. The latter has a horse placed forward to allow the staysail sheet to travel thereon.

LEECH.-The vertical edges of a sail.

LEEBOARD.-(For origin see text). Leeboards are specially shaped "boards" or wings placed on either side of a sailing craft to diminish her leeway or drift to leeward.

LuFF.-The forward edge of a sail. In the case of a cutter's mainsail, for instance, it is that edge which is next to and parallel with the mast.

Lugsail.-A quadrilateral sail bent on a yard which hangs obliquely to the mast at one-third of its length forward of the mast. In the case of the dipping-lug the sail has to be dipped at each tack and hoisted afresh, so as always to be on the lee side. In the case of both the standing-lug and the balance-lug no dipping is necessary.

Mizzen.-As applied to a mast, the word signifies the aftermost mast of a ketch or yawl, whereas in the case of a schooner the aftermost mast is called the mainmast and the other the foremast. As applied to a sail, the mizzen is that sail which is set on the mizzen-mast.

PEAK.-The upper, aftermost corner of a fore-and-aft rectangular sail.

QuANT. - $A$ pole employed both in Holland and the waterways of Norfolk and Suffolk for the purpose of propelling a craft in calms and light airs.

RAKE. - The inclination from the perpendicular, as, for instance, in the case of a mast. 
REACH. -When a vessel is sailing moderately close-hauled for a certain mark, she is said to be reaching.

Rubbing-STRAKE.-An extra stout piece of planking placed along both sides of the hull so as to prevent damage to the latter when coming alongside a quay or other vessel.

RunNer. - The tackle which is employed for tightening the backstays which give additional support to the mast.

ShackLE.-Pieces of iron of more or less semi-circular shape, with a pin to screw therein. They are employed for numerous purposes on a ship, as, for instance, to attach the staysail to the forestay.

SHEER.-The curve in a vessel's side longitudinally from bow to stern. SPINNAKER.-An extra, large triangular sail, set on fore-and-aft vessels when the wind is free in light weather.

SPREADERS.-These may be of wood or of iron, and are used for the purpose of extending a stay at an angle, and so enabling it to have greater power.

Spritsall. - The sprit of a fore-and-aft vessel is employed for the purpose of peaking the sail when there is neither gaff nor boom. The sprit extends diagonally from forward to aft. The mainsail of a Thames or Medway barge, for instance, is a spritsail.

STAYS.-Rope or wire employed for the support of mast or bowsprit.

Staysail.-Any sail which is hoisted on a stay. In the case of foreand-afters the word is usually employed when referring to the foresail.

SteEving.-The angle which a ship's bowsprit makes with the hull.

STORM-Jib. - The smallest sized jib of extra stout canvas for use in bad weather.

Stunsails, or more properly Studding-Sails.-These were extra sails which were set in moderate and steady breezes when running. They were run out beyond the yardarms, but are nowadays obsolete.

TABERNACLE. - An arrangement fitted for the reception of the mast in such a manner that the mast can be lowered and raised for going under bridges.

Turoat.-The name given to that part of a gaff which is next to the mast. Whereas the peak is the after end of the gaff, the throat is the forward end. 
Topping-LifT.-A rope used for the support of the boom of a sail when the latter has been stowed.

Transom-Sterned.-A transom-sterned craft is one whose stern ends abruptly with a bulkhead placed across the stern-post.

Travelcer. - A ring employed for the purpose of travelling up and down a mast, or along a horse. In the case of a lugsail, for instance, the halyard is attached to the ring, and the latter hooks on to the yard. Thus the halyard may be hoisted, but the ring still keeps the halyard close to the mast.

Trysait. - A small sail which a fore-and-after sets abaft the mast in the time of bad weather. It may be set on a small gaff, or may dispense with the latter and be of a triangular shape.

Tumble-Hоме.-That part of a ship's side which "tumbles home," or falls inward above the extreme breadth so as to make the vessel of less beam than on her lower-deck.

UNa-Rig.-(See text). This rig consists of one sail, viz. the usual gaff-and-boom mainsail of a cutter. As there are no headsails this sail is placed as far forward as possible in the boat.

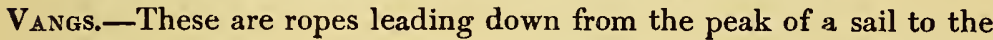
deck. They are especially noticeable in the old-fashioned Dutch craft and the present-day Thames and Medway barges.

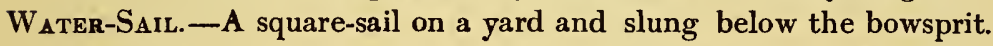
This sail is now obsolete, but, under the name of "Jimmy Green," it was in vogue on full-rigged ships during the early part of the nineteenth century. 



\section{N D E X}

A

Abrahams, Jan, 33

Admiralty Dutch yacht, lines of, 105 _- yachts, Dutch, 101

Adriatic, craft of the, 38

Advys-jaght or despatch-boats, 100

Alarm, the, 133, 205

Aline, the, 210

Alpha, the, 247

America, the Dutch in, 19

America, the, 174, 209

America Cup, the, 140, 204

American yachting, 259

Amstel, the, 60

Amsterdam, 20

Amunsden, Capt., 205, 284

Ann Sarah, the, 174

Anne, the Duke of York's yacht, 135 cost of building the, 144

Archer, Colin, 284

Architectura navalis mercatoria, 113

Arentzen, Arent, 73

Arrow, the, 205

Askgard, the, 286

Atalanta, the, 174, 197

Auxiliary motor fishing-boat, 282

B

Badiley, Capt. William, 144

"Badminton" yachting volumes, 171

Bakhuyzen, 56, 90

Balance-lug, the, 30

Ballast in Norwegian craft, 287

- of the Seal, 270 of the racing yacht, 257
Ballast of pilot-cutter, 246

- of shot and stone, 205

of the yacht Mary, 135

Baltic influence, 277

Baltimore clippers, 203

Barentsz, William, 64

Barge, Thames, 230

Barren-yard, the, 111

Batten, Sir W., 158

Bawley rig, the, 94

Bawley, the Thames, 230

Belanders, 72

Belgian lugger, the, 310

Bellevois, Jacob, artist, 53

Benthall, E. H., 212

Bergen-op-Zoom, defeat of the Spaniards at, 62

Bermuda rig, the, 79

"Beurtman" or freight-carrier, 114

Bezan, the, 137

- dimensions of the, 141

Pepys and the, 148

Billingsgate oyster boats, 175

Billy-boy, the modern, 167

Bisquines, 320

Blake, Admiral, 52

Blankenberg luggers, 225

Bloodhound, the, 211

Blue Dragon, the, 214

Boier, the, 102

- yacht, the, 301

Boijman's museum, 33, 77, 92, 110, 201

"Bolte-sprit," the, 63

Bomb-ketch, the, 107

Bonetta sloop, dimensions of, 143 


\section{0}

Bonington, 168

Bonnets, 55

Bosham, tombstone at, 191

"Boskoop boot," a, 292

Boulogne herring-drifter, the, 315

Bow-sprit, dangers of the, 83

- the, 99

Bowlines, 225, 278

Bragozzi, the, 38

Breton sailors, 324 sardine boats, 324

Brighton hoggies, 222

Bristol Channel, the, 242

Britannia, the, 253

British Mariner's Vocabulary, definition of a schooner, 203

British Museum, the, 126

Brixham, 238

Brocksprit or bowsprit, 201

Brooking, 168

Buckie boats, 240

Bulwarks, high, 289

Bureau Veritas, the, 258

Burlings, the, 37

Busses, seventeenth-century, 162

Buss-ship, sixteenth-century, 52

- influence of the English, 162

Calais, 20

"Calais Pier," Turner's, 179

Camper and Nicholson, 258

Cat-boat type of craft, 261

Catherine, the, 143

Centreboard, the, 73

- American preference for the, 260 craft, craze for, 210 sloop, the, 259

Chafing, damage caused by, 28

"Chaloep" or "boot," the, 68

Channel Isles, Charles II. sailing in the, 132

Chapman, Frederick Hennik Af., 113
Charles I. the Sovereign of the seas, 52

Charles II. at Breda, 128

- in the Channel Isles, 132

his knowledge of naval matters, 142

Charlotte, the, 143

Cherub III., 274

Childers, Erskine, 286

Children's Friend, the, 241

Chinese junks, 40

- trawlers, 40

Chioggia, craft of, 39

Clark, Capt., History of Yachting, 129

Classes, 258

Clayton, Harold, 247

Cleaveland, the, 143

Cobble, the, 226

Cockpit of pilot-cutter, 245

Codes of signals for yacht clubs, 173,195

Columbia, the, 260

Constable, 168

Constitution, the, 260

Cooke, E. W., 108, 166, 168, 175, 191, 204, 235

Coquette, the, 208

Cork yachts, 170

- yachts, rig of the, 172 club, 194

Cornish luggers, 240

Corsair, the, 214

Counter stern, the, 168

Cowes Yacht Club, 194

Creole, the, 214

Cruisers, 264

Cumberland Fleet, the, 173, 194

Cutter, origin of the modern, 96

Cutter-rig, 93

— for yachts, 197

Cutters as yachts, 178

D

Dagomar, the, 174

Dahabia, the mainyard of a, 31 
Daniell, William, 196

Dardanelles, the coaster of the, 39

Dead-eyes, the, 118

Deal lugger, the, 236

Deane, Sir Anthony, 97

Defender, the, 260

Delishaven, 61

Deptford, the yacht Mary at, 134

Devon seamen, 239

Dhow, the, 31

Dictionnaire de Marine of 1736, 99

Dimensions of the Britannia, 254

- of Cherub III, 274

- of Norma, 274 of the Satanita, $\mathbf{2 5 5}$

of the Seal, 270 of Sheila II., 272

Dinghy of the Seal, 271

- shipping a, 244

Dipping-lug, the, 56

Dordrecht Museum, the, 75, 201

Dord tsche Kil, the, 129

"Double-ended " craft, 268

Dulwich Gallery, the, 172

Dunkirk, the, 147

Dunkirk sloop, 143 fishing-ketch, 312

Dutch boier, the, 301

- botter, the, 295

- eighteenth-century yacht, a, 169

- East India Company, the, 133

- as explorers, the, 64

__ expeditions of discovery, 65

- galleot, 107

- hoogarts, 298

- in the East, 40

- klipper, the, 293

_- influence in America, 190 marine painters, 89 naval architecture, 87

Navy, the, 101

- painters of the seventeenth century, 53
Dutch Revenue-cutter, 183

- sailor-man, the, 21

- schokker, the, 297

- sloepe, the, 189

_ "schuyt," a, 175

- state yachts, 100

- Una-rig, 305

War, causes of the first, 52

Dutchman's love of the sea, the, 122

E

Egeria, the, 210

Egyptian boats, the square-sail of, 28

Elandts, the artist, 50

Emblem, the, 241

Enkhuizen " beurtman," an, 114

Ensign staff, the curved, 84

Equihen, fishing-craft of, 320

Evelyn's description of a yacht-race, 139

Experiment, the, 153

\section{F}

Faith, the, 247

Falconer's Dictionary, 180

_- definition of a yacht, 188

Fannes or Vanes, 163

Felucca, the Spanish, 41

Fend-offs on Dutch craft, 170

Ferrers, Lord, 179

Fife of Fairlie, 267

Fifie boats, 240

Fishing-boats and yachts, mutual influence of, 216

Fishing-pink, a three-masted, 103

Fishing-smack, the origin of the, 20

Flushing, 20

- defeat of the Spaniards at, 62 pilots, 304

Flute or pink, 53

Fly, the, 185 
Foreign influences in English shipbuilding, 136

Forty-tonners, famous, 211

Foxhound, the, 211

Fram, the, 284, 290

Fubbs, the, 143

- dimensions of the, 146

Gaff, the, 79

\section{G}

- origin of the, 96

Galleass, the, 35

Galleot, Dutch, 107

Galleots, 143, 279

Galley, the, 32

Galleys of Venice, the, 46

Gallic naval design and construction, 200

German sport, British influence on, 258

Germania, the, 259

Germanischere Lloyd, 258

Gilded leather for King Charles's yachts, 144

Gjoa, the, 205

Gladys, the, 252

Gloucester, the birthplace of the schooner, 202

"Goared " sails, 110

Gouda, 125

Goulding, John, captain of the Mary, 140

Government cutters and private yachts, 199

Grace, the, 245

Grand Banks, the, 326

Gravelines lugger, a, 312

Great Fire, influence of, on sport, 159

Greenwich Royal Observatory, founding of, 142

Greyhound, the, 143

Guest, Montague, history of the Royal Yacht Squadron, 195

Guns on yachts, 105
$\mathrm{H}$

Hatch-boat, the, 175

Henrietta, the, 143, 147

Henry VIII., 57

Herreshoff, 263

Herring-buss, the, 50

Herring-drifters of the Low Countries, 49

Herring industry, the, 52

Historical documents concerning the king's yachts, 145-146

History of Yachting, Captain Clark's, 129,154

"Hoeker," sails of the, 164

Hoggies, 222

Hollandsch Diep, unpleasant conditions in, 60, 104, 130

Hooy-schip, the, 126

"Horse, the breaking of the," 192

Hoy, the, 190

\section{I}

India, the Dutch in, 19

Ireland, yachting in, 159

Isabella, the, 143

Isle of Wight, dimensions of the, 142

Itchen Ferry craft, 268

\section{$\boldsymbol{J}$}

Jamaie, dimensions of the, 141

Java, the Dutch in, 19

Javanese vessel, sails of a, 30

Jenny, Charles II.'s yacht, 135

Jullanar, the, 211

\section{$\mathbf{K}$}

Katherine, Queen, a yacht owner, 158

Katwijk Pom, a, 308 
Kensington Palace, sea-pieces in, 168

Ketch rig, the, 109

King's Fisher, the, 173

Kitchen, the,

" Knock-toes," 237

Kof-tjalk, the, Ill

Kola in Lapland, 67

Kromhout motors, 114

"Kub-boot," the, 303

\section{L}

Lacing and hoops, 74

Lateen rig, the, 32 sail, the, 31,95 and square-sail, 48

Lead sheathing, 148, 153

Leeboards, 71

Leslie's Old Sea Wings, Ways, and Words, 47, 181

Lifeboat, Norwegian and English, 285

Life-lines, 169

Linschoten, Jan Huygen von, 64

Lloyd's, 258

Loch Fyne skiffs, 226

"Loodsloep," a, 304

Lowestoft drifter, the, 55

Lowestoft harbour, 229

Lug-sail, the, 39, 40, 50, 162

Lugger, evolution of the threemasted, 161

Lugger, speed of the, 162

Luggers and galleys, 57

\section{M}

Maas, the, 19

Mahommedan galleys, 40

Mainsail of seventeenth - century busses, 162

Manwayring, 177

Maria, centre-board sloop, 208
Marine painting, 88

Market-barge, the, 81

Marseilles fishing-boat, 33

Marshall, C. D., 267

Mary, the, England's first yacht, 22, 63,133

Mary, dimensions and rigging of the, 137

Mary IT., 22, 134, 143

dimensions of, 155

Mast and Sail, W. Smyth's, 122

Masts of Dutch yachts, 100

Maud, the, 266

Mauritshuis at the Hague, the, 55, 85,105

Measurement rules, 213

Measurement and rating of racing craft, international rule for the, 257

Mediterranean galleys, 57

Mediterranean, rigging on the, 31

Medway barge, dimensions of, 233

Merlin, the, 143

Meteor, 263

Middle Ages, rigging of the, 31

Middleburg, the abbey at, 62

Minion, dimensions of the, 143

Monamy, Peter, 168, 172

Monmouth, the, 143

Moore's Midshipman's . Ior British Mariner's Vocabulary, 188

Mosquito, the, 208

Motor auxiliary, the, 46

- pilot-ketches, 250

- power, 251

Mule, the, 228

Muletta, the, 33,36

"Mumble bees," 238

Municipal Museum at the Hague, 50

\section{$\mathrm{N}$}

Nabbies, 225

Naseby, the, 132 
National Gallery, the, 110

Nautical Almanac, founding of the, 142

Nautical nomenclature, carelessness in, 67

Navahoe, the, 254

Naval architecture during Charles II., 142

- designs, improvement in, 186 101 manœuvres by Dutch yachts,

Naval Architecture, Stalkartt's, 185

Navigation difficulties in Holland, 80

- impulse to, 142

Navy, the, 143

- dimensions of the, 146

Navy lists, yachts numbered in the, 143

Nellie Jane, the, 241

Netherlands, the, the "waggoners of the sea," 19

New York Yacht Club, the, 260

Newhaven, 20

Niobe, the, 214

Norma, the, 274

North-east Passage, the, 64

North-west Passage, discovery of the, 205

Norwegian " jaegt," the, 277

— pilot craft, 290

_ sailing lifeboat, 284

Nova Zembla, discovery of, 65

Nugger, sail-plan of Egyptian, 29

Nyria, the, 258

\section{0}

Oars of the "mule," 228

Oimara, the, 210

Old Sea Wings, Ways, and Words, Leslie's, 47, 181

Orange, the Prince of, and Charles II., 129

Ostend, 20

Outlook, the, 260

\section{$\mathbf{P}$}

Paid hand, the, 266

"Patron" or master, 55

Paviljoen-pom, the, 117

Pearl, the, 205

Penzance drifters, 241

Pepys, 97

- extract from his Diary, 134

love of yachting, 148-153

Peter-boat, the, 175

Pett, commissioner, 134

Pilot-boat, the origin of the, 20

Pilot-cutters, Bristol Channel, 242

Pink, rig of the, 94

Pinks, 143

Playue, influence of, on sport, 159

Plymouth hooker, 240

"Pom " or "Bom," the, 119

Pompe, Gerrit, 110

Poole fishing-cutters, 178

Poop-deck, the, 169

Popham, Sir Home, 195

Portsmouth barges, 235

Portsmouth, the, 143

_ rigging of the, 157

Portsmouth wherry, the, 60

Portuguese muletta, the, 36

Prichett, R. T., 171

Prince of Orange, the, 117

Prince Royal, the, 151

Pumps on Dutch boats, 99

\section{Q}

Queen Mab, the, 214, 255

Queenborough, the, $1+2$

$\mathbf{R}$

Racing yacht, the, 256

Ram, survival of the, 37 
Ramsgate, 20

Ramsgate harbour, 229

Rat o' Wight, Queen Elizabeth's pleasure ship, 97

Rating, 214

'Redningskoite," the, 285

Reefing-gear, 243

Regattas on the Thames, 173

Reliance, the, 260

Renaissance, influence of the, 47

Revenue cruiser, the, 179 ; dimensions, 181

Richmond, Duke of, a yacht-owner, 158

Riddle of the Sands, the, 286

Rijks Museum, the, 57, 59, 69, 98, $105,114,117,119,130,301$

Rigging at the beginning of the nineteenth-century, 174

- of Billingsgate oyster-boats, 175

of Charles II.'s yacht, 129

- of the cutter, 180

of Dutch Revenue-cutter, 183

of the hatch-boat, 177

of Mary II., 156

- of the Portsmouth, 157

of Thames barges, 235

Rig of the Cork yachts, 172

Royal Charles, the, 132

Royal Cork Yacht Club, 159

- Eastern Yacht Club, 207

Harwich Yacht Club, 207

Mersey Yacht Club, 207

Northern Yacht Club, 207

_ St. George's Yacht Club, 207

- Southern Yacht Club, 207

\section{7}

Thames Yacht Club, the, 173,

_ Victoria Yacht Club, 207

Western Yacht Club, 207

_ Yacht Club, the, 195

Yacht Squadron, 207

Rudder, the, 125
Rudder, hatchet-shaped, 109

Ruskin and Dutch marine paintera, 90

Russell, Scott, 208

Ruysdall, 110

\section{s}

Saenredam, Johannes, 70

Saevareid, the, 252

St. Helens, the, 250

St. Malo barquentines, 326

St. Malo, fishing craft of the Bay of, 320

Sail area of the Britannia, 254 of Cherul III., 274

- of Norma, 274 of the Seal, 270 of Sheila $I I ., 272$

Sail areas, increasing, 197

Sail-plan of fishing smack, 191

_ of the " redningskoite," 287

Sailnuakers and designers, influence of the America on, 210

Sailing Ships and their Story, 17, 285

Sails, cotton and silk, 214

Sails of the "hoeker," 164

of the Mary, the, 135

Sails, striped, 169

Satanita, the, 254

Scandinavians, influence of the, 42 , 44, 277

Scarborough ketch, 229

Schank's sliding keel, 185

Scheldt and Thames, 232

Scheldt, the, 19, 20, 48, 73

Scheveningen, Charles II. at, 132

- Church, painting in, 50 pink, the, 306

Schooner, the, 75 ; development, 81, 199

Scotch fishing craft, 224

Scotch smack, 190 
Seal, the, 268

"Semaque," the, 124

Semelle de derive, or leeboard, 71

Serres, 168

Shamrock, the, 133

Shamrock IV., 264

Sheila II., 271

Shipbuilding industry, the, 193

Skaffies, 226

Skiffs, 225

"Skimming dishes," 257

Slocum, Captain, 204

Sloepe, or sloop, the, 67, 201, 204, 304

Sloop in America, the, 189

Sloop, Falconer's definition of a, 187

Sloop, how the word is used in America, 68

Smack, Falconer's definition of a, 190

- origin of the, 124

"Smal-schip," the, 124

Smuggling, 178

Smyth's, W., Mast and Sail, 122

Solebay, the battle of, 155

Solent, the, 250

- barges, 236

"South Sea," shallow water of the, 115

Southampton water, 20

Sovereign of the Seas, the, 149

Spanish felucca, the, 41

_ fishing craft, 36

- galleys in Holland, 70

Spanker, the, 41

Spinnaker, the, 214

- the germ of the, 73

Spitzbergen, discovery of, 65

Sprit-rig, disad vantages of, 94

Spritsail of Holland, the, $\mathbf{2 7 8}$

- in Turkish waters, the, 39

Square-rigged ships, 23,28

Square-sail, usefulness of the, 27, 111

- on Chinese junks, the, 40

Square-sails disappearing, 198
Stalkartt's Naval Architecture, 185

Stanfield, Clarkson, 168

Steam trawler, the, 230

Steers, George, 208

Stern-formation, 281

Stern, the high, in Dutch boats, 116

- loftiness of the, 168

- post, the, 169

windows, 109

Sterns of Dutch vessels, the, 93,97

Storck, Abraham, 55, 105

Strijensas, 104

Stumpy, the, 234

Sussex lugger's, 222

Swiss lakes, the lateen rig on, 32

$\mathrm{T}$

Tapestry at Middleburg, 62

Tartana, the Mediterranean, 35

Thames, the, temp. Charles II., 149

- barge, the, 230

bawley, the, 230

- measurement, the, 21:

- skiff, the, 103

- yacht-racing on the, 173

Theories of designers, 208

Thistle, the, 133, 212

Thorne, Robert, map by, 62

Tiller, the, 116

Timber for King Charles's yachts, 144

Tjalk, the, 291

Tonnage, 197

Topsail, the, 191

- schooner, the, 27

Trabaccolo, the, 38

Transom stern, the, 168

Trawling industry, mulettas in the,

37

Trek-paard, or towing-horse, 98

Trial, the, 185

Turner, 168

Turner's "Calais Pier," 179 
Turner's early drawings, 63

Two Brothers, the, 192

\section{$\mathrm{U}$}

Una-rig, the, 60

Union, the, 204

\section{$\nabla$}

Valkyrie I., the, 254

Valkyrie II., the, 255

Van Beijeren, Abraham Hendricksz, 92

— der Capelle, Jan, 110

- Goyen, Jan Josephsz, 85

der Velde, 56, 90, 154

Vlooswyck and Charles II., 133

Vendéenne craft, 324

Venice, galleys of, 46

Verschuier, Lieve, 130

Vigilant, the, 254, 260

Vikings of the North, the, 31

Vlie-boot, the, 53

Voyage Round Great Britain, A, 196

W

"Waggoners of the sea," the, 19

Walcheren, the island of, 20,59

$W$ estward, the, 263

White Heather, the, 133, 258

White Heather II., 258

Willaerts, Adam, 75, 201

Willemstadt, 104

Willoughby, English navigator, 65

Windlass, the, 116

Winds prevalent in Holland, 130

"Water-sails," 36, 63

Water Tower Museum at Dordrecht, 111
Watson, G. L., 211, 254

Wykeham-Martin furling gear, the, 267

Wyoming, the, 203

\section{$\mathbf{Y}$}

Yacht, the origin of the, 20, 97

- origin of the word, 98

a strange, 77

of Charles II., 129

of 1815 , the, 189

club during the Victorian era,

207

- clubs in the early eighteenth

century, 160

— clubs, constitution of, 171

- Falconer's definition of a, 188

Yacht-racing, 139

- Association, the, 212 on the Thames, 173

Yachting, 22 club, the first, 159

Yachting Monthly, the, 268

Yacht's boat, the, 103

Yachts, development in size, 205

__ for pleasure and utility, 178 in warfare, 159

Yarmouth harbour, 229

Yawl, the, 199

Yawl-rigged barges, 235

"Yawls," double-ended, 278

\section{$\mathbf{Z}$}

Zeebrugge, 20

Zeland and Frisian leeboards, 72

Zuyder Zee, the, 19

Zulus, 225

Zwaard or leeboard, 71

Printed in Gieat Britain by the Riverside Press Limited

Euineurgh 



\section{THE IAN HARDY SERIES}

BY

\section{COMMANDER E. HAMILTON CURREY, R.N.}

Each Volume with Illustrations in Colour. 6s. each

IAN HARDY's career in H.M. Navy is told in four volumes, which are described below. Each volume is complete in itself, and no knowledge of the previous volumes is necessary, but few boys will read one of the series without wishing to peruse the others.

\section{IAN HARDY, NAVAL CADET}

\footnotetext{
"A sound and wholesome story giving a lively picture of a naval cadet's life."
}

- Birmingham Gazette.

"A very wholesome book for boys, and the lurking danger of Ian's ill deeds being imitated may be regarded as negligible in comparison with the good likely to be done by the example ot bis manly, honest nature. Ian was a boy whom his father might occasionally bave reason to whip, but never feel ashamed of."-United Service Magazine.

\section{IAN HARDY, MIDSHIPMAN}

"A jolly sequel to his last year's book."-Christian World.

"The 'real thing.' . . Certain to enthral boys of almost any age who love stories of British pluck."-Observer.

"Commander E. Hamilton Currey, R.N., is becoming a serious rival to Kingston as a writer of sea stories, Just as a former generation revelled in Kingston's doings of bis three heroes from their middy days until they became admirals all, so will the present-day boys read with interest the story of Ian Hardy. Last year we knew him as a cadet ; this year we get Ian Hardy, Midshipman. The present instalment of his stirring bistory is breezily written."-Yorkshire Observer.

\section{IAN HARDY, SENIOR MIDSHIPMAN}

"Of those who are now writing stories of the sea, Commander Currey bolds perhaps the leading position. He bas a gift of narrative, a keen sense of humour, and above all he writes from a full stock of knowledge."-Saturday Review.

It is no exaggeration to say that Commander Currey bears worthily the mantle of Kingston and Captain Marryat."-Manchester Courier.

"The Ian Hardy Series is just splendid for boys to read, and the best of it is that each book is complete in itself. But not many boys will read one of the series without being keenly desirous of reading all the others."-Sheffield Telegraph.

\section{IAN HARDY FIGHTING THE MOORS}

By writing this series the author is doing national service, for he writes of the Navy and the sea with knowledge and sound sense.... What a welcome addition the whole series would make to a boy's library."-Daily Graphic.

"The right romantic stuff, full of fighting and hairbreadth escapes. . . Commander Currey has the secret of making the men and ships seern actual." -Times.

" By this time Ian Hardy has become a real friend and we consider bim all a bero should be."

\section{SEELEY, SERVICE \& CO. LIMITED}




\section{THE NEW AR T LIBRA R Y}

"The Admirable New Art Library."-Connoisseur.

New Volume. Just Ready.

PER S P E C T I V E

As applied to pictures with a section dealing with architecture. By $\mathrm{R}$ zy Vicat Cole. With 472 Illustrations. Price 18 s. nett.

\section{WATER COLOUR PAINTING}

Alrred W. Rich. With over Sixty Illustrations. Price 108. 6s. netı

"No artist living is better qualified to undertake a text-book on water colour painting than Mr. Rich. Not only is he one of the most distinguished exponents of the art in this country, but be has had considerable experience and success as a teacher. This admirable volume ..."-Studio.

"A Book on the art of water colour painting by one of its best living practitioners."

\section{THE PRACTICE OF OIL PAINTING}

Solomon J. Solomon, R.A. With Eighty Illustrations. Price ros. 6d. nett.

"Eminently practical. . . Can be warmly recommended to all students."-Daily Mail.

"The work of an accomplished painter and experienced teacher."-Scotsman.

"If students were to follow bis instructions and, still more, to beed bis warnings, their painting would soon show a great increase in efficiency."-Manchester Guardian.

\section{HUMAN ANATOMY FOR ART STUDENTS}

Sir Alfred D. Fripp, K.C. V.O., C.B., Lecturer upon Anatomy at Guy's, and Ralph Thompsom. Drawings by Innes Fripp, A.R.C.A., Master of Life Class, City Guilds Art School. I 5 I Illustrations, 15 s. nett.

"The character of this book all through is clearness, both in the letterpress and the illustrations. The latter are admirable." - Spectator.

"Just such a work as the art student needs, and is probably all that he will need. It is very fully illustrated. There are 9 pates showing different views of the skeleton and the muscular system, 23 reproductions of photographs from life, and over r3o figures and drawings."-Glasgow Herald.

\section{MODELLING $E$ E SCULPTURE}

Alber T Toft, Hon. Associate of the Royal College of Art, Member of the Society of British Sculptors. With I 8 Illustrations. I 5 s. nett.

"Mr. Toft's reputation as a sculptor of marked power and versatility guarantees that the instruction be gives is thoroughly reliable."-Comoisseur.

"Will be exceeding useful and indispensable to all who wish to learn the art of sculpture in its many branches. Mr. Toft writes very clearly."-Field.

\section{THE PRACTICE E SCIENCE OF DRAWING}

Harold Spred, Member of the Royal Society of Portrait Painters. With 93 Illustrations. IO8. 6d. nett.

"This book is of such importance that everyone interested in the subject must read it."-Walter Sickert in The Daily News.

"Altogether this is one of the best volumes in the admirable series to which it belongs."-Literary World.

\section{THE ARTISTIC ANATOMY OF TREES}

\section{Rex Vicat Cole. With 500 Illustrations \& Diagram. I 5s. nett.}

"No work on art published during recent years is better calculated to be of practical assistance to the student."-Connoissers.

"Excellently and copiously illustrated."-Times.

"Like all volumes of the New Art Library, thorough in its teaching, eminently practical in its manner of presenting it, and so splendidly illustrated that not a rule is laid down or piece of advice given but what a drawing accompanies it. Mr Vicat Cole's ability as a landscape painter is well known, and be is an accoinplished teacher.'

SEELEY, SERVICE \& CO., LIMITED

Connoissent. 


\section{THE SCIENCE OF TO-DAY SERIES}

With many Illustrations. Exira Crown 8vo. 8s. 6d. nett each.

\section{NEW VOLUME}

CHEMISTRY OF TO-DAY. A Popular Introduction in Nontechnical Language." With over 150 Illustrations \& Diagrams. By P. G. Buri, M.A.(Oxon).

ANIMAL INGENUITY OF TO-DAY. By C. A. Ealand, M.A. Author of "Insects and Man," $\Xi " c$. With 26 Illustrations.

"A wholly fascinating natural history book."-Outlook.

SUBMARINE WARFARE OF TO-DAY. Telling how the Submarine Menace was met $\mathscr{E}^{\circ}$ vanquished. By C. W. Domville-Fire, Staff of H.M. School of Submarine Mining. With 53 Illustrations.

"A very striking book, revelation follows revelation, and magnificent stories or fighting $\&$ heroism at sea come practically on every page. One of the few war books which will survive the next no years."-Liverpool Courier.

AIRCRAFT OF TO-DAY. A Popular Account of the Conquest of the Air. By Maj. Charies C. Turner, R.A.F. With 62 Illustrations.

"Maj. Turner is well known as an authority on aeronautics. Of real value."

Aberdecr Journal.

GEOLOGY OF TO-DAY. A Popular Introduction in Simple Language. By J. W. Gregory, F.R.S., D.Sc., Professor of Geology at the University of Glasgow. With 55 Illustrations.

"An ideal introduction to a fascinating science. The romance and reality of the earth most brilliantly and soundly presented."-Globe.

SUBMARINE ENGINEERING OF TO-DAY. By C. 'W. Domville-Firx, Author of "Submarines of the World's Navies," Ëc.

BOTANY OF TO-DAY. A Popular Account of the Evolution of Modern Botany. By Prof. G. F. Scorrt-Ell10t, M.A., B.Sc., F. L.S.

"This most entertaining and instructive book. It is the fruit of wide reading and much patient industry."-Globe.

SCIENTIFIC IDEAS OF TO-DAY. A Popular Account, in Non-technical Language, of the Nature of Matter, Electricity, Light, Heat, Electrons, \&ैc. $\S^{\circ} c$. By C. R. Girson, F.R.S.E.

"As a knowledgeable writer, gifted with the power of imparting what he knows in a manner intelligible to all, Mr. C. R. Gibson has established a well-deserved reputation."

astronomy OF TO-DAY. By Cecil G. Dolmage, LL.D.,

F.R.A.S. 46 Illustrations.

"A lucid exposition much belped by abundant illustrations."-The Times.

ELECTRICITY OF TO-DAY. Its Work and Mysteries Explained. By Caaress R. Gibson, F.R.S.E. Extra Crown 8vo.

" One of the best examples of popular scientific exposition that we remember seeing."

ENGINEERING OF TO-DAY. T. W. Corbin. 39 Illustrations. "Most attractive and instructive."-Record.

MEDICAL SCIENCE OF TO-DAY. By Wrllmotr-Evans, M.D., B.Sc., F.R.C.S.

"A very Golconda of gems of knowledge."-Manchester Guardian.

MECHANICAL INVENTIONS OF TO-DAY. By T. W. Corrin.

"In knowledge and clearness of exposition it is far better than most works of a similar character and aim."-Academy.

PHOTOGRAPHY OF TO-DAY. A Popular Account of the Origin, Progress, and Latest Discoveries. Br H. Chapman Jones, F. I. C., F.C.S.

"An admirable statement of the development of photography from its very beginning to the present time." -Journal of Photography.

SEELEY, SERVICE \& CO. LIMITED 


\section{A CHARMING ANTHOLOGY BY “Q" THE PILGRIMS' WAY}

A LITTLE SCRIP OF GOOD COUNSEL, FOR TRAVELLERS BY SIR A. T. QUILLER-COUCH

Professor of English Literature at Cambridge University

Cloth, price, nett, 5s. Thin paper edition in leather, 7s. 6d. nett; buffed leather, yapp, in a box, price, nett, 7s. $6 d$.

"Prof. Quiller-Couch is the prince of anthologists." The Glasgow Evening News.

"A little book of grave and beautiful thoughts. It would be difficult to better the selections."-The Guardian.

"The poems and prose passages are chosen-as might bo safely foretoldwith taste and discrimination, and the volume will be found a heartening companion."-The Tribune.

"The very flower of a cultivated man's reading."-Country Life.

"Prof. Quiller-Couch's anthologies are the best of their kind in modern English literature."-The Morning Post.

\section{THE GOLDEN RECITER}

RECITATIONB AND READINGS IN PROSE AND VERSE SRLECTED FROM THE WRITINGS OF

RUDYARD KIPLING, R. L. STEVENSON, CONAN DOYLE, THOMAS HARDY, AUSTIN DOBSON, CHRISTINA ROSSETTI, MAURICE HEWLETT, A. W. PINERO, SYDNEY GRUNDY, छc. WITH A PRACTICAL INTRODUCTION

BY PROF. CAIRNS JAMES

Professor of Rlocution at the Royal College of Music and the Guildhall School of Music

Extra crown 8vo, over 700 pages, cloth, nett, 6s. ; also a thin paper pocket edition, with coloured edges, nett, $7 s .6 d$.

" An admirable collection of pieces, both in prose and rerse."-Spectator.

"Far superior to anything we have yet seen." -Western Press.

"A more admirable book of its kind could not well be desired." Liverpool Courier.

\section{THE GOLDEN HUMOROUS RECITER}

RECITATIONS AKD READINGS IN PROSE AND VERSE SELECTED FROM THE WRITINGS OF

F. ANSTEY, J. M. BARRIE, MAJOR DRURY, JEROME K. JEROME, BARRY PAIN, A. W. PINERO, OWEN SEAMAN, G. B. SHAW, छْc. छc.

WITH A PRACTICAL INTRODUCTION

\section{BY PROF. CAIRNS JAMES}

Extra crown 8vo, over 700 pages, cloth, nett, 6s.; also a thin paper pocket edition, with coloured edges, nett, 7s. $6 d$.

"Unquestionably the best collection of modern humorous pieces for recitation which has yet been issued."-The Dundee Advertiser.

"Packed with things that are fresh and unhackneyed."-Bookman.

"An excellent selection, three-fifths of them being taken from the work of the best modern writers." - The World.

"A most comprehensive and well-chosen collection of some hundreds of piecesa most catholic array of all that is good in English literature, and a small encyclopedia of English humour."-The Spectator.

SEELEY, SERVICE छ CO., LIMITED 






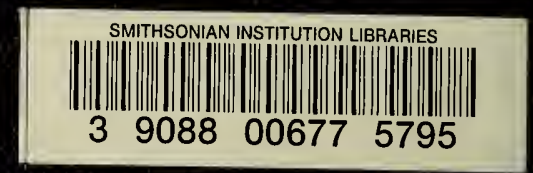

